$1(3)$

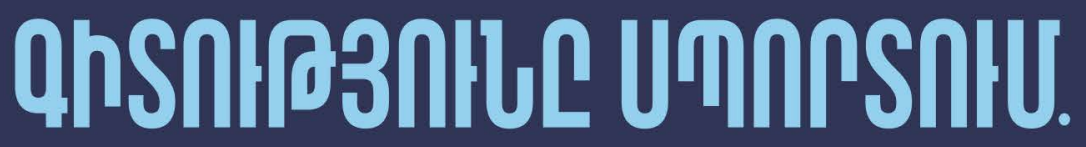

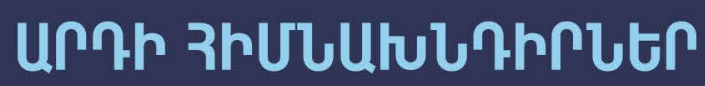

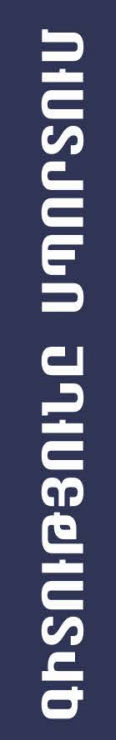




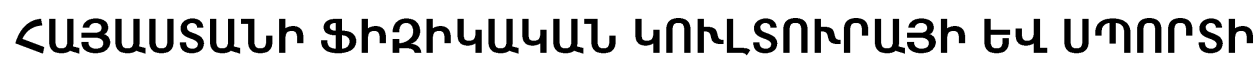 TESU4Uし hしUShsnks
}

\section{ARMENIAN STATE INSTITUTE OF PHYSICAL CULTURE AND SPORT}

ГОСУДАРСТВЕННЫЙ ИНСТИТУТ ФИЗИЧЕСКОЙ КУЛЬТУРЫ И СПОРТА АРМЕНИИ

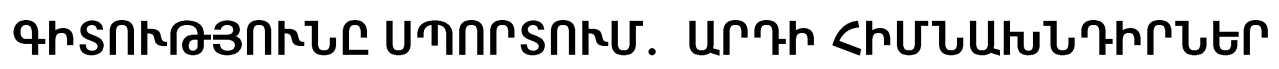

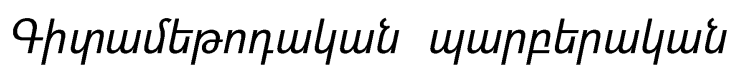

\section{SCIENCE IN SPORT: MODERN ISSUES}

Scientific and methodical journal

НАУКА В СПОРТЕ: СОВРЕМЕННЫЕ ПРОБЛЕМЫ Научно-методический журнал

№ 1 (3)

\author{
trtuul \\ YEREVAN - 2021 \\ EPEBAH
}




\section{UhZS UtR LtS}

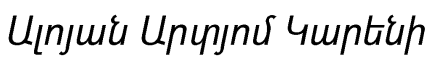

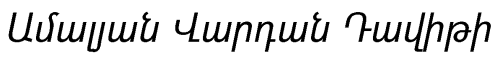

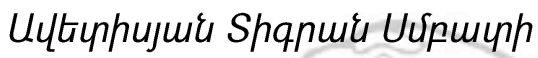

Unlhljwi qunhl Enhlh

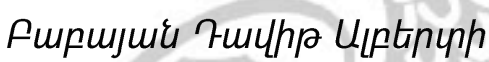

fupuquijui qunng 7urhph

fnnupjui <ulynp 9uqhlph

9hunujwer Zumtil <urilaunh

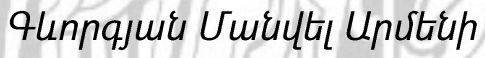

7uгчnnjuis Lhumunhun U2nunh

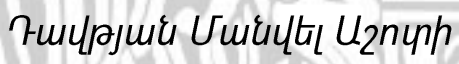

tnhgjue Zuntil Unquíh

Rupunjuie Yuhts Uuviltelh

Rnhnupjuis Uannuiuhl Uunnúh

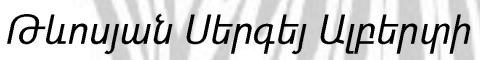

humpnjwi 7ushenph Utingtsh

tumsmunnjuí Uppnın quahlh

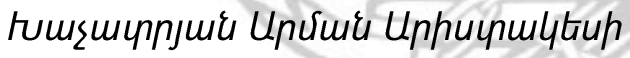

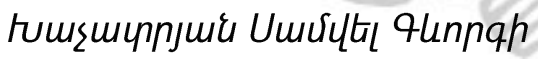

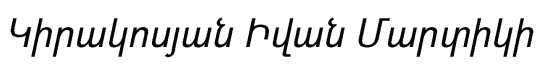

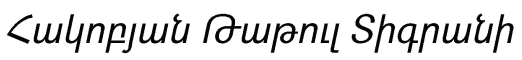

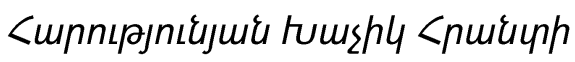

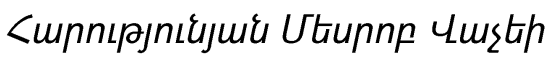

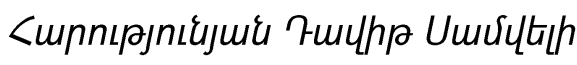

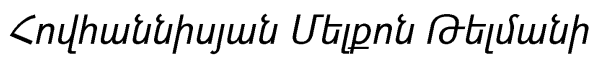

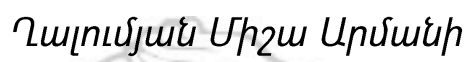

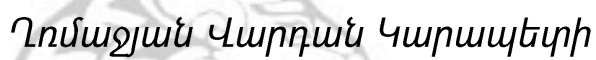

Uunqunjue Ruyhp Uhtiph

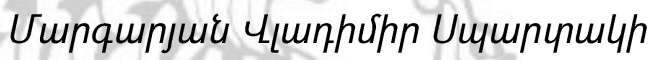

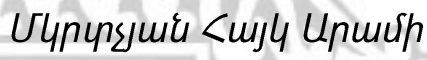

Vimgulymijue Ulimly fupuzhlh

乙uqupjuis U४uq Uppnıph

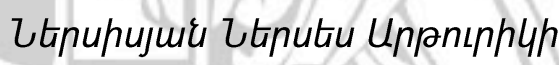

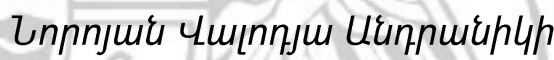

2npuijure Upté Uymah

Thisnnujuis 4nym cuhtiuh

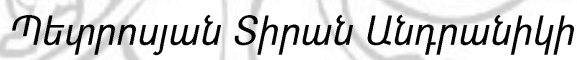

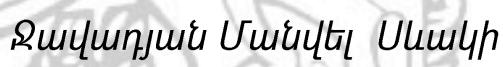

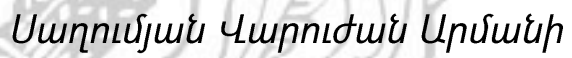

Umunujuir Unyjnư Umpquh

Uunqujuir Yuaqter Ulunush

Uumlhujwi 9 nn Znnwjph

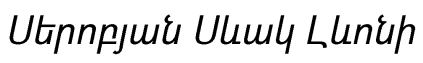

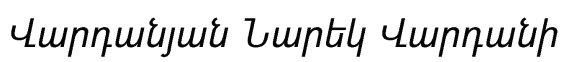

enshrumur Uhtin Uununhü 


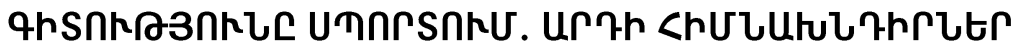

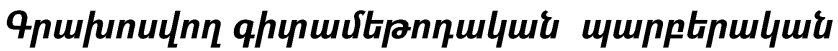

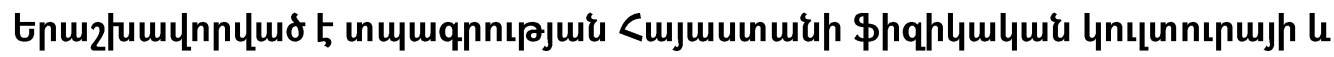

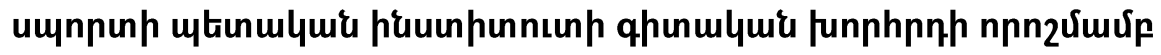

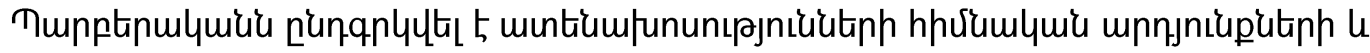

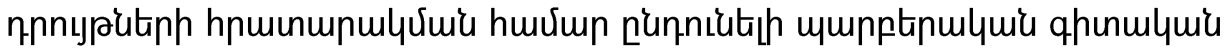

hpuunupulynıpjnıuutiph gnıgulynux: <húp' « F04-h 05.02.2021p. N 56 U hnuviulun:

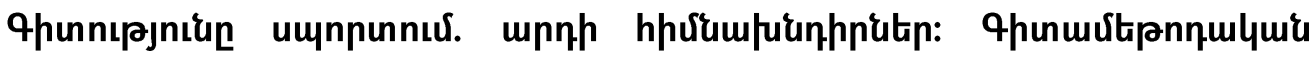

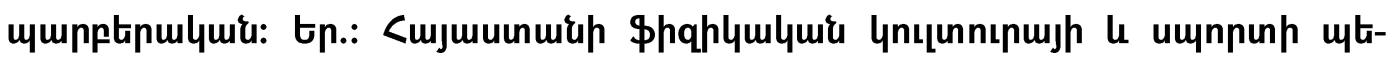
unulyuiz huuunhunniun, 2021, № 1 (3), 216 5.2:

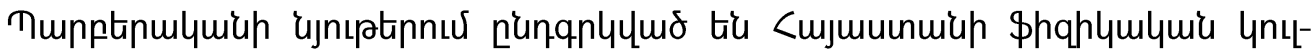

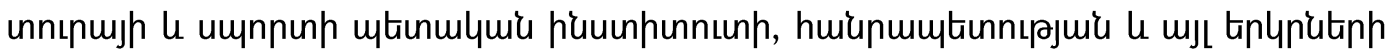

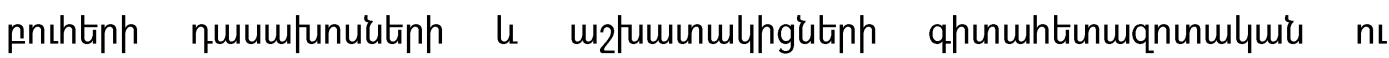

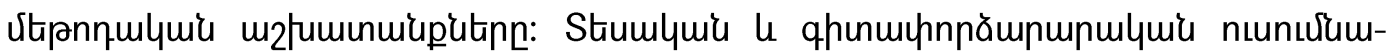

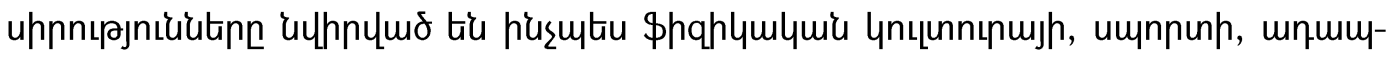

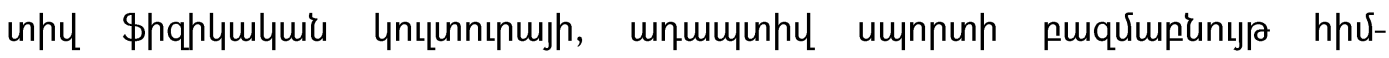

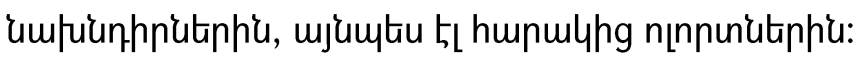

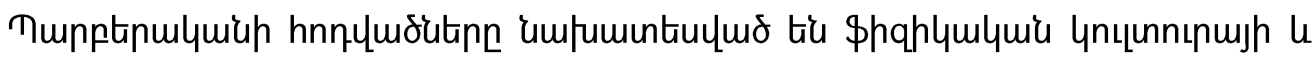

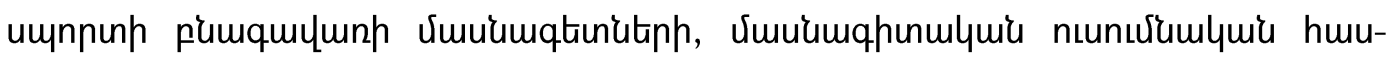

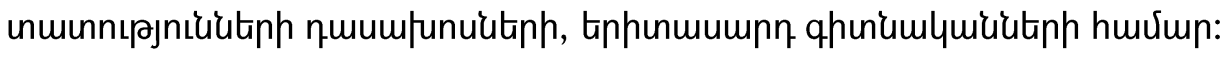

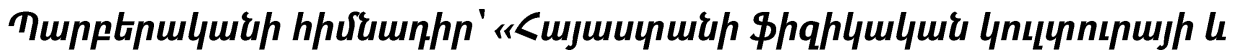

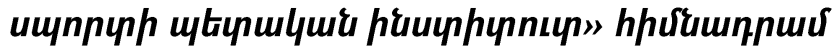

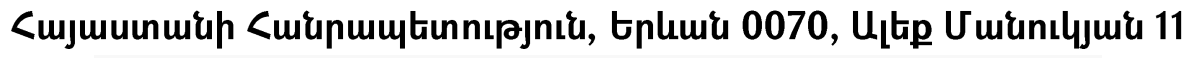

11 Alek Manukyan Str., Yerevan 0070, Republic of Armenia

$$
\text { info@sportedu.am }
$$




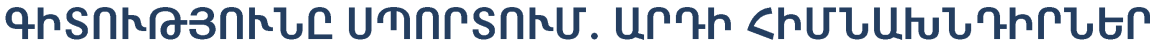

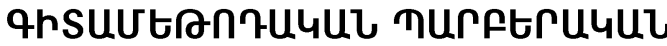

\author{
9.tumulnp luर्upuqhn' \\ १.U. huppunjuil

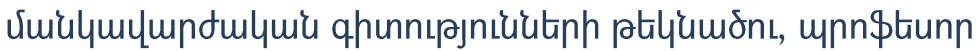

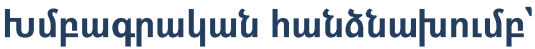

Unuíjuit 9. 4.

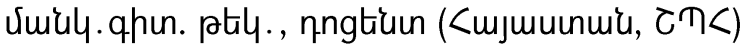

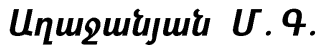

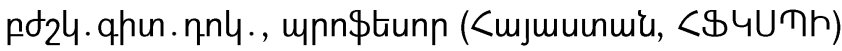

fupmumi <. $u$.

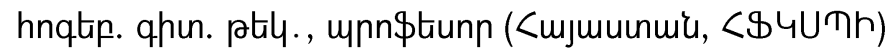

fnцширпци U. $U$.

vimily. qhun. nnl., unn\$tiunn (กıцnupium, กト\$4UU<)

9tпquरjuit 4. 2.

hnqtip. qhun. ptil., qngtiun (

Rnynum \$. $\pi$.

Umily.qhen. nnL., unn\$tiunn (กnsumuunuiu, T\$४USTU)

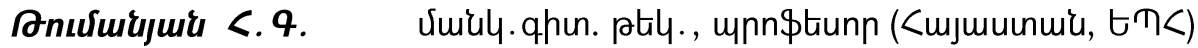

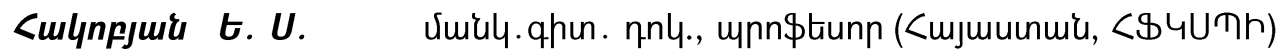

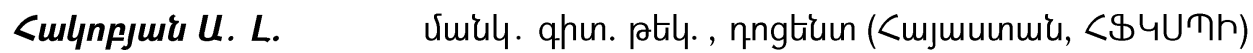

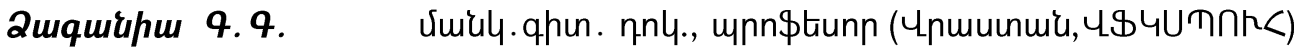

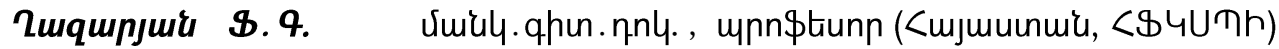

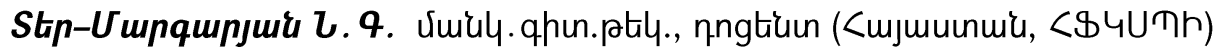

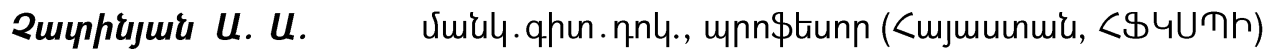

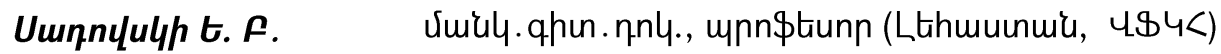

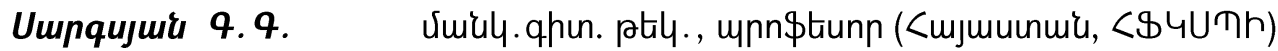

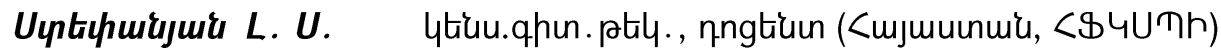

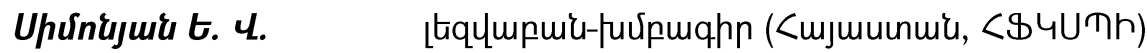

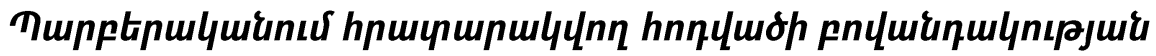

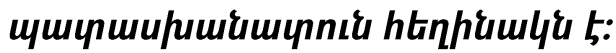




\section{SCIENCE IN SPORT: MODERN ISSUES}

\section{SCIENTIFIC METHODICAL JOURNAL}

\section{Chief editor}

D. S. Khitaryan - PhD of Pedagogy, Professor

\section{Professional Editorial Committee}

Aghanyan V. G.

Aghajanyan M. G.

$\mathrm{PhD}$ of Pedagogy, Associate Professor (Armenia, ShSU )

Doctor of Medicine, Professor (Armenia, ASIPCS)

Babayan H. A.

PhD of Psychology, Professor (Armenia, ASIPCS)

Bulatova M. M.

Doctor of Pedagogy, Professor (Ukraine, NUUPES)

Geghamyan V. Gh.

PhD of Psychology, Associate Professor (Armenia, ASIPCS)

Zotova F. R.

Tumanyan H. G.

Doctor of Pedagogy, Professor (Russia, VRSAPCST)

PhD of Pedagogy, Professor (Armenia, YSU)

Hakobyan Y.S.

Hakobyan A. L.

Dzagania G. G.

Ghazaryan F. G.

Doctor of Pedagogy, Professor (Armenia, ASIPCS)

$\mathrm{PhD}$ of Pedagogy, Associate Professor (Armenia, ASIPCS)

Doctor of Pedagogy, Professor (Georgia, GSTUPES)

Doctor of Pedagogy, Professor (Armenia, ASIPCS)

Ter-Margaryan N. G. PhD of Pedagogy, Associate Professor (Armenia, ASIPCS)

Chatinyan A. A.

Sadowski E. B.

Doctor of Pedagogy, Professor (Armenia, ASIPCS)

Doctor of Pedagogy, Professor (Poland, AWF)

PhD of Pedagogy, Professor (Armenia, ASIPCS)

$\mathrm{PhD}$ of Biology, Associate Professor (Armenia, ASIPCS)

Stepanyan L.S

Simonyan $E$. $V$. editor (Armenia, ASIPCS)

\section{НАУКА В СПОРТЕ: СОВРЕМЕННЫЕ ПРОБЛЕМЫ НАУЧНО-МЕТОДИЧЕСКИЙ ЖУРНАЛ \\ Главный редактор \\ Д.С.Хитарян}

кандидат педагогических наук, профессор

Аганян В. Г.

Редакционная коллегия:

Агаджанян М. Г.

Бабаян А. А.

Булатова М. M.

Гегамян В. К.

Зотова Ф. $P$.

Туманян Г. Г.

Акопян Е. C.

Акопян А. Л.

Дзагания Г. Г.

Казарян Ф. Г.

Тер-Маркарян Н. Г.

Чатинян А. A.

Садовски Е. В.

к.п.н., доцент (Армения, ШГУ)

д.мед.наук,профессор (Армения, ГИФКСА)

к.п.н., профессор (Армения, ГИФКСА)

д.п.н., профессор (Украина, УНУФКС)

к.п.н., доцент (Армения, ГИФКСА)

д.п.Н., профессор (Россия, ПГАФКСиТ)

к.п.н., профрессор (Армения, ЕГУ)

д.п.Н., профессор (Армения, ГИФКСА)

к.п.н., доцент (Армения, ГИФКСА)

д.п.Н., профрессор (Грузия, ГГУУФКС)

д.п.н., профессор (Армения, ГИФКСА )

к.п.н., доцент (Армения, ГИФКСА)

д.п.н., профрессор (Армения, ГИФКСА)

д.п.н., профессор (Польша, ВУФК)

Саркисян Г. Г.

Степанян Л. C.

к.п.н., професссор (Армения, ГИФКСА)

к.б.н., доцент (Армения, ГИФКСА)

Симонян $E$. В.

редактор (Армения, ГИФКСА) 
คกบนไนแนกหว3กเป

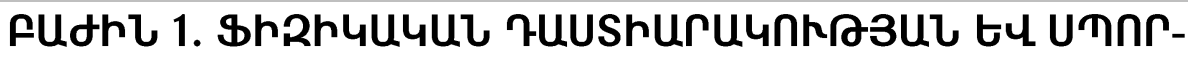

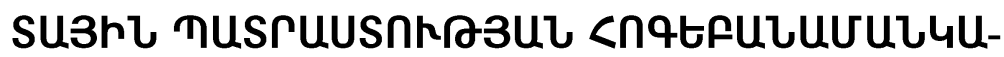

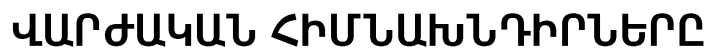

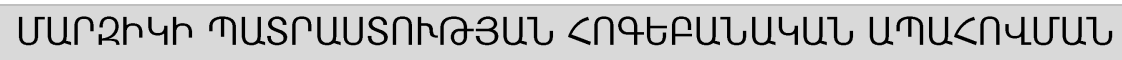

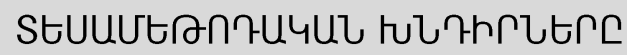

\section{<.U. Pupmјшir}

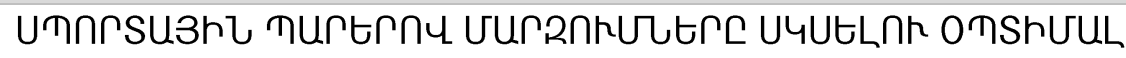
surhec

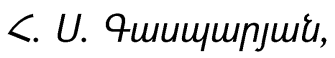

U. Ч. Umpцhnnujwur,

U. U. <uhultannjwir

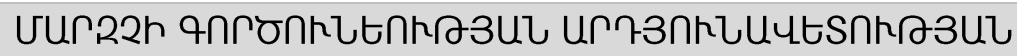

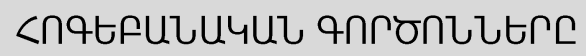

4. 2. 9tinuйлши

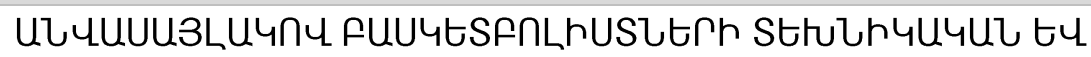

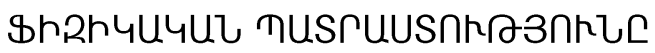

t. L. 7шицрјши,

U. t. 7шицрјши

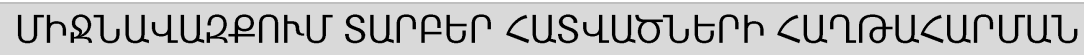

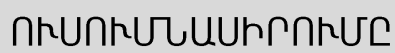

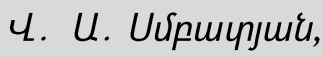

<.4. คnumujuir

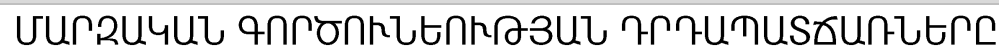

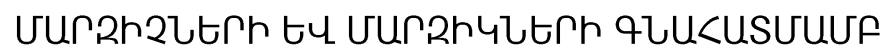

L.U. Untichmirymir,

9. U. Lщчшјши

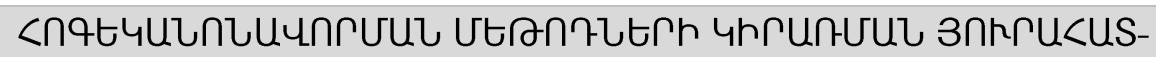

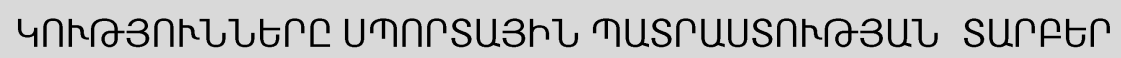
$\Phi \cap R L E \cap \cap R U$

ค. $\tau$. Unqjuir 


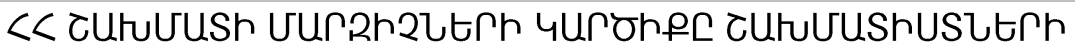

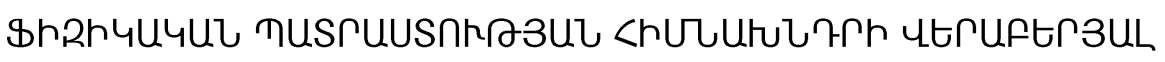

U. L. <ulynpjui,

<. <. <ulynpjuir

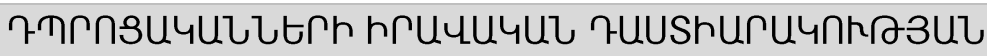

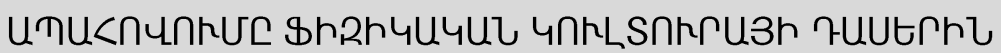

5. 5. Zuipaunsuir

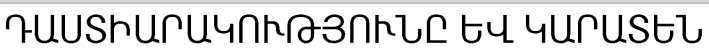

U. U. 2unmpumiguis

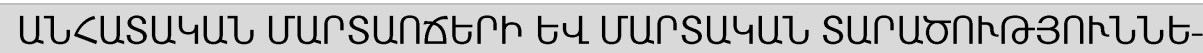

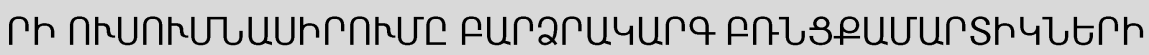

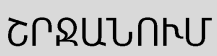

U. U. Utıpnusjui,

U. ก. Ruiptijuir,

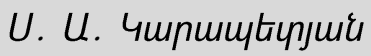

ОПРЕДЕЛЕНИЕ ОПТИМАЛЬНОГО ВРЕМЕНИ ПРИЦЕЛИВАНИЯ ИЗ ПНЕВМАТИЧЕСКОЙ ВИНТОВКИ

В. М. Авагимяни

УПРАВЛЕНИЕ МЕЛКОЙ МОТОРИКОЙУ ЖЕНЩИН, ЗАНИМАЮЩИХСЯ ОЗДОРОВИТЕЛЬНОЙ ФИЗИЧЕСКОЙ КУЛЬТУРОЙ: БИЛАТЕРАЛЬНЫЕ ПОКАЗАТЕЛИ
A. А. Чатинян,
E. С. Акопян

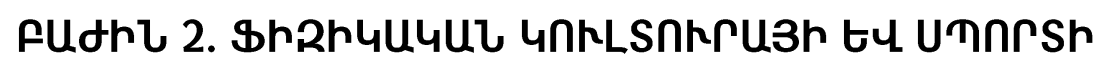

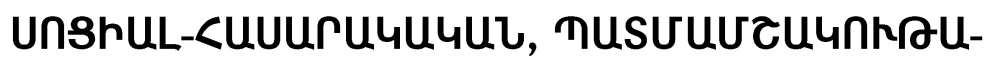
3hし <huしuhu?hกしtr

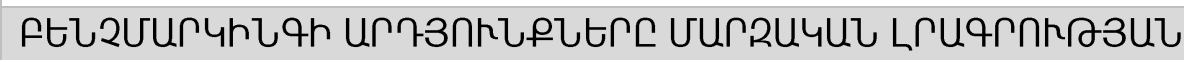

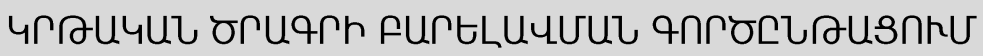

U. ก. คuпquишијше

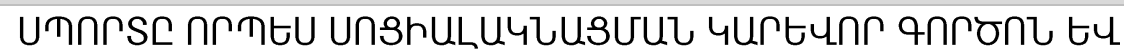
«7dчUก" ๆ

ᄂ. 5. qunnquшน 


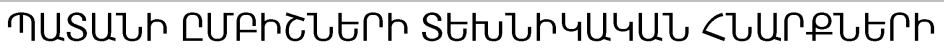

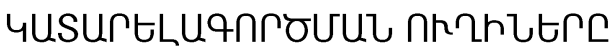

U. U. 7uицाши

<UนกUчก

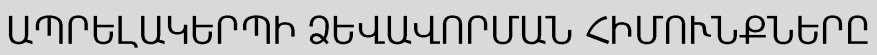

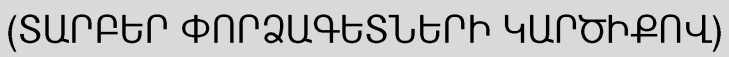

171

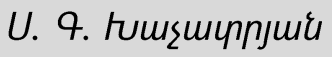

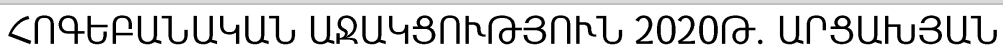

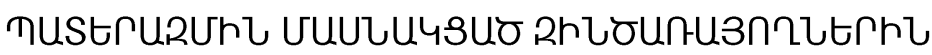

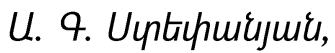

181

L. U. Untiцmirjur

ДЕТЕРМИНАНТЫ ОЗДОРОВИТЕЛЬНОЙ АЭРОБИКИ СКВОЗЬ

ПРИЗМУ МНЕНИЙ ЖЕНЩИН

Ф. Г. Казарян,

М. Н. Казарян

MYTHS AND REALITES OF STUDENT ASSESSMENT IN HIGHER

EDUCATION OF ARMENIA

200

G. A. Muradyan 


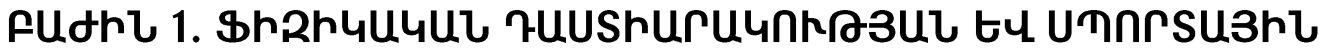

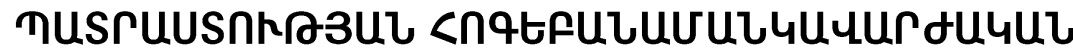

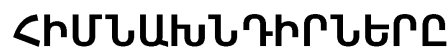

DOI: 10.53068/25792997-2021.1.3-9

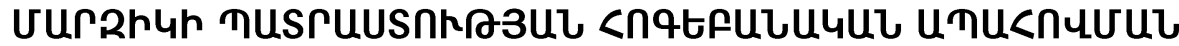

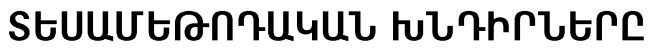

\section{<.q.p., upn\$tiunp <.U. Fupujuit}

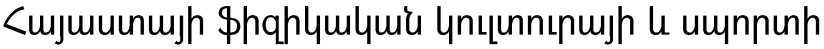

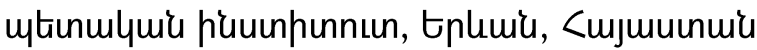
E-mail: harutyun.babayan@sportedu.am

Unuragpushis puntip: <nqtpulumquiu umunnuuunnıpniu, hnqtpuium-

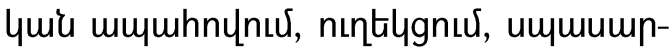

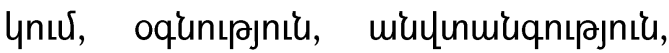

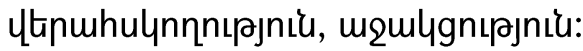

<tunwqnunnıرuis mpnhulymunt-

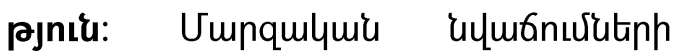
punăn vmlqunnulyn lu umnnonh qun-

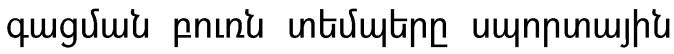

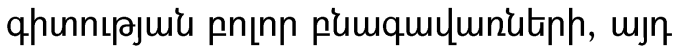
punuर Gumle hnqtipuiunıpuiu ungle up

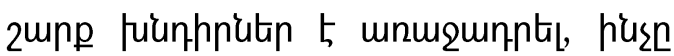

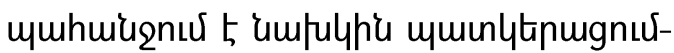

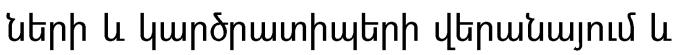
unnnulh ununtignux:

Ujn fưunhnutinng t5 hnqtipuiumlyuir

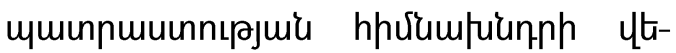
nuiumjnưn, h'usn uhus onu, umnnunujhé

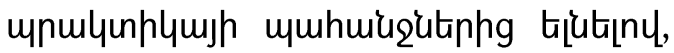
vimphhlh umnnunujhes equinnmuunnt- pjuí pununnuxumuting vtlye $5 \mathrm{l}$ umnnunh hnqtipuiunıpju'u unuiugpujph hhưumhungn:

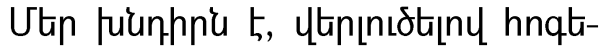

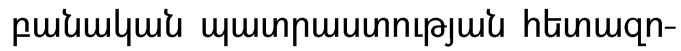

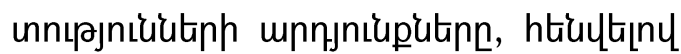

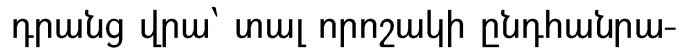
yuiu Ununtignưutatp umnnunh hnqtpuunıpjuí qunquaviuiu htinumqu nınhutiph ytrnuptipju[: Ttrnluu umnnunh hnqtipuiunıpjuí qhınulumì 6jnınn sălıw-

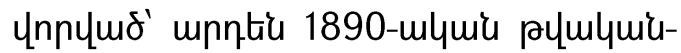

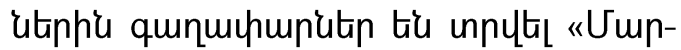
qhlph hnqtipulumlymir muinnuuunntगjuiu» ythuntipjuा [1,5,8]:

huU $\angle U$ umnnunp hnqtipuiunıpuiu

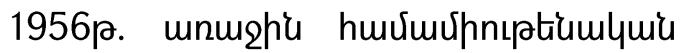
qhunmodnnnulhe hnqtipulumlymis umun-

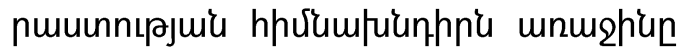
utiplumugnts 5 <mjununump \$hqhym- 


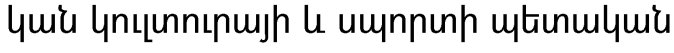
huuunpunnunh Uunnonp Suilymulupdnıрjuí le hnqtipuiunıpjuí uर्uphnuh hpulumnhn u yunhs, unn\$tiunn U.U. Lmqujuiun: Ujn muhhg $h$ ytan umun-

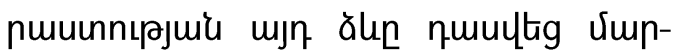

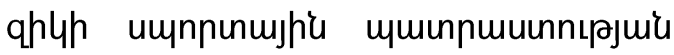

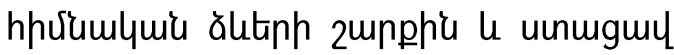
«hnqtipuiumlymis uminnuuunnıpnıı»

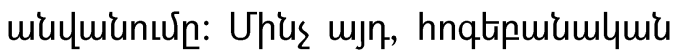

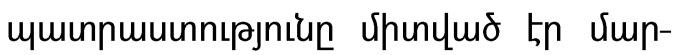
qhlütiph, phưp unuiuăh hnqtapuium-

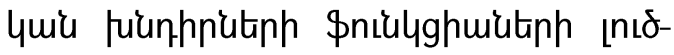

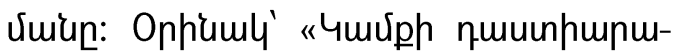

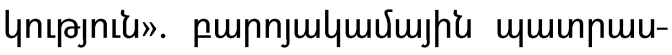

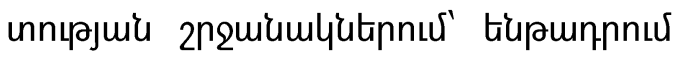
tn vimphlyh wiuăh muhumunulyuí u-

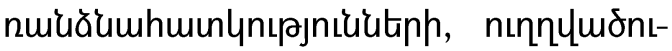

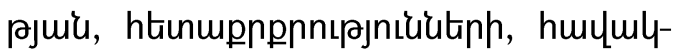

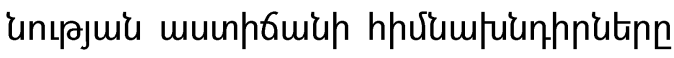
umnnunnuर, unu unupptip hnqtiquir

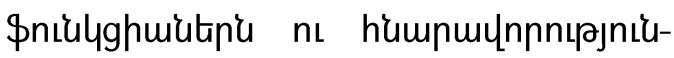

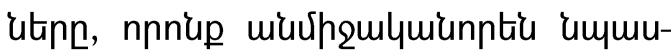

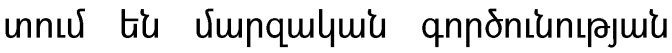

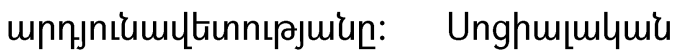
hnqtipuiunıрjuí qunqugưuiun qnıqnipug, umnnumujh hnqtpuiutitph 2nøuunư vimphlyh wuăh le vimpqulywiu phvitph unghur-hnqtapuiumlyuir unuiă-

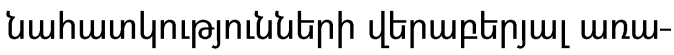
quguiu hungtin (hnqtipuiumlymi 4thưu-

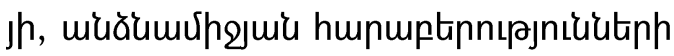

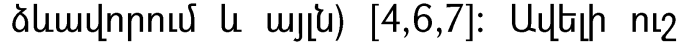

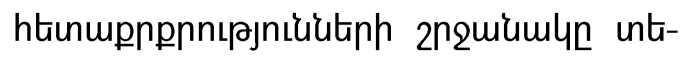
numhnfultas 5 sumphly hnqtiluiu uh-

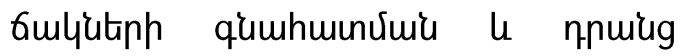

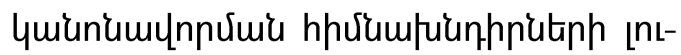

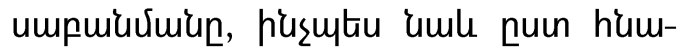

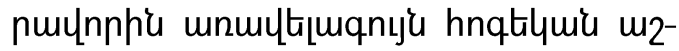

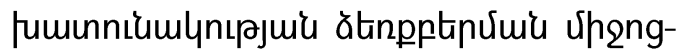

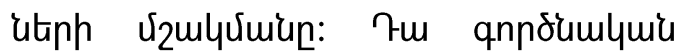
unulytal yuplunn hungtiphg t, nnp nın-

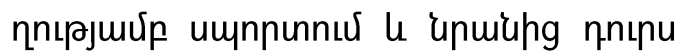

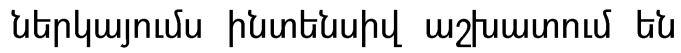
zmin hnqtipuiu viuuamqtinutin $[2,7]$ :

<munlumutu umnnunnuर vanmmitu

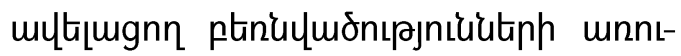
uny, m2łumunuiuputin tiu unmplnuर huu-

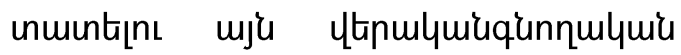
qnnoumlumi uhongutinn, npnup uhnun-

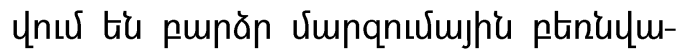

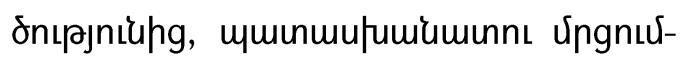

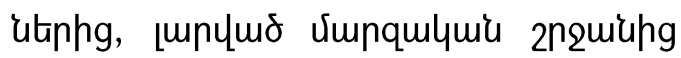
htiunn:

<ujunuh t, nn Etiplumphu umnnunn

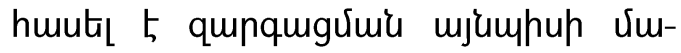
ympnulyh, nnnuर nıttinuqny'u vimp-

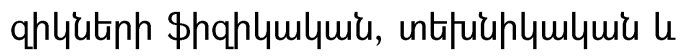

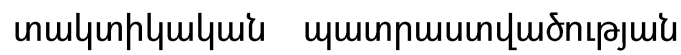

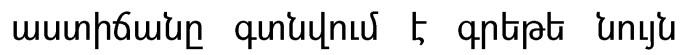
Julympnulyh \nu: Ujn hul muinfiunny

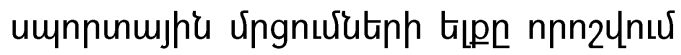

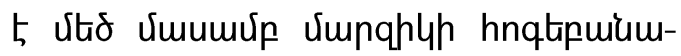

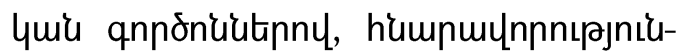


utipny le hnqtiquiuh ntiqtipuny: กppuiu ungnuरn muinmu|umiuminns 5 , umnn-

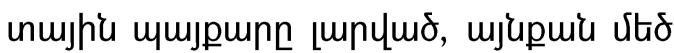

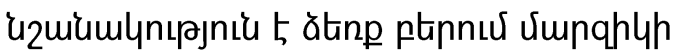

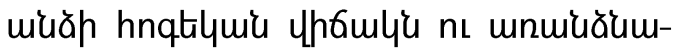
huunlynıjniuutinn:

\section{Stunuqnunnıرuis \&uquinulyn:} Umpqhlutiph umnnunujhis umunnumunnıpju' huviulympqnuर hpर्umiulnnts «hnqtipuiumlumi mumhnцnư» tiqnnıph

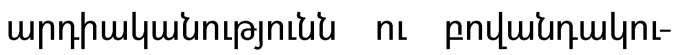
pjniun

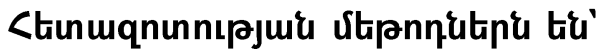

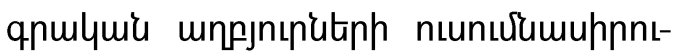

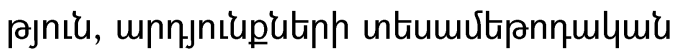

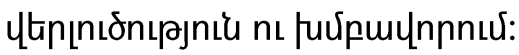

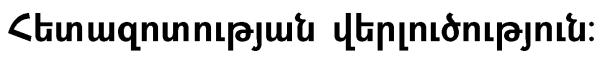

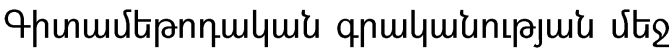
(U.3. Tniup, T.U. กnınhl, 乙.U. tunınuinny, U.U. Luцujui, U. 4. กn-

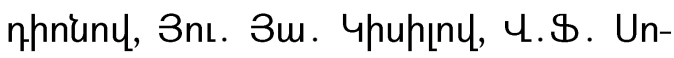

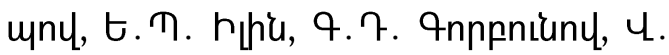
U. Utjuplynu, h.U. Unılny, U.h.

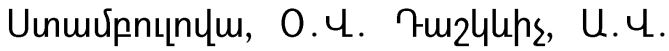
Ujtputil, 3ns. U. 4njnutujgh, U.?.

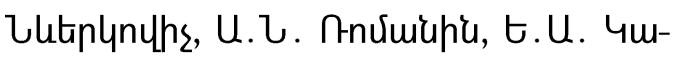
thüu, 9.F. 9nnulumju, U.3nı. 4nntu, F.R. 4ptinh, ก. Umנnh\$tan, t. tumiu $\mathrm{l}$

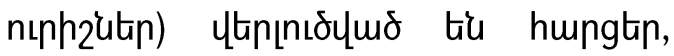
npnup ytamuptipnuर tú umnnunujhe hnqtipuiutitph qnnoniutinıpjuiun lu upunugnınu tiu hnqtipuiumlyuí muinnuu-

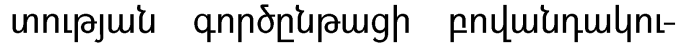

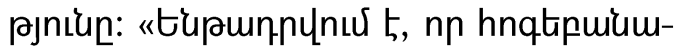
ymí umunnmuinnıpjuí unmly huulumg-

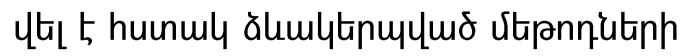
nt uhengutiph qnnóumlyui uhnunnt-

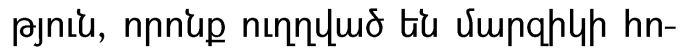
qtapuiumlumir uhfouly ălumunnưuin" (4.4. Utnuttnlu, 1989): U.3. Tnııu, UU. Luцuјuiuh, T.U. กnınhly, १. ?. Annpniunlh le mjıng ynnưhg huuunuunmqnumo hnqtapuiumlymis umunnumun-

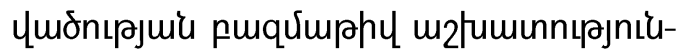

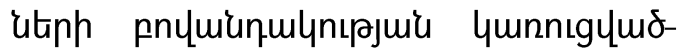
pnux 1985-mlumu pululuiutinh $\mathrm{h}$ yth

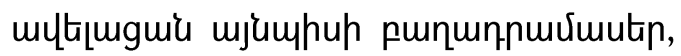

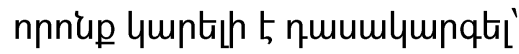

w/ muăh hnqtamiumlumi hurnlqu-

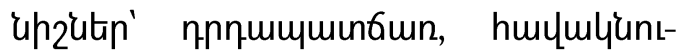

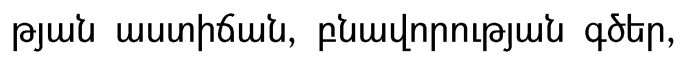

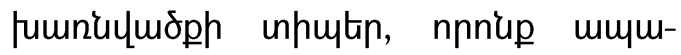

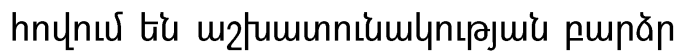

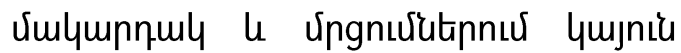
t_nupătine,

p/ hnqtiluiu qnnonupugitip $\mathrm{u}$

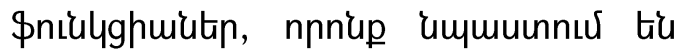
intipuahlymlymirs a inmlyonhlymlymís hamplutiph quinurjul inpnumutionvimun,

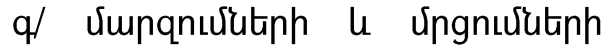

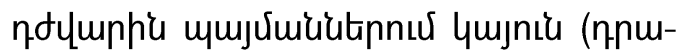

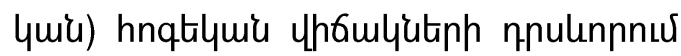
$[1,4,6,7]$ : 
Uju pnцnnny hưuntină ù tiup hnqti-

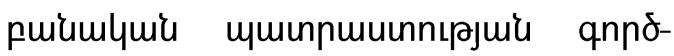
n'upugh qunqugưuir duviuiumlyming

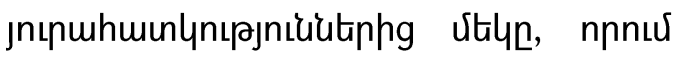

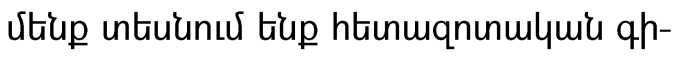
unuritipnnulymis jnıpnyh umunlytpu-

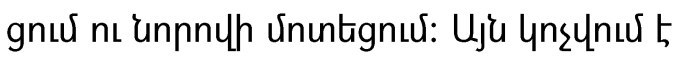
"hnqtipurumlyur umuhnцnư" nnutiu umnnunnuर hnqtipuiuh qhunmqnno-

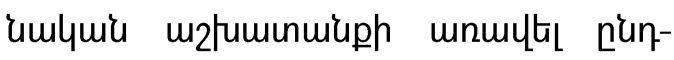

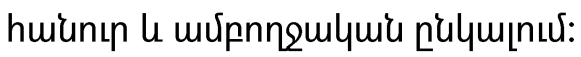

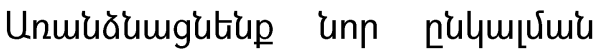

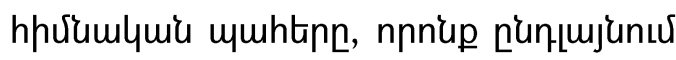

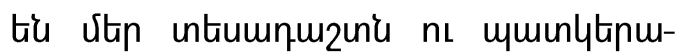

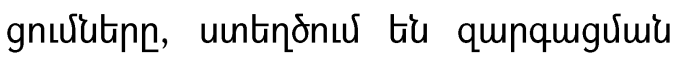
unn htnuilympitan qnofimlyuir umnnunujhe hnqtipuiunıpjuir hurump:

"<nqtipuimumiz mumhnunuर्य»

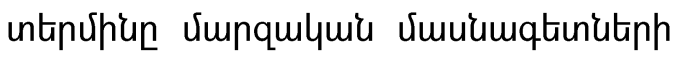

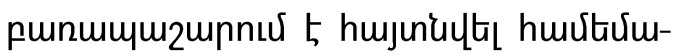

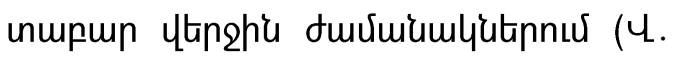

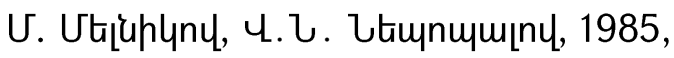
ч. Ч. Utinutank, 1989, 9.f. AnnulymJu, 1995, 4.\$. Ununu, 2000, 9.F. fupnı24hu, 2002 u nıph2utn): 2umjuס uju uर्utiupu, nn umnnunn 21-nп пu-

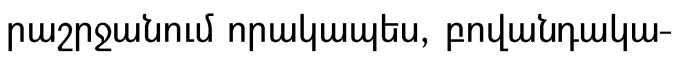

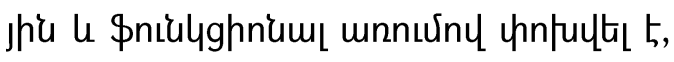
umlymju umnnunujhe vimu'umqtinuting

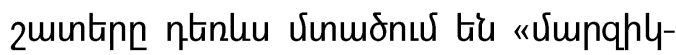

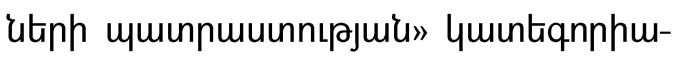

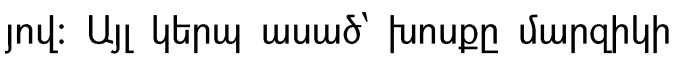

ümunnmunnıpjuis hnqtipuikulquir m-

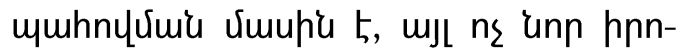

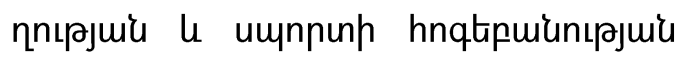

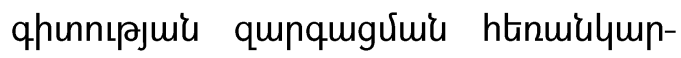
utiph [1,7]:

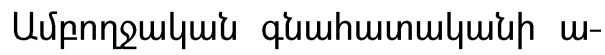

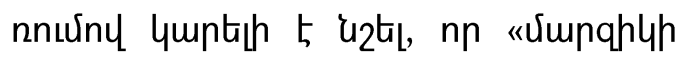
umunnuuunnıpjuis hnqtpuiumlquir m-

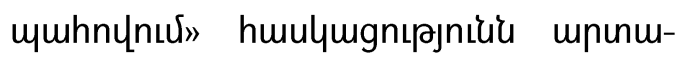
gnınuर 5 vimphlyutiph htion ununtignudutiph le hnulymiamgunn hnqtipuiumlymir m2łumunuiuputinh intumlytunutinn, n-

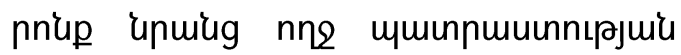

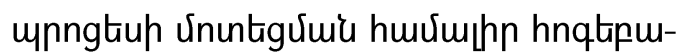

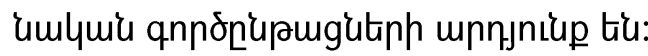

Ltiplumpu umnnunh unmiďumhuunynıpjniukitinh 5 u6nn ungulygnt-

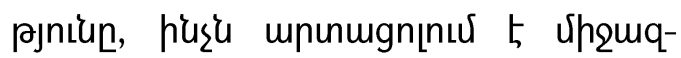

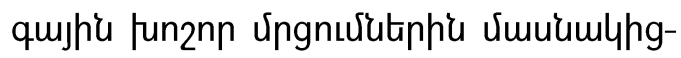

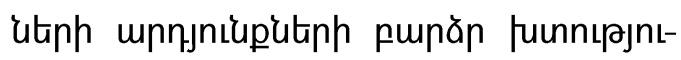
un, tipn hunponnutiphí unguiumlymuhnutiphg purduiunus tiu upuunnutiph,

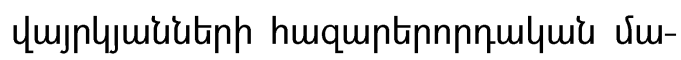

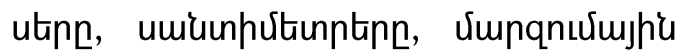

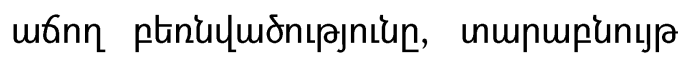
upptiunqtiu qnnonúutinn u ujulu, nnnup

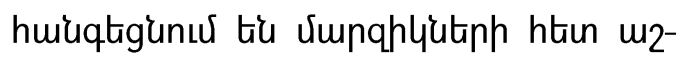
fumuntını unnnulh ălumsurhteph: Utinymjugutiup npuiughg úp puiuhun:

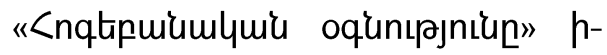
pulquiaminnu 5 umnnunusher quiphtpujh ununptip uhnццtpnux. 


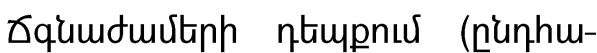

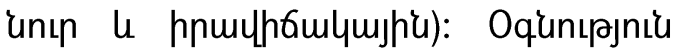
vemphlyhe a vimnqshi' umnnunujher Gqumomún hunpmhmptins u

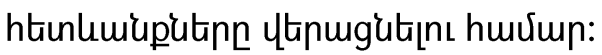

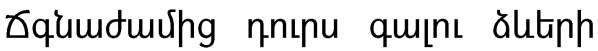
র̌mlynuर lu hnulymiumgnuर:

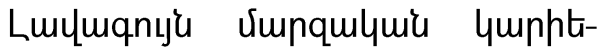
nujh unnţщuц|nnnuर:

Oqunıpjniu veunqshi' unnjnium-

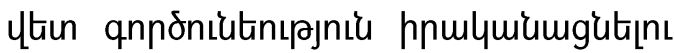
huvium (unupntip ununpph le utinh vimphlyutph, phưtiph, vimpquălutiph, hnqtipuiuh, pdolh, dunnutiph htion $u$ $m\rfloor(u):$

"<nqtipuiumlyuiu oqunıpniu» $\mathrm{l}$ «hnqtipuumumu nıntilgnuर्य» qnnónupurg-

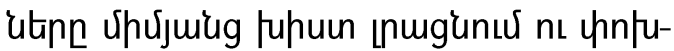

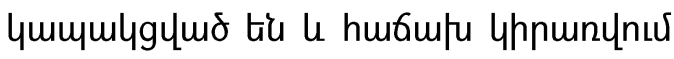

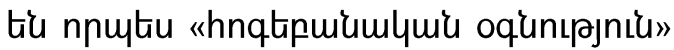

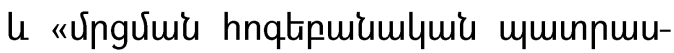
unnıpnıı», husn ns thnuhu lenntiqun b

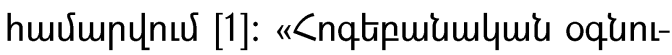

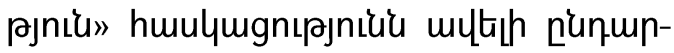
àmly nı jujumưuuzunup 5 shnqtipuium-

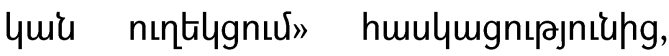
ujupuiuny, nn hnqtipuiun ympnn 5 oq-

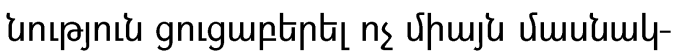

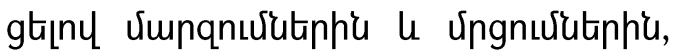

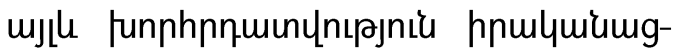

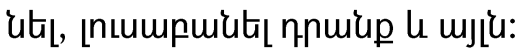

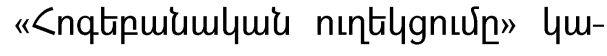

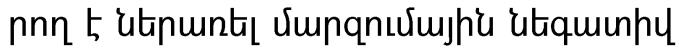

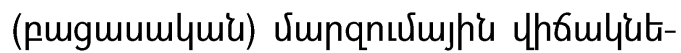

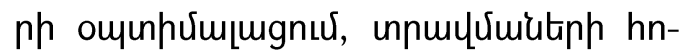

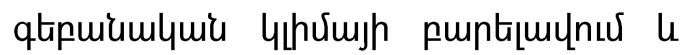
uj $u$ :

"Snqtipuiumlymís

nıntilgnuर्un"

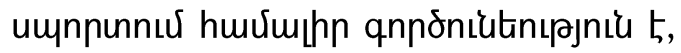

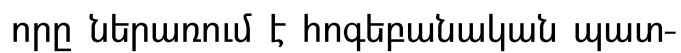

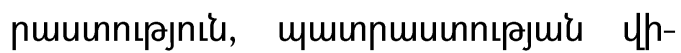

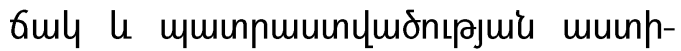

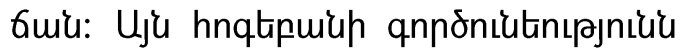

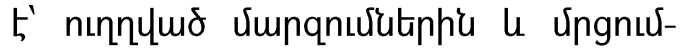
ratiphes vimnqhyitinh hnqtilumis \$niul-

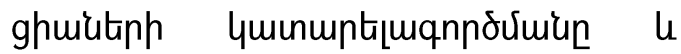
myunhumgưmin: U.ก. Fhunjuiunluiru

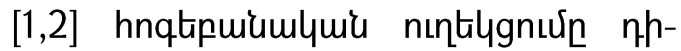

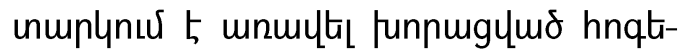

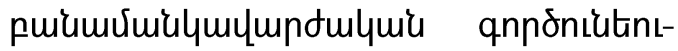

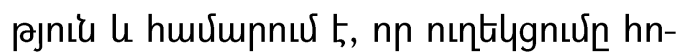
qtapuiuh unn\$tiupnumu qnnóniutntpjnı'üa

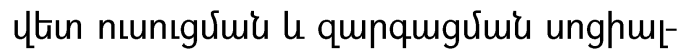

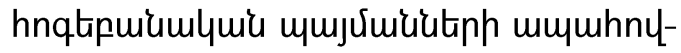
Uimun:

"<nqtipuiumlymí mqulygnıpniun" tupaunnnuर 5 oquta ns upuju vimp-

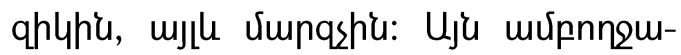

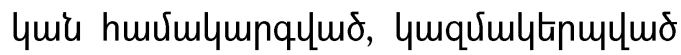

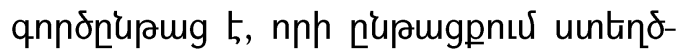

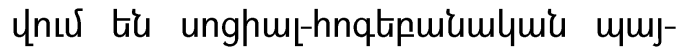
viuiutn vimnqhly lu vimnqsh huviun' 


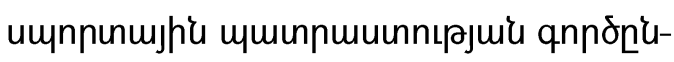

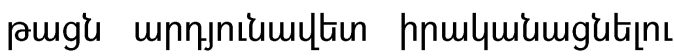
huviun:

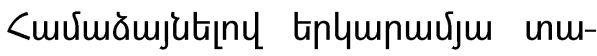
nhitaph hnqtapuiutinp npulquir $\mathrm{m}_{2}$ fumunuiuplitiph htion' umnnunnux unu¿h'u hujugphg uju nnutiu hnqtipuumlymir umunnmuinnıpjuis umunlytpugnuर $5:$

tqnulyugnıpjnit:

Ejutinny

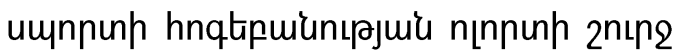

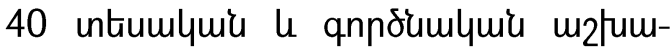

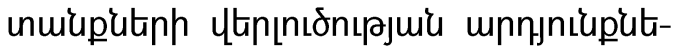
nhg' huiuqtighiup htinljul tiqnuyuguiuiu.

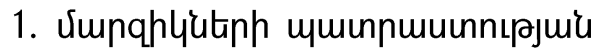
"hnqtipuiumlquiu mumhnunuर्un" uhen-

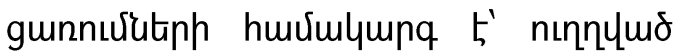

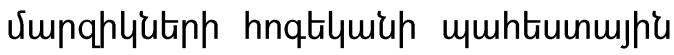

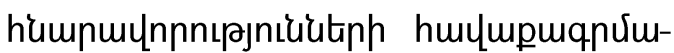

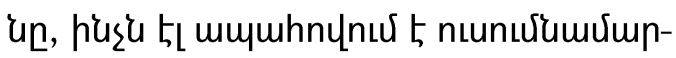

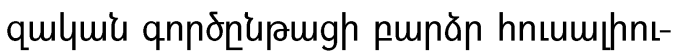

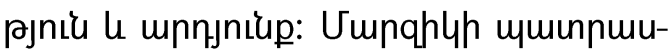

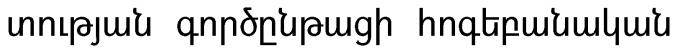

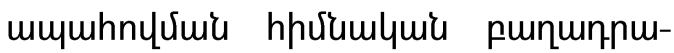

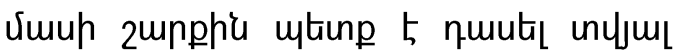

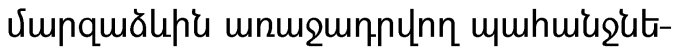

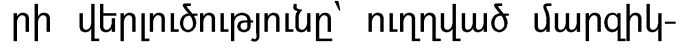

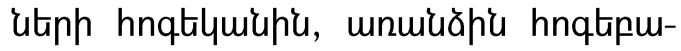
umlumis qnnonuiutiphis, wuhnudtan

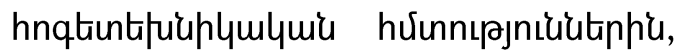
hnqtilumap unn\$tiupnum yuplunn huunynıpjniukutiph ălumunnưuiun, vimp-

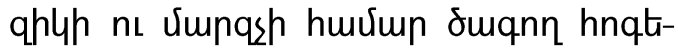

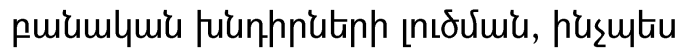

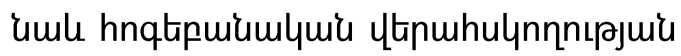

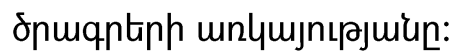

2. Umpqhyh umnnunujhe muinpuuunnıرuis «hnqtipuiumlymir mumhn4nuरn" huर्umph hnqtipuiumlumi qnp-

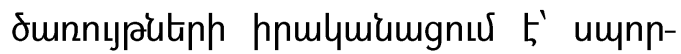

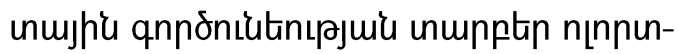

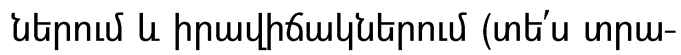
Uuqhe):

3. Cuin unpurumanp' umnnunujhé qnnoniutunıjuis «hnqtpuiumlumi u-

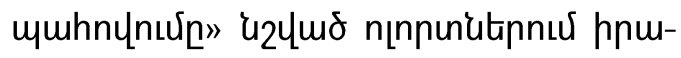

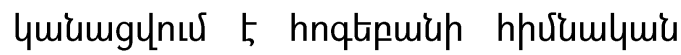

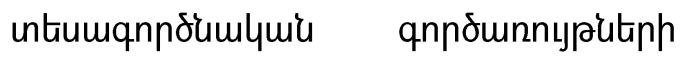

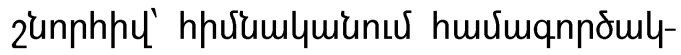

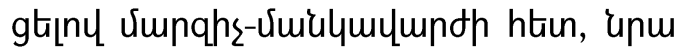

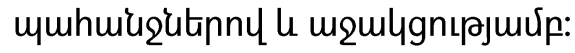




\section{Spurưuqhp}

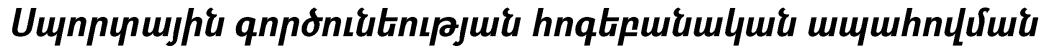

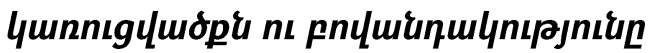

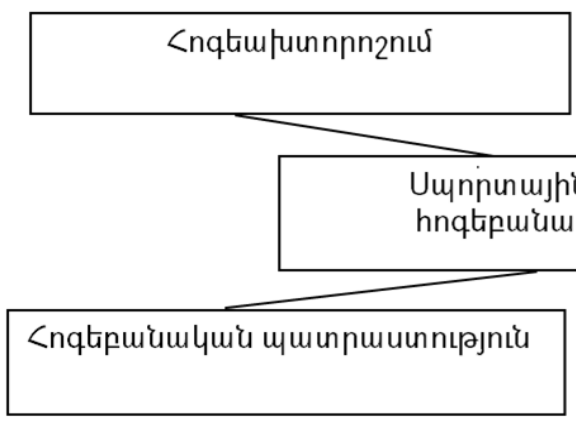

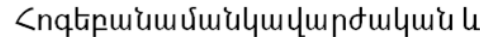

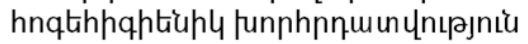

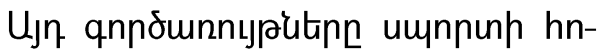

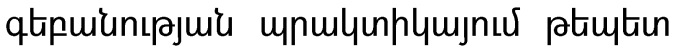

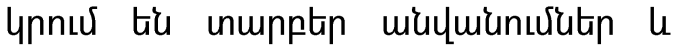
unupptip punıpmqptin, pujg fupuin

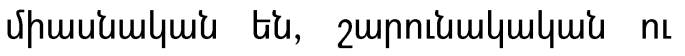

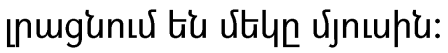

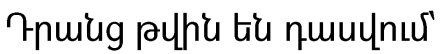

"<nqtipuiumlumis oqünıjnı'u», "<nqtapuiumlymir ummumplynud", "<nqtipuumlumi momugnıpnı'u», "<nqtipuium-

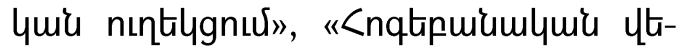

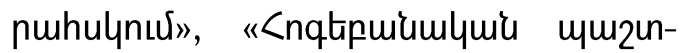

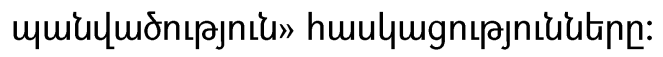

Umpqhyh ympph u hnqtiluiu

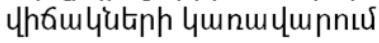

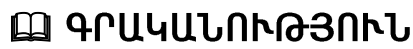

1. Битянова М.Р., Психолог в школе: содержание и организация работы /М.Р. Битянова. М.: 1998/

2. Горбунов Г. Д., Психопедагогика спорта: учеб. Пособие.: М. : Издательство Юрайт, 2019. - 269 с

3. Ильин Е. П., Психология спорта. - СПб.: Питер, 2012. - 352 с:

4. Лалаян А. Ц., Психологическая подготовка спортсмена.- Ерева́н.: 1985.168 c.

5. Пуни А. Ц., Психологическая подготовка к соревнованию в спорте «Физкультура и спорт» М.: 1969, 89 с.

6. Родионов А.В., Психология физической культуры и спорта М.: Издательский центр «Академия», 2010. - 368 с. 
7. Рудик П.А., Психология: учебник для студентов университетов фризической культуры-М. : ФиС, 1994. - 510 с.

8. Сивицкий В.Г., Психологическое сопровождение спортсменов высокого класса / В.Г. Сивицкий // На пути к Пекину: материалы метод. семинара. Минск: БГУФК, 2007с.

9. Pierre de Coubertin Essais de psychologie sportive. Lausanne: Payot. 1913. $266 p$.

\section{THEORETICAL AND METHODOLOGICAL ISSUES IN PSYCHOLOGICAL SUPPORT OF ATHLETE'S PREPARATION}

PhD in Psychology, professor H. Babayan Armenian State Institute of Physical Culture and Sport, Yerevan, Armenia

\section{SUMMARY}

Keywords: psychological preparation, psychological assurance, accompaniment, service, aid, security, control, support.

Introduction: Summarizing numerous publications, we would highlight the following components in the essence of psychological preparedness: a) personality, i.e. motivation, aspirations, character traits, temperament, ensuring a high level of working capacity and consistent performances at competitions; b) mental processes and functions that contribute to the perfect mastery of tricks, techniques and tactics; c) stable (positive) mental states manifested in challenging training and competition conditions.

Research objective: Justify the actuality and the content of concept on "psychological assurance" in the system of sports preparation of athletes.

Research methodology and organization: The study of scientific and methodical, educational literature, theoretical and methodical analysis and results grouping.

The features of modern perceptions of psychological preparation are a new concept and a new approach - "psychological assurance as the most common and complete vision of a psychologist's work in sports". 
The concept of "psychological assurance" has appeared in the lexicon of sports specialists relatively recently (V. Melnikov, V. Nepopalov, 1985; V. Medvedev, 1989; G. Gorskaya, 1995). Although sport had qualitatively, by content and functionally changed by that time, the majority of sports professionals used to think in the category of "training of athletes". That is why the new term, by tradition and the established way of thinking, was also attributed to the training process. In our opinion, when evaluating as a whole it can be noted that the formation of the concept of "psychological assurance of the athletes' training" reflects a change in the approach to the psychological aspects of working with athletes which in its turn is a consequence of a change in the approach to the process of their training as a whole.

Conclusion: Based on the analysis of modern trends and the transition from "psychological training" to "psychological assurance" as an organized process, the following concepts can be highlighted: psychological aid; psychological service; psychological accompaniment, psychological support; psychological control; psychological security. They are closely interrelated processes and complete each other.

\section{ТЕОРЕТИКО-МЕТОДИЧЕСКИЕ ПРОБЛЕМЫ ПСИХОЛОГИЧЕСКОГО ОБЕСПЕЧЕНИЯ ПОДГОТОВКИ СПОРТСМЕНА}

Кандидат псих. наук, профессор А.А Бабаян

Государственный институт физической культуры и спорта Армении, Ереван, Армения

\section{PEЗЮME}

Ключевые слова: психологическая подготовка, психологическое обеспечение, сопровождение, обслуживание, помощь, безопасность, контроль, поддержка.

Актуальность исследования. Обобщая многочисленные работы, мы выделим в содержании психологической подготовленности следующие компоненты: а) свойство личности, т.е. мотивация, притязания, черты характера, темперамент, обеспечивающие высокий уровень работоспособности и стабильные выступления на соревнованиях; б) психические процессы и функции, способствующие совершенному овладению приемами, техники и тактики; в) стабильные (положитель- 
ные) психические состояния, проявляемые в трудных условиях тренировки и соревнований.

Цель исследования: Обосновать актуальность и содержание понятия „психологическое обеспечение" в системе спортивной подготовки спортсменов.

Методы и организация исследования: Изучение научно-методической, учебной литературы, теоретико-методический анализ и группировка полученных результатов.

Особенности современного развития представлений о психологической подготовке - это новое представление и новый подход - „психологическое обеспечение как наиболее общее и целостное видение работы психолога в спорте”.

Понятие „психологическое обеспечение” появилось в лексике спортивных специалистов относительно недавно (В.М. Мельников, В.Н. Непопалов, 1985; В.В. Медведев, 1989; Г.Б. Горская, 1995). Несмотря на то, что спорт к этому времени качественно, содержательно и функционально изменился, большинство спортивных специалистов по-прежнему мыслили в категории „подготовка спортсменов”. Поэтому и новый термин, в силу традиции и устоявшегося способа мышления, был отнесен к процессу подготовки. На наш взгляд, оценивая в целом, можно отметить, что формирование понятия “психологическое обеспечение подготовки спортсменов", отражает изменение подхода к психологическим аспектам работы со спортсменами, которое, в свою очередь, является следствием изменения подхода к процессу их подготовки в целом.

Выводы: Основываясь на анализе современных тенденций и перехода от „психологической подготовки” к „психологическому обеспечению” как организованному процессу, можно выделить следующие понятия: психологическая помощь; психологическое обслуживание; психологическое сопровождение, психологическая поддержка; психологический контроль; психологическая безопасность. Это тесно взаимосвязанные процессы и дополняют друг друга.

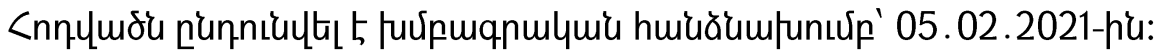

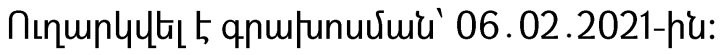


DOI: 10.53068/25792997-2021.1.3-19

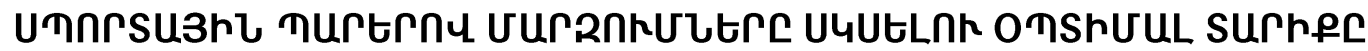
U.q.p., nngtiun <. U. 9uимшијшi,, v.q.p., nngtilup U. ч. Uupцphnnujui,

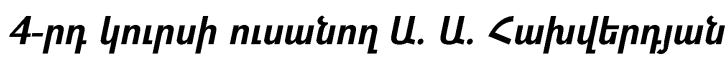

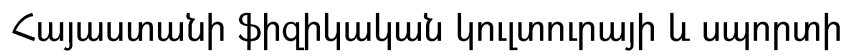

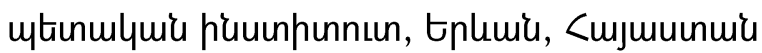
E.mail: hayk.gasparyan@sportedu.am, ani.martirosyan@spoertedu.am, amalya.hakhverdyan.2017@sportedu.am

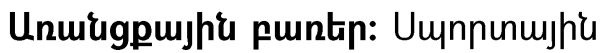

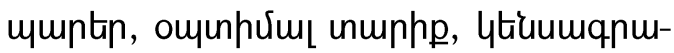
quǐ undjųutan, punăpulymng umunnn-

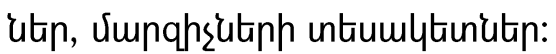

Ctunwqnunnıرuis upnhulyuiuntPjnılu: qununuhp st, nn 2uintinn vimnq-

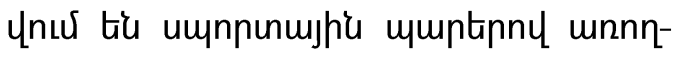

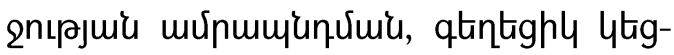

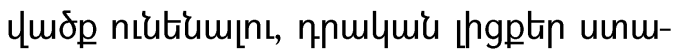
Güns hưump: Uju unnưny ununh-

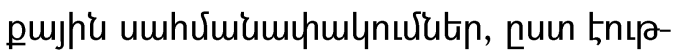

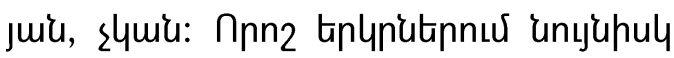
umunlyunţh unmphph quilump tiu qpunynuर umnnunushí umpinny: Uwpqnuरutinn ulutinı unuphpujh's gnıgu-

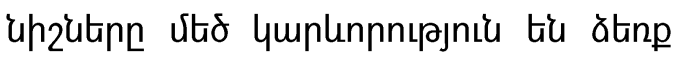

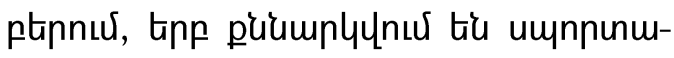

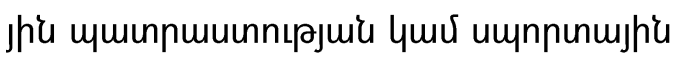

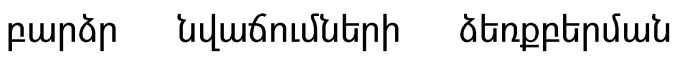
hurưuuntpuunnux: Uupnnunnuर Uumqnuरutnn ulutīns oupunhưul unuphpn nnn-

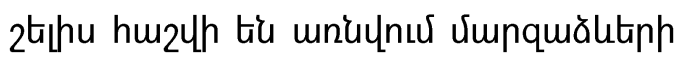

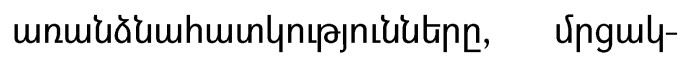

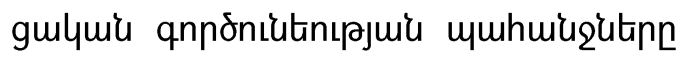

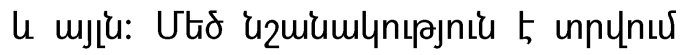
huunlumutu 2undnnulymí n'unniumlyntpjnıiutinh qqujniu 2nquiuutiph unuph-

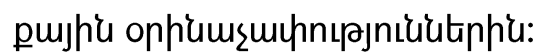

ntunufaumuphţny unuubjuly unpjnınutin' umunqultg, nn uщnnunujh's щуш-

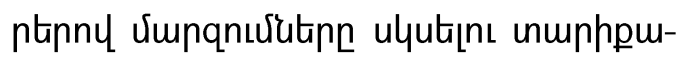

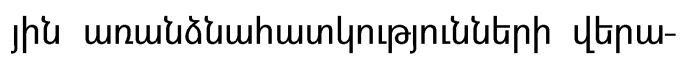

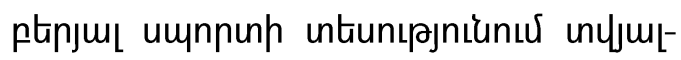
utip slymiu $[1,3,4]$, hul hurumguiugnus

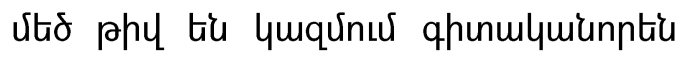
shpưumunnumo, pnumurtind untum-

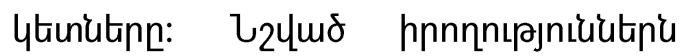

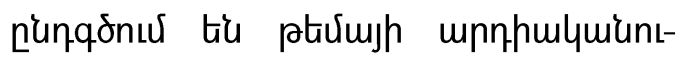
pjniun:

\section{Ctunuqnunnıpjur sumunuly}

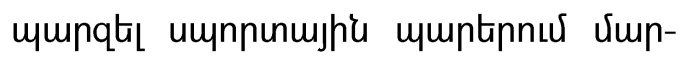

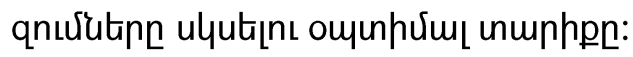

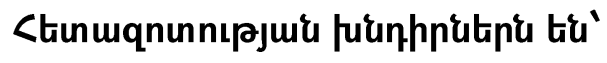

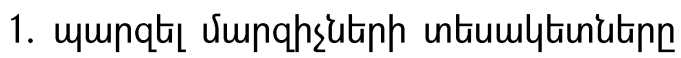




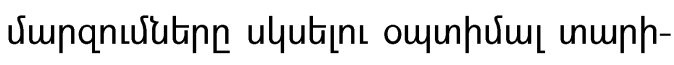

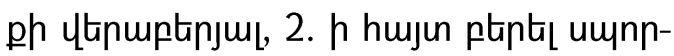

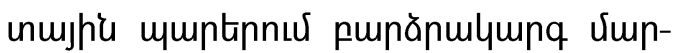

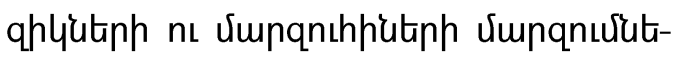

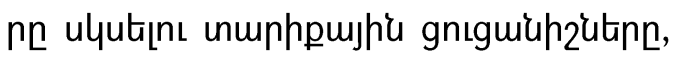

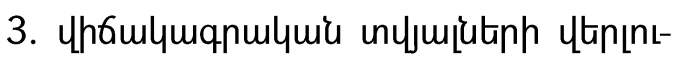

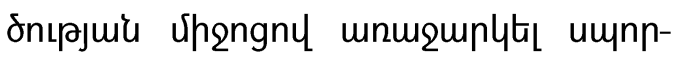

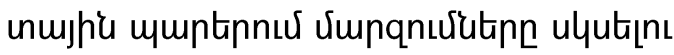
unuphpmjhu gnıguuh2utip:

Ctinmqnunnıpuis stapnnitinn $\mathbf{l}$ पuqưultenunıún: Ctunuqnunnıpuiu

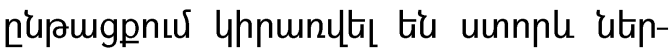
qujugy uo vitannitinn.

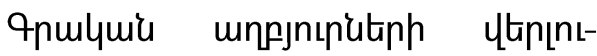

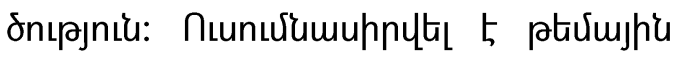
un'usunn hujtiptiu, nnsutintiu, miuqtentiu 40 qnulymir unpjnın (nsunuśumlymis

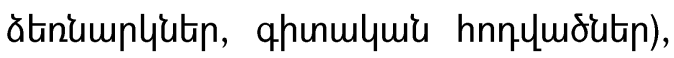

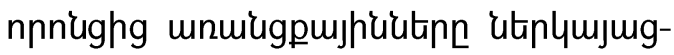

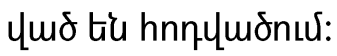

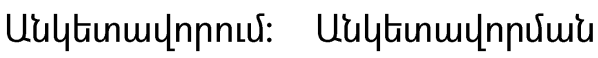
uhengny unnnăta tiup umpats Jumpqhsutph untumbtinutinn umnnunujhe

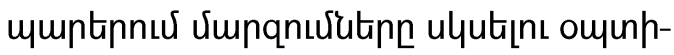

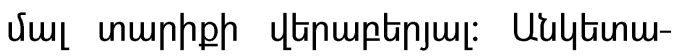
unnuimiun varuimugt 560 vimphs:

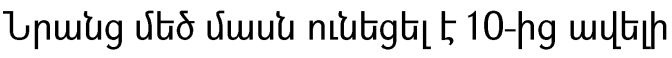

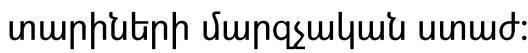

4tiuumqnulymír undjugutiph nunuर-

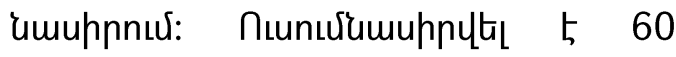
uphtiuunulume umunnnh ns umupnshns (ununptin unguzuntiph hunpannutin, unguiumlqulhprutin) vimnqnưlutinn ulyut-

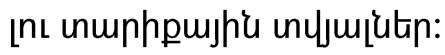

Umptrumunhlymlymir पhfimlumpnnpjuí Utapnnutan: <m24mplytal tiu huvimuরuptinn punspuqpnn hpưumlume

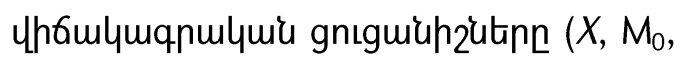
Me, $\sigma, \mathrm{m}, \mathrm{V})$ :

<urumpunptenn huvituimunt,hu 4h-

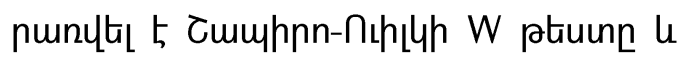
Uwiu-nıhpuhh U zurumuh22 [5]:

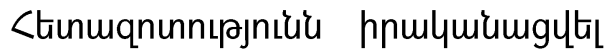
2021 р.: <tinuqnunnıpuiu nupmgpnux

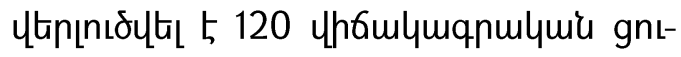
guiuh2:

\section{Ctunuqnunnıpjui unnjnituputiph}

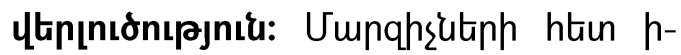

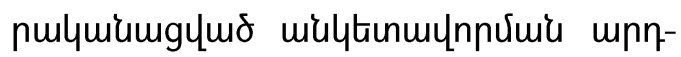

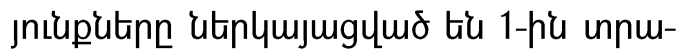

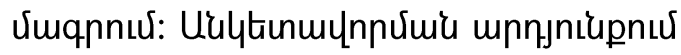
umunqutg, nn vimphsitiph vito vimun huvumpnu t, nn hupuptpulquiunntiu yun unmphphg vimpqutın umuinulym-

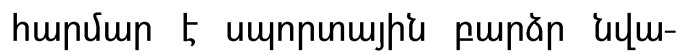

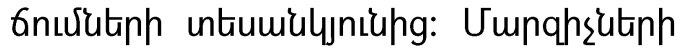

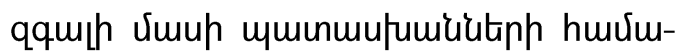

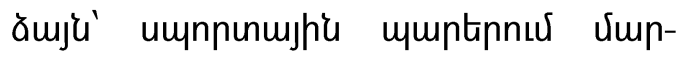
qnưlutinn ulyut_nı ouyunfưul unmphpn 5 unuptiluiuru b $\left(X=5,47, M_{0}=5, \quad M e=5\right.$, $\sigma=1,44, m=0,19, V=26,32)$ : Cun nnnuर' hungynnutiph 23,3 unnlynu'u ominhưul ununpp 5 huviunnux 4 inuntilumin:

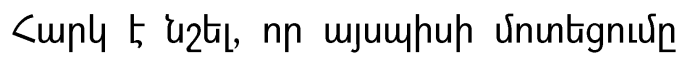




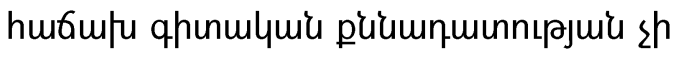

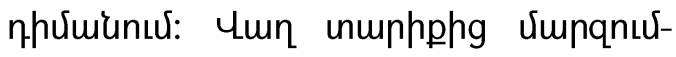

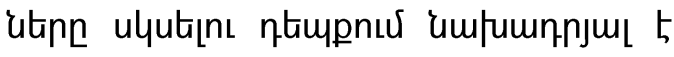

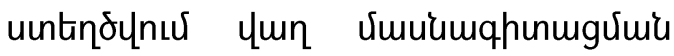

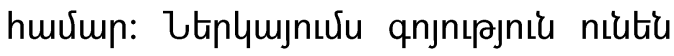
qhunulymir ununptip shuuunten, nnnup hpứumunnnuर tiu yun vimulumqhunugvivis purgmumlymí ynnutann $[1,8,9]$ : furgh mjn, umnnunujhí qtiutionhlumshg hujunup $5, \mathrm{nn}$ vimphly umnnumujh

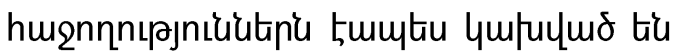
qtiutinnly qnodncutiphg: <uraupu unuquiunuunn vimpqhyuten' nı vimpqnıhp-

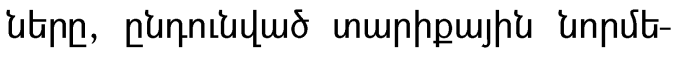
nhg up puiuh unuph nı2 ulutinny vimp-

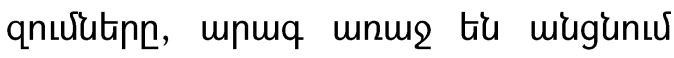

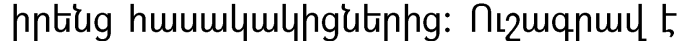

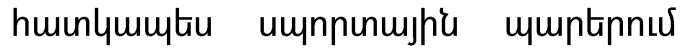
vito mpnjniuputin qnuiugmo 4mputiu uhustihn umnnumujher ytiuumqnnt-

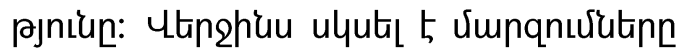

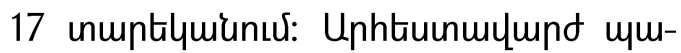
pnihp Uquit24m Utyhuglumir umnnunujhis umpinten ulutas 5 qpunyta 13 unuptiluiuhg, hujunuh hujuqqh upunnn Unvití Jumnnıpuiun' 9, Utinqtj njntuh'un' 13, uhlunnn Uplnululh'i $14 \mathrm{l}$

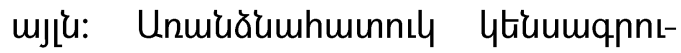

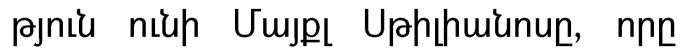

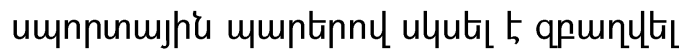
18 inumblyming [10]:

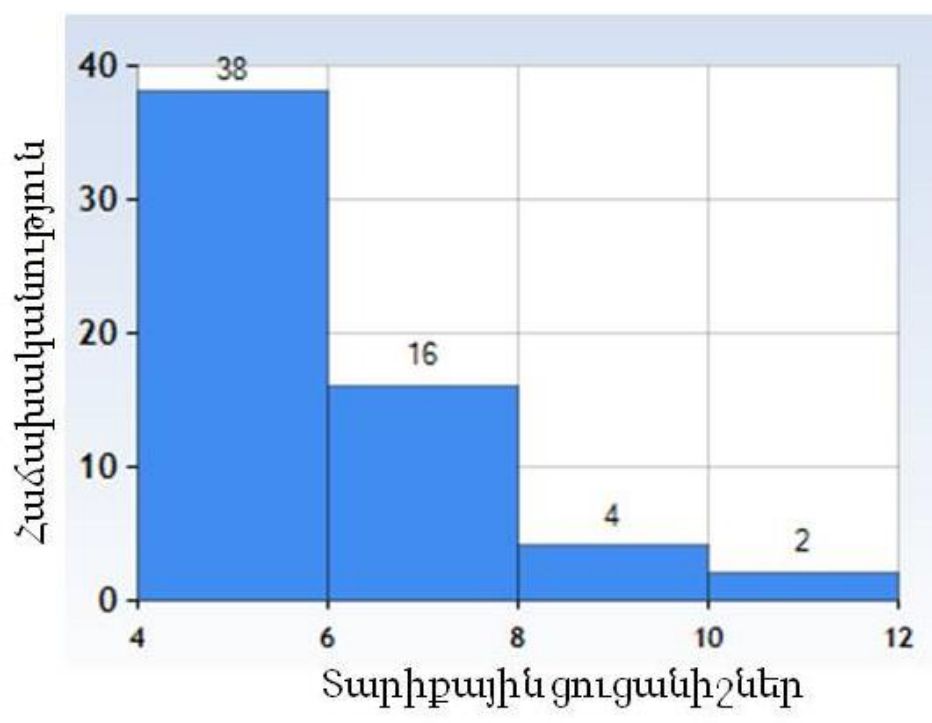

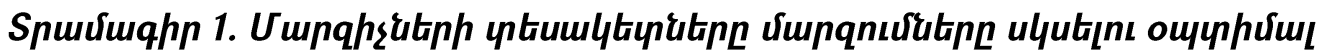
чиuphph ythuptpjuI 


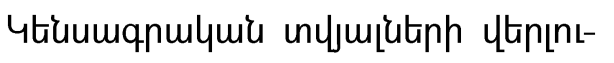

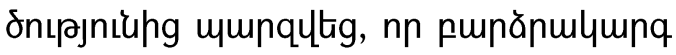
umunnnitiph nı umunnshpitinh vimpnnu-

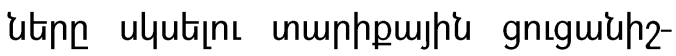

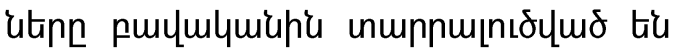
$\left(X=9,76, \quad M_{0}=5, \quad M e=10, \quad \sigma=3,74\right.$, $\mathrm{m}=0,48$ ): 3ntguiuh2utiph muhurumut-

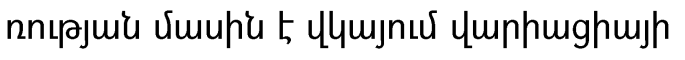
qnnomlhgn ( $V=38,31)$ (unnuviughn 2):

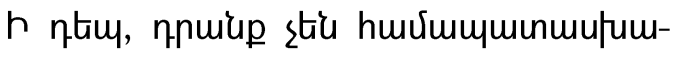

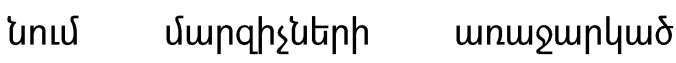

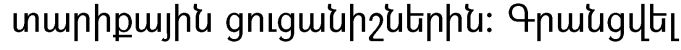

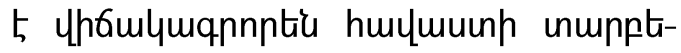
pnıpjniu $(U=512, p<0,05)$ : <uply 5 ù

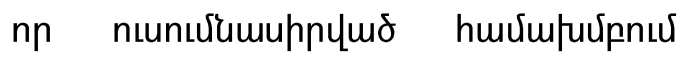
undjugutinn puzluyuro stiú unnưul

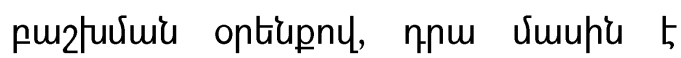

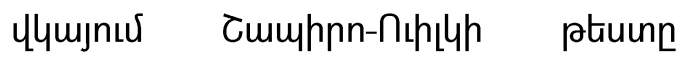
$(p<0,05)$ : 7m Glymununuर t5 Gum 2-nn

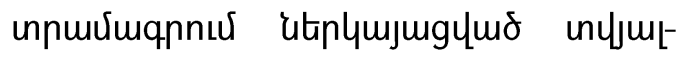
utuphg:

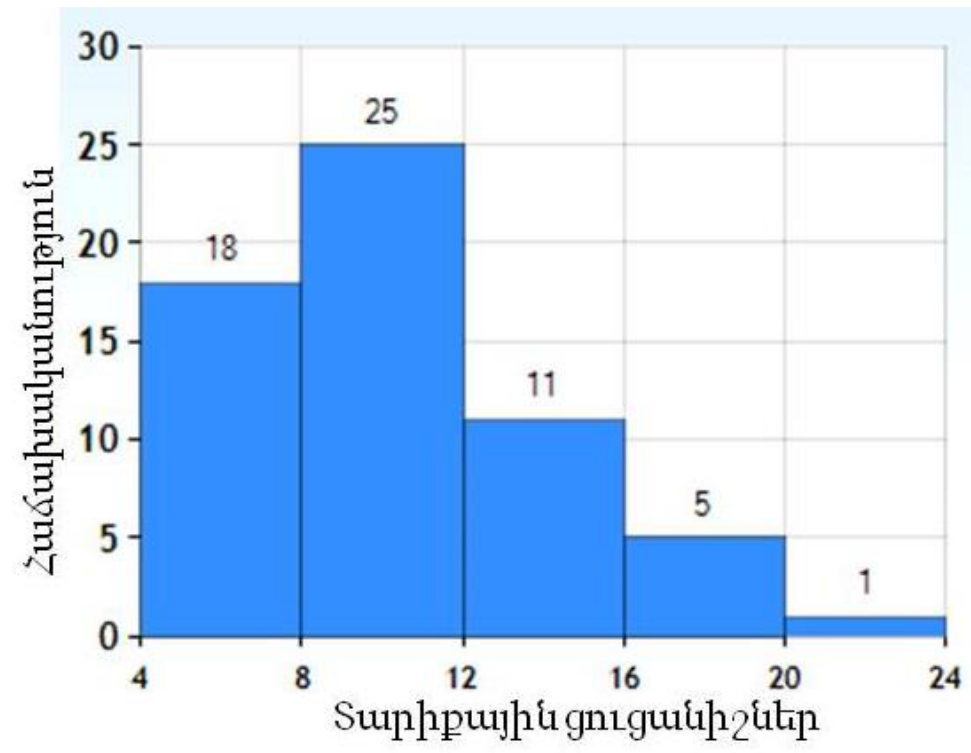

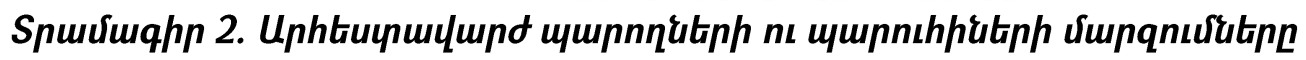

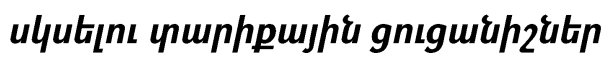

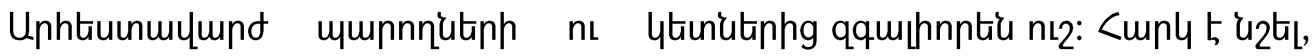

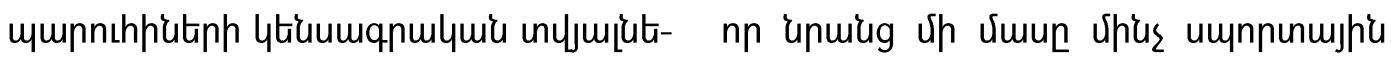

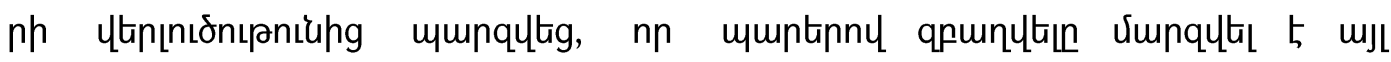

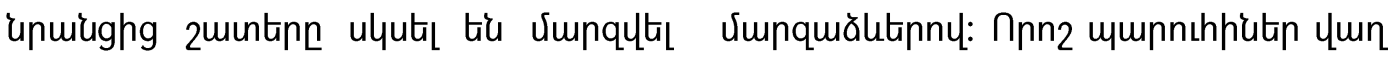

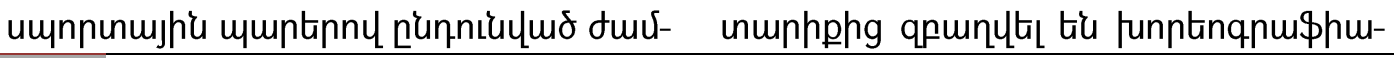




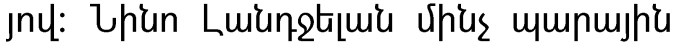
mynuर्up huratutin qpunyta 5 vimnonunltaunny: <mium 4mponniatiu 3 inuntiluming qpundtal 5 pustinny le upuju 10-n inmptymiunus t ulyuts qpunytal uunnunujhí uquntinny [10]:

Tumnniutph ns umunnshplutiph Jump-

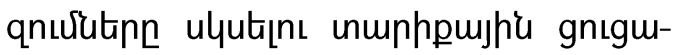

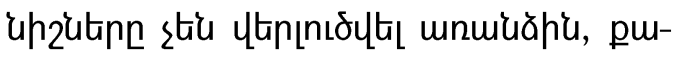
up nn ytanghuiutnhu gnımiunzutinnu Uhfulymqnnptis hulumuinh unupptipntpjnı'u sh qnuiuglta:

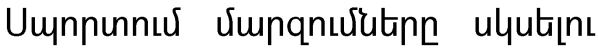

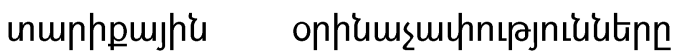
pulumplithu wuhnudtan 5 mianpu-

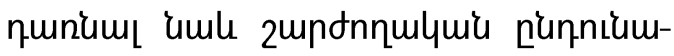

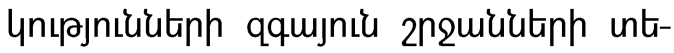
unıpjuiun $[1,2,6,7]$ : Ctiunuqnunnıpnııutnn gnug tiu unlta, nn nunngulyuís

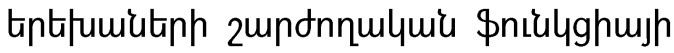

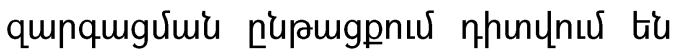

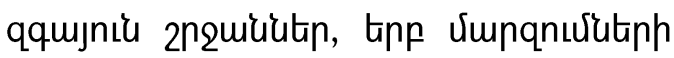

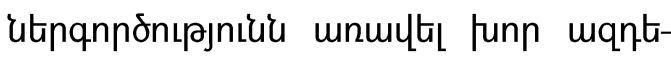
gnıpjniu 5 niutiunuर zundnnulyuiu nূu-

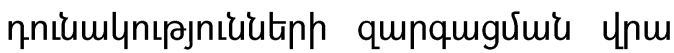
[2]: Cuin nniu hanhiumliutph' tipt tintfumitinn \$hqhlumlumi yundnıpniukitn

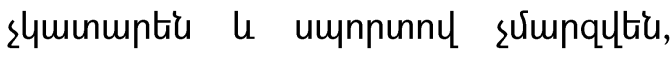
шщмш 13-14 unmptiluming mpuqujhis

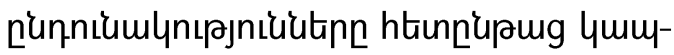
ptiú [6]: ๆ-u unulyta yun 5 mpnumhujununux huinlumutu unghlyutinh
Unun: Uunnunp nınnunp qhuniumlumüutiph intumbtinutinn huরumămju' zmondn-

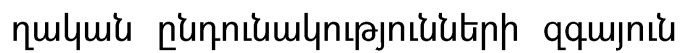

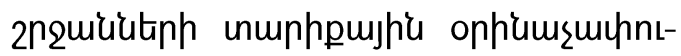

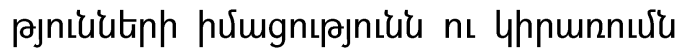

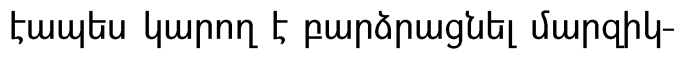

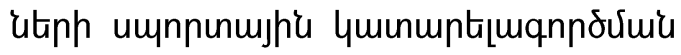

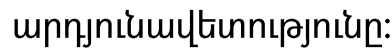

funn ynnnnpiumghne vimp-

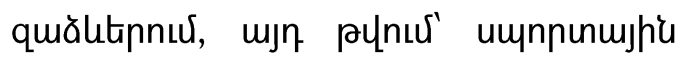

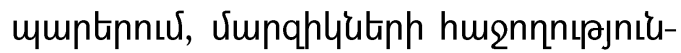

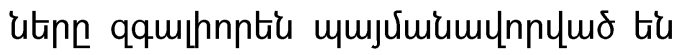

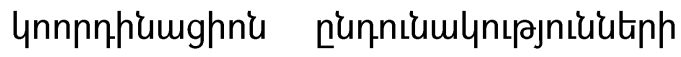

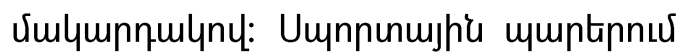
ymplunnnus tiu cumb mpuquzmpont-

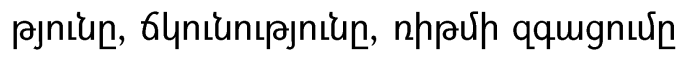

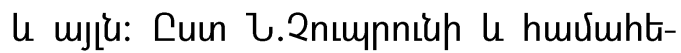
nhumlyutiph undjugutinp' ununutin nunn-

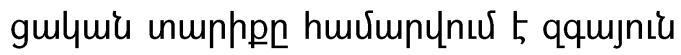

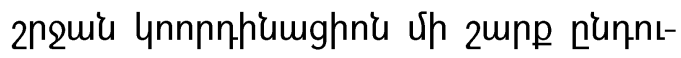

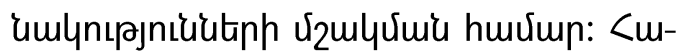
yuumpuly2nnıрjuiu, 2undnuxutiph

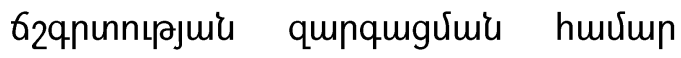
ytanghuiutinu qqujniz 2nquir tiu huvumnnu 7-8 ununtiluiu humuly, huly

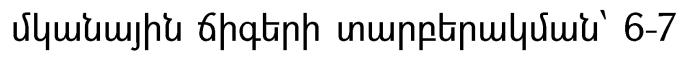
(unnuibin), 7-8 (unghlutitn) [7]: Cuin \$.9. 2uqumpuiuh undjujutinh' mnghliutnh Gupmlnnıرuí qqujnilu 2nquin

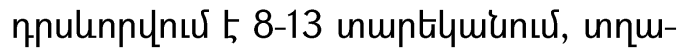
'utphiun' 8-9, 11-14 [2]: <unl 5 'ü

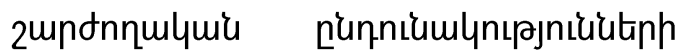




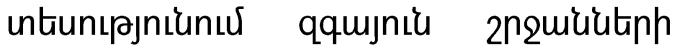

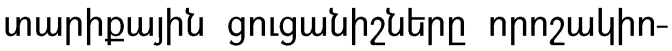
ntiu ununptinunux tiu: tpptiúu huiunhunnu tiu úpujuing hulymunn unujųutip: <trnhamliatiph qquih vimup unmemp-

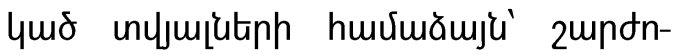

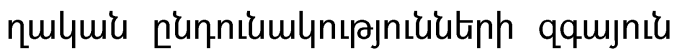
2nquiutunn ulyulnuर tiu 6-7 unuptilumung $[1,2,6,7]$ : กnutu yuiund' ynnnnh-

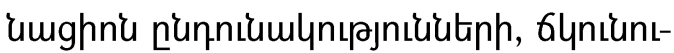
pjuí le unuquzmpdnıpju'u qqujniuntpjniun hupuptinulymiunntiu 2niun

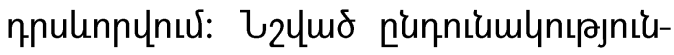

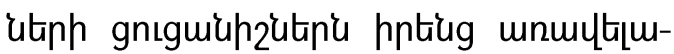
qnuju verlumpulyhe ununtiunus tiu

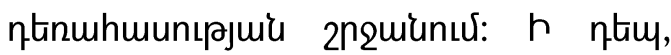

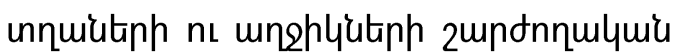
n'unnıłumlynıpjnı'uuteph qqujnı'u 2nquiu-

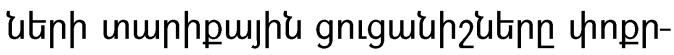
hús unupntanunư tú:

tqnulyugnıpjnıt: Ctinuqnunnt-

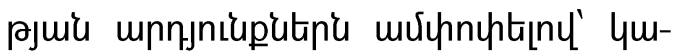

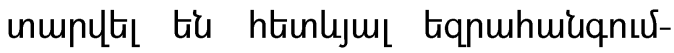
utinn.

Umpqhsutiph 87 unnlynun घumu-

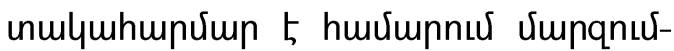
utnn ulyuts 4-6 inmpilymiahg, uhisntin vitn neunudamuhnmo mphtiunmulund

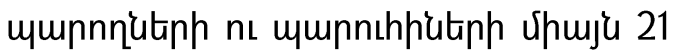
unnlynu's 5 ulyuts mju unmphphg vimpq-

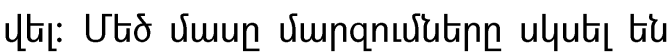
n'unniulud duर्ultiunutiphng nเ2:
Funănulyunnq umpnnnutiph nı

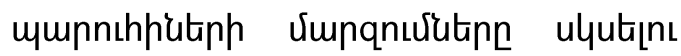
unuphpujhe gnıguuh2utinn puцu-

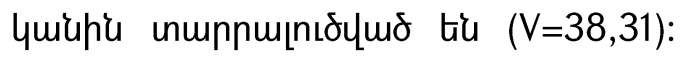

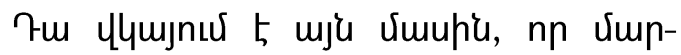
qnưlutinn ulyut_nı unuphpujhe unputann

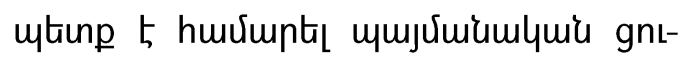
guiup2utip:

funnănulyming umunnnutinp nt

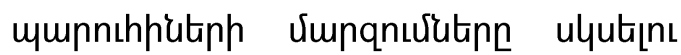

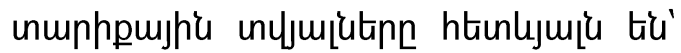
$X=9,76, m=0,48$ : Ujumpuny' umnnunu-

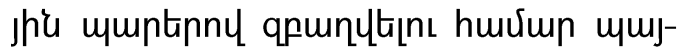
suiumlymiunntiu qunten 5 9-10 ununtiquiun huviuntis omunhưu[ ununhp:

Tuunnulitph ns umpnshplutiph

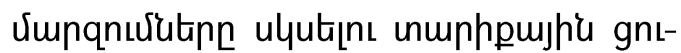
guinhzutinnuर uhfiulumpnntiu hurumu-

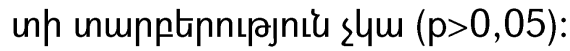

Uun unuphphg vimpqutin

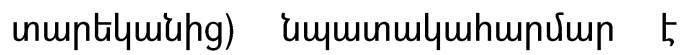

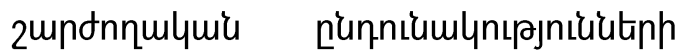

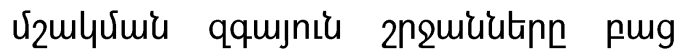

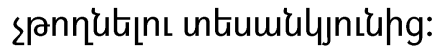

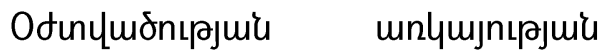

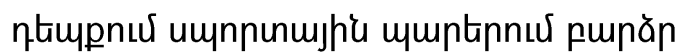

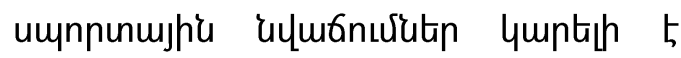

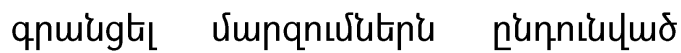

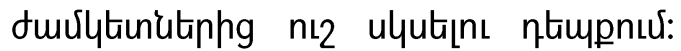

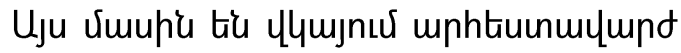

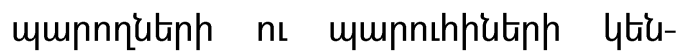
umqnulymí undjugutnn: 


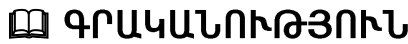

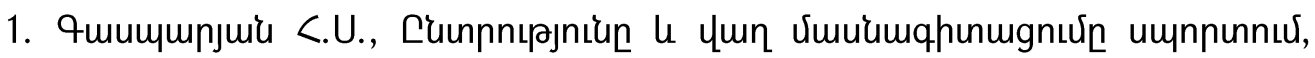
tplumiu, 2015, 88 52:

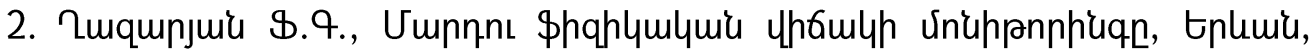
2007, 215 t2:

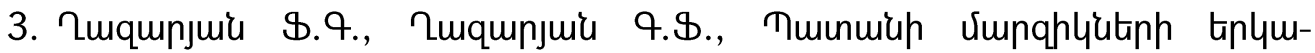

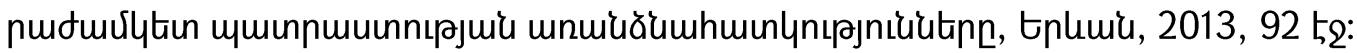

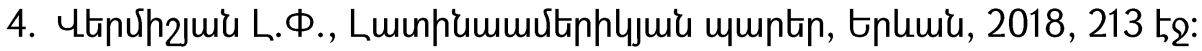

5. Иванов В.С., Основы математической статистики. - М.: Физкультура и спорт, 1990. - 176 с.

6. Тхорев В.И., Аршинник С.П., Сенситивные периоды развития двигательных способностей учащихся школьного возраста. Краснодар: «Физическая культура, спорт - наука и практика», 1/2010, с. 40-45.

7. Чупрун Н., Юрченко И., Юрченко Э., Возрастные особенности развития координационных способностей детей 6-9 лет. ГВУЗ :< Медицини, біології та спорту>> - 2020 - Том 5, № 2 (24), с. 296-300.

8. American Academy of Pediatrics, Committee on Sports Medicine and Fitness. Intensive training and sports specialization in young athletes. Pediatrics. 2000; 106 (1 pt 1): 154-157.

9. Malina R.M., Early sport specialization: roots, effectiveness, risks. Curr Sports Med Rep. 2010;9(6):364-371.

10.http://ballrooms.su/publ/3-5. 


\section{THE OPTIMAL AGE FOR STARTING SPORT DANCING TRAININGS}

\section{Ph.D. of Pedagogy, Associate Professor H.S. Gasparyan \\ Ph.D. of Pedagogy, Associate Professor A.V.Martirosyan}

Fourth year student A. A. Hakhverdyan

Armenian State Institute of Physical Culture and

Sport, Yerevan, Armenia

\section{SUMMARY}

Keywords: sport dancing (ballroom), optimal age, biographical data, professional dancers, coaches' opinions.

Research objective: to reveal the optimal age for starting ballroom sport dancing.

Research methods and organization. During the research, the following methods were used: 1 . analysis of literary sources (educational and methodical textbooks, scientific articles), 2. survey (60 coaches took part), 3.analysis of biographical data (biographical data of 60 male and female sport dancers were studied). Most of the coaches participated in survey were with more than 10 year working experience. The research was conducted in 2021.

According to the responses of a significant part of the coaches, the optimal age to start training in sport dancing is 5 years old $(X=5.47, M o=5, M e=5, \sigma=1.44, m=0.19$, $V=26.32$ ). At the same time, 23.3 percent of respondents consider, that the optimal age is 4 years old. However, the biographical data of professional dancers do not coincide to these opinions. From the analysis of biographical data, it turned out that a significant part of high-class dancers started dancing quite late $\left(X=9.76, M_{0}=5\right.$, $\mathrm{Me}=10, \sigma=3.74, \mathrm{~m}=0.48$ ). Most of them started dancing from the age of 8-11, some of them from 13-17, etc. The opinions of the coaches and the biographical data of the dancers are statistically different $(p<0.05)$.

Conclusion. The studied age data of high-class dancers have a great range $(V=38.31)$. This indicates that the age norms of the start of sport dancing trainings should be considered conditional data. Thus, the optimal age can be conditionally considered from 9 to $10(\mathrm{X} \pm \mathrm{m})$. Training from an early age (from 6-7 years) is ad- 
visable from the point of view of the implementation of sensitive periods of motor abilities.

\section{ОПТИМАЛЬНЫЙ ВОЗРАСТ ДЛЯ ЗАНЯТИЙ СПОРТИВНЫМИ ТАНЦАМИ}

К.n.н., доцент Г. С. Гаспарян, к.n.н., доцент А. В. Мартиросян, студентка 4-го курса А. А. Ахвердян Государственный институт физической культуры и спорта Армении, Ереван, Армения

\section{PEЗЮME}

Ключевые слова: спортивные танцы, оптимальный возраст, биографические данные, профессиональные танцоры, мнения тренеров.

Цель исследования: выявить оптимальный возраст для начала занятий спортивными (бальными) танцами.

Методы исследования и организация. В ходе исследования были применены следующие методы: 1) анализ литературных источников (изучены учебно-методические пособия, научные статьи); 2) анкетирование (в анкетном опросе приняли участие 60 тренеров); 3) анализ биографических данных (изучены биографические данные 60 спортивных танцоров и танцовщиц). Большинство тренеров, участвовавших в анкетном опросе, имели более десяти лет тренерского стажа. Исследование было проведено в 2021 году.

Согласно ответам большинства тренеров, оптимальным возрастом для начала тренировок в спортивных танцах является 5 лет $(X=5,47, M o=5, M e=5, \sigma=1,44$, $\mathrm{m}=0,19, \mathrm{~V}=26,32)$. При этом 23,3 процента респондентов считают оптимальным возрастом 4 года. Однако, биографические данные профессиональных танцоров и танцовщиц говорят о другом. Из анализа биографических данных выяснилось, что значительная часть высококлассных танцоров и танцовщиц начали заниматься танцами довольно поздно ( $\left.X=9,76, M_{0}=5, M e=10, \sigma=3,74, \mathrm{~m}=0,48\right)$. Большинство из них начали заниматься с 8-11 лет, некоторые из них с 13-17 и т. д. Мнения тренеров и биографические данные танцоров и танцовщиц статически достоверно различны $(\mathrm{p}<0,05)$. 
Заключение. Изученные возрастные показатели высококлассных танцоров и танцовщиц довольно сильно различаются $(\mathrm{v}=38,31)$. Это свидетельствует о том, что возрастные нормы начала тренировок следует считать условными показателями $(\mathrm{X}=9,76, \mathrm{~m}=0,48)$. Таким образом, оптимальным возрастом условно можно считать 9-10 $(\mathrm{X} \pm \mathrm{m})$. При наличии спортивной одаренности в спортивных танцах можно достичь высоких спортивных достижений даже в случае позднего начала тренировок. Тренировка с раннего возраста (с 6-7 лет) целесообразна с точки зрения реализации сенситивных периодов двигательных способностей.

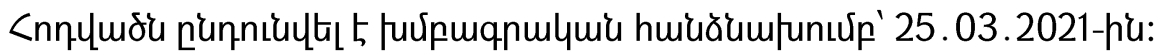

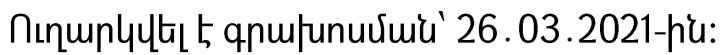


DOI: 10.53068/25792997-2021.1.3-29

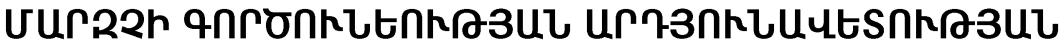

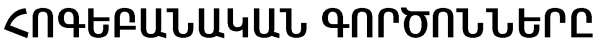

\author{
<.q.p., nngtinu 4. 2. 9tinuर्ujuis

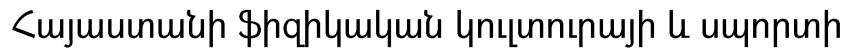

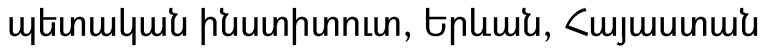 \\ vardan.geghamyan@sportedu.am
}

Unuiggumpq puntin: Uupqhs,

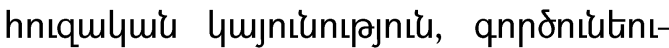
pjuiu unn.jniumultinnıpjniu, wiŭ:

Stonmqnunnıpuir upnpulquínt-

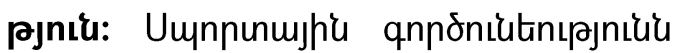

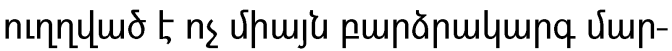

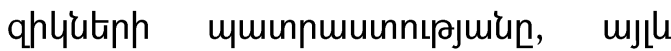

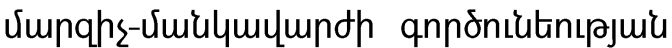

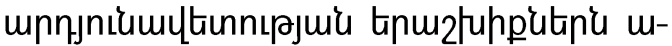

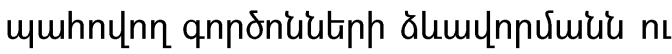
qunqugưuiun, husn 2min ynnutanny

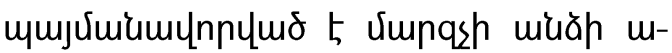

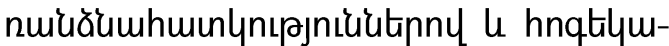

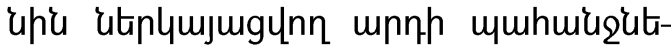
nny $[3,5]$ :

Ułăh ălumunnưừ mnwuăumuhmun-

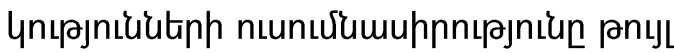

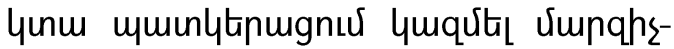

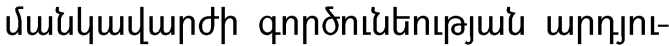
umultunnıpjnıu'u mumhnunn hnqtipu-

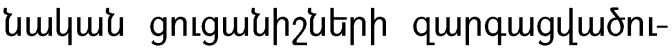

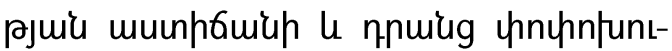

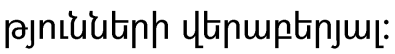

Dth puqưuphy htunmqnunnıpjnıน-

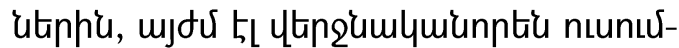

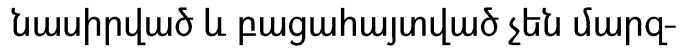
sh miăh hnqtipuiumlquí mnmquinum

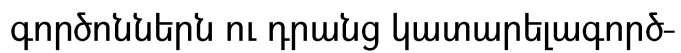
úüu nınhuitinn $[1,2,4]$ :

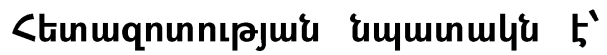
puguhmujunts unupntan veunquălutinn

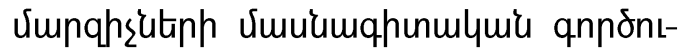

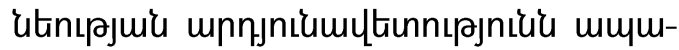

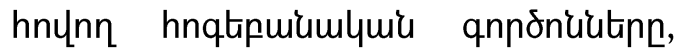

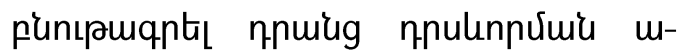

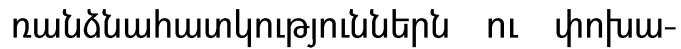

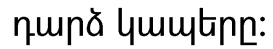

Ctunuqnunnıرuir vitpnnitinn $\mathbf{u}$

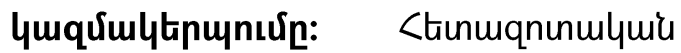

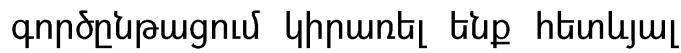
vtipnnitinn' qhunuरtipnnulquiu qpu-

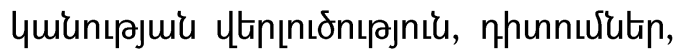
ptuuntin, mulytunmunnnuर, vimptiumunh-

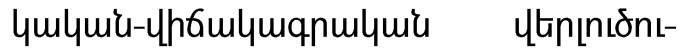
pjnilu:

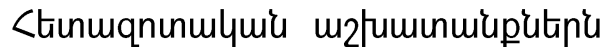

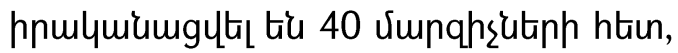


npnughg 20-n fumqujhú vimpquălutph

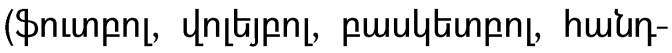

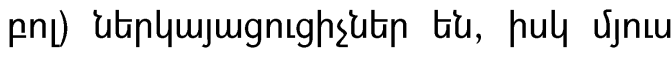

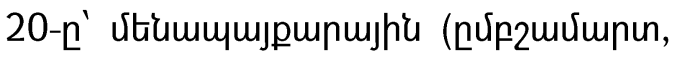
pnügpuưưnun, ăjnınn, umữpn): <tinu-

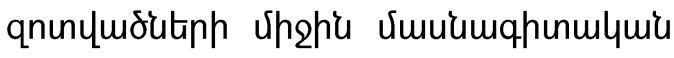

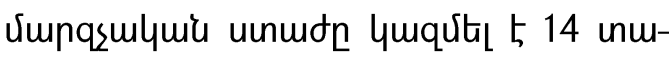
nh:

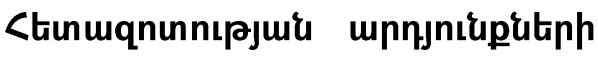

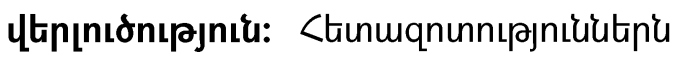

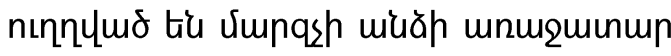

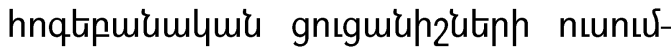

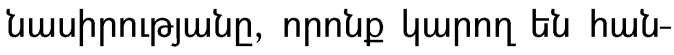

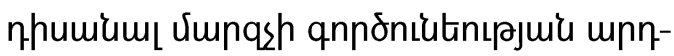
jnilumutiunnıpnilu' mumhnцnn unu-

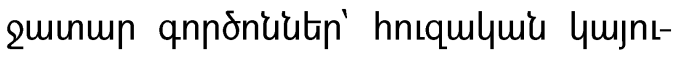

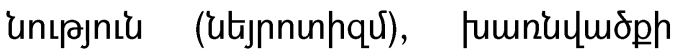

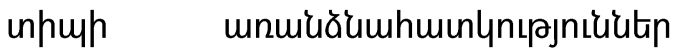

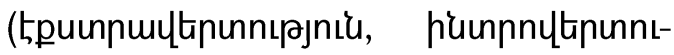

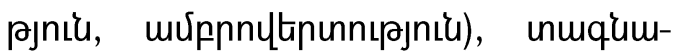

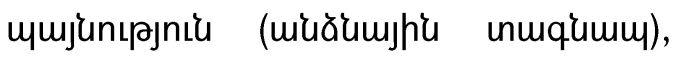
цnu\$เhlunujunıpjnı:

Uunqhşutiph hnıqulquiu 4ujnıunt-

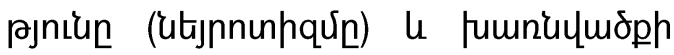

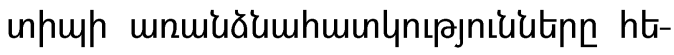
unuqnunlta tiu Ujqtiulyh hungunuiuh

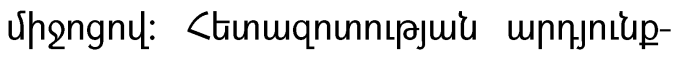

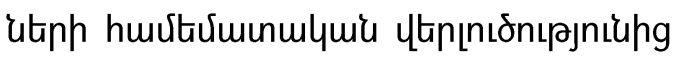
tpplunuर 5 , nn husutiu tpuinnuultinupush,

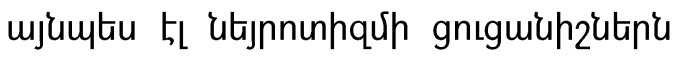

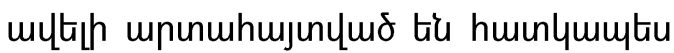

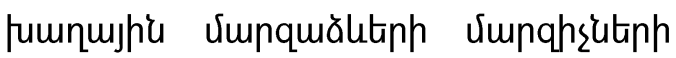

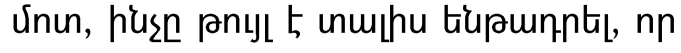
unwiup muth 24hynn tiu, hunnnqulgylthu mutth malqu2lumin tiu,

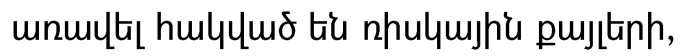
pưunцupy tiu, umpunumnnuर tiu qnnon-

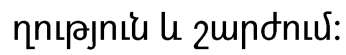

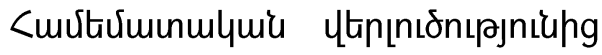
umunq 5 qununus, nn htunuqnunumo gniguiuh2utenh huquuunh unupptipntpjnı̌ 5 qpuiugltal utjpnnonhqúp gnıguuh2h ntiupnuर $(p<0,001)$ :

Utiumumjpunmuph vimpquălitiph

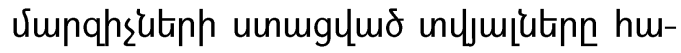

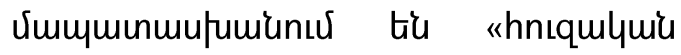

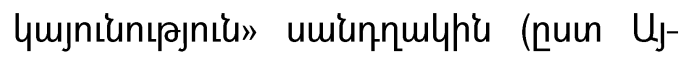
qtiulph hupamqumhumúura ptuunn' utjpnunhqư gnıguiuh2 9,6), h'usn чlym-

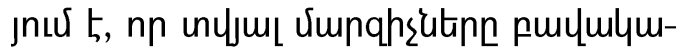

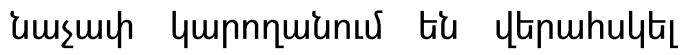

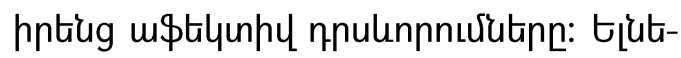

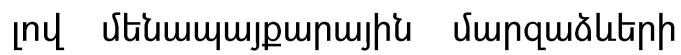

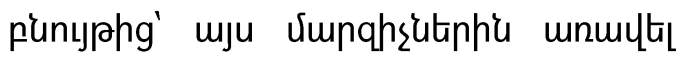

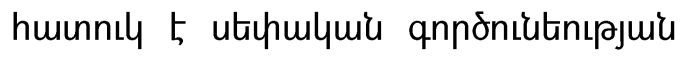

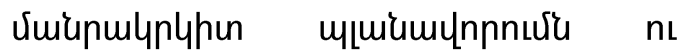

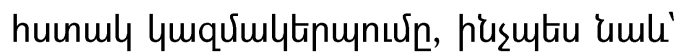

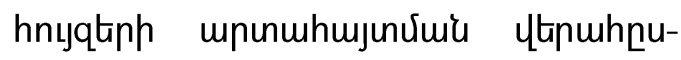
4nưn:

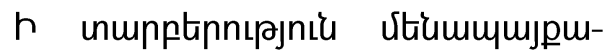
nujhé vimpquălitph, fumnujh's vimp-

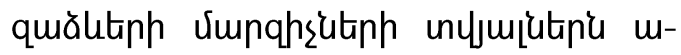

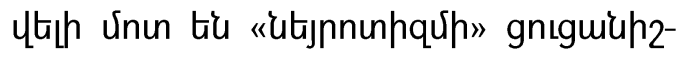
utaphí (utjpnonhqu 14,2): hisuliu 
hujunup 5, fumqujhé vernquălutiph

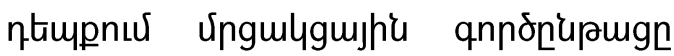

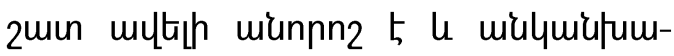

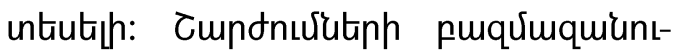

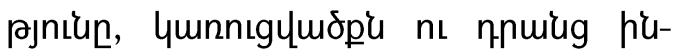

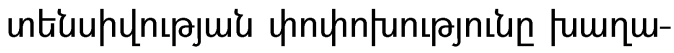

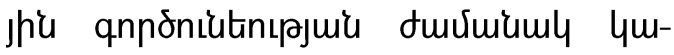

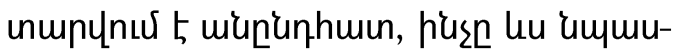

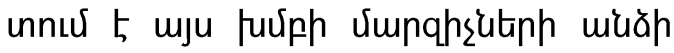

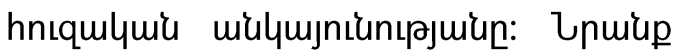

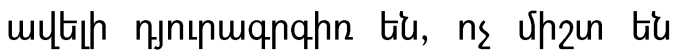

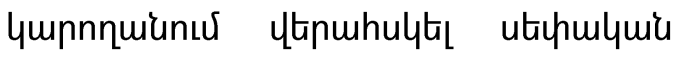
hnugtinn lu hulyumo tiu mqntiupцnıрјuน:

2umjus nn tpuinnulttpunnıрuiu gntguiuh2utph upgle huquuunh unmpptinnıpjnı'u sh qnuiugltı $(p>0,05)$, umquje mjuntin ue ulquinth tiu nnn2

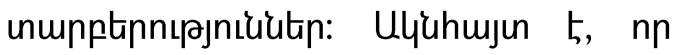
unnlnumjhe hupuptennıрјuर्up fumnu-

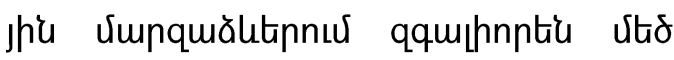

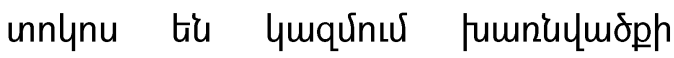

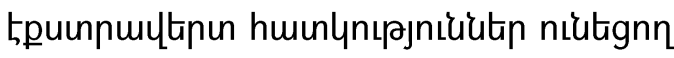
Uunqhs'utnn' 64\%, hiunnnytunumutinn

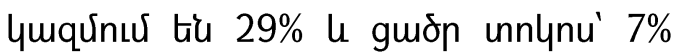
uर्upnnltanunutinn: Uju thuuunn vityum-

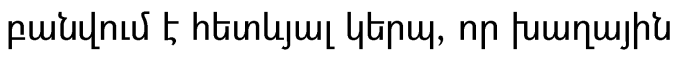

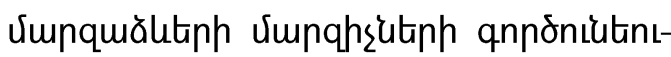

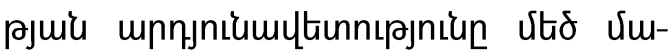

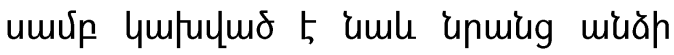

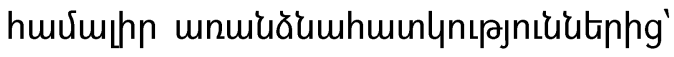

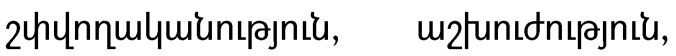

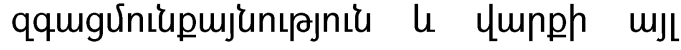
ununuhujunviuiu ălatp, npnup punnn2

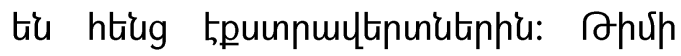

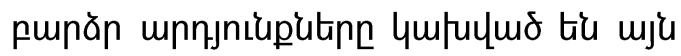
puiuhg, at nnpuiuny 5 umphes 24 ưuiru duviuiumly huzlh mounuर fumnugnn-

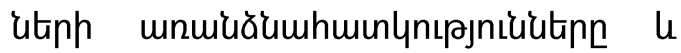

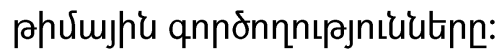

hus ytamuptinnuर t5 vitumumujpunujhé vimnquălitinh veunqhsutinher, muqu mjuntan ptile qtipuly2nnus tiu spuinnmultanuzitinn $\quad$ (40\%), umlymju

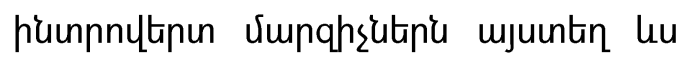

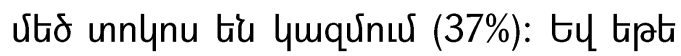

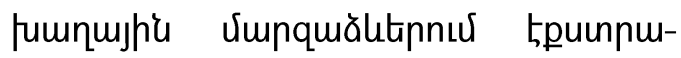

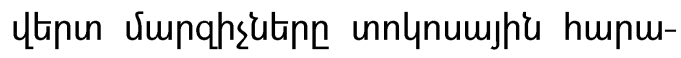

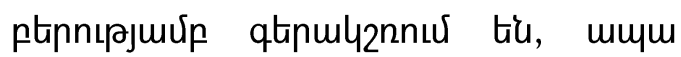

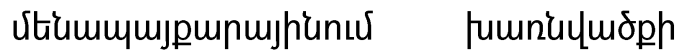
tpuinnuultanu $\mathrm{l}$ hiunnnytapun huunynıрjniưtinny vimnqhsiatinn qptipt huymump tiu, huर्umumunua|umiumpup' 40\% l 37\%: Snlnumjhe tulquid unupnt-

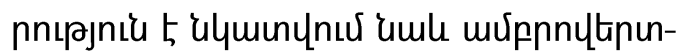

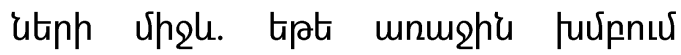
ytanghuiutnu quqưnu tiu nunuritiun 7\%,

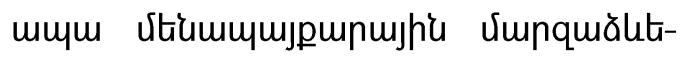

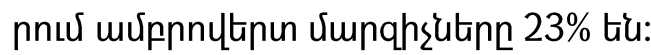

umpnn tiup mut, nn hiunnnyltinun-

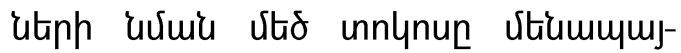

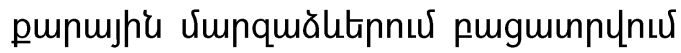
5 unuiuny, nn n'unnyud vimpquălup

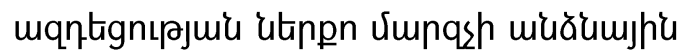




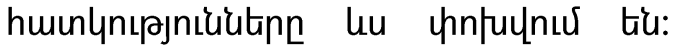

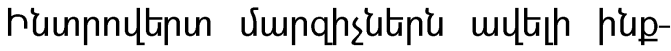

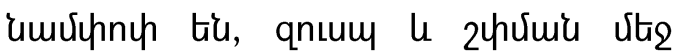

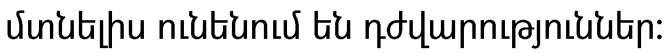

tumuhin-Uuphptepqtiph hupumqum-

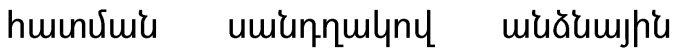

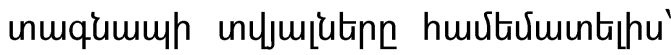
hurluuunh inupptipnıpnicu sh qpuing-

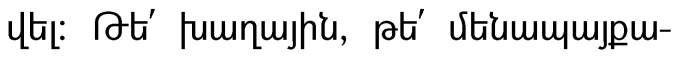

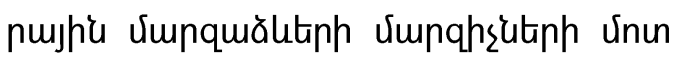

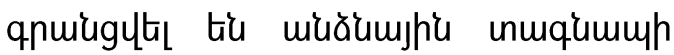

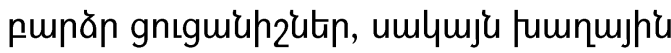

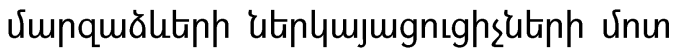

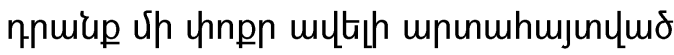

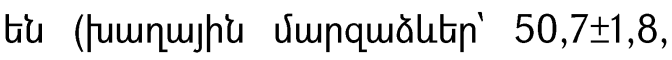

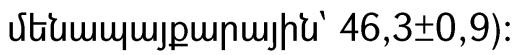

Eupunnunuर 5, np husutu upntiu

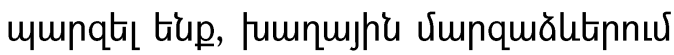

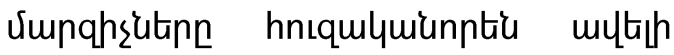

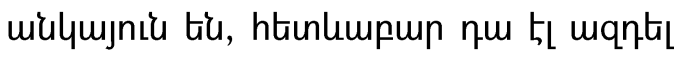

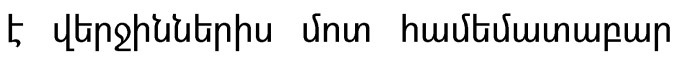

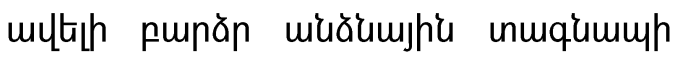
пnulunnúuiu ynu:

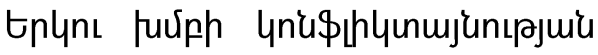

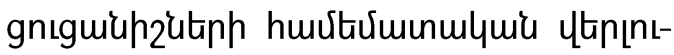

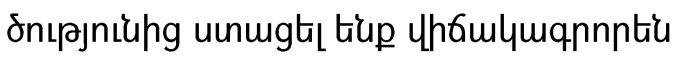

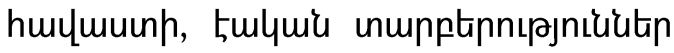
$(p<0,05)$ : Utiumumjpmpujhis vimp-

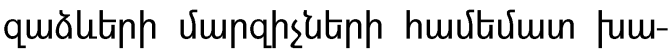

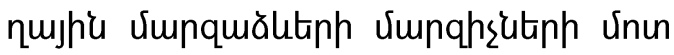

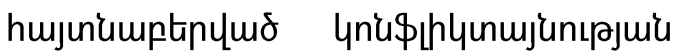

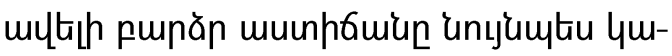

nnn tiup qumuts ytinghiutitiphu unnon

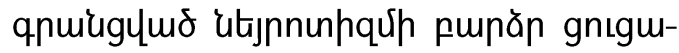

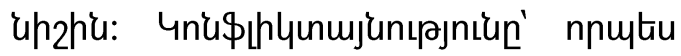

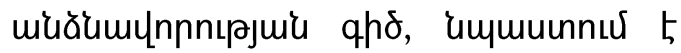

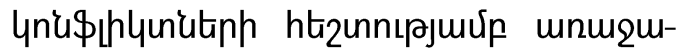

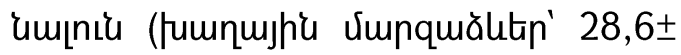

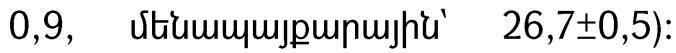

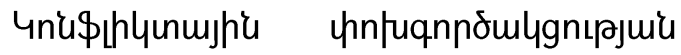

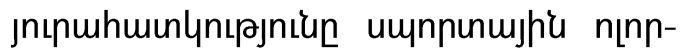

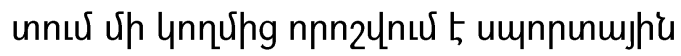

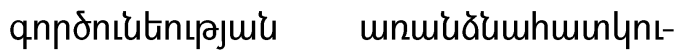

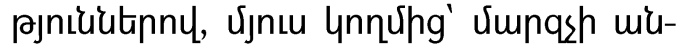

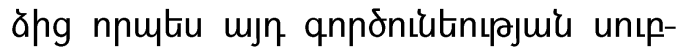
jtilunh: $t 4$, puiuh nn fumnujhí vimp-

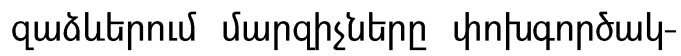
gnuर्u tú muth 2uin vimphlyutiph htion,

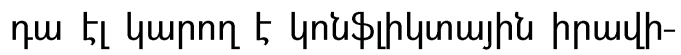

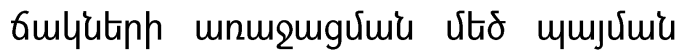
huiunpumium[: Fugh mjn, vimphs'u mjuuntin equnumulnn t5 qunquulnntis ns uhuju hn le vimphlyh uhqle unmemgur

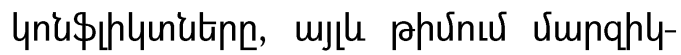

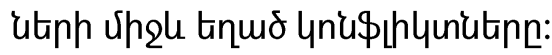

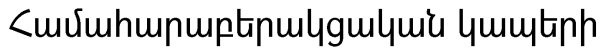

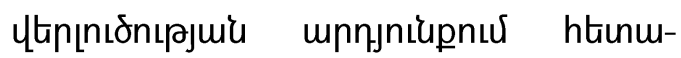

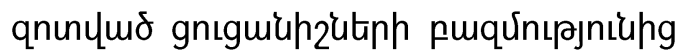

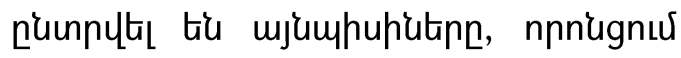

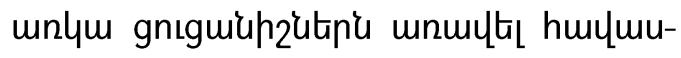

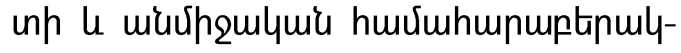

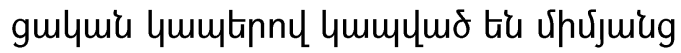
u hptiug punusany ltiunnniumlyuiu n.pn- 


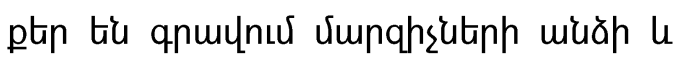

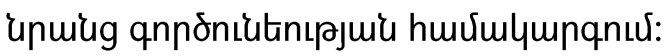

Cuin Ujqtiulyh hungmpuih htinu-

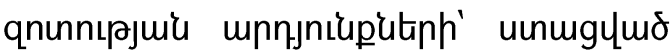
gnıguiuh2utph puqữnıpnıung unwiuă-

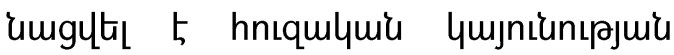
(utjpnonhquip) gnıguiah2n, nnh htin

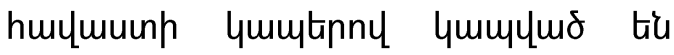
úunqş wiuăh hnqtilquiu unumptip gntguuhzutitip:

<tinmqnunymo hnqtipuiumlymí gnt-

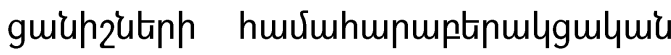

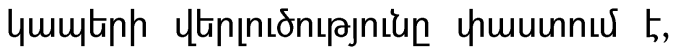
nn tiplns fữph vumphšutnp wuăh

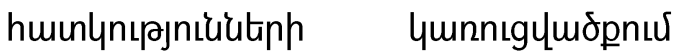
ytünnnumlyuiu untin 5 qpuntigunu fumnulumoph unpuph hnıqulyuir ymuntunıpjuiu gnıguiuh2n: Sujuı gnıguiuh2n

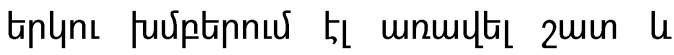

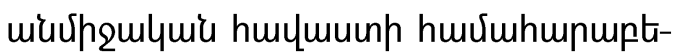
nulygulymir yumitn 5 nnulunntal hnunu-

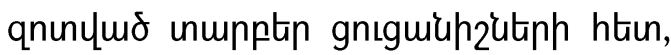

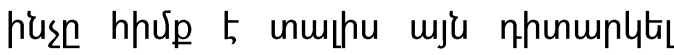
nputiu vimpqhštiph wiăh unmquinum u hpứumlumi hnqtapuiumlyuiu gnıguiah2:

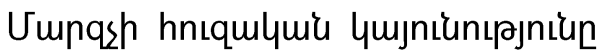

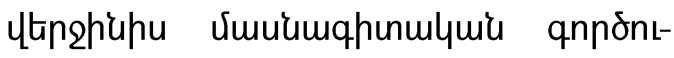

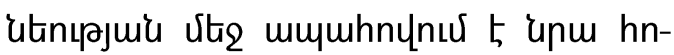
qtymir hurquumpuly2nnıpjniun, hntquiluir yhrulyutph huunuinniunt-

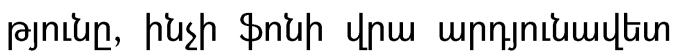

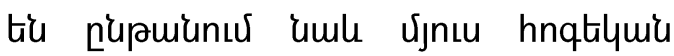

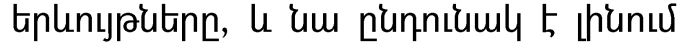

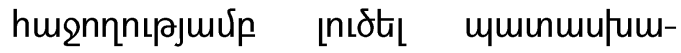
'umunns le punn fu'unhnutinn' hnıqulyuunntiu junцmó hnuulh6ulyutinnux:

乙24

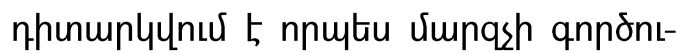

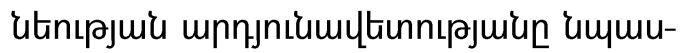
unnn wiuăh unmemunum qnnonu, hüh

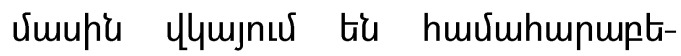
nulygulymir hurluuunh ymutinn:

tounumhé vimpquălutiph vimpqhétiph htinmanunumo gnıguinzutiph

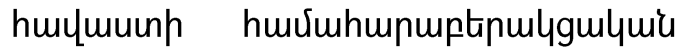

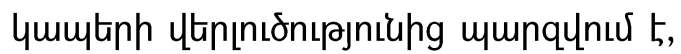
nn hnıquiluí qujnı'unıpjnı̌u (utjpn-

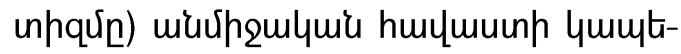
nny чшщц $(r=+0,62)$, tpuinnuultinupujh $(r=-0,40)$,

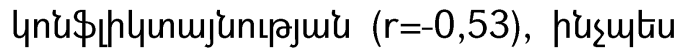
umle vimphsitiph unuphph $(r=+0,68) \mathrm{u}$ u2łumunuiupujh's uunudh $(r=+0,55)$ gnıguiah2utiph htin:

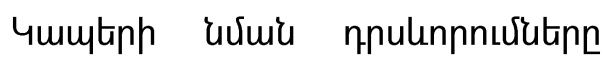

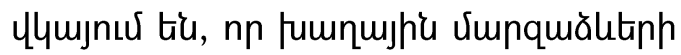

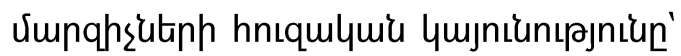
nnutu unuing miăh unmequinum gnıguih2, vimnqulquiu qnnonılutnıрjuiu

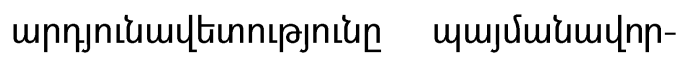

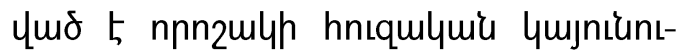

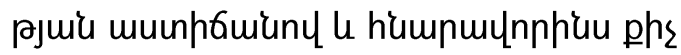

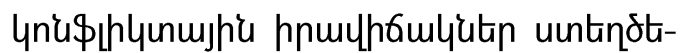

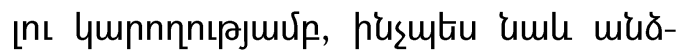




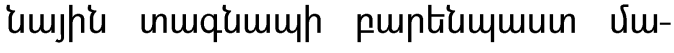

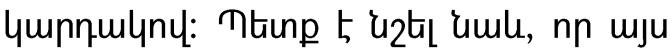

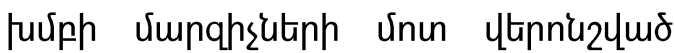

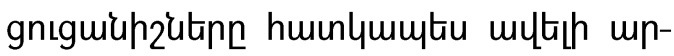
unuhujunhs tín nununus tplymp w2łum-

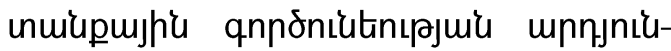

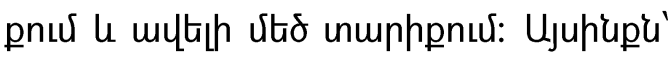

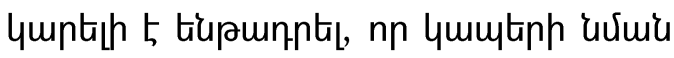

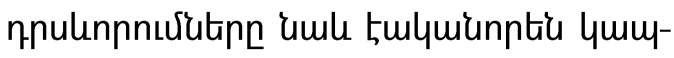

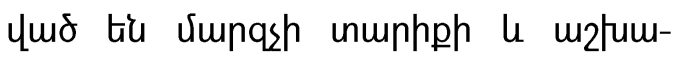
unuiupujhic unuodp htin:

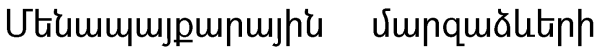

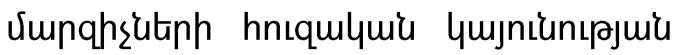

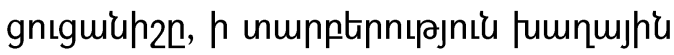
viunquălutph viunqhšlatph, npulunnts

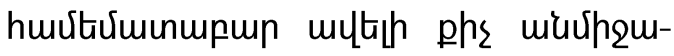

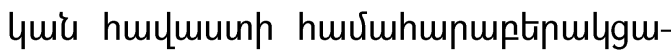

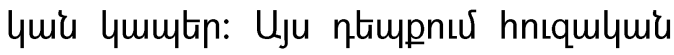

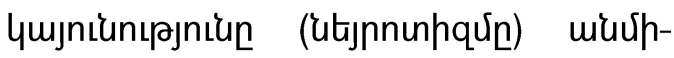

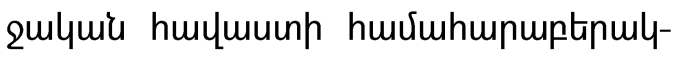

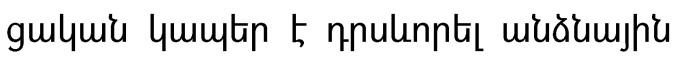
unuqumum $(r=+0,40)$ le tpuinnuultanupush $(r=-0,65)$ gnıguinhzutph htin:

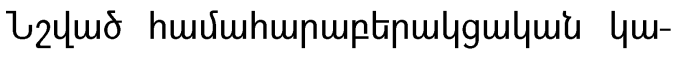

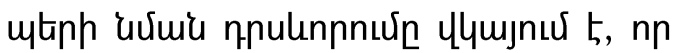

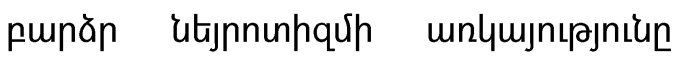

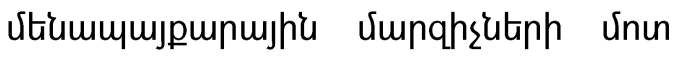

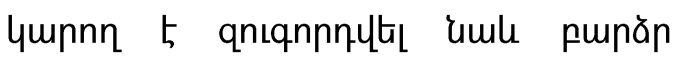

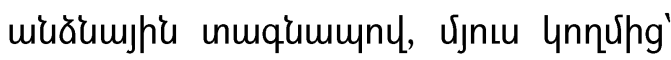
ulumq utjpnnonhquny, le hnsqulyuir

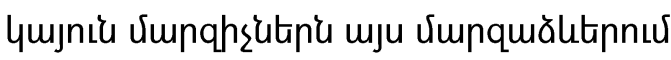

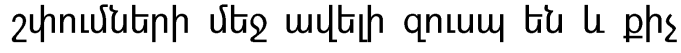
hunnnnulygunn:

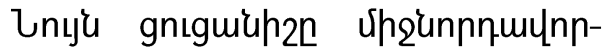

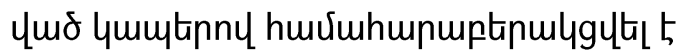

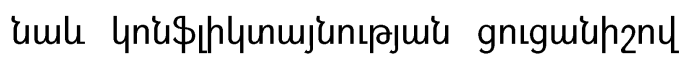

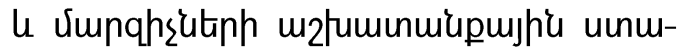
ony:

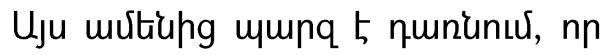

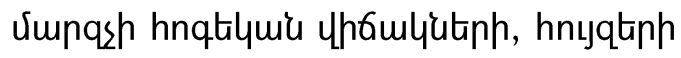

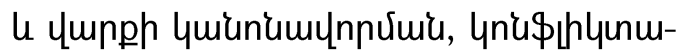

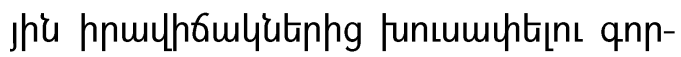

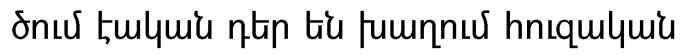

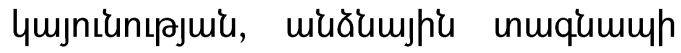

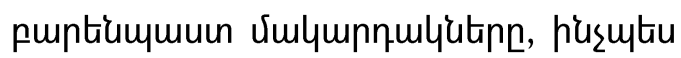

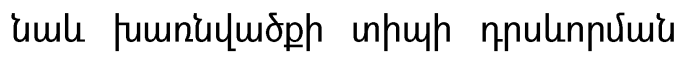
unuiuăumhuunynıpjnı̇üunn:

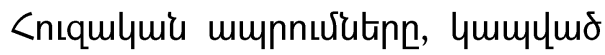

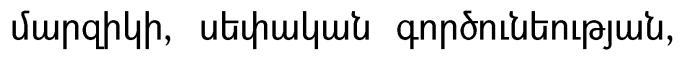

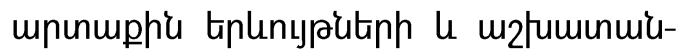

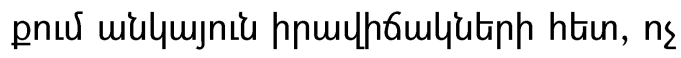

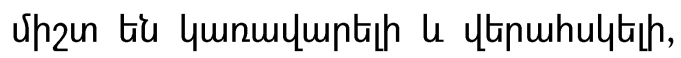
huša th hufautu vimpsch unon huiuqtigunuर 5 ujunnuhnqtilum uhfiulh jun-

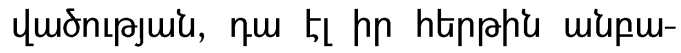

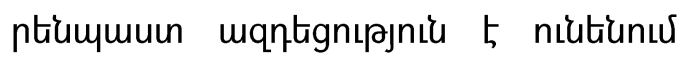

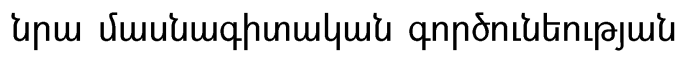

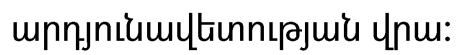

teutiny mju mutiung' ymptin t5

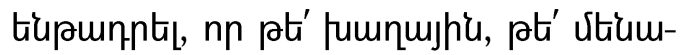

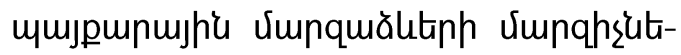

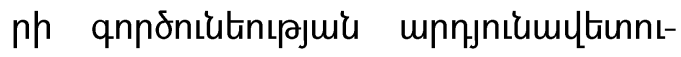

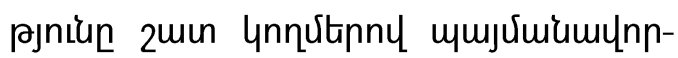




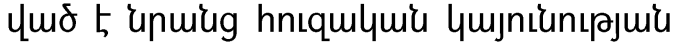
(utjpnunhqưh) muunhfiuiuny:

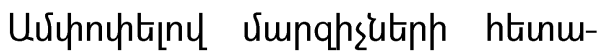

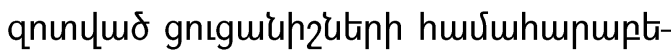

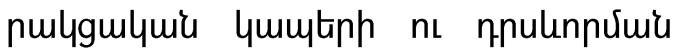

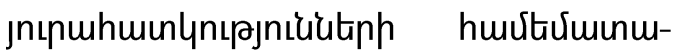

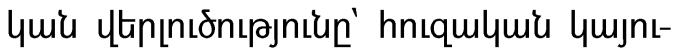

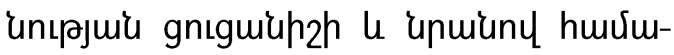

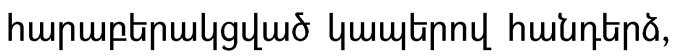
yunnn tiup uju umhưulats nnmitu

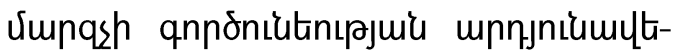

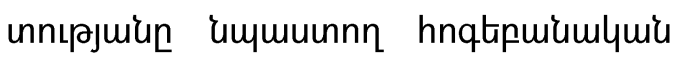

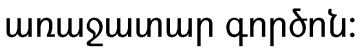

tqnulqugnıpjnıl: Umu'umqhunu-

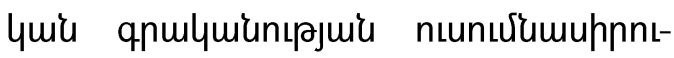

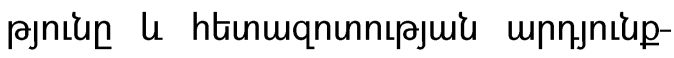

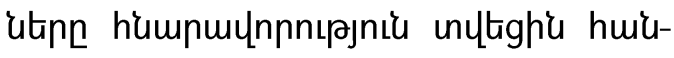
qti hGinlju[ tiqnulymgnıpjuí.

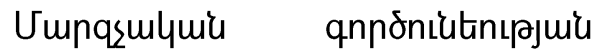

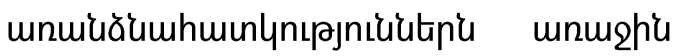

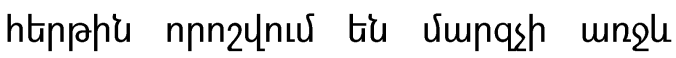

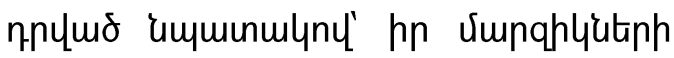
lnnưhg punăn umnnunujh's ympugt-

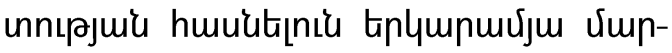
qnưututph unnjniupnux: Uunqhyutinh

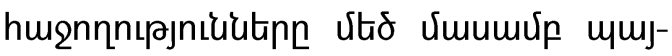
vimimunnymo tiu vimpash miăny' unm

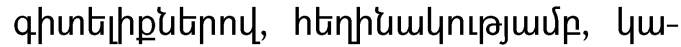

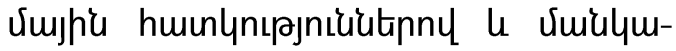

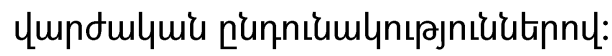

Umpssh viulymulundulymir qnn-

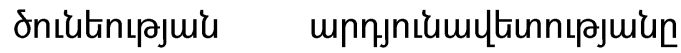
umuuunnn yuplunn qnnon's tú hu-

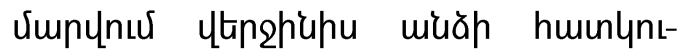

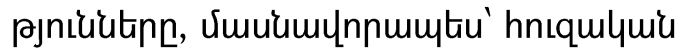

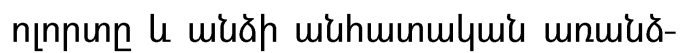

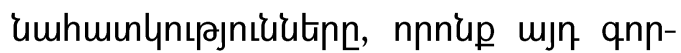

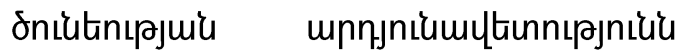

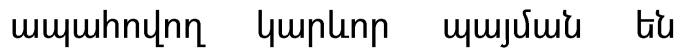
huiunpumiunux:

Uunqsulyuiu qnnoniutinıpjniun qquuh surhny ălumunnnuर t ytanghüu

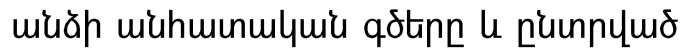

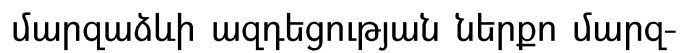

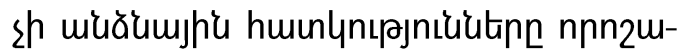
uhnntiu unnfulnuर tiu: <tunuqnunnıpuiu

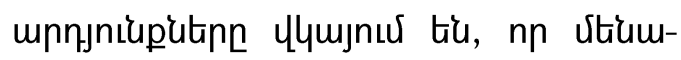
umjpunujhé vernquălitinnuर qta-

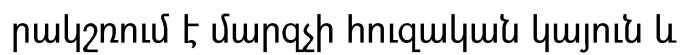
huчumummly2numo intumly, hul fum-

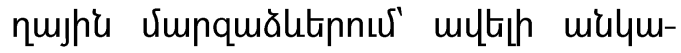

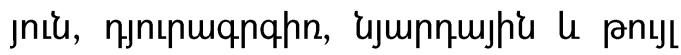
unmumunugynn unhun:

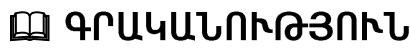

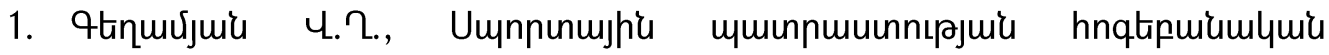

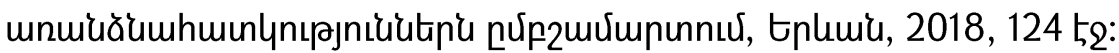

2. Ильин Е.П., Психология спорта. СПб.: Питер, 2011. - 352 с. 
3. Мельник Е.В., Психология тренера: теория и практика: методические рекомендации. - Витебск: ВГУ имени П.М. Машерова, 2014. - 58 с.

4. Михайлова Т.В., Эффрективность деятельности тренера и определяющие ее факторы. Теория и практика физической культуры N 1. 2007, - стр. 34 - 38

5. https://studme.org/273648/psihologiya/psihologiya_trenera\#google_vignette

\section{PSYCHOLOGICAL FACTORS ENSURING A COACH'S EFFECTIVE ACTIVITY}

Ph.D in psychology, associate professor V.Kh., Geghamyan

Armenian state institute of physical culture and sports, Yerevan, Armenia

\section{SUMMARY}

Key words: coach; emotional stability; success of the activity; personality.

The article presents the psychological characteristics of the personality of coaches of various sports, which can be the leading indicators ensuring the productivity of their professional activities.

Research objective: to identify the psychological factors that ensure the effectiveness of coaches' professional activities in various sports, to describe the features of their manifestation and the interrelations between them.

Research methods and organization: analysis of scientific and methodological literature, observations, tests, questionnaires, mathematical and statistical analysis.

The study was conducted among 40 coaches, 20 of them were representatives of playing sports (football, volleyball, basketball, handball) and the other 20 were those of combat sports (wrestling, boxing, judo, sambo). The average professional coaching experience of the respondents was 14 years.

In general, the following indicators were studied: emotional stability (neuroticism), characteristics of temperament type (extraversion, introversion, ambiversion), anxiety (personality anxiety), conflictuality.

As a result of the comparative and correlation analysis, psychological indicators were singled out, underlined which by their specific features are central to the personality and activity of the coach. 
A comparative analysis of the correlations between the indicators of the coaches under study and the features of their manifestation, taking into account the indicator of emotional stability with its correlations, are identified as the leading psychological factors that contribute to the effectiveness of the coach.

The results of the study show that an emotionally stable and balanced coach type predominates in combat sports, while a more unstable, irritable, nervous and weakly adaptable type predominates in competitive sports.

\section{ПСИХОЛОГИЧЕСКИЕ ФАКТОРЫ ОБЕСПЕЧИВАЮЩИЕ ЭФФЕКТИВНОСТЬ ДЕЯТЕЛЬНОСТИ ТРЕНЕРА}

К. п. н., доцент В.К., Гегамян

Государственный институт физической культуры и спорта Армении, Ереван, Армения

\section{PЕЗЮМЕ}

Ключевые слова: тренер; эмоциональная устойчивость; успешность деятельности; личность.

В статье представлены психологические особенности личности тренеров различных видов спорта, которые могут быть ведущими показателями обеспечивающими продуктивность их профессиональной деятельности.

Цель исследования - выявить психологические факторы, обеспечивающие эффрективность профессиональной деятельности тренеров по различным видам спорта, описать особенности их проявления и взаимосвязи.

Методы и организация исследования. В процессе исследования использовались следующие методы: анализ научно-методической литературы, просмотры, тесты, анкеты, математико-статистический анализ.

Исследование проводилось с 40 тренерами, 20 из которых - представители игровых видов спорта (футбол, волейбол, баскетбол, гандбол), а остальные 20 единоборств (борьба, бокс, дзюдо, самбо). Средний профессиональный тренерский стаж респондентов составил 14 лет. 
В целом изучались следующие показатели: эмоциональная устойчивость (нейротизм), особенности типа темперамента (экстраверсия, интроверсия, амбивертность), тревожность (личностная тревожность), конфрликтность.

В результате сравнительного и корреляционного анализа были выделены психологические показатели, которые по своим специфический особенностиям занимают центральное место в личности и деятельности тренера.

Сравнительный анализ взаимосвязей показателей исследованных тренеров и особенностей их проявления учитывая показатель эмоциональной устойчивости с ее соотнесительными связами, определены как ведущие психологические факторы, способствующие эфффективности деятельности тренера.

Результаты исследования показывают, что в видах спорта типа единоборств преобладает эмоционально устойчивый и уравновешенный тип тренера, а в игровых видах спорта - более неустойчивый, раздражительный, нервный и слабоадаптируемый тип.

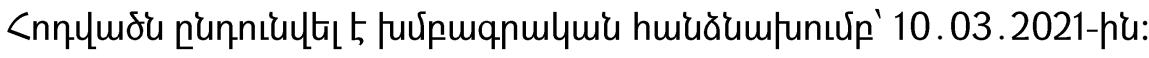

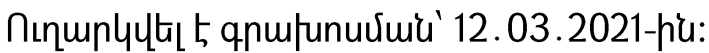


DOI: 10.53068/25792997-2021.1.3-39

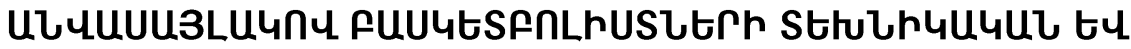

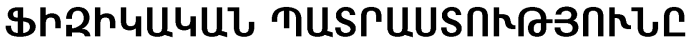

\author{
U.q.P., upn\$tiunn G.L. Ruy/pju氏, \\ U.t. ₹uц/קנwน

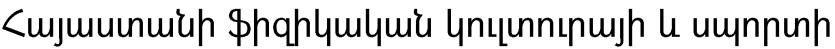

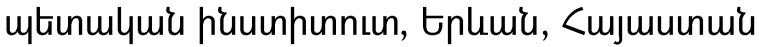

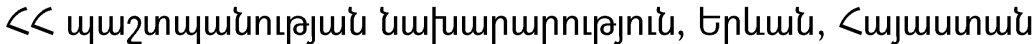 \\ E.mail:coachdavtyan@yahoo.com \\ levdavtyan@gmail.com
}

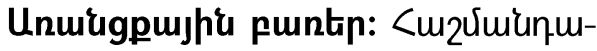

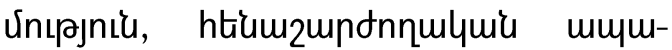

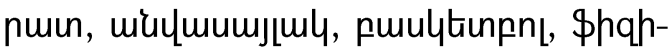

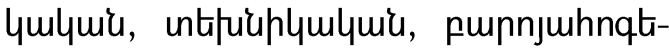
puiumlquil muinnmuunnıpjnil:

Ctinuqnunnıpuir mpnpulquiuntPjnilu: Utrq hujunup hujntiumlymí le mpunuumhưuiujuiu qnulquiunıpuiu vitg phs

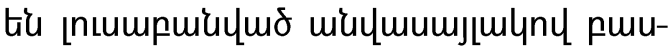

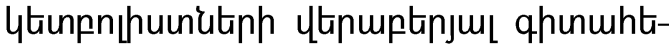
unuqnunulyuir m2łumunuiuputinn,

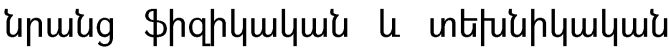
umunnmuinnıрjui, punnjuhnqtipu-

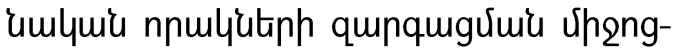
utinn le Utipnnitinn: Uaulumujumlyny

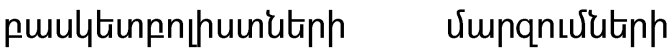

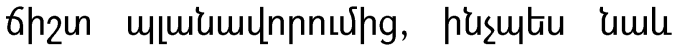

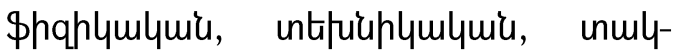
unplqulymid, hnqtipuiamlymis muinnum-

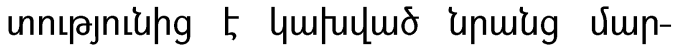
quiluis hugnnnıpjniüutinn: бh2un u

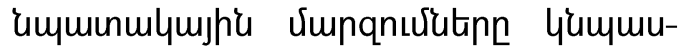

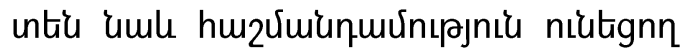
muăming punnjuhnqtapuiumlumis th-

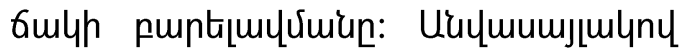

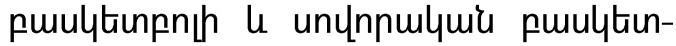

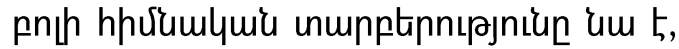
nn fumqugnnitinn stiu 4unnn unt-

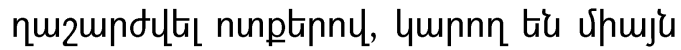

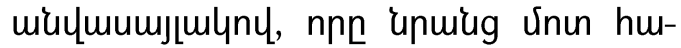

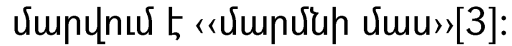

Uayumumjulyny purytinnngnu

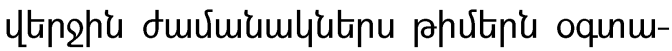

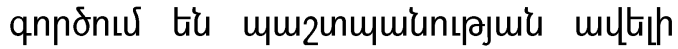

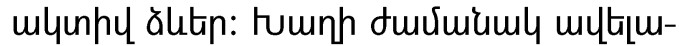

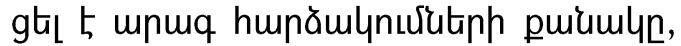

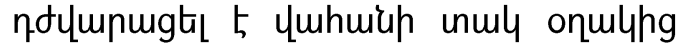
htion pnsnn qunqulpie inpnumutintin:

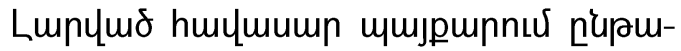

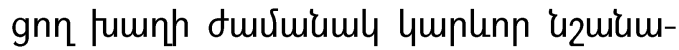
unıpjniu niap fumqugnnutiph \$hqh-

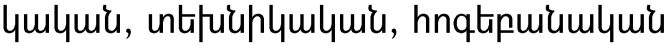


щuminnuuunnıpjniun [2]: FuultiunpnLhuunutinn mting 5 ympnnuiumis du-

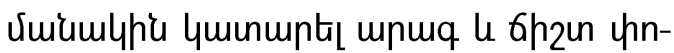

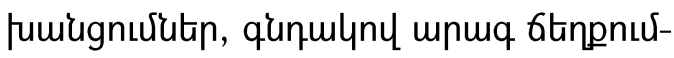
utip, onmly unuly umupurtic onmuhg htin pnsnn qunulyhu inhnumbintąnเ

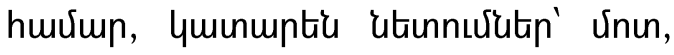

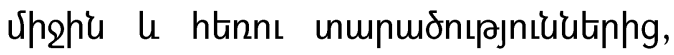

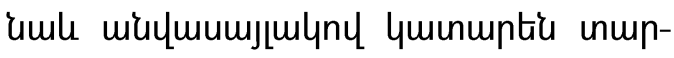
ptip nınnnıpjniuktipny unmqugnưutitn,

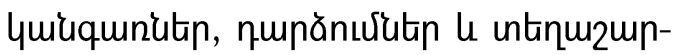

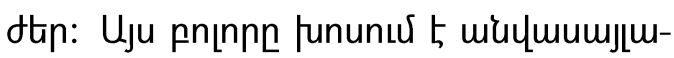
yny puulfiunnnhuinitiph juy \$hqh-

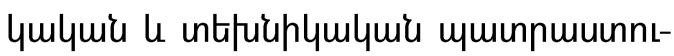

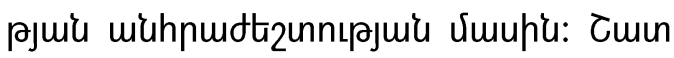
hanhiumlitin mnmomplynu tiu wuym-

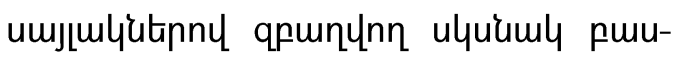

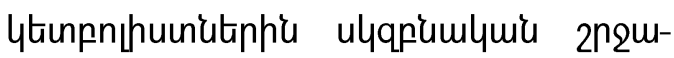

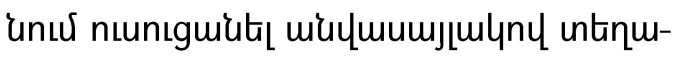

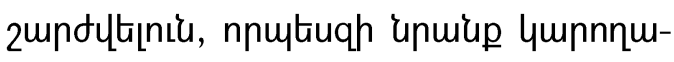

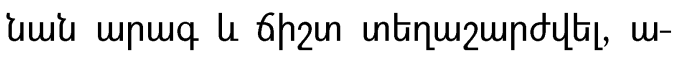
nus, htin,me, àmu, quinumtiu nup-

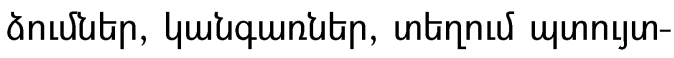
utip[5]: Uaumumjumlyny pualytinnn-

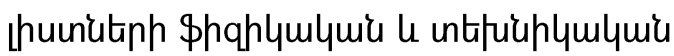

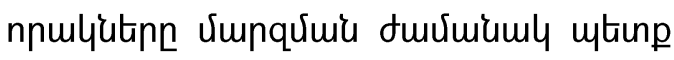

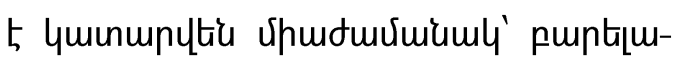

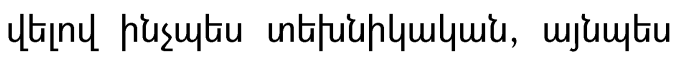
5t \$hqhlqulumir muinnmuinnıpjuir gntguiuh2utinn [4]:

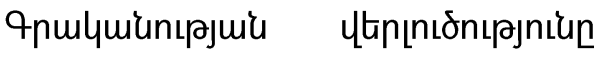
gnug unutig, nn minumumjlulyny puu-

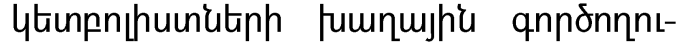

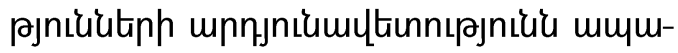

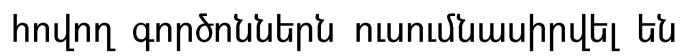
ns purlunmen: Ztiplumnulu mlynnhy unnnă umphitin lu ungngutin, nnnup wuhnudtron tiu mulumumjulyny puultionnn-

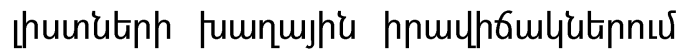

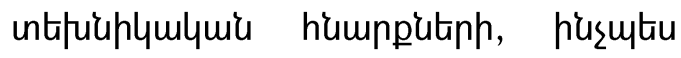

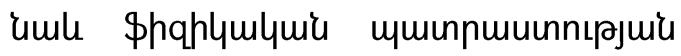

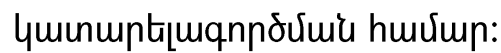

Unnjniumuttin fumqujhis qnnont-

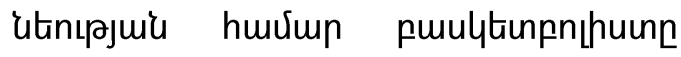

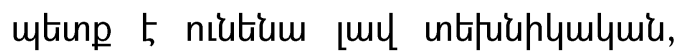

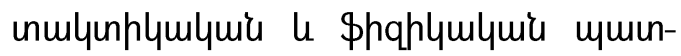

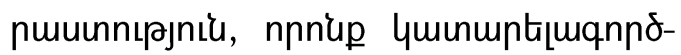

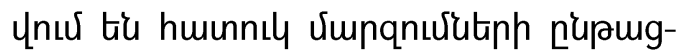
pnux [1]: Unmulta yuplunn t5 minlumumjulyny puulytinnn huonitiph huvium hu-

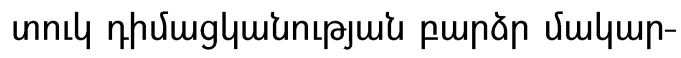

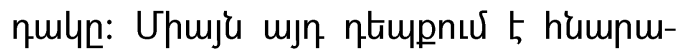
unn uर्upnn? fuunh nupaugpnux umuumiuts fumqujhí unnjniumultinntpjnılun:

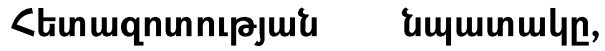

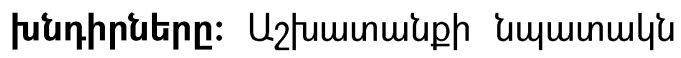

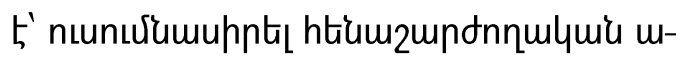
umunuinh y'umuluofputin niutignn wit-

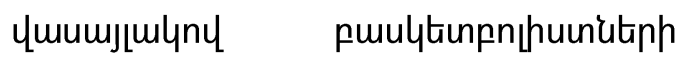

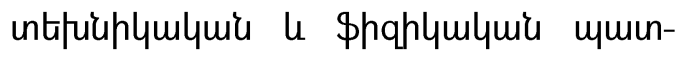
nuuunnıрjuí রulympnuln: 


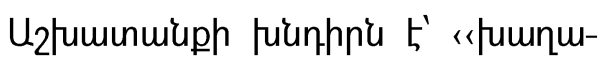

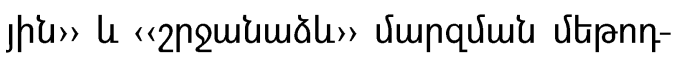

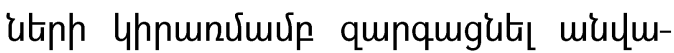

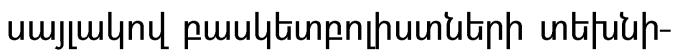

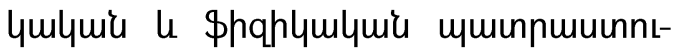
pjuiu gnıguiuh2utinn:

Stunuqnunnspuiru vitpnniting u

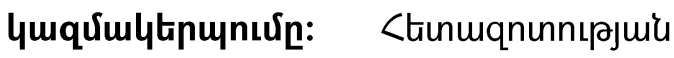

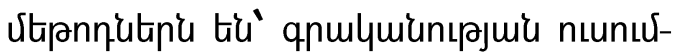

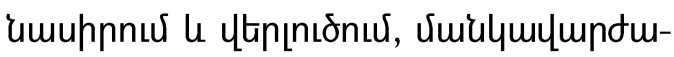
ymí ptuunurunnnuर' 1. 4x28u. Uumpn-

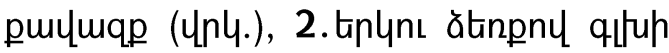

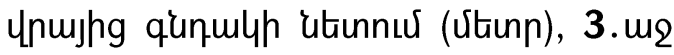

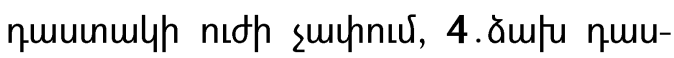
unulyh nıdh suuhnux, 5. me ynnúng onulyh unulyhg qunulyh 5 utiunnu

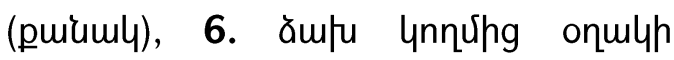
unulyhg qunulyh 5 itinnus (puiuml), 7. munlymo uhfomlhg utinunus, htiunus (pmiaml), 8. minquumjumlny mpmqugnư' 28u (4n4.), 9. unnıquiumphu 10 Utinnuर, (puiumly), 10. unmptip ytuntnhg unghu unmpurnıpju'i' 10 'utunnus (puirum), 11. qhqquqny mingnu 10

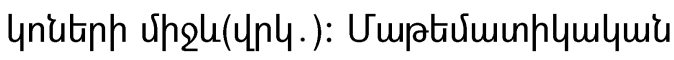

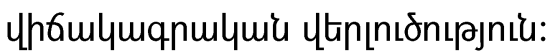

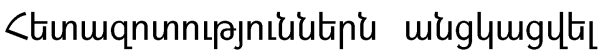

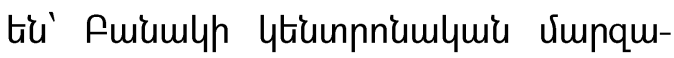

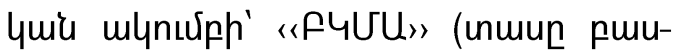
ytinnnphuin) a Unumulump hnurhthouly-

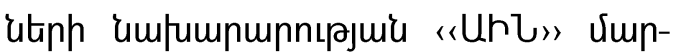

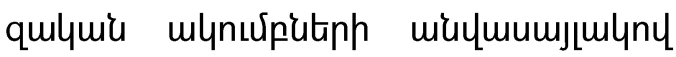

(jnp) puulytinnn_huenutinh htin: Ctinumqnunnıpjniưu minglumgltas 5 tiplns unnt-

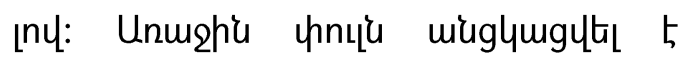
2020p. oqnunnu-utumenturptiphú (um-

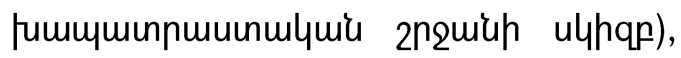

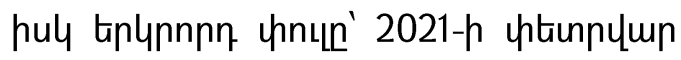

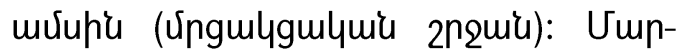

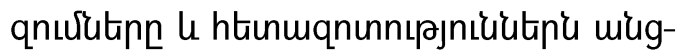

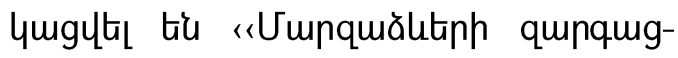

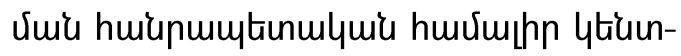
nnunud»" rumfulhí "Uh4U»" vunqu-

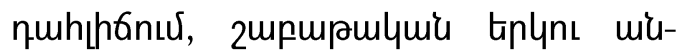
quuर:

\section{Stunuqnunnıpjuis upnjnituputpp}

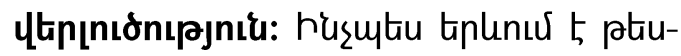

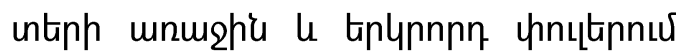

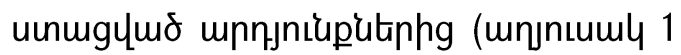

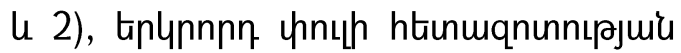
unnjniupnux untinh tiu niutgita nnulquir

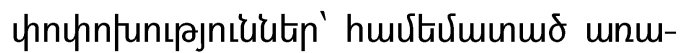

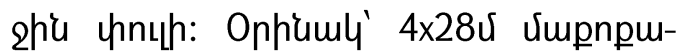
umqph ptuunh unnjniupa unmehu unnunuर fuúph unghiu gnıguiuhan tints 5

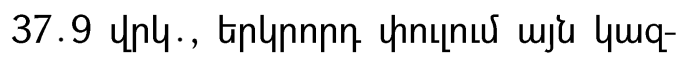

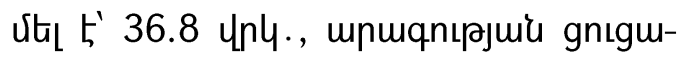
uh2n' 28 u, unmeghu unnцnư' 8,2 4n4.,

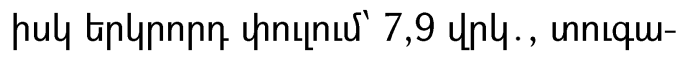

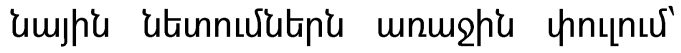
uhohiun' 2,2 utunnuर, tipunnnn unццnư' 3,8 utunnux (unmun cutinnưututing), up-

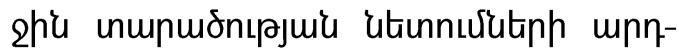

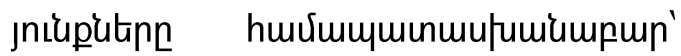


2,3 u 3.2 utunnux: 7pulyuiu thnupnfunt-

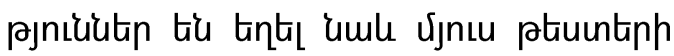
upn.jniuputunnux:

Ununulyung hnulhtoulyitiph um-

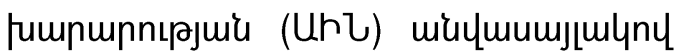

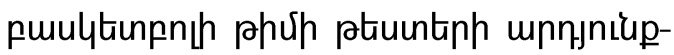

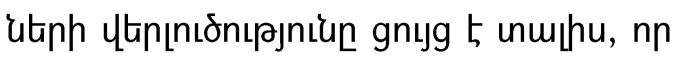

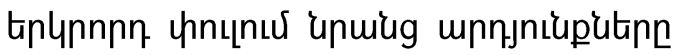
unsjumtiu puntjuulytal tíu, pujg

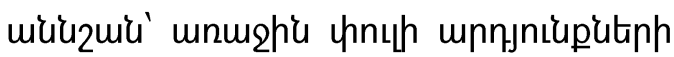

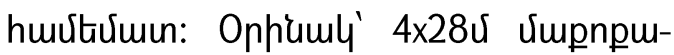
umqph ptuunh unnjniupe unwehis

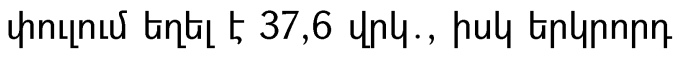
чhnцnuर' 37,3 un4., 28u ptuunh unn-

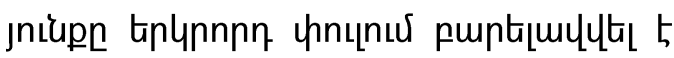
0,5 4n4., qhqququtinny unutiph ungle u'ugnux ptiuunh upnjnı̌uputann' n'unuvitun 0,14n4.-nu:

fugh ptiuuntiph unnjnıluputiph пnulymir unuhnfunıpjnıuutinhn,

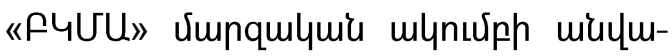

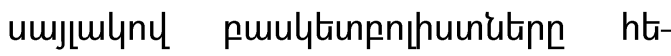

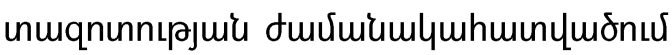

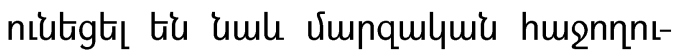

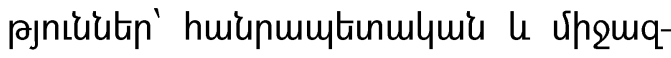

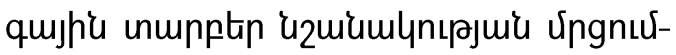
utaph duviuiumly:
«F५UU» vimpqulumi mynuर्up mi-

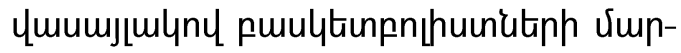

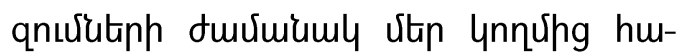

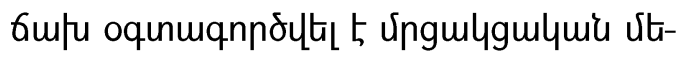

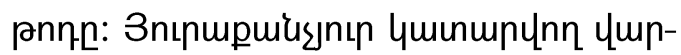
dnıpjníu unnitigltal 5 fumqujhe hnu-

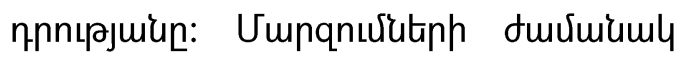

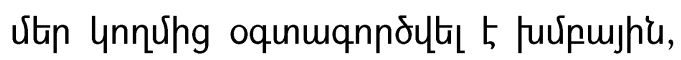

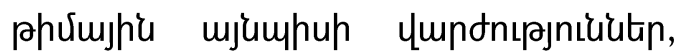

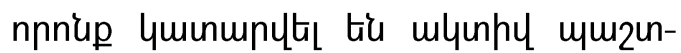

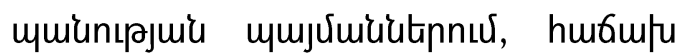

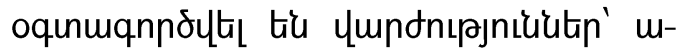

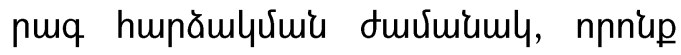
umbhuiugnux tiú \$hqhlqulquir punăn

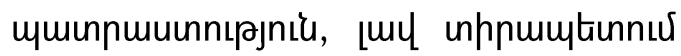

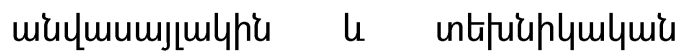

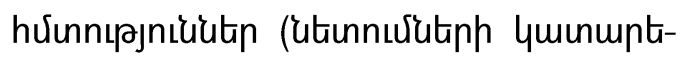

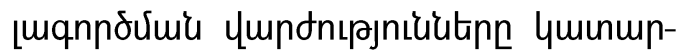

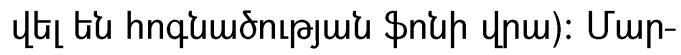

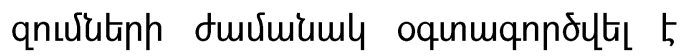

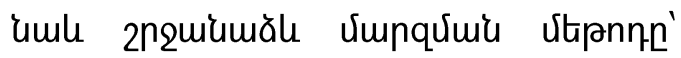

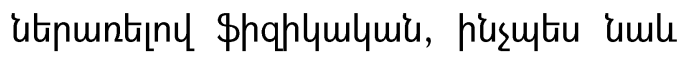
untipunlymumis humpzutiph (qunulyh

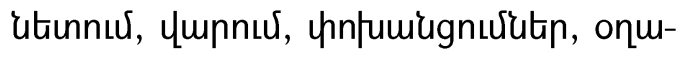
lhg htin pnsnn qunqulh inhnumbinnux)

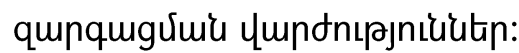




\section{Unjniumly 1}

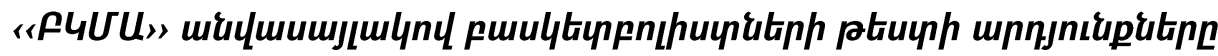

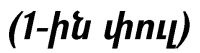

\begin{tabular}{|c|c|c|c|c|c|c|c|c|c|c|c|}
\hline U. U. (ptiuntin) & 1 & 2 & 3 & 4 & 5 & 6 & 7 & 8 & 9 & 10 & 11 \\
\hline U. Uumunnju'u & 37.4 & 9.50 & 55 & 75 & 3 & 4 & 30 & 7.6 & 1 & 3 & 11.3 \\
\hline U.<nyhu'üuhuju'u & 33.6 & 9.90 & 75 & 72 & 2 & 2 & 35 & & 4 & 3 & 11.8 \\
\hline U. Umpquju'u & 35.4 & 11.70 & 65 & 62 & 4 & 3 & 31 & 7.5 & 1 & 1 & 13.3 \\
\hline hu. 9lunnqjw'u & 33.2 & 11.10 & 80 & 75 & 2 & 2 & 40 & 7,4 & 4 & 3 & 10.7 \\
\hline U. 4mpumbinjuiz & 33.4 & 8.90 & 120 & 115 & 1 & 1 & 60 & 7.7 & 1 & 0 & 13.9 \\
\hline 4. Uupunhnnujuiu & 44.2 & 9.20 & 55 & 55 & 1 & 1 & 7 & 8.9 & 0 & 0 & 16.8 \\
\hline Ł. Umpqujuǐ & 40.0 & 6.30 & 76 & 62 & 3 & 2 & - & 8.8 & 3 & 7 & 14.2 \\
\hline U. quцuinju'u & 44.3 & 5.80 & 58 & 50 & 2 & 1 & 29 & 10.2 & 1 & 1 & 15.8 \\
\hline U. ไmฉшnjw'u & 40.1 & 8.90 & 74 & 76 & 2 & 1 & 32 & 8.6 & 3 & 2 & 12.6 \\
\hline 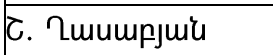 & 37.0 & 10.30 & 65 & 68 & 2 & 2 & 30 & 8.0 & 4 & 3 & 12.5 \\
\hline$\overline{\mathbf{X}}$ & 37,86 & 9,16 & 72,30 & 71,00 & 2,20 & 1,90 & 32,67 & 8,25 & 2,20 & 2,30 & 13,29 \\
\hline$\sigma$ & 4,19 & 1,88 & 19,06 & 17,83 & 0,92 & 0,99 & 13,67 & 0,88 & 1,55 & 2,06 & 1,94 \\
\hline$m(x)$ & 1,33 & 0,59 & 6,03 & 5,64 & 0,29 & 0,31 & 4,56 & 0,28 & 0,49 & 0,65 & 0,61 \\
\hline
\end{tabular}

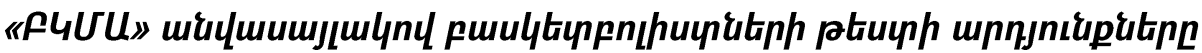

Unjnıuml 2

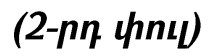

\begin{tabular}{|c|c|c|c|c|c|c|c|c|c|c|c|}
\hline U. U. (ptiuuntin) & 1 & 2 & 3 & 4 & 5 & 6 & 7 & 8 & 9 & 10 & 11 \\
\hline U. Uumunnjwitu & 37.1 & 9.60 & 60 & 80 & 4 & 4 & 32 & 7.4 & 4 & 4 & 11.2 \\
\hline U. <nyhu'u'uhujuiu & 33.2 & 10.0 & 80 & 75 & 3 & 2 & 37 & 7.2 & 5 & 3 & 11.6 \\
\hline U. Umpquju'u & 34.4 & 11.90 & 75 & 70 & 4 & 4 & 33 & 7.3 & 6 & 3 & 13.1 \\
\hline ก. 9lunnqjuiu & 33.2 & 11.20 & 85 & 85 & 3 & 3 & 42 & 7,2 & 4 & 3 & 10.5 \\
\hline U. 4mpumbinjumit & 33.2 & 9.10 & 120 & 105 & 3 & 2 & 63 & 7.4 & 3 & 2 & 13.0 \\
\hline 4. Uumunhnnujuiu & 39.2 & 9.25 & 55 & 55 & 2 & 1 & 9 & 8.6 & 2 & 2 & 16.2 \\
\hline Ł. Umuqujuitu & 40.0 & 6.35 & 80 & 70 & 3 & 2 & - & 8.5 & 4 & 7 & 14.0 \\
\hline U. qmцuилјu'u & 43.3 & 5.85 & 65 & 70 & 2 & 1 & 33 & 10.0 & 2 & 2 & 15.8 \\
\hline U. ไmฉmpјu'u & 39.1 & 9.00 & 75 & 80 & 3 & 2 & 35 & 8.3 & 4 & 3 & 12.3 \\
\hline 厄. Zmumpjuǐ & 35.0 & 10.40 & 75 & 70 & 3 & 2 & 36 & 7.5 & 4 & 3 & 12.2 \\
\hline$\overline{\mathbf{X}}$ & 36,77 & 9,27 & 77,00 & 76,00 & 3,00 & 2,30 & 35,56 & 7,94 & 3,80 & 3,20 & 12,99 \\
\hline$\sigma$ & 3,52 & 1,91 & 17,83 & 13,08 & 0,67 & 1,06 & 13,82 & 0,91 & 1,23 & 1,48 & 1,88 \\
\hline$m(x)$ & 1,11 & 0,60 & 5,64 & 4,14 & 0,21 & 0,33 & 4,61 & 0,29 & 0,39 & 0,47 & 0,59 \\
\hline
\end{tabular}




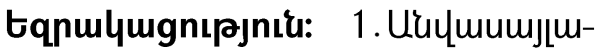

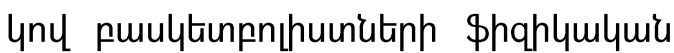

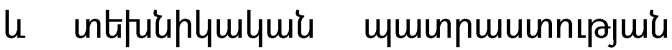

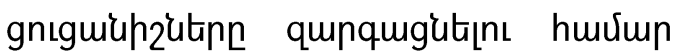

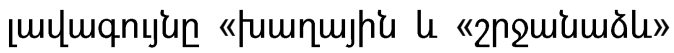

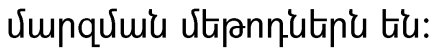

2. Umpqnuरlutiph u jumntiph du-

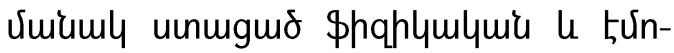

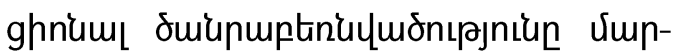

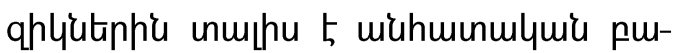
nnjuhnqtipuiumlymu, unghuцmlquis pu-

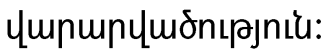

9nposumlume unuquplynıpjnit-

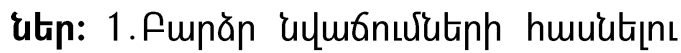

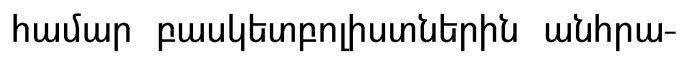

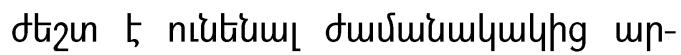
htiunmulund vimpqulquir minumums-

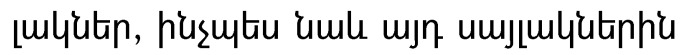

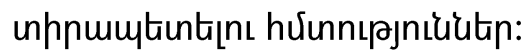

2. Uuhnurtizun 5 ununtilumid viunq-

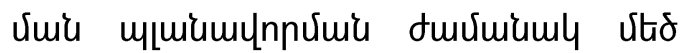
untin huunlymgital midumujןmlnny puuytinnnphuinutiph unthuaplymlyuiu, \$hqh-

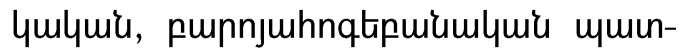

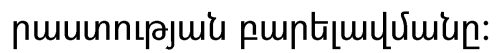

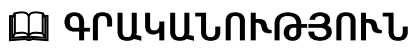

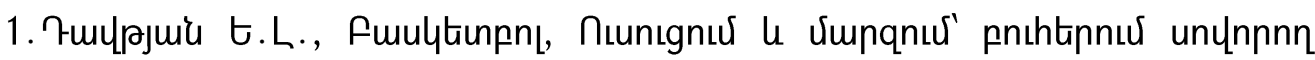
numuiunnutiph huưum, 2013, 52 5:

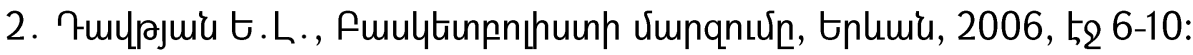

3. Марк Волкер, Баскетбол на колясках 2010. стр.20-23

4.<<Правила соревнований по паралимпийским видам спорта: В сб.: Паралимп. комитет России «сост).А.В.Царик,-М.: Совет. спорт.- 2011, 152 стр..

5. КостюнинаЛ.И, Материалы докладов всероссийской научно-практической конференции.<<Современное проблемы теории и практики спортивной медициныи физической реабилитации. Кам Гафкси Т,2009.-С 112-114. 


\section{TECHNICAL AND PHYSICAL PREPARATION OF WHEELCHAIR BASKETBALL PLAYERS}

PhD of Pedagogy, Professor Y. Davtyan,

A. Davtyan

Armenian State Institute of Physical Culture and Sport, Yerevan, Armenia RA Ministry of Defense, Yerevan, Armenia

\section{SUMMARY}

Keywords: disability, musculoskeletal system, wheelchair, basketball, preparedness, physical, technical, moral-psychological preparation.

Research purpose and issues. The main goal is to identify the level of technical and physical readiness among wheelchair basketball players with musculoskeletal disorders. The central issue consists of increasing the level of physical and technical readiness of basketball players by "playing" and "circular" training methods.

Methods and organization. The following research methods were applied to solve the set tasks: study and analysis of literature data, pedagogical testing, mathematical analysis of the data obtained. The research was conducted with wheelchair basketball players from "CSCA" (Central Sports Club of the Army) and "Ministry of Emergency Situations" in two stages. The first stage was held in AugustSeptember of 2020, the second one- in January of 2021. The research and team training took place at the formerly known as "Republican Sport Development Complex Center".

Analysis of research results. The final results testify to the attainment of positive changes in both teams. For example, For example, the average result of the group shuttle run $4 \times 28 \mathrm{~m}$ at the first stage was 37,9 seconds, at the second stage - 36.8 seconds, the speed indicator was $28 \mathrm{~m}$, at the first stage 8.2 seconds, and in the second -7.9 seconds, free throws in the first round - an average of 2.2 throws, in the second round -3.8 throws (out of ten), the result of throws at medium distances is 2.3 and 3.2 throws, respectively. Positive changes have occurred in the results of other tests as well.

While for the team "Ministry of Emergency Situations" the $4 \times 28 \mathrm{~m}$ shuttle run test resulted in 37.6 seconds at the first stage, and 37.3 seconds at the second stage, the 
$28 \mathrm{~m}$ test result was improved by an average of $0.5 \mathrm{sec}$. The zigzag cone test results improved by merely 0.1 seconds.

Conclusions. The testing results indicated that the best way to develop technical and physical preparation of wheelchair basketball players is "playing" and "circular" training method. Physical and emotional load received during training and games of basketball players provide them with moral, psychological and social satisfaction.

Proposals. In order to succeed in sports achievements, basketball players need modern professional sports wheelchairs, as well as skills in using these wheelchairs. When planning annual training, great attention should be paid to improving the technical, physical, moral and psychological preparedness of wheelchair basketball players.

\section{ТЕХНИЧЕСКАЯ И ФИЗИЧЕСКАЯ ПОДГОТОВКА БАСКЕТБОЛИСТОВ НА КОЛЯСКАХ}

К.п.н., профессор Е. Л. Давтян,

А. Е. Давтян

Государственный институт физической культуры и спорта Армении, Ереван, Армения Министерство обороны РА, Ереван, Армения

\section{PEЗЮME}

Ключевые слова: инвалидность, опорно-двигательный аппарат, коляска, баскетбол, подготовка, физический, технический, морально-психологическая подготовка.

Цель и задча исследования. Цель-исследовать уровень технической и физической подготовленности у баскетболистов колясочников с опорно-двигательными нарушениями.

Задача - возможности повышения уровня физической и технической подготовленности баскетболистов с использованием методов “игровой” и “круговой” тренировки.

\section{Методы и организация исследования:}

1. изучение и анализ литературных данных,

2.педагогическое тестирование, 
3.математический анализ полученных данных.

Исследования проводилось с баскетболистами-колясочниками из “ЦСКА» (Центральный спортивный клуб армии) и “МЧС» в течение двух этапов: 1-й этапавгуст-сентябрь 2020 года, 2-ой этап - февраль 2021г. в спортзале “Республиканского комплексного центра развития спорта".

Анализ результатов исследования. В результате проведенного тестирования выяснилось, что данные второго этапа улучшились у обоих команд по сравнению с первой. Например, средний показатель результата группового челночного бега 4×28 м на первом этапе составил 37,9 секунды, на втором этапе - 36,8 секунды, показатель скорости 28 м, на первом этапе составил 8,2 секунды, а во втором 7,9 секунды, штрафные броски в первом раунде - в среднем 2,2 броска, во втором раунде - 3,8 броска (из десяти), результат бросков на средние дистанции соответственно 2,3 и 3,2 броска. Положительные изменения произошли и по результатам других тестов.

Однако у команды “МЧС»результат теста челночного бега4х28м на первом этапе был 37.6 сек., а на втором этапе -37.3сек., результат теста 28м. улучшился в среднем на 0.5сек. Результаты теста зигзагообразного конуса улучшились всего на 0,1 секунд.

Выводы. Результатами тестирования установлено, что лучшим способом развития технической и физической подготовки баскетболистов-колясочников является “игровой” и “круговой” метод тренировки. Полученные физические и эмоциональные нагрузки во время тренировок и игр обеспечивают моральнопсихологическую и социальную удовлетворенность баскетболистам.

Для достижения высоких результатов баскетболистам необходимы современные профессиональные спортивные коляски, а также навыки владения этими колясками.

При планировании ежегодных тренировок нужно уделять большое внимание совершенствованию технической, фризической, моральной и психологической подготовки баскетболистов-колясочников.

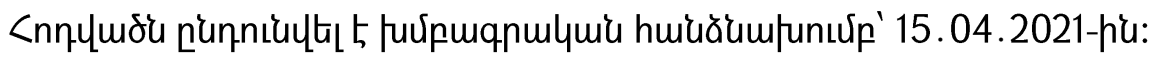

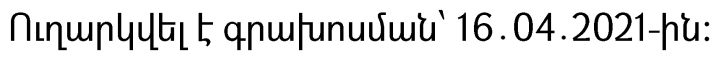


DOI: 10.53068/25792997-2021.1.3-48

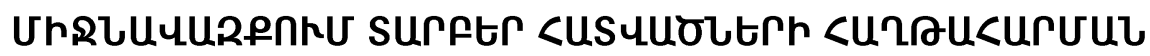
nhUnhUนUUhrnhUe

\author{
U.q.p., nngtiqu 4.U. Uspumsui,, \\ nuumunu <.4. คnumujuit,

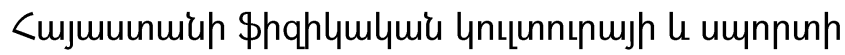

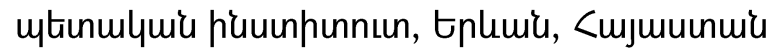

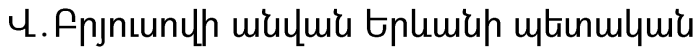 \\ hurumumpuiu, tplumi, <mjuuunuis \\ E.mail: vardansmbatyan@yandex.ru, hasareg@yandex.ru
}

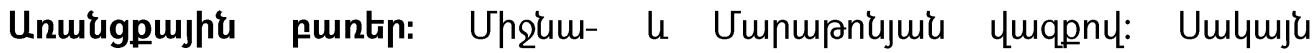

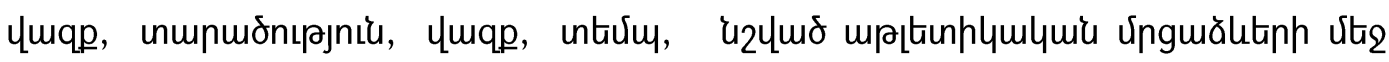

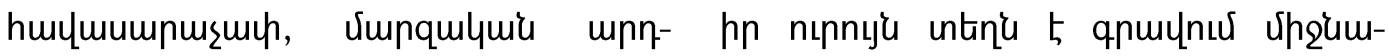
jniup, huunцmo:

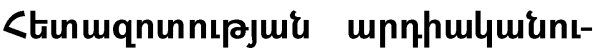

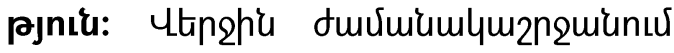

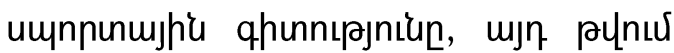
umle umqptiph untiunıpnıiu'u nı vitipnnupuiunısniun, uluts tiu qunquiums

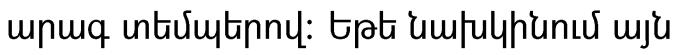
hpuramlyuiunus qpununu tp puguinnulyuiu qnndunnıjpny lu phs th oq-

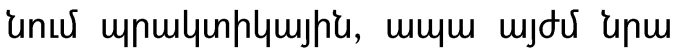

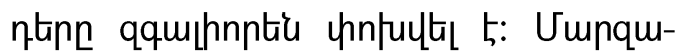
quís ungnuर́utin's mjlue munqumitu

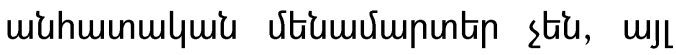

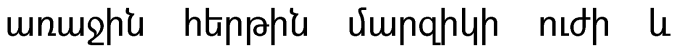
hưunnıpjuiu gnıgunnnuर्u tiu $[3,4]$ :

Ujuon múupnng m2łumphn mqqu-

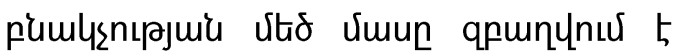

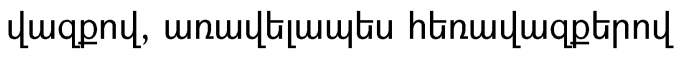
4mqpn: Uhqumumqpn mpltinhlymlymir

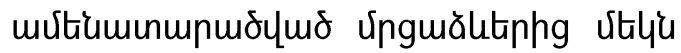

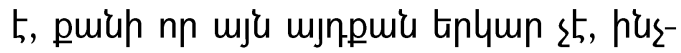

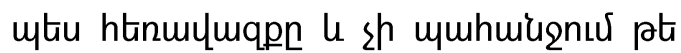
Junqhlyuting $u$, pt upnnnulymuluting

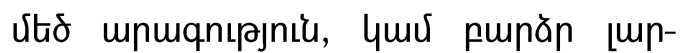

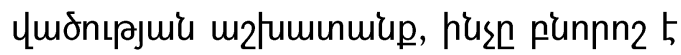
unuquuluqphi:

Uhqumulmqptinn unupptinunuर tiu

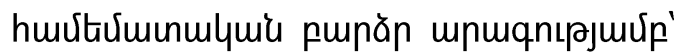

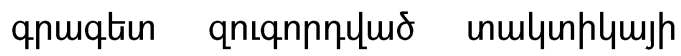
htin: Uju Чmqpuinumuonıpjniuutinnuর punăn viunqualuiu upnjniuputiph huu-

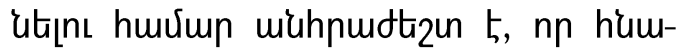

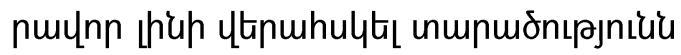

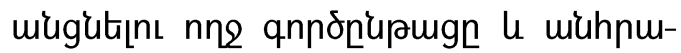

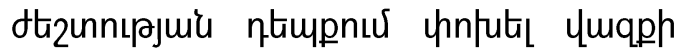

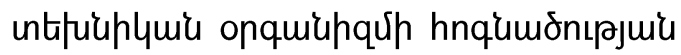




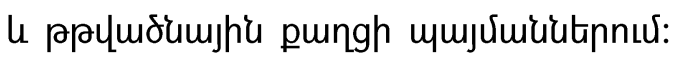

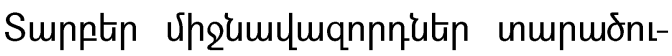

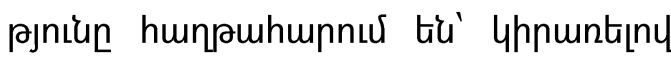

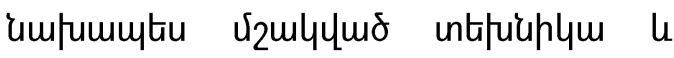
unmlynhlqu: Umlyuju nnn2 Umpqhlutin uju hunpuhmpnuर tu' uर्upnng ununu-

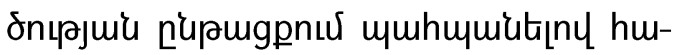

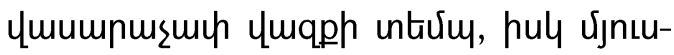

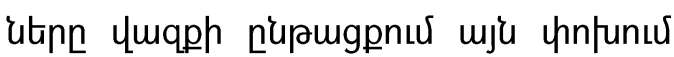

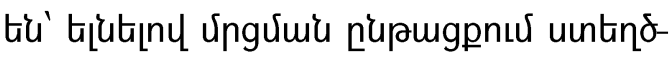
чuí hnuulh6ulyhg $[1,2,5,6]$ :

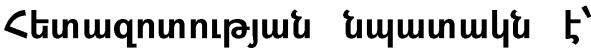

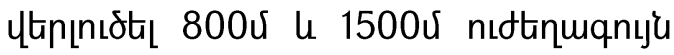
uhqumumqnnnutiph ymqpuinumuront-

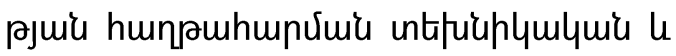

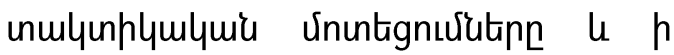

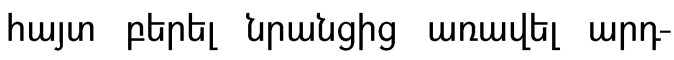
jnilumultinn:

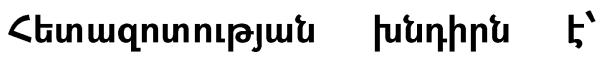
nıftinuqnu'u úpqumumqnnnitiph unup-

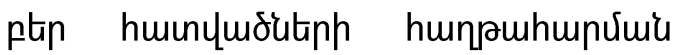

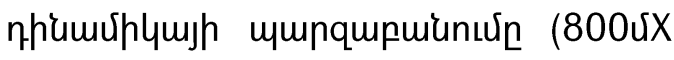
200u) (1500X300u):

<tunuqnunnıرuis vitpnniting tí'

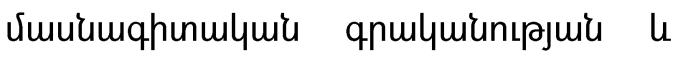

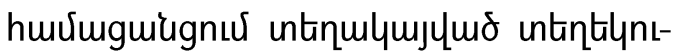

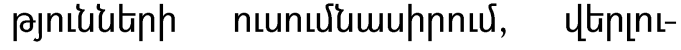

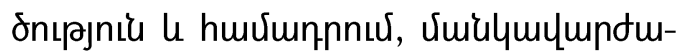

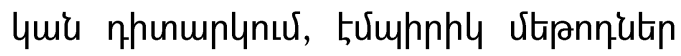

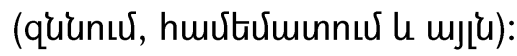

\section{Ctunuqnunnıpuir upnjnituputiph}

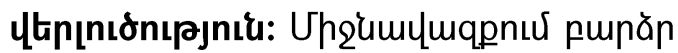

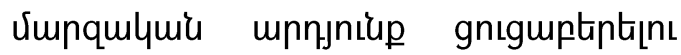

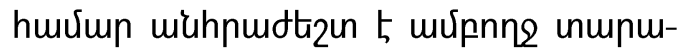

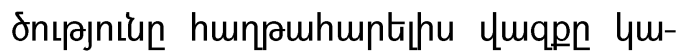

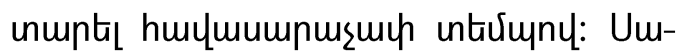

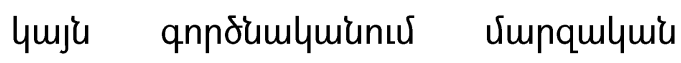
unmulunhlywir gnug 5 unmphu, nn ns pnınn punăn vimnqulquí unnjniupüatp gnıguptinnn umqnnnutinn umqpuinu-

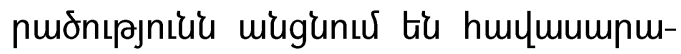
such untưumnl: 3nıpmpuiusınıp ungnux

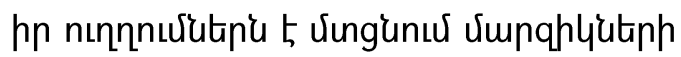

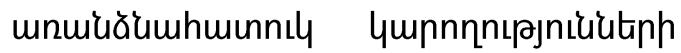
oqunuqnnoर्umu qnnonuर:

Utip lnnuरhg hnulymiumgymo purq-

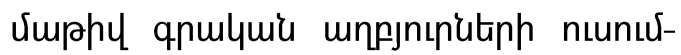

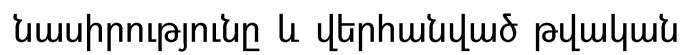

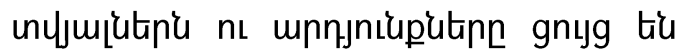

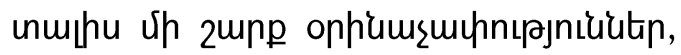
nnnup huưunnon yutinlumjugutiup uunnplu: 


\section{Unjniumly 1}

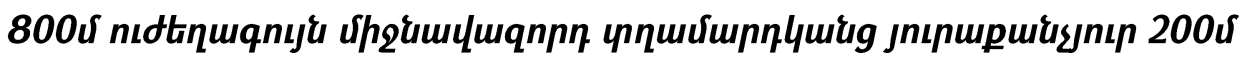

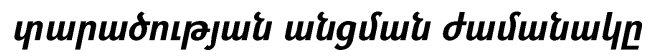

\begin{tabular}{|c|c|c|c|c|c|c|c|c|}
\hline$u u$ & 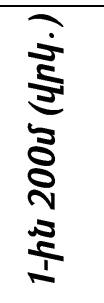 & 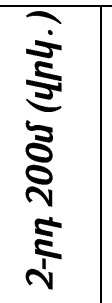 & 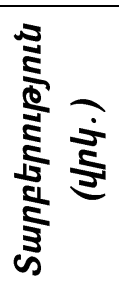 & 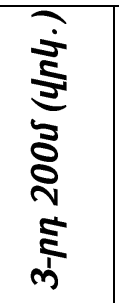 & 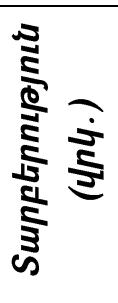 & 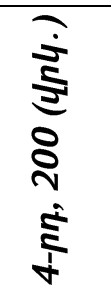 & 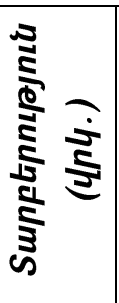 & 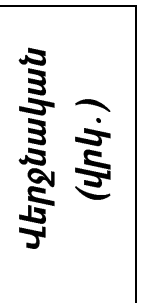 \\
\hline Utinh Fuu & 25.03 & 26.01 & 0.98 & 26.08 & 0.07 & 26.03 & +0.05 & 1.43. \\
\hline 3nıph Funquulynuluh & 25.10 & 26.01 & 0.91 & 26.09 & 0.07 & 27.0 & -0.91 & 1.44 .20 \\
\hline nıhцund 4hulfiuntin & 24.13 & 26.06 & 1.93 & 26.08 & 0.02 & 26.05 & +0.03 & 1.42 .3 \\
\hline 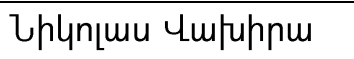 & 25.14 & 26.04 & 0.09 & 26.07 & 0.03 & 27.19 & -1.12 & 1.44 . \\
\hline 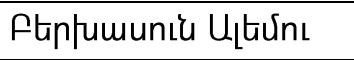 & 26.03 & 26.10 & 0.07 & 26.17 & 0.07 & 27.05 & -0.88 & 1.45 . \\
\hline 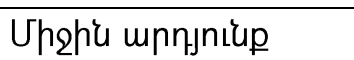 & 25.09 & 26.04 & 0.96 & 26.10 & 0.05 & 26.66 & 0.60 & 1.43. \\
\hline
\end{tabular}

1-hus unjnumulnnu utplymjugymo

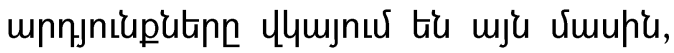
nn nıttnuqnuju unquर्umpn úpqumuluqnnnutinn 800र्u ymqpuinumurnıрjuis unmehí 200u huunymón mingunus tiu mर्utumumuqn, tiplnnnn 200र्u-u mutth unmq tinnnnnhg, umlquju ujuuntin

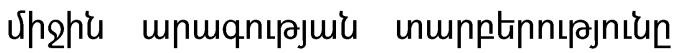

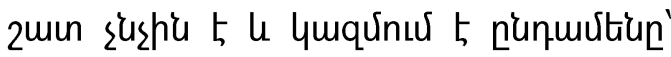

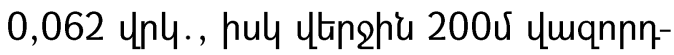

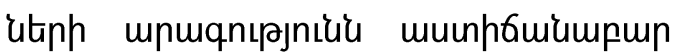

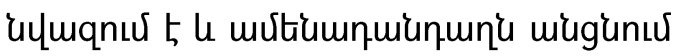
tiu 800 vtiunph Utanghí 200u unumu-

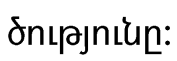

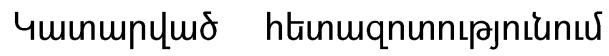

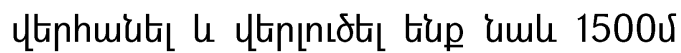

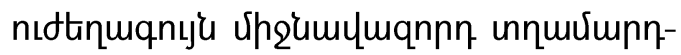

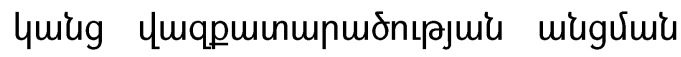
unupptip huunludoutnn: Uunugluo

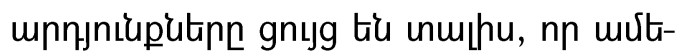

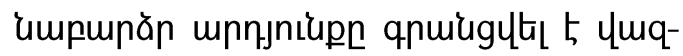
puinumurnıpjuís unmehí 300v huin-

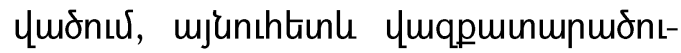
pjuís jnıpupuizsjnı vjnıu 300v huin-

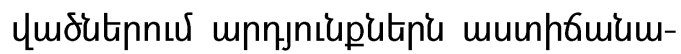

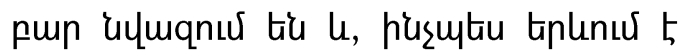
unjnıumlyhg' mर्utiumguron upnjniupn

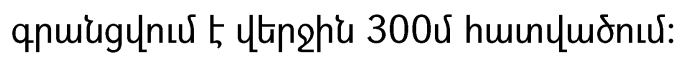


Unjnıuml 2

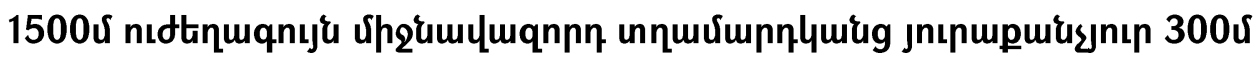

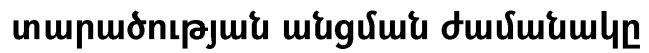

\begin{tabular}{|c|c|c|c|c|c|c|c|c|c|c|}
\hline uU & 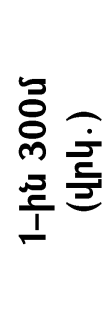 & 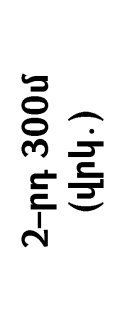 & 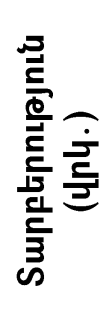 & 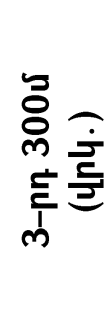 & 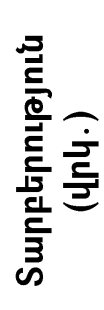 & 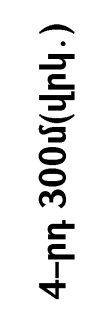 & 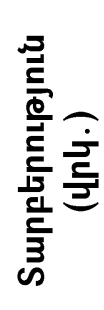 & 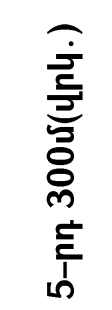 & 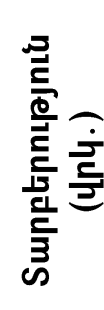 & 疍 \\
\hline 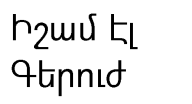 & 40.04 & 41.01 & 0.97 & 42.22 & 1.21 & 42.32 & 0.10 & 41.30 & +1.02 & 3.26 .89 \\
\hline $\begin{array}{l}\text { unnüLLhnu } \\
\text { RhnshL }\end{array}$ & 41.02 & 42.01 & 0.99 & 42.06 & 0.05 & 42.13 & 0.07 & 43.02 & -0.89 & 3.30 .24 \\
\hline $\begin{array}{l}\text { Чjuštiuguy } \\
\text { Cupnцhu }\end{array}$ & 42.03 & 42.08 & 0.05 & 42.15 & 0.07 & 43.01 & 0.86 & 43.10 & -0.09 & 3.32.37 \\
\hline $\begin{array}{l}\text { Snıwn } \\
\text { Znıph }\end{array}$ & 42.10 & 42.16 & 0.06 & 42.24 & 0.08 & 43.33 & 1.09 & 44.10 & -0.77 & 3.33 .93 \\
\hline $\begin{array}{l}\text { Rnu } \\
\text { Umunp }\end{array}$ & 42.06 & 42.32 & 0.26 & 43.05 & 0.73 & 43.25 & 0.20 & 44.21 & -0.96 & 3.34 .89 \\
\hline $\begin{array}{l}\text { Uhqhi } \\
\text { upnjnıup }\end{array}$ & 41.45 & 41.92 & 0.47 & 42.35 & 0.43 & 42.81 & 0.46 & 43.15 & 0.75 & 3.31 .60 \\
\hline
\end{tabular}

tqnulqugnıpjnıש: 4munuplü ht-

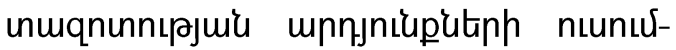

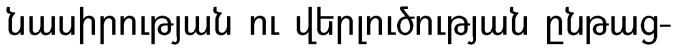
pnux huiuqtighiup htinlum tqumyugnıрjuit.

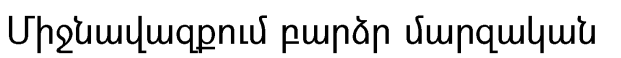

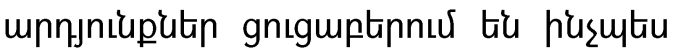

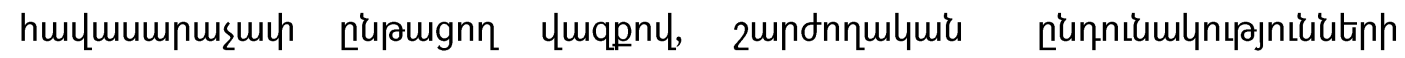


qunquguimis $\mathrm{l}$ inmlynplymlymis uminnuuunnıpjuí punăp viulunnum, husultu cumb ungnưutitiph quinlun-

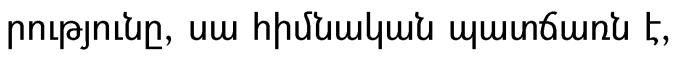
nn ymqnnnutinn unzun stü oqunuqnn-

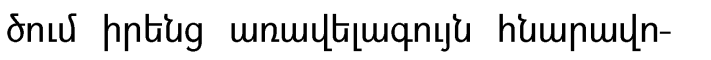

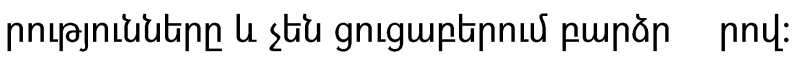
unn.jniuputap:

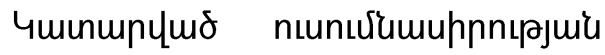
unnjniuputann gnug tiu unuphu umu, nn punănulympq uhozumumqnnnitinn ymqpuinumurnıpjuir unupptip huinymơtinn hunpaminnnu tiu pntiug

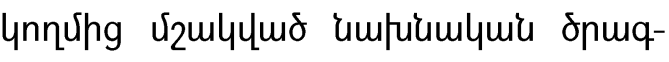

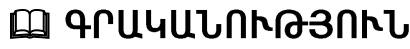

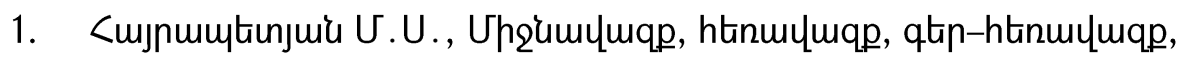

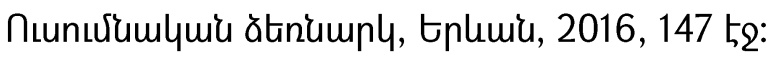

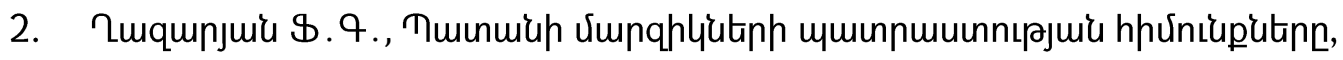
Łplumu, 1990, 114 t\&:

3. Вайнбаум Я.С., Дозирование физических нагрузок бегунов: учебное пособие// Я.С. Вайнбаум. - М.: Просвещение, 2000. - 362 с.

4. Макаров А.Н., Бег на 1500 метров, М.: Ф.С. - 1955.

5. Суслов Ф.П., Попов Ю.А., Кулаков В.Н., Тихонов С.А., Бег на средние и длинные дистанции, М.: ФиС. -1982г.

6. Кузнецова В.В., Бег на средние и длинные дистанции: Система подготовки учебник- М.: ФиС, 2007. - 250 с. 


\title{
OVERCOMING DIFFERENT SITES IN MIDDLE DISTANCE
}

\author{
Ph.D., associate OF professor V.A. Smbatyan, \\ lecturer A.V. Kosakyan \\ Armenian state Institute of Physical Culture \\ and Sport, Yerevan, Armenia \\ Yerevan State University named after \\ V. A. Brusova, Yerevan, Armenia
}

\section{SUMMARY}

Keywords. Middle distance, running, pace, evenly, athletic performance, distance section.

Middle distance running is one of the most popular event of athletics, as it is not long as long-distance running and not as fast as sprint. Middle distance running is distinguished by high speeds, competently combined with tactics and technics. To achieve high results in the above disciplines of athletics, it is necessary to be able to control the entire process of passing the distance, to change the technique in conditions of increased oxygen starvation and body fatigue. According to various experts, in order to achieve high results in running at medium distances, it is necessary to run it evenly, at a pre-planned pace.

Research relevance - By searching and analyzing technical and tactical methods of overcoming the distance of $800 \mathrm{~m}$ and $1500 \mathrm{~m}$ among the strongest runners, to identify the most effective of them for further use in training and competitive activities.

The objective of the research is to find out the dynamics of overcoming various sections of distances among the strongest runners at middle distances $(800 \mathrm{~m} \mathrm{X}$ 200m) (1500m X 300m).

Conclusion. As a result of our research, we made the following conclusions: in running at middle distances, both runners who run separate sections of the distance at regular intervals and those who develop high speed in these sections achieve high sports results. It is also necessary that athletes have a high level of tactical training, and developed motor abilities characteristic of middle distances. The results also suggest that the majority of the strongest runners stick to their pre-planned running pace. 


\section{ПРЕОДОЛЕНИЕ РАЗЛИЧНЫХ ОТРЕЗКОВ В БЕГЕ НА СРЕДНИЕ ДИСТАНЦИИ \\ К.n.н., доцент В.А.Смбатян, преподаватель А.В. Косакян}

Государственный институт физической культуры и спорта Армении, Ереван, Армения Ереванский государственный университет им. В.А.Брюсова, Ереван, Армения

\section{PEЗЮME}

Ключевые слова: средняя дистанция, бег, темп, равномерно, спортивный результат, отрезок, участок дистанции.

Бег на средние дистанции является одним из популярных видов легкой атлетики, так как не такой продолжительный, как бег на длинные дистанции, и не настолько быстрый, как спринт. Бег на средние дистанции отличают высокие скорости, грамотно сочетаемые с тактикой. Чтобы добиться высоких результатов в вышеперечисленных дисциплинах легкой атлетики, необходимо уметь контролировать весь процесс прохождения дистанции, изменять технику в условиях повышенного кислородного голодания и утомления организма. По мнению разных специалистов для достижения высоких результатов в беге на средние дистанции необходимо пробегать ее равномерно, по заранее спланированному темпу.

Цель исследования - путем поиска и анализа технических и тактических приемов преодоления дистанции на 800 м и 1500м у сильнейших бегунов, выявить наиболее эффективные из них для дальнейшего использования в тренировочной и соревновательной деятельности.

Задача исследования - выяснить динамику преодоления различных участков дистанций у сильнейших бегунов на средние дистанции (800м X 200м) (1500м X 300m).

Выводы. В итоге проведенного исследования сделаны следующие выводы.

В беге на средние дистанции высоких спортивных результов добиваются как бегуны, проходящие отдельные участки дистанции раномерно, так и те, которые развивают большую скорость на этих участках. Так же необходимо, чтобы спортсмены обладали высоким уровнем тактической подготовки, и свойственным средним дистанциям развитыми двигательными способностями. Результаты, так же свидетельствуют о том, что большинство сильнейших бегунов придерживаются заранее запланированному темпу бега.

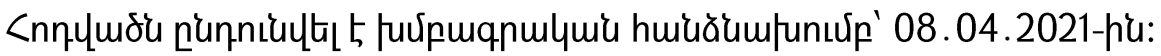

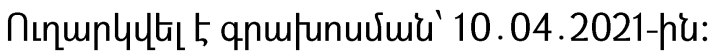




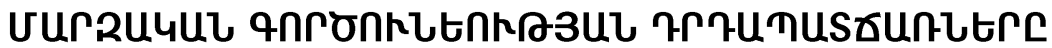

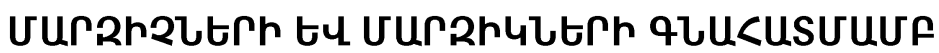

4.q.P., nngtiun, L.U. Uythyuirjui,

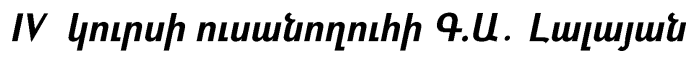

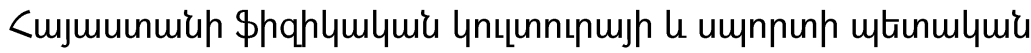

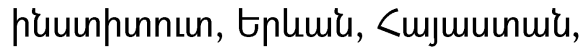

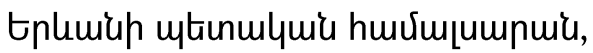
tplumiu, <mjuurnuiu, E.mail: lusine.stepanyan@sportedu.am, gayane.lalayan1@ysumail.am

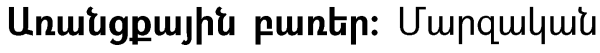

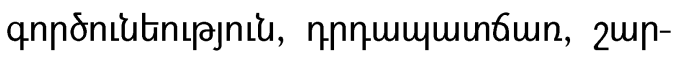
dunhp, qumburnnuर, vimphl, vimphes,

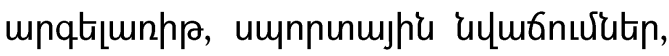

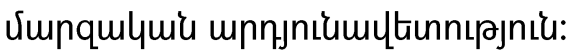

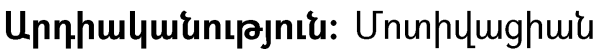

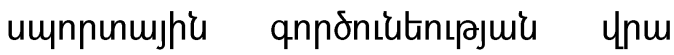

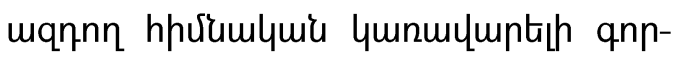

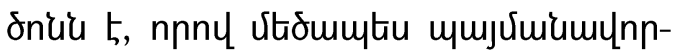

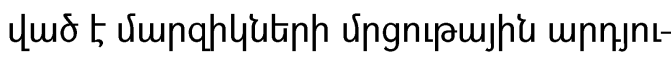
umLltinnıpjuiu gnıguiun2utinn, nunhum-

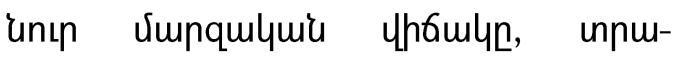

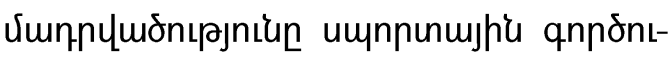

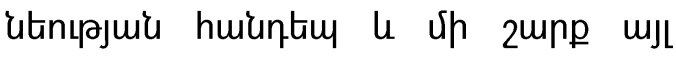

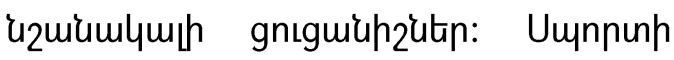

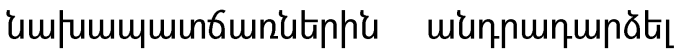
tiu mjumpup uzuiumunn htunuqnunnnuth, husumhupp tu' t. huhun, ก. Фh!n-

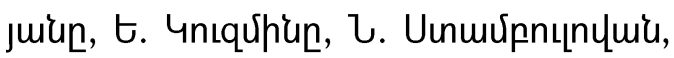

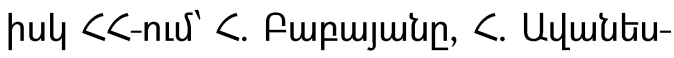

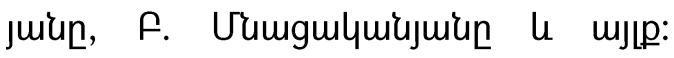

Uunnunp zundunnpataphes $u$, nun-

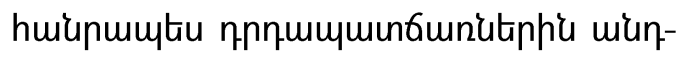

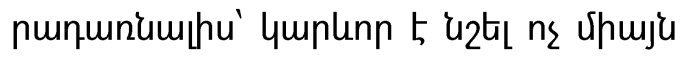

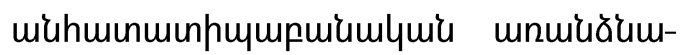

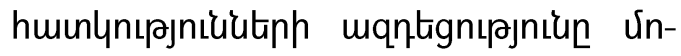

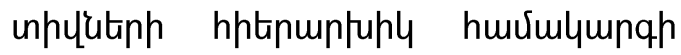

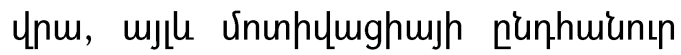

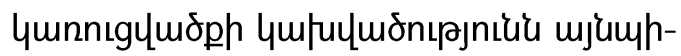
up qnnonuiutinhg, husuphupp tiu' tpanhl,

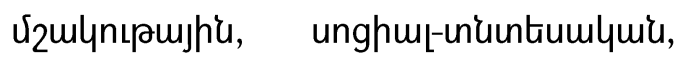

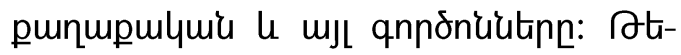
ution umnnunh zundunppoutnn $\mathrm{u}$ npuiug ynu uqnnn qnnonuutinn ymplunnunuर tiu $u^{\prime}$ Uumphšutiph, $u^{\prime}$ Junqhliutinh, $u^{\prime}$ umnnonh hnqtipuiutitnp ynnuरhg, umlumju unlym m2fuminuiup-

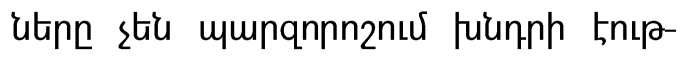
jniưu uर्upnпిnıрјuर्up:

Cunhuiupmutu únunhymghu huu-

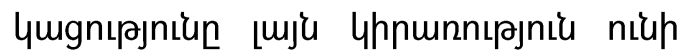

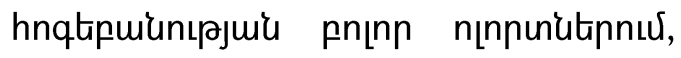




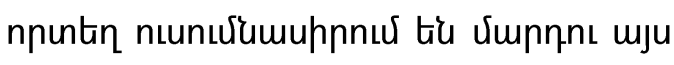

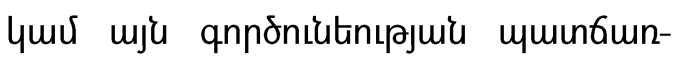

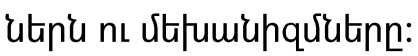

7pnumuinfiunn (Ununplughw) unıpjtyunh ympph le qnnoniutnıрjuiu

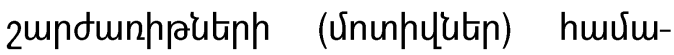

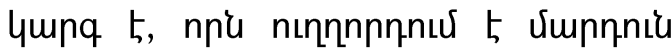
nnnzwly qnnoniutnıрjuiu, umuinulyh,

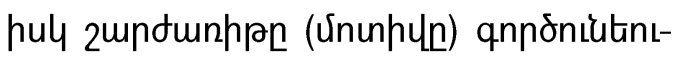

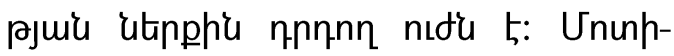

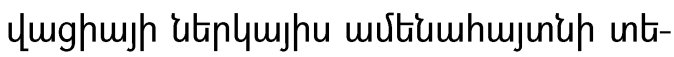

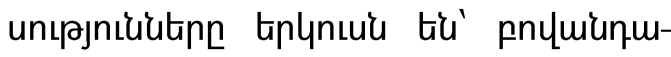

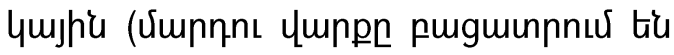

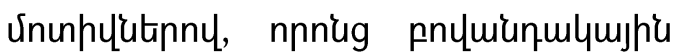

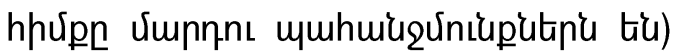

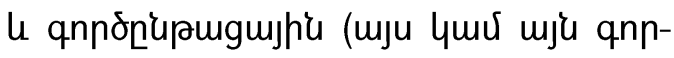

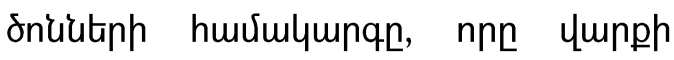
unnunnfuर्umu zundunpper 5) [2]:

fnumiunulyumpir ununhymghmsh untunıpjnıuutuphg 5 U. Umunnnı untunt-

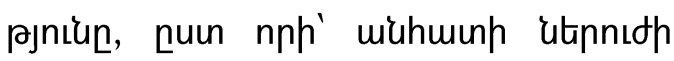

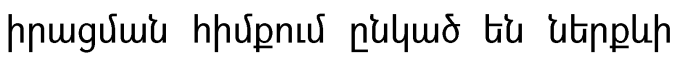

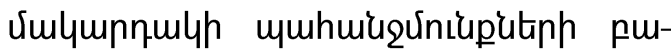

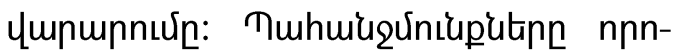
2nuर tú yunph 2undunhplutinn, hul purumpunnuxhg htunn' mqntignıpjnıนn nunumnux 5 [5]: hul \$. Ctiugptinqh

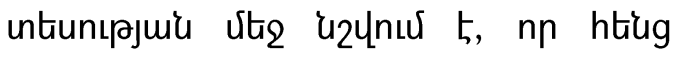

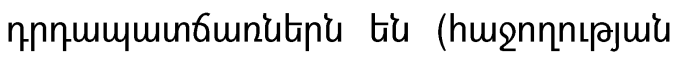
qqugntu, hunquiup, muinmujumiumun-

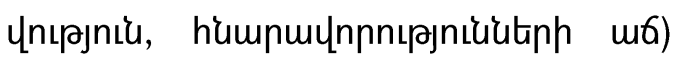

mqnnux nünhwiunın unnnhumghump punănugưưu unu [8]:

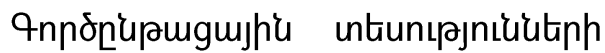

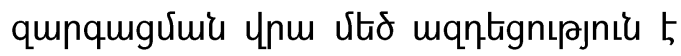

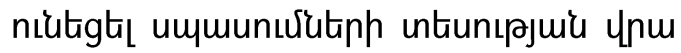

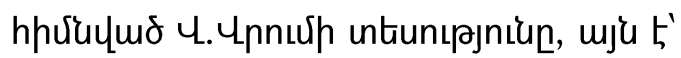

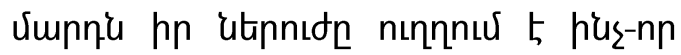

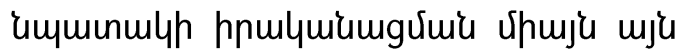

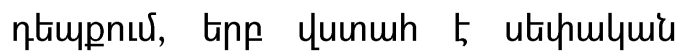

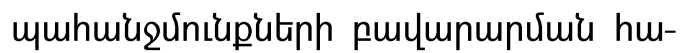
Чuiumlyuiunıpjuiu पnu [2]:

Ununhymghm huulumgnıpnilu'u u-

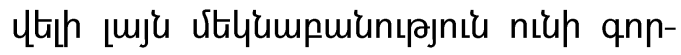

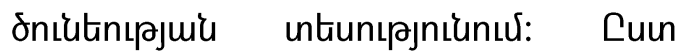

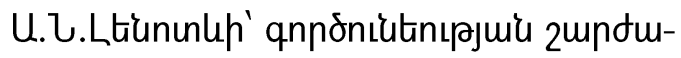
nhpe unıptilunp' opjtyunitiph htion

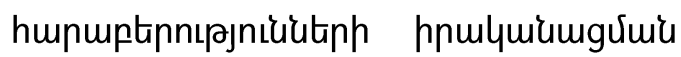
unupptip ălitiph huviulqung t5, hul

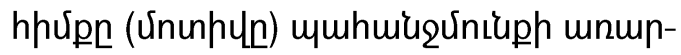

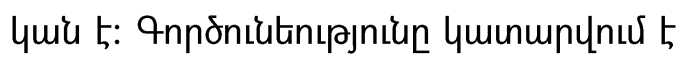
qnnonnnıpjnıüutinh ăleny, hul ytunghu-

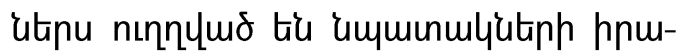
yuiumgưuiun [9]:

Ujuщhuny' qnnonıiutnıрjuí jnıрu-

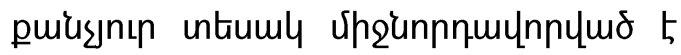
nnlts zundurnpany, nnny щujर्uium-

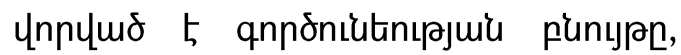

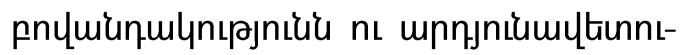

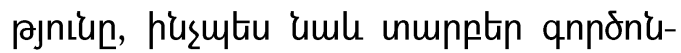
'utp' umuhu'uqưnı'uphtin, htinupnpnnt-

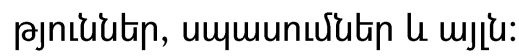




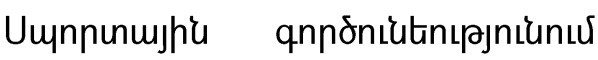

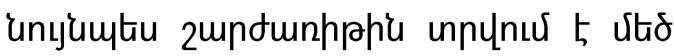
u2miumlynıpniu: Uju untumlquí le qnno-

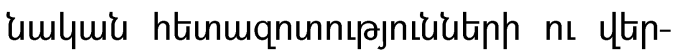

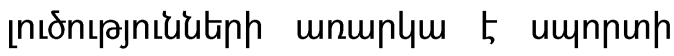

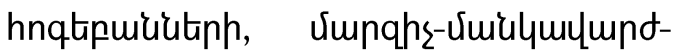

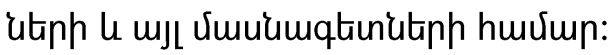

Umnnunusher Ununhymghmjh u-

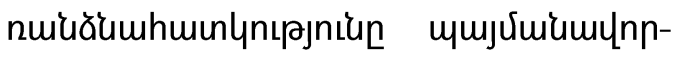

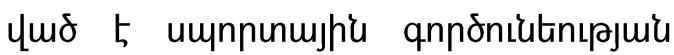
opjtyunh jnınuhuunlynıрјuर्up: Uupnnun

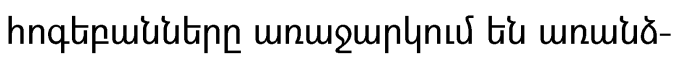
umguts umnnunny qpunythıns uju пnпuщuintiunutinn, nnnup puntpuqpnuर tiu vimphlyh wpn. yh6ulyn, husn umuuunnux 5 undjul umhhis

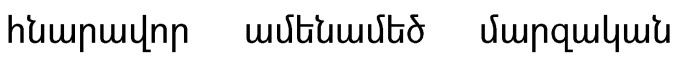

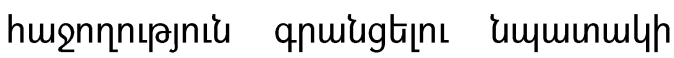

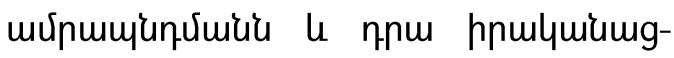
vimun: ก.U. Фhınjuiun umnnunujhí ununhymghuis umhưuinus 5 nnukiu vimphlyh wiăh nnnzmly yh6uly, nnn

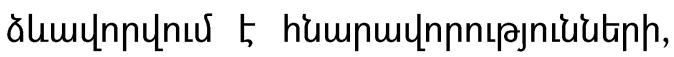

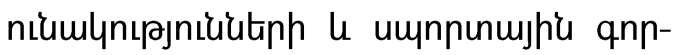

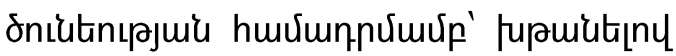

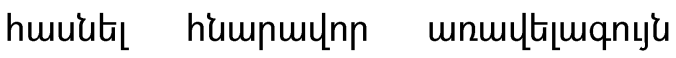
uunnunujh'u unnjnı'uph [7]:

4.4.Um\$nuny'u ns 3.h.\$hphưnutiu-

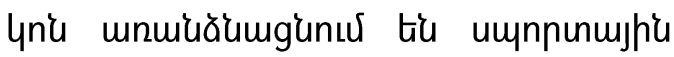
ununhumghump tiplns untuml' 1. nunhuiunın ununpymghm, nph ălumunnnuर्un nп2 viulymulundmlumi qnnonupamgh

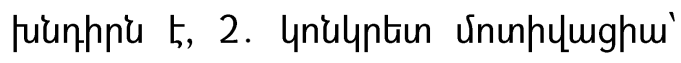

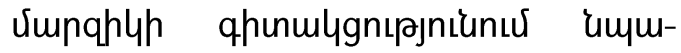

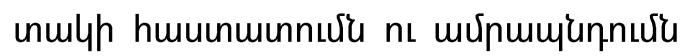

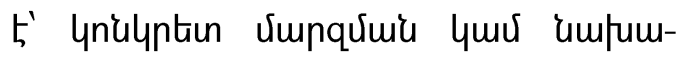

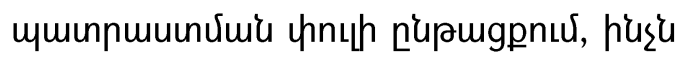

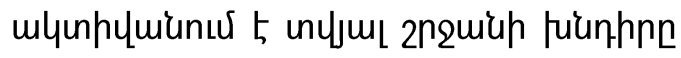

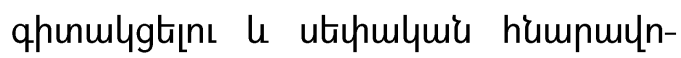

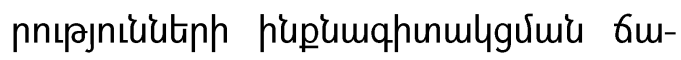
umumphny[4]:

Uunnunp zundunppn zuin ymplunn 5 , puiuh nn uju umnnunujhe unnjniuputiph Чnu uqnnn upuly yunuuluntıp qnnoniu $5:$

Umpqhlutinh t_nupatitph Unu tintp hhưumlumiu qnnon's 5 mqnnuर'

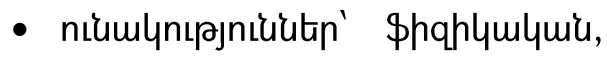
untipunhlymlymir $\mathrm{u}$ vinuunn, nnnup hu-

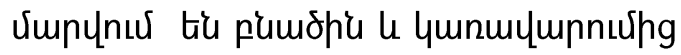
пnıpu,

- Ungnưulatiph punnnıpjniu' ungum-

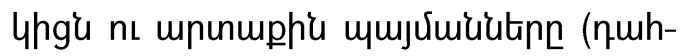

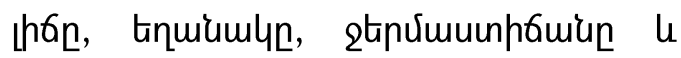

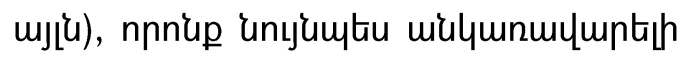
tiú,

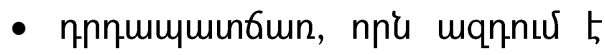

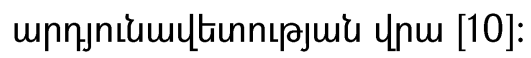

<ujunuh 5, nn up ynnưhg umnnunujh's ununhymghuiu mqnntu 5 vimnqsulquiu qnnoniutinıpjuí le ungulygujhís

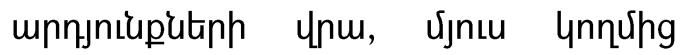

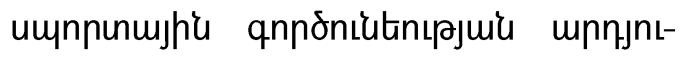
umultunnıpjnı̌n purănugưnu 5 uщnn- 


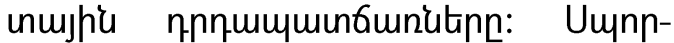
unmjhe ununhumghmup qunquagnuरn

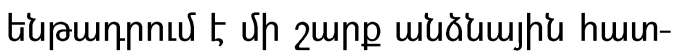
quiuhzutnp punăp vilyunnulyh

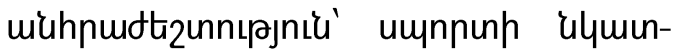

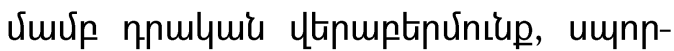

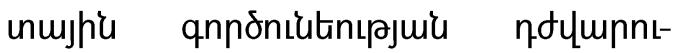

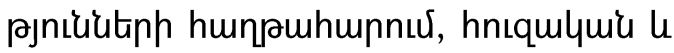

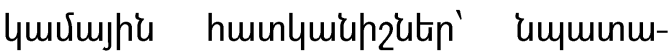

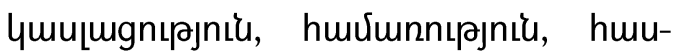

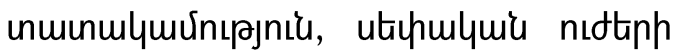

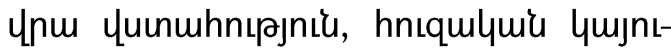
unıpjnic lu mృ u:

Umlumje vemphlyutinhis ns uh2un t5

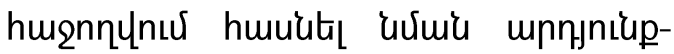
utph, nph upnjniupnus bl $\mathrm{h}$ humen b quцhu unqtiunhpon (ntuínunhymghwiu): Unqtiunpph quर्u zundunpph pugu-

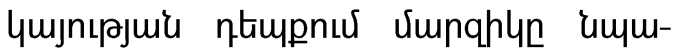

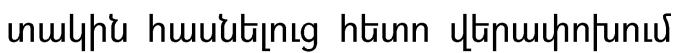

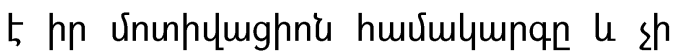

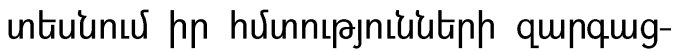
vimu pưmuin [3]: Uju lumbih 5 umh-

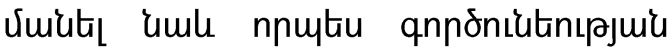
unnjniumultinnıрjuí le npuly yunnnıl

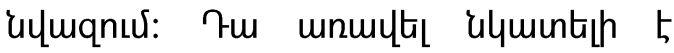

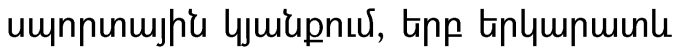
u hnqukignighs viunqnưlutiph htinn quцhu 5 umh, nnhg quүuцmo b

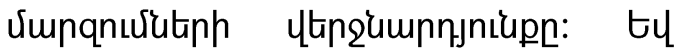
htiug wın umhhi, tip \$hqhnцnqhulymu u ytiunumuiumlymí undjujutinn stiu hu-

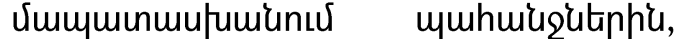
fumiqqununuर tiu htinmque qnnon-

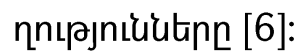

Unqt_unhpr quर्u zundunpph pugulqujnıpjniun u'uunuर 5 utipphí $u$

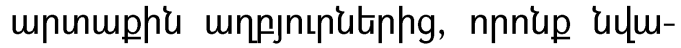

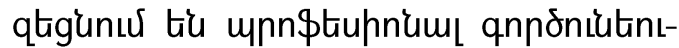
pjuir huiuntiu Umpnns htinupnpnnt-

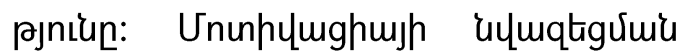

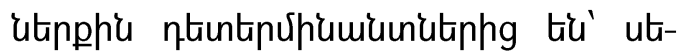

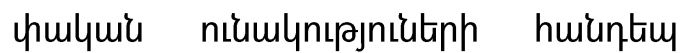
hurluinh pugmumjnıpjniun, ym/un'

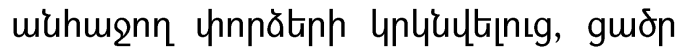

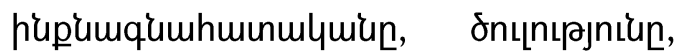

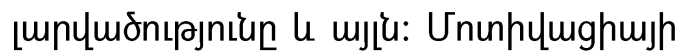

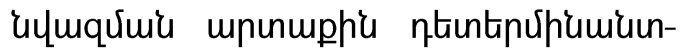

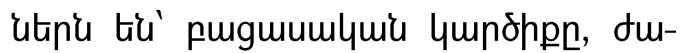

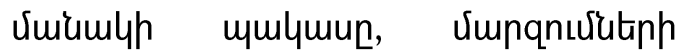

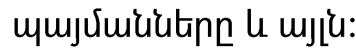

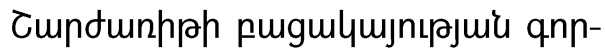

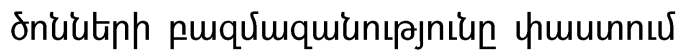

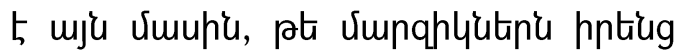
umnnunujher qunphipujh n'upugpnuর nnpuir tiu tüamplyunu 2 tinnn un-

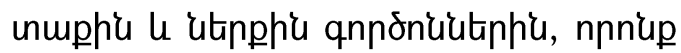

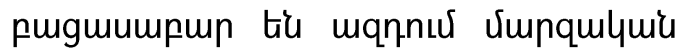

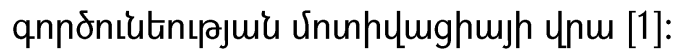

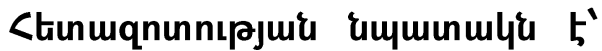

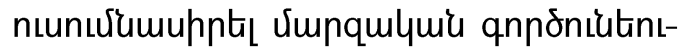

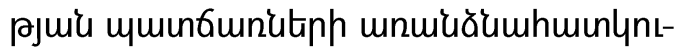

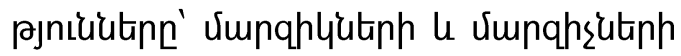
qumuhuunưứ: 


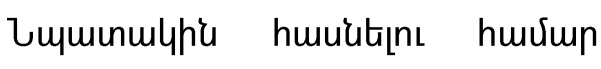

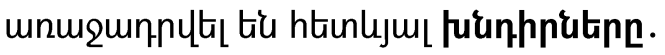

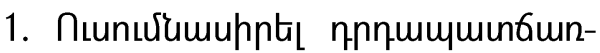
utph, 2undunnpaltiph lu unqtiu-

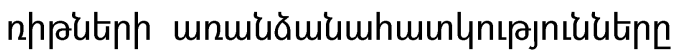
vimnqulyuiu qnnóniutnıрjui vitis:

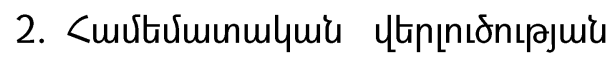

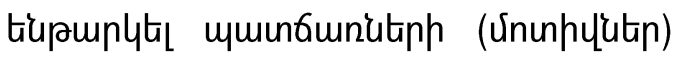

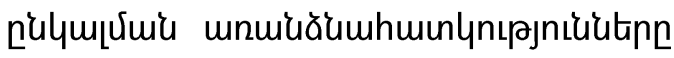
vimphliutinh u vimphsitiph qumhume umun:

<tunuqnunnıpjuir opjtyunn vimpquiluis qnnoniutenısuiu 2undunhputnu (Ununhlutinn) tu:

Chunmqnunnıpuir unuplyuir

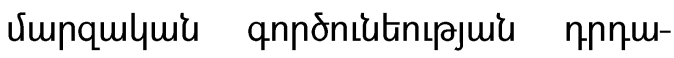

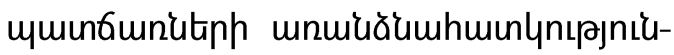
utnn vimphlyutinh u vimphsitinh quuhuinuluúp:

Stinmqnunnıرuir vitionnutinn $\mathbf{u}$

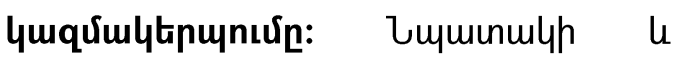

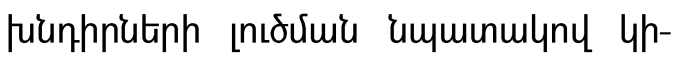
nunuts tiu hungưuie le ynuintian-

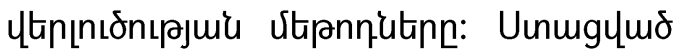
unnjniuputinn tiupmplylta tiu hu-

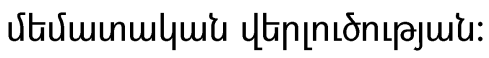

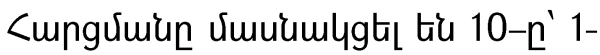

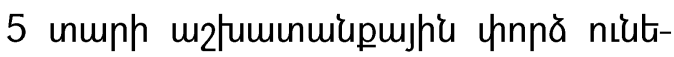

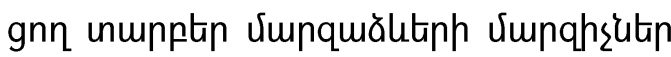

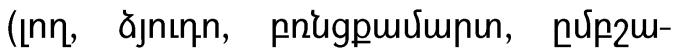

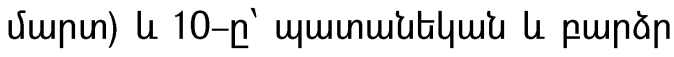
unuphpushis fuরuph (16-20 ununtiluiu) unupptip vimpqulquí punăn hugnnnt-

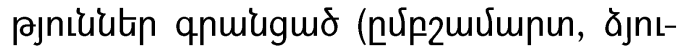

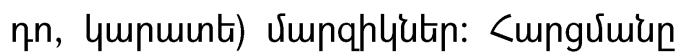
Juukumgum pnınn vimphlyutinn <m-

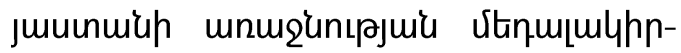
utap tiu, Jumphlyuting 5 (mquin nfh

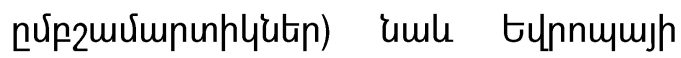

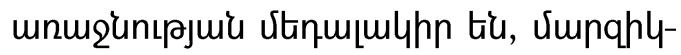
'utiphg tiplnnun' uunnunp y unutiunutan:

Stunuqnunnıرuir upnjniupatph

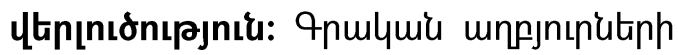

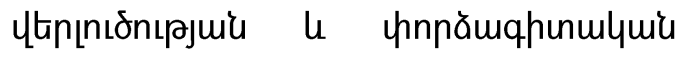

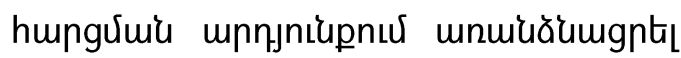

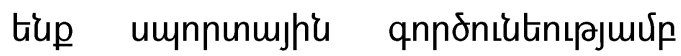

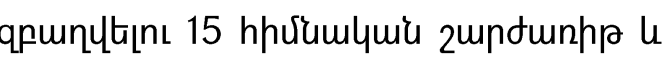

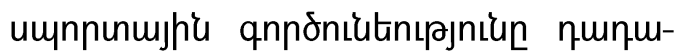
phgutinn 15 unqt_unnpp qnnonuiutin,

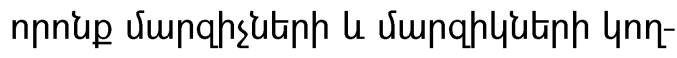
uhg qumhumulta tiu 1-5 pujujhru huvimlungny (hurumumunmulumiumpun uju qnnornüutnn, npnup mqntugnıрnı'u

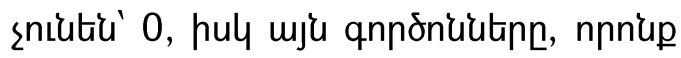
myutiple mqnnuर tu' 5):

Unumgymo mpnjniuputinn, nuin

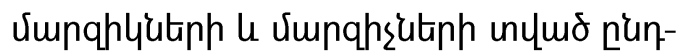

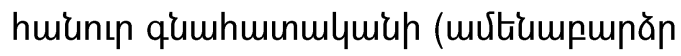

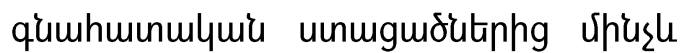

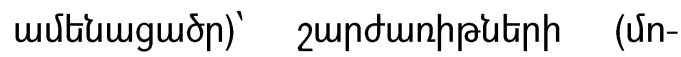

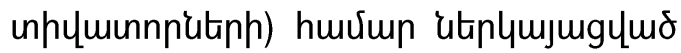
tí 1-p'u unjnumunux, pul mpqtalunhputaph (ntưnunhumunnnutnh) huưur' 2-

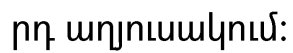




\section{Unjnıuml 1

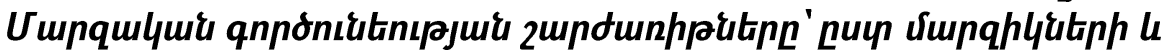

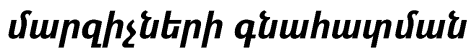

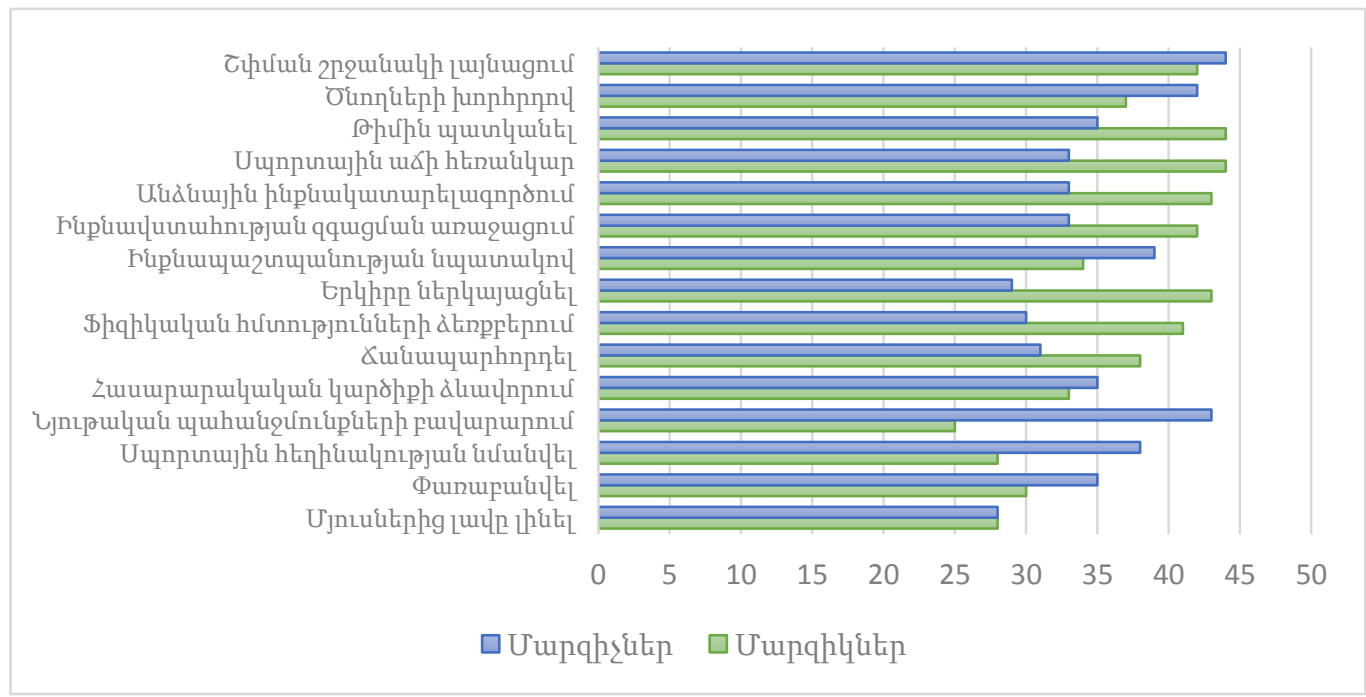

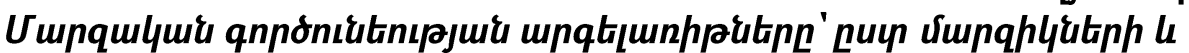

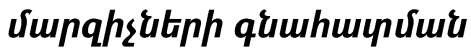

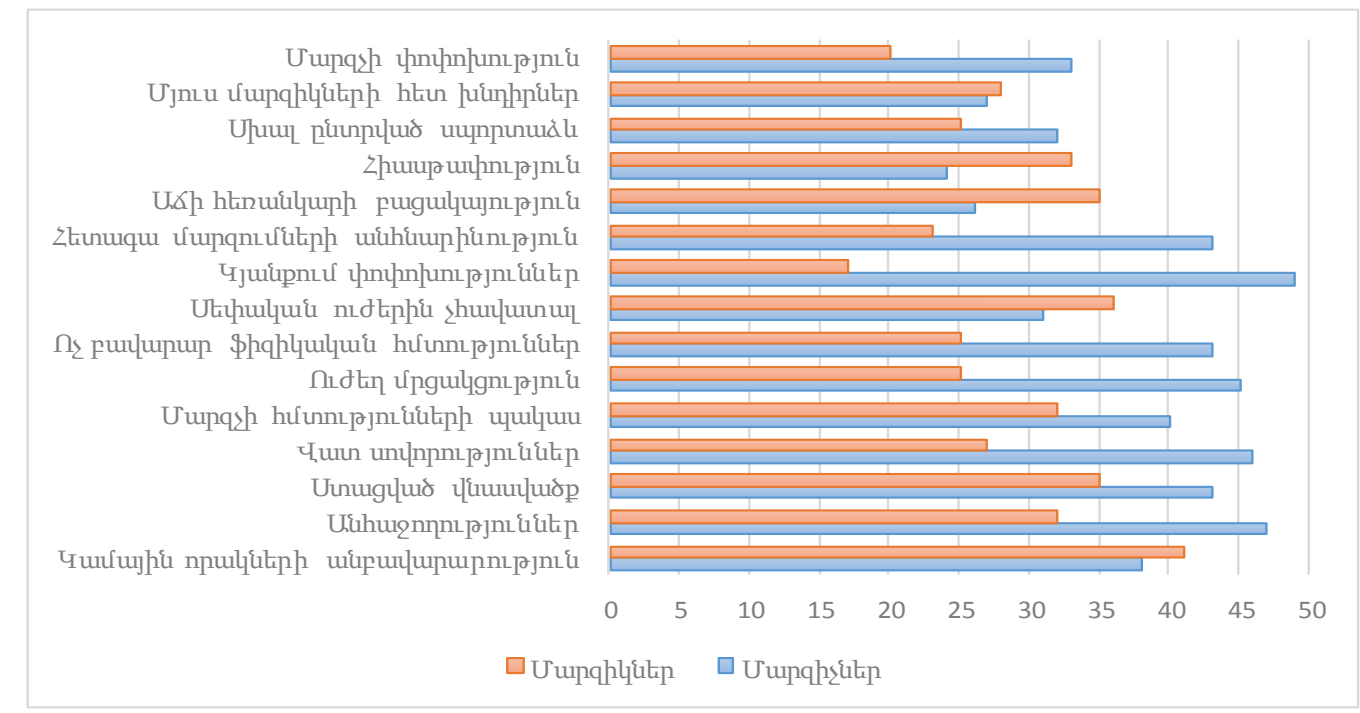


Unnnle Uatplymjugymo tiù vimp-

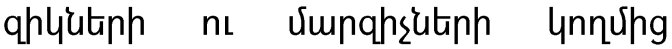
unuuăumgyud zundunhph (Ununh-

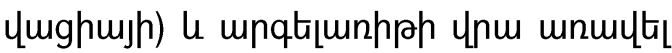

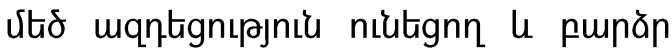
qumhumulquiutitph mpduiumgur 5-

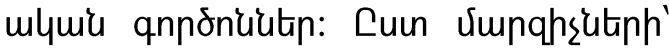

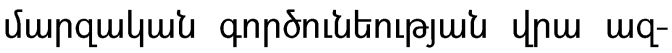

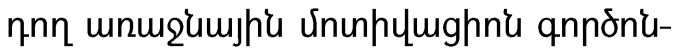

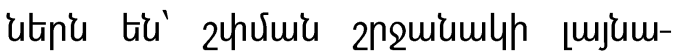

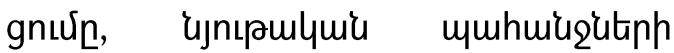

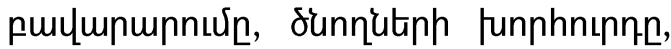

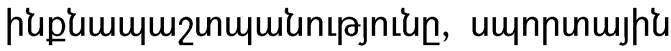

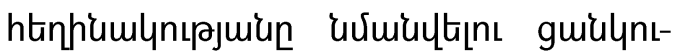

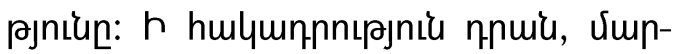

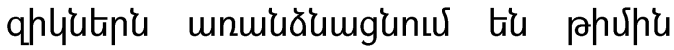

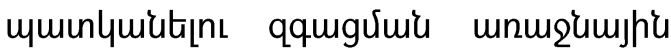

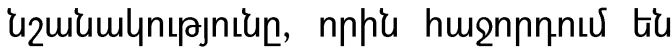
umnnunujhe w6h htnuilymen, trphnn

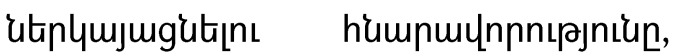

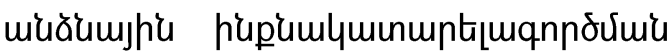

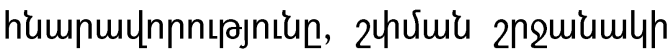
[ujumgnnun:

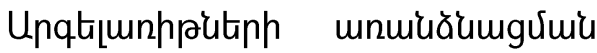
hungnư luu vimphsitiph le vimnghy-

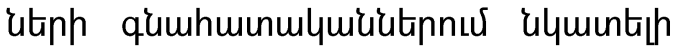

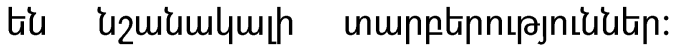
Cuin Uumphs'utiph' umnnung htnu-

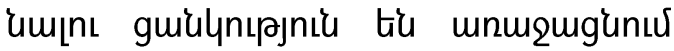

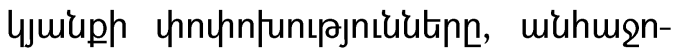

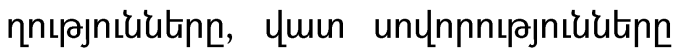

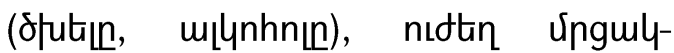

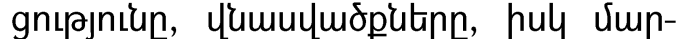

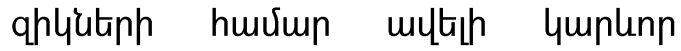

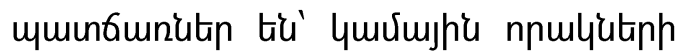

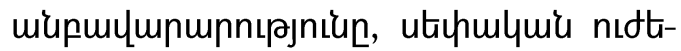

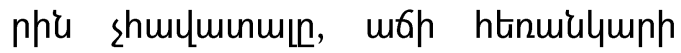

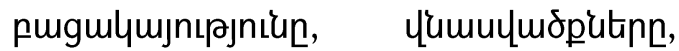
hpuupurhnıpjnıนn:

<tngptingh Ununhumghn's intiunt-

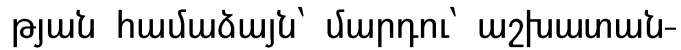

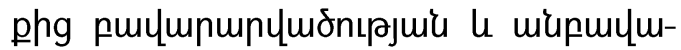

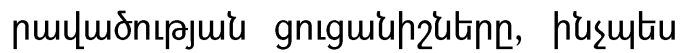

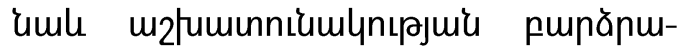

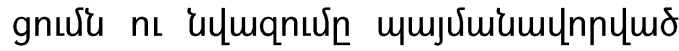

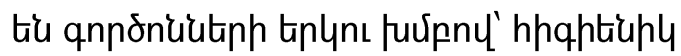

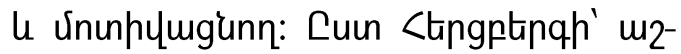

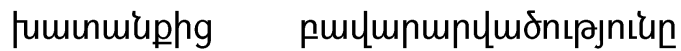

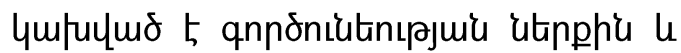
pnumiunulyushiu punspuqnhs'utinhg, hul

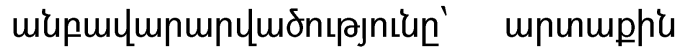
umujuiuututing [8]:

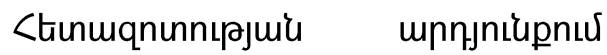

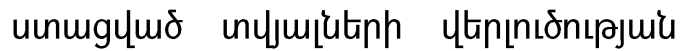

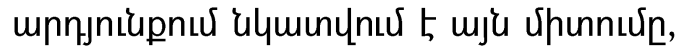

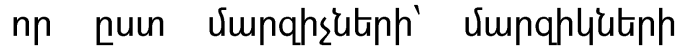
umnnunujhis qnnonilutnıрjuर्up qpun-

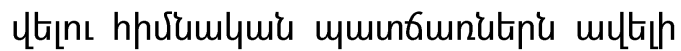

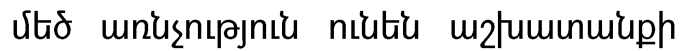

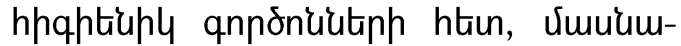

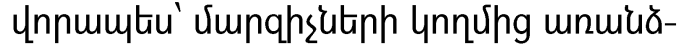

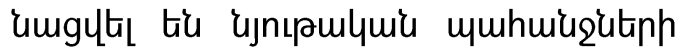
purumunnuर्un: Uunnunush's qnnontutnnıرuí цnu mqnnn hpqhtiuply qnn- 


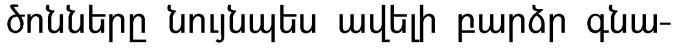

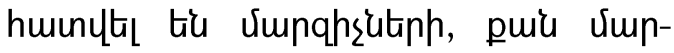
qhlutinh ynnưhg (Ulungsh ns purumum vimulumqhunmlymis hưunnıpjniuutut, Uunqş unnunnfunıpjnıu, htinuqu vimp-

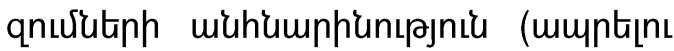
untinh unnunfunıpjniu, \$hamiumulyuir jưnhpiutn):

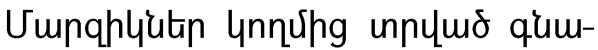

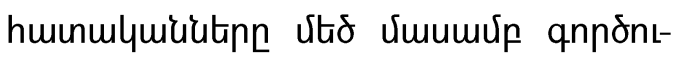

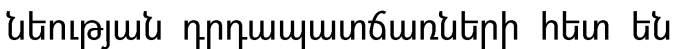

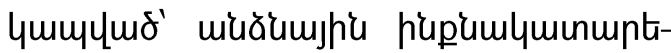

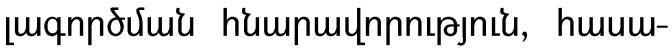
nulymír punăn lumpopph ălumunnnuর, umnnunujh's wap htnuilyme, h'up-

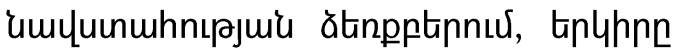

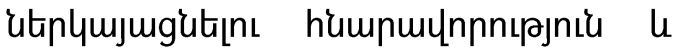

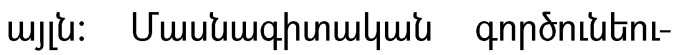

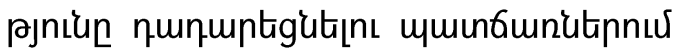

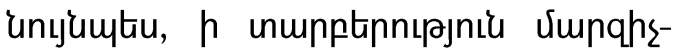

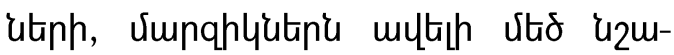
umlynıpjnı tú unlta 2undunppeutiph

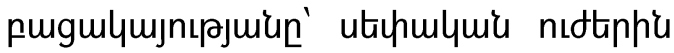

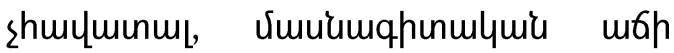
htnuulymph pugulymjnıpлniu, hpuu-

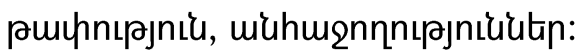

Cuin <tngptinqp' htiug ununpumghnu qnnoriutiph qtipulumsnıرuर्up

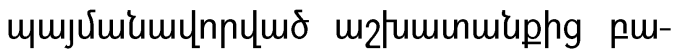

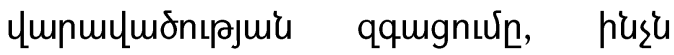

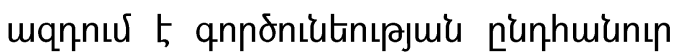

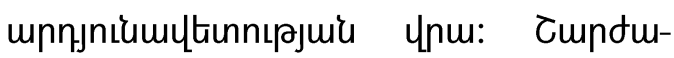

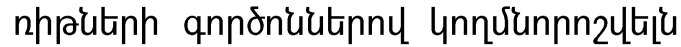

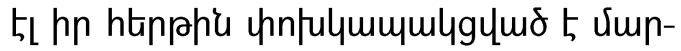

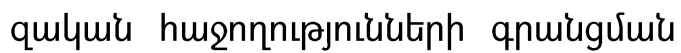

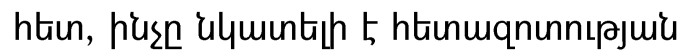

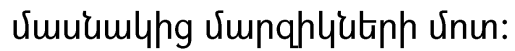

<tingptingh ununplughmugh tipl-

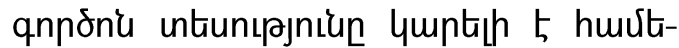

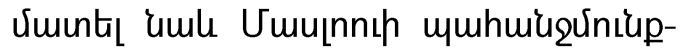
utph pnınqh htion [5], nnuntin hpqptiuply qnnonuutinn umbuiuguniuputinn citnphú vimlumnulynu quñulnnutinu tiu,

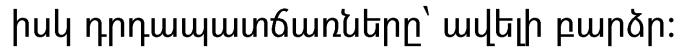

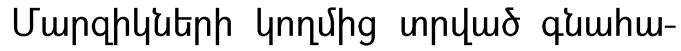
unmlquiutitn's nuin Umu[nnıp' 4huuunnuर

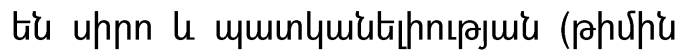
umunlymutins qqugnıर), hunquiuph (hmumpulyulumúu punān yunohph ălum-

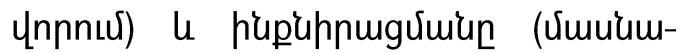

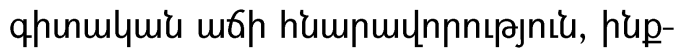

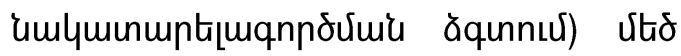

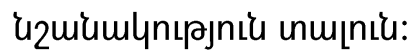

tqnulyugnıpjnil: Uunqhęutinn

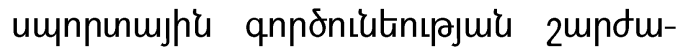
nhputinh lu unqtiunpplatiph qnnon'u-

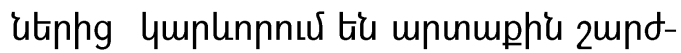
unpputiph le mpqtiunhputiph unuqugvimis muinfiunatinn, hul vimphy-

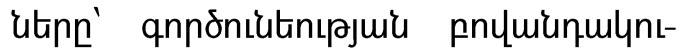

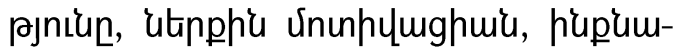

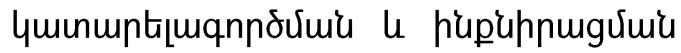

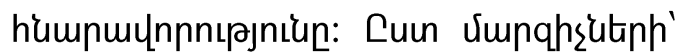

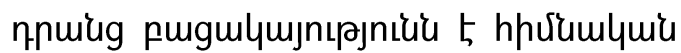


mpqtiunhph muinfiunn: Um jununuर्u 5

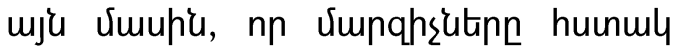
umunlytpugnux sniutiu vimnqhliutinh

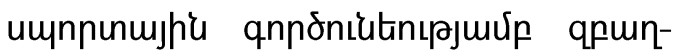

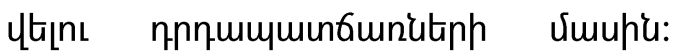
Unuiup ymponku tiu' vimphlyh umnn-

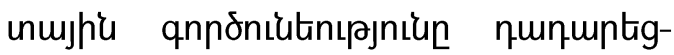
utjns umunfiunn ns pt vimphsh upnunnfunıpjnı̌n, htinumqu vimpqnulutiph

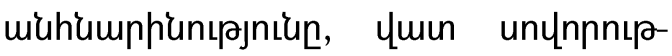

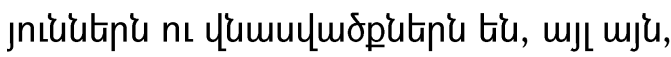

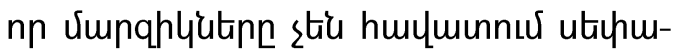

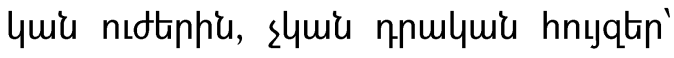

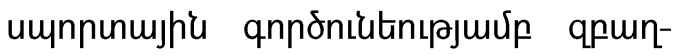

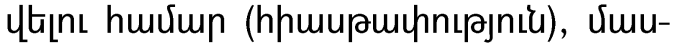

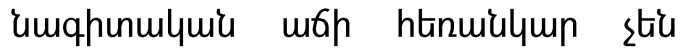
untuúunux:

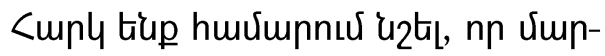

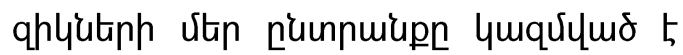

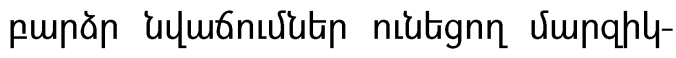

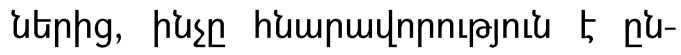

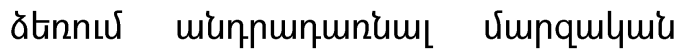

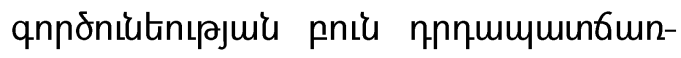
utiphu:

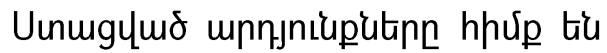

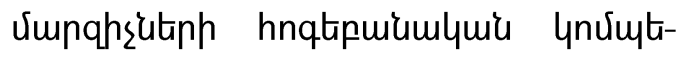
untiuunnıرuí (hnuqtilnıрjui) qunqugUuiu huưum:

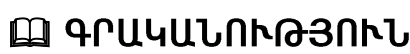

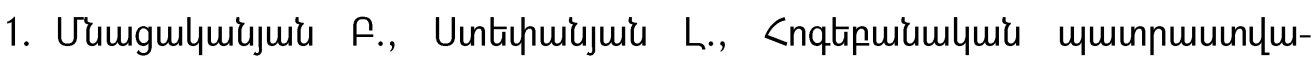

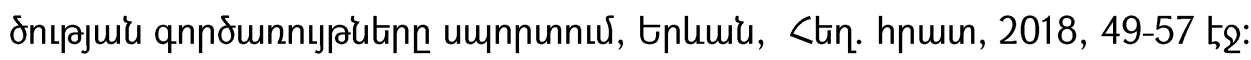

2. Дейнека А.В., Современные тенденции в управлении персоналом: учебное пособие / Дейнека А.В., Жуков Б.М.. - Москва: Академия Естествознания, Южный институт менеджмента, 2009. - 403 с. [5[thlunnnumjhu ntunınu]:

https://monographies.ru/ru/book/section?id=2119

3. Кокурин А. В., Кудашкин Е. А., Значение мотивации в достижении результата в спортивной деятельности, №10/1, 2013

4. Кузьмин Е.Б., Денисенко Ю.П., Драндров Г.Л., Формирование спортивной мотивации как психолого-педагогическая проблема, Педагогико-психологические и медико-биологические проблемы физической культуры и спорта, 2009, стр. 8793

5. Маслоу А., Мотивация и личность, 3-е изд./ Пер. с англ. - СПб.: Питер, 2009 - 352 с. - (Серия “Мастера психологии”) - стр. 60-96 
6. Мнацаканян Б.Х., Факторы демотивации в спортивной деятельности, Российский государственный университет физической культуры, спорта, молодежи и туризма (ГЦОЛИФК), М.: 2016.

7. Пилоян Р.А., Мотивация спортивной деятельности и индивидуализация подготовки фехтовальщиков/ Пилоян Р.А., Пузенков Н.Ф. // М.: 1985 - стр. 10

8. Herzberg F., How do you motivate employees?, Harvard Business Review, 65(5), Sep-Oct 1987, pp.109-120

9. https://studfile.net/preview/5132802/page:8/

10.https://www.psychologytoday.com/us/blog/the-power-prime/200910/sportswhat-motivates-athletes

THE MOTIVES OF SPORTS ACTIVITIES

\section{BY ASSESSMENT OF ATHLETES AND COACHES}

PhD of Biology., associate professor L.S. Stepanyan, Student of $4^{\text {th }}$ course $\mathbf{G}$. A. Lalayan,

Armenian State Institute of Physical Culture and Sport, Yerevan, Armenia, Yerevan State University, Yerevan, Armenia,

\section{SUMMARY}

Key words: sports activity, motive, motivation, assessment, athlete, coach, demotivation, sports achievements, sports efficiency.

Research objective: to study the motivation in sports activity and the features of motives of sports activity assessed by athletes and coaches.

Research methods: to study the features of motivation, motivators and demotivators in sports activities, to carry out a comparative analysis of motive perception characteristics. The methods of survey and content analysis were used. A comparative analysis of the results obtained was carried out.

Research result: As a result of the analysis of literary sources and an expert survey, 15 main motivational factors and 15 demotivating factors were identified for being engaged in sports. These factors were assessed by coaches and athletes on a 
scale from 1 to 5: respectively, factors having no impact are 0 and factors that definitely have an impact are 5 .

Conclusion: The assessments of the factors of sports motivation and demotivation given by athletes and coaches differ: the coaches state, that external motivation and causes of demotivation are important, while the athletes highlight the content of the activity, internal motivation, the possibility of self-improvement and self-realization. Thus it suggests that coaches do not have a clear idea of the motivation of athletes in sports activities. The reasons for demotivation are not a change of the coach, inability to continue training, bad habits, injuries, but the lack of other motivational factors, like loss of self-confidence, disappointment, no prospects for professional and personal growth, etc. The results can serve as basis for developing psychological competence of coaches.

\title{
ОЦЕНИВАНИЕ МОТИВОВ СПОРТИВНОЙ ДЕЯТЕЛЬНОСТИ СПОРТСМЕНАМИ И ТРЕНЕРАМИ
}

\author{
К.б.н, доцент, Л.С. Степанян, \\ студентка IV-ого курса Г.А. Лалаян
}

Государственный институт физической культуры и спорта Армении, Ереван, Армения Ереванский государственный университет, Ереван, Армения

\section{PEЗЮME}

Ключевые слова: Спортивная деятельность, мотив, мотивация, оценка, спортсмен, тренер, демотивация, спортивные достижения, спортивная эффрективность.

Целью данной статьи является исследование мотивации в спортивной деятельности. Цель исследования - изучить особенности мотивов спортивной деятельности в восприятии спортсменов и тренеров.

Для достижения цели были выдвинуты следующие задачи: изучить особенности мотивации, мотиваторов и демотиваторов в спортивной деятельности, провести сравнительный анализ особенностей восприятии мотивов. 
Для достижения цели и решения проблем использовались методы опроса и контент-анализа. Проведен сравнительный анализ полученных результатов.

В результате анализа литературных источников и экспертного опроса, были выделены 15 основных мотивационных фракторов для занятий спортом и 15 демотивирующих факторов. Данные факторы были оценены тренерами и спортсменами по шкале от 1 до 5: соответственно факторы, которые не имеют влияние - 0 и факторы, которые определенно имеют влияние: 5 .

Оценки факторов спортивной мотивации и демотивации, которые дали спортсмены и тренеры, различия между наиболее важными факторами, а также тот факт, что, по мнению тренеров, важны внешняя мотивация и внешние причины возникновения демотивации, а по мнению спортсменов: содержание деятельности, внутренняя мотивация, возможность самосовершенствования и самореализации и их отсутствие является основной причиной демотивации, говорит о том, что тренеры не имеют четкого представления о мотивации спортсменов в спортивной деятельности. Причины демотивации не смена тренера, невозможность продолжения тренировок, вредные привычки, травмы, а отсутсвие других мотивационных факторов: спортсмены не верят в собственные силы, отсутствуют положительные эмоции заниматься спортом (разочарование). отсутствуют перспективы профессионального и личностного роста и. т. д. Полученные результаты могут быть использованы в повышении психологической компетентности тренеров.

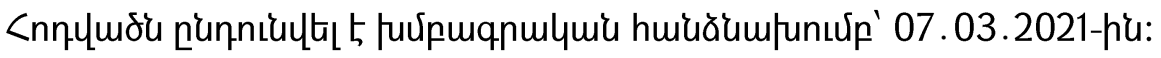

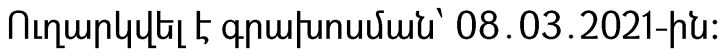


DOI: 10.53068/25792997-2021.1.3-67

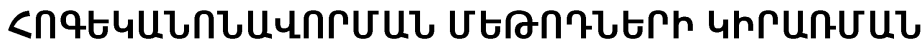

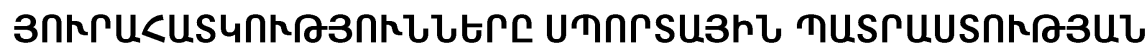 SURFtr ФாRLERחトU}

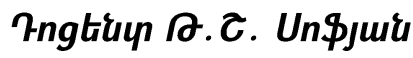

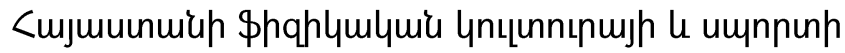

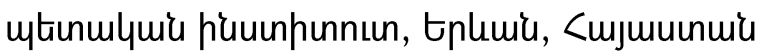
E.mail: tatevos.sofyan@sportedu.am

Unwiggpujhน puntip: Uunnunu-

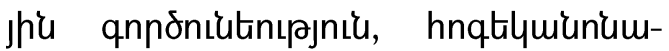

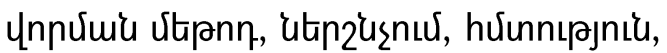

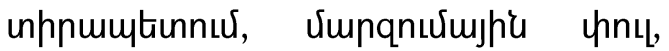

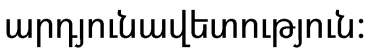

Ctunuqnunnıرuir upnhulquiunt-

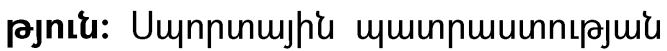
unnh fưnhnuting 5 viunqhlutinh ynnưhg hnqtilumunzumunnưuiru hưunntpjniuiutiph unpnumbinnuरn: <nqtiluiun-

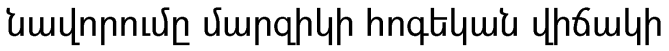

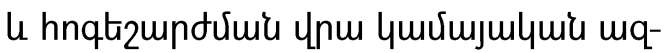

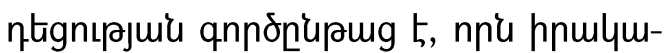

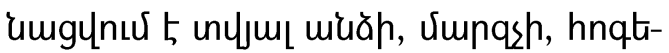

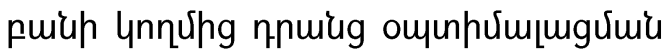
ummunmlyny: <nqtiquiunumunnưure

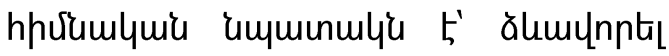
huiunnly hnqtiulh6uly, nnn kumuuunnuर 5

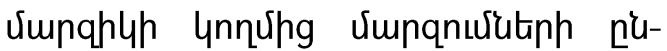

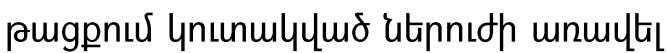
himpttp oqunuqnnofluiun:

<nqtilumunzumunnnuxn n.punuplunư 5 up puiup untumutionny'

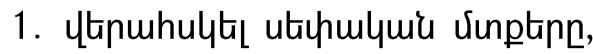
hnugtinn l y unpn,

2. hnul|h6ulyhg tiutinnl' 4unnnu-

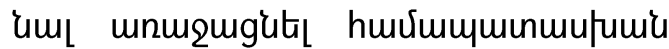
hnqtilhfurl,

3. unpnumutint! huviumph hnqtyuuniumunnưu'u vipnnutiph, npnup 44h-

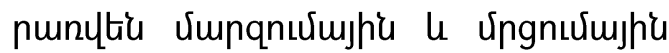
qnnon’upuguthnnuर:

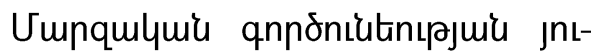
nupuiusjnıp ălunuर hnqtymunumuln-

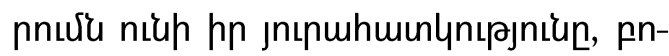

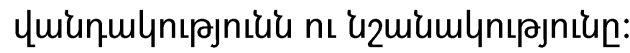

<nqtilquiunimunnnuxn qhunuultapn-

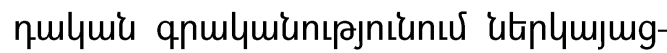

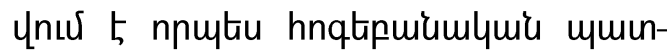

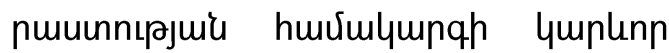

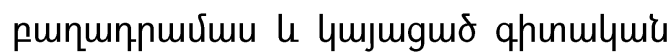

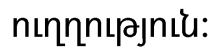

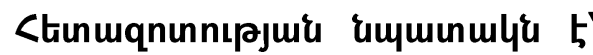

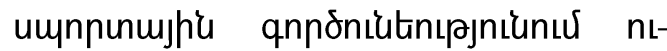

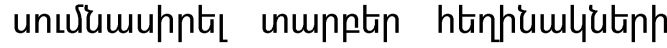

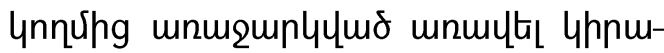




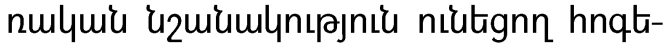

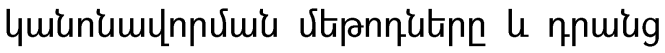

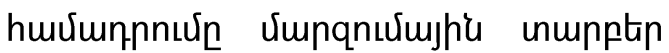
unnццtinnux:

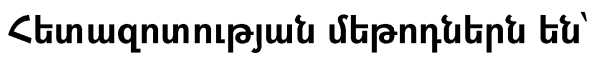

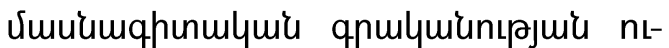

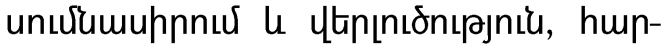
guqnnugutin, qpunuplynuरutip, hnqtpuiumlumí milytinuulnnnu:

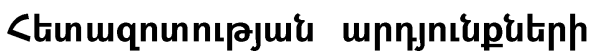

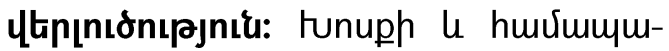

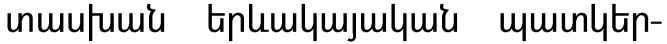
utiph uhęngny wiăh ynu mqntignt-

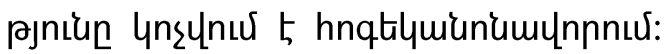
Uju ympnn 5 hnulquiumgltal hip-

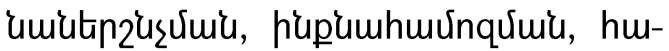
yuinh uhengny: <húlamlumir uhnu-

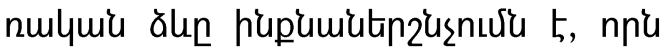

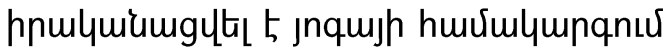

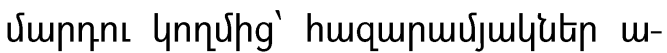

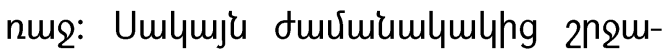
unuर hnqtilumunumunnưuid uju ălep

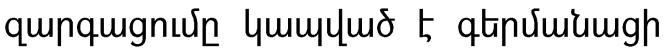
hnqtiptipumuin h. 9. Znıgh htiun, nnn 1932p. hnuunumultigg "Ununnqtie Uunqnư» qhppn [9]: Ununnqtiu Uumqnứ hnulyuiumgunuर 5 húp'um-

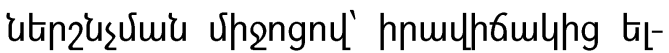

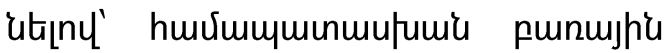

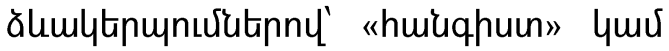
"mlyunhu» hnqtilhfurly unmomgutiny $[4 ; 2]$ :

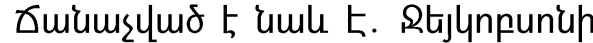
"Tnnqpitupy ntjupu» ('ujunnuर्ulquiumJhu pnцाugnuर) vtipnnn, nnn hnıqulyuunıpjư htun punănugunuর 5 yर्uma-

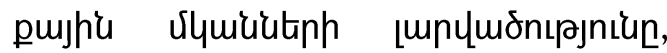
htinlumpun, pnцщughtinny huर्umum-

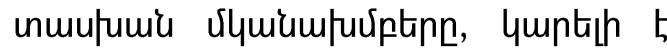
hnıqulquiunspjnıiun unnfuta miuhnuotizun

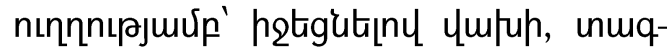
umumh qqugnnnıpjnıuutinn [5]:

smiumnugh qhenzumlyui L. Ttipupymin mnmomplitg hnqtilumunimunn-

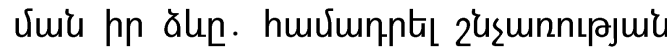

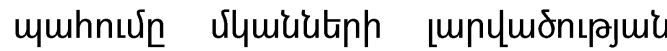

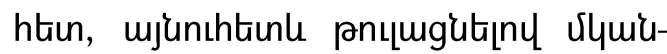

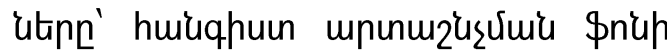

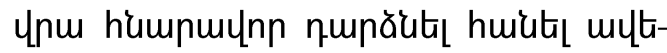

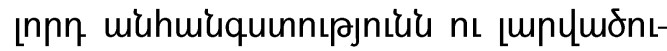

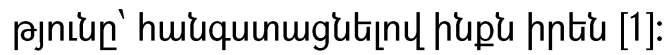

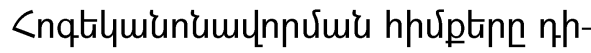

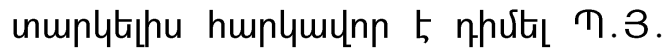
Uunfuhup \$niulyghnume huviulympqtiph untunıpjuin, nnn utplqujugyur punnnıрjuir unupptip uuunh6uiuh

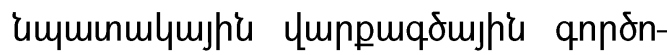
nnıpjnılukinny [3]:

Cuin U.4. Yh2ujulynumsh' 2'usu-

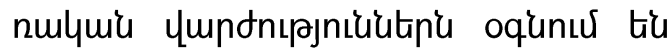

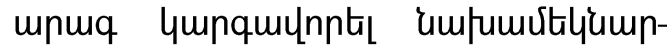

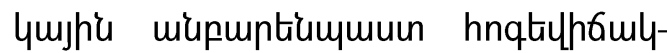
utinn (umpumstilumplymphe intiun,

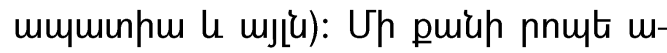




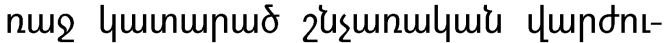

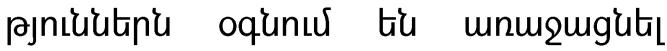

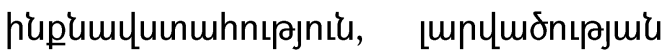
pnцugnuर्य l ptiplenıpjuiu qqugnuर [6]:

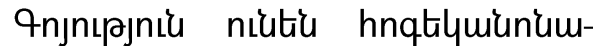

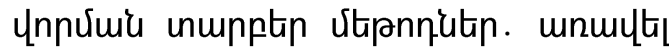
hujunup $\mathrm{u}$ humuitigh 5 vitannutiph htinlumu quaulympqnuर्u (unt'u unnuUuqph 1):

\section{Utronnutn}

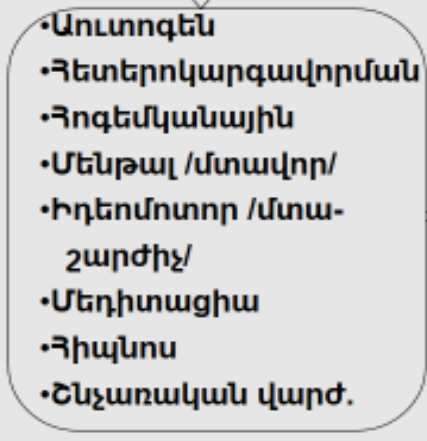
Unu: oqunuqnnoulis

$$
\text { •ヒnLuuLujnıpjnıl }
$$

-Uunuulnn utanzlźnuJ

- uuưph nnulennnsu
乙24

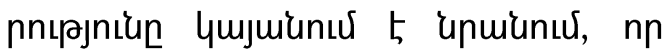

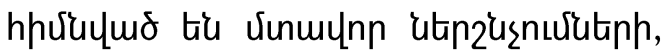
tiplumlymjulymí muinltaputiph le mutt-

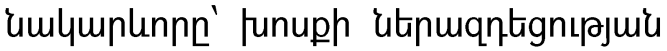

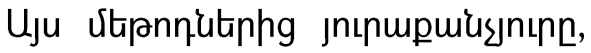

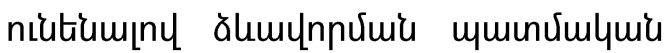

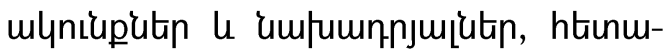

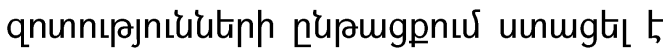
qhunmumis hpứumunnnux: canniutenny

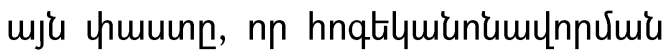
vtapnnutiph up vimup ntuntưumupnntpjniuhg htiunn umpnn tiu hüpunınnıju viunqhisutiph

u uzmiumlynıpjniun vimpqulymí htinmqu

\section{hunup}

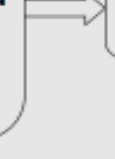

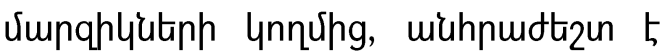

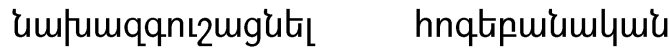

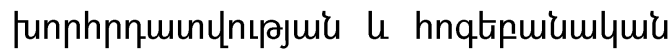

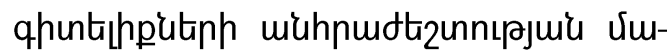
upi [1]:

<nqtilumunamunnuimis haumputiph

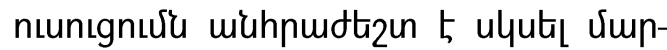
qnưujhe qunhtinujh myniuputanhg' uunniqtany veunqhlütiph ejunnujhe

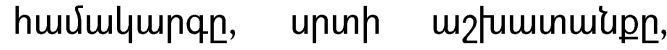
htiumzundhe mumumuinn [3]:

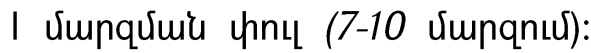
Uunqhlitiph qhunulgnıpjuin huu-

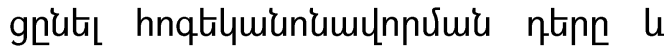
www.sportedu.am 


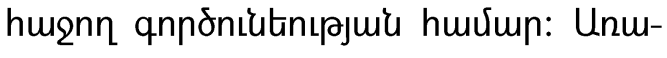

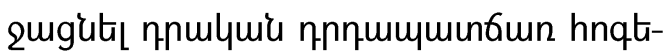

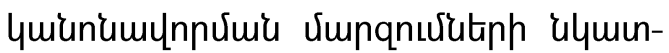

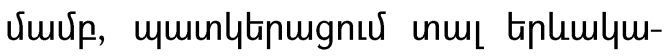
julquí umunlatputiph, funuph mqnt-

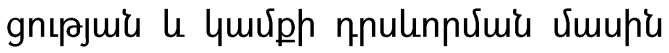
(ununntigutis unupptip qqugnnntpjniuututiph):

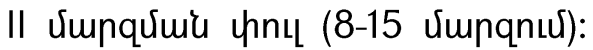
4mununtjuqnnota ytann 'u24ur hnqtquís \$niulgghwiutnn u ununntigutis hnqtymiunumunnúuiu vtapnnutitnhg' ht-

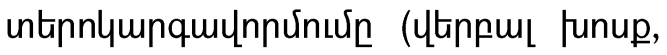

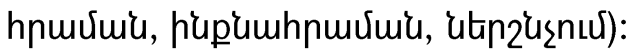

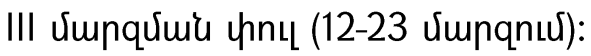

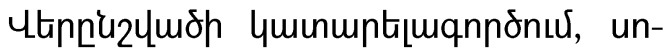
Unntigutis ununnqtie vitpnn. hiumputnn' huvoumpntiny htintipnlyunquunnưuilu htien:

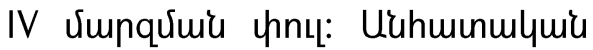

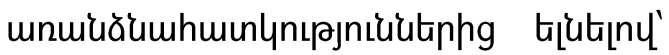
ungulggujhe $u$ vumqnuvujher qnno-

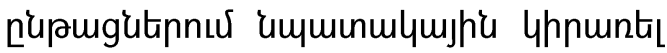
hnqtilumiunumunnưư humpütin [7]:

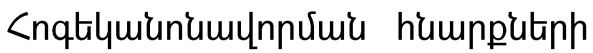

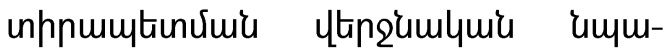

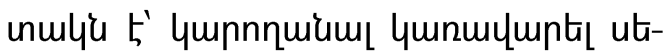
umuluir vinptinn, hnugtinn, ymppn $\mathrm{u}$,

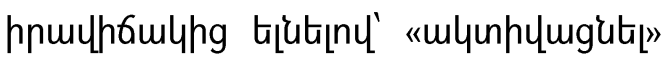

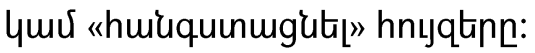

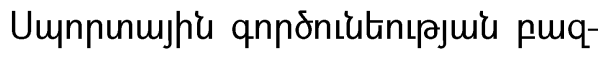

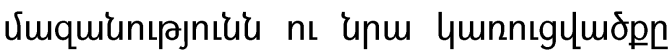

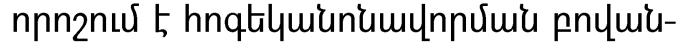

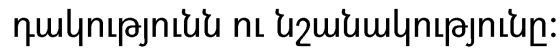

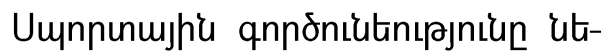
nunnus 5 hnuphg tulquiunntiu unup-

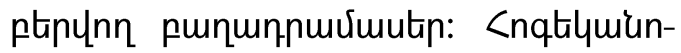

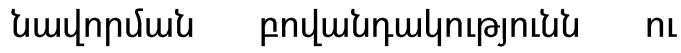

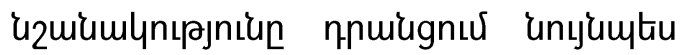
unupptpunuर tiu:

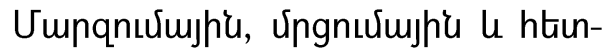

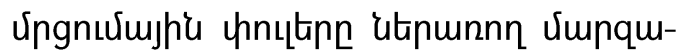

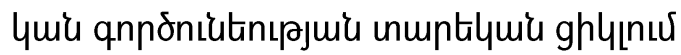
hnqtiluman'umunnuiviu pnyminnulynt-

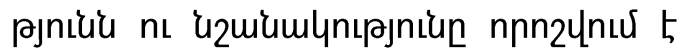

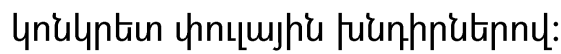

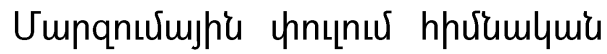

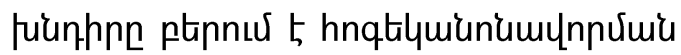

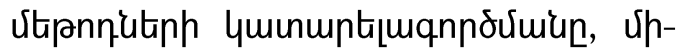

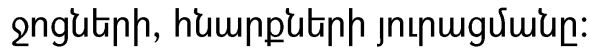

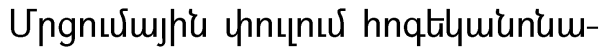
unnnuर्u hnulquiumgunus t5 vimphly

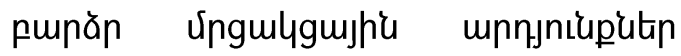

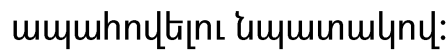

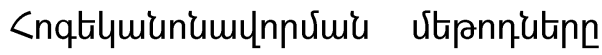

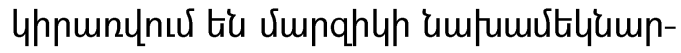

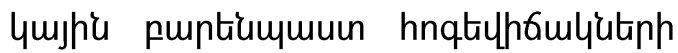

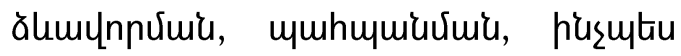
umb umunnmunnıpjuie vjnıu ăletph (\$hqhlymlquiu, intipunhlymlymin, unmlyonh-

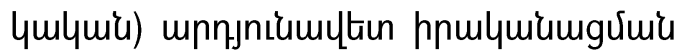
umumulyny:

Ctunúngnudumper unnцnuर hnqtilumunumunnưuir humplutin oqunuqnnd- 


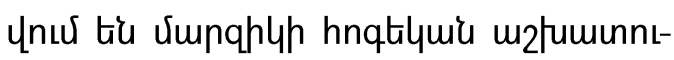

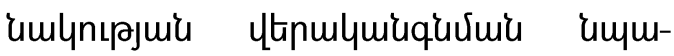
unulyny:

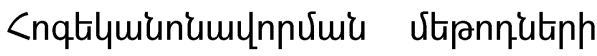
uhnunviuiu m2łumunuiuph pnymunulyntpjuí vite 5 vinunu umb vimphlyutinh

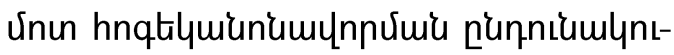

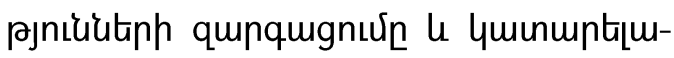

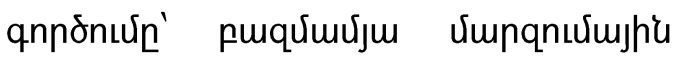

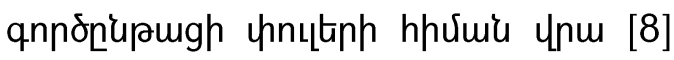
(unt'u unpuruiuqhn 2):

tqnulymgnıpjnit: กıunıर्umup-

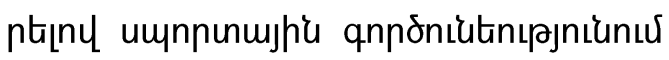
ununptin hanhiumliatiph ynnưhg hn-

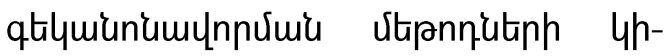

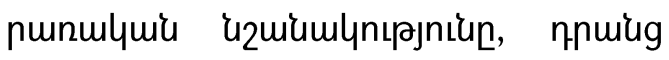

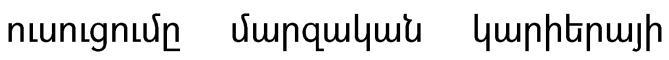
n'upugpnuर le huर्umpnnuर्u vimpqulquie

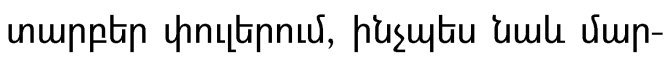

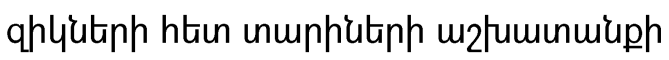
utan unnnăn huiuqtighup htinlyul tiqnulymgnıрjuí.

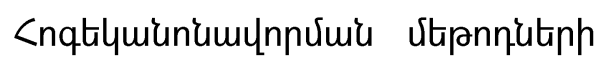

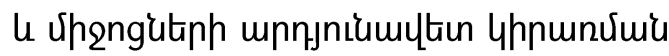

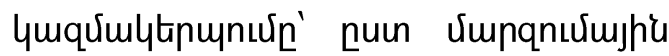
ununtiluiu ghlih, vimphlyatiphis hum-

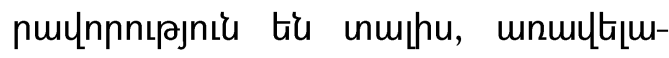
qnujuu oqunuqnnotl \$hqhlumlyui,

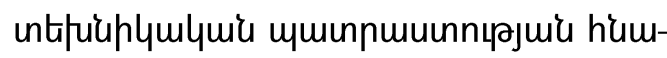
nuunnnıpjnıนüunn:

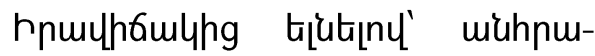

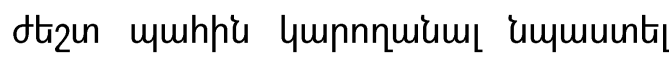
vimphly puntiammuin hnqtilhfiuly ălemunnuimiun:

<unl 5 unta nn jnıpupuiusjnın

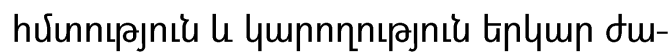

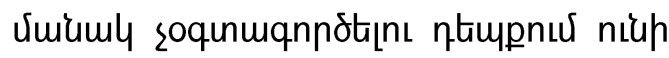
pnц्ugưư hulynuर:

<mplumunn to muhumiata ălumųnn-

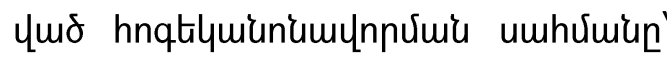
ymünumunn oqunuqnnotinny mju nt-

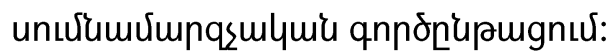




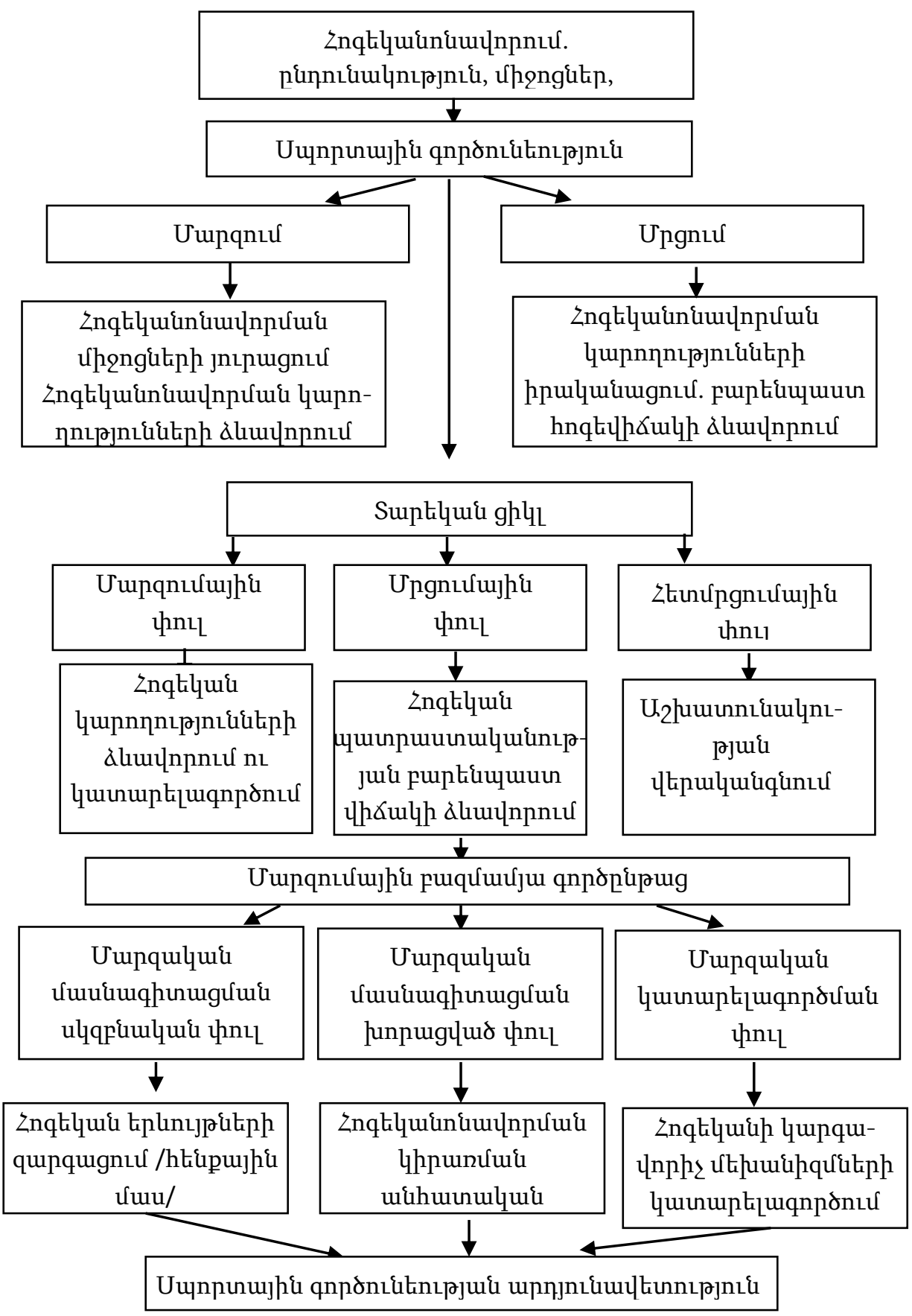

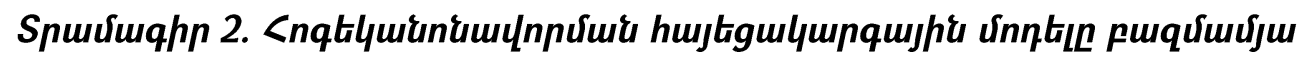
vumqnusfitph qunnıgyudpny (Ч. 乙. Uvinltiglum) 


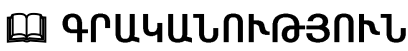

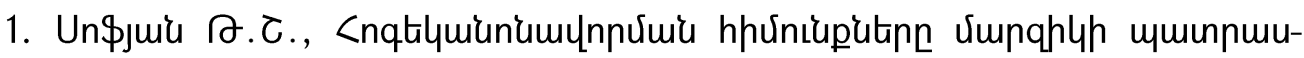

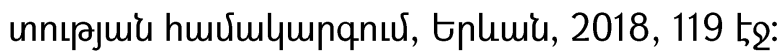

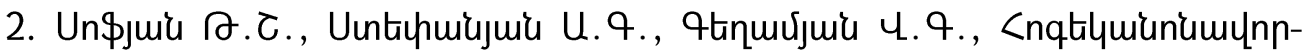

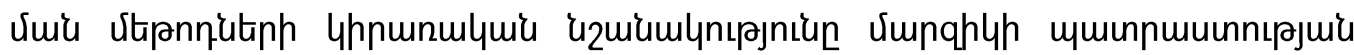
qnnonupumgnu, <\$4UTh, 2019, 208 5,

3. Анохин П. К., Очерки по физиологии функциональных систем. М: Медицина, 1975. - 166с.

4. Алексеев А.Б., Себя преодолеть. -М: ФиС 1985.-192с.

5. Багадирова С.К., Основа психорегуляци в спортивной деятельности Уч.пос. Майкоп.- 2015. 148с.

6. Вишнякова С.В., Методика использования дыхательных упражнений на начальном этапе подготовки Волгоград 1999с.

7. Смоленцева В. И., Развитие навыков психорегуляции у спортсменов в процессе спортивного совершенствования.Уч. пособие. 2010., 162 с.

8. Смоленцева В.Н., Психорегуляция в годичном цикле тренировки.: "Психология и педагогика средной и вышей школы" 1999, №2 с 56

9. Щульц И.Г., Аутогенная тренировка., М.: Медицина 1975.-166с

\section{FEATURES OF APPLICATION OF METHODS OF PSYCHOREGULATION IN T DIFFERENT STAGES OF SPORTS PREPARATION}

Associate professor $T$. Sofyan

Armenian State Institute of Physical Culture and Sport, Yerevan, Armenia

\section{SUMMARY}

Keywords: sports activity, psycho-regulation method, suggestion, skill, possession, annual cycle, efficiency.

One of the current problems in sports preparation is the acquirement and application of psycho-regulation skills by athletes at different training stages. 
Research objective: to study psycho-regulation most practical methods in sports activity which are of significant importance by different authors, and their combinations at different stages of training.

Research methods: study and analysis of professional literature, interviewing, observation, psychological questionnaire.

Research results: studying the international experience of practicing the psychoregulation methods in sports psychology, their training at the early stages of sports activity and their combination with the annual sports cycle as well as based on the perennial working experience with athletes, we came to the following conclusion:

Conclusion: the organization of the effective application of psycho-regulation methods during preparation and competitions allows the athletes extremely taking the advantages of physical and tactical preparation.

It should be noted that abilities and skills lose the effect not being used for a long time. It is necessary to maintain the scope of the psycho-regulation acquired, regularly using it in the educational and sports activities.

\section{ОСОБЕННОСТИ ПРИМЕНЕНИЯ МЕТОДОВ ПСИХОРЕГУЛЯЦИИ В РАЗНЫХ ЭТАПАХ СПОРТИВНОЙ ПОДГОТОВКИ}

Доцент Т.Ш. Софян

Государственный институт физической культуры и спорта Армении, Ереван, Армения

\section{PEЗЮME}

Ключевые слова: спортивная деятельность, метод психорегуляции, внушение, навык, владение, годовой цикл, эффективность.

Одной из актуальных проблем спортивной подготовки является овладение и применение спортсменами навыков психорегуляции на разных спортивных этапах.

Цель исследования - изучить предложенные разными авторами наиболее практичные и имеющие существенное значение в спортивной деятельности методы психорегуляции и их сочетание на разных тренировочных этапах.

Методы исследования: изучение и анализ профессиональной литературы, интервьюирование, наблюдение, психологические анкетирование. 
Анализ результатов исследования: изучая международный опыт применения методов психорегуляции в области спортивной психологии, их обучение на ранних этапах спортивной деятельности и сочетание с годовым спортивным циклом, а также исходя из нашего многолетнего опыта работы со спортсменами, мы пришли к следующему выводу:

Выводы: Организация эффективного применения методов психорегуляции во время тренировок и соревнований позволяет спортсменам максимально эффективно воспользоваться возможностями физической и технической подготовки.

Следует отметить, что способности и навыки имеют тенденцию ослабевать, если не применяются в течение длительного времени. Необходимо поддерживать предел установленной психической регуляции, регулярно используя ее в учебностренировочном процессе.

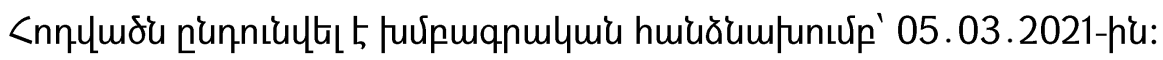

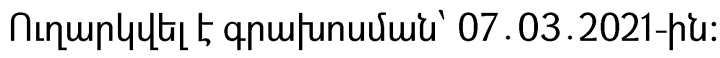


DOI: 10.53068/25792997-2021.1.3-76

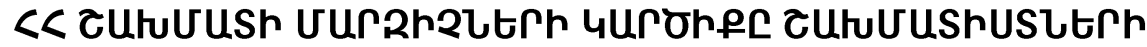

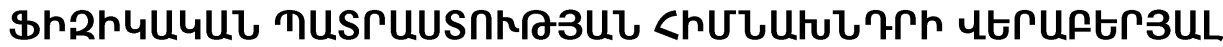

\section{U.q.P., nngtiny U.L. <ulynpjwi,

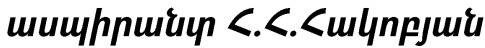

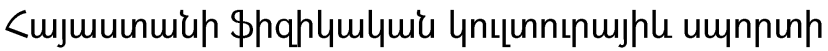

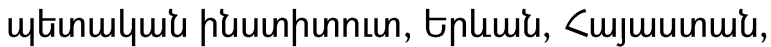
E.mail:armen.hakobyan@sportedu.am, hovogerb01@mail.ru

Unuiagpujhis puntin: Uunqhs,

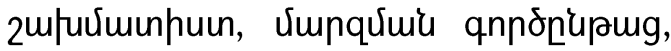

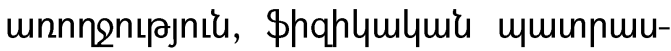
unnเpjnเu:

Ctunmqnunnıرuis upnhulyuiant-

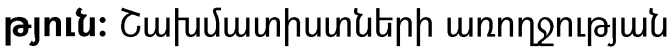

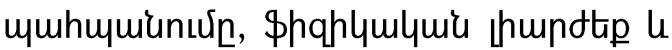
utnnuz'umly qunqugnunn, umnnunujh's

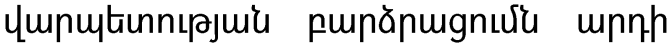

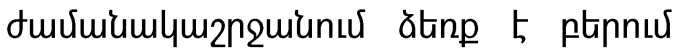
hnuj umplunn uzuiumlynıpjniu: Tpn\$t-

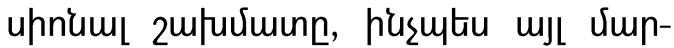

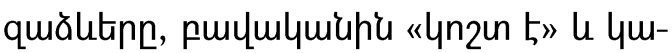

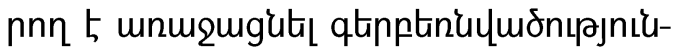
utan [3]:

tpts \$hqhymlquís muinnmunulu-

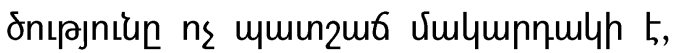

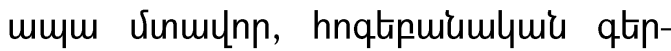

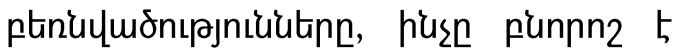
uju vunquălupu, ympnn tíu pu-

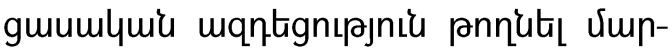
qhuh unm: Onquiuhquर पnu pugu-

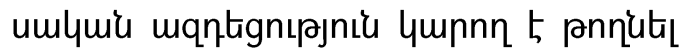

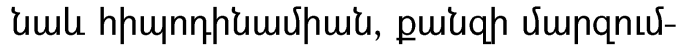
utph le vuiumuluian ungnudutiph du-

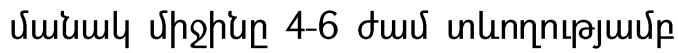

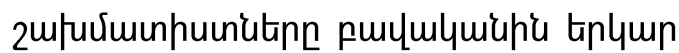
duviuiuml qunulnut tiu qpipts phe

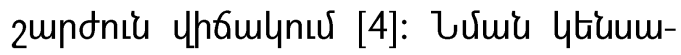

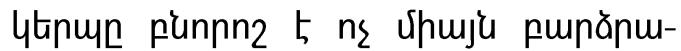

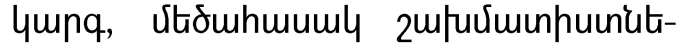

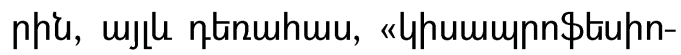
um[" (II l I qunqujhí) vimphlyutphis $[2,1]:$

Fugmumlymir htunlumiuputiph

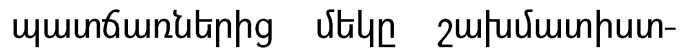
utph \$pqhlymlumis muinnmuinym-

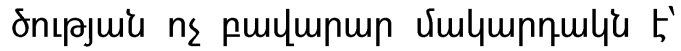

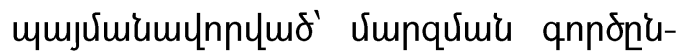
pugnıu nunhwiunın \$hqhlumumiu muin-

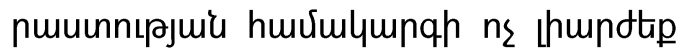

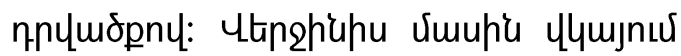

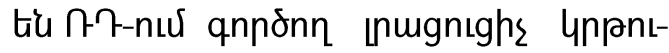




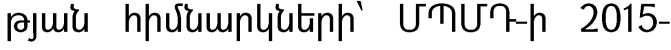
2020pp. zmfuরumin vimpquălup umnn-

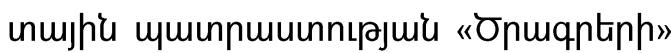

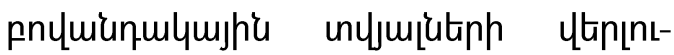

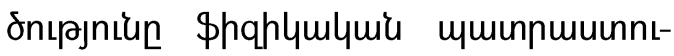
pjuí Чtinuptipju[:

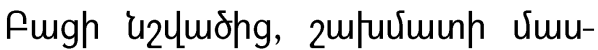
umqtinutinh 2nomiunus slym upmu-

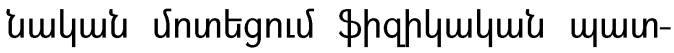

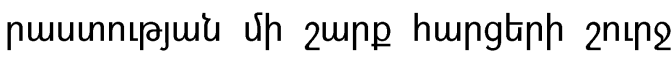

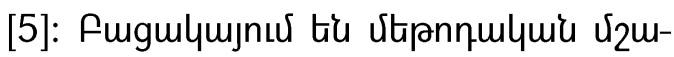

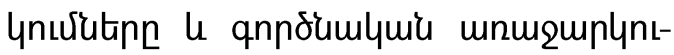

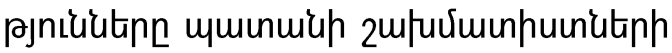

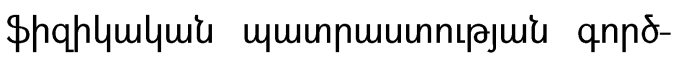
n'upargé unnjnitumultion quqưulytin-

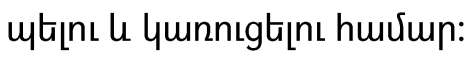

\section{Stinuqnunnıpuiu}

\&umuunulyn:

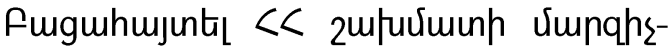

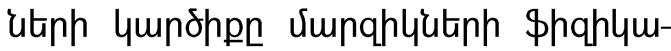

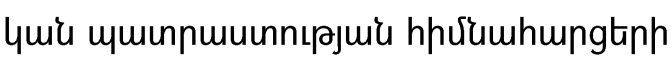
ythnuptinju!:

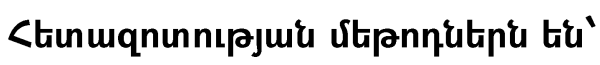
qhunuर्utipnnulymís qnuluiunıpuiu nt-

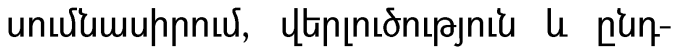
huiupugnuर, unghnцnqhulymi hungnuर,

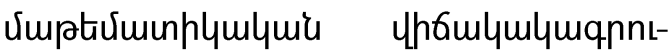
pjnıน:

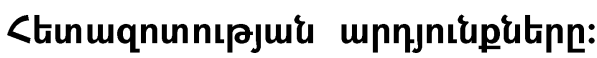

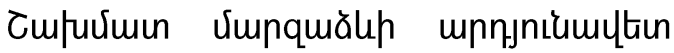
qunqugर्uiu, umnnumujhe hųnnnt-

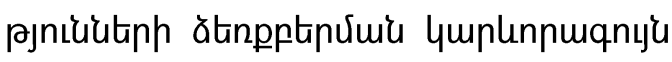

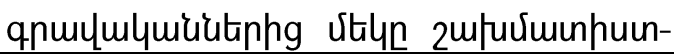

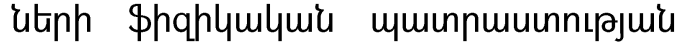

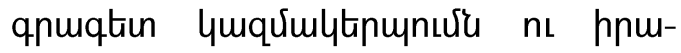

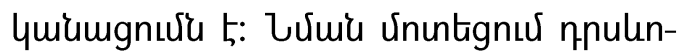

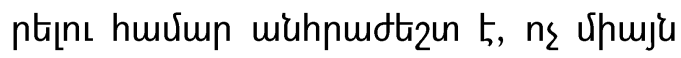
nunuरamuphts huvimumunmulumis qh-

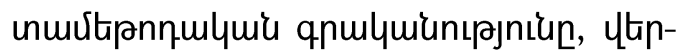

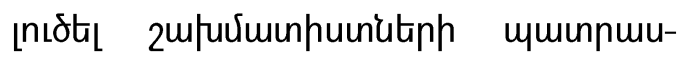

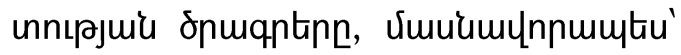

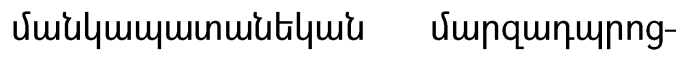

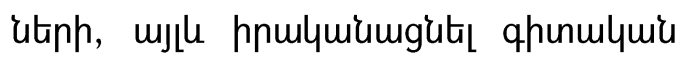
htinuqnunnıpjnıüutp' puguhujunţnı,

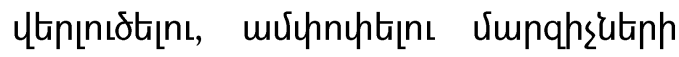

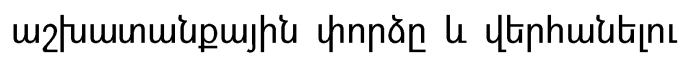

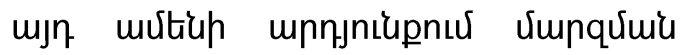

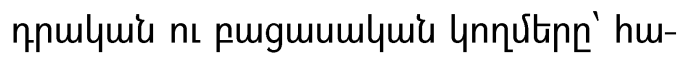

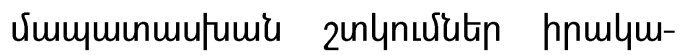

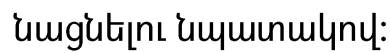

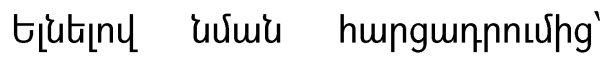

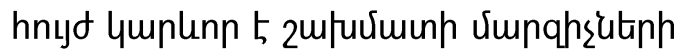
2nquiunus pnulyuiaughta unghnцn-

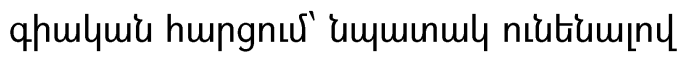
puguhmusutins unuiug lumohpn \$hqhymumis umunnmunnıpjuis hpर्utumfưnhnutiph ytanuptinju[: Ytenghüu

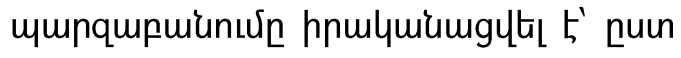

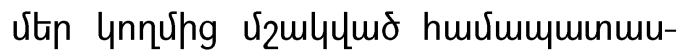
jumid hunguptipphlp: Unghnцnqhulymir

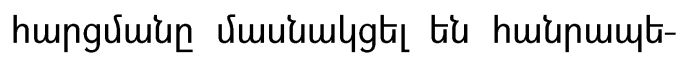

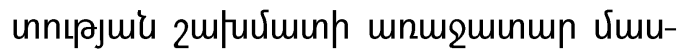
'umqtinutan' 40 vimpn, npnup nictíu m2-

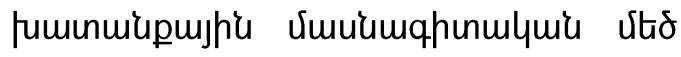




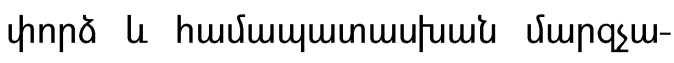
чuiu ynşnưutin:

< wngy urdutinhg tiplnniun $\ll$ umnnunh yuuunmlymunn, tiptpn Sh?t-h vimphs'utn, v'umgurdn' vemphs viulym-

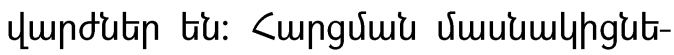

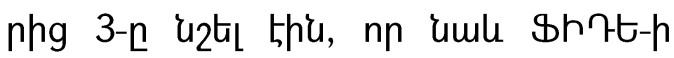
yupution tiu, 2-n' "Uhquqqujh'u ympmkin», 4-n' qpnuvumjuintip, $3-n '<<$ umnnunh ympultin, 3-n' $\ll$ umnninh чunutiunh ptylumóns: Funăn nnulyu-

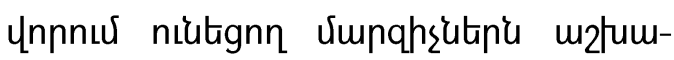

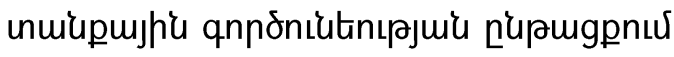

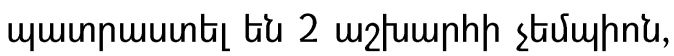

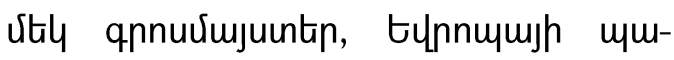

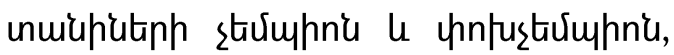

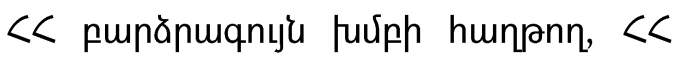
umunuiuhutiph ungurmph hunpannutip

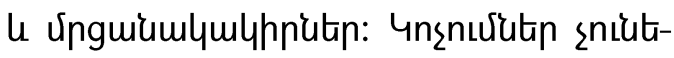

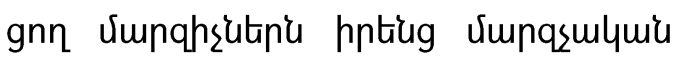

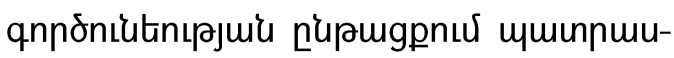

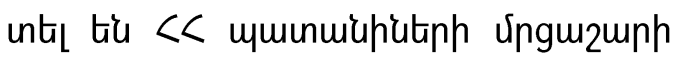
humpnnitip $\mathrm{u}$ unguiumlymlyntutin,

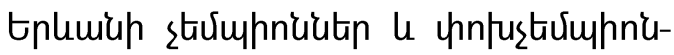
utn, pusutiu Gumle up zunp 1-hu \& 2-pn qunqujhiutun:

Cuin unghnцnqhulymir hungưuru

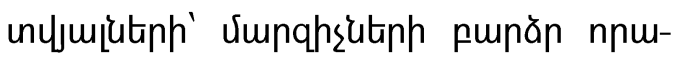

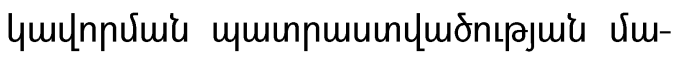

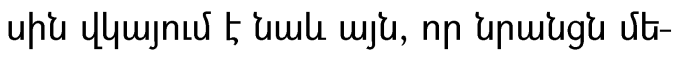

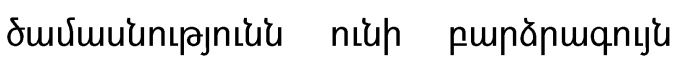

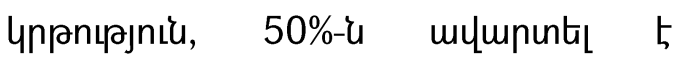

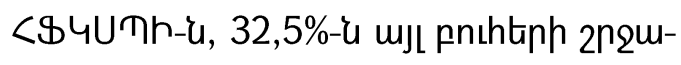
umulununatan tiu: funnān nnulymunn-

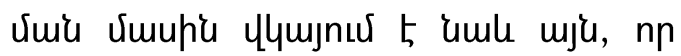
57,5\%-n 2016-2020pp. duviuiumlyhuunludonu mumpunt tiu vimphesutaph

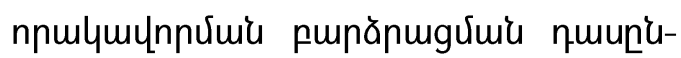
pugutinn:

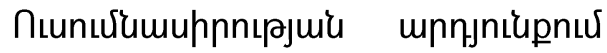

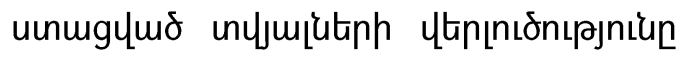
gnug 5 unmihu, nn hungưuiun vimu-

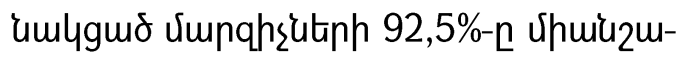
umu mpămưuqnnư tiu, nn vimnqnuर्uutannux muhnuotizen 5 pnulquiumguta

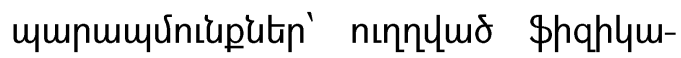

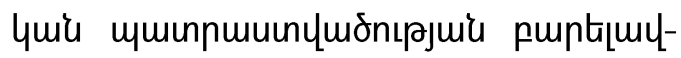

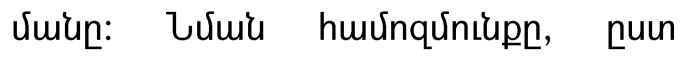

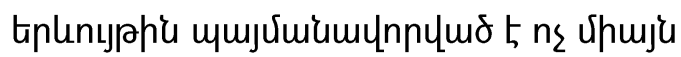

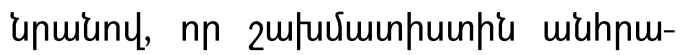

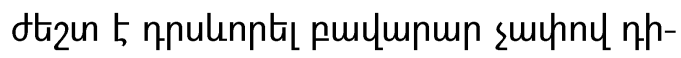

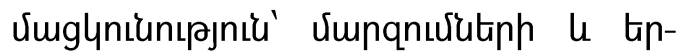

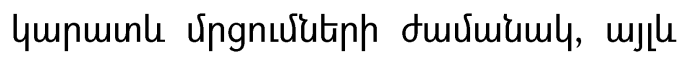
uju, nn \$hqhlumlumír muinnmuiny mornt-

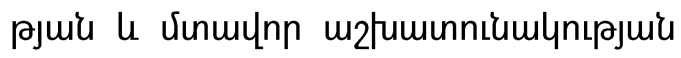

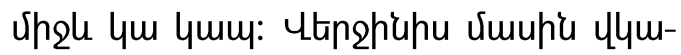
jnuर tiu hungưuiu gnımiuh2utinn. Jum-

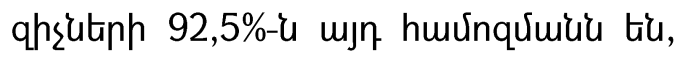
nuin 7,5\%-h mృn 4mun qnnonuर 5 vimumunp: fungh ujn, nuin 85\% vimnqhe'utph' \$hqhlumlumi yundnıرniuutenn

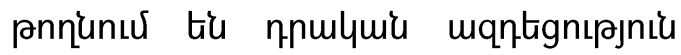

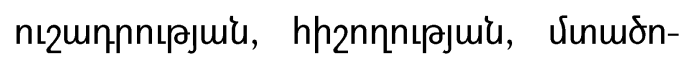

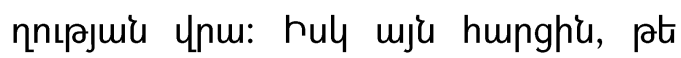




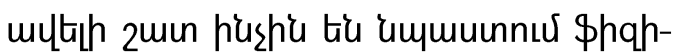

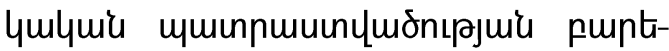

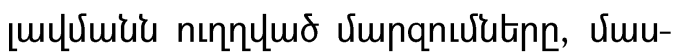

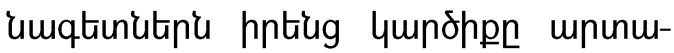

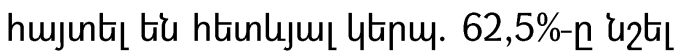

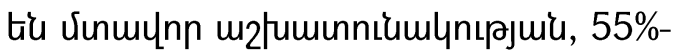

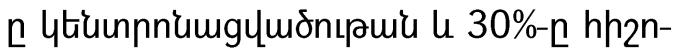

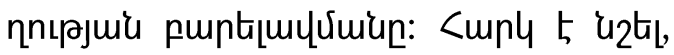

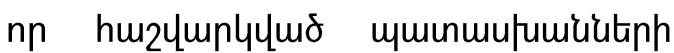
unnlnumjhe qnusumn vito 5 100\%-hg,

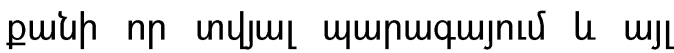

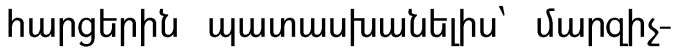

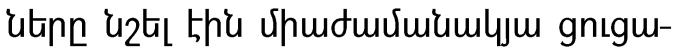
unzutinh un puiuhun:

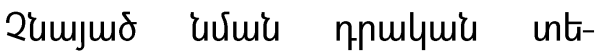
umialyniuh \$hqhlumlume muinnmuinnt-

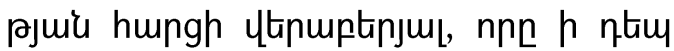
huxumumunmu|umis qhunuर्utipnnmumis

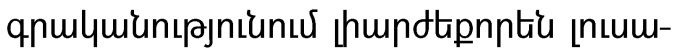

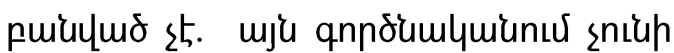

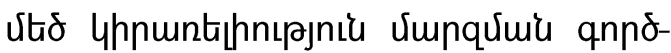
n'upmennu:

<tunuqnunnıpjuiu nupamgpnuर vita htinupnpnnuर tn, pts vimpqnuर्utunnuर,

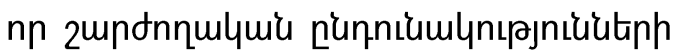

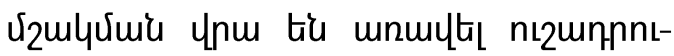

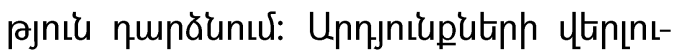

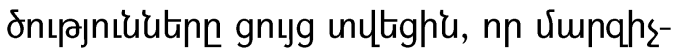

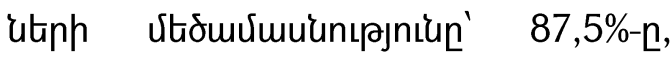

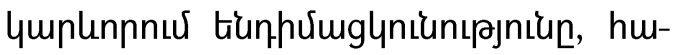

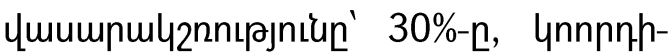

'umghuiu' 15\%-n l Gumulynıpjnı’un' 10\%$\mathrm{n}:$

Ctinmpnpnulymi tn, Gum uju, pt vimphsitinn \$hqhlumuiu umunnuu-

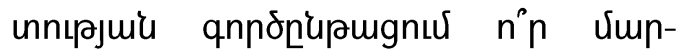

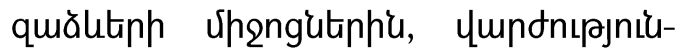

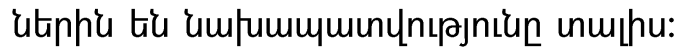

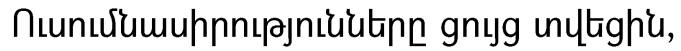

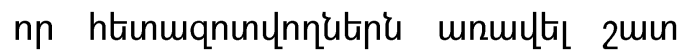

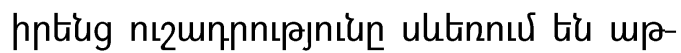

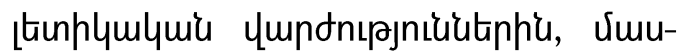
umunnumitu umqph'i 42,5\%-n, Snun-

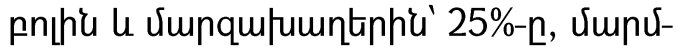

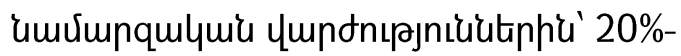

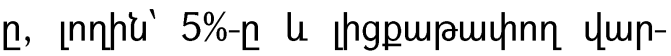
dnıpnizuatnhi' 5\%-n, hul nnn2 vimpqhestan hunghis sthis muinumutumitis:

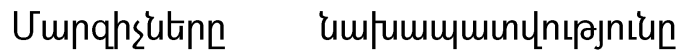

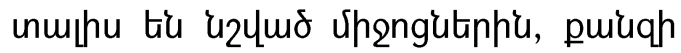
пpuiug uhnunviuiu unnjniupnux humnuunn 5 punteuulta n'unhwiunıp \$hqh-

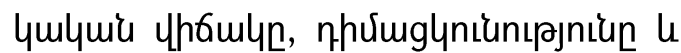
qunquaghts vimpilup pnann v́lumumpunptinn: hul hís \$hqhlumlyuí yun-

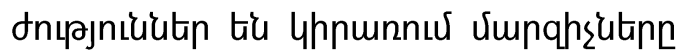

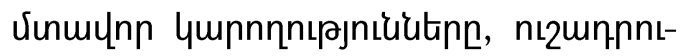

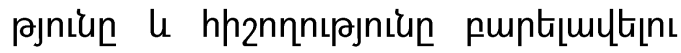

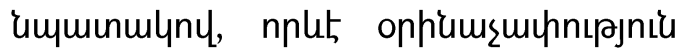
slumnnumguiup purguhmunts upuing umunmufumiutitnpg, puiuh nn pnuiup purlulume puquimquis the, ns

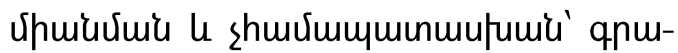




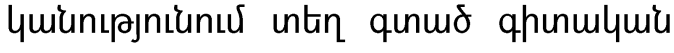

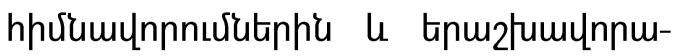

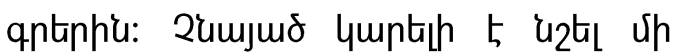

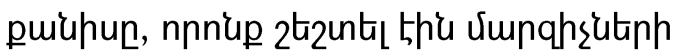

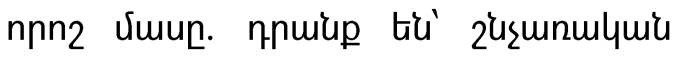

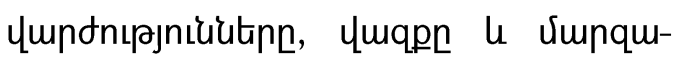
juuntinn:

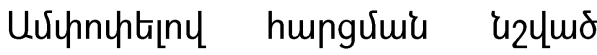
hurnymon unyjujuting' yuntigh t5 tiqnulymghta, nn vimphsitinn ymplinn

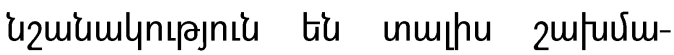
unpuunutiph \$hqhlqulymir umunnmuinnt-

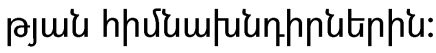

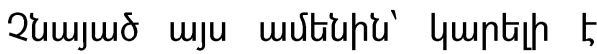

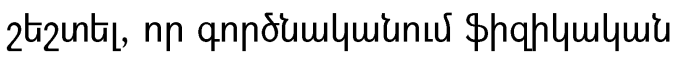
uquinnuuunnıرuiu hhर्ulumhungtiph [nt-

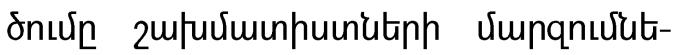
pnux htnns 5 quinumjuing: Cuin tplunıpp'i' \$hqhlymlymir umunnmuinnt-

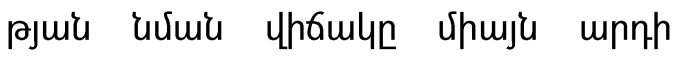

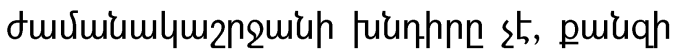

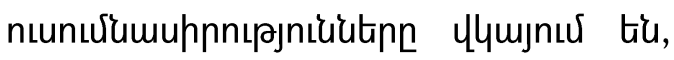

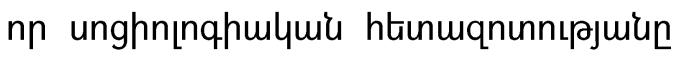
vimuiumlyhg ns pnınn vimpqhsutph htion

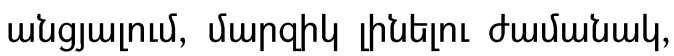

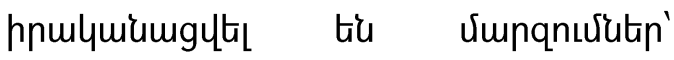

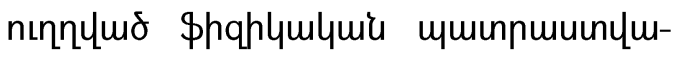

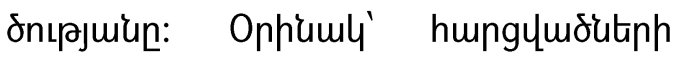
upuju 52,5\%-h htien 5 4hnunytal Gưuiu vimpnusutin, 30\%-h' vimumurp le 17,5\%h' ns: Unghnцnqhulymí up 2 mpp

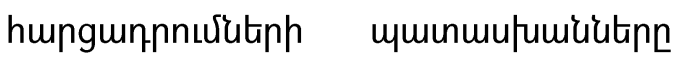

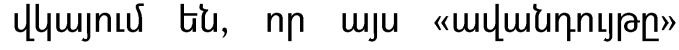

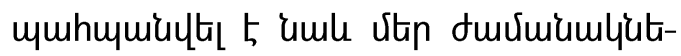
pnux: Ujumtu' ophiuml' Umpqhęutph 70\%-n u2ta thu, nn hnting vimpqu-

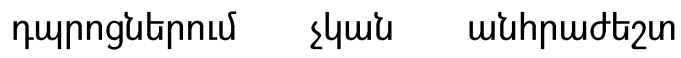

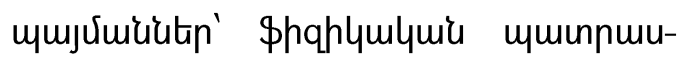

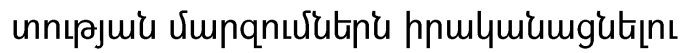
huviur: Uunqununngutpnnuर vimpqnuर्u-

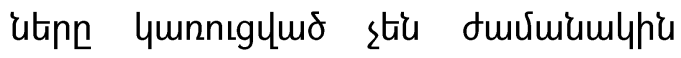

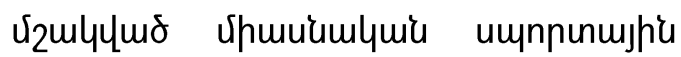

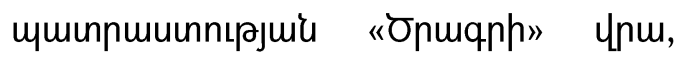

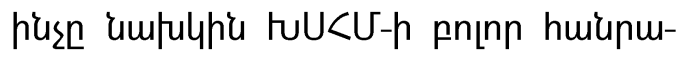

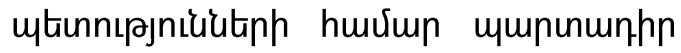

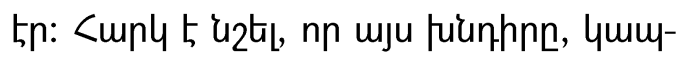

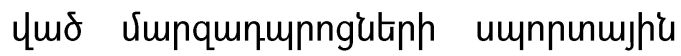

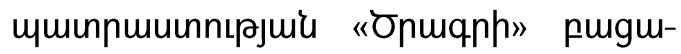

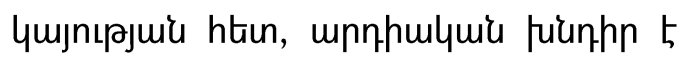
huiunumitunnıpjnı́unus qnnonn pnınn vimpquălteph huvium: <mngymótitph

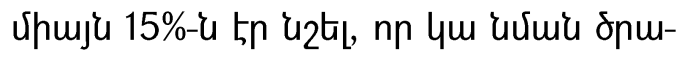
qhn, umlumja quntsh t tupaunnta, nn

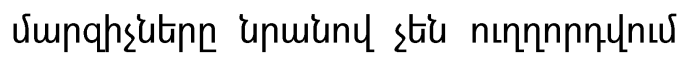

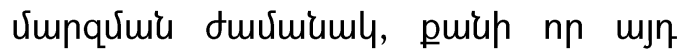

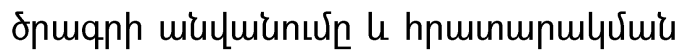
ununtiphun sthe 4unnn 'u2ta: <urum-

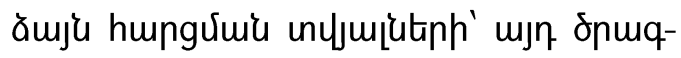
nny nınnnnпunus tn upuju viunqheutinhg vGlyn: Uunqhsutinh nnn2 Umun'

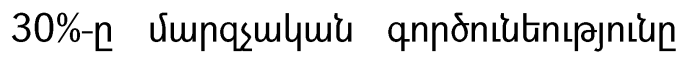

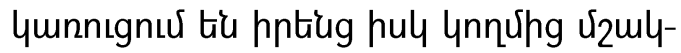

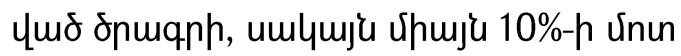
5 uju humunuunymo sempqununngh 


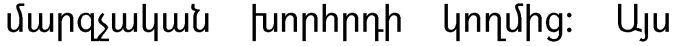

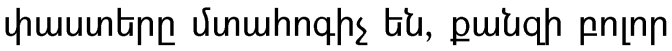

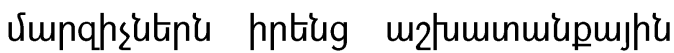

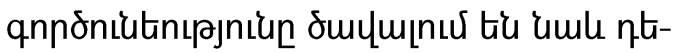

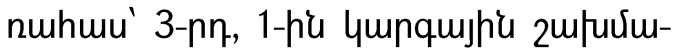
unpuunutiph htien: Uinumnqhe t5, Gumle mje

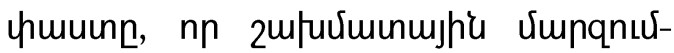

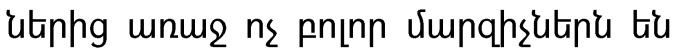

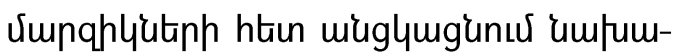

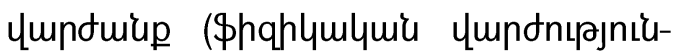

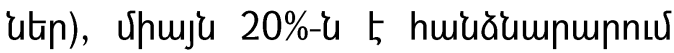

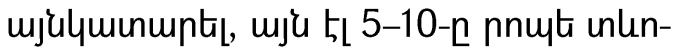

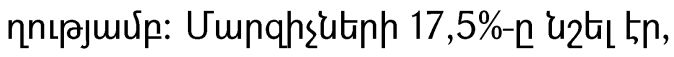

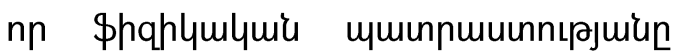

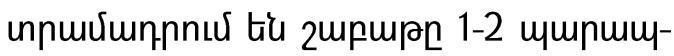
Unı'up, 3-4 w'uquuर' 15\%-n, jnıpupuiuzjnıр op' 5\%-n, hul 62,5\%-n hungn pnnta

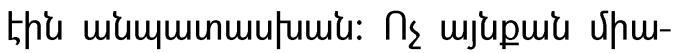

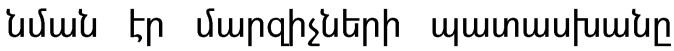
uju hungh 2nıne, pt nnpuiu uting Lhuh ununh qunlitiph ominhưul hu6ufumluiunıpniun \$hqhlquluiu umun-

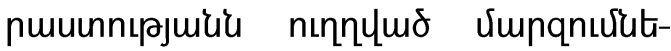

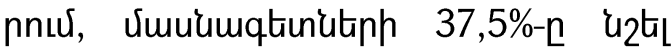
thu, np uju mkinp 5 4mqú 100-130 q/n, 7,5\%-n 'u2tal thi' 130-160 q/n, hul 55\%-n hunghe ndulunughs the umunuupumitis:

4mplunntiny \$hqhlqulumi umun-

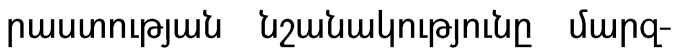

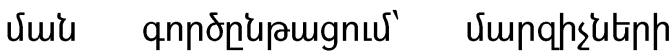

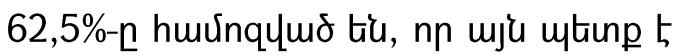

untin qunuh umnnunujhè muinnuuunnt-

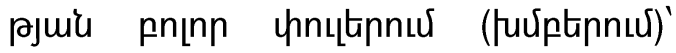

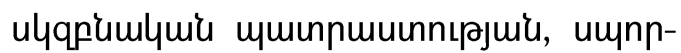

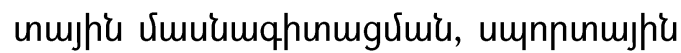

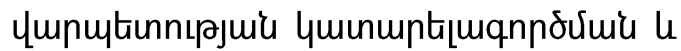
punänuqnuju umnnunujhé ymputinnt-

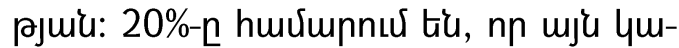

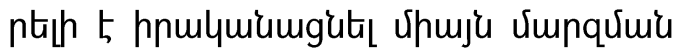

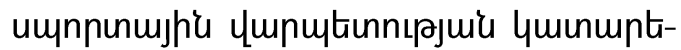

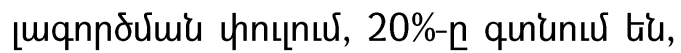
nn purqunum 5 mja quinumb! umnn-

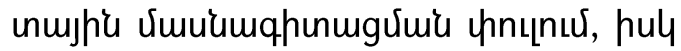
vimulumqtinutiph 10\%-n hurunqumo tiu,

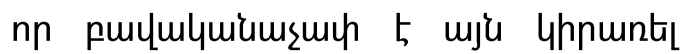

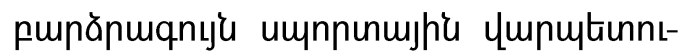

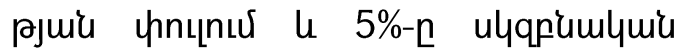

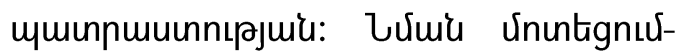

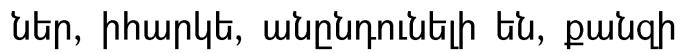
\$hqhlqulumir umuinnumunnıpuiu qnnonupaugn uting 5 thup vimphesutiph

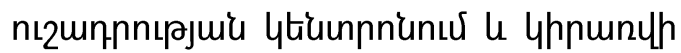

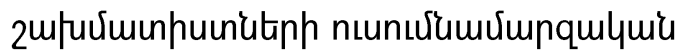

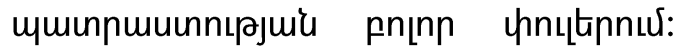

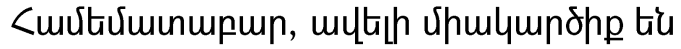

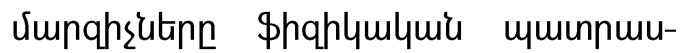

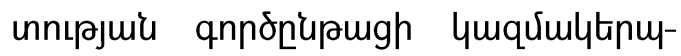

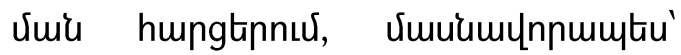

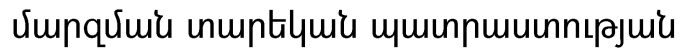

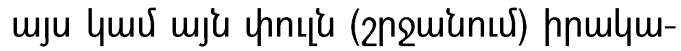
umgutahu: Umpqhsutaph 75\%-n qununu tú, nn \$hqhlumlume uminnuuunnıpuiun

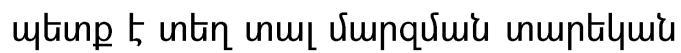




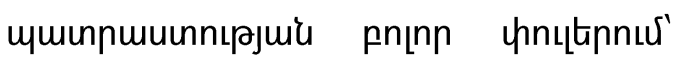

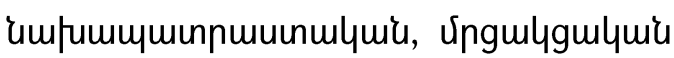
lu mignnumphis: Umuiumqtinitinh 15\%-n hurưunnuर्u tiu, nn purumen 5 minglymg-

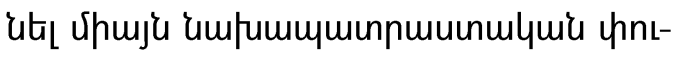
[nuर, 7,5\%-n qununuर tiu, nn uting b

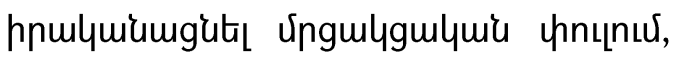
hul vity vimph punănugymo hunghe

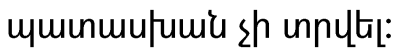

<tunmqnunnıpuiu 2nquiumlnnu wiunpurtizen tn puguhumunta cumb, pts

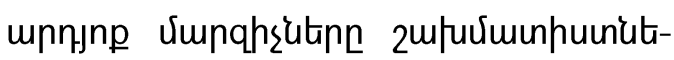

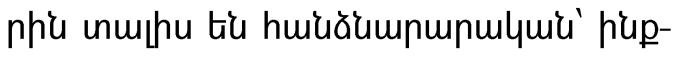
unıpny'u qpunytal \$hqhlqulquir umun-

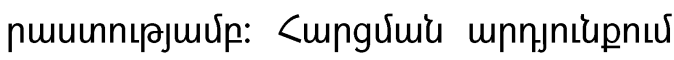

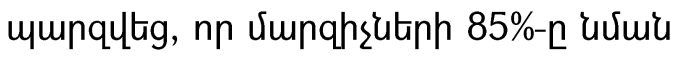

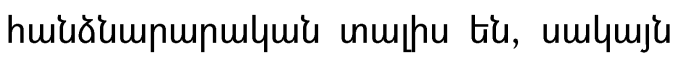

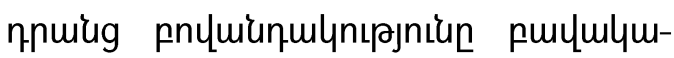
uper puquiuquis tn, onhiuml' 30\%-n

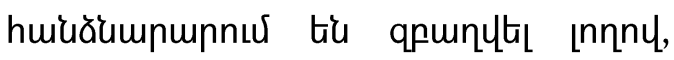
25\%-n' ymqpny, 17,5\%-n łumqu! \$nın-

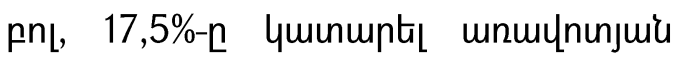

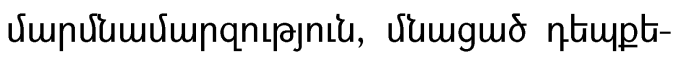

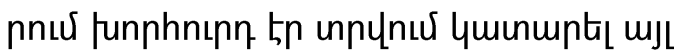

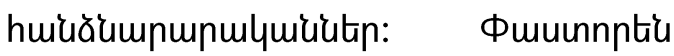
uzmiumlynuर 5, nn uju qnnoñupmgn

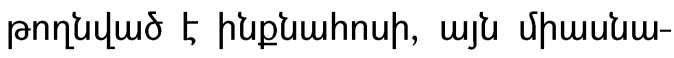

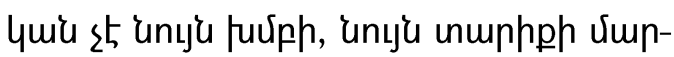
qhlutiph huvium: Utip mju hunghu, pt

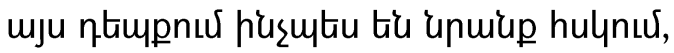
mpnjn’p quinumntu tiu vimphlyutinn

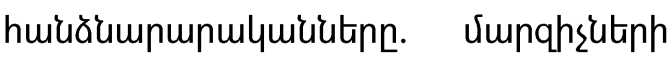

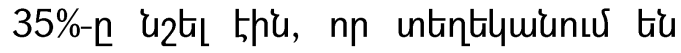

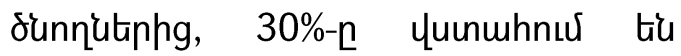
Junqhliutinh milytind muinumulumiutaphu, 7,5\%-h'̌ muămúp tiu hulnnu,

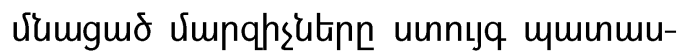

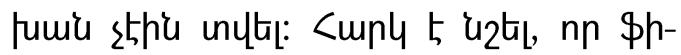

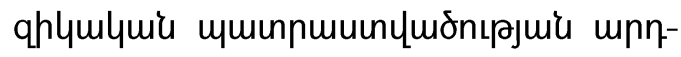

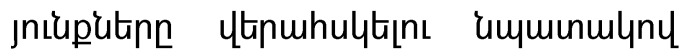
Junqhestiph qtinuly2hn vimun' 62,5\%-n hunghus stiú umunmu|umit, hul 17,5\%-

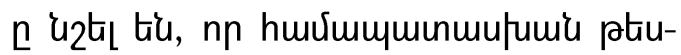

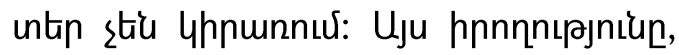

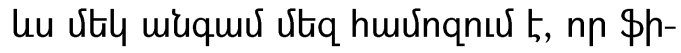

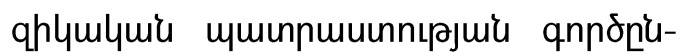

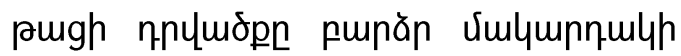
Unu st: Uunuhnqhs 5 uju huiuqu-

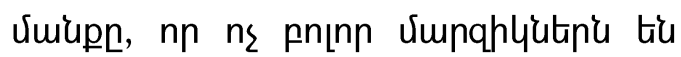

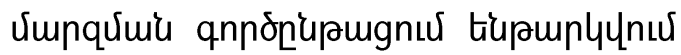

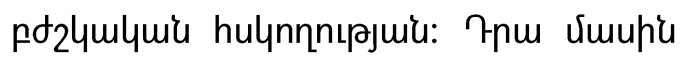
tú ylumnnu vimpqhsutinh 60\%-h pugm-

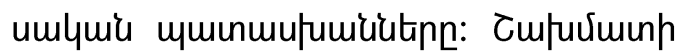

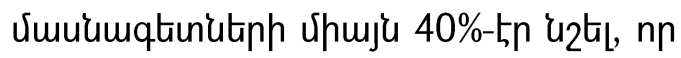
pntiug umitinn mingunus tiu pd24mumir

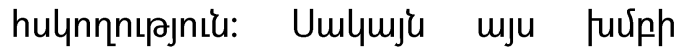

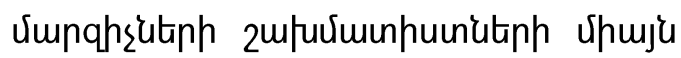

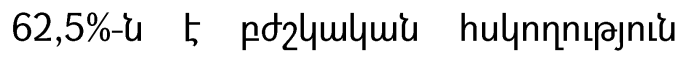
mingunus unuptymiu 2 miqquर:

Utip uju hunghe, pt vimpquiuru

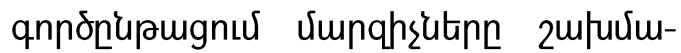
unpuinutiph htin mugglumgunud tiu untum-

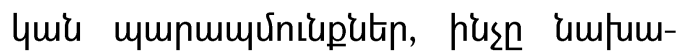

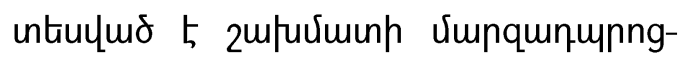




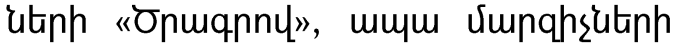

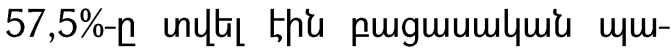

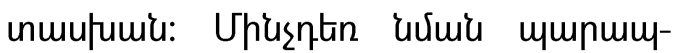
Unıluputinn, nuin vitn lumosph, surhuquiug lumbnn tiu, puiugh nnuiug ungn-

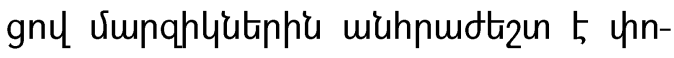

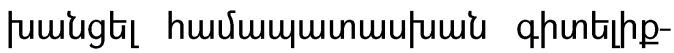

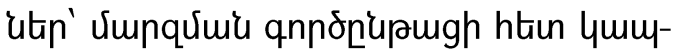

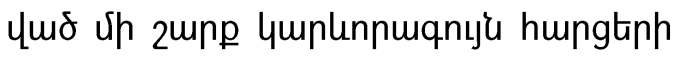
2nınе: Umu'umunnmutiu' onцm ntedhúp

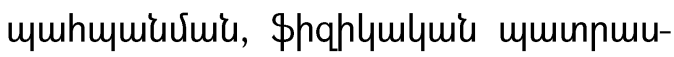

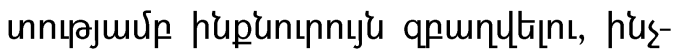

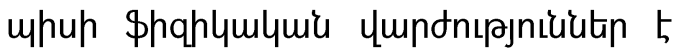

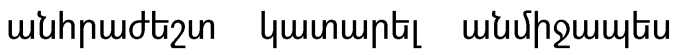

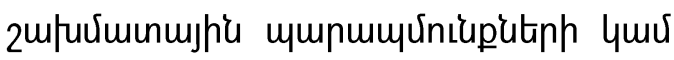
unguimis duviuiuml' \$hqhymlumi 4

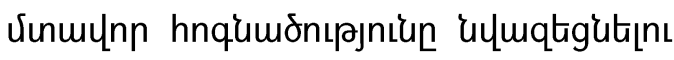

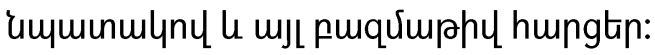

h'us ytipuptipnư t hungh \$hqhlum-

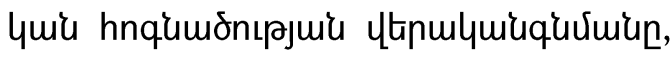

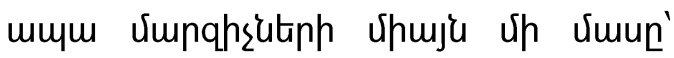
35\%-n funphnıpn tiu unuphu qpunytal myunhy huiuquinny' puj!ta, qpnuibt, hul hungymoutiph up uinymp quiuq-

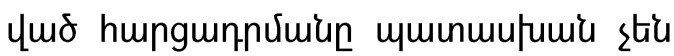

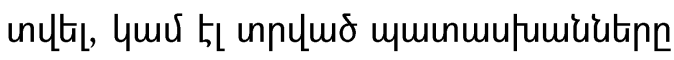

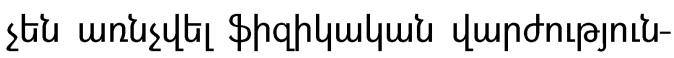
utph uhpunviuiu htiun: Uunuunn hnquum-

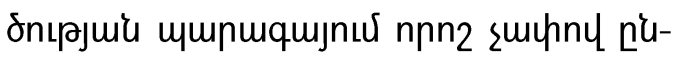

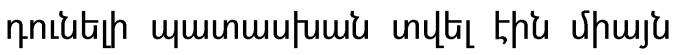
viunqhsutinp 35\%-n:

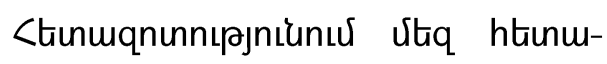
pnpnnux tn umle, pts pusutiu 5 mpunuhujununuर vimnqhyutinh unun vunuulnn

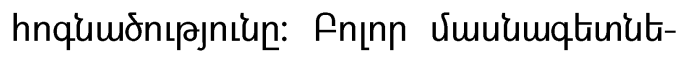

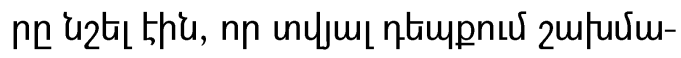

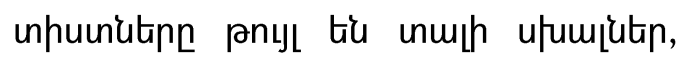

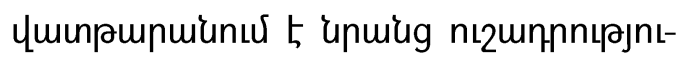
un le litumnnumugymornıpniun: hul pt

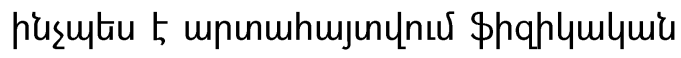
hnquumonıpjniun, Umpqhsitiph 82,5\%-n

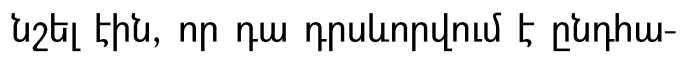

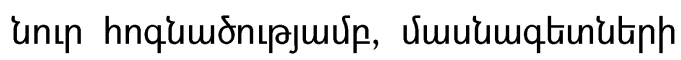
22,5\%-n 2tranta this, nn vimphlyutinh

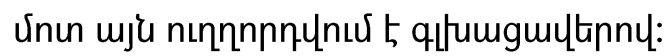

<ungunnnnúutiph 2unpnux wiu-

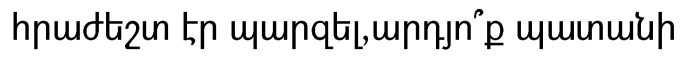

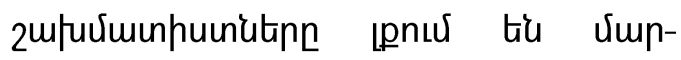

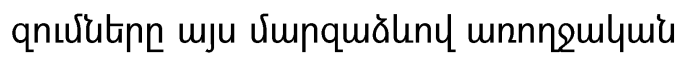
jưnhputiph muinfiunny, muinuu|umun hnsumnnnn lu puguumlymie this:

tqnulyugnıpjnil: Ctinuqnunnıp-

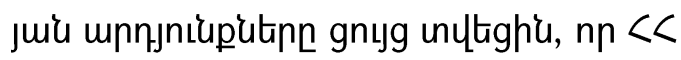
zmpuviuinh unmquinum vimphesutiph qtipuly2hn vimun' 92,5\%-n huviumnnu

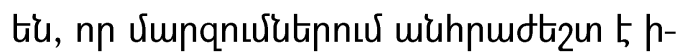
nulyuiumguts uмmumuर्uniuphatip'

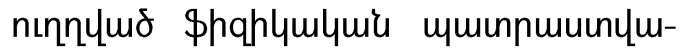

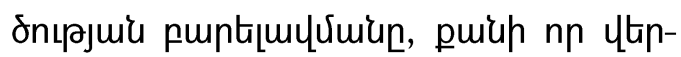

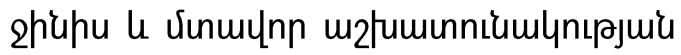

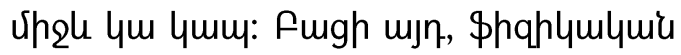

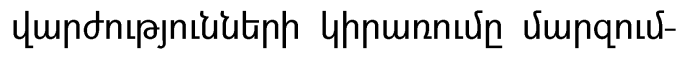
utannuर pnnunuर 5 nnulquí mqntignt- 


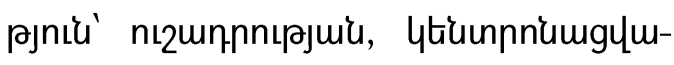

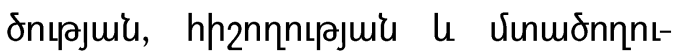
गjuí पnu:

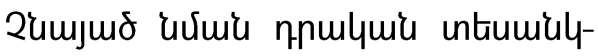

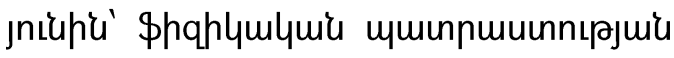

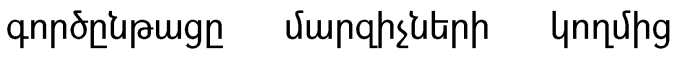

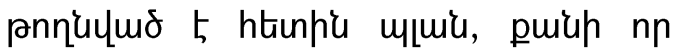

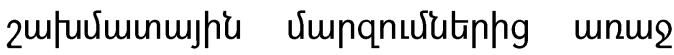

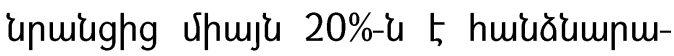

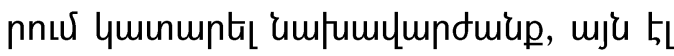

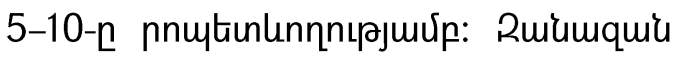

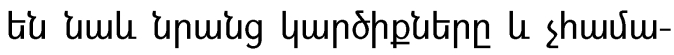

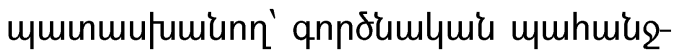
utphis, pt zmpupmlquí puith miqui

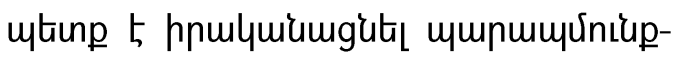

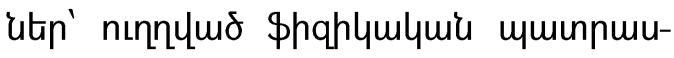

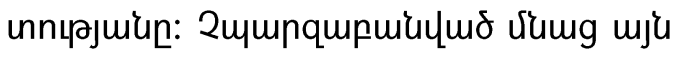
hungn, pts ununtiluiu yunnymopnuर nn-

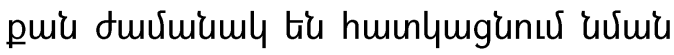
vimpqnưutiphi:

Shqhymlymis umunnuuunnıpuis

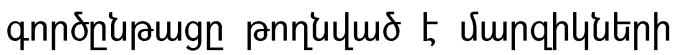

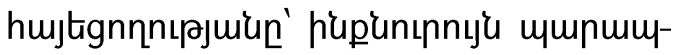
unıluputiph miuglymgưuiu ăluny:
Tuinzm6 ltipund sh hnulymiumg-

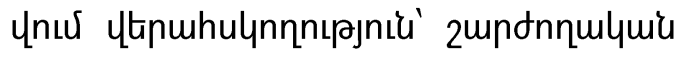
n'unniumlynıpnı'üutph qunquguviuiu vim-

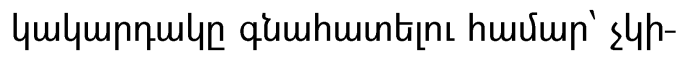

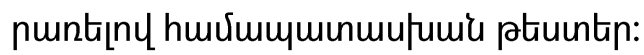

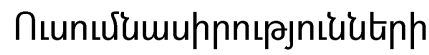

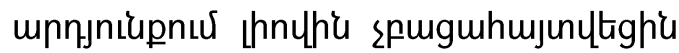

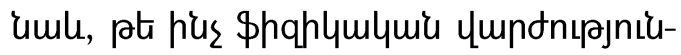

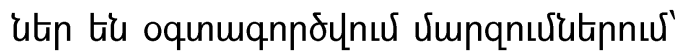

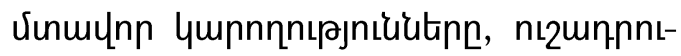

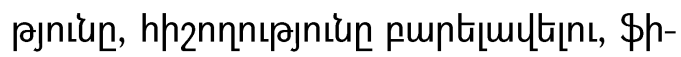

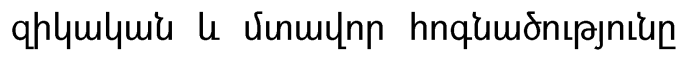

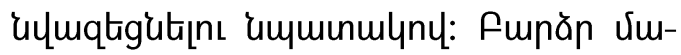
ympnuly unu st cumb intumlymir

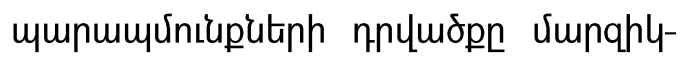

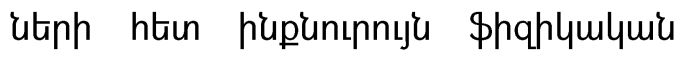

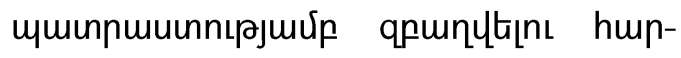
gtiph 2nıng:

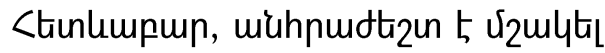

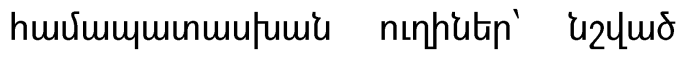

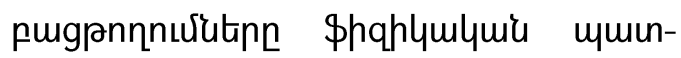

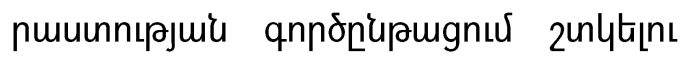
umumulyny:

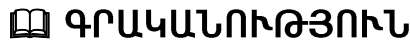

1. Бегун С.А., Как шахматы влияют на детей и не только. - 2009.

2. Бейлин М.А., Что вы знаете о шахматах?, М.: Знание. - 1979.

3. Бектемиров Ф., «Инсульт Буквашина нельзя было предвидеть», Спорт, Шахматы.- 2016. 
4. Геллер Я. В., Исследование специальной физической подготовки в процессе специальной тренировки высококвалифицированных шахматистов, Тольяти. - 2016. - 69 с.

5. Побегунц С.Н., Исследование физической подготовленности и свойств внимания детей, занимающихся шахматами, Белгород. - 2018. - 49с.

\section{OPINION OF ARMENIAN CHESS COACHES ON THE PROBLEM OF PHYSICAL TRAINING OF CHESS PLAYERS \\ PhDof Pedagogy, Associate Professor A.L.Hakobyan \\ Phdstudent H.H.Hakobyan}

Institute of Physical Culture and Sports of Armenia

Yerevan, Armenia

\section{SUMMARY}

Keywords: coach, chess player, training process, health, physicaltraining.

Relevance.The article addresses the issues of physical training of chess players, as an athlete's mental health needs are as important as their physical health needs, and both are likely to contribute to optimising the athlete's overall wellbeing in conjunction with performance excellence. In this regard, it is necessary to study the raised problem, identify opinions and approaches of coaches.

The study aimis to reveal the opinion of Armenianchess coaches on the issues of athletesphysical preparedness.

Research methods and organization. The paper uses: analysis and generalization of scientific and methodical literature, sociological survey and methods of mathematical statistics.

The survey was conducted on a specially developed questionnaire amongst 40 leading trainers of the Republic of Armenia who prepared both chess award winners and highly qualified athletes.

Research results. According to the survey data analysis $92.5 \%$ of the surveyed coaches definitely state that it is highlyencouraged to conduct classes for improving the physical preparedness of chess playersin the training process.Such a conviction is probably driven not only bythe fact that the chess player needs to show sufficient 
endurance during trainings and long-term competitions, but also by a direct connection between physical preparation and mental performance.In addition, 85\% of respondents prove thatexercise classes leave a positive impact on memory, attention, focus and thinking of chess players.

Despite the fact that the absolute majority of coaches sharethe same point of view, physical training of chess players is not at the proper level of execution.In their labor activity, coaches are not guided by the "program" of sports training developed for the CYSS due to its incomplete nature, and the programs operating in the Russian Federation. Actually scientific-methodical elaborations do not entirelyshed light on the problem under consideration.

Such circumstances of the case are explained by the fact that the opinions of coaches on the number of physical training sessions in the annual training cycle, per week, as well as their opinions on the warm-up exercises duration in the training process, on the control over the physical preparednesslevel, on the optimal heart rate in physical trainings, do not fully comply with scientific and methodical recommendations. The organization of independent physical training of chess players is also not up to the mark, as well.

Conclusion. The abovementionedshortcomingscall for the development of appropriate ways to organizephysical trainings more efficiently and to increase the level of physical preparedness of chess players.

\title{
МНЕНИЯ АРМЯНСКИХ ТРЕНЕРОВ ПО ШАХМАТАМ О ПРОБЛЕМЕ ФИЗИЧЕСКОЙ ПОДГОТОВКИ ШАХМАТИСТОВ
}

\author{
К.п.н., дочент А.Л.Акопян, \\ acnuрант O.A.Акопян
}

Государственный институт физической культуры и спорта Армении, Ереван, Армения

\section{PEЗЮME}

Ключевые слова: тренер, шахматист, тренировочный процесс, здоровье, физическая подготовка. 
Актуальность. В статье затрагиваются проблемы физической подготовки шахматистов, поскольку от уровня развития фризической подготовленности во многом зависит умственная работоспособность спортсмена. Без должной физической подготовленности шахматиста может ухудшиться не только уровень спортивных результатов, но и его здоровье. В связи с этим возникает необходимость изучить поднятую проблему, выявить мнения и подходы тренеров по столь актуальному вопросу.

Цель исследования: выявить мнение тренеров РА по шахматам о проблемах физической подготовки спортсменов.

Методы и организация исследования. В работе использованы: анализ и обобщение научно-методической литературы, социологический опрос и методы математической статистики.

Социологическое исследование было проведено по специально разработанной анкете в группе ведущих тренеров РА по шахматам в количестве 40 человек, подготовивших как спортсменов разрядников, так и высококвалифицированных спортсменов.

Результаты исследования. Анализ данных опроса выявил, что 92,5\% опрошенных тренеров считают,что в тренировочном процессе необходимо проводить занятия по улучшению физической подготовленности шахматистов. Такое убеждение обусловлено не только тем, что шахматисту необходимо проявлять определенную выносливость во время тренировок и особенно при длительных соревнованиях, но и тем, что между физической подготовленностью и умственной работоспособностью имеется прямая связь. Кроме того, занятия фризическими упражнениями по мнению 85\% опрошенных оставляют положительное влияние на память, внимание,сосредоточенность имышление.

Несмотря на то, что абсолютное большинство тренеров придерживаются такой точки зрения, тем не менее физическая подготовка шахматистов в тренировочном процессе не находится на должном уровне. В своей трудовой деятельности они не руководствуются "Программой» спортивной подготовки предусмотренной для ДЮСШ в связи с ее неразработанностью, а программы действующие в РФ и научно-методические разработки не в полной мере освещают рассматриваемую проблему. 
Кроме того, такое положение дел объясняется тем, что мнения тренеров по вопросу о количестве занятий по физической подготовке в годичном тренировочном цикле, в неделю, о продолжительности разминки в тренировочном процессе, о контроле за развитием уровня физической подготовленности, об оптимальном ЧСС в тренировках по фризической подготовкене в полной мере соответствуют научно-методическим рекомендациям. Не на должном уровне находится и организация самостоятельных занятий по физической подготовке шахматистов.

Заключение. Отмеченные недостатки требуют разработать соответствующие пути для более эффрективной организации тренировок по физической подготовке и повышению уровня физической подготовленности шахматистов.

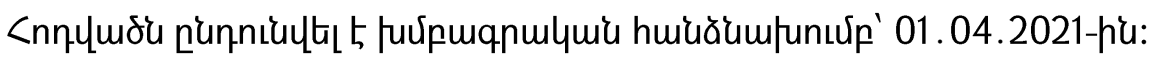

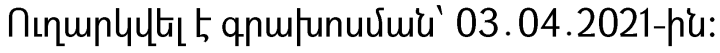


DOI: 10.53068/25792997-2021.1.3-89

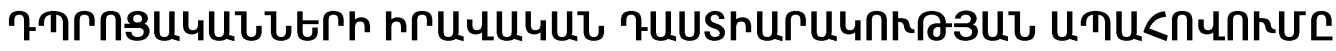

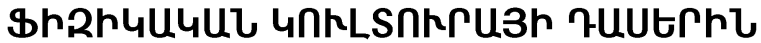

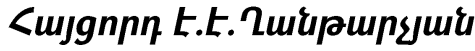

<mjuuunuiuh \$hqhlumluik ynцınnıрujh le umnnunh

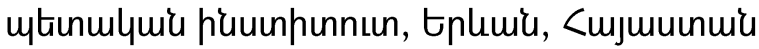
E.mail: evelina.ghantarchyan@sportedu.am

Unuiggpujp's puntip: 7upnngu-

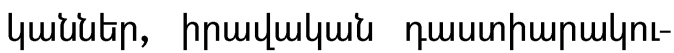

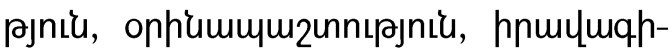

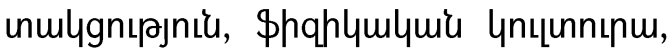
uunnun:

Stunuqnunnıرuis upnpulyuiant-

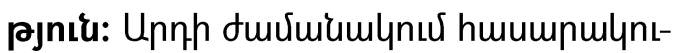

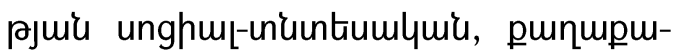

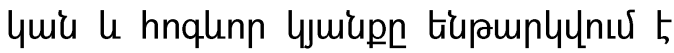

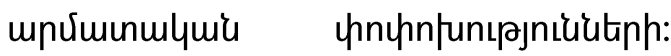

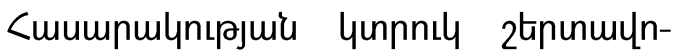

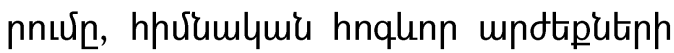

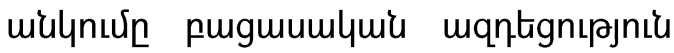

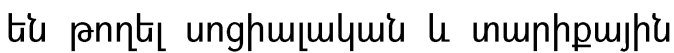

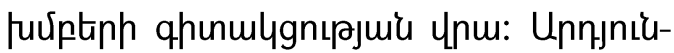

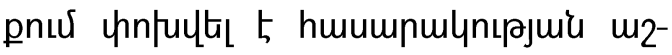
fumphujuggpn \& undtpujph ynnưunnn$2^{n u U n}[1,2,6]:$

duviumuh uphemieny humu-

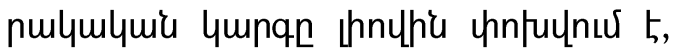

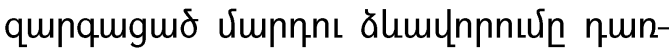

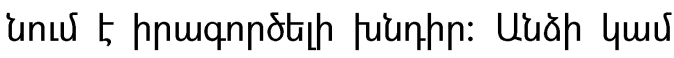

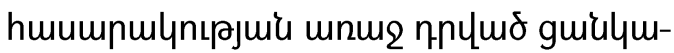

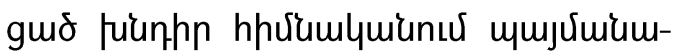

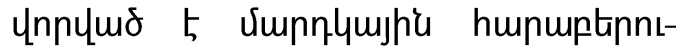

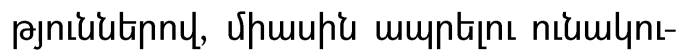
pjuर्up, nunhwiunın undtputinn uhut_nı

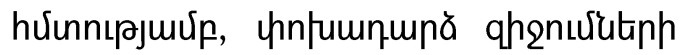

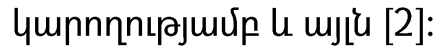

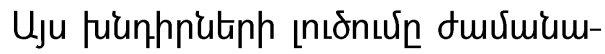

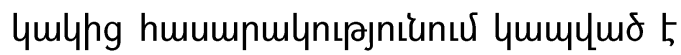

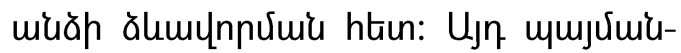

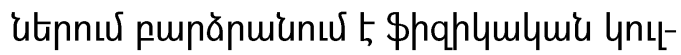

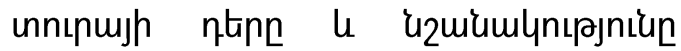

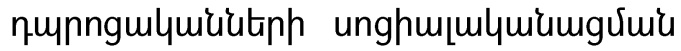

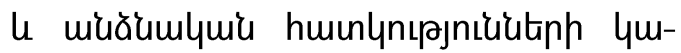

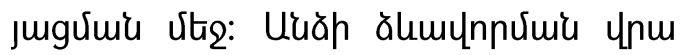

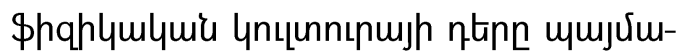

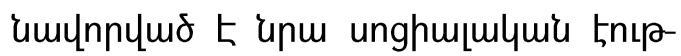

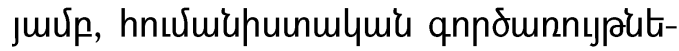
nny, Umpnnı hnqtiluiuh qunqugưuun: กpuliu humummlymlymir tiplnup' \$hqh-

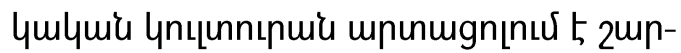

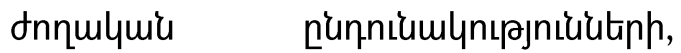

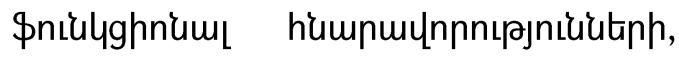
qhunulygnıpjuís (hurưnqưniuputin, undtapujhu unnưunnn2nư, qhunt,hputip, 


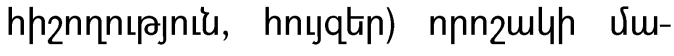
ympnuly [7]:

Uuăh puquiulynnưuiuh qunqug-

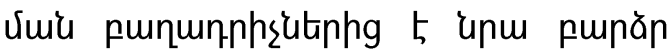

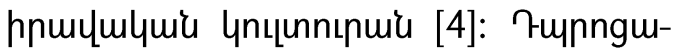
quiutitiph optiuputiph umuhumiuruiu,

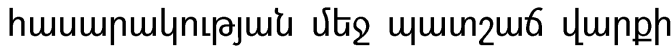

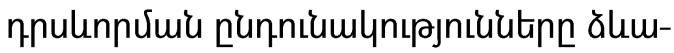

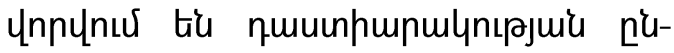
pugphis u unupntip qnnoniutinıpjniu-

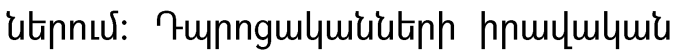

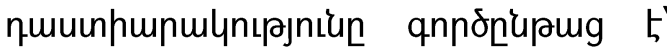

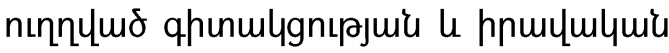

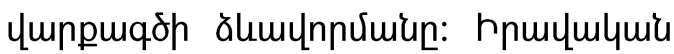

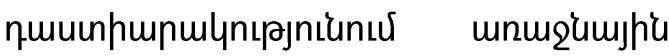

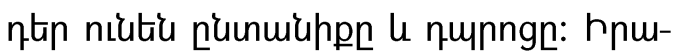

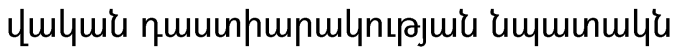

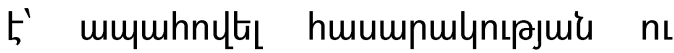

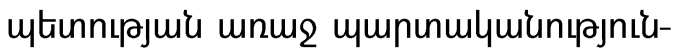

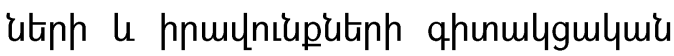

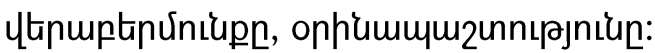

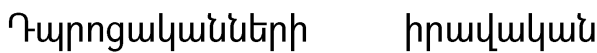

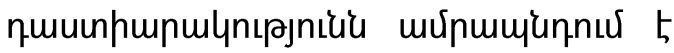

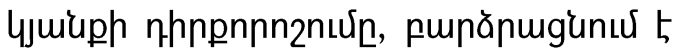
upuing punupughulymir myunhuntpjnıนun [3,5]:

7-unngulquiutinh \$hqhlymlumi

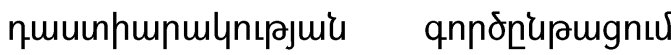
purquimlnnर्umin \$hqhlymlumis qunqugvimis le zmpdnnulymir muinnmuinym-

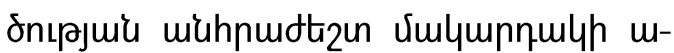
upunnyuuiu, humnnıl qhuntıhputiph

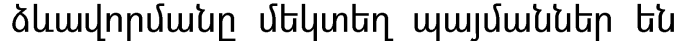

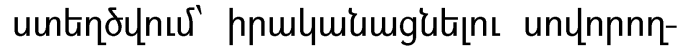

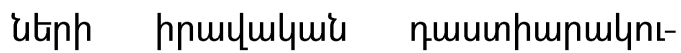

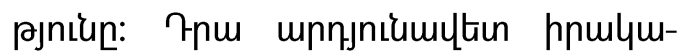

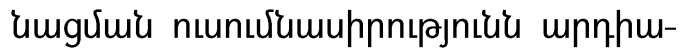

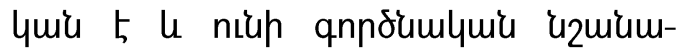
цnเрjnı:

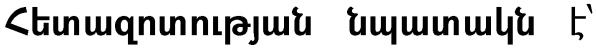

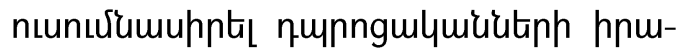

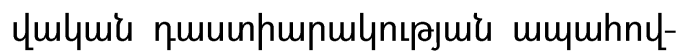

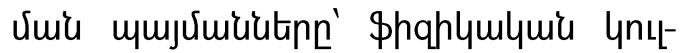
unnıpujp quutiphu:

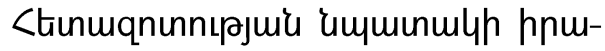

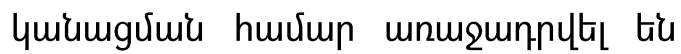
htinlumul fuiunhnitinn.

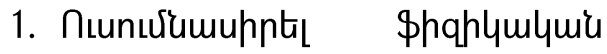

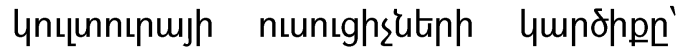

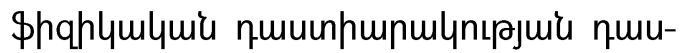

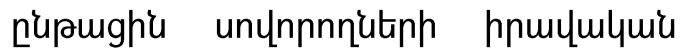

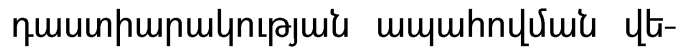
nuptinju!:

2. Fuguhumunt! qunngulquiutitiph

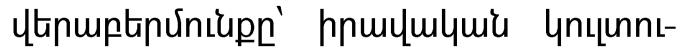

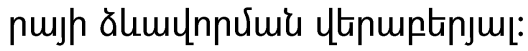

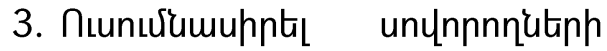

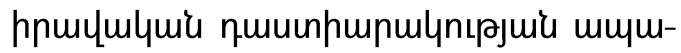

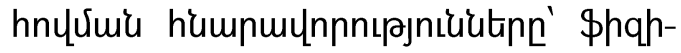

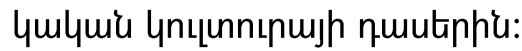

\section{Ctinuqnunnıpjuí vitpnnutinn $\mathrm{u}$}

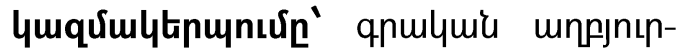

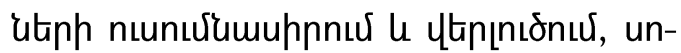


ghnınqhulymir hungnu, umptiumunhqulymiz uh6ulymqnnıрлnı:

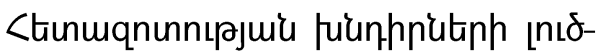

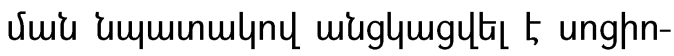

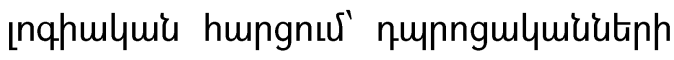
2nथuiunus:

Tuunnmuunltal 5 hungmptinphl, nnc punlymgur tn 17 hunghg, nnnup

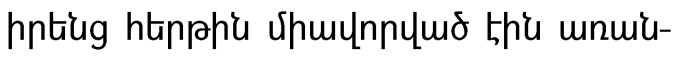
ăhu tiupujuরuptinnu.

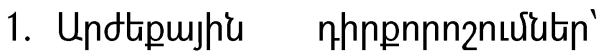
wuăh pumunnnıрjứ qottph ălumunnUimi ytenuptipju[:

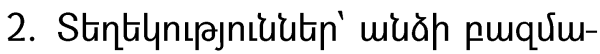

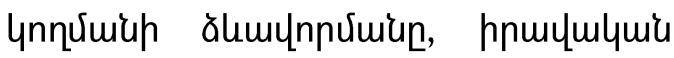

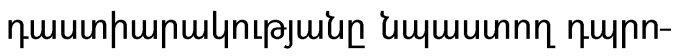

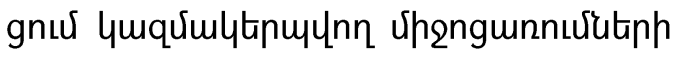
ythnuptinju[:

3. 7upngulyuiutitnp huर्जumuunuu|umiu yunpuqdo npulunnnuर:

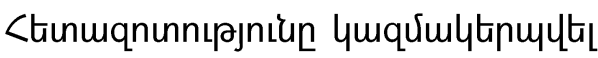
5 2018p: Cunguimun vimulumingtı tiu

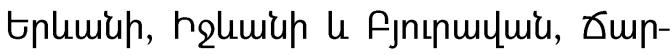
Gunhu, Gtrqunhn, Ltanumumu, бpцmp qjnıntinh uhq'umlyunq nunngutinh 8-11 quumpuiutitph 418 m2mlytpun:

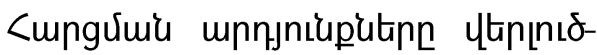

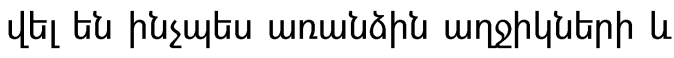

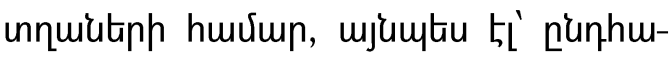
unıp:

nıunıghsitiph huvium quqưulta th 22 hunghg punlymgur hunguptipphl:

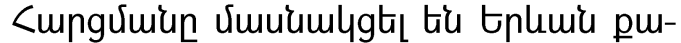
nupp l <mjununuiup <minmmutinnt-

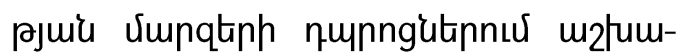
unnn 42 nuuntghs: U2łumunuiupujhís uunudn luquita 5 upghunud 12 unuph:

\section{<tunuqnunnıpjuí upnjnituputiph} цthцnıonıpjnı\&:

Ctunmqnunnıرuís nupamgphí vita htinupnphn tn puguhmjunta, pt du-

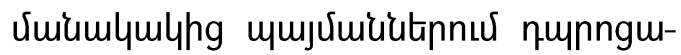

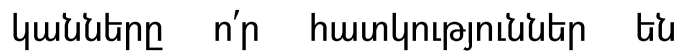
ymplunnnux: <mpngnuरng umpquthg, nn uhehiu nunngh tiplns utinh mzmlytinu-

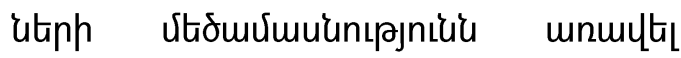

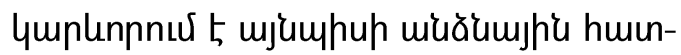

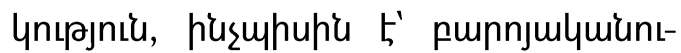
Pjnı'un' 95.85 unnlynu: ?puís vityuntin

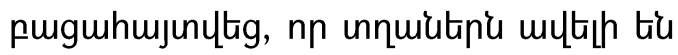

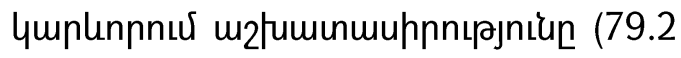
unnlnu), \$hqhlumlyuir muinnumunym-

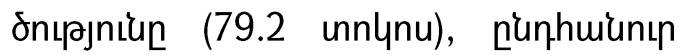
Uunuulnn qunqugnuरn (66.7 unnlynu), quпuцumumjunıpjniun (62.5 innlnu),

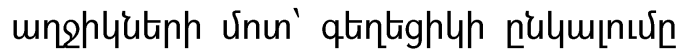
(63.6 unnlynu): Uunuhnqhs 5 4huuunn, nn uhehí qunngh unynnnnutiph upuju 46.2 unnlynu's 5 unuulta ymplennnu oph-

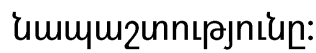

tpt unuphitiph nupugphí unnuutph unin qntiptr sh ulyminunu ophium-

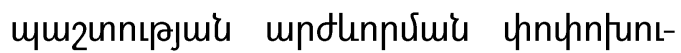

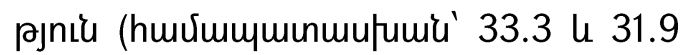


unnlynu), mщм mumq quampmiatitiph

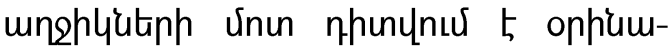

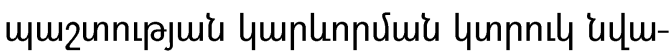
qnuर ( 59.1 unnlynuhg 19.2 unnlynu):

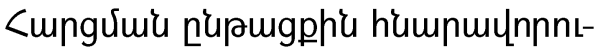

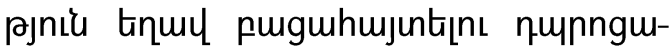

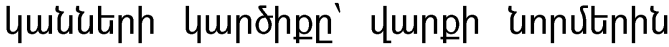

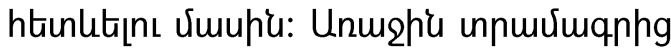
tpplunu 5, nn 8-9-nn quumpurututph unnuiutinp 83.3 unnlynun vimumuरp tiu

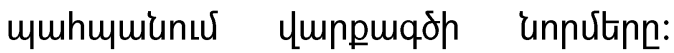
Unumnqhs 5 quiunn, np ulumq nunngulquiuktiph 18.2 unnlynun stiu

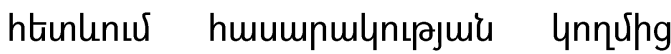
n'unniaumo unnutaphu: Unghlyatph unun

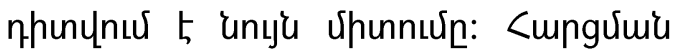
unnjniupnux umunqutgg, nn hungynnutph úpuju 10.6 innlynup vanmutiu htionlunu tiu yupph unnutiphis:

Utiq hurump ymplinn tp munqu-

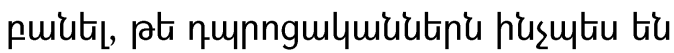

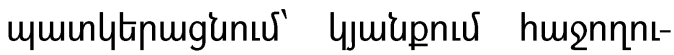

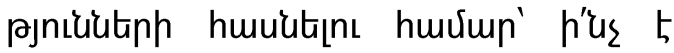
yunlunn: Uhoh'u nunngulquiutianh úmuju 50 unnlynu'u nunqónuर tiu ophium-

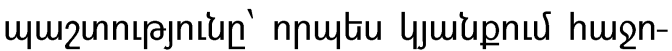

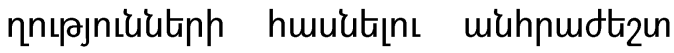

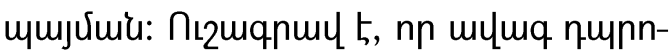

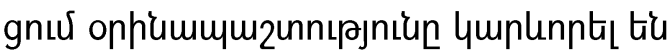

unnuiutiph nunuustiun 40.9 u unghlUtiph 30.8 unnlynun:

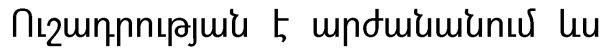
vtly qnuingymo qumuin. 8-9-nп пuumpuiutinp unghlutiph upuju 63.6 unnynun ujuiupnư hmennnıpjniuktiph huuutjns hurump quplennnuर tiu unnng hhutun:

<ungnuluhg umunquthg, nn hungunnutinh úpuju 39.8 unnynu'u n'unqonuर tú optiuputaph le punnjulquí unnutaph

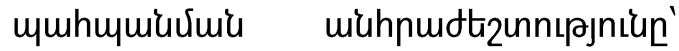

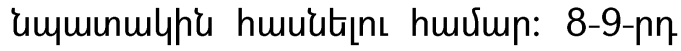
quumpuiutitph unnuiatph 62.5 unnlynun

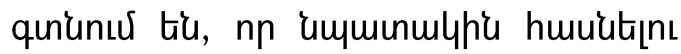

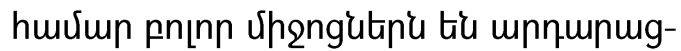
पmo:

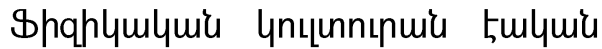

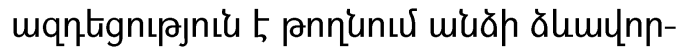

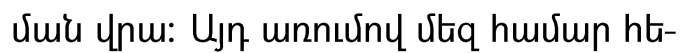
unupnphn tn umunqta nunngulymulutiph

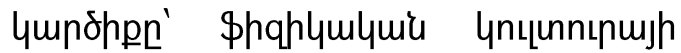
quutiph nupaugpnuर quuunpunulynt-

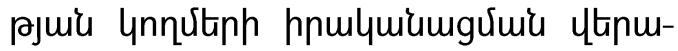

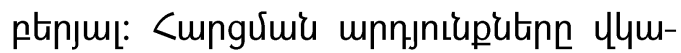

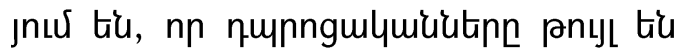
uquinltapugunus \$hqhymlymü ynцunnt-

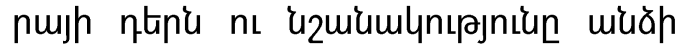

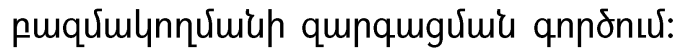




\section{Snuitin}

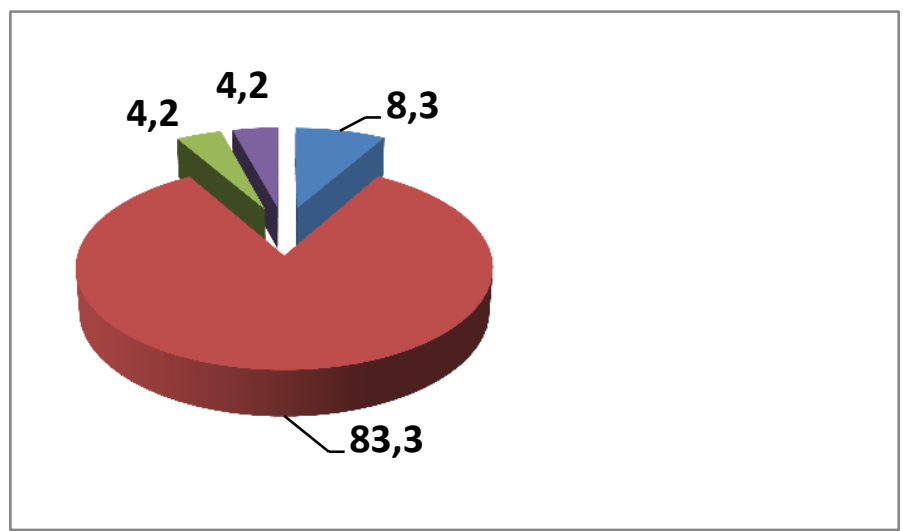

\section{Unghlititn}

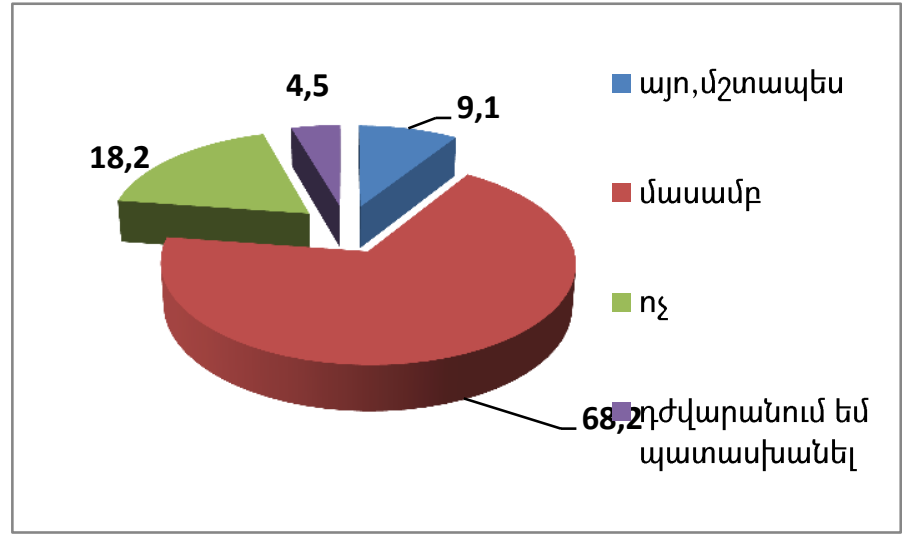

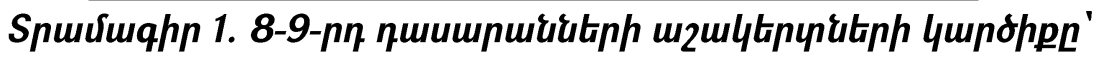

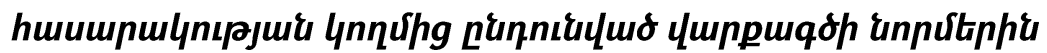
htrylut_nı vuuht (\%)

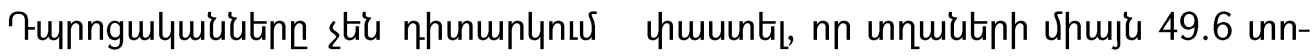

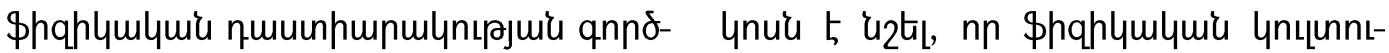

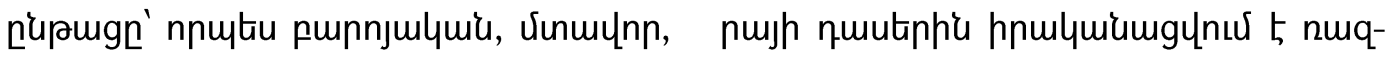

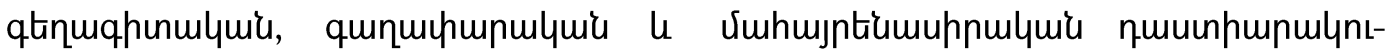

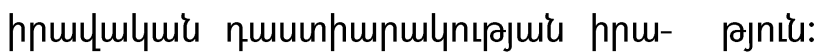

quiumgưuiu ungng: 3munp, mking b 


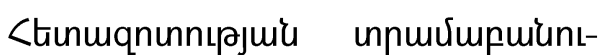

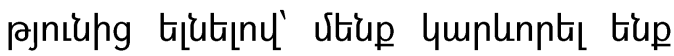

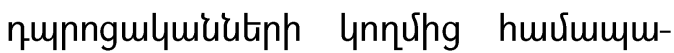

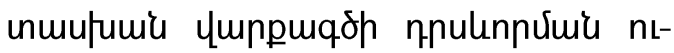
unuরkumuhnnuरn:

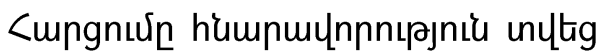

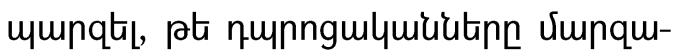
fumntiph, zmpdufumntiph, ungnusutitph

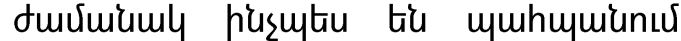

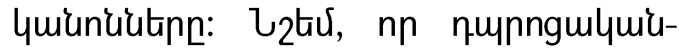
utaph úmuju 35.5 unnlynun vimpqułum-

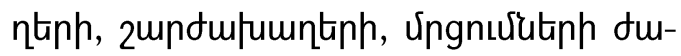
vimiamly uh2un muhmminnu tiu quiuniutinn, 46.4 unnlynu'u pnuyh6ulyhg tiuta-

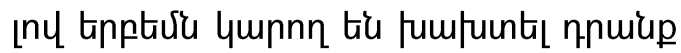
(minnıum4):

Unjnıumly

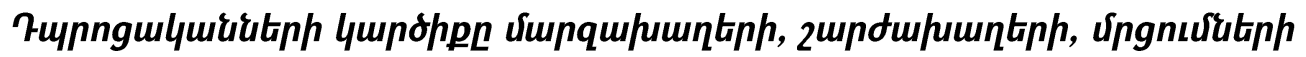

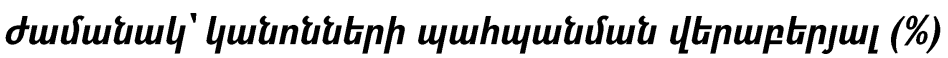

\begin{tabular}{|c|c|c|c|c|}
\hline \multirow{3}{*}{ 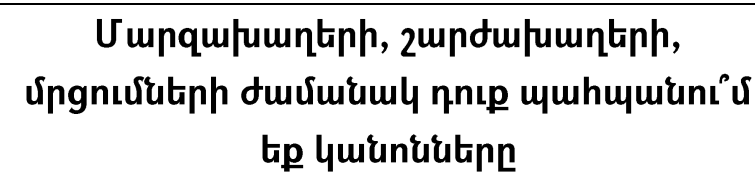 } & \multicolumn{2}{|c|}{ Squitun } & \multicolumn{2}{|c|}{ Unghlutitn } \\
\hline & \multicolumn{4}{|c|}{ Tuumumulutip } \\
\hline & uhqhu & mumq & uhehu & mumq \\
\hline Ujn, Uh2un & 25 & 50 & 36.4 & 30.8 \\
\hline 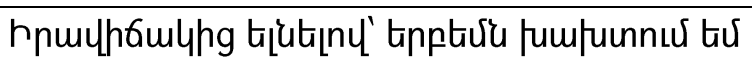 & 58.3 & 36.4 & 40.9 & 50 \\
\hline 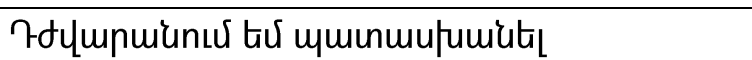 & 16.7 & 13.6 & 18.2 & 19.2 \\
\hline
\end{tabular}

<ungnưun puguhumjuntig, nn qunn-

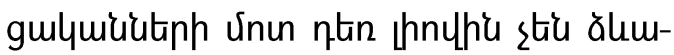

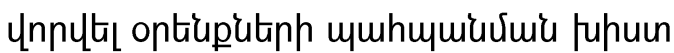

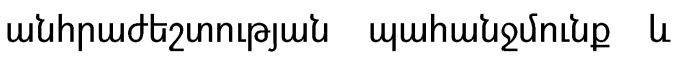

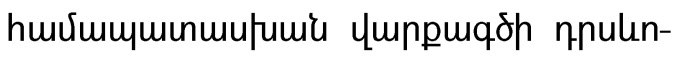
pnư:

Unynnnnutiph Unun unhuumpuly

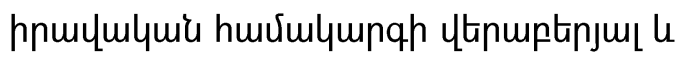

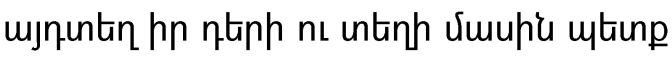
5 umunlytpnugnư ălumunnuh: Ujn umm-

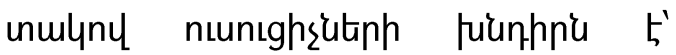
ununnnnutphí ptintı Uunph, nn unuiup tü hntiug mpunputinh le ophimquiugnt-

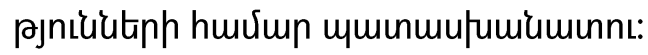

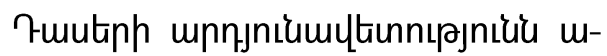

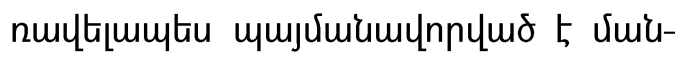

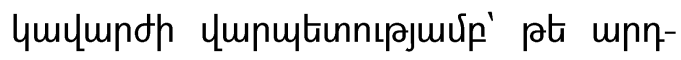
jn'p um hnulumiumgunus $5 \mathrm{hp}$ unme

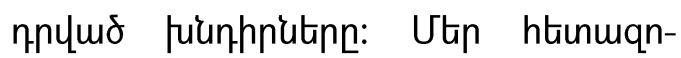

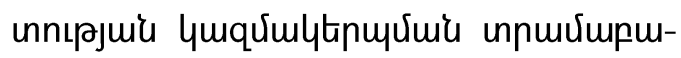

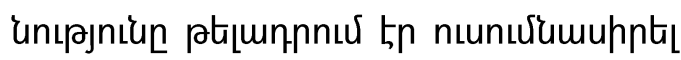
\$hqhlumlumír lnıınnıpujh nıunıghsuteph

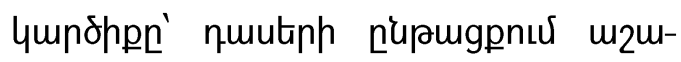

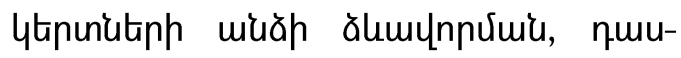

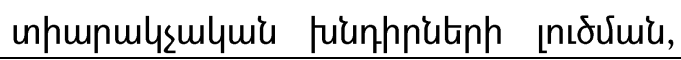


upuing htin hnulumluie hungtiph

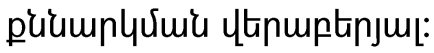

<ungnuúng uqunq qupămu, nn ntuntghsutiph 42.5 unnlynứ mamlytinu-

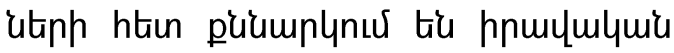
hungtin, 36 unnynun' tipptiớ miannu-

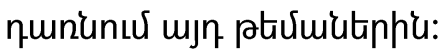

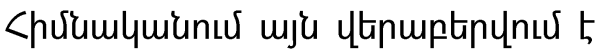

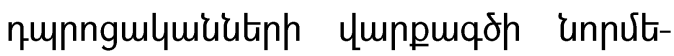

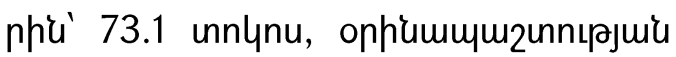
vemup'a' 13.78 unnlynu le umhưuiumnntpju'u Umuhi' 2.9 unnlynu:

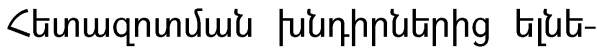
[ny' htunupnphn th puguhumunts nuunıghsutiph 4undppn mzmlytpunutiph

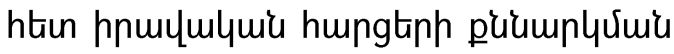

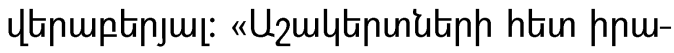

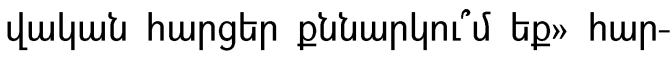
gh'u «mjn» uquinuufumita the neunighsutph 42.9 unnlynun, hul «mjn» umunmu-

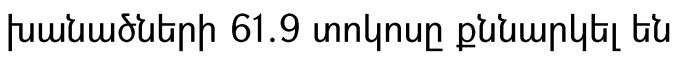
ymppuqdo 'unnultan' 14.3 innlynun' oph-

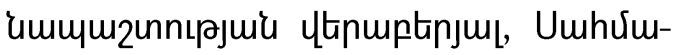

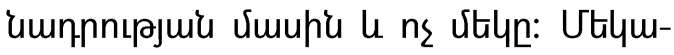

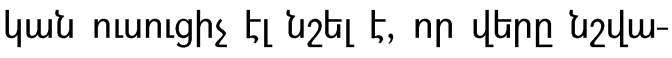
ong quin unuing htion pulumplynu tiu

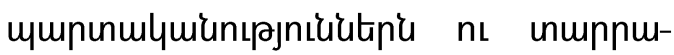
quiuktiph htion nnn2 ytamumuhnuरatin

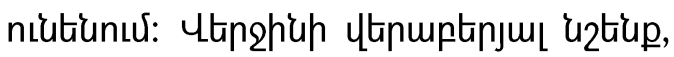

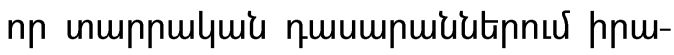

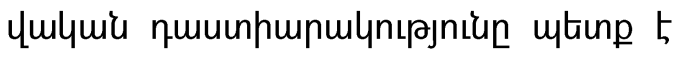
unupptinlh pupnjuqtinuqhunulymir punujany' ununnnnutiphí epnfumingtiny y unph tpplqulquie unnutin le uintindtany punnjuhnqtipuiumlyuid htiup:

ounnutiph htien hnululymir humgtin puumplynu t5 nuunıghsuteph nunu-

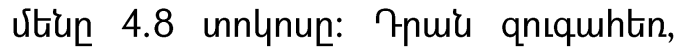
umlumju, nunıghsitiph 95.2 unnlynun ymplunn t5 huvoumnnư miăh qunurhu-

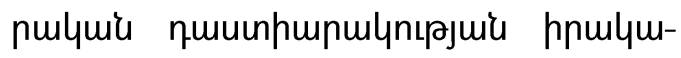

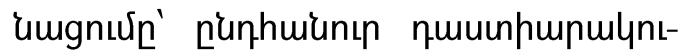

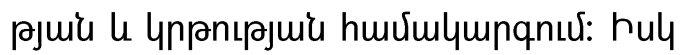

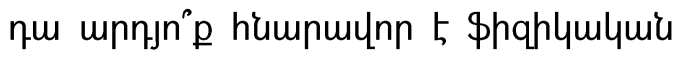

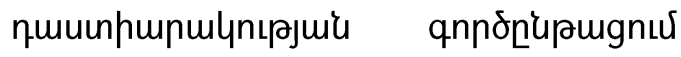

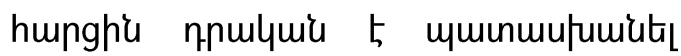
hungynn nuunıghsutiph 66.7 unnlynun:

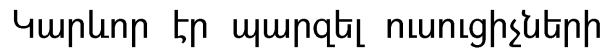

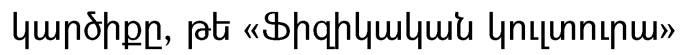
unmplumulquis spmqph intiumlymis

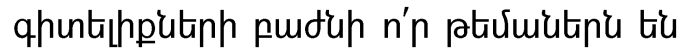

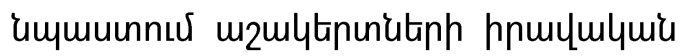
quuunpunulynıрjuiun:

Ununnnnutiph's hnuumumu utinpn-

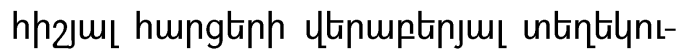

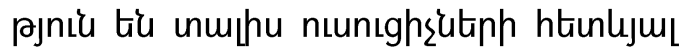
unnlynun. «\$hqhlumlymir ynцunnınujh

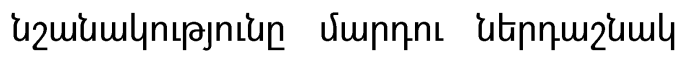
qunqugưuiu qnnónul» ptưump duviuiuly nuuntghsutinh 66.7, «Unnn? munt_ulytрuщ»' nuunıghsitiph 54.8, "Unnumugh fumn»' 52.4, "\$hqhlumlyuir

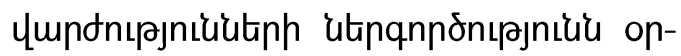
quiuhqư unu»' 38.1, "<mj vimnqhy- 


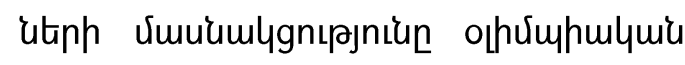
fumntinhu»' 31:

Utiq huviun yuplenp th munqu-

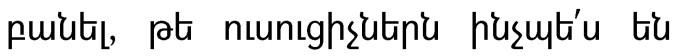
mpămquiupnư mzmlytpunutiph ns muin-

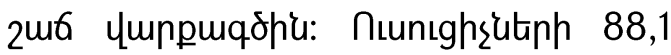

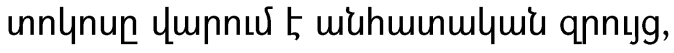
2.4 unnlnup muhwiugnuर 5 , nn nilutium

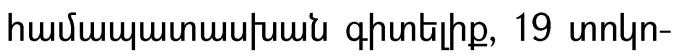

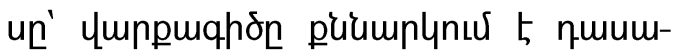
nuiunux u 61.9 unnlynun' hnuqtilnnu dunnutiphu, nuuntilhu:

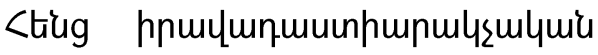

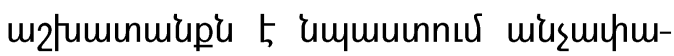
huvutuph unun mjumpup hrớumpun

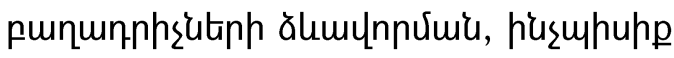

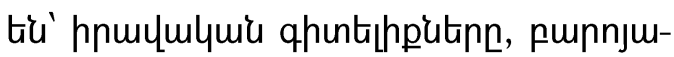

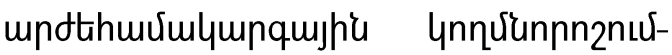
utnn, hunquihg ythmuptinúnı'up optiuph

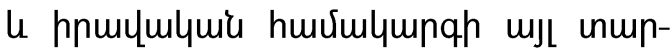

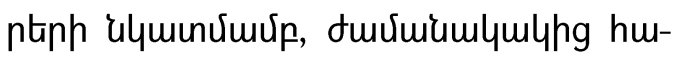

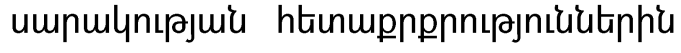

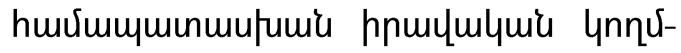
unnn2nứtutin lu mృ ü:

tqnulyugnıpjnil: <ungưuid unn-

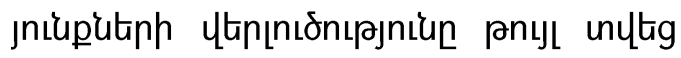
umunltapugnus uintindta qunngnuर

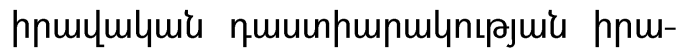

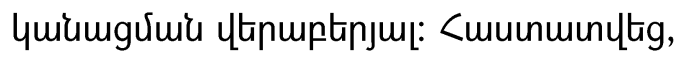

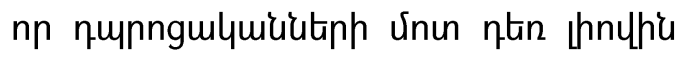

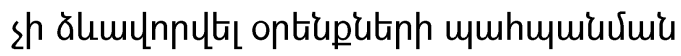

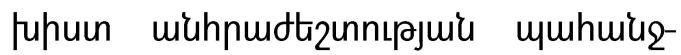

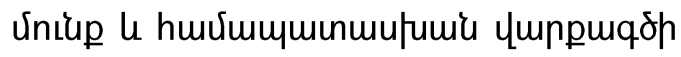

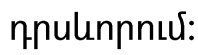

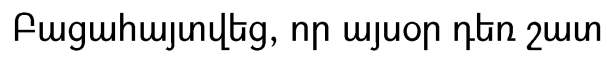

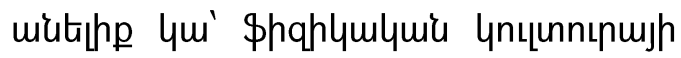

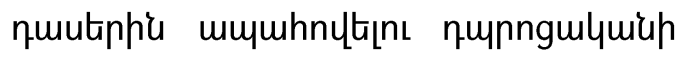
muăh puqưulynnưuiuh qunqugưuiu,

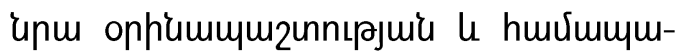

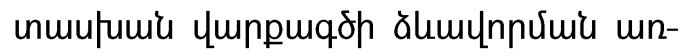
чu hüunuunnnıpjnıłüunn:

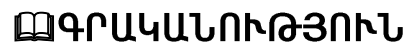

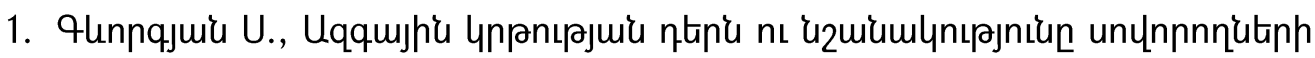

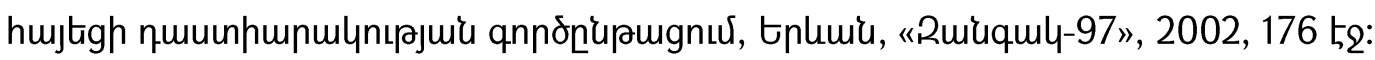

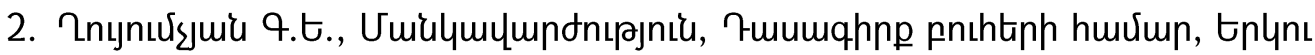
qnpny, qhnp I, tplumu, Ruiqquy-97, 2005, 464 52:

3. Агеевец В. И., Выдрин В. М. Влияние спорта на воспитание интеллектуальных, нравственных качеств и социальной активности личности. В кн.: Спорт в современном обществе. М., 1980. С. 110-123.

4. Гранат Н.Л., Правосознание и правовая культура // Юрист. - 1998. №11/12. 
5. Зотов Ю.И., Воспитательные возможности физической культуры и спорта. //Воспитание подростков в спортивном коллективе. М., 1984. С. 5-14.

6. Колесникова И.А., Воспитание духовности и нравственности в эпоху глобальных перемен|| - Педагогика.- 2008.- № 9.- с. 25.

7. Лубышева Л.И., Современный ценностный потенциал фризической культуры и спорта и пути его освоения обществом и личностью // Теория и практика физической культуры. 1997, № 6, с. 10 - 15.

\section{LEGAL EDUCATION OF SCHOOLCHILDREN IN PHYSICAL CULTURE LESSONS}

\section{PhD student E.E. Ghantarchyan}

Armenian State Institute of Physical Culture and Sports,

Yerevan, Armenia

\section{SUMMARY}

Key words: Schoolchildren, legal education, law-abidingness, legal awareness, physical culture, sport.

Relevance. High level of legal culture is a key component for sophisticated development of a person. Legal education of schoolchildren strengthens their position in life, increases their civic engagement. The physical education process of schoolchildren, consistent with complex physical development, adequate physical preparedness and ensuring the development of special knowledge, creates quite favorable conditions for the legal education of pupils.

The research aim has centered on the study of conditions for ensuring the legal education of schoolchildren in physical education lessons.

Research methods and organization. Methods include the study and analysis of literary sources, sociological survey, mathematical statistics.

In order to solve the tasks set, a sociological survey was conducted among students of 8-11 classes from 16 schools in Yerevan and regions of Armenia alongside 42 physical education teachers.

Analysis of the results obtained. The survey results indicated that schoolchildren have poor understanding of the role and importance of physical culture 
in the midst of multifaceted personality development. They do not consider the process of physical education as a tool of moral, intellectual, aesthetic, ideological and legal education.

During the survey, we managed to find out the opinion of schoolchildren on the observance of behavioral norms. It turned out that only 10.6 percent of the respondents constantly adhere to the norms of behavior, 42.5 percent of teachers discuss legal issues with students, 36 percent - only occasionally touch on these topics.

Conclusion. It has been established that schoolchildren have not yet fully developed a strong need for strict observance of the law, except for own appropriate behavior.

It was revealed that actually there is still much to be done for the comprehensive development of schoolchildren, the formation of their law-abiding and adequate behavior owing to the physical education classes.

\section{ОБЕСПЕЧЕНИЕ ПРАВОВОГО ВОСПИТАНИЯ ШКОЛЬНИКОВ НА УРОКАХ ФИЗИЧЕСКОЙ КУЛЬТУРЫ}

Соискатель Э.Э. Кантарчян Государственный институт физической культуры и спорта Армении, Ереван, Армения

\section{PEЗЮME}

Ключевые слова: Школьники, правовое воспитание, законопослушность, правовое осознание, фризическая культура, спорт.

Актуальность исследования. Одна из составляющих многогранного развития человека - его высокая правовая культура. Правовое воспитание школьников укрепляет жизненную позицию, повышает их гражданскую активность.

В процессе физического воспитания школьников наряду с комплексным физическим развитием, необходимым уровнем физической подготовки, обеспечением развития специальных знаний создаются условия для правового воспитания школьников.

Целью исследования является изучение условий обеспечения правового воспитания школьников на уроках физического воспитания. 
Методы и организация исследования. Методы включают изучение и анализ литературных источников, социологический опрос, математическая статистика.

С целью решения поставленных задач организован социологический опрос среди учащихся 8-11 классов 16-и школ Еревана и районов Армении и 42 учителей физической культуры.

Анализ полученных результатов. Результатами опроса выявлено, что школьники слабо представляют роль и значение физической культуры на фоне многогранного развития личности, не рассматривают процесс физического воспитания как средство нравственного, интеллектуального, эстетического, идеологического и правового воспитания.

В ходе анкетирования удалось узнать мнение школьников о соблюдении норм поведения. Выяснилось, что только 10,6 процентов респондентов постоянно соблюдают нормы поведения. 42,5 процентов учителей обсуждают со школьниками правовые вопросы, 36 процентов - лишь иногда касаются этих тем.

Выводы. Установлено, что у школьников еще не полностью сформировалась необходимость в строгом соблюдении закона, помимо соответствующего поведения.

Выявлено, что сегодня еще многое предстоит сделать для всестороннего развития школьника, формирования у него законопослушного и адекватного поведения с помощью уроков физической культуры.

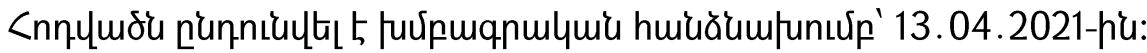

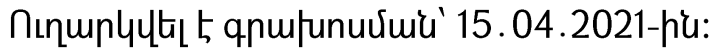


DOI: 10.53068/25792997-2021.1.3-100

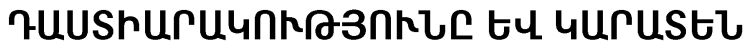

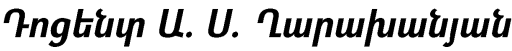

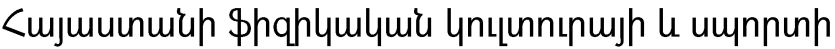

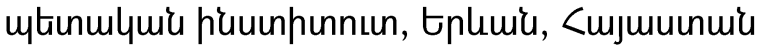

E.mail: arman-karakhanyan@mail.ru

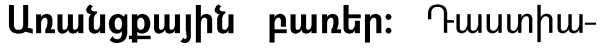

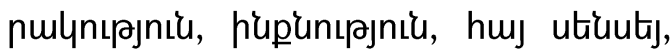
qhuntihp, \$hqhlumlquiu quuunpurulynt-

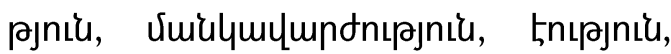
huj pnpuinnuju:

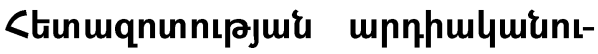

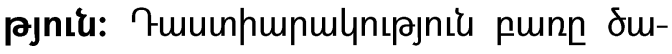

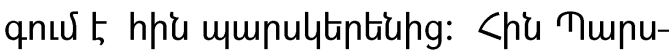

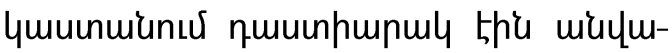

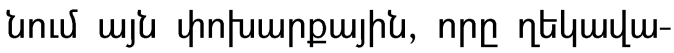
nnuर tn w6nn utpunp hnqunn qunqugnứn [3]:

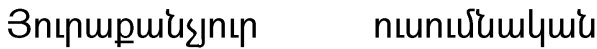

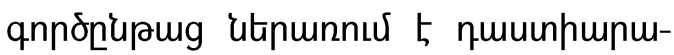

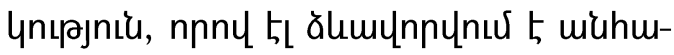
unn' hn hnqunn $\mathrm{u}$ vinuulnn pnumünuцпเрјши्up:

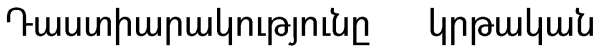

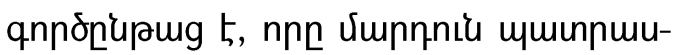

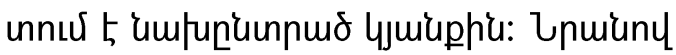

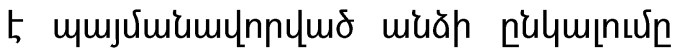

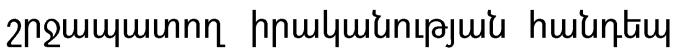

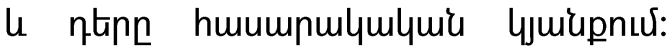

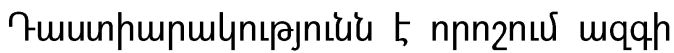

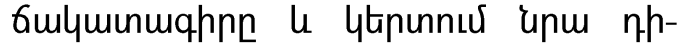
vimqhon:

Chinlumpun, ounup undtputinnl' h'usuhuhp unlyu tí qunuintinu, huj-

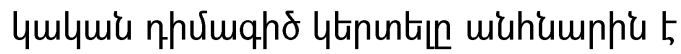
u Gulymunuqnny yunuiuquulnp:

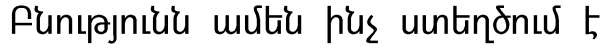

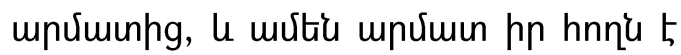

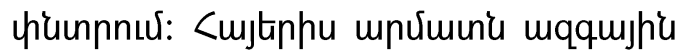
nqhe 5, hul letumpun hnnn' <ujuuunuiu m2 fumphn: <tinlummbu, huj utiu-

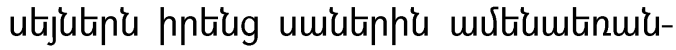

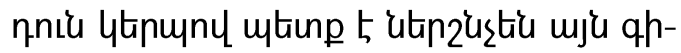

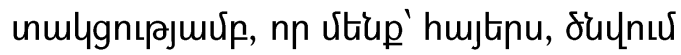

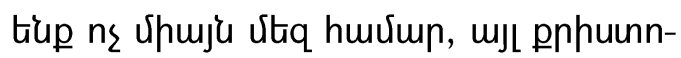

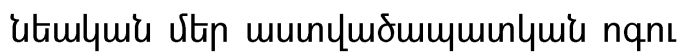
u vitp munulmommunqle hujntiuhph huvium:

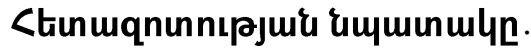

1. ไtiplumughts quaunpunulynt-

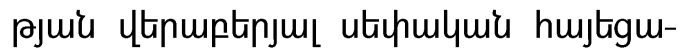

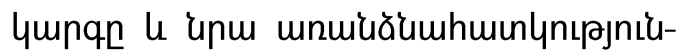
utinn: 
2. 4mplinntis huj utiuutjutiph ntinn vimphliutinh hujtigh quuinhunmuntpjuiu qnnonuर:

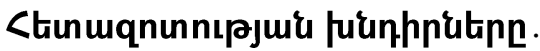

1. Lmj qunuinthuinutiphis unpts hujtigh quuunhmpmlnnıرuर्up' mqqujhu qhunulgnıрјuर्up:

2.Lnıumpuits qupuunth hnqunn

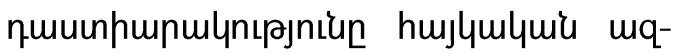

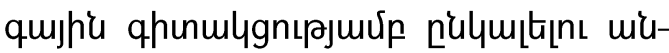

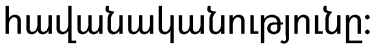

3. <uj utiuutjutiph quunnwemulsw-

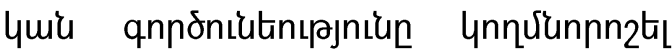

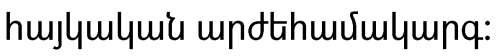

<tunuqnunnıرuid vitannitinn $\mathrm{l}$ पuqưulttpunntoun.

1.qnulquí unpjnınutiph nıunứumuppnıpjniu,

2. unupptip qunurhuplitiph huUumpnuर्u u huviulympqnuर,

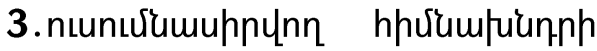

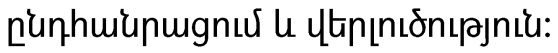

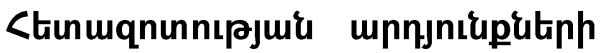
Lthpцnıonıpjnılu:

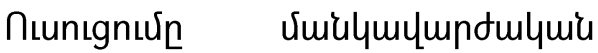

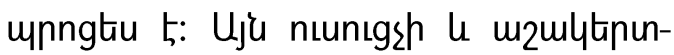

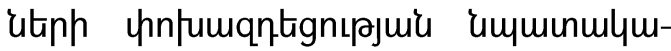

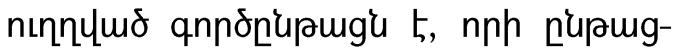
pnư hnulymiumgunuর tiu vimnnı unpnt- pjniun, quuunhumulynıpjniun u qunqugnuर्up [2]:

hu funphis huuरnquiurup quuunhwpulynıpлn'un' nnutu umhuiugúnı'up, niup tiptp 2 thpun humunmlymlymid, Jumumunn la lnnimumu: Unmehin mponm-

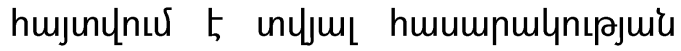

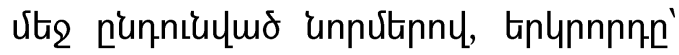

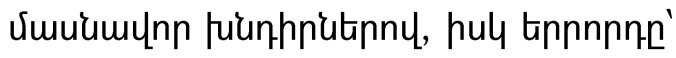
hurluunpny: <tinlumpun, quuunhumu-

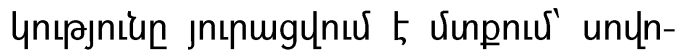

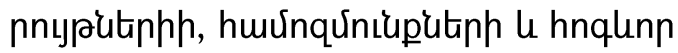

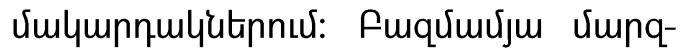

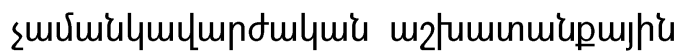

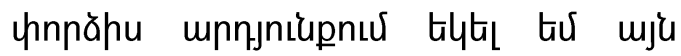

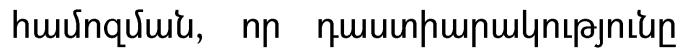

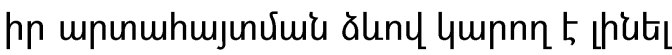
umunhy (mpunuhmjunцnuর 5 রhmju miăh

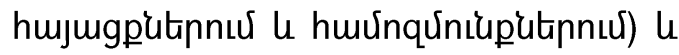
myunhy (ununuhmjunцnux 5 qnnonnntpjuर्up): tu 4unonuर tuर, nn quuunhu-

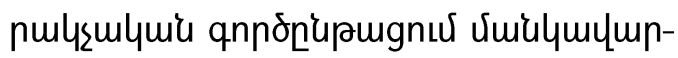

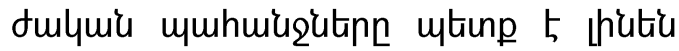
humunumniu, hul mpnjnizputinn humnuulnn unnunnfutihh, nnh unlumlumiunt-

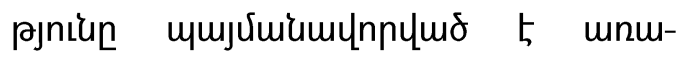

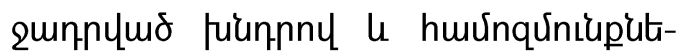
pnu:

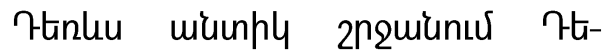
Unlnhinh, Unlnmintiup, Tluunnup $\mathrm{u}$

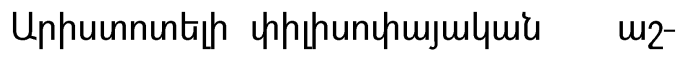

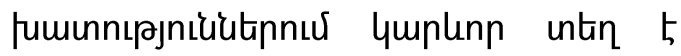


humlyugyth vinuulnn, hnqtilumur ns

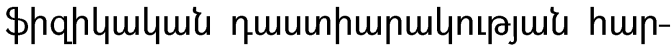
gtiphe [3]: Umilymumponıpjuis vits

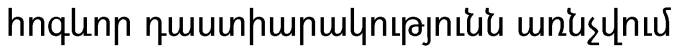

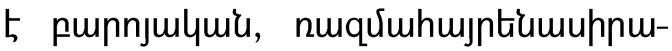

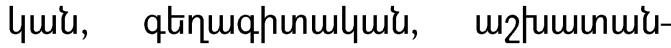
pujhu, unnumlymí, husutiu cumb hnqunn nuuunhumulynıрjuiu htion:

hu punnnzưứ hnqunnn lumu' Uuunon lu hnqnı uhole, $\mathrm{u}$ mje mutiun,

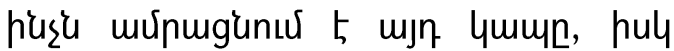

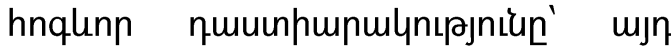

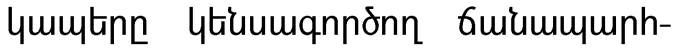
utinn: Umilymumpdnıpjuí vite hujunuh tiu hnqunn quuunpupulynıpjuí nnn2

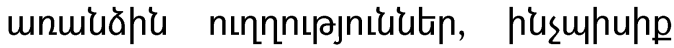
tí' m2łumunuupnnıpjniun le \$hqhlum-

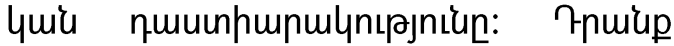
munqumbu ympnn tiu phuts nunnium-

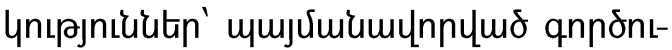

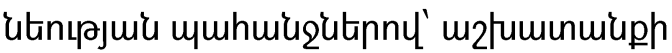

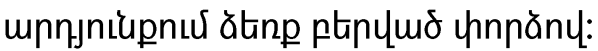

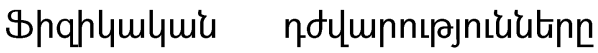

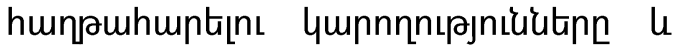

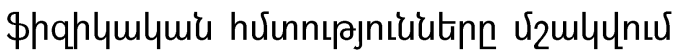
tiu Uumqnưutinh unengnd' \$hqhlumlum

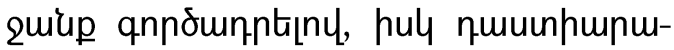
4tı lumbih 5 hnqpis lu qhunulygnıpjniun,

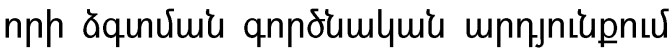
ympnn tiu ălumunnutal hujugputan,

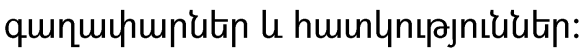

7uuunhumulynıpjnitun sh pugut-

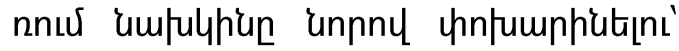
ytanunuuunhunulytans humpulnnnt-

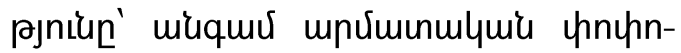

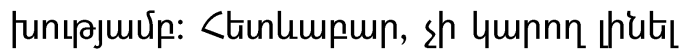
\$hqhlumlumis quuinnumulynıpjniu, npnyhtinle \$hqhymlumis nnulyutinh hpurdunytal munqumutiu humpuunn st ns ununnnujph, ns hưưnqưniuph ns hl hnqunnh vimlumpulyutipnus: hu qun-

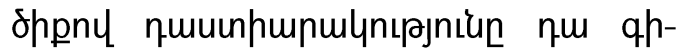

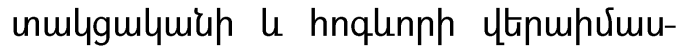
unuulnnnuर́u t:

\section{$U_{2}$ łumunuippujh\& nuuunhwpulynt-} Pjnit: Utip ontipnuर up zupp htnhiumly-

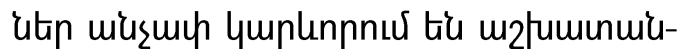

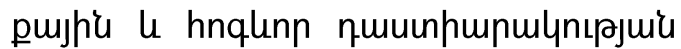

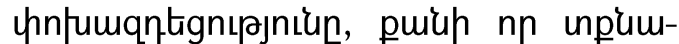
2uiu w2fumunuiuph zunnhpy tú uuntindunuর mpltuunp qnndtp, hnqunn undtputip: Cuin 'unming' untindmqnnomlume

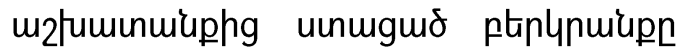

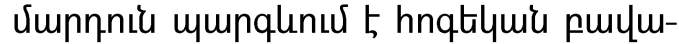

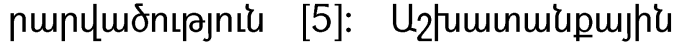
quuunhumulynıpjniun tupaunnnuर 5 m2-

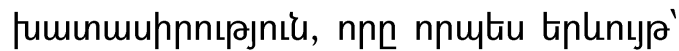
sh 4mpnn hupunınnju huiuntiu qu[. mృ

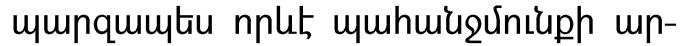

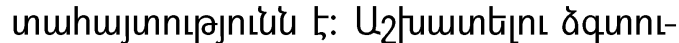
un nnulunnunus 5 upu unnjniuph

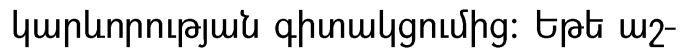
fumunu'upp' nnuku hupunınny'u 


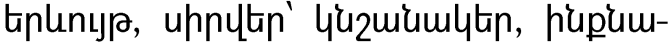

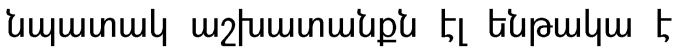
upnltant: U2łumunuiupg uting 5 qn-

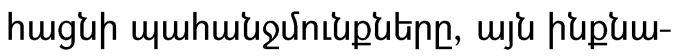

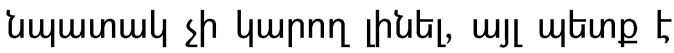

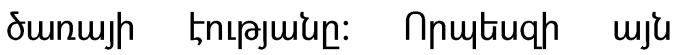

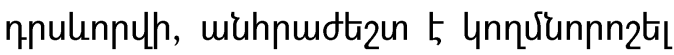

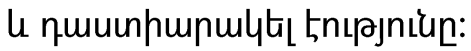

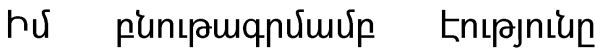

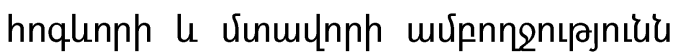
5, hul nunnıłumlynıpjnıuutinn \& hơunnt-

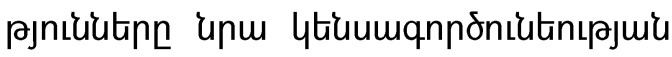

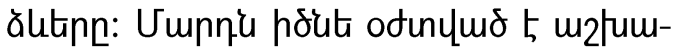

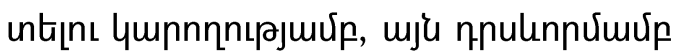

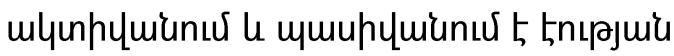
hpuviujulquiund' 'unu wuhpuottzunntpjuiu qhunulygưur:

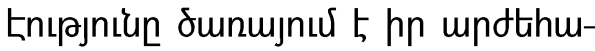
vimlunqhi, nnny hưuuumulnnynuर $5 \mathrm{hn}$ qnjnıpjniun: <tiunlumpun, quuunhumulta ukting 5 tnıpniun, nnutiuqh

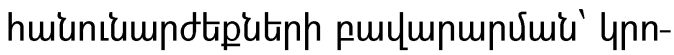

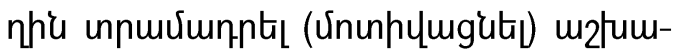

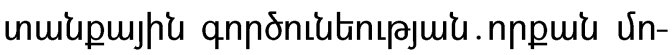
unhumghuir hiunus 5 hpर्umulnn, yuunu-

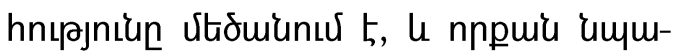
unuly Ч

чmunupur hpर्uamunnnuरatiphu

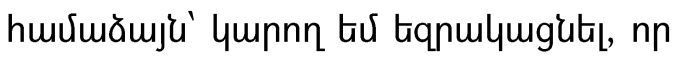

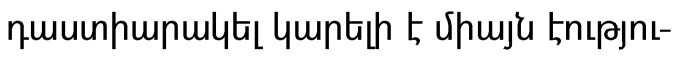

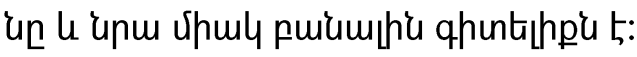

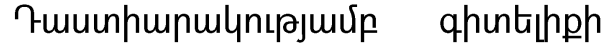
nıony Utenqnnơnu tiup qhinulygnıpuiun u qhunmlgmpun, Чundnıpjuर्up unЦn-

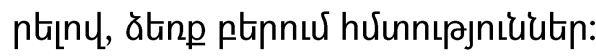

Gupuuntnuर vitp hnqlenp unuiggpn uting 5 thêp vite pnhuinnutiulywi hurluunuर्upn lu nuquiuhmuntiamuhnulyuí quuunhupulynıرniun:

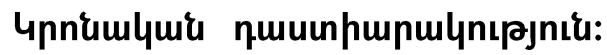
upnun hnqunn quuunpunulynıрјü unuiugpe 5, nnn quntinny quuunpunulyt! 5 ununptip mqqtiph 4 dnnnunınnutph, upuis hnqunn shgptip hurnnnta, mquyumgnts, ytahugnts le alumunnts

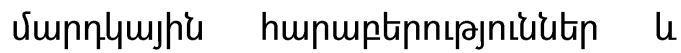

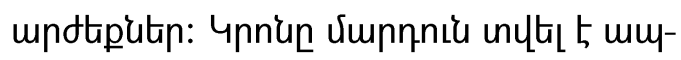

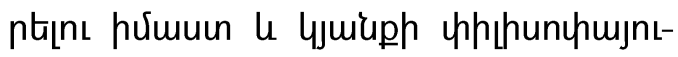
Pjniz, hul hujtiphu' 'umle mqqujhí nqh le mưưuhnıpjnı:

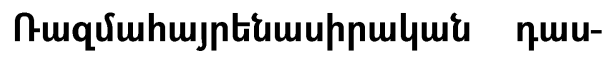
inhumulynıpgniu: ก-uquarhujntiumuh-

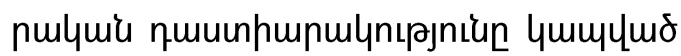
5 hnqunn quuunhumulynıрjuil htin, nnnuhtiunle humntiuhpn hnqniu unmph 5 "punupughnıpjnı"u», hul upu uquzun-

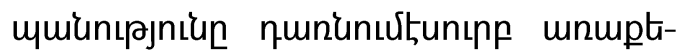
¿nıpjniu: Utap hnqhi huslumluie t, $\mathrm{l}$

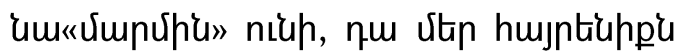
5: Utip hujntiuhpn' < ujumunuiu məłump-

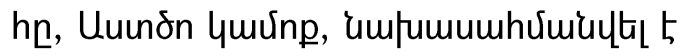
nnutu hustiphu pionnuid, le unuiug unu huje sh yunnn n's lutil hujtintiu, n's 
untuiuts hujtintiu, n's funuts hujtintiu,

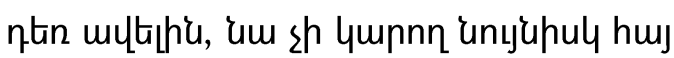

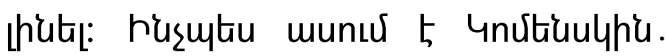
"Umpúpun mkinp 5 muzunumits hp-

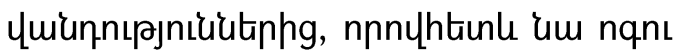
qtiontinupuiue 5» [4]: Ujnutiu 5L hujntuppn utiunp 5 umzunumits nunfung, npnyhtiule unuing unu vitp mqqh nqhe

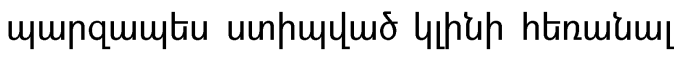
Utrquiuhg:

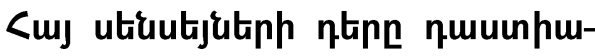

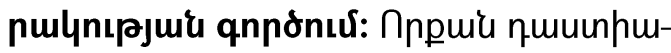

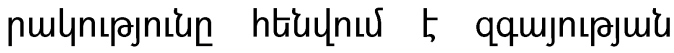

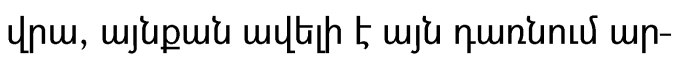

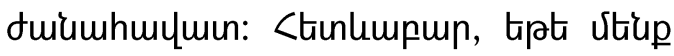
nıqnuर tiup umitin quaunpunmlyt,

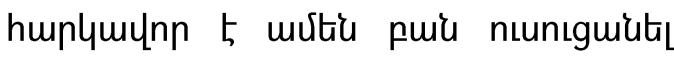

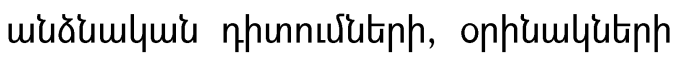
u qqujulymil mumgnıgnudutiph uhengnu: furumlumunıرuiun vitup huцluunnuर tiup snl mjupuiu, nnpuí humpu-

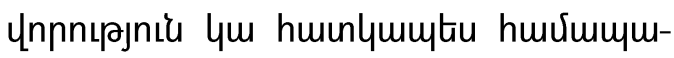
unuulumis ophumlyute ptptinn uhengny humunuints mjn (nnuigg undwiumhuumunnıpjnıiun uunnıqunuर 5 qqujntpJuर्up) [4]:

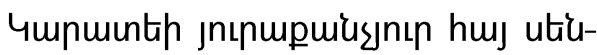
utj uting 5 qhunulggh hn ynsuluid 'u2uumlynıpjnıนn: Unwiup suting t5 huiunh-

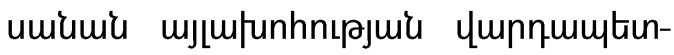

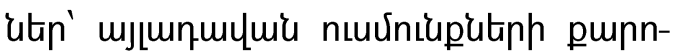
qhsiate, uj nnutiu huslumlquí hüpunt-

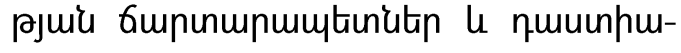
nulyutin:

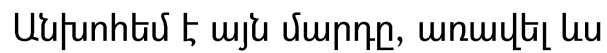
huj nıunıghsn, nnn qhunulygnud $5 \mathrm{hn}$

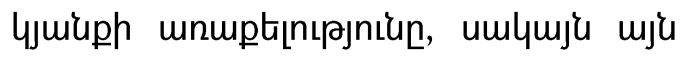

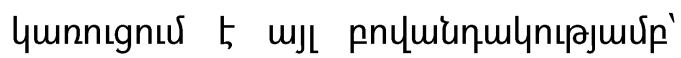

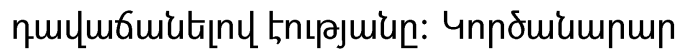
5 humumumitu uju niunıghsn, nnu hn

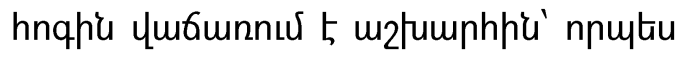
"2uhurltiun qnnompp":

Utiuntjp mumiunulymir ytpumunn' shuiunnındnn $\mathrm{l}$ «tiumliturnnn' yunu-

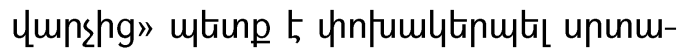

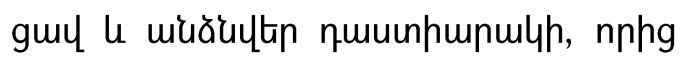

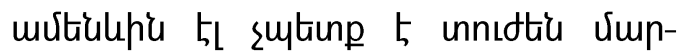
quiluí punān mpnjniupüann: 7uu-

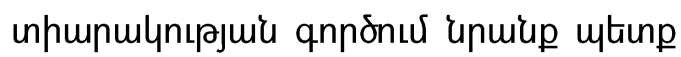

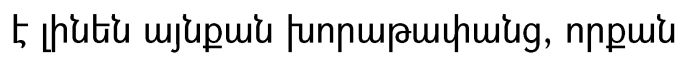

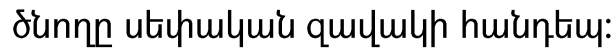

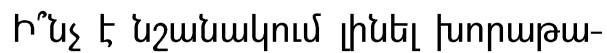
thuing. qu huj neunıgsh equpunpe $5 \mathrm{hn}$ umutiph huiuntiu' ıglta hus pnhuunniju umunnmuintins molitumulth unmpt-

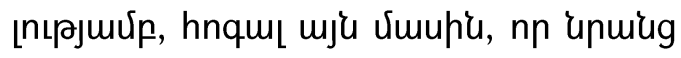

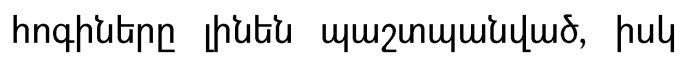

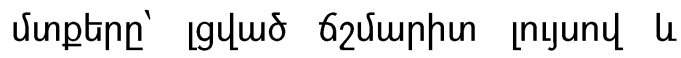
hर्umuunnıpuuर्u:

tqnulymgnıpjniu: Tuinưurर्u2u-

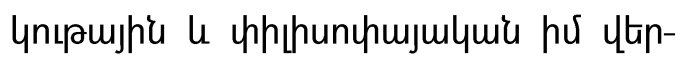

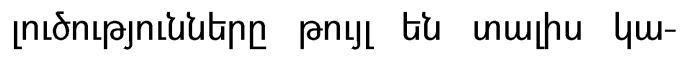

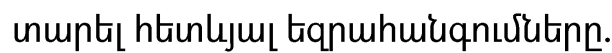




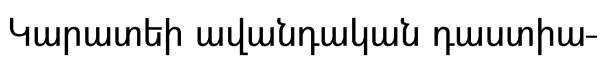

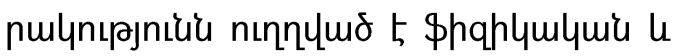

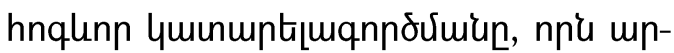
unuhmjunयnus 5 qupuuntentu huunnıl

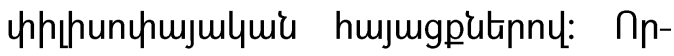

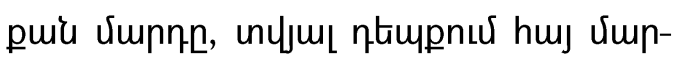
qhln, zmin 5 mnušlnuर mju huviulymp-

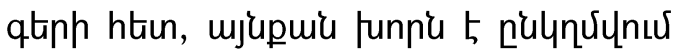

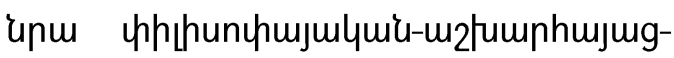

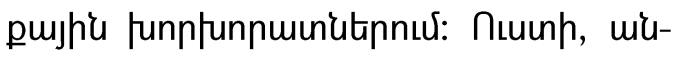

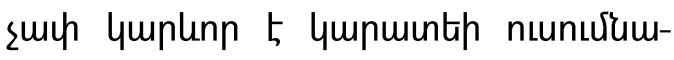

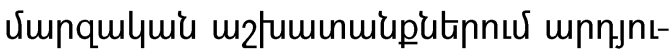

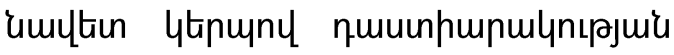

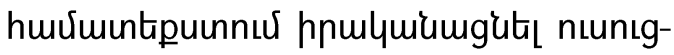

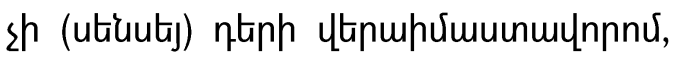

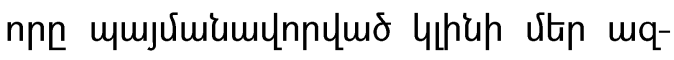

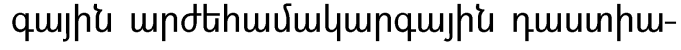
nulszulquie ununtgnututinny $\mathrm{l}$ pưuu-

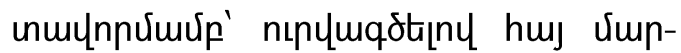

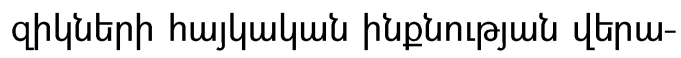
4tpnunumu unn purăniuputann: Uju unnữny miuăh hnqunn qunqugưuiu

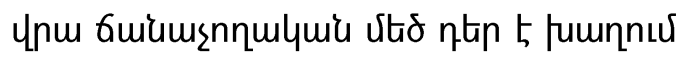

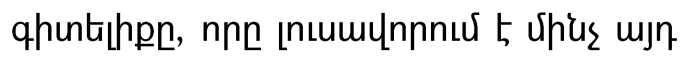

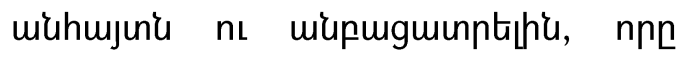
ympnn 5 hnqtilnphs ntip luinumbis huj qupuinthuunutiph ujuiupnux:

"४npnıpniu, unuing uqqujhí

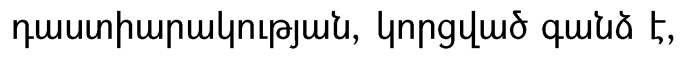

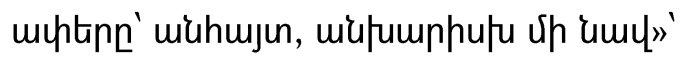
U. ¿umupuminjuit:

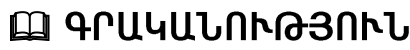

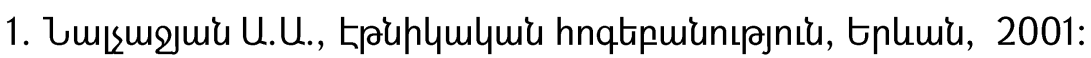

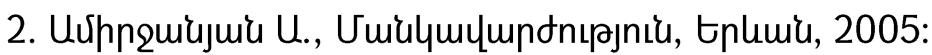

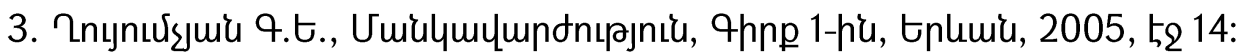

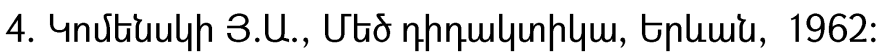

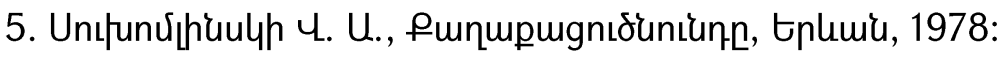

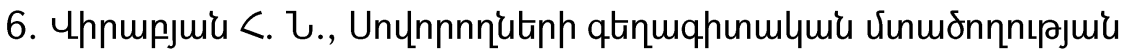

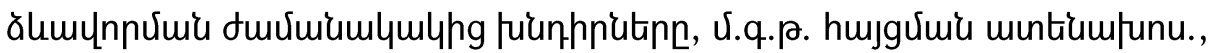
utnumaph, Łplumi, 2005:

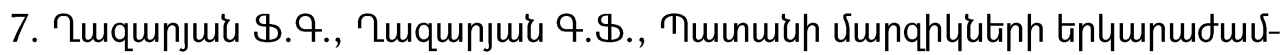

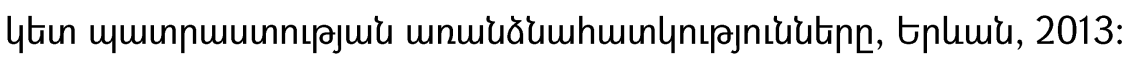




\section{UPBRINGING AND KARATE}

\section{Associate Professor A. S. Gharakhanyan}

Armenian State Institute of Physical Culture and Sport,

Yerevan, Armenia

\section{SUMMARY}

Key words: Upbringing, identity, Armenian sensei, knowledge, physical education, pedagogy, essence, Armenian Christian.

\section{The research purposes are}

1. tointroduce the concept of upbringing and its features.

2. to emphasize the role of Armenian sensei in the upbringing of Armenian athletes.

\section{The research issues are}

1. to educate Armenian karatekastaking into account the features of nationalidentity.

2. to reveal the impossibility of perceiving the spiritual essence of karate with the Armenian national consciousness.

3. toaddress the educational activity of Armenian senseis towards the Armenian system ofvalues.

\section{Research methods and organization.}

1. Study of literary sources,

2. Combination and systematization of different ideas,

3. Generalization andanalysis of the problem under consideration.

Analysis of research results. Teaching is a pedagogical purposeful process based on the interaction between teachers and students, it leads to upbringing, educating and developing an individual [2].

I am deeply convinced that upbringing has three levels: public, private and religious. The first is expressed by the norms accepted in the given society, the second- by individual issues, and the third - by faith. Therefore, upbringing is assimilated at the level of habits, beliefs and spirituality.My years of coaching and pedagogical work experience allows me to distinguish two types of upbringing: passive (expressed only in the views and beliefs of a person) and active (expressed in action). To my mind pedagogical requirements though the educational process should be 
clearly steady, while the results - possibly variable, the duration of which is conditioned by the given problem and beliefs.

Conclusion. On the basis of historical-philosophical analyses I drew the following conclusions:

upbringing trough traditional karate underpins physical and spiritual improvement in connection with particular philosophical views. The more a person, in this case an Armenian athlete, is involved in these systems, the deeper he plunges into its philosophical worldview. Consequently, it is important to re-interpret the teacher's (sensei) role in karate practicing and training classes, it will be achieved through our national value-based educational approaches, shapingthe national identity of Armenian athletesin anewlight. In this respect, knowledge plays a huge cognitive role in the spiritual development of a person bringing into light the previously unknown and unexplained, which in his turn is essentially vital for Armenian karatekas.

\section{ВОСПИТАНИЕ И КАРАТЕ}

Доцент А.С.Караханян

Государственный институт физической культуры и спорта Армении, Ереван, Армения

\section{PEЗЮME}

Ключевые слова:армянский сенсей, воспитание, идентичность, знание, физическое воспитание, педагогика, сущность, армянский христианин.

\section{Цель исследования:}

1. представить концепцию воспитания, ее особенности.

2. использовать роль армянского сенсея в воспитании армянских спортсменов.

\section{Проблема и задачи исследования:}

1. воспитать армянских каратистов, учитывая особенности образа национального самосознания.

2. раскрыть невозможность восприятия духовного воспитания карате армянским национальным самосознанием.

3. направить воспитательную деятельность армянских сенсеев на армянскую систему ценностей. 


\section{Методы исследования и организация:}

1. изучение литературны хисточников,

2. сочетаниеи систематизирование разных идей,

3. обобщение и анализ исследуемой проблемы.

Анализ результатов исследования. Обучение-педагогический целенаправленный процесс взаимодействия учителя и учеников, в ходе которого происходит образование, воспитание и развитие человека[2]. Мы глубоко убеждены, что воспитание имеет три уровня: общественный, частный и религиозный. Первый выражается нормами, принятыми в данном обществе, второй- индивидуальными вопросами, а третий - верой. Следовательно, воспитание осваивается в уме на уровне привычек, убеждений и духовности. В результате многолетнего опыта тренерской и педагогической работы мы пришли к выводу, что воспитание может быть пассивным (выражающимся только во взглядахи убеждениях человека) и иактивным (выражающимся в действии). Считаем, что в образовательном процессе педагогические требования должны быть устойчивыми, а результаты вариативными, продолжительность которых обусловлена данной проблемой и убеждениями.

Заключение. Наши исторические и философские анализы позволяют сделать следующие выводы: традиционное воспитание карате направлено на физическое и духовное совершенствование, выражающееся в карате с особыми философскими взглядами. Чем больше человек,в данном случае армянский спортсмен вовлечен в эти системы, тем глубже он погружается в свое философское мировоззрение. Следовательно очень важно переосмыслить роль учителя (сенсея) в контексте эффективного обучения карате, что будет обусловлено нашими национальными образовательными подходами, основанными на ценностях, очерчивающими новые высоты реконструкции нацональной идентичности армянских спортсменов. В этом плане знание играет большую познавательную роль в умственном развитии человека, в жизни армянских каратистов, освещая ранее неизвестное и необяснимое.

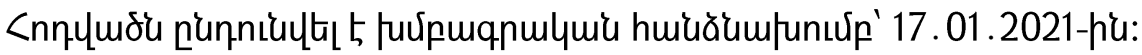

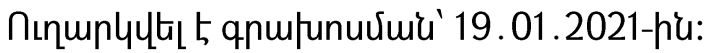


DOI: 10.53068/25792997-2021.1.3-109

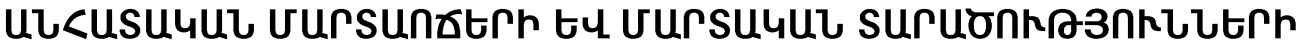

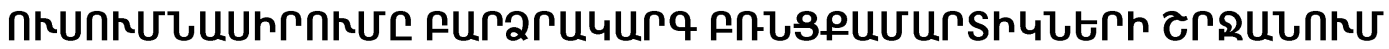

Uupuytiny U. U. Utıpnúujui, upn\$tiunn U. ก. Rwiptyut,

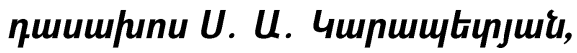

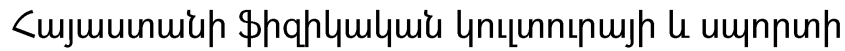

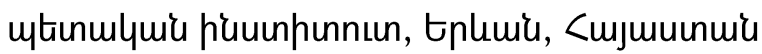
E.mail: Arturmelkumyan2020@sportedu.am,

Ashotdanielyan2020@sportedu.am, Serobkarapetyan2020@sportedu.am

Unwagpujhis puntip: fnugpu-

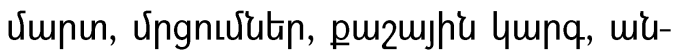

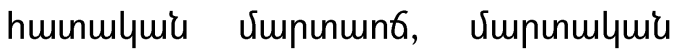

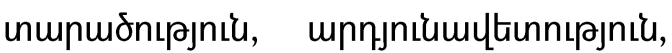
hunpuiuml:

Stunuqnunnıرuis upnpulquínt-

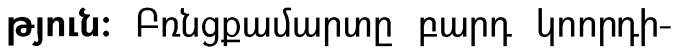
umghnu, mpuqunı

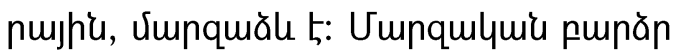

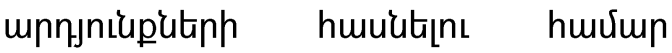
duruiumlymlyhg pnugpurumennuर zuin yuplunn tiu ư zunp qnnonulutin, nnnup

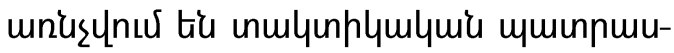
unnıpjuiun: Cuin pnugpurumpnn Guiumsчuภ vimuiumqtinitiph [1, 3, 4, 5]' Jumqhlutinn npizqnus vtiumulununnu tiu

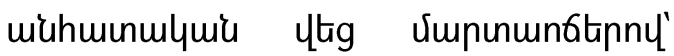

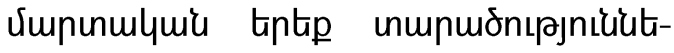

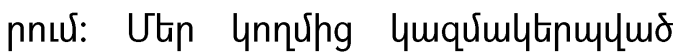

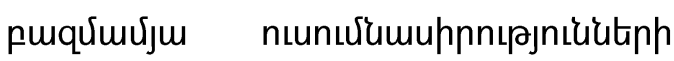

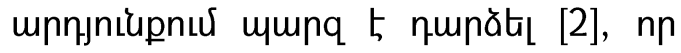

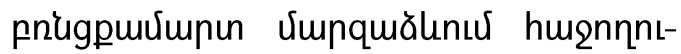

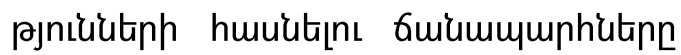

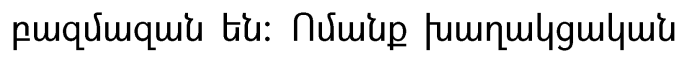

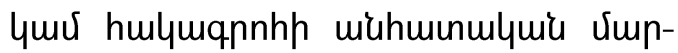

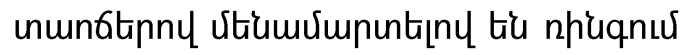

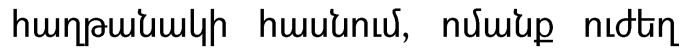

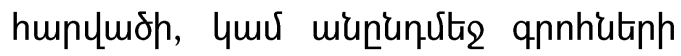
Jumununfitinny stiumudununtind, hul

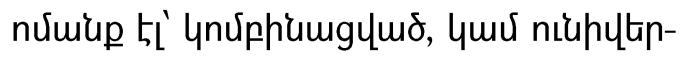
uml Umpununfitinnl: Uunqhliutinh up

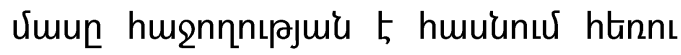

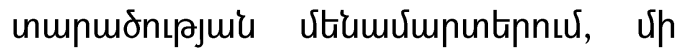

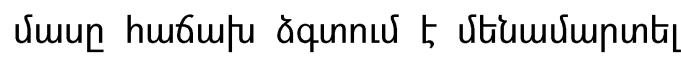

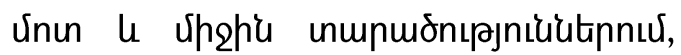

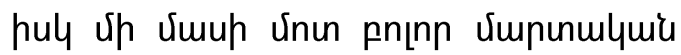

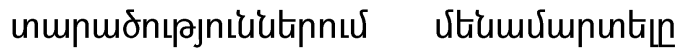

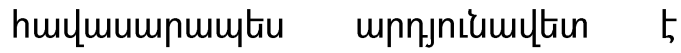

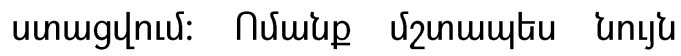

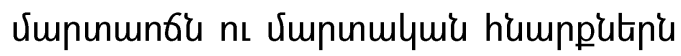




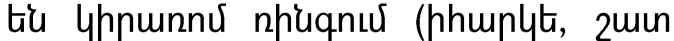

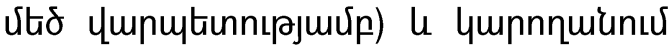
tiu huennnıpjniuitin qnuiugta, hul nưulup th unmpeten ungulyhguteph htien vitumúupuntshu unupptip vimpununfitp

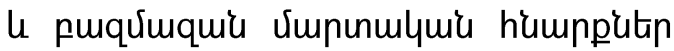

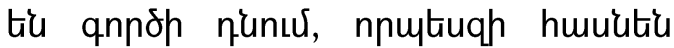
hųnпnıpjnıüutiph:

Utip ynnưhg hnulymiumgymo ung-

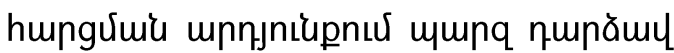
[2], np 《 vimulumqtinutiph up vimup

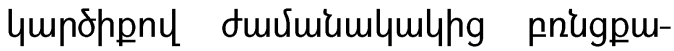

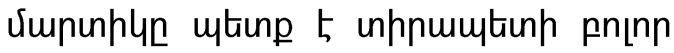

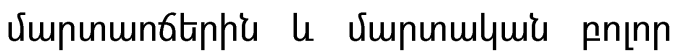

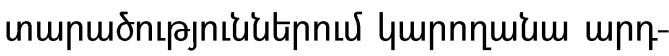

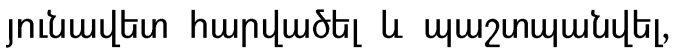

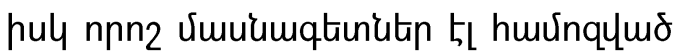
tiu, nn punănulympr veunqhlüutnn yunnn tiu vity vimununfny le ns hupniuin unthuahlymlyuir qhimiungny huu-

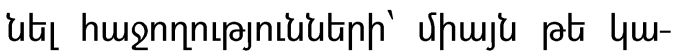
unuptiu mju, huse hntiug unun muptiph uunmgynuर: Uh 2mpp vimuamqtinutin

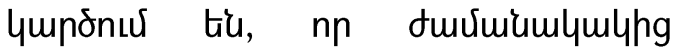

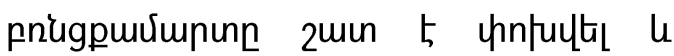

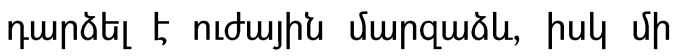

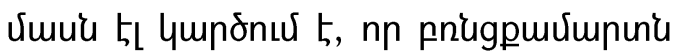

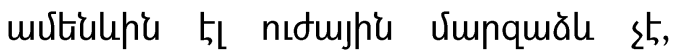
ujuuntin yuplunn tiu vinph Glyniunıpnnun, zundnưutiph 62qnunnıpniư nı upuqnıрjnı́un:
Utip funphis huvinquiurup, nputiuqh

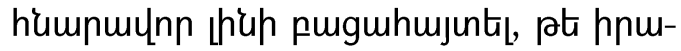

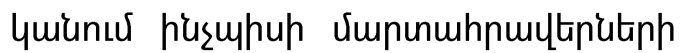
unme tú quiuqumo $p t^{\prime}$ pnigpurumpunplutitnn, la pt' unuing Vumphs'utinn,

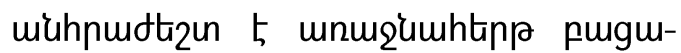
hujunt, pt p'us 5 ptןunnnuर्u duviuium-

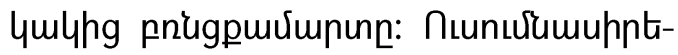

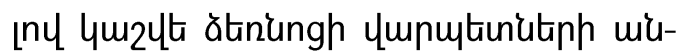
huunulyuir sumununfitinn 4 unuing

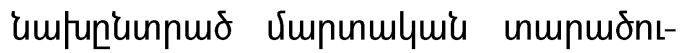

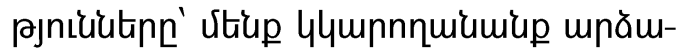

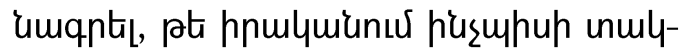
inplumlymír umunnuuunnıpnicu niutgnn

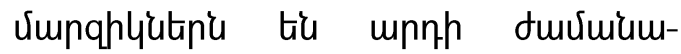

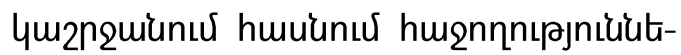
nh, lu húsuphup epnunnfunıpniuzutan

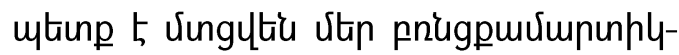

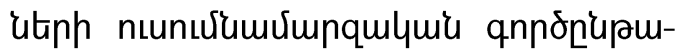
gnuर, nnutiuqh unuiup ympnnuiumis Jun2nn uhquqqujhe ungnuरutinnuर umuinumunn ungmiumlymjhr untnitn qumultal:

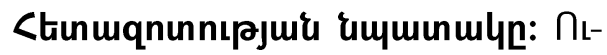
unudumunntal punănulyung pnigpuvimponplyatiph muhmonmlymís vimpnu-

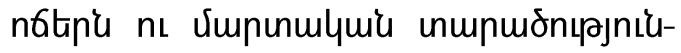

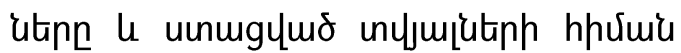

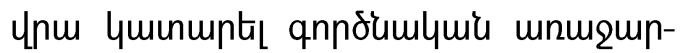

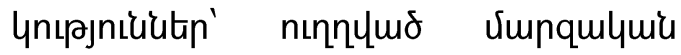
qnnonupmgh punt_uulumun: 
tounhnutnn: Umuunulyh huu-

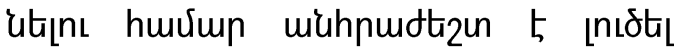
htionljuı füunhnitinn.

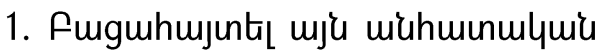
vimpumantinn, nnnug vpengny duxumumlyming pnigpurumpunnu jun2nn

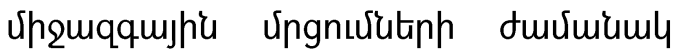
unmults hufuru huennnıpjnıüutp tiu qpuiugnuर pnugpuuxupunhlutunn:

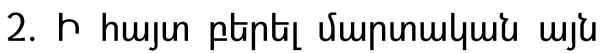

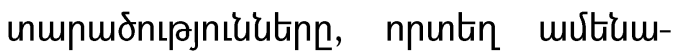

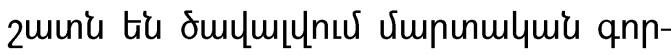

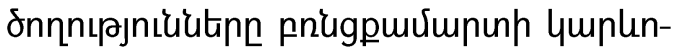

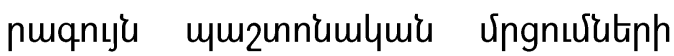
duviuiuml:

3. 4mununtal unmqunlynıpniukitn pnugpurumpun verumqtinutiph's'

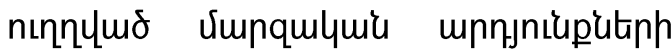
purtịuquimin:

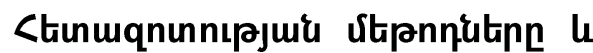

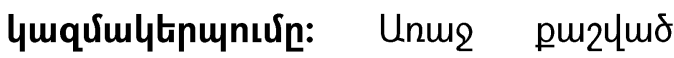

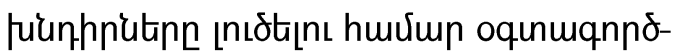

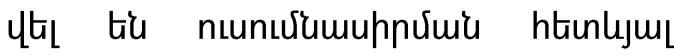

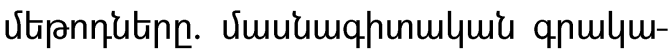

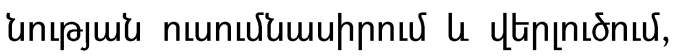

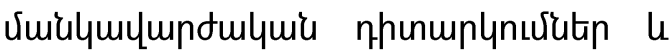
qnunnurutin, ungulygulyuis qnnont-

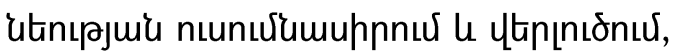

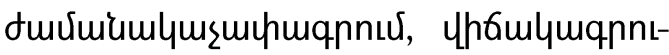
Pjnilu:

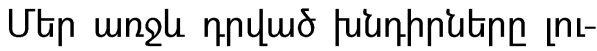

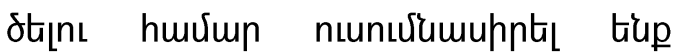

2008p. Othưuhulquí fumntiph, 2013, 2015 l 2019pp. innuxumpnlyuing m2-

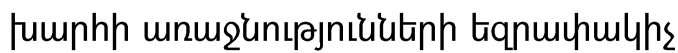
39 vtiumulununtp: Cuun nnutiutiph' nnn$2^{\mathrm{G}}$ L tiup, pt jnıpupuius

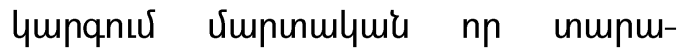

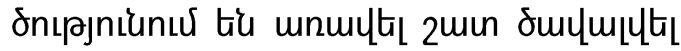
Uupunulyuiu qnnonnnıрjnilukitinn:

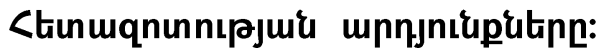

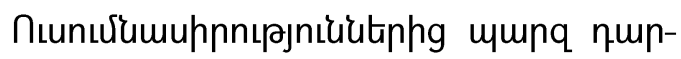
ămu, nn 2008p. Ophưuhmumír stuरupnuiutinh 4-n (36,3\%) vtiumurumunt

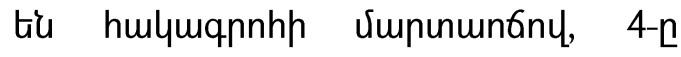
$(36,3 \%)^{\prime}$ nıdtn hunцmon Jupununfiny, 2-n (18,2\%)' niuhultnumu Jupununtiny, hul 1-n (9,1\%)' ynúphiumgymo le nıdtin hunumón vimpununfitinny: hus ytanu-

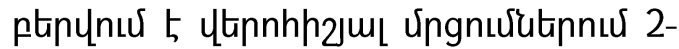

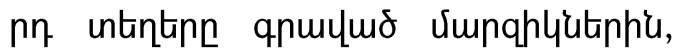

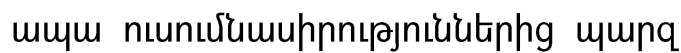

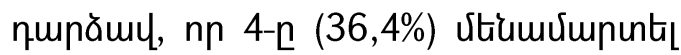
tiu nıttin hupluroh vimpununfny, 3-n (27.3\%)' hulymqnnhp Jupununtiny, 2-n $(18,2 \%)^{\prime}$ hulymqpnhp le nıdtin hupluof Jupununfitipny, 1-n (9,1\%)' Jumnulyguymí u hulquqnnhp vimpununfitipny, pul 1-n (9,1\%)' ynúphiumgymo le nıdtin hunцmof Umpununfilinnl:

Cuin 2013p. unquiviunnlyuing $\mathrm{m}_{2}$

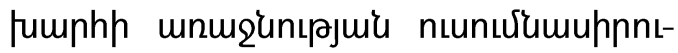

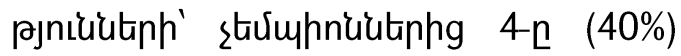

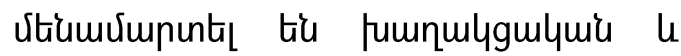


hulymqnnhp Umpununtitinny, 2-n (20\%)'

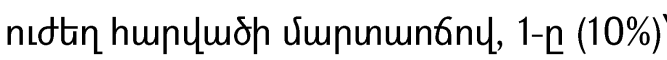

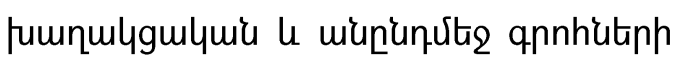
vimpununfitinny, 1-n (10\%)' Jumnulgguquǐ vimpununfny, 1-n (10\%)' ynúphiumgymo vimpununfny, pul 1-n (10\%)'

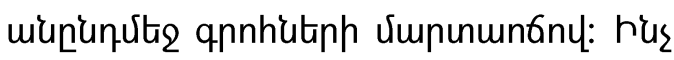

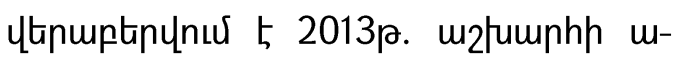

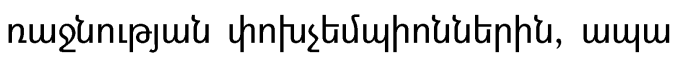

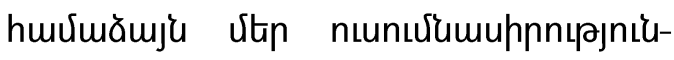
'utph' unuing 30\%-n vitumudununta b

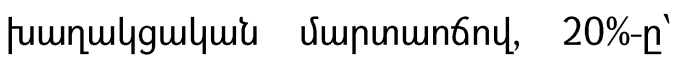
fumnulgmulumi $\mathrm{u}$ hulymqnnhp vimpnunftinny, 20\%-n' miun'unutis qnnhutiph úmunun6ny, 20\%-n' jumnulygulymí $\mathrm{l}$

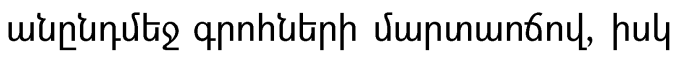

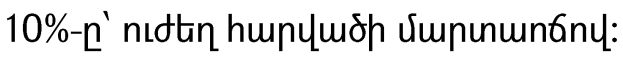

2015p. unnuर्umpnlyuing m2fumph

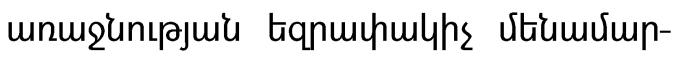

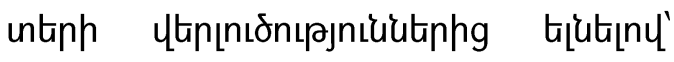

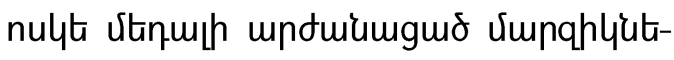
nhg 3-n (30\%) vthumumpuntal tiu fum-

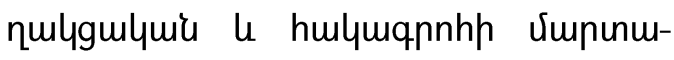
nfitinnl, 2-n (20\%)' nıttin hunumó umpunun6ny, 1-n (10\%)' jumnulygulymir

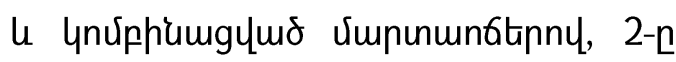
(20\%)' fumnulygulymu vimunumbny, 1-n (10\%)' ynu्uphumgymo u hulquqpnhp vumununfitinny, 1-n (10\%)' miun'unutis qpnhutiph Uumununfny: his ytheu-

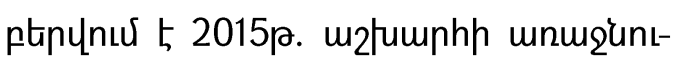

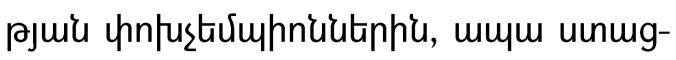

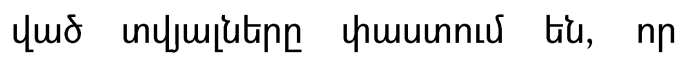

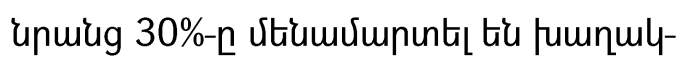
gulquir le hulquqnnhp vimpnunfitipny, 30\%-n' hulymqnnhh vimununfiny, 20\%n' nıdtin humymof Jumunun6ny, 10\%-n'

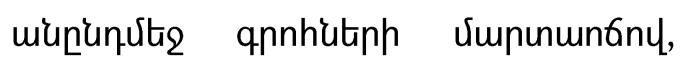
10\%-n' ynúphüugy uro vimunun6ny:

Cuin 2019p. unquर्umntyming m2-

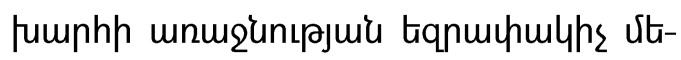

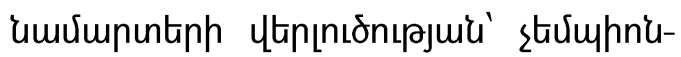
utiph 2-n (25\%) vtiumulununta tiu fumnulggulquis vimpununfny, 2-n (25\%)' ntdtin humyuroh Jumunumbny, 1-n (12,5\%)'

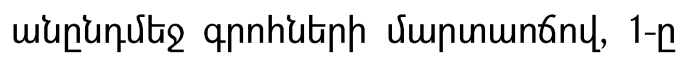

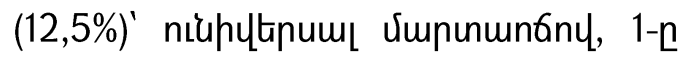

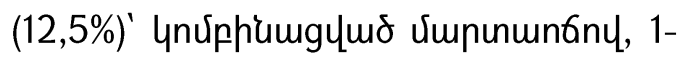
n (12,5\%)' fumpulggulymir u hulymqunhh vunununflipny: hus ytupupten-

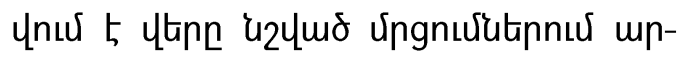

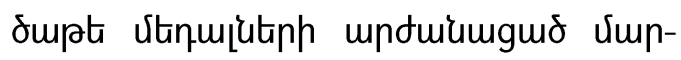

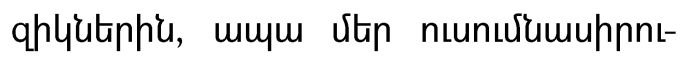
Pjniüutnhng umpqutag, nn unwiug 25\%-n

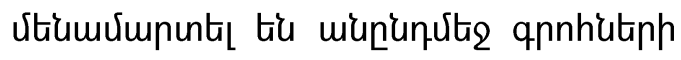
Jupunun6ny, 12,5\%-n' jumnulygulymu Jupununfiny, 12,5\%-n' nıttin hunymô Jupunun6ny, 12,5\%-n' jumnulygulymu nL miununutis qpnhitiph úmpununfiknny, 12,5\%-n' hulquqpnhp nı miun'unutits qunhiutph Uumununftinny, 12,5\%-n' nt-

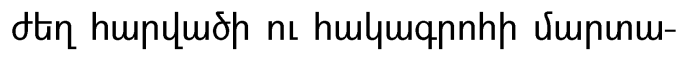
nfiknny, 12,5\%-n' hulquqnnhp vimpunun6nu: 


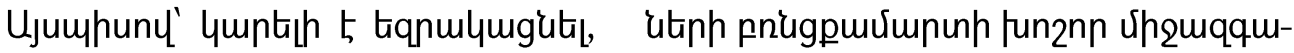

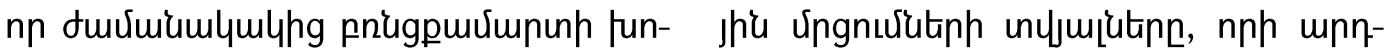

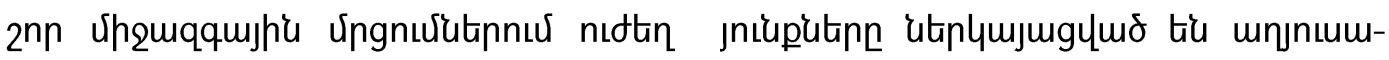

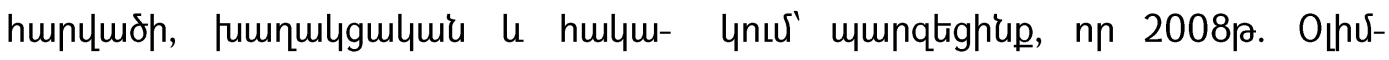

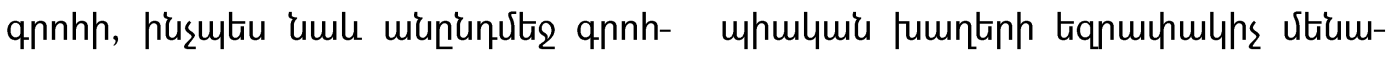

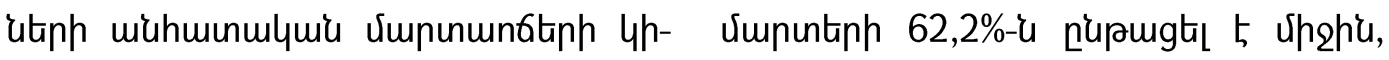

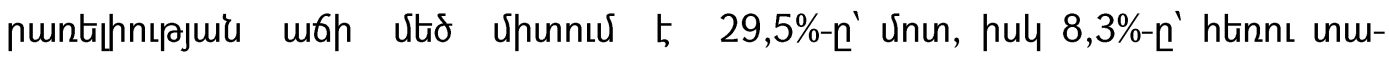
ülumununu:

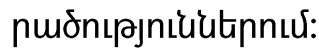

nuunưumuhptiny ytanghu 11 ununh-

Unjnıuml 1

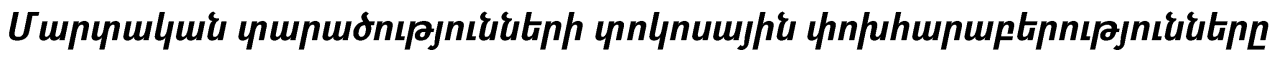

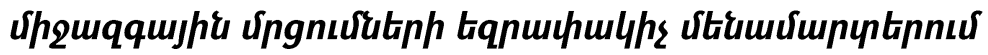

\begin{tabular}{|c|c|c|c|c|c|c|c|}
\hline \multicolumn{4}{|c|}{ 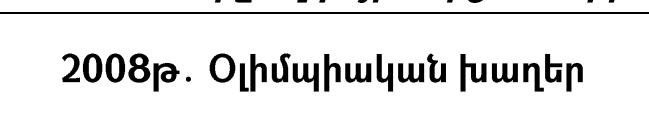 } & \multicolumn{4}{|c|}{ 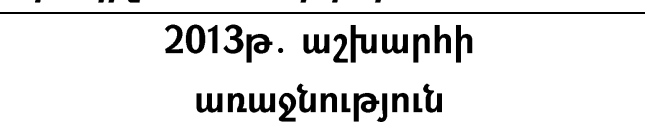 } \\
\hline \multirow{2}{*}{$\begin{array}{l}\rho_{u 2} . \\
\text { yunq }\end{array}$} & \multicolumn{3}{|c|}{ 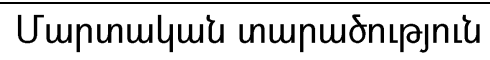 } & \multirow{2}{*}{$\begin{array}{l}\text { Pun. } \\
\text { yming }\end{array}$} & \multicolumn{3}{|c|}{ 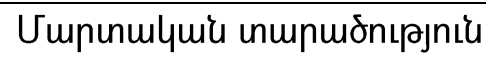 } \\
\hline & <tinnı \% & $\begin{array}{c}\text { Uhehu } \\
\%\end{array}$ & $\begin{array}{c}\text { Unun } \\
\%\end{array}$ & & $\begin{array}{l}\text { CGnnı } \\
\%\end{array}$ & $\begin{array}{c}\text { Uh2hu } \\
\%\end{array}$ & $\begin{array}{c}\text { Unun } \\
\%\end{array}$ \\
\hline 48 & 17.2 & 57.8 & 25 & 49 & 91.1 & 8.3 & 0.6 \\
\hline 51 & 8.2 & 81 & 10.8 & 52 & 82 & 13.8 & 4.2 \\
\hline 54 & 17.8 & 59.7 & 22.5 & 56 & 15.9 & 47.5 & 36.6 \\
\hline 57 & 5.5 & 58.5 & 36 & 60 & 33.8 & 53.3 & 12.9 \\
\hline 60 & 6.4 & 55.4 & 38.1 & 64 & 33 & 50 & 17 \\
\hline 64 & 5.1 & 48.3 & 46.6 & 69 & 42.7 & 44 & 13.3 \\
\hline 69 & 2.6 & 73.5 & 23.9 & 75 & 27 & 43.3 & 29.7 \\
\hline 75 & 12.6 & 40.6 & 46.8 & 81 & 79.6 & 13.8 & 6.6 \\
\hline 81 & 5.5 & 75.8 & 18.7 & 91 & 42.4 & 30 & 27.6 \\
\hline 91 & 4.7 & 59.7 & 35.6 & +91 & 58.4 & 33.3 & 8.3 \\
\hline+91 & 11.2 & 68.8 & 20 & - & - & - & - \\
\hline Cun. & 8.3 & 62.2 & 29.5 & Cun. & 50.3 & 34 & 15.6 \\
\hline
\end{tabular}




\section{Unjniuml 1-p 2upnifumlynıpjni\&}

\begin{tabular}{|c|c|c|c|c|c|c|c|}
\hline \multicolumn{4}{|c|}{ 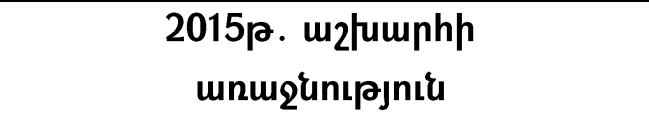 } & \multicolumn{4}{|c|}{ 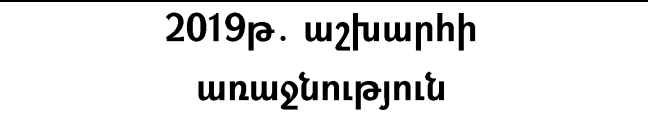 } \\
\hline \multirow{2}{*}{$\begin{array}{l}\text { fur. } \\
\text { yunq }\end{array}$} & \multicolumn{3}{|c|}{ 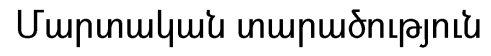 } & \multirow{2}{*}{$\begin{array}{l}\text { f } \mathrm{m}_{2} \text {. } \\
\text { yminq }\end{array}$} & \multicolumn{3}{|c|}{ 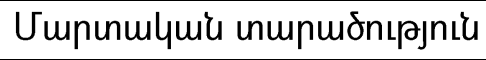 } \\
\hline & $\begin{array}{l}\text { Ctinnt } \\
\%\end{array}$ & $\begin{array}{l}\text { Uhohu } \\
\%\end{array}$ & $\begin{array}{c}\text { Unun } \\
\%\end{array}$ & & $\begin{array}{l}\text { Ctunnt } \\
\%\end{array}$ & $\begin{array}{l}\text { Uhehiu } \\
\%\end{array}$ & $\begin{array}{c}\text { Unun } \\
\%\end{array}$ \\
\hline 49 & 23.7 & 46.2 & 30.1 & 52 & 50 & 36.6 & 13.4 \\
\hline 52 & 44 & 46 & 10 & 57 & 32.5 & 27.5 & 40 \\
\hline 56 & 16.5 & 48.7 & 34.8 & 63 & 68.3 & 23.3 & 8.3 \\
\hline 60 & 45.3 & 47.6 & 7.1 & 69 & 30 & 40 & 30 \\
\hline 64 & 20.9 & 57.7 & 21.4 & 75 & 46.6 & 30 & 23.3 \\
\hline 69 & 32.7 & 58.3 & 9 & 81 & 23.3 & 33.3 & 43.3 \\
\hline 75 & 19.6 & 61.4 & 19 & 91 & 66.7 & 25 & 8.3 \\
\hline 81 & 23 & 62.2 & 14.8 & +91 & 48.3 & 38.3 & 13.3 \\
\hline 91 & 20.3 & 65 & 14.7 & - & - & - & - \\
\hline+91 & 18.1 & 61.4 & 20.5 & - & - & - & - \\
\hline - & - & - & - & - & - & - & - \\
\hline cun. & 25.7 & 55.8 & 18.5 & Cun. & 45.7 & 31.7 & 22.5 \\
\hline
\end{tabular}

2013p. unnuxumpnlyuing m2łumph

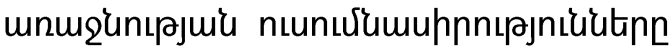
gnyg unytighiu, nn tiqnumulyhs vitumUumuntiph 50,3\%-u nupugta 5 htnns, 34\%-n' Uheh'u, hul 15,6\%-n' Unun unupu-

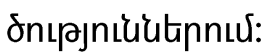

2015p. unnuर्umntyuiug pnigpu-

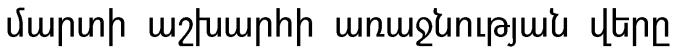

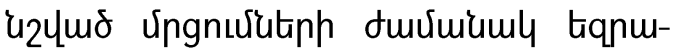

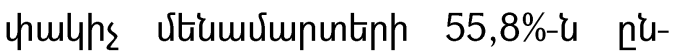
pugta tiu uhehu, 25,7\%-n' hanns, hul

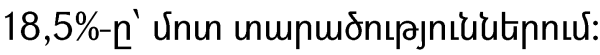

2019p. pnuggpuưununh unnuर्umpn-

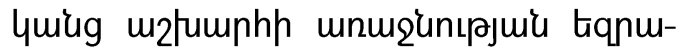

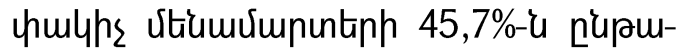
gta tiu htnns, 31,7\%-n' uhehu, hule

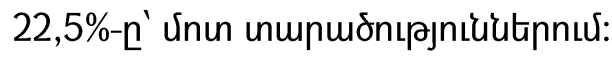

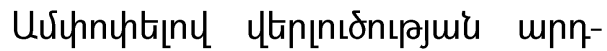

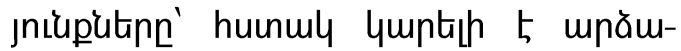

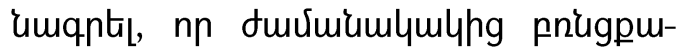

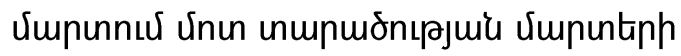

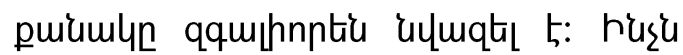

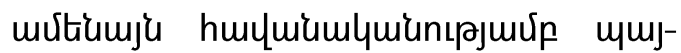

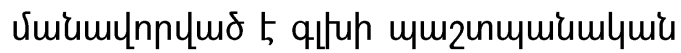




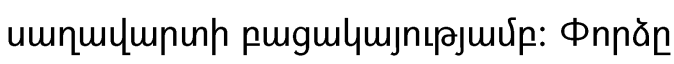

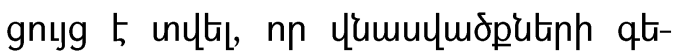

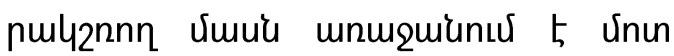
unupmonıpjuí vimpuntiph duर्uiumul:

tqnulqugnıpjnı: 2008-2019 рр. pnugpuiviunun fun2np unguqqujhí ungnufutiph tqnumbulyhs vtiumulument-

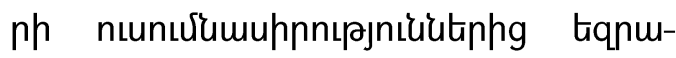
huiuqtightup.

1. U2łumphh nıdtnuqnuju pniggpuvimpunhliutph qtipuly2nnn viuun 4hnunta 5 nıdtin hupludo vimpnumb (23\%), fumnulgmulumi $\mathrm{u}$ hulymqnnhp vimpnunfitp (17,9\%), hulymqnnhp Jupununt $(14,1 \%)$, fumnulggulymir vimpinunt

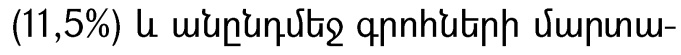
n6 $(10,2 \%)$ :

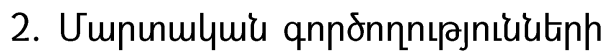
46\%-u n'upungta t5 uhgh'u, 32,5\%-n' ht-

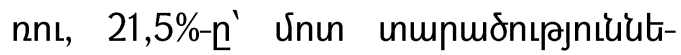
pnux:

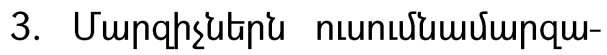

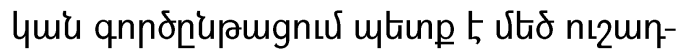

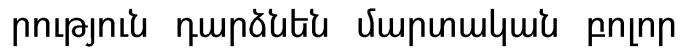

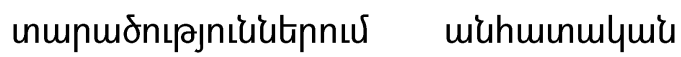

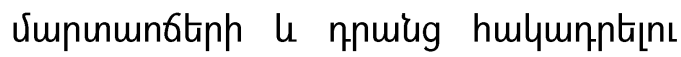

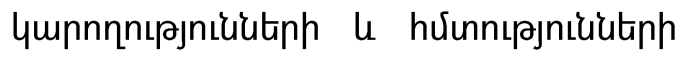

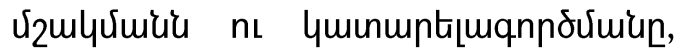
Juu'umunnmutiu' nıttin hupludo, fum-

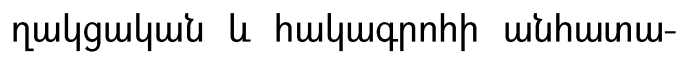
yuiu vimnumantinpis:

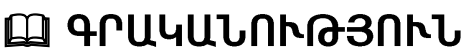

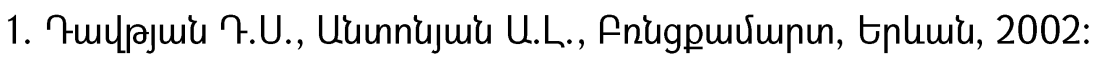

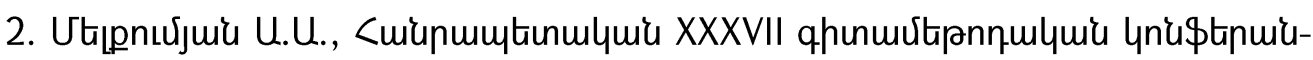
up ujnıptp, ঢplumi, 2010:

3. Ширяев, Бокс учителю и ученику, Санкт-Петербург, 2007:

4. Дектярев И.П., Бокс, Учебник для институтов физкультуры, М.: ФиС., 1979:

5. Буличев А.Н., Бокс, М. Фис. 1965. 


\title{
RESEARCH OF INDIVIDUAL FIGHTING STYLES AND COMBAT DISTANCES OF HIGHLY QUALIFIED BOXERS
}

\author{
Assistant A.A.Melqumyan, \\ PhD of Pedagogy, Associate Professor A.R.Danielyan, \\ Lecturer S.A.Karapetyan \\ Armenian State Institute of Physical Culture \\ and Sport Yerevan, Armenia
}

\section{SUMMARY}

Keywords: Boxing, competitions, weight categories, individual fighting style, combat distance, efficiency, victory.

The research purpose is to reveal the characteristics of individual fighting styles and combat distances among highly qualified boxers and draw practical recommendations based on the data collected.

Research issues comprise:

1. disclosure of the most effective individual fighting styles which lead majority of boxers to success at major international boxing competitions.

2. determination of combat distances when operating fights most frequently during the most important official boxing competitions.

3. development of recommendations for boxing specialists to help achieve higher sports results.

Research methods and organization. The following research methods were applied to solve the set tasks: study and analysis of specialized scientific-methodical literature, pedagogical observations and records, research and analysis of competitive activity, timekeeping, statistics. The final 39 boxing matches of the Olympic Games on 2008 and the Men's World Championships on 2013, 2015, 2019 were analyzed.

Analysis of the results obtained. As a result of the study, it turned out that at the largest international competitions there is a tendency to conduct fights in various manners or styles: attacking, counterattack, defensive. The result analysis shows that at the 2008 Olympic Games and the 2015 World Championships fights between boxers were held at medium distance, while at the 2013 and 2019 World Championships, the final fights were mainly held at long distance. In addition, it was revealed that the combat distance at close range was significantly reduced. 
Conclusions. By summarizing the obtained data we can state that

1. the vast majority of world-class boxers used strong kick-fighting style $(23 \%)$, playing-counterattack combat style (17.9\%), counterattack fighting style (14.1\%), playing fighting style (11.5\%) and continuous attack fighting style (10, 2\%).

2. the strongest boxers in the world carried out the final fights in duels, at an average combat distance (46\%), at a long distance (32.5\%) and close (21.5\%).

3 . in the training process of boxers, coaches are expected to pay more attention to the development and improvement of individual fighting manners at all distances, enhancing their abilities and skills to counteract styles such as attacking, counterattacking and playing.

\section{ИССЛЕДОВАНИЕ ИНДИВИДУАЛЬНЫХ МАНЕР ВЕДЕНИЯ БОЯ И БОЕВЫХ ДИСТАНЦИЙ СРЕДИ ВЫСОКОКВАЛИФИЦИРОВАННЫХ БОКСЕРОВ}

Ассистент Мелкумян А.А., профессор Даниелян А.P., преподаватель Карапетян С.A.

Государственный институт физической культуры и спорта Армении, Ереван, Армения

\section{PEЗЮME}

Ключевые слова: бокс, соревнования, весовые категории, индивидуальная манера ведения боя, боевая дистанция, эффективность, победа.

Цель исследования: выявить особенности индивидуальных манер ведения боя и боевых дистанций у боксеров высокой квалификации и на основе полученных результатов предложить практические рекомендации, направленные на улучшение тренировочного процесса.

\section{Задачи исследования:}

1. выявить наиболее эфрфективные манеры ведения боя, благодаря которым боксеры чаще всего добиваются успеха на крупных международных соревнованиях по боксу.

2. определить боевые дистанции, на которых чаще всего ведутся боевые действия во время официальных соревнований по боксу; 
3. разработать рекомендации для специалистов по боксу, способствующие достижению спортивных результатов.

Методы и организация исследования. Для решения поставленых задач использовались следующие методы исследования: изучение и анализ специальной научно-методической литературы, педагогические наблюдения и записи, изучение и анализ соревновательной деятельности, хронометраж, математическая статистика. Проанализированы 39 финальных боксерских поединков среди мужчин на Олимпийских играх 2008 года, на чемпионатах мира 2013, 2015, 2019 гг.

Анализ полученных результатов. В результате проведенного исследования выяснилось, что на крупнейших международных соревнованиях проявляется тенденция ведения боя в различных манерах (под стилях): силовой, игровой, темповой (контратакующий и непрерывных атак). Анализ полученных результатов показывает, что на Олимпийских играх 2008 года и чемпионате мира 2015г. поединки между боксерами проводились на средней дистанции, а на чемпионатах мира 2013 и 2019 годов финальные поединки в основном проводились на дальней боевой дистанции. Кроме того выявлено, что боевые дистанция на ближнем расстоянии значительно сократились.

Выводы. Обобщая полученные результаты, можно утверждать, что

1. подавляющее большинство боксеров мирового уровня использовали силовую /23\%/, игровую (контратакующий стиль) /17.9\%/, контратакующую /14.1\%/, игровую /11.5\%/, темповую (стиль непрерывных атак) /10.2\%/ манеру ведения боя.

2. Сильнейшие боксеры мира проводили финальные боевые действия в поединках на средней боевой дистанции (46\%), на дальней (32,5\%) и ближней - $(21,5 \%)$.

В тренировочном процессе боксеров, тренерам следует уделять большое внимание развитию и совершенствовнию индивидуальных манер ведения боя на всех дистанциях, а также способностей и навыков противодействовать им, в частности силовым, контратакующим и игровым манерам.

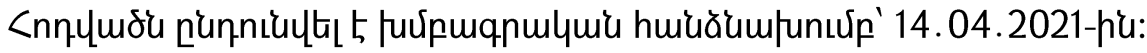

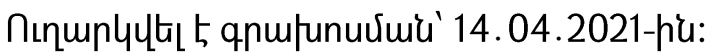


DOI: 10.53068/25792997-2021.1.3-119

ОПРЕДЕЛЕНИЕ ОПТИМАЛЬНОГО ВРЕМЕНИ ПРИЦЕЛИВАНИЯ ИЗ ПНЕВМАТИЧЕСКОЙ ВИНТОВКИ

\author{
Профессор В. М. Авагимянц \\ Ереванский государственный университет, \\ Ереван, Армения \\ E.mail: vladimir.avagimyants@gmail.com
}

Ключевые слова: статическая устойчивость, самоконтроль, дыхание, определение оптимального времени прицеливания.

Актуальность исследования. В течение последних 60-70 лет во многих странах в сорере физического воспитания средних и высших учебных заведений прочно утвердился принцип прикладности, отражающий объективную связь физического воспитания с трудовой и оборонной деятельностью общества [ 4 ].

Международная организация $\mathrm{OOH}$ рассматривает спорт как средство, которому отведена важная роль в охране здоровья, в нравственном, культурном и фризическом воспитании общества, укреплении мира и международного взаимопонимания [ 7 ].

Одним из приоритетных направлений физического воспитания во всех развитых странах мира является пулевая стрельба. Рост массовости пулевой стрельбы положительно влияет на подготовку молодёжи к службе в армии. Не всем, кто занимается этим видом спорта, хватает умения, терпения и таланта войти в большой спорт. Но всем понадобятся те качества, которые развивает пулевая стрельба: трудолюбие, воля, выносливость, зоркий глаз, предельная собранность [ 8 ].

По данным литературы первые стрелковые соревнования из огнестрельного оружия были проведены в Швейцарии в 1452 году. Соревнования по стрельбе из винтовки и пистолета были включены в программу современных Олимпийских игр в 1896 году.

Одним из инициаторов и вдохновителей включения в программу Олимпийских игр соревнований по пулевой стрельбе был Пьер де Кубертен. Сам он был семикратным чемпионом Франции по стрельбе из пистолета.

Пневматические ружья впервые появились в Германии в XVII столетии. 
В 1790 году в пограничных войсках Австрии было принято на вооружение магазинное пневматическое ружьё, которое давало возможность произвести подряд 20 выстрелов.

В спортивных целях пневматическое оружие стало использоваться только в конце XIX века сначала в Америке, а затем в Англии.

Стрельба из пневматического оружия на дистанции 10 м пользуется большой популярностью во многих странах мира. Это объясняется тем, что нет необходимости В капитальном строительстве тиров. Для соревнований можно использовать любые спортивные залы или иные помещения. Кроме того, пневматическое оружие стоит гораздо дешевле, чем малокалиберное или крупнокалиберное.

На 39-ом чемпионате Мира по пулевой стрельбе, который проходил в Висбадене (ФРГ) 14-24 июля 1966 года, в общую программу была включена стрельба из пневматической винтовки (дистанция 10 м 40 выстрелов).

Начиная с 1971 года ежегодно проводятся чемпионаты Европы по стрельбе из пневматической винтовки и пистолета по мишени с чёрным кругом среди мужчин, женщин и юниоров.

С 1984 года в Олимпийскую программу была включена стрельба из пневматического оружия среди мужчин и среди женщин [ 5 ] .

Одним из наиболее трудных упражнений в стрельбе из винтовки является стрельба из положения стоя. При стрельбе стоя все точки опоры (стрелок-оружие) доведены до минимума.

Правильная поза стрелка в положении стоя обеспечивает статическую устойчивость, что является важной и неотъемлемой частью меткой стрельбы. Положение тела стрелка должно быть достаточно устойчивым, чтобы не приходилось затрачивать лишнее усилие мышц на удержание равновесия всей системы (стрелок-оружие).

Поэтому детальный анализ всех факторов, способных изменить эту устойчивость в том или ином направлении, представляет сугубо практический интерес. Для равновесия тела необходимо такое сочетание и направление приложенных сил, при котором геометрические суммы веса оружия и мышечных усилий, приложенных на его удержание, будут равны нулю. Одновременное управление стабиль- 
ностью мышечных усилий многозвеньевой системы тела с равномерным удержанием оружия связано с большими трудностями.

Сложности эти заключаются в необходимости непрерывной и согласованной деятельности многих рецепторов: мышечно-сухожильных, кожных, зрительных и др., информация от которых непрерывно поступает в центральную нервную систему (ЦНС).

Деятельность ЦНС при малейшем отклонении тела от положения равновесия немедленно приводит в действие антигравитационные рефлексы, которые быстро восстанавливают утраченную устойчивость. Эта сложная система управления именуется академиком Бехтеревым “статической координацией”.

При исследовании было выявлено, что показатели среднего значения времени, во время которого происходит смещение оружия при выстреле и возвращение его в исходное положение, значительно варьируют в зависимости от квалификации стрелков: MCMK-0,14c, MC-0,18c, KMC и । разряд-0,20с [ 3 ].

Устойчивость оружия является одним из основных элементов техники стрельбы во всех упражнениях. Извест- но, что в результате выстрела ощущается воздействие оружия на руку и туловище стрелка, что приводит к смещению оружия в пространстве. Величина смещения оружия В пространстве обусловлена конструкцией оружия и способностью стрелка удерживать его в момент выстрела.

Уменьшение смещения оружия может произойти за счет большего напряжения мышц стрелка в позе изготовки. Но слишком большое напряжение мышц может ухудшить сложно координированную работу стрелка. Стрелку просто необходимо иметь критерий выбора оптимального распределения усилий мышц. Практика показала, что уменьшение величины смещения оружия приводит к уменьшению рассеивания пробоин и повышает результат стрельбы.

Нужно отметить, что время смещения и возврата оружия после выстрела весьма изменчиво и зависит от степени жесткости изготовки и ее кинематики, величины возбуждения и характера предстартового состояния спортсмена.

Высококвалифицированным стрелкам требуется значительно меньше времени, чтобы удержать оружие с наименьшим его смещением в про- 
странстве в момент выстрела. Наименьший разброс величин времени выстрела у высококвалифицированных стрелков свидетельствует о стабильности мышечных усилий и наличии автоматизма в действиях стрелков.

Стабильность мышечных усилий характеризует степень жесткости изготовки стрелка, от которой зависит расположение пробоин на мишени, а также определяет время, затраченное на смещение оружия под воздействием отдачи, что может вызвать уменьшение времени прицеливания.

Особую ценность для повышения качества подготовки высоко квалифицированных спортсменов представляют технические средства срочной информации. На этой основе В.С. Фарфелем был сорормулирован методический принцип срочной информации [1].

В стрелковом спорте информация от всех применяемых технических средств (лазерные стрелковые тренажёры, электронные экраны и т.д.) подается непосредственно после окончания выстрела. На основе срочной информации спортсмен приобретает способность регулировать движение, время, вносить необходимую коррекцию, исправлять ошибки и совершенствовать технику.
Нет сомнения, что дальнейшее развитие методики тренировки квалифицированных стрелков должно идти по пути внедрения технических средств с последующим их совершенствованием, вплоть до автоматизированных систем управления на базе электроники.

Изучение вопроса обеспечения техническими средствами тренировочного процесса в стрелковом спорте позволило выработать определенные требования к их подбору (использование стандартных регистрирующих приборов и датчиков, малогабаритность аппаратуры, пригодность ее для работы на различных стрельбищах и Т.д.).

Важным аспектом в стрельбе является умение регулировать дыхание, так как в процессе стрельбы при каждом выстреле приходится на несколько секунд задерживать дыхание для обеспечения максимально неподвижного состояния.

Одним из эфрфективных упражнений для регулирования дыхания - это глубокое дыхание животом. Глубокое дыхание животом производит массаж органов брюшной полости, увеличивая подвижность диафрагмы в 4-5 раз. Такое дыхание стимулирует перисталь- 
тику желудка и кишечника, усиливает аппетит, улучшает внутри-секреторную функцию и способствует укреплению и оздоровлению организма [6]. Дыхание не только поставляет воздух организму, но и является мощным рычагом по управлению самой сокровенной его деятельностью - активного обмена веществ. Активный обмен веществ и насыщение тела кислородом помогают стрелку при задержке дыхания регулировать время прицеливания для выполнения наилучшего выстрела. Успех каждого стрелка зависит от хладнокровия, физической и психологической выносливости, умения точно распределять оптимальное время прицеливания, что невозможно без многократных повторений техники стрельбы и психологической подготовки.

Известно, что спортсмены, находящиеся в предстартовом сильном возбуждении (предстартовой лихорадке), склонны к недооценке временных интервалов. Они могут значительно ускорять свои действия, находясь в излишне возбужденном состоянии, что может привести к бесконтрольной быстрой стрельбе с низким результатом. А затягивание стрельбы, что также приводит к низкому результату , говорит о предстартовой вялости стрелка.
Очевидно, что стрелок должен уметь контролировать и регулировать свое психологическое состояние и, в первую очередь, уровень эмоционального возбуждения и мысленные процессы.

При повышении эмоционального состояния у человека увеличивается частота пульса, повышается потовыделение, может даже повыситься температура, могут начаться спазмы желудка и, что особенно важно, непроизвольно напрягаются разные мышечные группы. На соревнованиях такое состояние может привести к регулярному недобиранию большого количества очков.

Стрелок должен уметь концентрировать внимание на правильном воспроизведении технических приемов стрельбы.

Для развития концентрации необходимо умение анализировать свои действия вслух. Анализируя свои действия вслух, а затем мысленно (по мере повышения спортивного мастерства), стрелок передает свои ощущения памяти, что приводит к правильному выполнению техники стрельбы и глубокой концентрации до конца выстрела. Стрелок запоминает под каким углом вылетела пуля, как щека прикасается к оружию, ошибку 
руки, удерживающей оружие, какое дыхание, положение затыльника, нажатие спускового курка, распределение оптимального времени прицеливания и т.д. и вносит поправки перед следующим выстрелом.

Надо стрелять в таком темпе, чтобы на серию из 10-ти выстрелов из малокалиберной винтовки затрачивать 10-12 минут, а из крупнокалиберной 1217 минут [9].

На тренировке стрелки, как правило, стремятся равномерно распределять выстрелы во времени при выполнении данного упражнения, что обусловливается стереотипом их действий на каждом выстреле. Однако некоторые психологические факторы, особенно в условиях соревнований, заставляют стрелка изменять темп стрельбы.

Стрелку необходимо изучать и запоминать все временные параметры техники стрельбы, для чего нужно периодически включать в тренировочный процесс специальные упражнения на развитие чувства времени.

Необходимо планировать непрерывную работу до 5-10 минут в зависимости от подготовки стрелка, а отдых 1,5 - 3 минуты с опорой оружия. Подобные схемы надо отрабатывать до 30 минут на каждом занятии.
Приклад все время должен находится в выемке плеча, руки должны устойчиво держать винтовку, положение ведущего глаза относительно прицела нужно фиксировать прижатой к прикладу щекой.

Дыхание ровное и неглубокое. Через равные промежутки времени дыхание надо задерживать на полувыдохе на 7-15с для выработки полного автоматизма, однообразного и плавного нажатия на спусковой крючок и оптимального распределения времени выстрелов [2].

1. Для этого в процессе тренировки необходимо использовать специальные упражнения с длительным удержанием оружия и имитацией выстрелов. Чтобы усилить специфическую нагрузку на участвующие в этой работе мышцы, необходимо удержание оружия выполнять более длительно, а интервалы отдыха-сокращать.

2. Мнения специалистов и наш многолетний опыт работы со стрелками-спортсменами показали, что навык оптимального времени прицеливания тренируем и нужно систематически в процессе тренировок применять методику фиксации оптимального времени каждого выстрела. 
- Цели и задачи исследования. Определить оптимальное время прицеливания у мужчин и женщин при выполнении 10-и зачётных выстрелов из положения стоя.

- Методы и организация исследования. Изучение, обобщение и анализ научно-методических источников, исследования и метод математической статистики.

В исследовании приняли участие 38 студентов Гос. Университета (20 мужчин и 18 женщин) спортивной секции пулевой стрельбы с тренировочным циклом 3 раза в неделю по 2 часа, которые были разделены на две равные мужские группы (экспериментальную и контрольную) и две равные женские группы ( экспериментальную и контрольную). Выполнялись 3 пробных и 10 зачётных выстрелов из пневматической винтовки из положения стоя на дистанции 10 м по мишени N8.

Контрольные группы мужчин и женщин тренировались по обычной программе тренировок стрельбы.
Экспериментальные группы мужчин и женщин кроме обычной программы обучались умению фиксировать время каждого выстрела, анализировать и выделять лучший результат и время, потраченное на этот выстрел.

Время прицеливания определялось электронным секундомером. За время прицеливания принят промежуток времени с момента наведения оружия на мишень до выполнения выстрела. После окончания всех зачётных выстрелов данного упражнения результаты и время каждого выстрела занесены в протокол, на основании которых построены таблицы, отражающие связь между временем прицеливания и результатом.

Затем определены среднее время прицеливания и средний результат во всех группах. 


\section{Обобщенные данные анализа и результатов исследования}

\begin{tabular}{|c|c|c|c|c|c|c|c|c|c|c|c|c|c|c|c|}
\hline \multirow{11}{*}{ 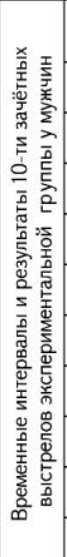 } & № & $\begin{array}{l}\text { Время } \\
\text { (сек.) }\end{array}$ & Результат & \multirow{11}{*}{ 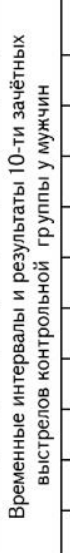 } & № & $\begin{array}{l}\text { Время } \\
\text { (сек.) }\end{array}$ & Результат & \multirow{11}{*}{ 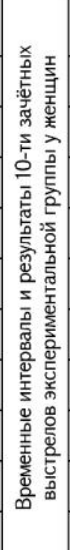 } & № & $\begin{array}{l}\text { Время } \\
\text { (сек.) }\end{array}$ & Результат & \multirow{11}{*}{ 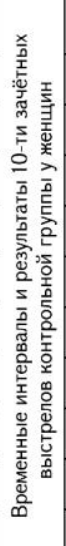 } & № & $\begin{array}{l}\text { Время } \\
\text { (сек.) }\end{array}$ & Результат \\
\hline & 1 & $5,3-12,0$ & 96 & & 1 & $10,9-20,1$ & 91 & & 1 & $7,2-18,0$ & 96 & & 1 & $11,9-23,5$ & 90 \\
\hline & 2 & $6,1-15,2$ & 94 & & 2 & $8,5-19,7$ & 80 & & 2 & $6,0-18,2$ & 95 & & 2 & $9,0-21,8$ & 92 \\
\hline & 3 & $7,4-17,0$ & 95 & & 3 & $12,7-22,1$ & 89 & & 3 & $5,5-19,1$ & 91 & & 3 & $12,2-24,7$ & 75 \\
\hline & 4 & $5,8-17,3$ & 95 & & 4 & $9,8-20,2$ & 78 & & 4 & $9,1-18,5$ & 97 & & 4 & $10,1-19,4$ & 90 \\
\hline & 5 & $6,0-14,5$ & 96 & & 5 & $15,3-25,4$ & 72 & & 5 & $10,3-19,4$ & 92 & & 5 & $13,5-24,2$ & 73 \\
\hline & 6 & $7,0-15,5$ & 94 & & 6 & $11,8-24,0$ & 90 & & 6 & $8,2-18,3$ & 95 & & 6 & $10,8-23,0$ & 89 \\
\hline & 7 & $5,9-14,2$ & 91 & & 7 & $14,9-18,2$ & 82 & & 7 & $11,1-17,5$ & 94 & & 7 & $11,4-20,9$ & 91 \\
\hline & 8 & $7,8-18,0$ & 96 & & 8 & $10,5-18,5$ & 93 & & 8 & $10,0-17,0$ & 96 & & 8 & $12,8-21,3$ & 88 \\
\hline & 9 & $8,5-15,0$ & 89 & & 9 & $13,7-27,2$ & 80 & & 9 & $8,1-20,2$ & 87 & & 9 & $12,4-23,8$ & 75 \\
\hline & 10 & $9,0-14,2$ & 95 & & 10 & $14,4-23,4$ & 85 & & & & & & & & \\
\hline
\end{tabular}

\begin{tabular}{|c|c|c|}
\hline Мужчины & $\begin{array}{c}\text { Среднее время } \\
\text { (сек.) }\end{array}$ & $\begin{array}{c}\text { Средний } \\
\text { результат }\end{array}$ \\
\hline $\begin{array}{c}\text { экспериментальная } \\
\text { группа }\end{array}$ & $6,8-15,2$ & 94,1 \\
\hline $\begin{array}{c}\text { контрольная } \\
\text { группа }\end{array}$ & $12,2-21,8$ & 84 \\
\hline
\end{tabular}

\begin{tabular}{|c|c|c|}
\hline Женщины & $\begin{array}{c}\text { Среднее время } \\
\text { (сек.) }\end{array}$ & $\begin{array}{c}\text { Средний } \\
\text { результат }\end{array}$ \\
\hline $\begin{array}{c}\text { экспериментальная } \\
\text { группа }\end{array}$ & $8,3-18,4$ & 93,6 \\
\hline $\begin{array}{c}\text { контрольная } \\
\text { группа }\end{array}$ & $11,5-22,5$ & 84,7 \\
\hline
\end{tabular}

\section{Выводы.}

1. Для каждого стрелка, выполняющего упражнение из пневматической винтовки из положения стоя по мишени N8 на дистанции 10 м, существует определённая величина времени прицеливания.

2. Средняя величина времени прицеливания экспериментальной группы мужчин и женщин меньше, чем контрольной группы.

3. Проведённые исследования показали, что у стрелков экспериментальной группы мужчин и женщин, которые в процессе тренировок применяли методику фиксации времени каждого выстрела, более высокий результат.

4. Сравнение экспериментальных данных стало основой для выявления оптимального времени прицеливания и совершенствования техники выстрела, что свидетельствует об эффрективности использованной методики. 


\section{Ф СПИСОК ЛИТЕРАТУРЫ}

1. Германов Г.Н., Двигательные способности и физические качества. Разделы теории физической культуры 2-е изд.- М.: Юрайт.- 2017.- С.22.

2. Дворкин А.Д., Стрельба из пневматических винтовок. -М.: ДОСААФ - 1986.С. $81-82$.

3. Жилина М.Я., Методика тренировки стрелка-спортсмена.- М.: ДОСААФ 1986.- С.69-70.

4. Казарян Ф.Г., Григорян А.А., Теоретические и прикладные основы профессионально-прикладной фризической подготовки студентов. Росс.-Арм. (Славянский) Гос. унив. - Ереван.- 2003.- С. 53.

5. Корейс М.К., Справочник “Пулевая стрельба”.- М.: ФиС.- 1982.- С.161-162.

6. Кун Цзянь, Чжан Яолун, Цигун и спорт.- М.: Прогресс.-1991.- N5.- С. 4-5.

7. Мелёхин А.В., Правовое регулирование физической культуры и спорта. Учебник для бакалавриата и магистратуры.- М.: Юрайт.- 2015.- С.16.

8. Романов Е.А., Разноцветные мишени.- М.: ФиС.- 1986.- С. 3-5.

9. Юрьев А.А., Пулевая спортивная стрельба.- М.: ФиС.- 1973.- С.308-309.

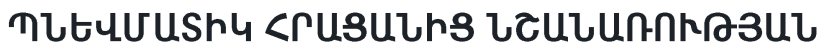

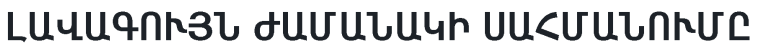

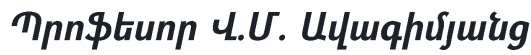

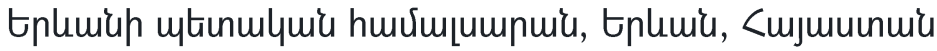

\section{UUФПФU१मก}

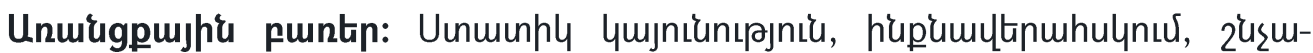

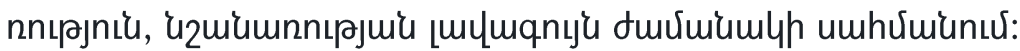

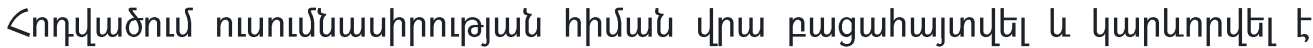

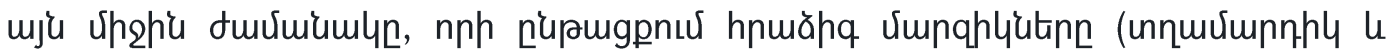

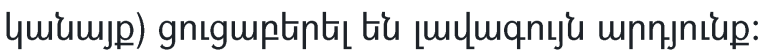

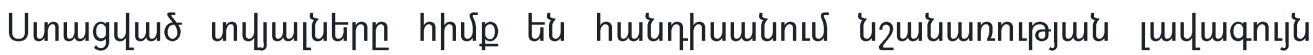

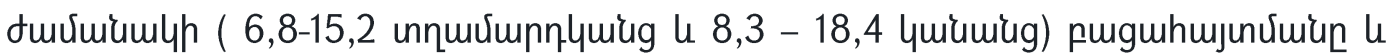

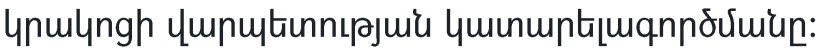




\section{A DEFINITION OF AN OPTIMAL AIMING TIME FROM THE PNEUMATIC GUN}

Professor V.M. Avagimyants

Yerevan State University, Yerevan, Armenia

\section{SUMMARY}

Keywords: static stability, self-control, breathing, a definition of an optimal aiming time.

This article, based on research, revealed and valued an average time for shooters (men and women) demonstrating the best results.

The data obtained become the basis for identifying the optimal aiming time (6,8 15,2 men, 8,3 - 18,4 women) and improving the shooting technique.

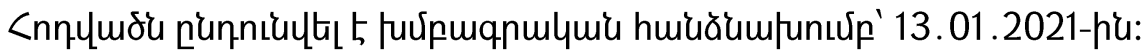

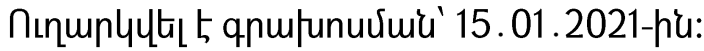


DOI: 10.53068/25792997-2021.1.3-129

\title{
УПРАВЛЕНИЕ МЕЛКОЙ МОТОРИКОЙУ ЖЕНЩИН, ЗАНИМАЮЩИХСЯ ОЗДОРОВИТЕЛЬНОЙ ФИЗИЧЕСКОЙ КУЛЬТУРОЙ: БИЛАТЕРАЛЬНЫЕ ПОКАЗАТЕЛИ
}

\author{
Д.п.н., профессор А.А. Чатинян, \\ Д.п.н., профессор Е.С.Акопян \\ Государственный институт физической культуры \\ и спорта Армении, Ереван, Армения \\ E.mail:ashot.chatinyan@sportedu.am, elena.hakobyan@sportedu.am
}

Ключевые слова: Женщины, о3доровительная ффизическая культура, билатеральные конечности, мелкая моторика, тремометрия.

Актуальность исследования. Управление движениями- сложная многообразная форма целенаправленной деятельности человека, эффективность которой обусловлена взаимодействием сенсорных и двигательных систем организма, проявляющаяся в показателях точности, частоты, силы, координации движений.

Инволюционные процессы прежде всего сказываются на самых сложных формах деятельности. Старение нервной системы объясняет присущую пожилым людям большую медлительность в их действиях по сравнению с молодыми. Меняется походка, реакции становятся более медленными, они утрачивают былую ловкость и допускают все больше ошибок в своем двигательном поведении. Снижение лабильности центральной системы вынуждает пожилых людей все больше времени тратить на подготовку, организацию и управление собственными действиями. При старении в первую очередь ослабевают процессы саморегуляции наиболее мелких движений: пожилые становятся неспособными эфрфективно контролировать и соответственно точно управлять движениями пальцев (отсюда и появление неразборчивости в их письме) [2]. Большинство перечисленных симптомов ослабления двигательных функций взрослых и пожилых людей связаны не только с изменениями, происходящими В самих мышцах, но и в системе регуляции двигательной деятельности, т.е. в центральной нервной системе (ЦНС). Именно в ЦНС наиболее четко выражена инво- 
люция самых диффференцированных нервных клеток - нейронов. Их число в коре головного мозга, гипоталамусе и мозжечке, например, после 45 лет начинает прогрессивно снижаться. Вследствие этого происходит значительное уменьшение объема мозга, хотя место погибших нейронов замещает соединительная ткань. Однако уменьшение числа нейронов и дистрофические нарушения еще сохранившихся нервных клетках идут неравномерно, что является причиной нарушения согласованной деятельности ЦНС [6].

С возрастом закономерно снижается скорость распространения сигналов по структурам нервной системы. В связи с этим значительно замедляются психомоторные реакции на самые различные раздражители.

Изучение особенностей управления движениями у людей зрелого и пожилого возраста, поиск путей снижения отрицательного влияния на функции организма инволюционных процессов, особенно актуально в аспекте обеспечения безопасности и комфортности жизнедеятельности, сохранения на долгие годы здоровья.

В контексте данной проблемы ужепроведен ряд исследований особенностей управления движениями правой и левой рук. В частности, А.С. Солодков., Е.Б.Сологуб выявили, что у 75\% людей правая рука является ведущей, а среди женщин левши встречаются в 23 раза реже, чем среди мужчин. При этом ведущая правая рука у правшей превосходит левую по длине, размеру кисти, она имеет большую мышечную массу, ее мышечные волокна толще и сильнее. Примечательным является тот факт, что ведущая правая легче и быстрее включается в выполнение двигательных актов, а главное выполняет их более координировано, точнее регулирует мышечные усилия [5].

Интересными являются результаты исследования, в котором было изучено развитие базовых двигательных способностей женщин 55-74 лет, проживающих в Архангельской области России. Тестирование пожилых женщин предполагало оценку степени развития симметричности, подвижности в тазобедренных, коленных и голеностопных суставах, подвижности в плечевых суставах, устойчивости туловища и равновесия. Авторами было установлено, что исследуемые двигательные способности женщин находятся на среднем уровне развития. Высокие показатели имели место в тесте на подвижность в 
плечевых суставах, устойчивости туловища и равновесии тела [4].

Как показывают результаты собственных исследований, активные занятия физической культурой, помогают в определенной степени замедлить инволюционные изменения, стабилизировать процесс управления движениями, сохранить двигательную функцию на уровне, достигнутом в зрелом возрасте [1,7].

В контексте вышесказанного научный интерес представляет проблема изучения особенностей влияния оздоровительной физической культуры на показатели управления мелкой моторикой лиц пожилого возраста.

Цель исследования: изучить особенности влияния систематических занятий оздоровительной физической культурой на точность мелкой моторики билатеральных конечностей у женщин пожилого возраста.

\section{Методы и организация исследо-} вания: изучение и анализ литературных источников, динамическая тремометрия, математическая статистика.В работе использовался электронный тремометр, позволяющий определять точность обведения (количество касаний стенок) различных по сложности фригур: в форме квадрата с крестообраз- ными линиями, треугольника (І группа), двух концентрических кругов, зигзага (II группа), прямой линии и волны (III группа) [3]. Одновременно фриксировалось время выполнения заданий на каждой группе движений. Для изучения точности выполнения различных по сложности движений все задания были распределены в три группы: сложные (I), менее сложные (II) и простые (III), каждая из которых включал по две фигуры. Распределение фигур в три группы было обосновано экспериментальным путем [8]. Исследование динамической тремометрии проводились по принятой в спортивной психологии методике [3]. Движения выполнялись по часовой стрелке.

В исследовании, организованном в октябре-ноябре 2019 года, приняли участие 30 женщин 55-75 лет, занимающиеся оздоровительной ффизической культурой в группе здоровья при государственном институте фризической культуры и спорта Армении. В соответствии с принятой классификацией женщины были распределены в две возрастные группы: 55-64 лет и 65-75 лет. Средний стаж занятий в оздоровительной группе соответствен-

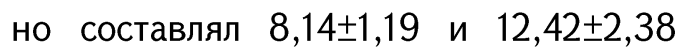
лет. Занятия проводились 2 раза в не- 
делю, длительностью 1 час, под руководством Е.С. Акопян. В программу занятий были включены упражнения, имеющие всестороннее воздействие на работу различных органов и систем организма: тренировка кардио-респираторной системы, поддержание необходимой подвижности позвоночника и суставов, укрепление мышечно-связочного аппарата, сохранение на достигнутом уровне координации движений, равновесия. Упражнения подбирались с учетом симметричности воздействия на обе конечности, и выполнялись как по часовой стрелке, так и против.

Анализ результатов исследования. Ранее проведенными исследованиями было выявлено, что многолетние занятия оздоровительной физической культурой позволяют сохранить определенный уровень мобилизации нервной системы и точность управления пространственной характеристикой движения [1]. Вместе с тем было установлено, что с увеличением стажа занятий наблюдаются незначительные изменения точности выполнения различных по сложности групп движений на тремометре как по часовой, так и против часовой стрелке. Примечательно, что первые пять лет регулярных занятий оздоровительной ффизической культурой позволили несколько улучшить точность мелкой моторики. В дальнейшем, с увеличением стажа занятий, на фоне инволюционных процессов, происходит стабилизация изучаемых показателей[7].Авторами были изучены также взаимосвязи между исследованными показателями психомоторики женщин в соответствии со стажем занятий. Их анализ показал, что достоверные взаимосвязи имели место в первой и второй по сложности паре движений в группе женщин со стажем занятий 1-5лет: $r=-0.60$ и $r=-0.48$ [1].

В аспекте исследуемой проблемы научный интерес представляет изучение особенностей управления мелкой моторикой билатеральными конечностями с учетом сложности выполняемых заданий. Предполагалось, что точность выполнения заданий ведущей рукой при обведении наиболее сложных по конфигурации фигур на тремометре будет выше, чем неведущей конечностью.

Полученные данные проанализированы как в возрастном аспекте, так и по сложности выполнения заданий разными конечностями (таблица).

Вначале представим показатели точности мелкой моторики правой и левой руки в возрастной группе жен- 
щин 55-64лет. Анализ данных таблицы не выявил у женщин данной возрастной группы достоверных различий между точностью движений в билатеральных конечностях. Как и ожидалось, хуже всегоисследуемыевыполняли задания самой сложной группы движений, в которой по сравнению с результатами самых легких заданий,показатели правой руки былихуже на 3,6 и составили 6,36 касания. Примечательно, что при сравнении данных в сложных и простых группах движений левой руки разница была менее выражена и составила в среднем 2,6 касания.Точность обеих конечностей (количество касаний стенок фигур)в менее сложной (II) и простой (III) группе заданий отличалась незначительно и была недостоверна.

При сравнении показателей правой руки в сложной (I) и простой(III) группах движений у пожилых женщин (6575 лет) было выявлено ухудшение точности на 5,57 касания при выполнении движений в первой группе заданий. Это на 2 касанияхуже тех же показателей женщин 55-64-лет, у которых разница составила 3,54 касания. Причина большей разницы может состоять в некотором ухудшении способности управлять мелкими движениями в старшей возрастной группе женщин, что, скорее всего, является следствием отрицательного влияния усиливающихся в этом возрасте инволюционных процессов. Из всех сравниваемых показателей правой и левой рук были установлены достоверно более худшие показатели левой руки при выполнении первой сложной группы заданий в процессе обведении фигур в виде квадрата с внутренними крестообразными линиями и треугольника. Разница между показателями точности обеих рук составила в среднем 3 касания.

Изучение степени точности выполнения отдельных заданий у женщин зрелого возраста показало, что в сложной и средней по сложности группе движений выявлены существенные различия в показателях правой руки. В частности, точность обведения квадрата (I группа) и круга (II группа) соответственно в 2,3 и в 5 раз была хуже, чем при обведении фригур в виде зигзага и треугольника. В отношении показателей левой руки разница между точностью в тех же фигурах была менее выражена (соответственно в 1,9 и 1,5 раза). Аналогичная картина имела место и в данных билатеральных конечностей у женщин пожилого возраста. 
Таблица

Сравнительные показатели динамической тремометрии билатеральных конечностей у женщин, занимающихся оздоровительной физической культурой (количество касаний), $X \pm m$

\begin{tabular}{|c|c|c|c|c|c|c|c|c|c|}
\hline \multirow{2}{*}{$\begin{array}{c}\text { Bозраст } \\
\text { лет }\end{array}$} & \multicolumn{9}{|c|}{ Группыдвижений } \\
\cline { 2 - 10 } & \multicolumn{2}{|c|}{ І (сложная) } & \multicolumn{3}{c|}{ II ( менее сложная) } & \multicolumn{3}{c|}{ III (простая) } \\
\cline { 2 - 10 } & правая & левая & $\mathrm{t}$ & правая & левая & $\mathrm{t}$ & правая & левая & $\mathrm{t}$ \\
\hline $55-64$ & $6.36 \pm 0.85$ & $6.93 \pm 0.71$ & 0.51 & $3.43 \pm 0.65$ & $5.07 \pm 0.51$ & 1.97 & $2.79 \pm 0.57$ & $4.29 \pm 0.56$ & 1.89 \\
\hline $65-75$ & $8.88 \pm 0.8811 .81 \pm 0.94$ & 2.29 & $4.94 \pm 0.46$ & $6.63 \pm 0.68$ & 1.92 & $3.31 \pm 0.46$ & $4.25 \pm 0.78$ & 1.04 \\
\hline
\end{tabular}

Сравнительный анализ полученных данных у женщин 55-64 и 65-75 лет при выполнении заданий всех групп движений в целом не выявил достоверных различий между билатеральными конечностями. Однако в отношении показателей второй возрастной группы, были установлены несколько худшие средние показатели точности мелкой моторики обеих рук, относящиеся ко всем группам движений. В частности, если средняя величина точности на всех заданиях у зрелых женщин составила 4,81 касание, то у пожилых она достигла величины 6,63 касания.

Примечательно, чторазница между показателями правой руки по на всех групп движений у исследуемых 55-64 года составила 4,2 касания,а в возрасте
65-75 лет она была несколько хуже: 5,7 касания. В показателях выполнения задания левой рукой выявлена почти идентичная картина.Так, в возрастной группе 55-64 года средний показатель точности составил 5,4 касания, а у женщин 65-75 лет он был на 2,3 показателяхуже - 7,6 касания.

Выводы. Результатами исследования установлено, что управление мелкой моторикой билатеральными конечностями в трех группах движений у женщин зрелого и пожилого возраста, занимающихся оздоровительной фризической культурой, в целом имеют схожую картину. Выявлен лишь один достоверный случай менее точного управления мелкой моторикой левой руки у женщин 65-75 лет в первой наиболее сложной группе движений. Как и 
предполагалось наиболее низкие показатели точности были выявлены при обведении фригур в виде квадрата с крестообразными линиями и круга.

Можно заключить, что многолетние занятия оздоровительной фризи- ческой культурой, в целом, способствовали сохранению одинаковой степени точности управления мелкой моторикой билатеральными конечностями.

\section{Ф ЛИТЕРАТУРА}

1. Акопян Е.С., Чатинян А.А., Влияние занятий оздоровительной физической культурой на психомоторику женщин.Материалы межд. науч. конф. «Проблемы психологического обслуживания в спорте высших достижений». - Ереван, 2017.C.339-344.

2. Ильин Е. П., Психомоторная организация человека. - СПб.: Питер, 2003. $384 \mathrm{c}$.

3. Методы психодиагностики в спорте / В.Л. Марищук, Ю.М. Блудов и др. М.: Просвещение, 1984. -С. 141 -150.

4. Нечаева Е.А., Корельская И.Е. Оценка базовых двигательных способностей пожилых женщин в возрасте 55-74 лет, проживающих в условиях городской среды арктического региона (архангельской области) // Международный студенческий научный вестник. - 2018. - № 3-5.http:// eduherald.ru /ru /article/ view?id=18464

5. Солодков А.С., Сологуб Е.Б., Физиология человека. Общая. Спортивная. Возрастная: учебник.- Изд.6-е, испр. и доп.- М.: Спорт, 2016. - С. 583-585.

6. Физиологические механизмы старения. Под. ред. Д.Ф. Чеботарева, В.В. Фролькиса. -Л.:Наука,1982. - 228с.

7. Чатинян А.А., Акопян Е.С., Особенности влияния занятий оздоровительной физической культурой на точность движения у женщин. Материалы межд. научнопракт. конф. "Спорт и спортивная медицина», посвященной 40-летию со дня основания Чайковского гос. института физической культуры. - Чайковский, 2020.C. 431-438.

8. Чатинян А.А., Мониторинг возрастного развития точности движений человека. -Ереван: Авторское изд. 2010. - 72 с. (На армянском языке). 


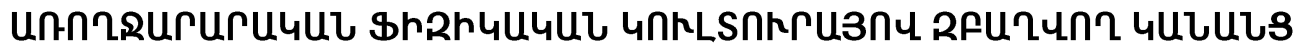

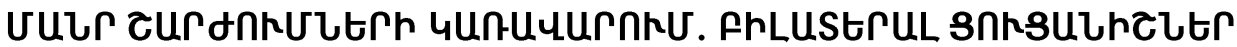

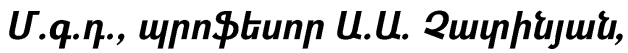
U.q.n., upn\$tunp 6.U. <ulynpJuit <mjuuunuiuh \$hqhlumlumi ynцunnıpujh le umnnunh

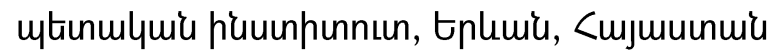

\section{UUФПФИ१फৎ}

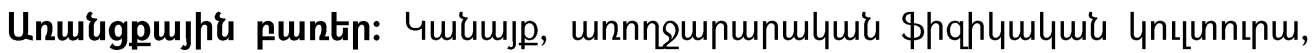

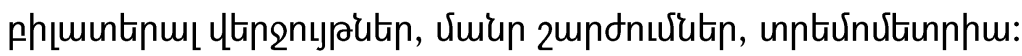

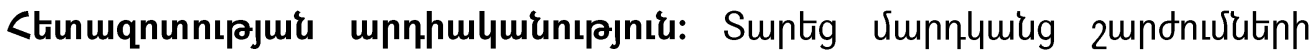

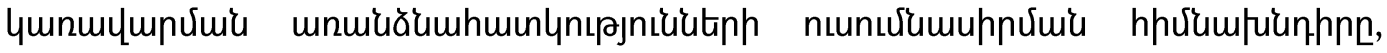

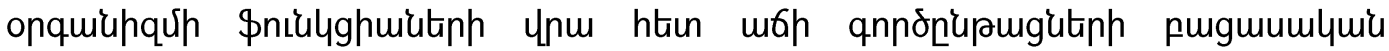

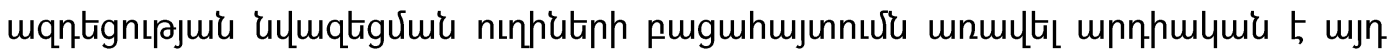

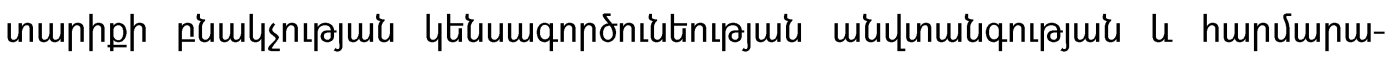

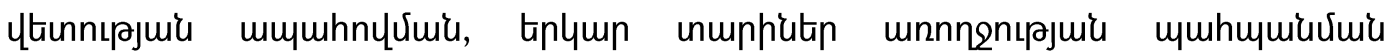
untumulyjniuhg:

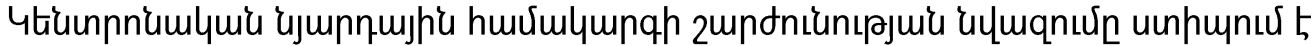

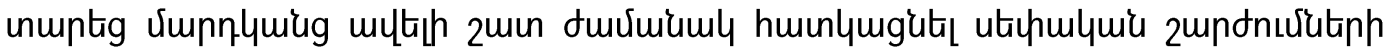

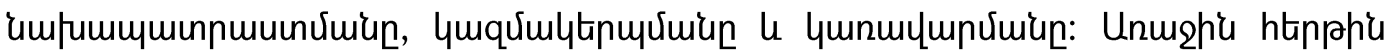

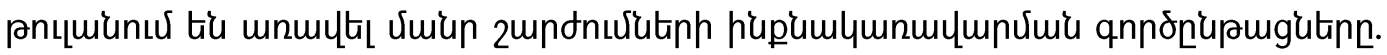

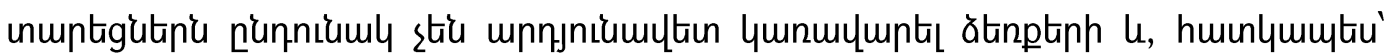

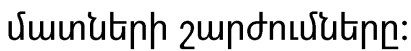

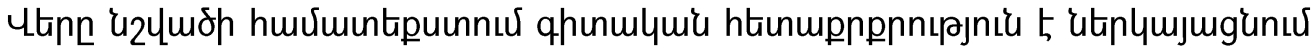

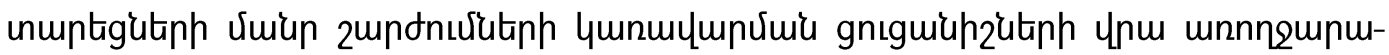

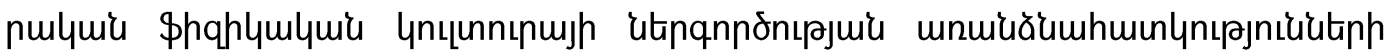

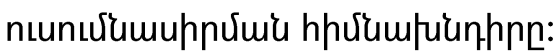

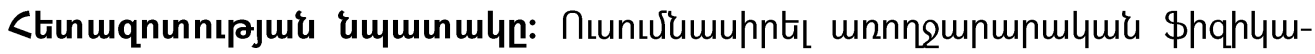

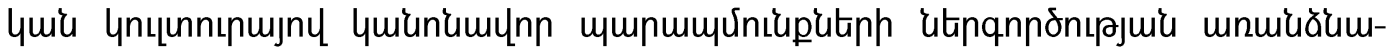

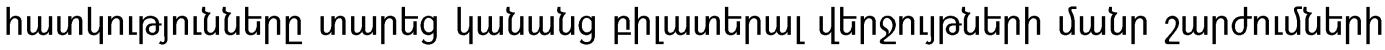

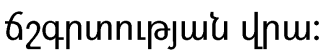




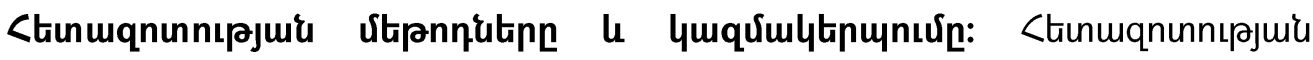

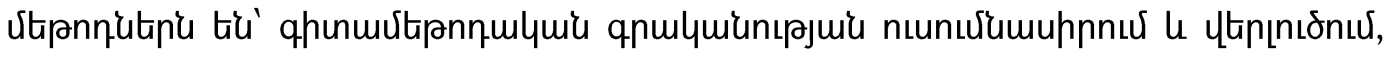

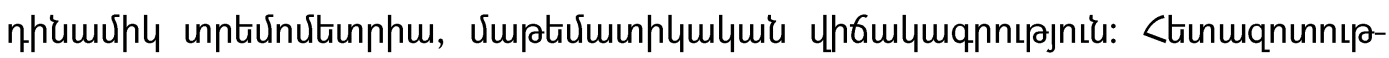

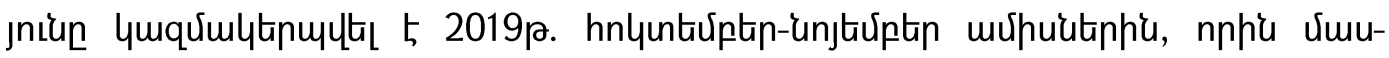

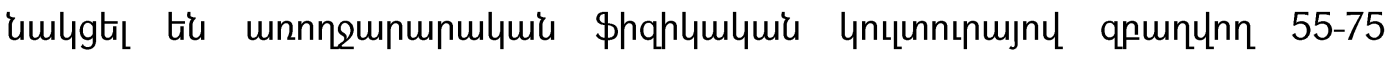
unuptyuiu 30 uhu:

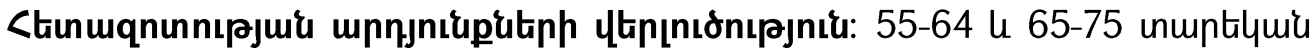

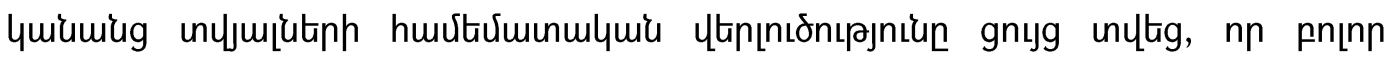

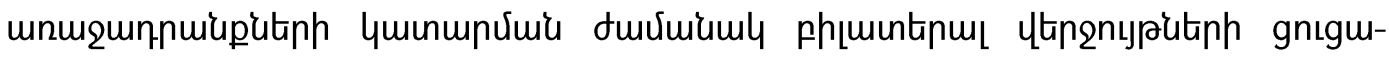

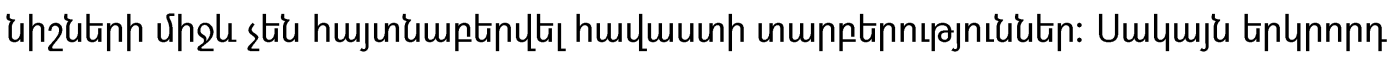

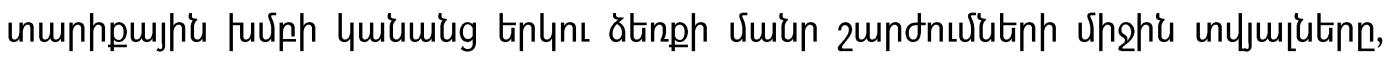

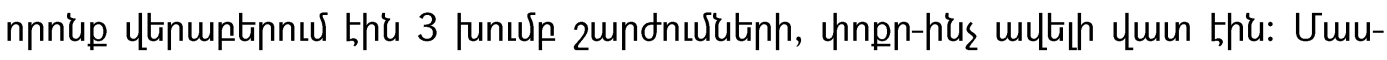

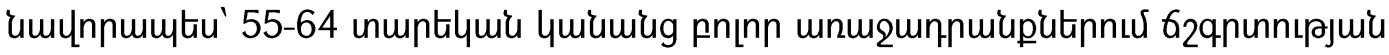

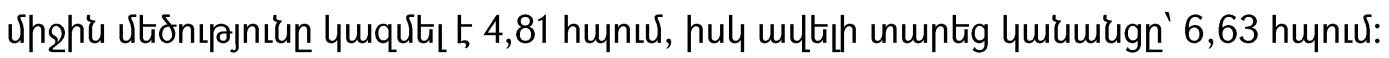

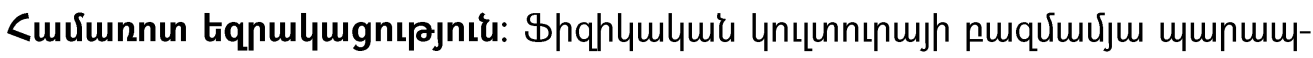

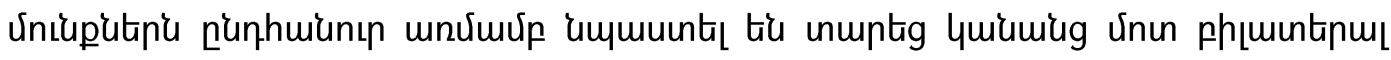

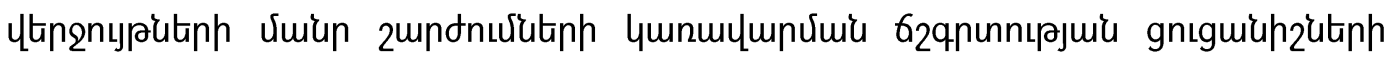
upuhumuiviuin:

\section{CONTROL OF FINE MOTOR SKILLS IN WOMEN ENGAGED IN RECREATIONAL PHYSICAL CULTURE: BILATERAL INDICATORS}

Doctor of Pedagogy, Professor A.A.Chatinyan, Doctor of Pedagogy, Professor E.S. Hakobyan

Armenian State Institute of Physical Culture and Sport, Yerevan, Armenia

\section{SUMMARY}

Key words: Women, recreational physical culture, bilateral extremity, fine movements, tremometry.

Relevance. The issue of studying the features of movement control among elderly people and the disclosureof ways to reduce the negative impact of involutional processes on the body functions areup-to-dateand relevant in terms of ensuring long- 
term health care safety and wellbeingfor the population in that age group. The reduced mobility of central nervous system forces older people to spend more time preparing, organizing and managing their own actions. First of all, self-regulation processes of the finest movements weaken: the elderly become unable to effectively control the movements of hands and especially fingers.

In this regard, the issue of studying the influenceof recreational physical cultureon the indicators of fine movements control among the elderly is of scientific interest.

The research purpose is to study the features of systematic recreationaltrainings' impact on the accuracy of bilateral extremity fine movements in elderly women.

Research methods and organization comprise study and analysis of scientificmethodical literature, dynamic tremometry, mathematical statistics. The study, organized in October-November 2019, involved 30 women aged 55-75 years engaged in recreational physical culture.

Analysis of research results. A comparative analysis of the data obtained in women aged 55-64 and 65-75 years when performing tasks of all movementsno significant differences were revealed between the indicators of bilateral extremities. However, in the second age group of women, slightly worse average accuracy of fine movements with both handswas found, referring to the three groups of movements. In particular, the average accuracy value for all tasks in women aged 55-64 was 4.81 touches, and in older women-6.63 touches.

Conclusions. Long-term trainings in recreational physical culture substantially contributed to preserving the control accuracy of bilateral extremities fine movements among elderly women.

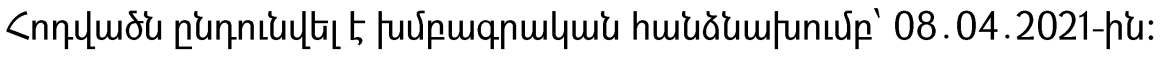

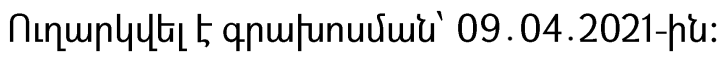




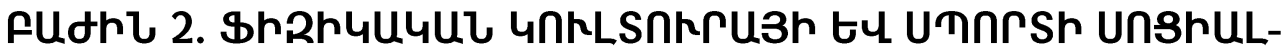

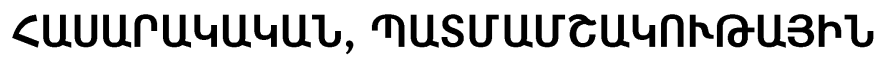 <hUしUtulqhrしtr}

DOI: 10.53068/25792997-2021.1.3-139

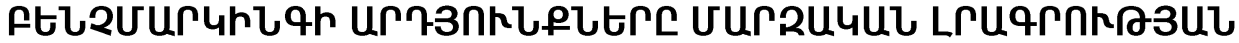

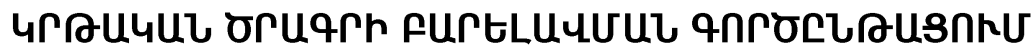

Uupuytitin U. ก. Funquumpjuis

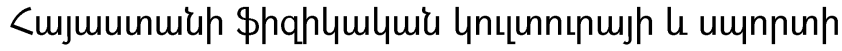

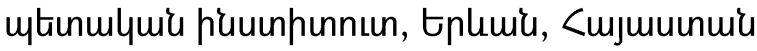
E. mail:arevik.baghdasaryan@sportedu.am

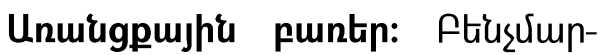

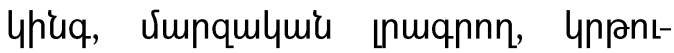

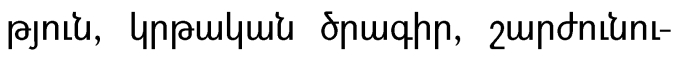
pjuik:

Stinuqnunnıpjuis upnpulquiunt-

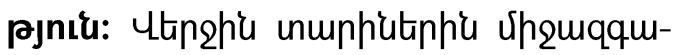

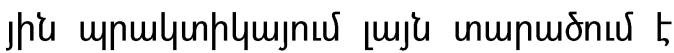

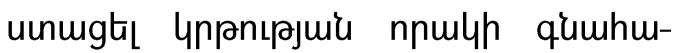
unviuiu 'unp qnnohpn' ptiusulumphuqu,

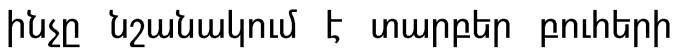

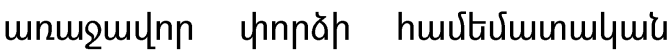

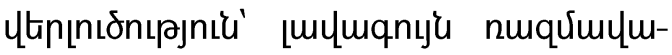

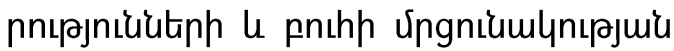
punănugưứ kumuinulynu: Funănu-

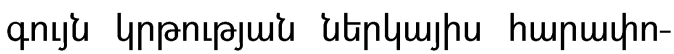
unntu uhquumjnn uintindts 5 unn umj-

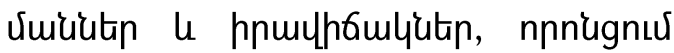
pnshtinn utienp 5 qunnnuitume unmq

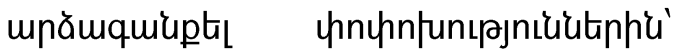

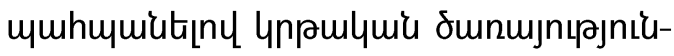

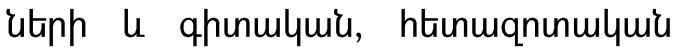

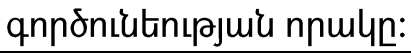

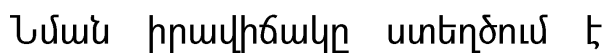

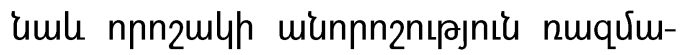

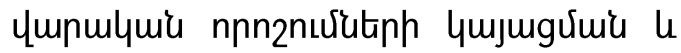

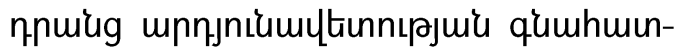
Juiu humgnux: ftúşumphiugh (hurutt-

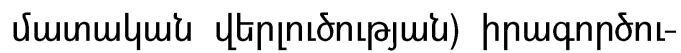
un humpulnnnıpjniu 5 unuphu quuhu-

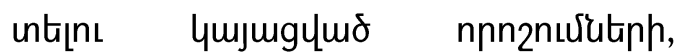
nunnymo nuquiulummlquí ninhiutiph

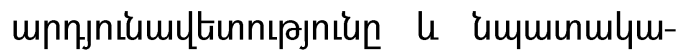

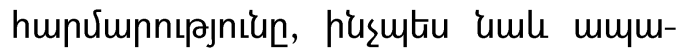

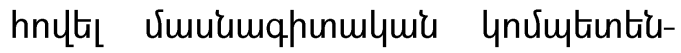

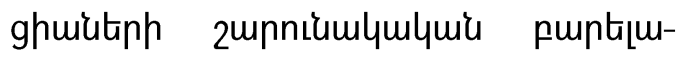
unuরu $[1,3,4]$ :

\section{Stinuqnunnıpuid \&uquinuln:}

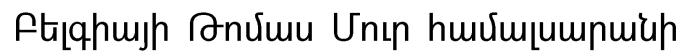

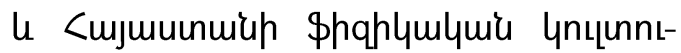

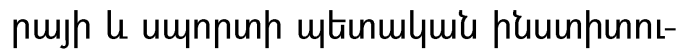

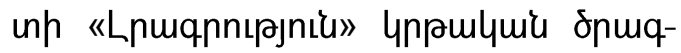

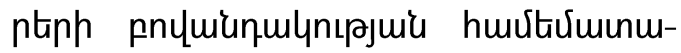

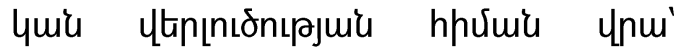
puguhmusutis tiplns pnshtipnuर्य npuljum 


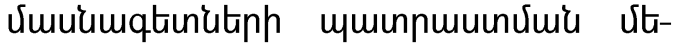
fumiuhqun:

\section{Ctunuqnunnıرuis vitpnnutipn $\mathrm{l}$}

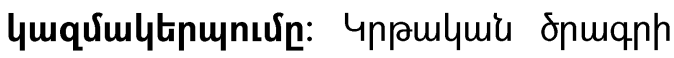

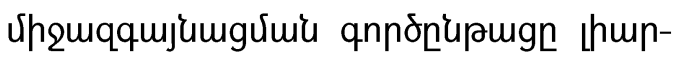

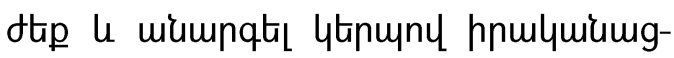

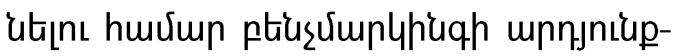

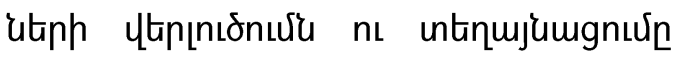

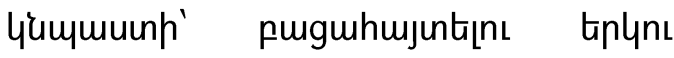

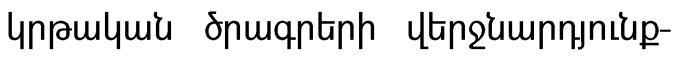

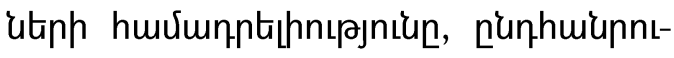

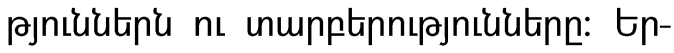
yns tplynitph vemuiumqtinutiph umin-

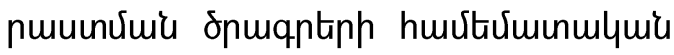

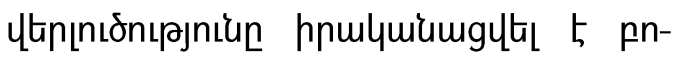
чuiunulymjhu htunuqnunnıpjuí (content analiz) Utiannh uhengnu:

ftucusumpliugh unujugutiph le unn-

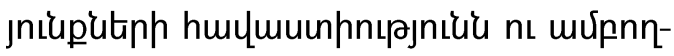

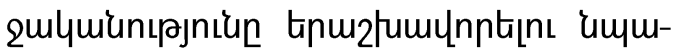

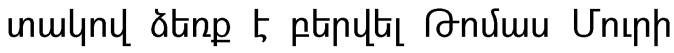

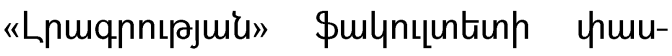

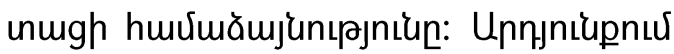

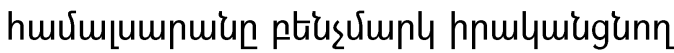

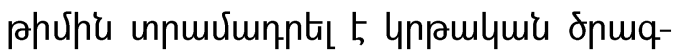
nh l hupulyhg thuuumupnstiph uर्upnnsulquis thuption, nne humuitith stn

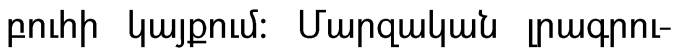

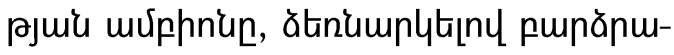

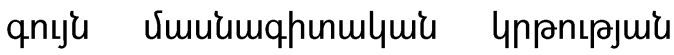

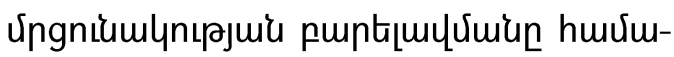

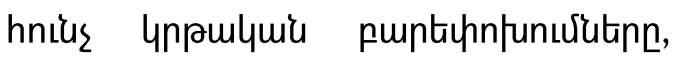

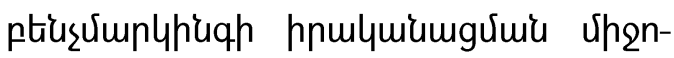
gny ăqunnuर 5 utapphú le ununuphí 2nt-

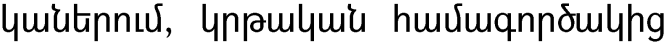

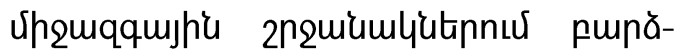

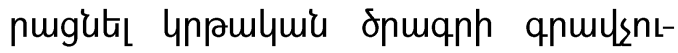

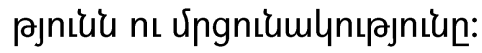

funăn yunlyuiuh2 niukgnn pnıhti-

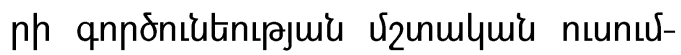

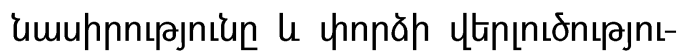
un ymplunn tipuzlupp tú ynpulymir qnnonıutunıرuiu mumuptiqnuर ungnt-

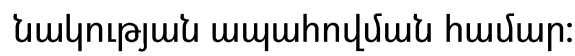

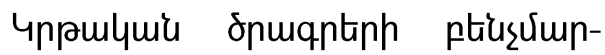

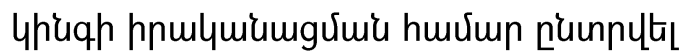

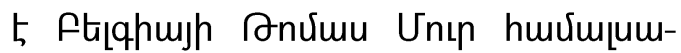
nuiup Lpuqnnıрjuí \$ulynıuntions

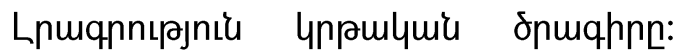
Uhquqqujhe qnnonulytin pnihh htion

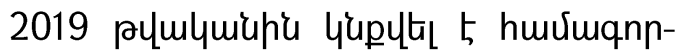

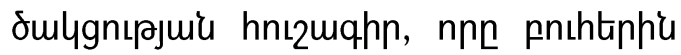

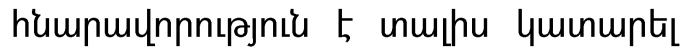

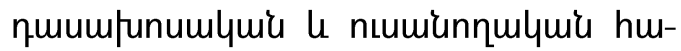

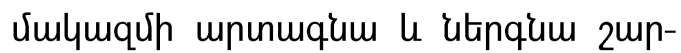

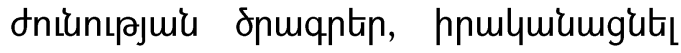

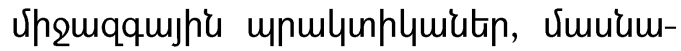

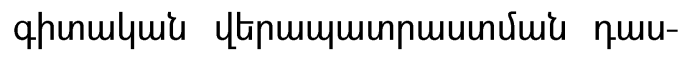

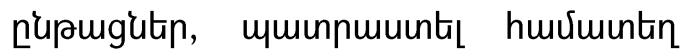

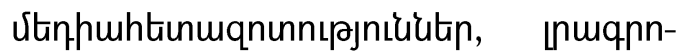

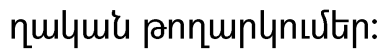

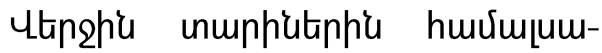

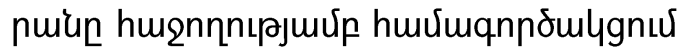
$5 \ll$ l mJ tiplnutiph htin unquqqujhí

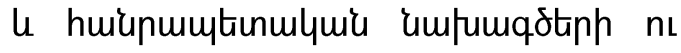

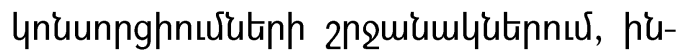

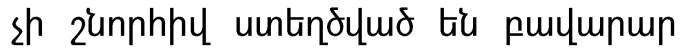

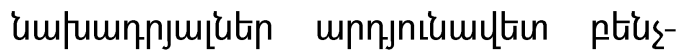




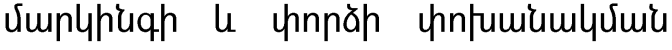

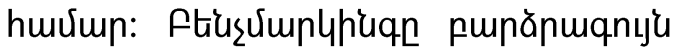

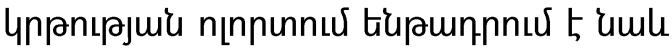

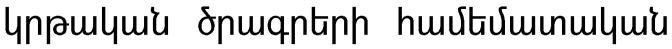

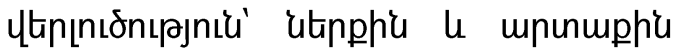
2nılumitinnux npuiug qnuusnıpjniun

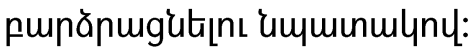

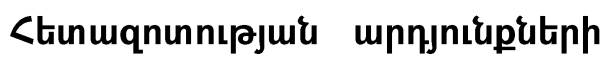

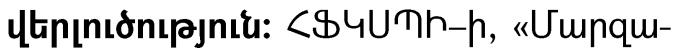

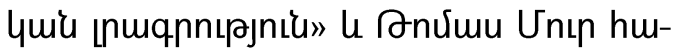

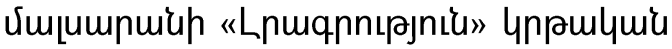

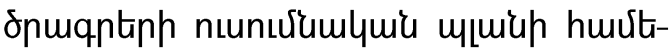

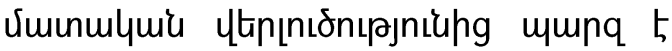

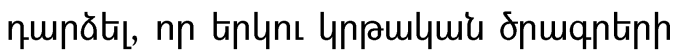

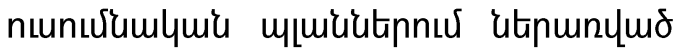

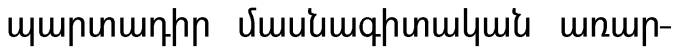

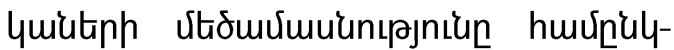
unuर 5 pnymunulymghe unnưny (unjniumly 1): Umlquju onmqntinn unup-

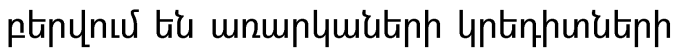

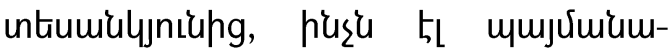

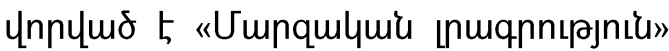
u Anर्umu Unıp hưर्ugumpuiup «Lnuq-

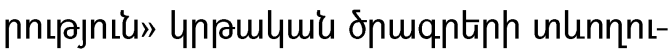

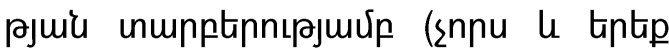
unuph huर्dmumunmu|umiumpun): fugh

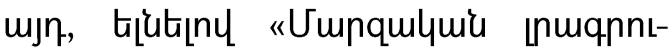

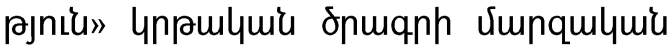

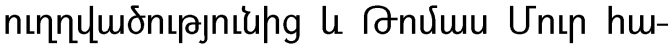

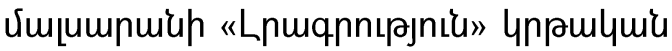

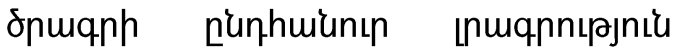

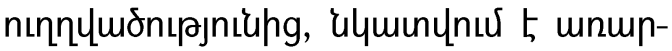

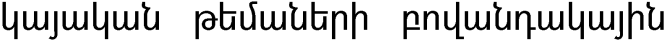

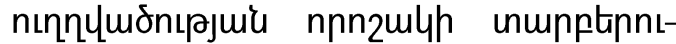
pjniu (unjniumly 1):

Ltipnhp2jm pnumunulymjhe le du-

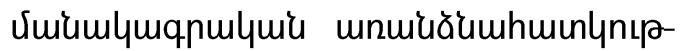

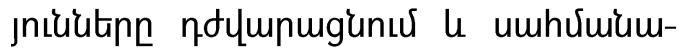

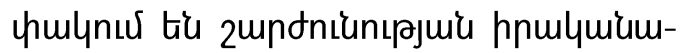
gnưn:

<u24h unatiny innuxumnnunn

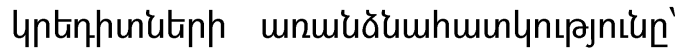

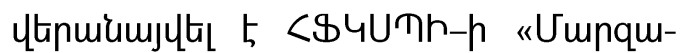

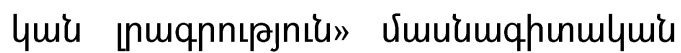
цпрuцшi 2019-2020 nuununym nt-

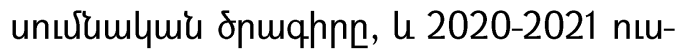

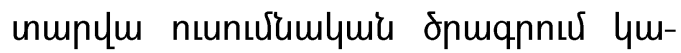

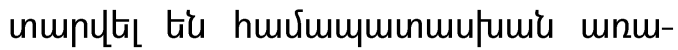

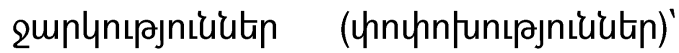

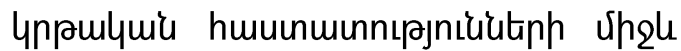
nıumunnutiph 2undniunเрjuí hnu4uitumgưu'u kumunulyny:

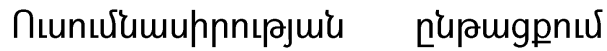
umpqtighup umu, np Oिर्umu Unıр hu-

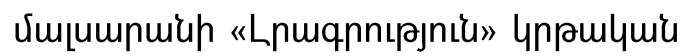

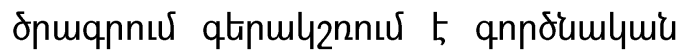

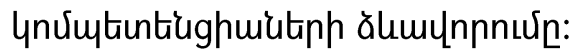

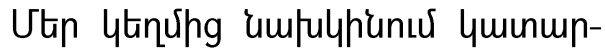

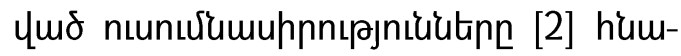
nurЦnnnıpjniu nuătintighu umunlyt-

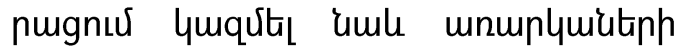

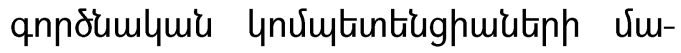
upu: 


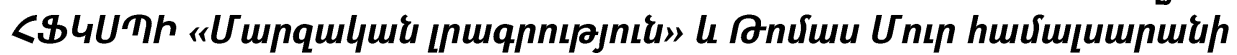

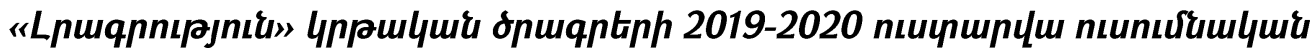

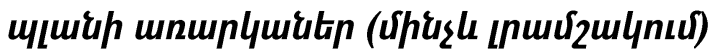

\begin{tabular}{|c|c|c|c|}
\hline \multicolumn{2}{|l|}{$\begin{array}{c}\angle \$ 4 U T h \\
\text { Uunqulyui „puqpnipjnit }\end{array}$} & \multicolumn{2}{|l|}{$\begin{array}{l}\text { Anviuu Unın } \\
\text { Lpuqpnıpjniu }\end{array}$} \\
\hline Unwnlumsh wiulumunu & 4ptinhun & Unmplumjh miulmiunuर & untinhun \\
\hline 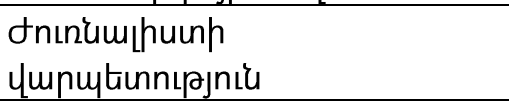 & 3 & 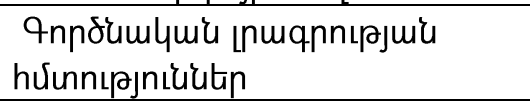 & 3 \\
\hline 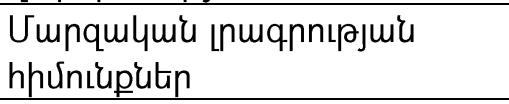 & 1 & 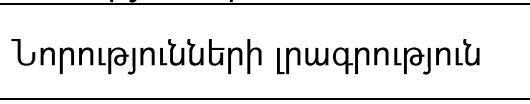 & 3 \\
\hline Suquqhp RLU прquju & 2 & 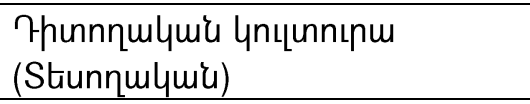 & 3 \\
\hline 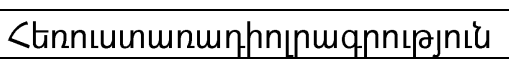 & 2 & Unın-pnuhqnım ¿tiqnı & 3 \\
\hline Umưnuh duiuntin & 1 & Lnuqnnnulumu duiuntin & 3 \\
\hline lunuph lnıınnıpu & 4 & <ungumqnnıgh hưunnıpjnıǔutin & 3 \\
\hline 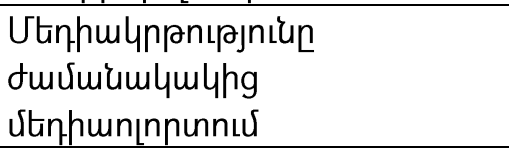 & 4 & Utanhu UhunnuJutin & 3 \\
\hline 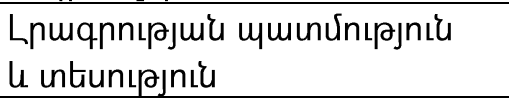 & 1 & 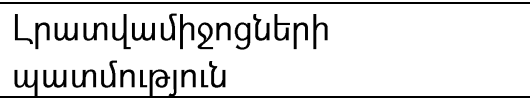 & 3 \\
\hline 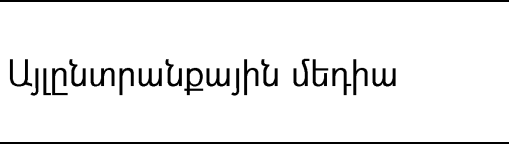 & 4 & 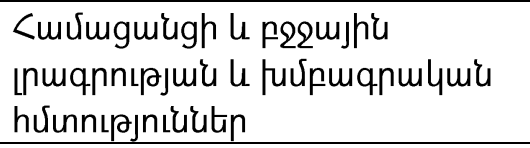 & 3 \\
\hline 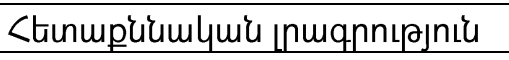 & 3 & Stunmqnunulyuiu hưnnıpjnıukutip & 4 \\
\hline 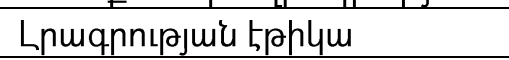 & 2 & 5phlumцmis ntimptin & 3 \\
\hline 乙lumpuhmüunud unciunud & 3 & Annoumulquí untumüunı & 3 \\
\hline$-1+2$ & & Anndrumlumi untipuin l muinltin & \\
\hline Iunuph цnцunnıpu & 4 & 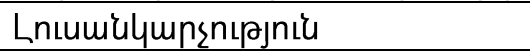 & 3 \\
\hline $\begin{array}{l}\text { 9numann } \\
\text { Łnuinuluúhengütipnuर }\end{array}$ & 3 & 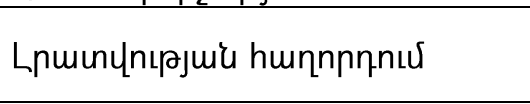 & 3 \\
\hline & & Uẗnһw htunmqnunnıpjnıน & 3 \\
\hline
\end{tabular}


Unjniumly 2

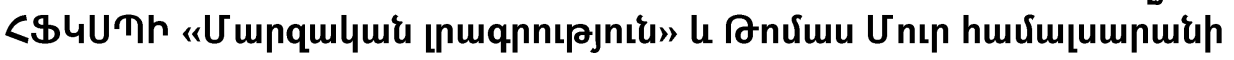

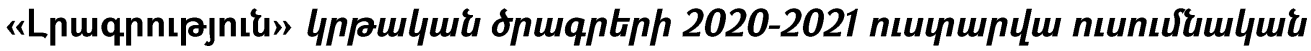

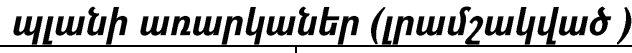

\begin{tabular}{|c|c|c|c|}
\hline \multicolumn{2}{|l|}{$\begin{array}{l}\text { S\$4UTh } \\
\text { Uupquiqui „puqpnıpjnit }\end{array}$} & \multicolumn{2}{|l|}{$\begin{array}{l}\text { Anúuuu Unın } \\
\text { Lnuqunıpjniu }\end{array}$} \\
\hline Unwnlump wนumunud & untinhun & Unwnlüh шiquminuर & untinhun \\
\hline 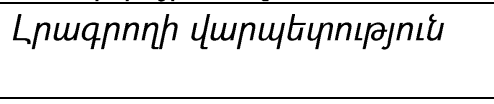 & 4 & 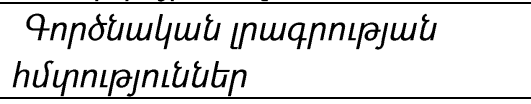 & 3 \\
\hline 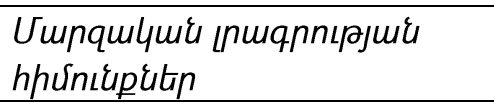 & 4 & 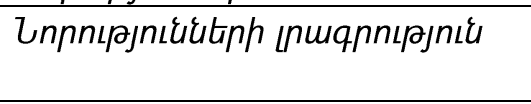 & 3 \\
\hline 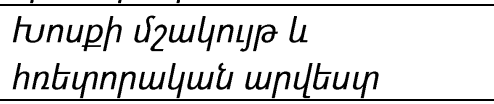 & 2 & 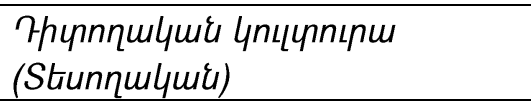 & 3 \\
\hline 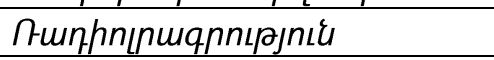 & 4 & Unınhnu/hqnıml leqnı & 3 \\
\hline Uuunuh dwuptin & 4 & Lnшqnnпulqui dwinten & 3 \\
\hline 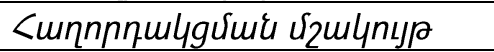 & & 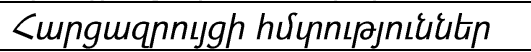 & 3 \\
\hline 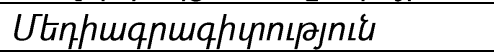 & 2 & Utinhu uhunnusaten & 3 \\
\hline 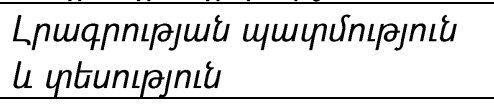 & & 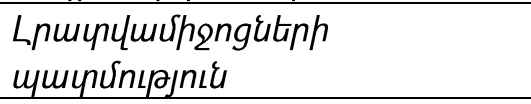 & 3 \\
\hline Unguing ınuqnnıpлnเU & 4 & 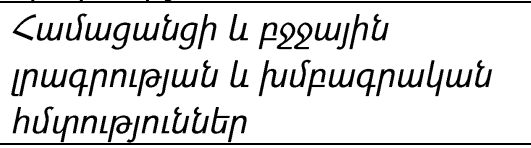 & 3 \\
\hline 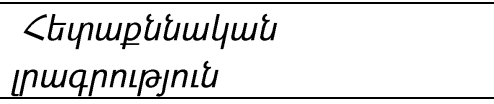 & 4 & 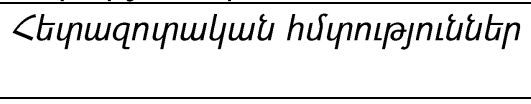 & 3 \\
\hline 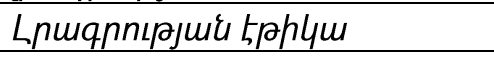 & 4 & 5phlumumu ntтuptin & 3 \\
\hline Outnuщnnnulyшu qnnd & 4 & 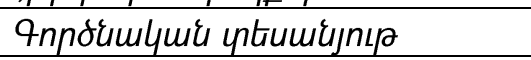 & 3 \\
\hline 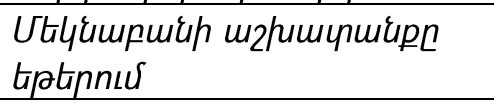 & 4 & 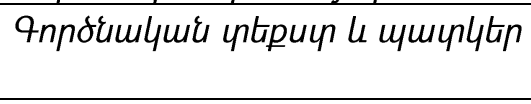 & 3 \\
\hline 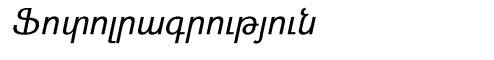 & 4 & 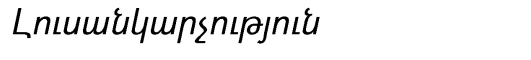 & 3 \\
\hline 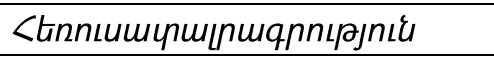 & 4 & & 3 \\
\hline 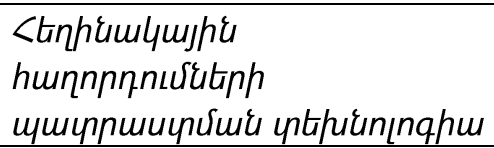 & 4 & 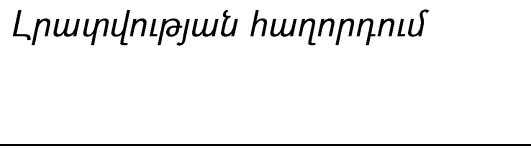 & \\
\hline $\begin{array}{l}\text { Utinhump htrumqqnuviuir } \\
\text { Stapnnuten }\end{array}$ & 4 & 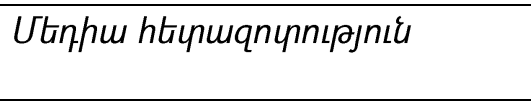 & 3 \\
\hline
\end{tabular}




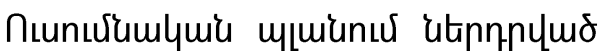

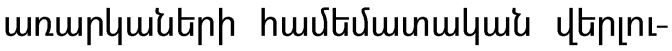

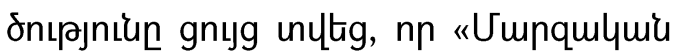

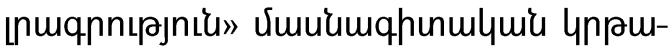

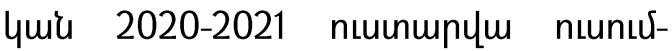

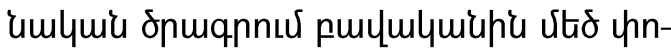

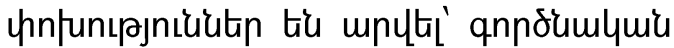

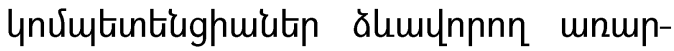

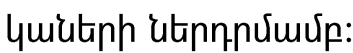

7u ytapuptinnux 5 ophiumly "<t-

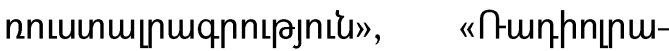

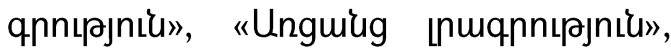

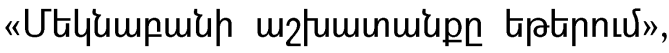

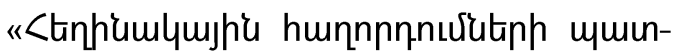

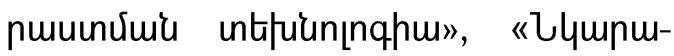
huiunuर्u unuunud» unuplyuitaphis:

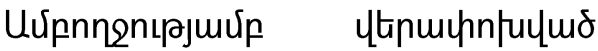
2020-2021 nuununym «Umpqulymis

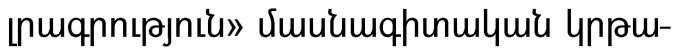

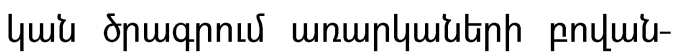

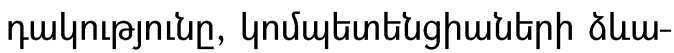

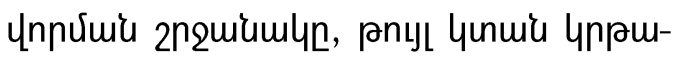

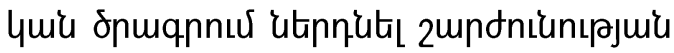

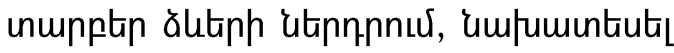

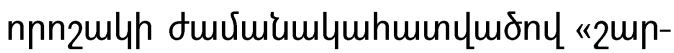

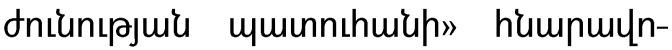
pnıpjnıน:

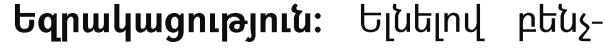

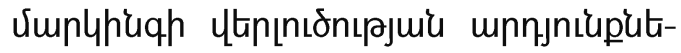
nhg' yuntish 5 tqnulymgits, $\mathrm{nn}$ ¿\$4UTh-h «Uunqulymir inuqnnt-

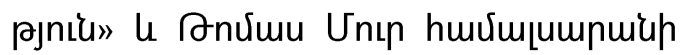

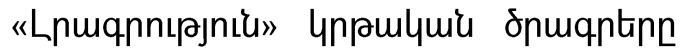

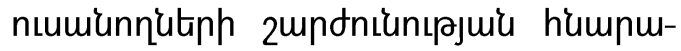

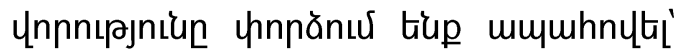
unuplymitiph u untinhunctiph huviu-

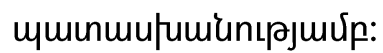

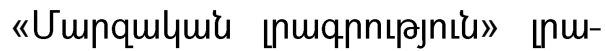

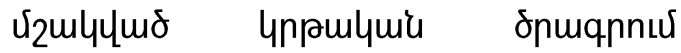

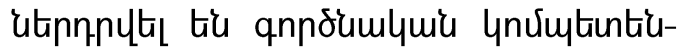
ghuilta ălumunnnn ununlumitin, цm-

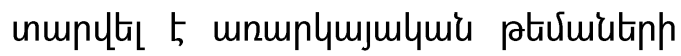

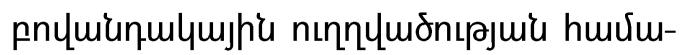

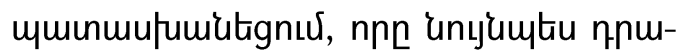

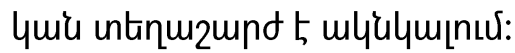

Umlumu, <\$4UTh-h "Umpqulymu

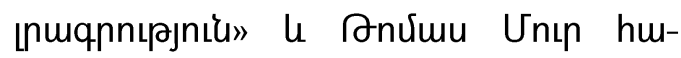

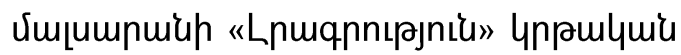

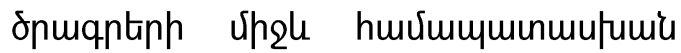

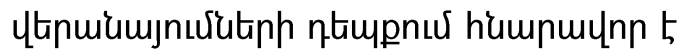

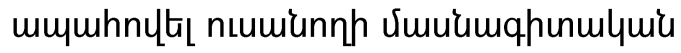
zundnı'unıpjnı̌u: 


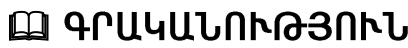

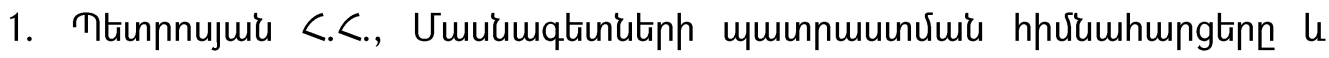

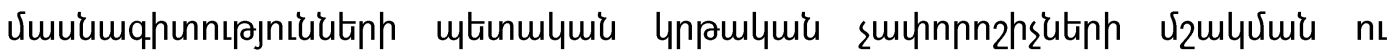

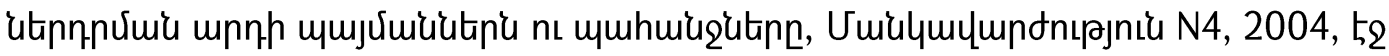
14-23:

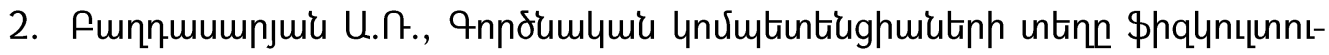

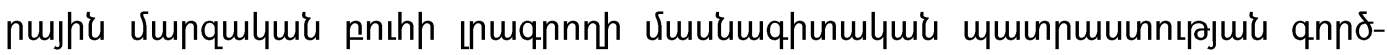

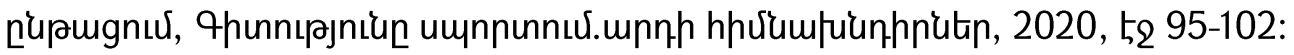

3. Михайлов Е.А., Основы бенчмаркинга.-М.:2002. С. $10-18$.

4. Генералова С., Формирование конкурентного потенциала с помощью метода бенчмаркинга // Проблемы теории и практики управления. - 2007. - №1. C. $20-23$.

5. Градобоев В. Б., Бенчмаркинг как направление стратегического планирования // Человек и труд. - 2006. - № 12. - С. 33-38.

\section{BENCHMARKING RESULTS IN THE IMPROVEMENT PROCESS OF THE EDUCATIONAL PROGRAM IN SPORTS JOURNALISM}

\section{Assistant A. R. Baghdasaryan}

State Institute of Physical Culture and Sports of Armenia

Yerevan, Armenia

\section{SUMMARY}

Keywords: benchmarking, sports journalist, education, educational program, mobility.

The study purpose is to identify the mechanism of preparing qualified specialists in both universities based on the comparative content analysis of the educational programs in "Journalism" of the Belgian Thomas Moore University and the State Institute of Physical Culture and Sports of Armenia.

Study methods and organization. A comparative analysis focused on the educational program "Sports Journalism" of State Institute of Physical Culture and Sports of Armenia and "Journalism" of Thomas Moore University, showed that most of 
the mandatory subjects included in the curricula of both universities coincide in content, but differ in terms of subject credits anticipated.

Taking into account the specifics of credits provided, the curriculum "Sports Journalism" for the 2019-2020 academic years was revised and appropriate changes were made to the curriculum for 2020-2021, making it possible to ensure the implementation of student mobility between educational institutions.

Conclusion. Benchmarking analysis results approve the opportunity of student mobility in accordance with subjects and credits within two educational programs "Sports Journalism" of ASIPCS and "Journalism" of Thomas Moore University, thus contributing to the formation of the necessary practical competencies.

\section{РЕЗУЛЬТАТЫ БЕНЧМАРКИНГА В ПРОЦЕССЕ УЛУЧШЕНИЯ ОБРАЗОВАТЕЛЬНОЙ ПРОГРАММЫ СПОРТИВНОЙ ЖУРНАЛИСТИКИ}

Ассистент А. Р. Багдасарян

Государственный институт физической культуры и спорта Армении, Ереван, Армения

\section{PEЗЮME}

Ключевые слова: бенчмаркинг, спортивный журналист, образование, образовательная программа, мобильность.

Цель исследования: на основе сравнительного анализа содержания образовательных программ "Журналистики" Бельгийского университета Томаса Мура и Государственного института физической культуры и спорта Армении выявить механизм подготовки квалифицированных специалистов в двух вузах.

Методы и организация исследования. Сравнительный анализ образовательных программ ГИФКСА "Спортивная журналистика" и "Журналистика" университета Томаса Мура показывает, что большинство обязательных предметов, включенных в учебные программы двух вузов, совпадают по содержанию. Однако программы отличаются с точки зрения предусмотренных кредитов. Учитывая особенности предоставляемых кредитов, была пересмотрена учебная программа "Спортивная журналистика" на 2019-2020 учебный год и внесены соответствующие изменения в учебную программу 2020-2021 годов, которые 
позволяют обеспечить осуществление мобильности студентов между образовательными учреждениями.

Заключение. Исходя из результатов анализа бенчмаркинга, можно сделать вывод, что новые образовательные программы “Спортивная журналистика» ГИФКСА и «Журналистика» Университета Томаса Мура направлены на обеспечение мобильности студентов в соответствии с предметами и кредитами, способствуют формированию необходимых практических компетенций.

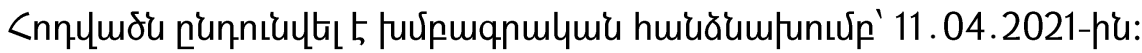

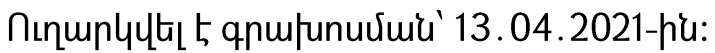


DOI: 10.53068/25792997-2021.1.3-148

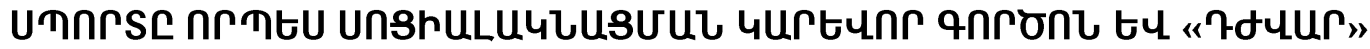

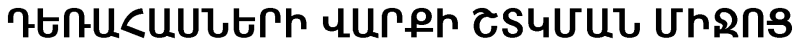

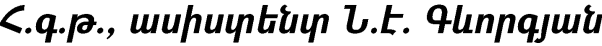

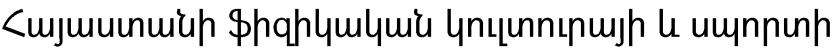

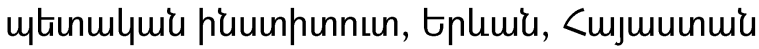
E.mail: natalya.gevorgyan@sportedu.am

Unuiggpujp's puntin: Unghuqu-

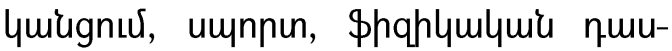

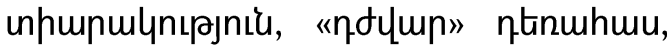

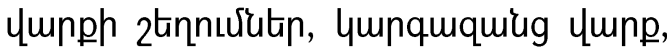

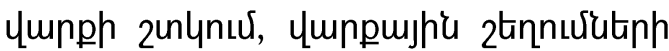
umpumqqnı2mgnuर, ununppujhe Gqumomu, muhmunulymiumgnuर:

<tunuqnunnıpuis upnpulymunt-

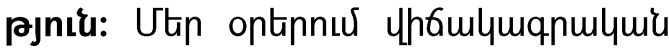

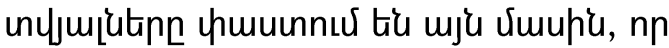

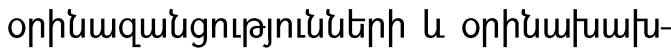

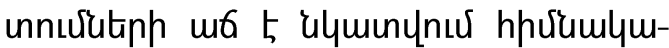

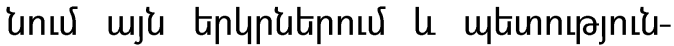
utipnux, nnnup qunulnux tiu unghw-

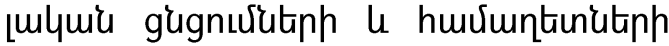

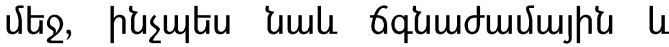

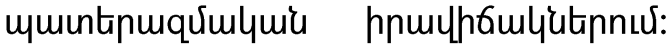

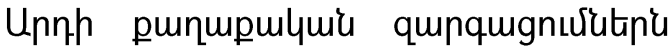
unme tiu ptipnuर mjumpup hnulhGulyutin, nnnug hunpashunviumu huvium

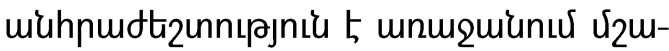

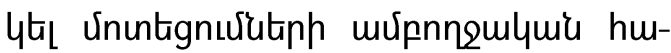
vimlunq: <mfintu mjuonlw hmumpm-

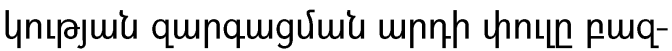

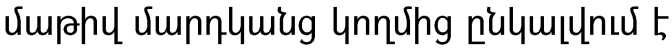

nputiu fqumourर, nıp purgmumlymí

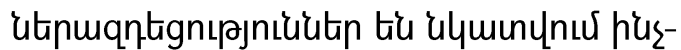

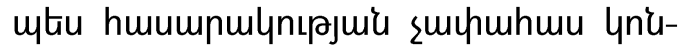

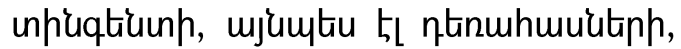
umunumbitinh le tppunuumpnitiph 2nथwiunus:

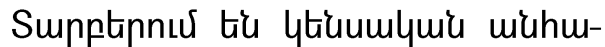
2nnnısniulutiph le punn pnuulh6uly-

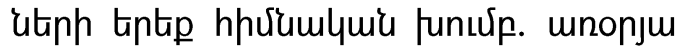
unhu6 tiplenspatin, ljuiuph unupptip

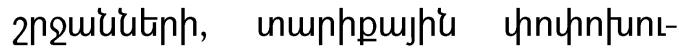

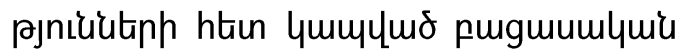

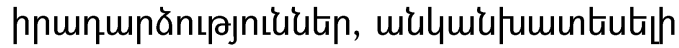

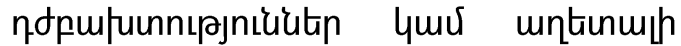

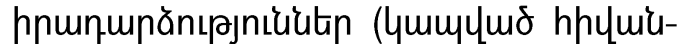

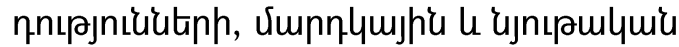
ynnniuunutiph, muintinuquivitiph $u$

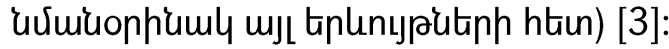

husutiu duviuiumlyulyhg hnqtipu-

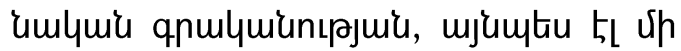

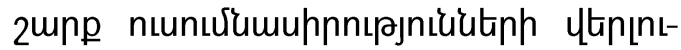

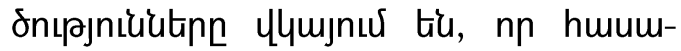

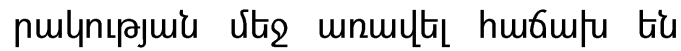
humanhurnux unupmuntumuly mjumpup

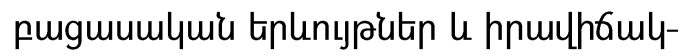




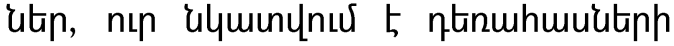

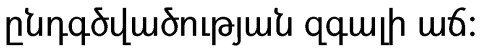

Ulumiuulnn hnqtpuituta L.U. Fu[upuiunulh [4], 乙.も. Fusknplynuh, U. T. Unnnugnulh, h.S. Ttinnjulyh, U. 3m.

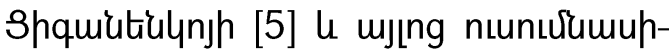
pnıpjniukutiph uqunqunu 5, np uppt-

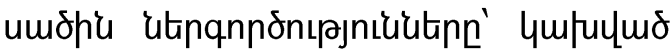

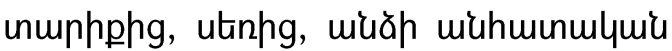
hnqtipuiumlymís unwiăbumbunlynı-

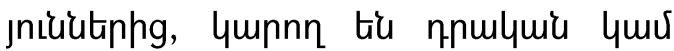

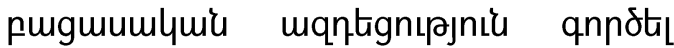

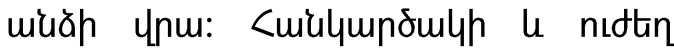
hnsqulymiu qnqnhsitinn vimplquiug vits

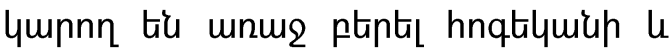

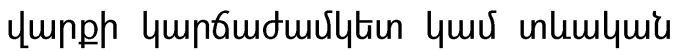

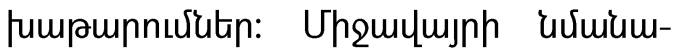

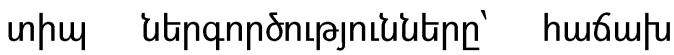

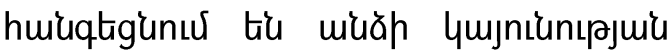

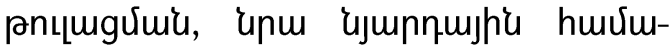

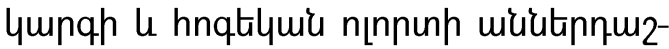
umlцnıرuiu [3]:

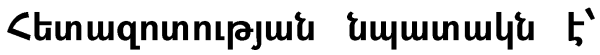

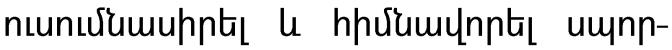

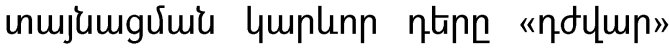

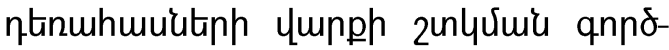
nupumgnux:

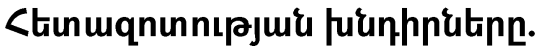

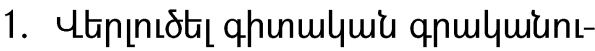

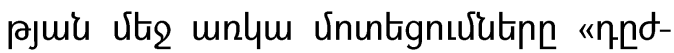

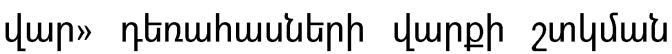
uhengutinh ythnuptipum:
2. Chứumunnta umnnunujher qnn-

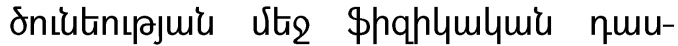

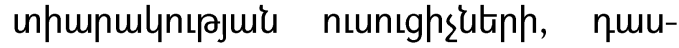

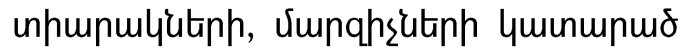

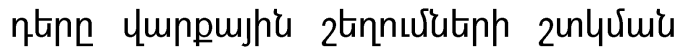
qnnonul:

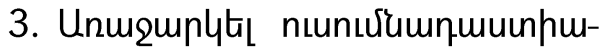

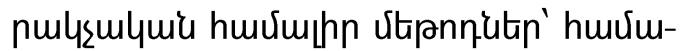

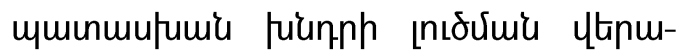
phipjur:

Ctunuqnunnıpuur vitpnnutinn $\mathbf{u}$

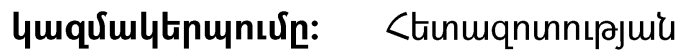
nupamgpnud hnulumumgytal 5 qnulymunıрjuís untumuktannulymís ytapnn-

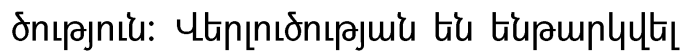

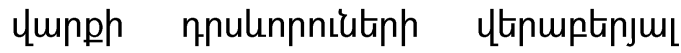

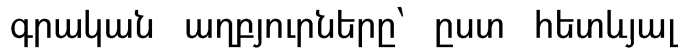

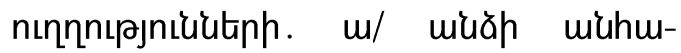

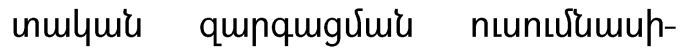
pnıpjniuutin (U. tunınnjuiu, U. Ehhu, 4. Spmialy, 4.3niuq u nıph2utip), p/ umnnenujumgumo quatip $\mathrm{l}$ umnnonp

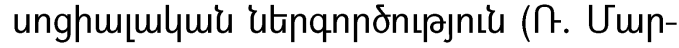
untiuu, L. Lృnıph2um u uృ!p), q/umpph

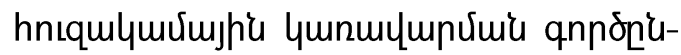

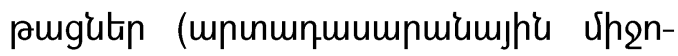

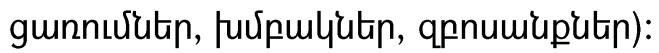

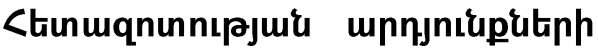

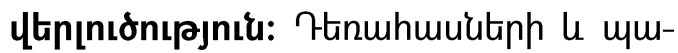

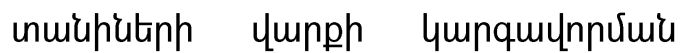
qnnonupaugnuर umnnunujh'u qnnont-

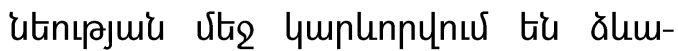

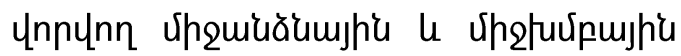




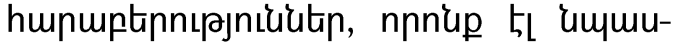
unnuर tiu 2tinunn umpph ytupurhnjuUwiun:

<mjunup sumuen 5 , nn vimpne sh

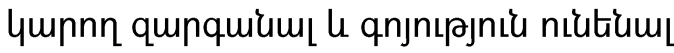
huumpulynıpjniuhg, Junnlymjhe hu-

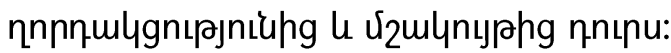

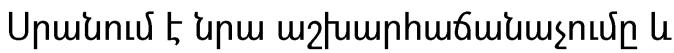

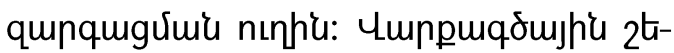

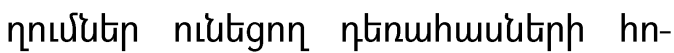

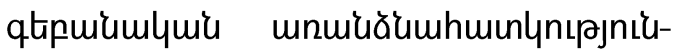
uting fupuin inmpuintiumly tiú $\mathrm{l}$ uqu-

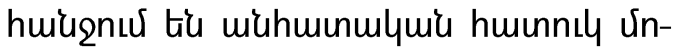
untignuर, huunuly qhuntshputiph, hưunnt-

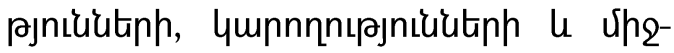

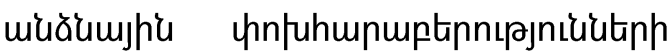
пnulunnưuiu ălutip:

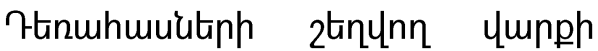

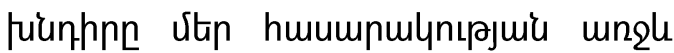

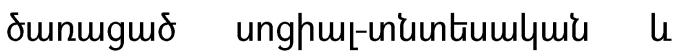
unghul - hnqtipuiumlumu punn fünnp-

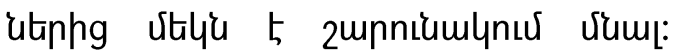

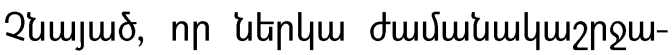

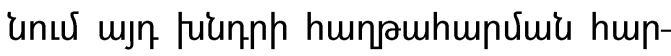
gny htinmpnpnymo tie puscutu ugt-

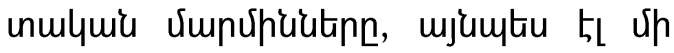

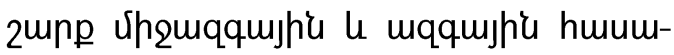

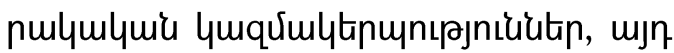

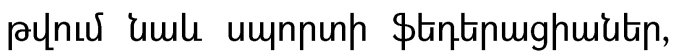

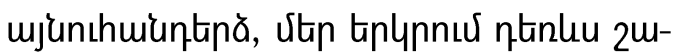

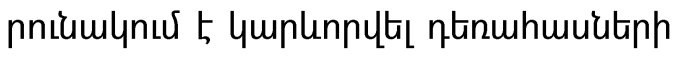
2tnunn yunph hrúumpưn.pnn:
Cuin U.łunınnjuiuh [2]' wiuăh wiu-

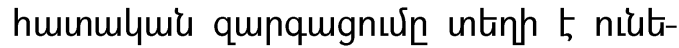

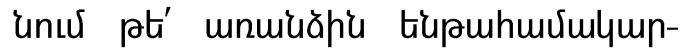

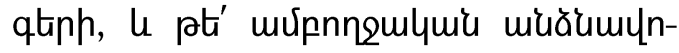

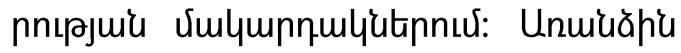

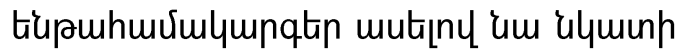

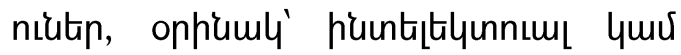
hnıqulyuir nınnunutinn, punnjulymunt-

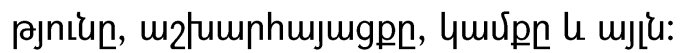
Unuiughg jnıpupuiusnnın, pugh onpumsuuchntiu untinh niukignn quinqu-

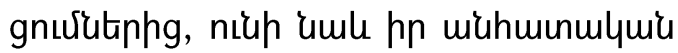
qunquagnưutinn, n'un nnnư' $u^{\prime}$ puium-

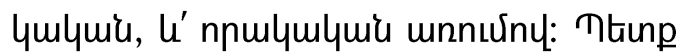

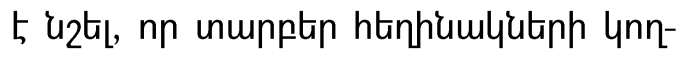

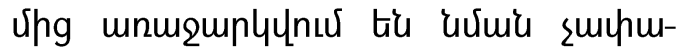
uh2tin, ophuml' hnqtiptimumhujnuर jujunntís nunnilulud 5 nnutu su-

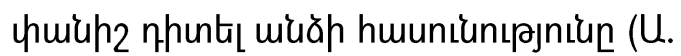

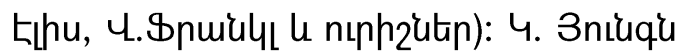

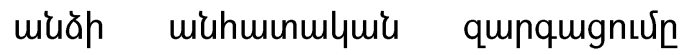

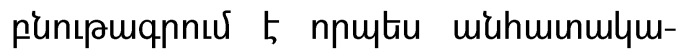

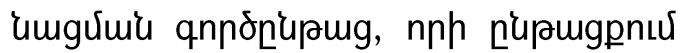
Jupnn huviunud 5 hn pniu tnıpuiun, huiuntiu qujhu nnutiu wuhuin, hun-

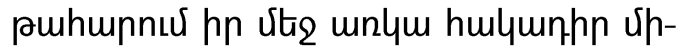
unnulutinn [7]:

Uuhpurotizun 5 'u hurnulymir qunqugưuiun punısmqnu-

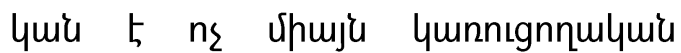
(4nuuunnnılyunhy), unmenupmg qun-

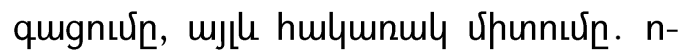
pnzmuh ununuphis mujưuiutitph, qun- 


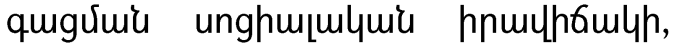

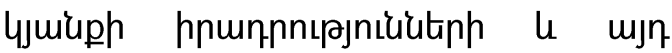
huikquưuiphitiph mqntgnıрjuis unuly

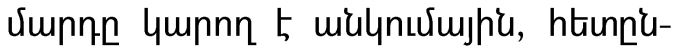

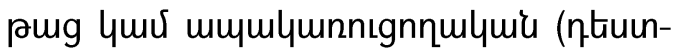

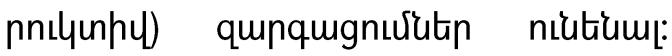

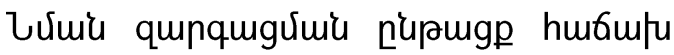

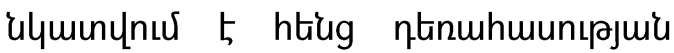
unuphpnux, le htiug \$hqhlumluiu nuu-

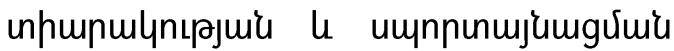

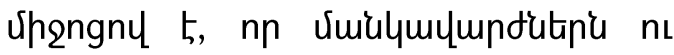

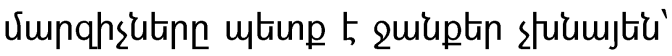

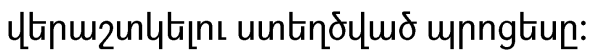

<nqtipuiunıpuiu vits yunnıg v2multal $\mathrm{l}$ mjuon th jujunptiu oqunuqnnoulnux 5 wuăp 2tnunn ympph tiqnnıرan:

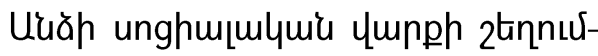

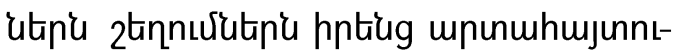

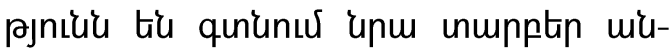
qunqnıpjniüutiph, quiuguiuputiph,

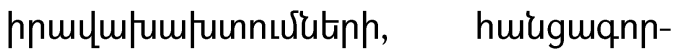

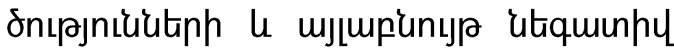
qnulunnnufutinh utis:

Uuăh 2tqưừ Gumpumpnjugutann

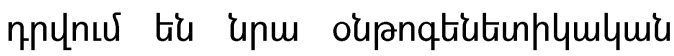

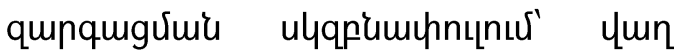

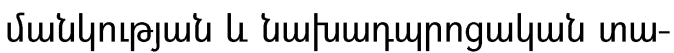

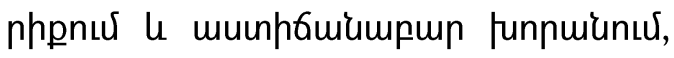
unরumunmunnynuर tiu huennn unuphpujh'u 2nquiututipnux:

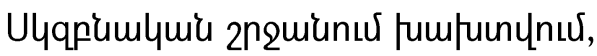
fumpununsu tíu tintipumsh hnsqulymu hupuptipnıpjnıüutinn dunnh htiun. tipt-

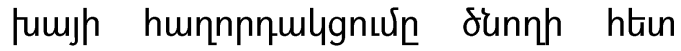
unuir purumumunıpjic sh umin-

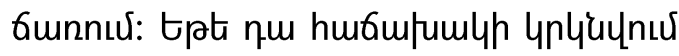

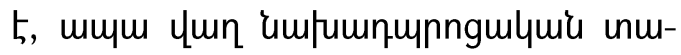

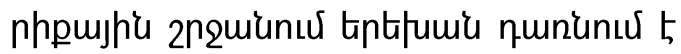

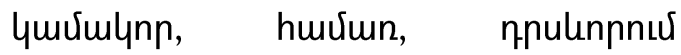
5 utiquinhyhqu u dunnutinh umhuiusutpric hulqunuly qnnonnnıpniulutin

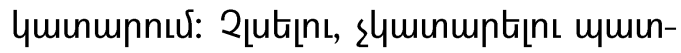
Gunny junynux 5 unu hupuptenntpjniuutinn dunnutuph htin:

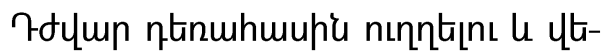

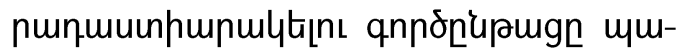

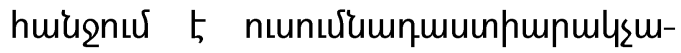
ymu unupptip রhengutiph huviughn 4hpunnux, nnn vito quiuptin le htionlun-

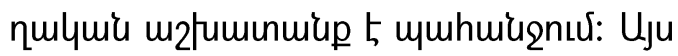

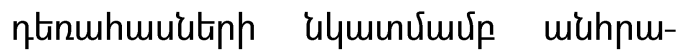

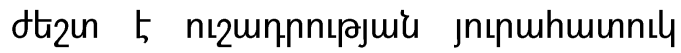

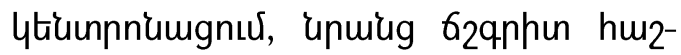

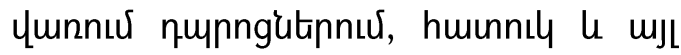

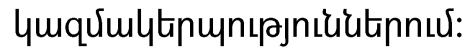

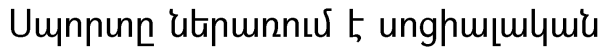

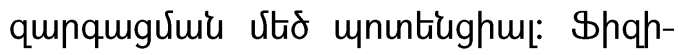

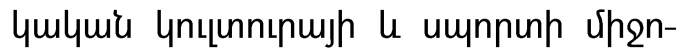

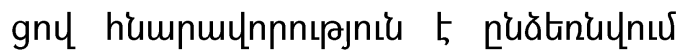

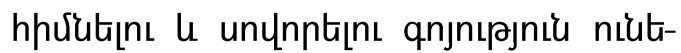
gnn humupulyulymu ympph unnútanu nı optiuputinn, lu npuiug huinuly 4hnu-

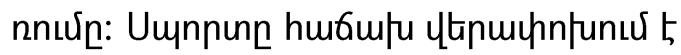

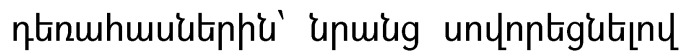

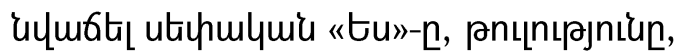


\$hqhymlumir ptinqunqugluonıpjniun' qunitinny le qunqughtiןny ns uhmju nt-

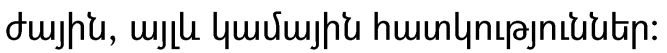

Unynnupun umnnunujumgymo

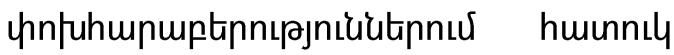

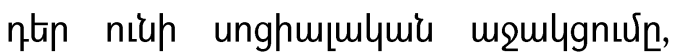

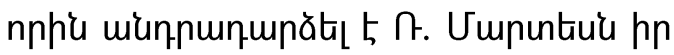

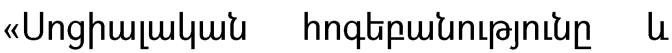

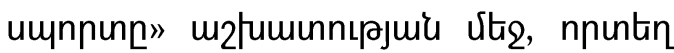

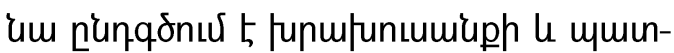

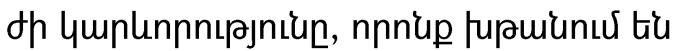

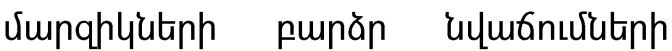

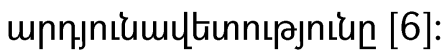

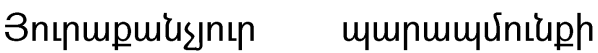

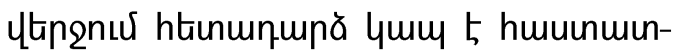

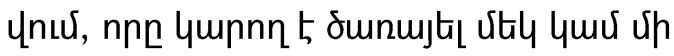

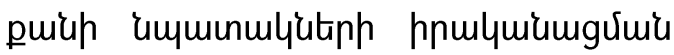
huvium '

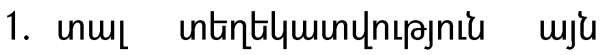

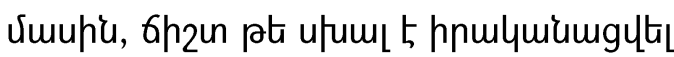
yundnıрлnı'un,

2. unnfuts Uumnns Ununhlughnn's Uh6ulyn' nnutiu vimphliutiph u¿mugưuiu uheng unuiug yunph unnfunt-

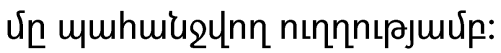

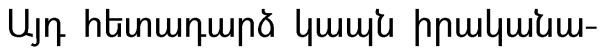
unuर 5 uvitumunumptip unengutinnl: $\langle\mathrm{G}-$ ununumă qumh unughu nunhtuínugyumo ălitiphg 5 mpnjniuph hưugnt-

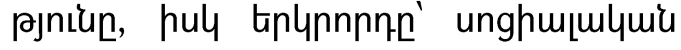
uqulygnıpnı̌un:

Ujdu n.hunuplitiup, pt his ulqqpniupny 5 unghmimluiu mqulygnıpjnıúu myunhymgunuर lu nınnnnпnuर्u yunpn:

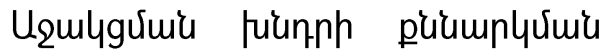
duviuiumly unhmumpuly tununuर tí mon

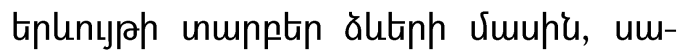

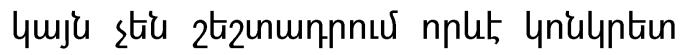
huulumgnıpuuxp: Ujn hưuuunny mí-

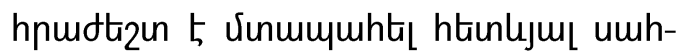

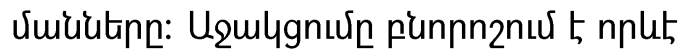

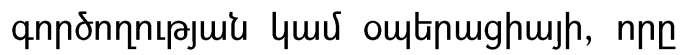
uhunumo 5 nıdtinugutal ynulyntion ntiulyghujh untumul:

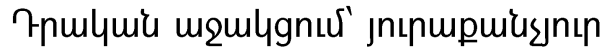

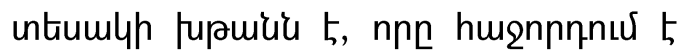

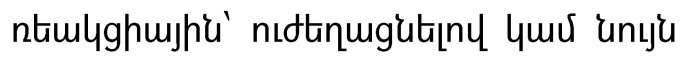
vimlunnmuntu muhtinny mju:

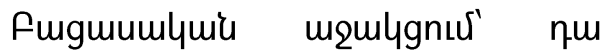

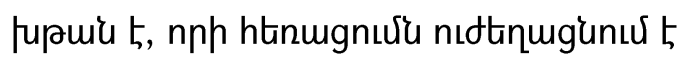
ntimlghuiu: Umlymju mju huulymgntpjniun phe 5 nu्upnuy nuर hn 6h2un hưuuunnu: <ufiulu funutiny pugmumlymir məmignıرu'u vimupi' vtiup tiupmnnnu tiup hus-nn up pumgjul unhur tupuiu:

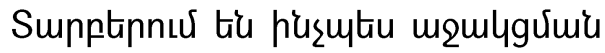

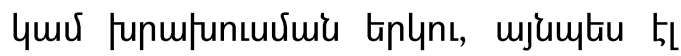
umundp tiplnı quu: 


\begin{tabular}{|c|c|c|}
\hline \multicolumn{3}{|c|}{ U2ulgưui uptumlitinn } \\
\hline 7nulymì & 1. nnulymitu mqulygnuर & 2. uquinhd \\
\hline furgunulymin & 3.upuunhd & 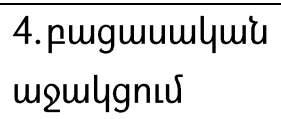 \\
\hline & 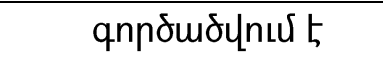 & vtundumic \\
\hline
\end{tabular}

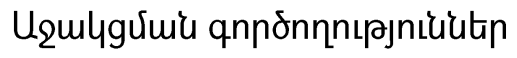

\section{Ulyun}

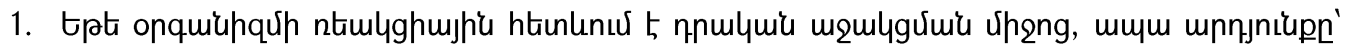

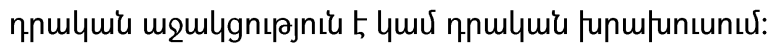

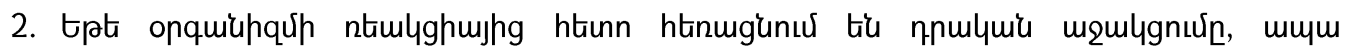

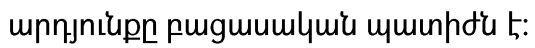

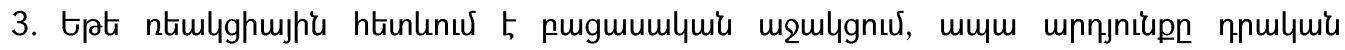
umunhơu 5 :

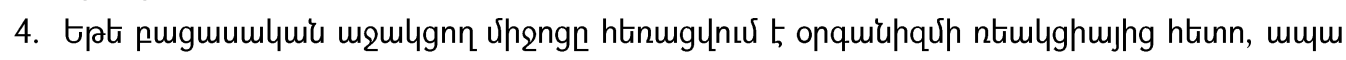

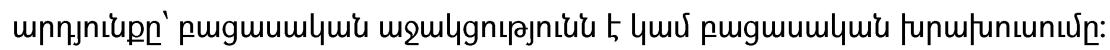

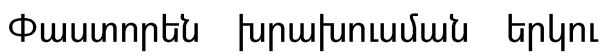

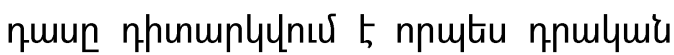
mquilgnıpjniu (1 u 4), hul muindh tiplns quun' nputiu pugmumlymí (2 lu 3):

Enp Umpqhen qnunuर 5 hmennumo

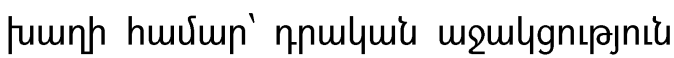

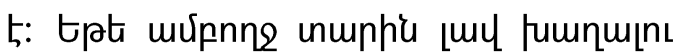
huruum viunqhen uh2un qnunuर 5 uर्utu t_nujphg htiunn, pujg up op qu sh muntu, samjur, nn jux fumn 5 intinh

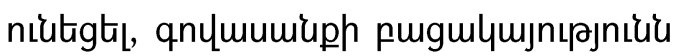

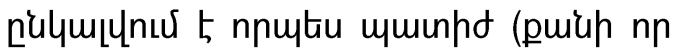
pnцnnn ununn tiu qnu(mumuph):
Anumumiup u ulymunnnnıpjnıiu,

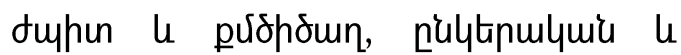

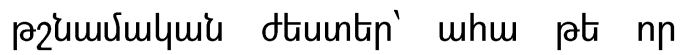

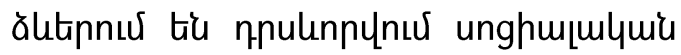

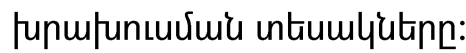

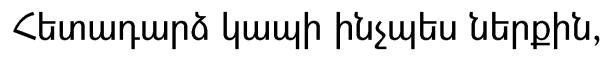

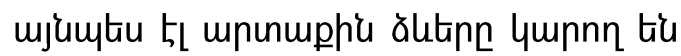

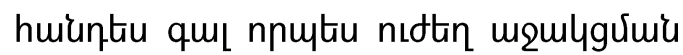

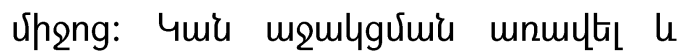
pnumbtu 2n2mutth untumlytate, huzush-

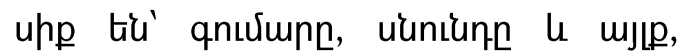
nnnip hujunup tí unsjumtiu nnutiu m-

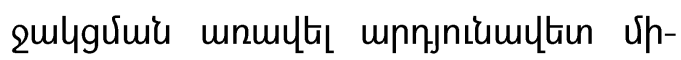
engitip: 
Utip optinnux \$hqhlumluir ynu-

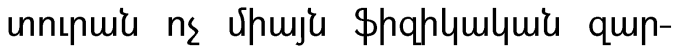

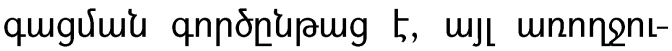

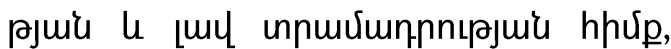

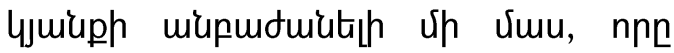

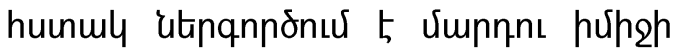

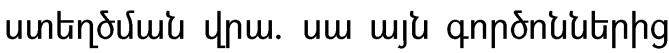

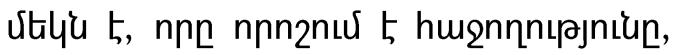

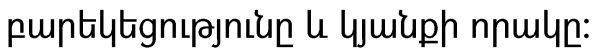

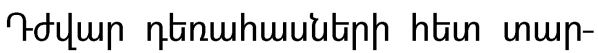

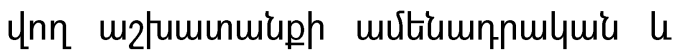
yuphnnmqnuju uhengn umnnun' t:

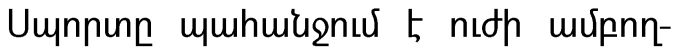

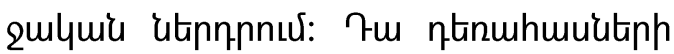

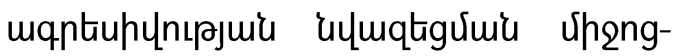
utiph vityu t: Umpqnưutinh, ungnut-

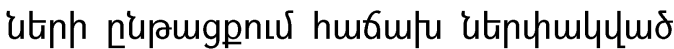

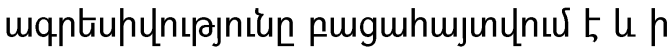

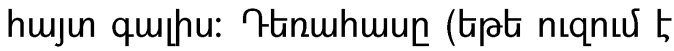
hunpaiumly niatium), uting t titpnuh hupgumunhnumbinnur, ythnuhulyh

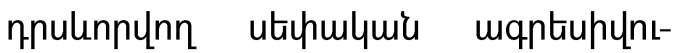

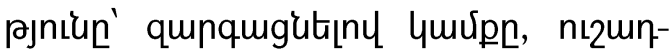

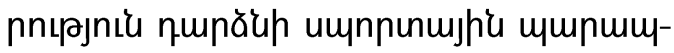
uniuputiph punnjuhnqtipuiumlymirs ynnu्upi:

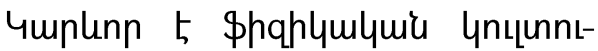
nujh quutiph qnulquil mqntignıpjniun

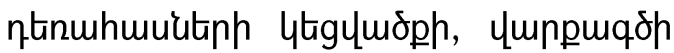

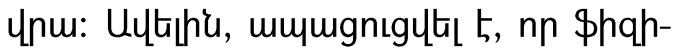
ymumiu ynıınnımujh quatiph z'unnhpl

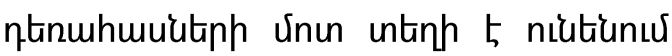

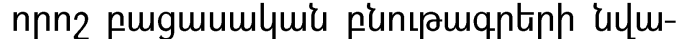

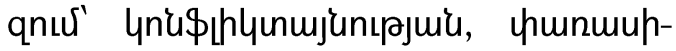

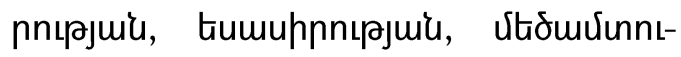
pjuí nnulunnưuíu [1]:

5. 3nt. Uymutiunulh "quynngu-

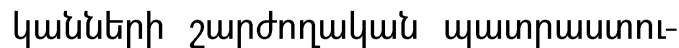

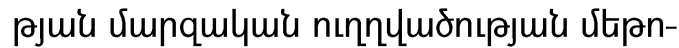

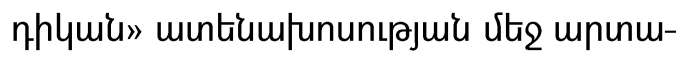

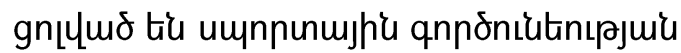

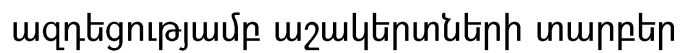

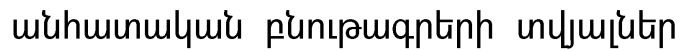

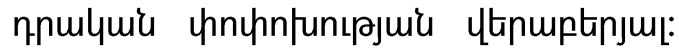

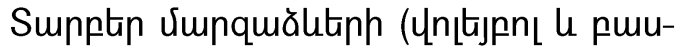

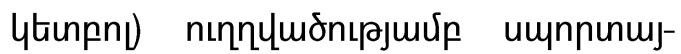

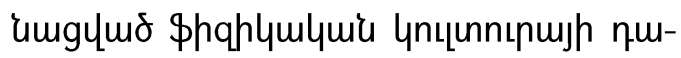

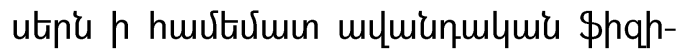

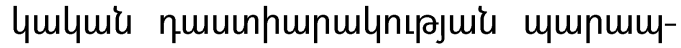

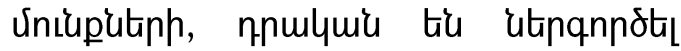

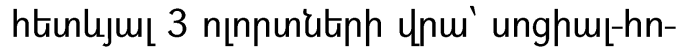
qtipuiamlymiu, \$hqhymlquí le unnngu-

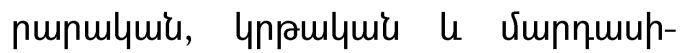

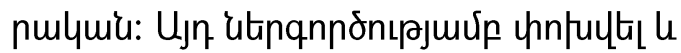

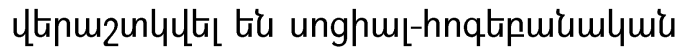

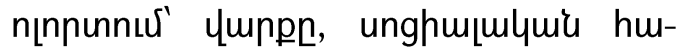
ymulunıpniukutnn, huiunnındnnulym-

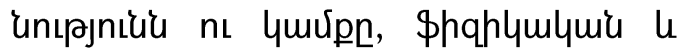

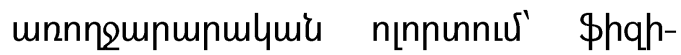

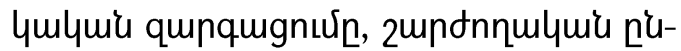

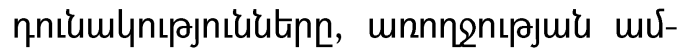

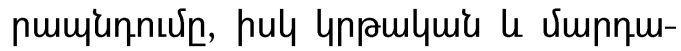

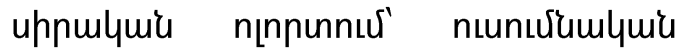
unųunhưnıpjniun, vinuunn pu- 


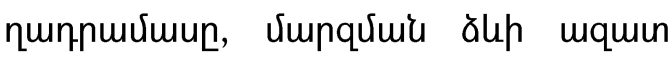

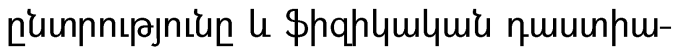

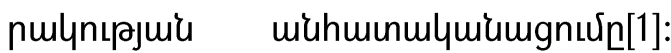
Umnnumujumglus \$hqhlymlumi quu-

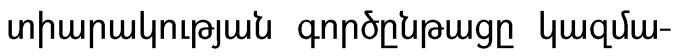

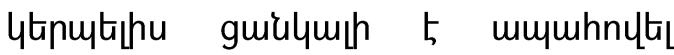

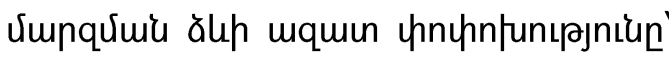

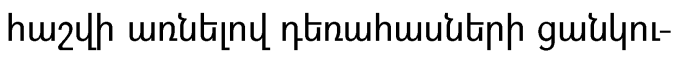

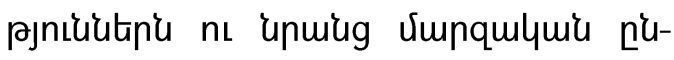

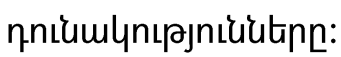

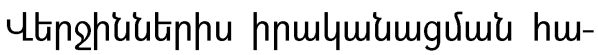

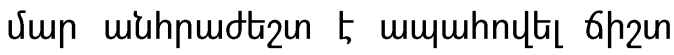

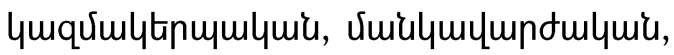

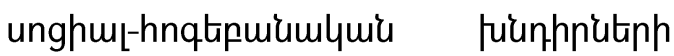
[nเonıún:

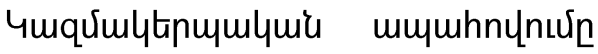

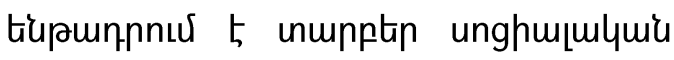

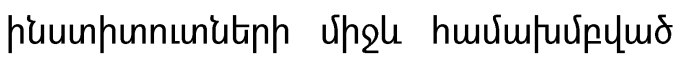

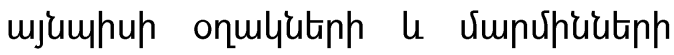

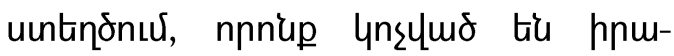

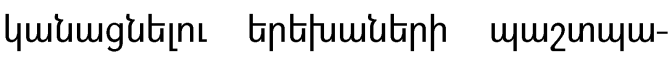

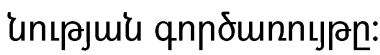

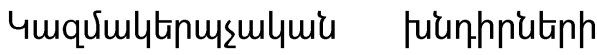

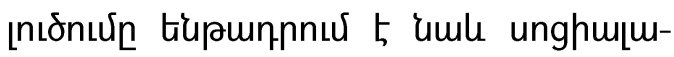
quir matumunnnutinh le vimilymumpdutph, qnnofumlquir hnqtipuiutitph

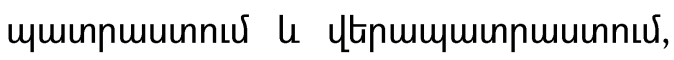
viunqhsutiph, umnnunujpu hnqtipuiuutph ytimumuinnumuinnux, nnnup hnuymuns ythutiu hnulymiamghtins vimu'umqhunmlumi, unghmqulume, hnqt-

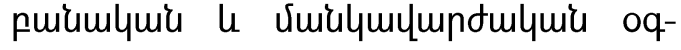
unıpjnı:

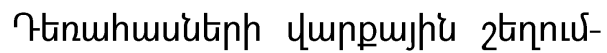

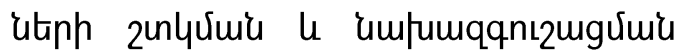
hungtinnuर vito ntip yunnn tú niutiumL puquimphy unıpjtyenutan' ns upuju

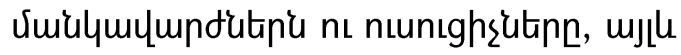

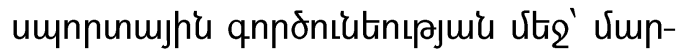
qhétipu ns umnnunujhe hnqtipuiüutinn: Uulymju unuiug qnnoniutunıpjniưu

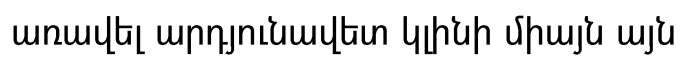

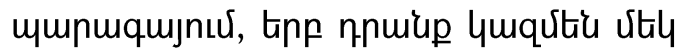

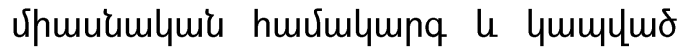

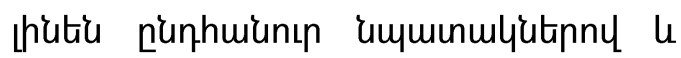

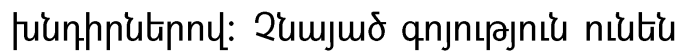

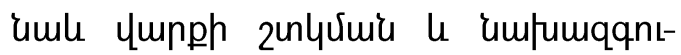
zmgưuir puquimphy mJ uhengutin (unghm[mlumi, hnqtipuimumiu, unghm!-

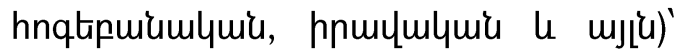

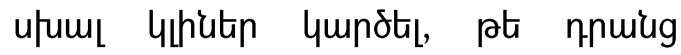

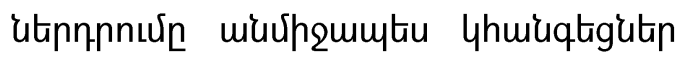

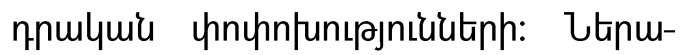

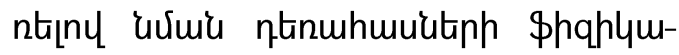

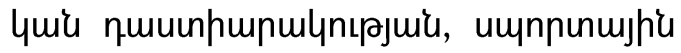
qnnoniutunıju'u vitr, pnuqnnotinul

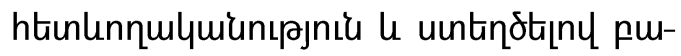

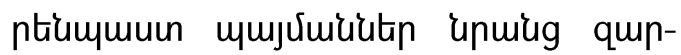

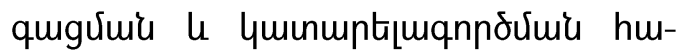

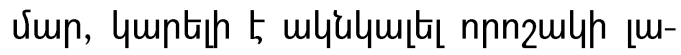
yuuntunıpjıiu:

tqnulymgnıpjnitu: Ujumpuny' цm-

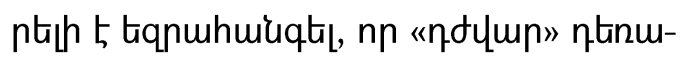


huuititnh htion m2tumunuiupnux nnn2hs

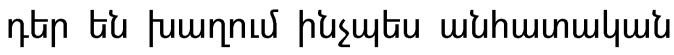

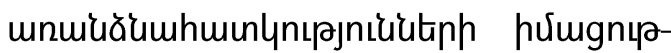

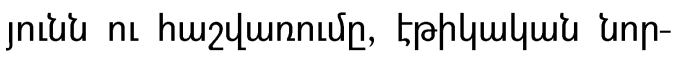

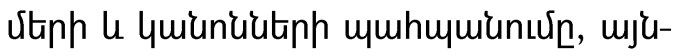
mbu th unghmi-hnqtipuiumlymiu, цnрu-

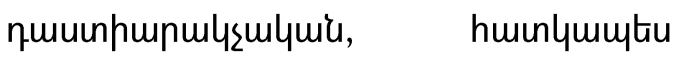

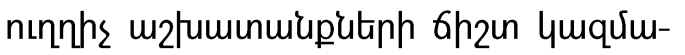

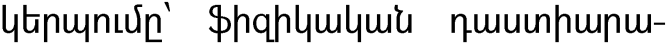

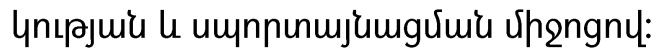

Sujul hnnumon ympnn 5 nnn2muh

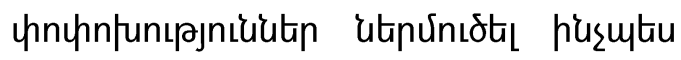

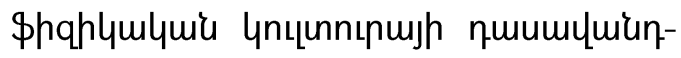

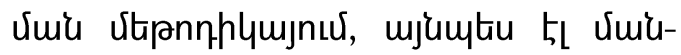

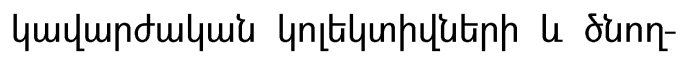

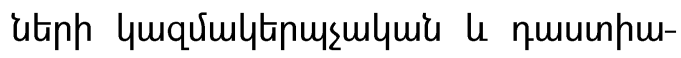

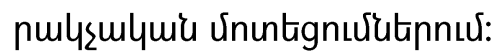

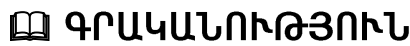

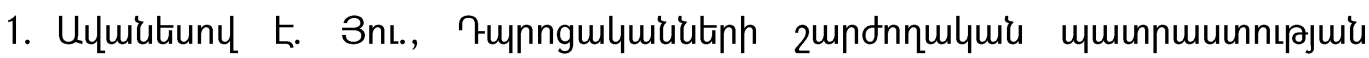

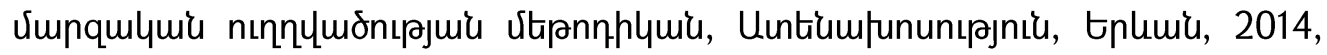
169 t2:

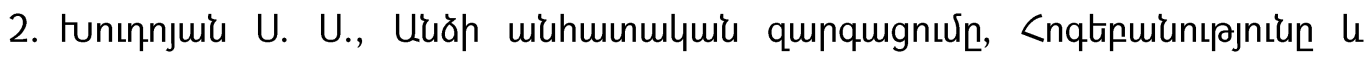
4juiupn huiuntiu, «Ruiuquil-97», ఈplumiu 2005, 5 5,:

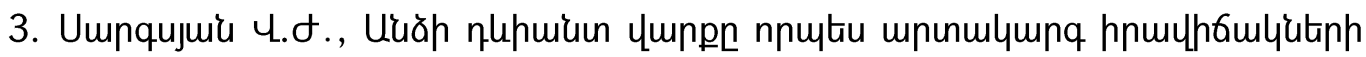

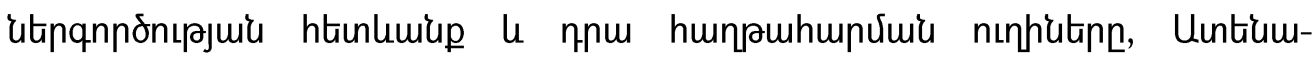
Jununıpnı'u, Łplumi, 2005, 165 t:2:

4. Балабанова Л.Г., Судебная патопсихология, Л., 1996.432 с.

5. Бачерников Н.Е., Воронцов М.П., Петрюк И.Т., Цыганенко А.Я., Эмоциональный стресс в этиологии и патогенезе психических и психосоматических заболеваний. Харьков, Основа, 1995, 276с.

6. Мартенс Р., Социальная психология и спорт. Изд.: М.: Физкультура и спорт. 1979. 176c.

7. Юнг К. Г., Психология бессознательного., М. Канон, 1994. 


\section{SPORT AS AN IMPORTANT FACTOR OF SOCIALIZATION AND A WAY TO MODIFY "TROUBLED" TEENAGERS BEHAVIOR \\ PhD in psychology, associate professor N. Gevorgyan}

Armenian State Institute of Physical Culture and Sport, Yerevan, Armenia

\section{SUMMARY}

Keywords: socialization, sport, physical education, "troubled" teenager, deviant behavior, behavior modification, deviant behavior alerts, teenage crisis, personalization.

Research relevance: Currently, according to statistics, crime and violation of law are common mainly in countries and republics undergoing social shock and disasters as well as crisis or post-war period. Recent political issues create situations that require a complete system of approaches to overcome them. Current stage of the development of modern society is often perceived as a crisis where some negative influences are observed both among the elder contingent of society and teenagers, adolescents and youth.

Research objective: to explore and establish the unique role of sport in the process of behavior modification among "troubled" teenagers.

Research problems: 1 . Analyze the existing approaches in scientific literature related to behavior modification of "troubled" teenagers. 2. Study the role of physical culture teachers, educators, coaches in the modification of deviant behavior during trainings. 3. Introduce complex educational methods to solve the relevant problem.

Research methods and organization: During the research, observation and conversation methods, literature analysis were used. The research was conducted in high schools, sports and culture centers.

Research results: In sports activities, during the process of regulating the behavior of adolescents and teenagers, interpersonal and intergroup relationships are important as they contribute to transformation of deviant behavior. It is well known that people cannot evolve and exist outside of human society, communications and culture. This is where worldview and path of development lies. The psychological 
characteristics of teenagers with deviant behavior differ greatly. They require special individual approach, clear knowledge, skills, abilities and interpersonal relationships.

The problem of deviant behavior among teenagers remains one of the most difficult socioeconomic and socio-psychological problems that our society has faced. Although at present the state bodies as well as many international and national nongovernmental organizations, including sports federations are interested in overcoming this problem, the problem of deviant behavior among teenagers is still actual.

Especially recently special attention is paid to harmonious personal development and formation of the growing generation as well as to the improvement of organization of educational processes and the increase of teaching efficiency.

In this process, the problem of regulating deviant behavior by involving teenagers in sporting activities is highly important.

Conclusion: It is hereby concluded that in the process of working with "troubled" teenagers both the knowledge and consideration of individual characteristics, maintaining the ethical standards and norms and socio-psychological, educational, especially proper organization of correctional works through physical education and sports play an important role.

This article may contribute to some changes in the teaching methodology of physical culture as well as the organizational and educational approaches of the pedagogical staff and parents.

\section{СПОРТ КАК ВАЖНЫЙ ФАКТОР СОЦИАЛИЗАЦИИ И КАК СПОСОБ КОРРЕКЦИИ ПОВЕДЕНИЯ “ТРУДНЫХ” ПОДРОСТКОВ}

К.п.н., ассистент Н.Э. Геворгян

Государственный институт физической культуры и спорта Ереван, Армения

\section{PEЗЮME}

Ключевые слова: социализация, спорт, физическое воспитание, “трудный” подросток, отклонения в поведении, девиантное поведение, коррекция поведения, признаки девиантного поведения, подростковый кризис, персонализация. 
Актуальность исследования. В настоящее время, по статистике, преступность и нарушение закона распространены в основном в странах и государствах, находящихся в состоянии социальных потрясений и бедствий, а также в кризисных и послевоенных условиях. Политические развития последнего времени формируют ситуации требующие разработки полной системы подходов к их преодолению. Текущий этап развития современного общества часто воспринимается как кризис, когда наблюдаются негативные влияния как среди взрослого контингента общества, так и среди подростков, юношей и молодежи.

Цель исследования - изучить и обосновать важную роль спорта в процессе модификации поведения “трудных” подростков.

Проблемы исследования: 1. Проанализировать существующие в научной литературе подходы коррекции поведения “трудных” подростков.2. Изучить роль учителей физкультуры, воспитателей, тренеров в изменении девиантного поведения при занятиях спортом.3. Внедрить комплексные образовательные методы для решения данной проблемы.

Методы и организация исследования: В ходе исследования использовались методы наблюдения и беседы, анализ литературы. Подверглись анализу литературные источники, касающиеся коррекции поведенческих аномалий по следующим направлениям: а. исследование индивидуального развития (С. Худоян, А.Элис, В.Франкл, К. Юнг и др.), б. уроки по различным видам спорта в направленности спортивного социального воздействия (Р. Мартенс, Л. Любышева и др.), в. Процесс эмоционально-волевого управления поведением (внеклассные мероприятия, кружки, соревнования, прогулки).

Анализ результатов исследования: В процессе регулирования поведения подростков и юношей в спортивной деятельности важны межличностные и межгрупповые отношения, поскольку они способствуют трансформации девиантного поведения. Известно, что человек не может развиваться и существовать вне человеческого общества, коммуникаций и культуры. В этом и заключается его познание мира и направление развития.

Психологические характеристики подростков с девиантным поведением слишком разные. Они требуют особого индивидуального подхода, четких знаний, навыков, умений и межличностных отношений. 
Проблема девиантного поведения подростков остается одной из самых сложных социально-экономических и социально-психологических проблем, с которыми столкнулось наше общество. Несмотря на то, что в настоящее время государственные органы, а также многие международные и национальные общественные организации, в том числе и спортивные федерации, заинтересованы в преодолении этой проблемы, проблема девиантного поведения среди подростков по-прежнему остается актуальной.

Особенно в последнее время особое внимание уделяется гармоничному развитию личности и формированию подрастающего поколения, а также совершенствованию организации учебного процесса и повышению эффективности обучения.

В этом процессе очень важна проблема коррекции девиантного поведения путем вовлечения подростков в спорт.

Заключение. Таким образом, можно сделать вывод о том, что решающую роль в процессе работы с “трудными” подростками играет как знание, так и учет индивидуальных особенностей, соблюдение этических стандартов и норм, а также правильная организация социально-психологических, образовательных, особенно коррекционных работ посредством физического воспитания и спорта.

Данная статья может внести некоторые изменения в методику преподавания физической культуры, а также в организационных и образовательных подходах педагогического коллектива и родителей.

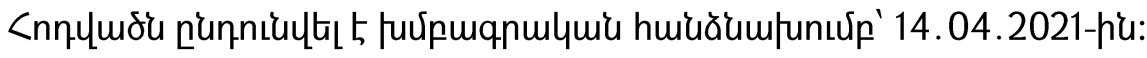

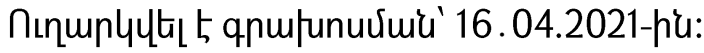


DOI: 10.53068/25792997-2021.1.3-161

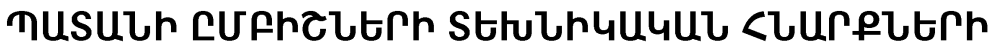 чusurtLuqnกסUUน กR2hutre
}

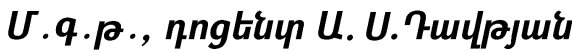

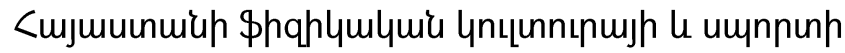

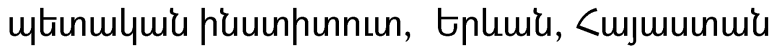 \\ E-mail: artyom.davtyan@sportedu.am
}

Unuragpujhr punten: 9punuutt-

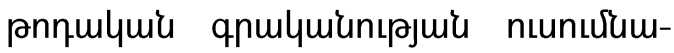

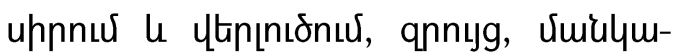

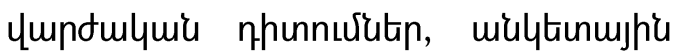
hungnus, vimptuimunhlyulume th6ulumqnnıрльน:

Stunuqnunnıpuir upnhulyuiunt-

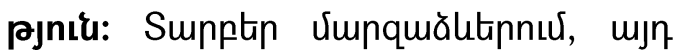

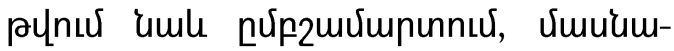
qtinutinn u vimnqhşutinn puquíngu

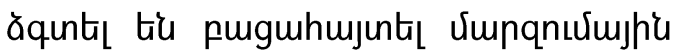

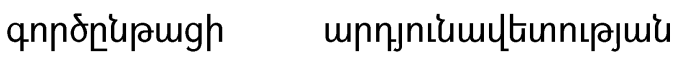

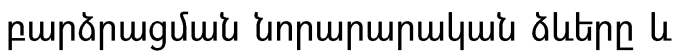

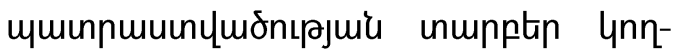

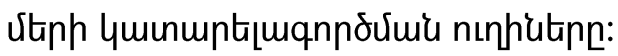

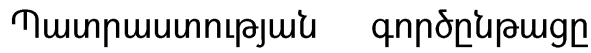
puquiuphy hrर्umutuanphitiph htin

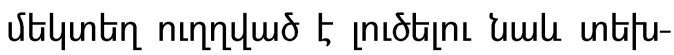

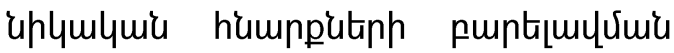

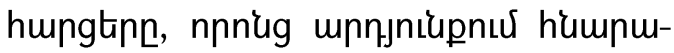

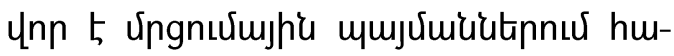

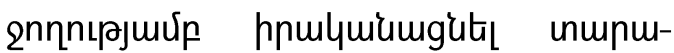

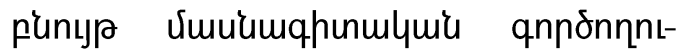
pjniüutin:

Tuunuiup nưphritiph 2nquiunu

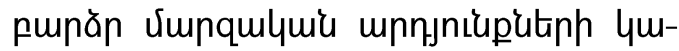

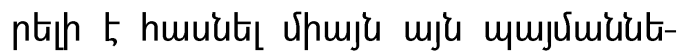

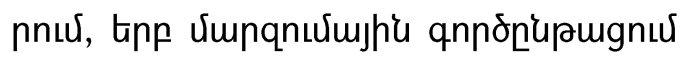

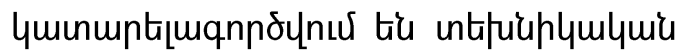

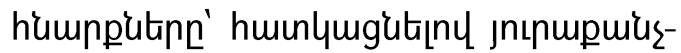
jnın humpphí ominhưul duviuiumlymhuinumo:

Cúp2uưununh unmpntip ălutinnư

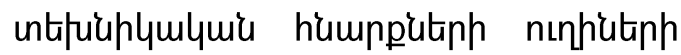

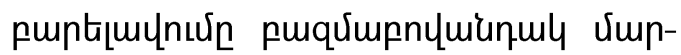
qnưumphu qnnozhupaug 5 :

cuppriutph vimpnnumjhe $\mathrm{u}$

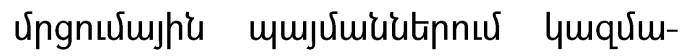

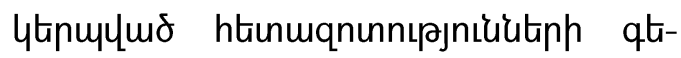

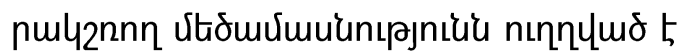

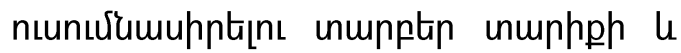
nnulymunnoumu vemphlyutiph intipuap-

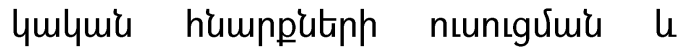

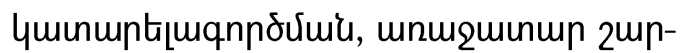

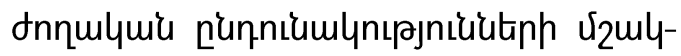


viui, vemphliutiph hnqtipuiumlymis

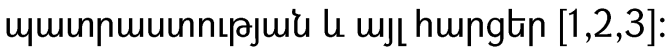

nıuinh, umunq 5 qununux, np upuin-

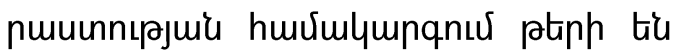

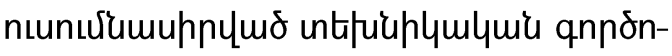

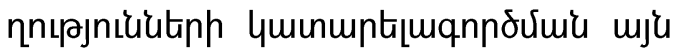

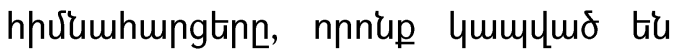

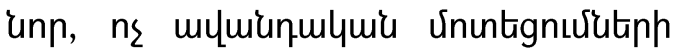
htin:

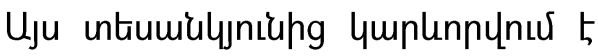

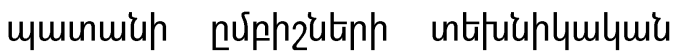

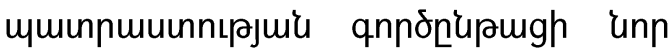
ununtigniutph $\mathrm{u}$ htiumuqnunnıpniüutiph

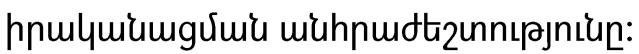

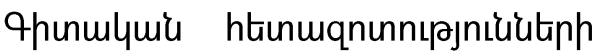

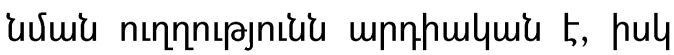

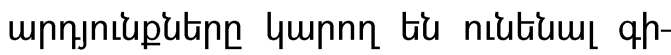

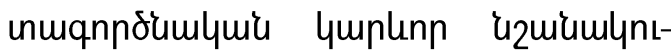

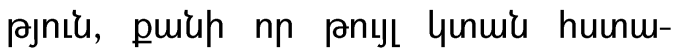

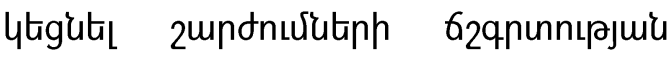

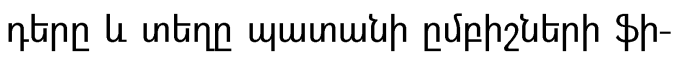
qhymlymis umunnmuinnıpjuis huर्um-

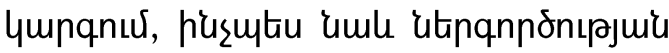

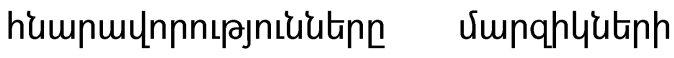

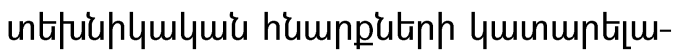
qnnovimiu le mpnjnilumultion pnulquium-

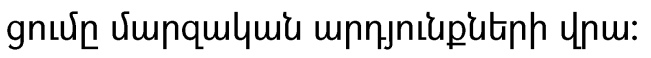

huly qu hn htipph's hpưp lhwil-

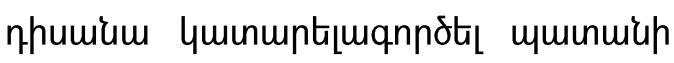
nu्uph2utiph umunnuuunnıрjuís qnnon'u-

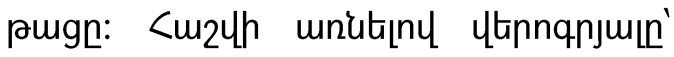

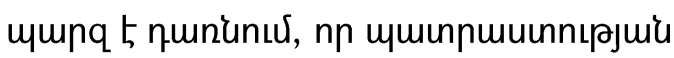

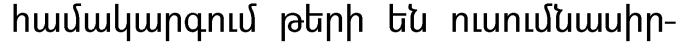

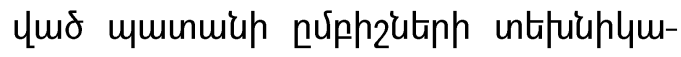

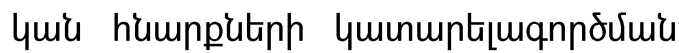

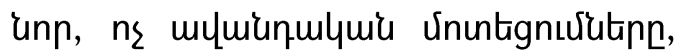
unn uhenguthn:

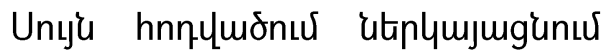
tup htinumqnunnıpniukutiph unn unn-

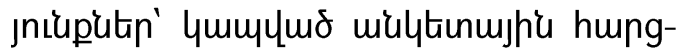

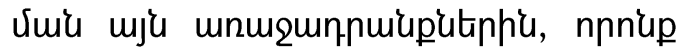

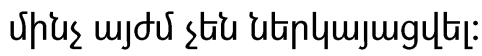

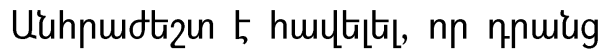

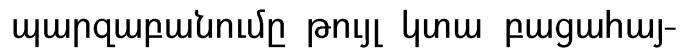

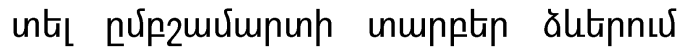

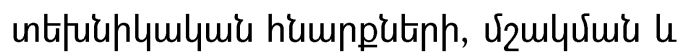

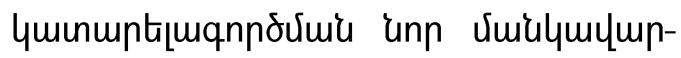

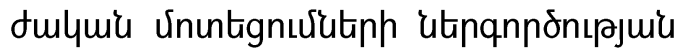
muinhfimup vimupis:

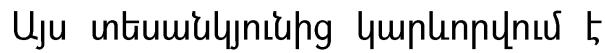

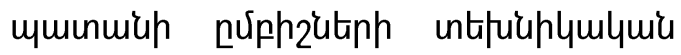

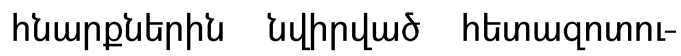

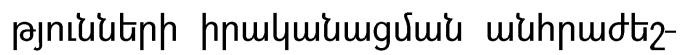
unnıpjnıนu:

\section{Stinuqnunnıرuis \&uquinuln:} Uulytinumpir hungưuiu uhengny puggu-

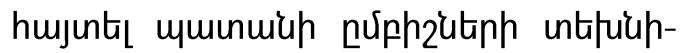

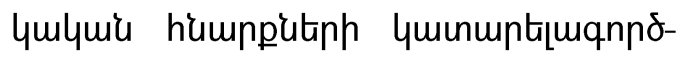

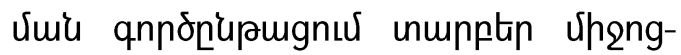
utiph, ununtignưutiph oqunuqnnơumiu

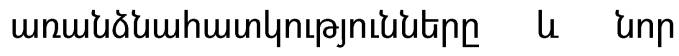
nınhüinn:

\section{Stunuqnunnıرuis vitpnniting}

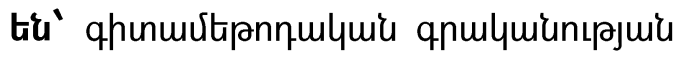




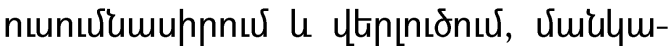

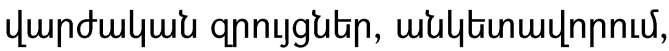
vmptiumphlymlymi पh6ulymqnnıрnil:

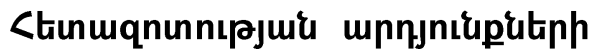
丩tnцnıðnıрjnılu:

Umulumqhunmlquil qrulymintpjuí

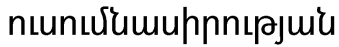

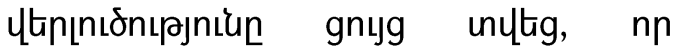

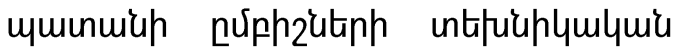

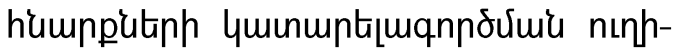

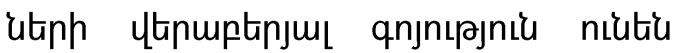
unupptip hujtgulytiontip, nnnip hntiug

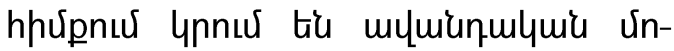
untgnuxutin: Utinghiu tiupaunpnux b

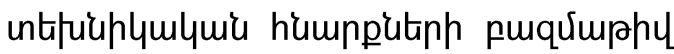

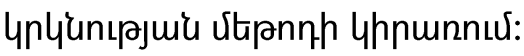

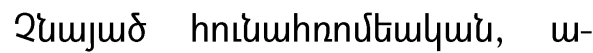

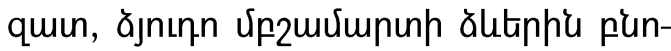

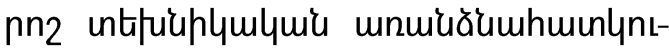

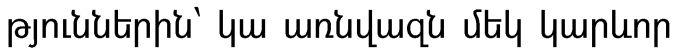
huiuquưuiup, nn uuntnonuर 5 unwiug

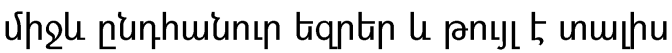

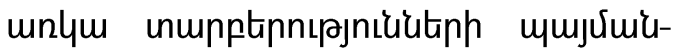

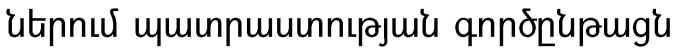

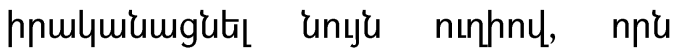

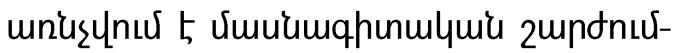

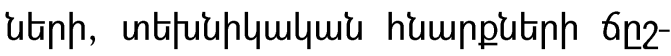

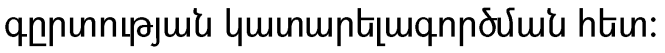

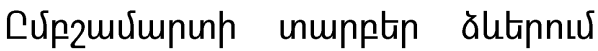
untuuuplymlyuís humpeutiph htien unišlnn puquiumphy mpnhulymiz hum-

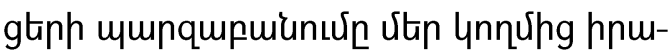

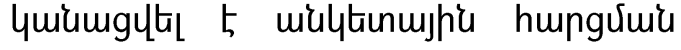
uhengnu:

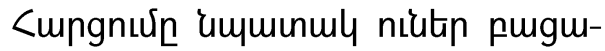

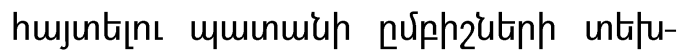

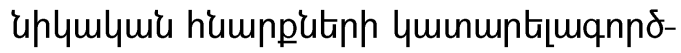

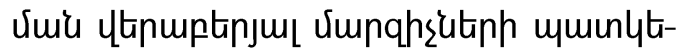

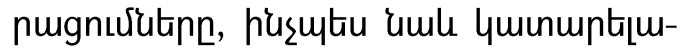

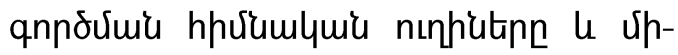
2ngutin:

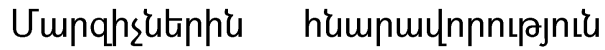
nuătanultg nnn2 hungtaph muinuuutumí-

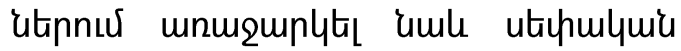

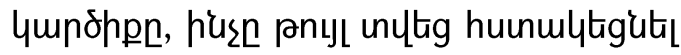
u ti2qnunta nunusumupnynn hpu-

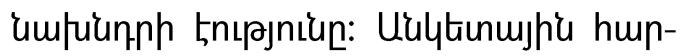
gnuरa minglymgltas 5 qhunmlymu qnulymunıpjnı́unuर utplqujugymo tinu2łum-

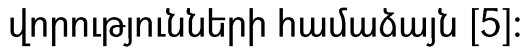

<unguiviur nunqnlyltal tiu hntumhnnưtumlquiu, uquin, ăjnınn nứp2uJupunh unupptip npulyuunnnuर niutgnn 70 vimphs: Uju ququimltipuyltal 2019-2020pp. tplumí punupp unupptip vimimlqummenmitilumer vimp-

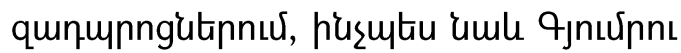

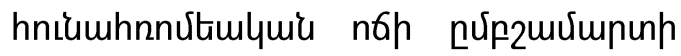
unmemntur vimnghsutinn:

<ungynn vimphşitiph vtiouviuuunıpjniun umnnunp ymputinutitn $\mathrm{l}<m-$

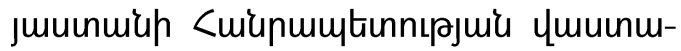

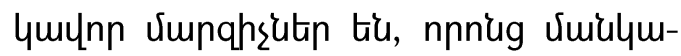




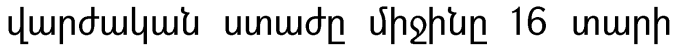
5n:

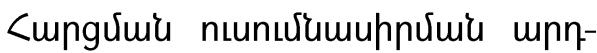

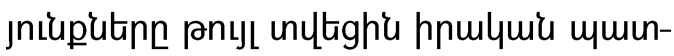

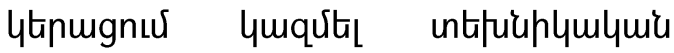

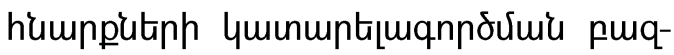
vimphy hpưumhungtiph ytpuptpju[:

<tunuqnununnutiph hungnulutung umunq 5 qununu, nn vimpqusutiph 94 \%-h yundhpny humpuulnn 5 Juuumqhunulyuiu qnnonnnıрjnılütiph

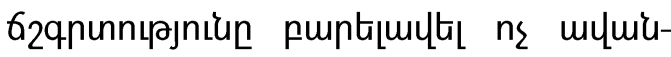
quiluiu Guiumumphny:

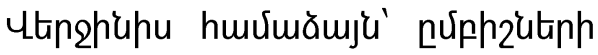

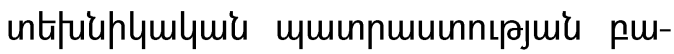

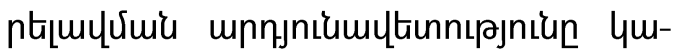

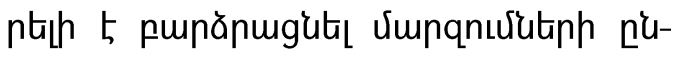
pugpnuর unupptip vimpquălitiph nnn2 yundnıpniuiutiph (unupntiph) utip-

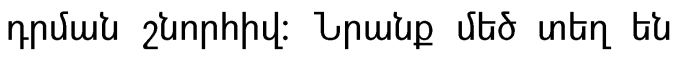

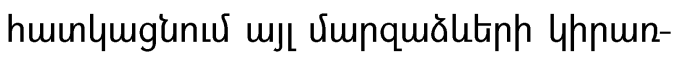

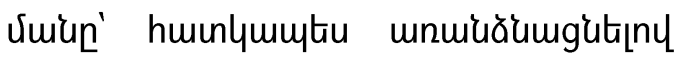

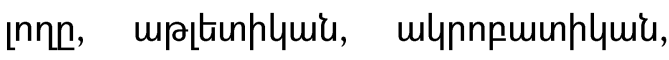

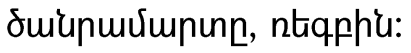

Cuin U.U. Ynnuti2nulh [4] htinumn-

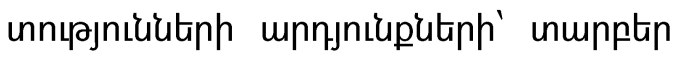
Uunquălutph uhnunnıuñ muinnmuinnt-

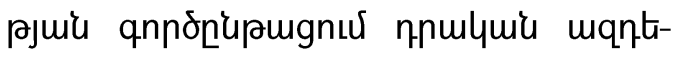

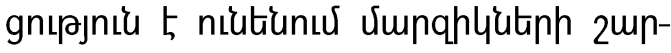

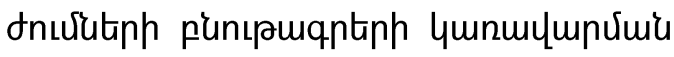

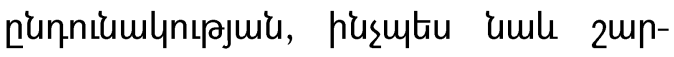

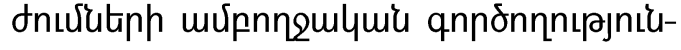
utph 62qnunnıرuiu unu:

<ungưuiu unnjniupnux viunqhe-

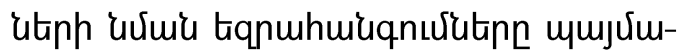

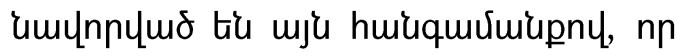

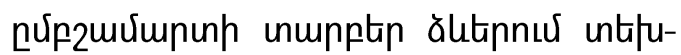

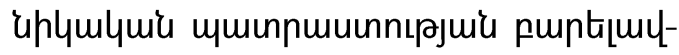

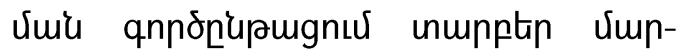

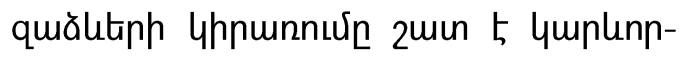

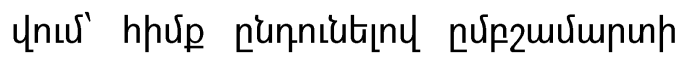
nunuरamlymís quamqnptiph, viulym-

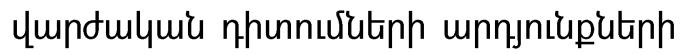

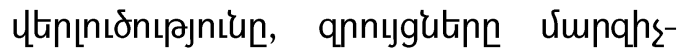
utiph htiun:

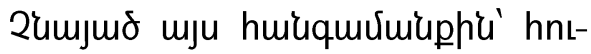
Gumnnútimlquiu, uquin nfip u ăjnınn

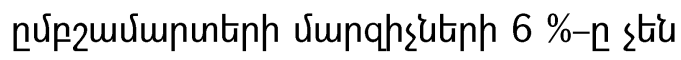
pugunnuर, np umunumin vimpqhyutiph

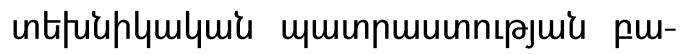

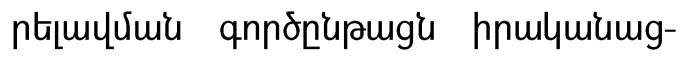

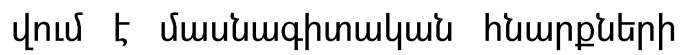
puquiuphy unlunıpjniulutiph vhengny,

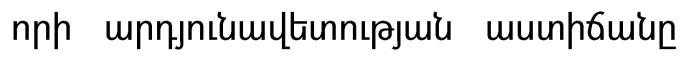

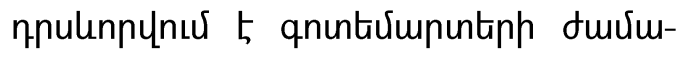
uml:

Uhlüny'u duviuiuml vimphesutinn

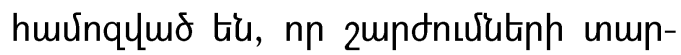

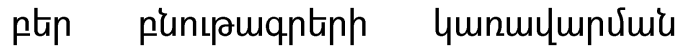

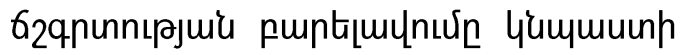

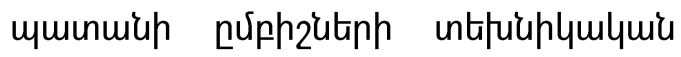

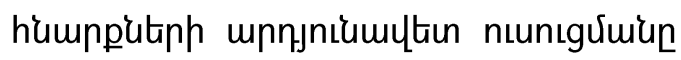

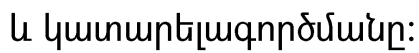




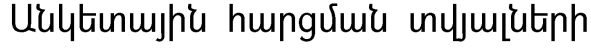

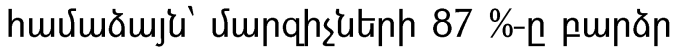

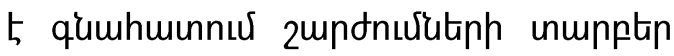

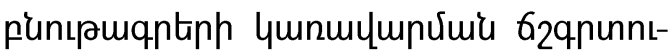
pjuí ¿zmiumlynıرniun, hul 13 \%-n ns

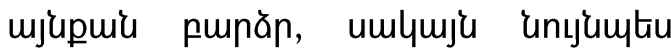

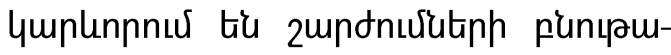

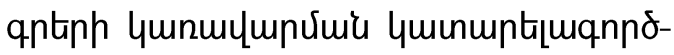

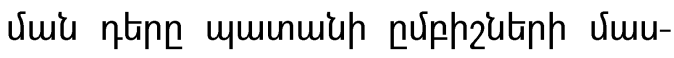

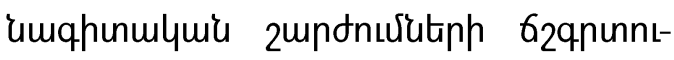

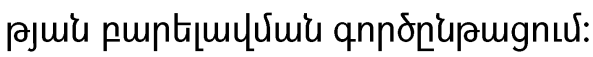

Umpqhsutinn, quplunnting 2mp-

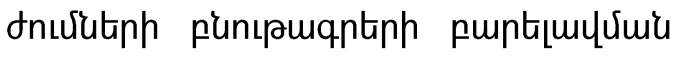

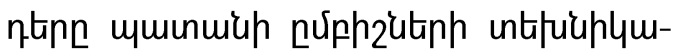

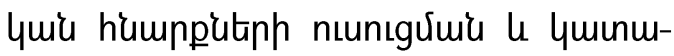

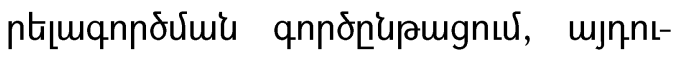

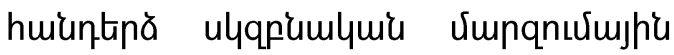

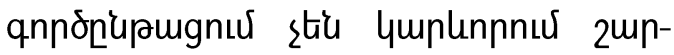

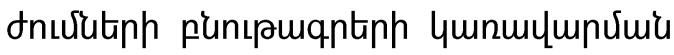
62qnunnıpjuí punănugưưu hurưun umpumintiulus huinnily \$hqhymlymir hnqtizundhs ymodnıpniculating (unu-

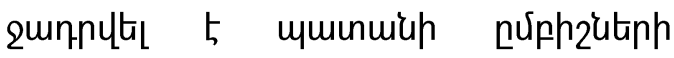

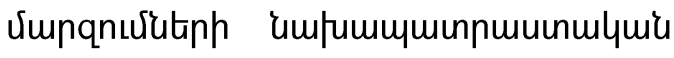

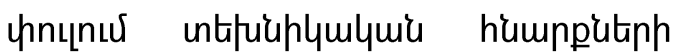

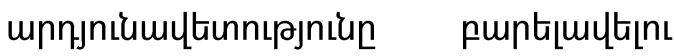

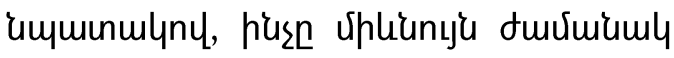

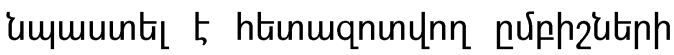

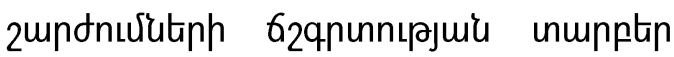

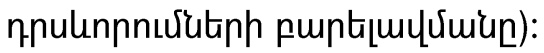

Uju unnưny nnn2 htnhiumlititn

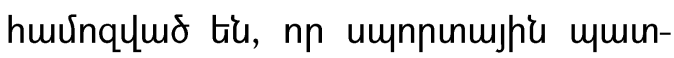

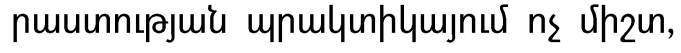

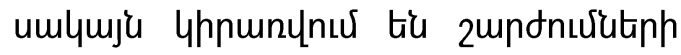

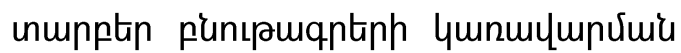

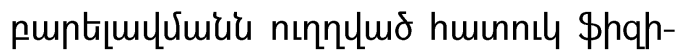

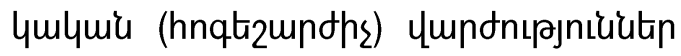
$[(6,7]$ :

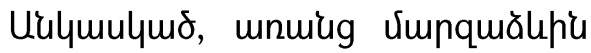
punnn2 unthưuplumlyui humputaph

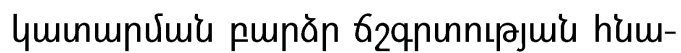
nuunn st huukta vimpqulymir huen-

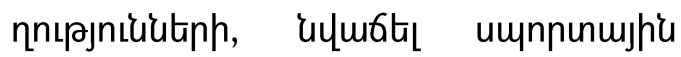

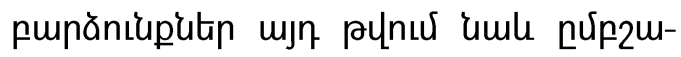
Uumunnux:

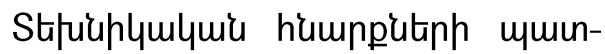
puuunumonıpjuiu le uJ qnnonulutiph htien vityuntin, uminuiup núuphouteph

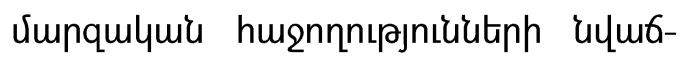

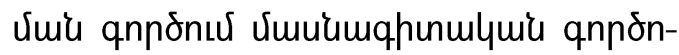

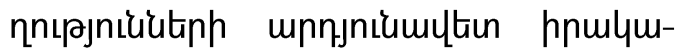

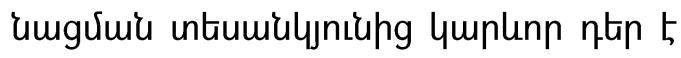
jumnnus untjuaplymlymis humpeitiph

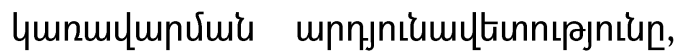
nnh surhuiuh2ting vitiln quinth t5

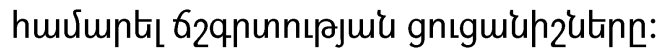

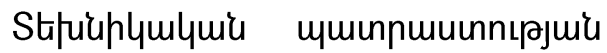

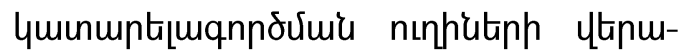

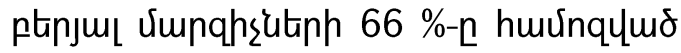

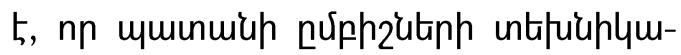

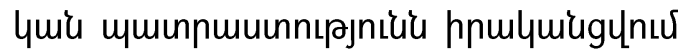

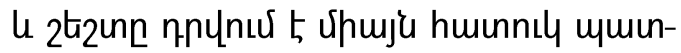

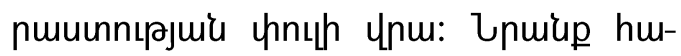
ymuunhughunus tiu, nn huunnily umun- 


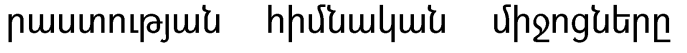

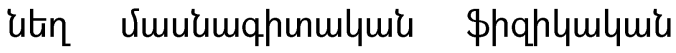

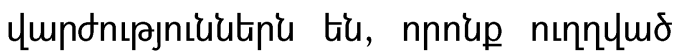

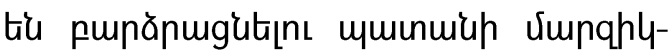

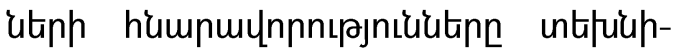

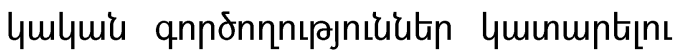
durúuiumly: Umphsilitph 12 \%-h

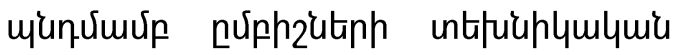

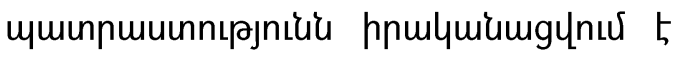
umpumumunnumunulymir unnцnuर, hul $22 \%$ - p' pnцnn upnцtinnux:

Funăn nnulymunnnux niutgnn Uunqhsutinh qunopputinh upnjniup-

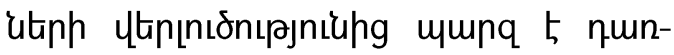

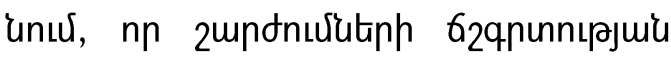

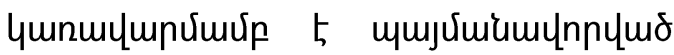

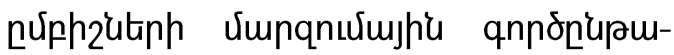

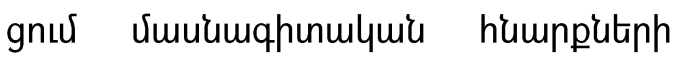
unnjnıłumultinnıрjnı'un:

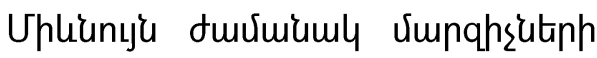

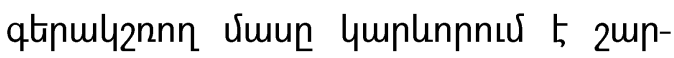

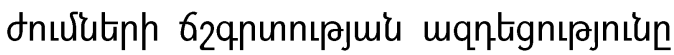

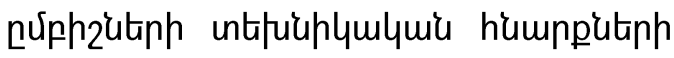

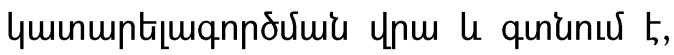
nn uju nnnzhs nten t tuwnnuर vimpqhy- ütph umnnumughtu üumanudutitph qnp-

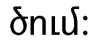

tqnulyugnıpjnıı: fupănulyunq

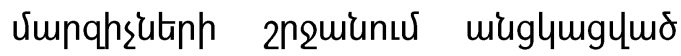

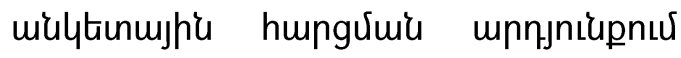

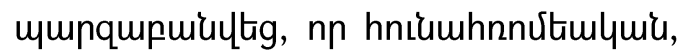

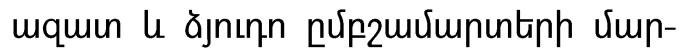
qhétinn qunlunnnux tiu mJL vimpquăltinn uhnunnữn muinuiup nu्uph2-

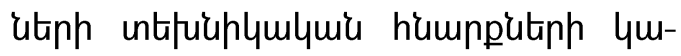

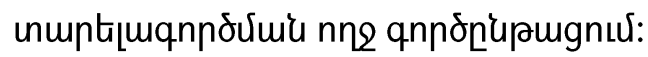

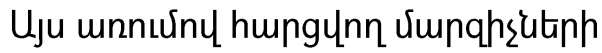

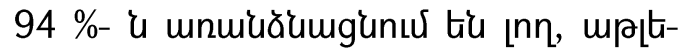

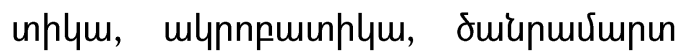
Junquălutph nnnzmuh ununntep:

Unuigg qtinuly2nnn vitomuluuunt-

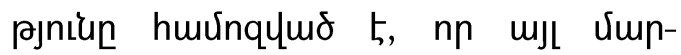
quălitiph nnnzulh ununptiph 4hpun-

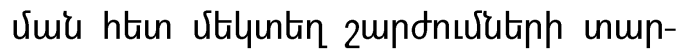

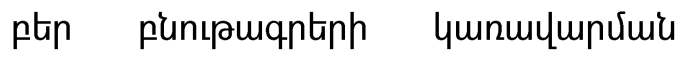

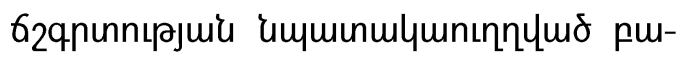

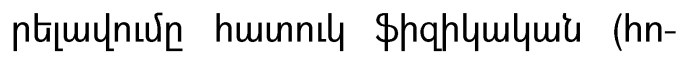
qtizmonds) ymodnıpjniuutiph uhengny

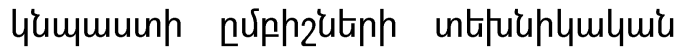

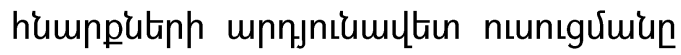
u quinumitumqnnớuiun: 


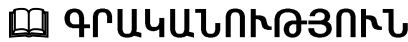

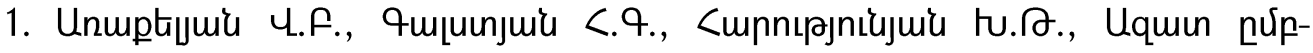

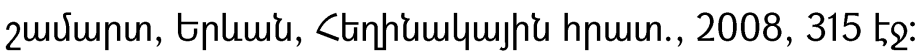

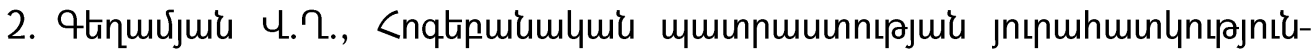

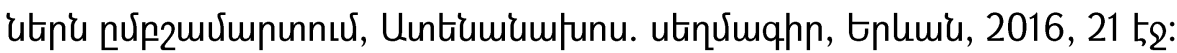

3. Воробьев В.А., Содержание и структура многолетней подготовки юных борцов на современном этапе развития спортивной борьбы: Автореф. дисс... док. пед. наук. - СПБ, 2012. -56 с.

4. Корнешов А.А., Чувство времени и его детерминация в осознанном управлении двигательными действиями в спорте: Автореф. дисс. канд.пед.наук. М. $2003-24 c$.

5. Тавокин Е.П., Основы методики социологического исследования: Учебное пособие. М.: ИНФРА-М, 2009. - 239 с.

6. Уатфи Улфать,- Иследование способностей школьников управлять движениями,-/Теория и методика физического воспитания, Ереван,-2000, 173с.

7. Чатинян А.А., Научно-методические основы совершенствования точности двигательных действий: Автореф. дисс... док. пед. наук. - Ереван, 2009,-288с.

\section{WAYS TO IMPROVE TECHNICAL TRICKS OF YOUNG WRESTLERS \\ PhD of Pedagogy, Associate Professor A. S. Davtyan}

Armenian State Institute of Physical Culture and Sport, Yerevan, Armenia

\section{SUMMARY}

Key words: study of scientific-methodical literature, analysis, conversation, pedagogical observations, questionnaire, mathematical statistics.

Relevance. The vast majority of researches conducted within trainings and competitions of wrestlers is aimed at studying issues pertaining to instruction and improvement of technical skills among athletes of different ages and qualification, as well as development of advanced motor skills, psychological preparation of athletes and so on.( V.B. Araqelyan, Kh.T. Harutyunyan, 2008, V.Gh. Geghamyan, 2016, V.A.Varabyev, 2012 and others) 
Thus, it becomes clear that in the training system technique improvement issues related to advanced and non-traditional approaches are poorly studied.

The research purpose is to reveal through a questionnaire the peculiarities and ways to use different means and approaches in the process of improving technical tricks of young wrestlers.

The research methods comprise study and analysis of scientific-methodical literature, pedagogical conversations, questionnaire, mathematical statistics.

Overall 70 coaches of greco-roman and freestyle wrestling, judo with various qualifications got involved in the survey, among them masters of sports, honored coaches of the Republic of Armenia with average pedagogical experience of 16 years. The survey was organized in 2019-2020 and encompassed a variety of Yerevan children and youth sports schools. The purpose of the survey was to find out the coaches' ideas on how to improve the technical skills of young wrestlers, as well as the main ways and means to do so. Development of technique in different types of wrestling is a multi-faceted training process.

Conclusion. As a result of survey conducted among the high qualified grecoroman, freestyle and judo wrestling coaches the use of other sports to enhance technical tricks of young wrestlers was turned out to be most important.

In this regard, $94 \%$ of surveyed coaches give preference to certain elements of sports like swimming, acrobatics, athletics and weightlifting.

The majority of coaches are convinced that alongside particular elements from other sports the purposeful improvement of various movement parametres control accuracy will contribute to effective instruction and perfection of wrestlers' technical tricks through special (psychomotor) exercises. We are planning to check this assumption during the pedagogical experiment. 


\section{ПУТИ СОВЕРШЕНСТВОВАНИЯ ТЕХНИЧЕСКИХ ПРИЕМОВ ЮНЫХ БОРЦОВ}

\section{К.n.н., дочент А. С. Давтян}

Государственный институт физической культуры и спорта Армении, Ереван, Армения

\section{PEЗЮME}

Ключевые слова: Изучение научно-методической литературы, анализ, беседа, педагогические наблюдения, анкетный опрос, математическая статистика.

Актуальность исследования. Подавляющее большинство исследований, проводимых в тренировочных и соревновательных условиях борцов, направлено на изучение вопросов, таких как обучение и повышение технических навыков спортсменов разного возраста и квалификации, развитие продвинутой моторики, психологическая подготовка спортсменов разного возраста, технических навыков квалифицированных спортсменов, развитие продвинутой моторики, психологическая подготовка спортсменов. (В.Б. Аракелян Х.Т. Арутюнян,2008, В.Г. Гегамян,2016, В.А. Воробьев, 2012 и другие).

Таким образом, становится ясно, что в системе обучения недостаточно изучены вопросы технического совершенствования, связанные с продвинутыми, нетрадиционными подходами

Цель исследования: с помощью анкетного опроса выявить особенности и способы использования различных средств, подходов в процессе совершенствования технических приемов юных борцов.

Методы исследования включают изучение и анализ научно-методической литературы, педагогические беседы, анкетный опрос, математическую статистику.

В опросе приняли участие 70 тренеров по дзюдо, греко-римской и вольной борьбе различной квалификации, в том числе мастера спорта, заслуженные тренеры Республики Армения, педагогический стаж которых в среднем составлял 16 лет. Опрос был организован в 2019-2020 годах в различных детско-юношеских спортивных школах Еревана. Целью опроса было - узнать идеи тренеров о том, как улучшить технические навыки юных борцов, а также основные способы и 
средства для этого. Освоение техники в разных видах борьбы - многогранный тренировочный процесс.

Заключение. По результатам социологического опроса выяснилось, что армянские высококвалифицированные тренеры по греко-римской, вольной борьбе и дзюдо отмечают важность использовании других видов спорта для улучшения технических приемов юных борцов.

При этом 4\% опрошенных тренеров отдают предпочтение определенным элементам следующих видов спорта: плавание, легкая атлетика, акробатика, тяжелая атлетика.

Подавляющее большинство тренеров убеждены, что наряду с отдельными элементами из других видов спорта целенаправленное улучшение точности управления различными параметрами движений будет способствовать эффеективному обучению и совершенствованию технических приемов борцов при использовании специальных (психомоторных) упражнений. Данное предположение планируется провести в ходе организуемого нами педагогического эксперимента.

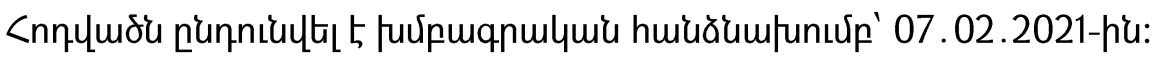

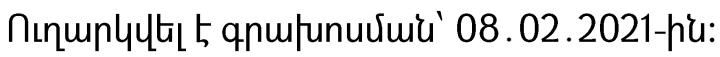


DOI: 10.53068/25792997-2021.1.3-171

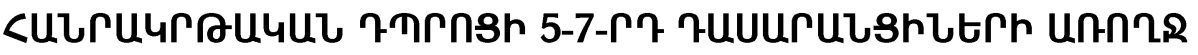

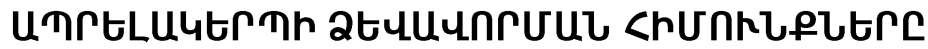

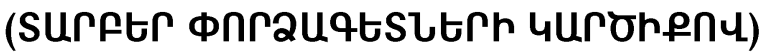

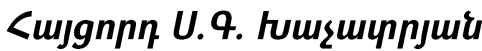

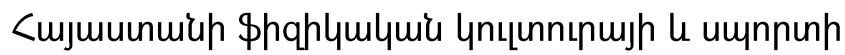

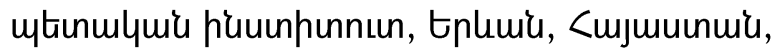
E.mail:satenik.khachatryan@sportedu.am

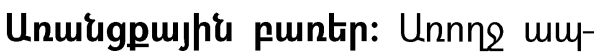

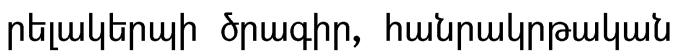

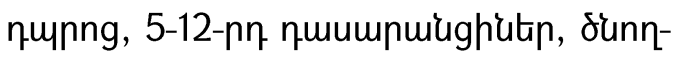
utan, nuunsghšlutp:

Stunuqnunnıpuir upnpulymuntPjnil: fnцnn duviulumlititiph, ujuon u-

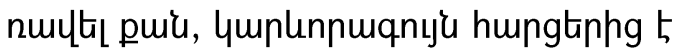

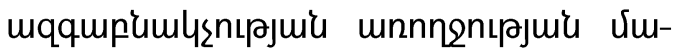

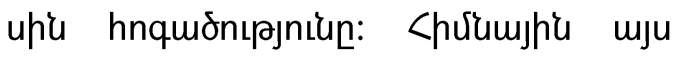

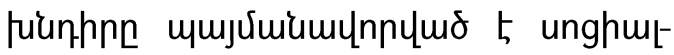

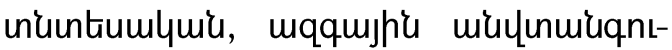

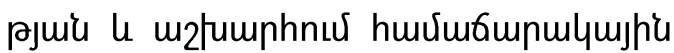

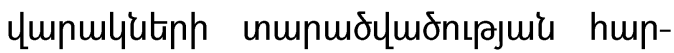
gtipnu:

<ujonup 5 imb, nn mqqupinul-

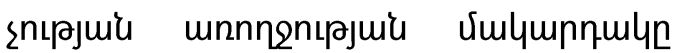

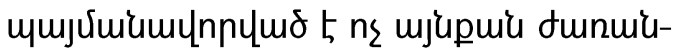
quiluir qnnonuny, nnpuir unuing

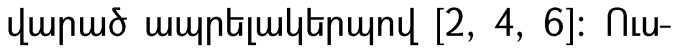
unh, punupughütph unnngumuhu-

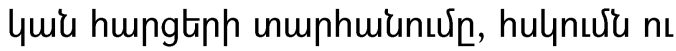

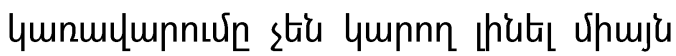
pnıdu2fumunnnutinh fuiunhnn:
Unnngulymi juinhnitiph yuunpunugnula puguumpun lumnn 5 minn-

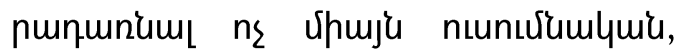

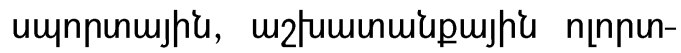
utph le ltiugunumpir hungtinh ynu,

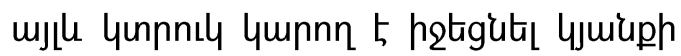
nnulyn: <tionlumpun, unnng muntīu-

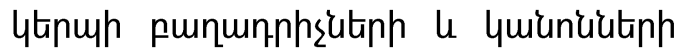
umuhumuunurn minnp 5 qunim opmyunqh punlymgnıghs vimu [5]:

4juiuph nupugpnuर unnng 4tiuumltnuh pununnhsitinh yminnumunn

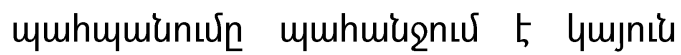
unцnnnıpjnıüutph ătenpptpnnuर: Cuun

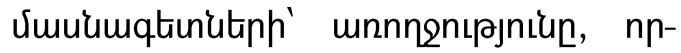

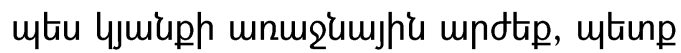

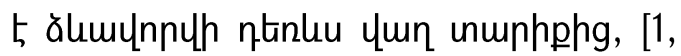

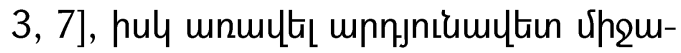

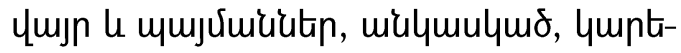

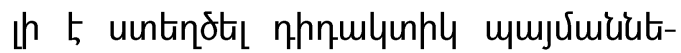

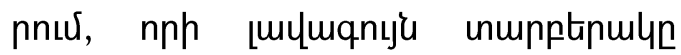
huiupulynpulyuiu nunngu $5:$ 
<m24h unitiny tintifumitiph hnqtautnulymis qunqugnuxn le m2mlytnonutiph ununnmlyming uhgh's nunngh mignnuरn, nnn huviumunus t5 Gquarduviujhe ununhp [4], unnumugh t5 huidnulnpauluiu nunngutinnuर unnng ltiuumltapuph ălumunnnuरn uluta 5-pn quuumuiuhg:

<tunmqnunnıرuis \&uyuunuly: U2ulyta huiupulynpulyuiu nunngh 5-

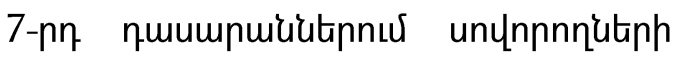

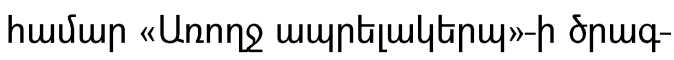
nh pnymunulynıpnıiu:

\section{tưunprutinn:}

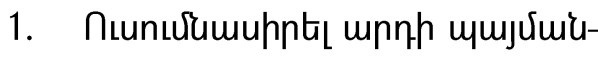
utph le ndulup unuphph tipt|umitiph ujuiuph fưnnuhumnyg pnurlh6ulyutnn:

2. Furguhumuntis 5-12-nn quumnuikghitiph, unwiug dunnutiph, \$hqh-

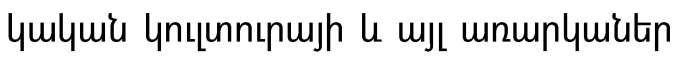

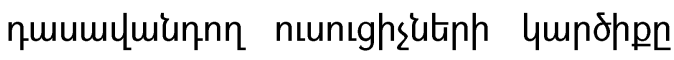

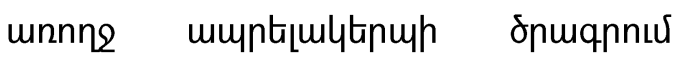

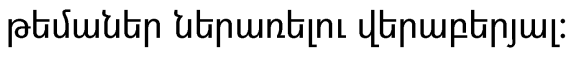

\section{Stunuqnunnıpuir stipnnitinn $\mathrm{l}$}

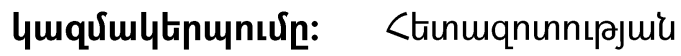

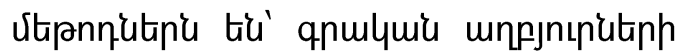

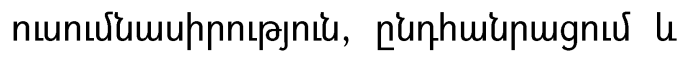

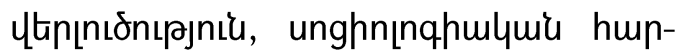
gnus:

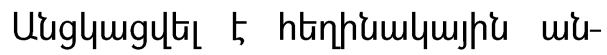

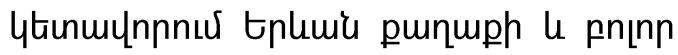
Junqtinh huiunmunparlyuir nunngutinh

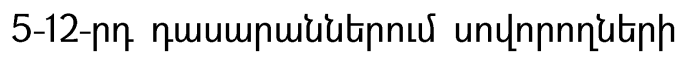

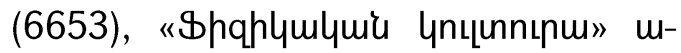
nuplymjh (760) \& mJ mnuplumitip nuumulünnn niunsghsutinh (2350) \& 5-

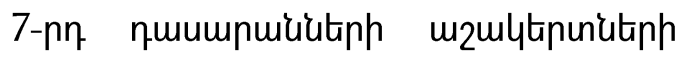
dunnutiph 2nquiunu (1531):

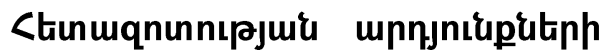

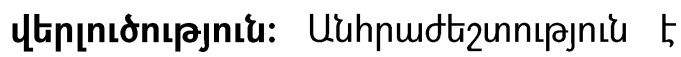

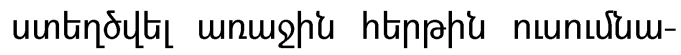

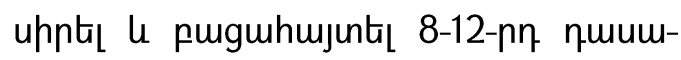

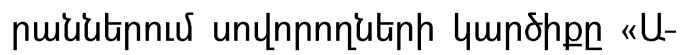

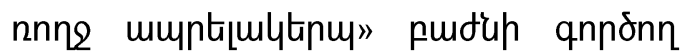

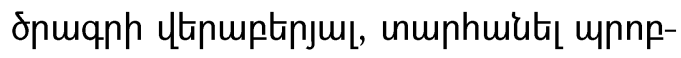

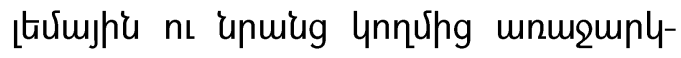

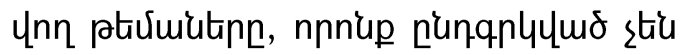
unıju dpuqpnuर (un. 1.): 
Unjnıumly 1

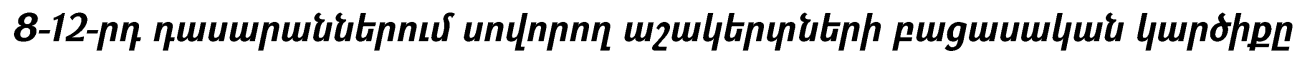

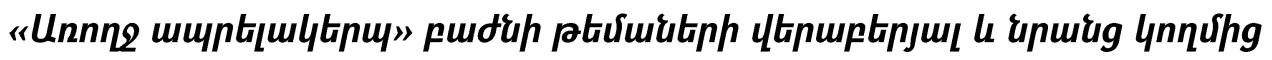
unwounlynn ptusuittnn (\%)

\begin{tabular}{|c|c|c|c|c|c|c|c|}
\hline \multirow{3}{*}{$\mathrm{N}$} & \multirow{3}{*}{ 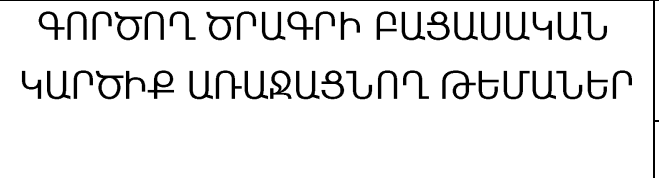 } & & \multicolumn{5}{|c|}{ ๆUUUกUし孔ヒก } \\
\hline & & & 8 & 9 & 10 & 11 & 12 \\
\hline & & $n$ & 715 & 682 & 686 & 651 & 558 \\
\hline 1. & \multicolumn{2}{|l|}{ 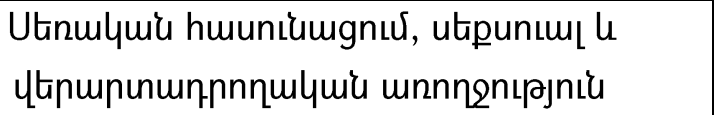 } & 26.4 & 24.0 & 27.5 & 30.7 & 30.6 \\
\hline 2. & \multicolumn{2}{|l|}{ 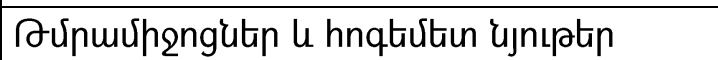 } & 7.6 & 4.9 & 9.7 & 6.2 & 5.3 \\
\hline & \multicolumn{2}{|l|}{ 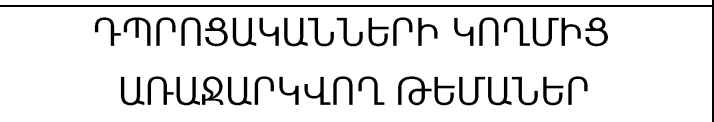 } & & & & & \\
\hline 1. & \multicolumn{2}{|l|}{ Uumnun } & 26.4 & 19.7 & 29.1 & 19.2 & 24.0 \\
\hline 2. & \multicolumn{2}{|l|}{ 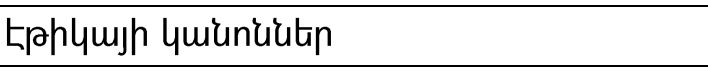 } & 2.9 & - & 1.7 & 0.7 & 3.5 \\
\hline 3. & \multicolumn{2}{|l|}{ 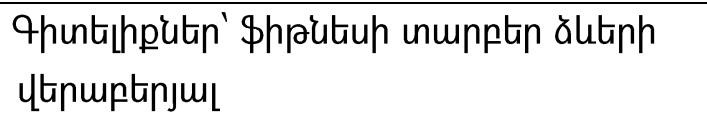 } & 17.2 & 32.1 & 18.0 & 25.3 & 25.8 \\
\hline 4. & \multicolumn{2}{|l|}{ 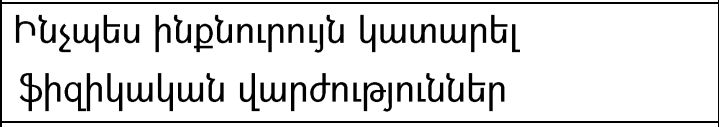 } & 13.5 & 15.1 & 8.0 & 10.1 & 9.1 \\
\hline 5. & \multicolumn{2}{|l|}{ 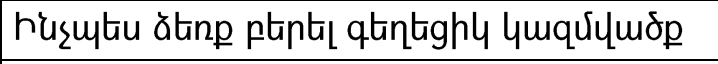 } & 36.9 & 30.7 & 28.7 & 15.5 & 17.7 \\
\hline 6. & \multicolumn{2}{|l|}{ 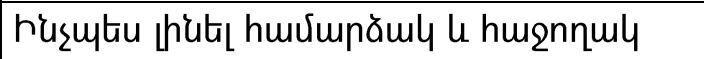 } & 7.2 & 4.5 & 6.7 & 1.8 & 4.1 \\
\hline 7. & \multicolumn{2}{|l|}{ 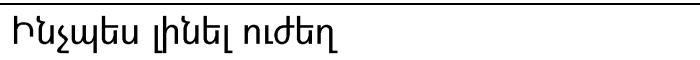 } & 1.8 & 4.2 & 4.8 & 3.3 & 0.1 \\
\hline 8. & \multicolumn{2}{|l|}{ 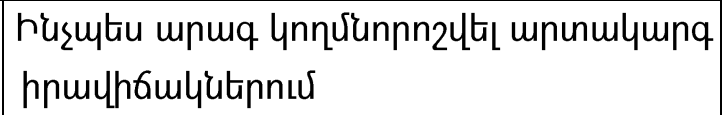 } & 16.5 & 8.5 & 6.9 & 3.0 & 1.2 \\
\hline
\end{tabular}

1-he unjnumling tplunur $5, \mathrm{nn}$

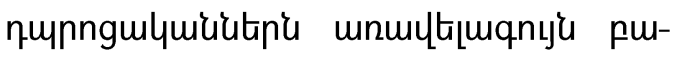

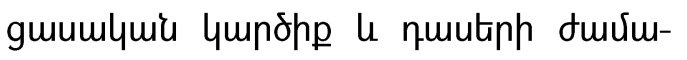

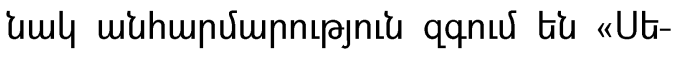

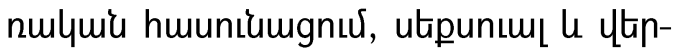

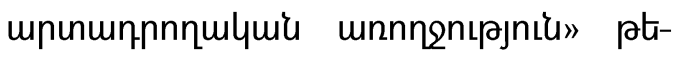

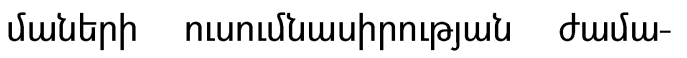

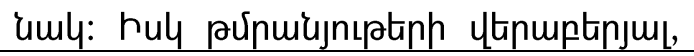

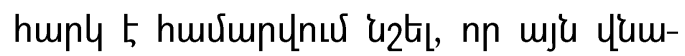
umlump ununnnıpjniuutinh upulye 5 ,

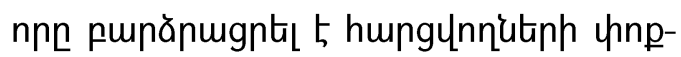

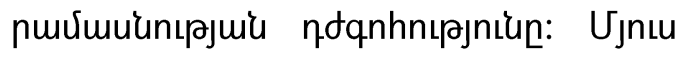

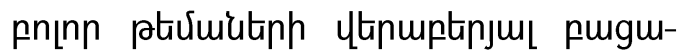
umlumi lumphp sh qnuiugltal:

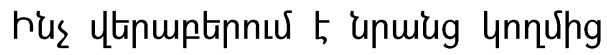

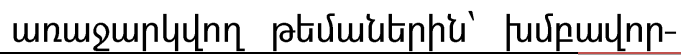




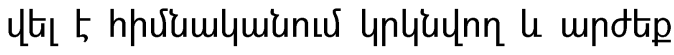
utplqujugunn up puiup ptưuiutn, nnnup cumle htiupushe tiu 5-7-nп quumnuiautph hanhiumlyujhe snuqph uuntinouluiu huưur:

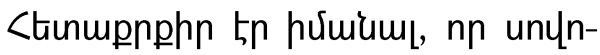

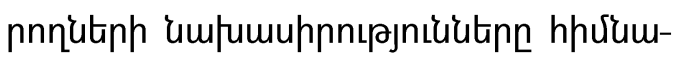

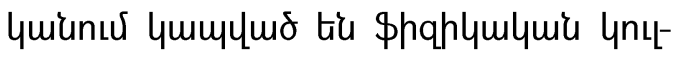
unnınujh le umnnunh ninnunh htion, la nu

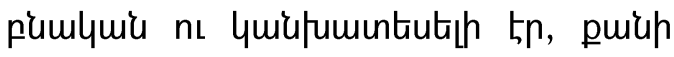

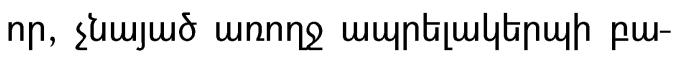

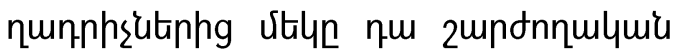

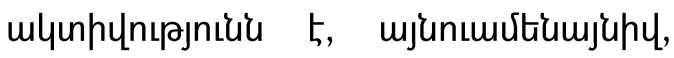

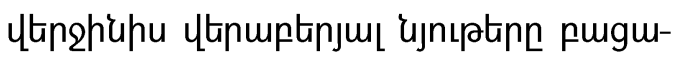

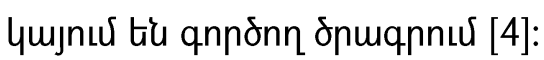

fuù nn unnnămpunulquí spu-

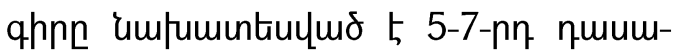

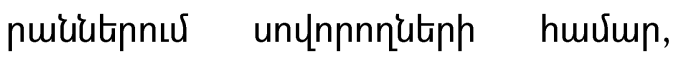
htinlumpun htiupuypic th umpatins iull unwing ympoppn:

<ungnưhg purguhmusultig, nn

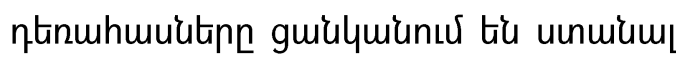

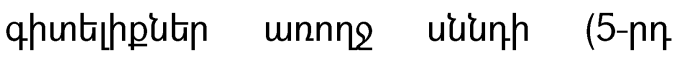
quumpuiunud' 76.3\%, 6-nu' 72.5\%, 7-

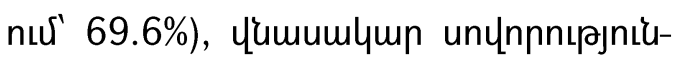
utph (5-nu' 95.2\%, 6-nu' 95.9\%, 7-nu' 91.9\%), umpưup 4nuhưuiu (5-nu' 56.4\%, 6-nư' 51.6\%, 7-nu' 37.6\%), ujunnujhu

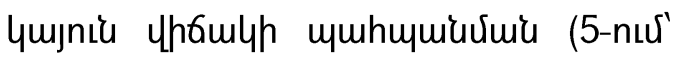
60\%, 6-nu์' 64\%, 7-nu์' 63.9\%), \$hqh-

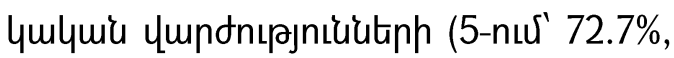
6-nư' 69.4\%, 7-nu' 71\%), onцu ntuduर्य (5-nu' 52.7\%, 6-nu' 47.1\%, 7-nu'45.7\%),

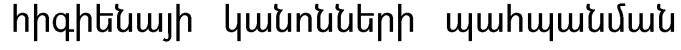
(5-nu์' 69.6\%, 6-nı์' 66.1\%, 7-nư' 68.1\%) u ukthulquiu purh nı humulh 4minquunnưuiu (5-nuर' 59.4\%, 6-nuर' 53.6\%, 7-nuर 53.2\%) पtinuptinju[:

fumlquiumpun, uјu pnцn ptivu-

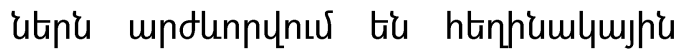

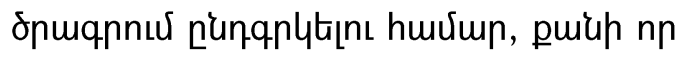
nuunıgưuí unngtiup unnjniumultinnt-

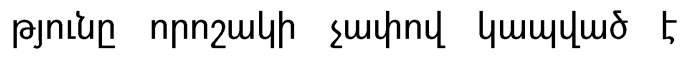

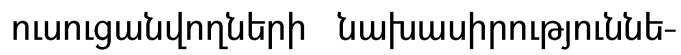

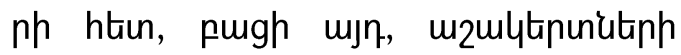

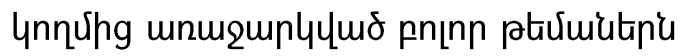

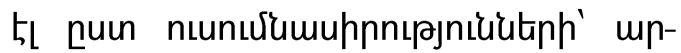

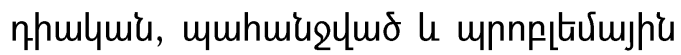
tiu:

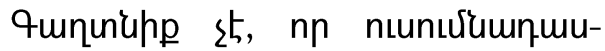
unpunmusulymí qnnonupugn sh $u-$

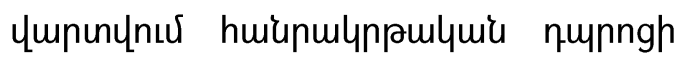

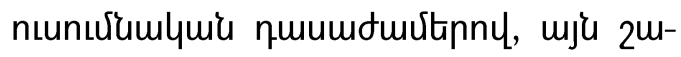

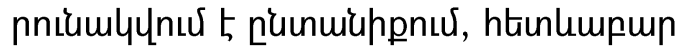
fupuin wiuhnudtizun th dunnutiph

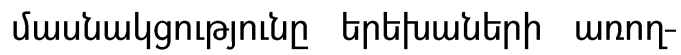

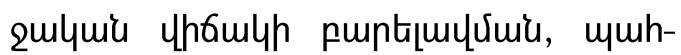

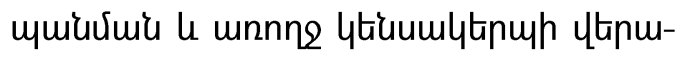

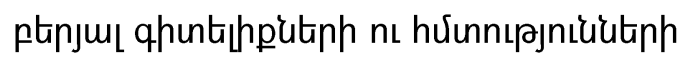
ălumunnưuiu qnnonus:

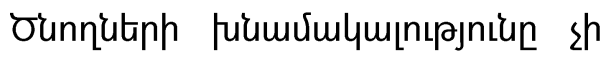

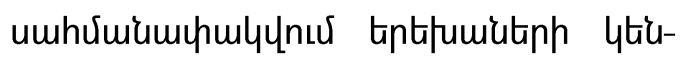

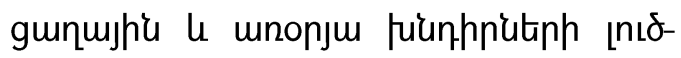
Jurup: <mj nultinump qpnn, muinvimqhn tnh2tiu (V qun) muta t. "Sutap

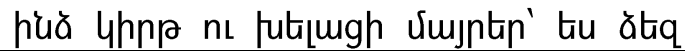


yunuu uhnp nt futjugh humumulynt-

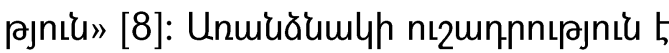
qunăyta puguhmjuntinni pt deunnutinn nppuiuny tiu vuuumugnu tipt|umitiph

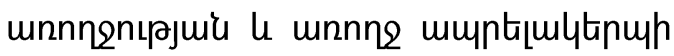

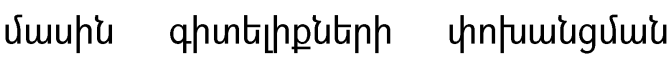
unnngtupü: Ctionlumpun, unnă b̆

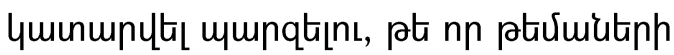
vemuper tiu unynnupun deunnutinn

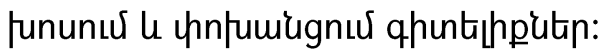

fuguhumunytas $t$, nn unnng uiunn

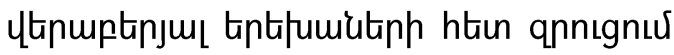
tiu dunnutinh 58.7\%-n, onцm ntudhúp uquhumidưu' 28.6\%-n, nulytaktiph, nt-

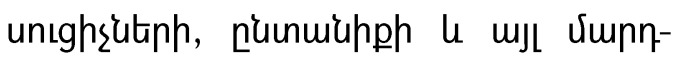

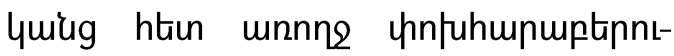
pjniuiutiph' 51.7\%-n, hpqhtiumsh umbuqu'uरu'u' 43.2\%n, y'umumlymp unynnnt-

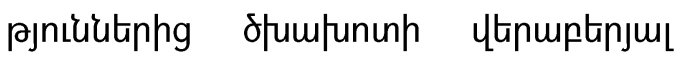
4.2\%-n, hul milnhnц' 6.9\%-n, 'jumnu-

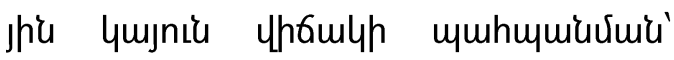
5.1\%-n, 4juiuph undtputiph le nnulyh

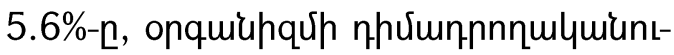
pjứ punnănugưư 5.2\%-n, upınu-

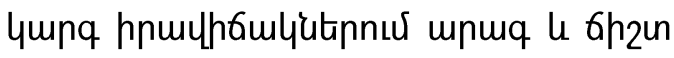
lnnưunnnzưu' 26.5\%-n, umnnunp' 2.1\%-n, duviuiumlymlyhg inthuun nnqhu-

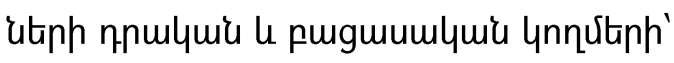
70\%-n, utnulymir humeiumgưu' 2.2\%-n, huj unnưumpnniu punnn2 huinquiunzutuph ălumunnưữ' 3.8\%-n, humnt- hniłu punnn2 huunlumuh2utiph ălumunnUuid' 18.1\%-n:

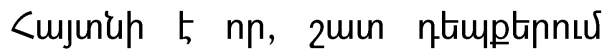

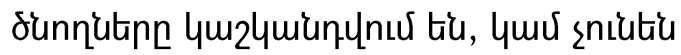

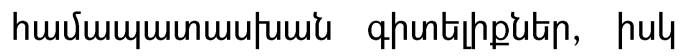

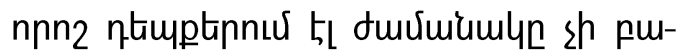
ympunnux tintjumitiph unnng ytiuumytpump ălumunnoumu hungtinny qpurn-

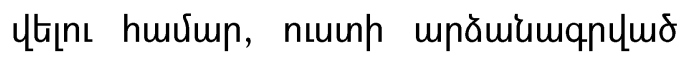
unnjniuputinn unlumulh mununuunntig-

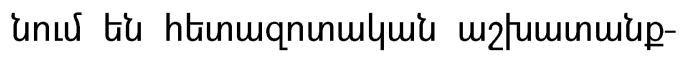

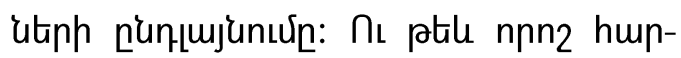
gtpnnux qnuiugltal 5 punăn unnynu, ujunıurtumjuhy, stiup yunnn hurưnq-

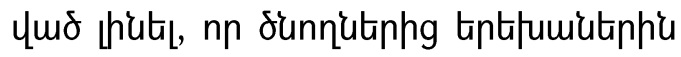
unfumiugynn qhuntihputinn yuunumunuर

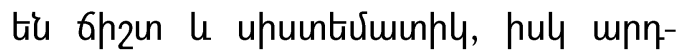
jniuph vimupis unujupuly muttannn junutin:

<ungh püumplưum qnnonupungu miapnıjuiunntןh tn, unuiug «\$hqhlym-

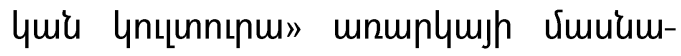

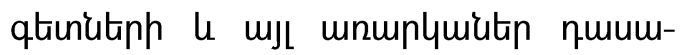

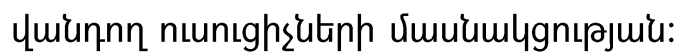

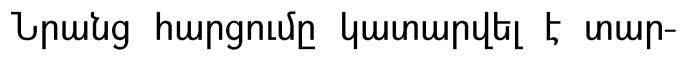

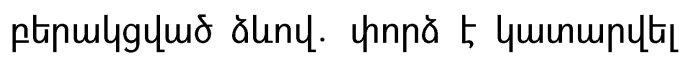
puguhmuntinn viulymumpdutiph ymp-

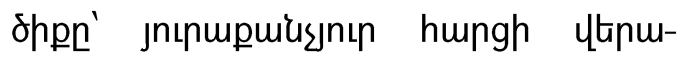

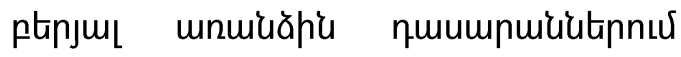

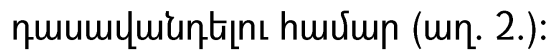




\section{Unjnıuml 2}

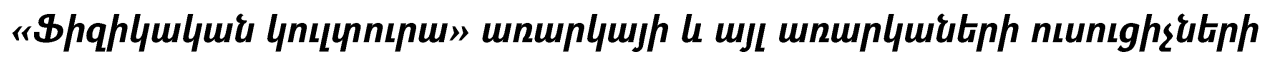

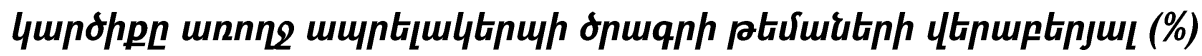

\begin{tabular}{|c|c|c|c|c|c|c|c|}
\hline \multirow[b]{2}{*}{$\mathrm{N}$} & \multirow{2}{*}{$\begin{array}{l}\text { <mungh } \\
\text { pnumunqulnıpjniun }\end{array}$} & \multicolumn{2}{|c|}{ 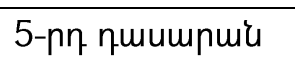 } & \multicolumn{2}{|c|}{ 6-рп пшишишіи } & \multicolumn{2}{|c|}{ 7-nп пuишишиน } \\
\hline & & $\begin{array}{c}\$ 4 \\
\text { ntuntghs }\end{array}$ & $\begin{array}{l}\text { UJL un. } \\
\text { ntuntghs }\end{array}$ & $\begin{array}{c}\$ 4 \\
\text { ntuntghs }\end{array}$ & $\begin{array}{l}\text { UJL wn. } \\
\text { ntuntghs }\end{array}$ & $\begin{array}{c}\$ 4 \\
\text { ntuntghs }\end{array}$ & $\begin{array}{l}\text { UJ un. } \\
\text { ntuntghs }\end{array}$ \\
\hline 1. & 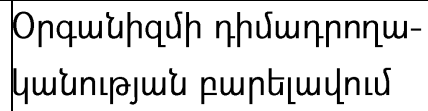 & 100 & 62 & 100 & 44.9 & 100 & 46.8 \\
\hline 2. & Opum ntudhú щuhu. & 100 & 79.3 & 100 & 80.8 & 100 & 64 \\
\hline 3. & 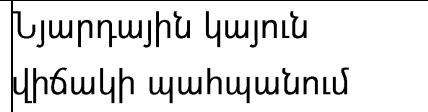 & 563 & 89.5 & 100 & 97.8 & 100 & 100 \\
\hline 4. & 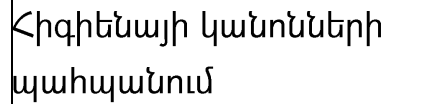 & 100 & 100 & 100 & 81.3 & 100 & 91.8 \\
\hline 5. & n-ughn'umu ưuniun & 100 & 100 & 100 & 100 & 100 & 100 \\
\hline 6. & 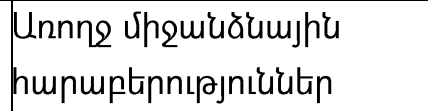 & 100 & 98.2 & 100 & 99.7 & 100 & 100 \\
\hline 7. & $\begin{array}{l}\text { 4juiuph mndtpititn l } \\
\text { nnuly }\end{array}$ & 56.5 & 69.4 & 70.7 & 72.3 & 72.5 & 86.1 \\
\hline 8. & 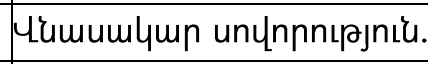 & 100 & 100 & 100 & 100 & 100 & 100 \\
\hline 9. & 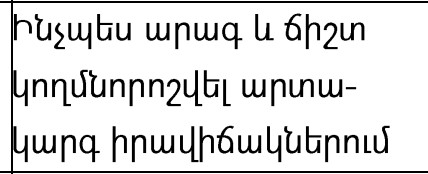 & 81.9 & 66.1 & 56.8 & 56.4 & 27.6 & 30 \\
\hline 10. & Uunnin & 47.3 & 21.4 & 50.5 & 29.2 & 42.5 & 39.1 \\
\hline 11. & 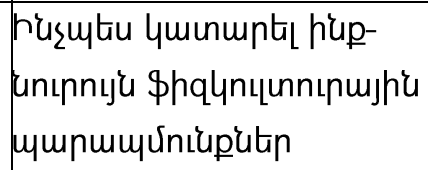 & 59.8 & 21.4 & 68.8 & 27 & 63.1 & 17.4 \\
\hline 12. & 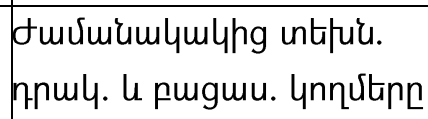 & 100 & 100 & 100 & 100 & 100 & 100 \\
\hline 13. & Utinulymí quuunhmpul. & 14.4 & 8.5 & 19.7 & 25.4 & 45.3 & 74.7 \\
\hline 14. & 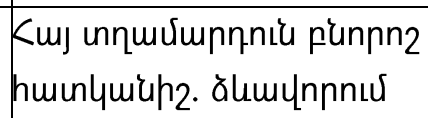 & 92.1 & 91.1 & 94.7 & 95.1 & 100 & 100 \\
\hline 15. & $\begin{array}{l}\text { Kujnıhniù punnn2 } \\
\text { huunlumü2. ălumunnnuर }\end{array}$ & 100 & 100 & 100 & 100 & 100 & 100 \\
\hline
\end{tabular}


2-nn unjnumulhg tplentu $5, \quad n n$

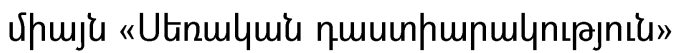
u nnn2 surhny Giule mJ mnuplumitiph vimuiumqtinutiph ynnưhg «Uupnon» ptiumjh Utinuptipjui 5 mpămiumqnyts

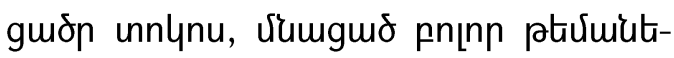

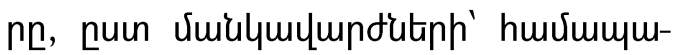
unuulumiunus tiu ntinuhuulutiph unnng

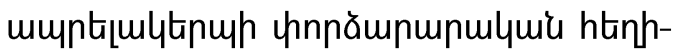

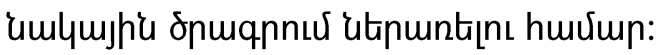

hus ytenuptinunux 5 niunıghsutiph

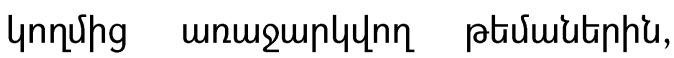

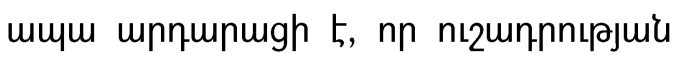

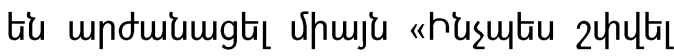

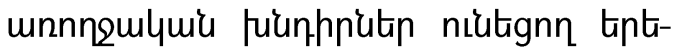
fumitinh htin (4UT4กト)», "Uqqujhe

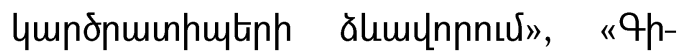

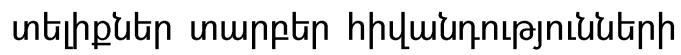

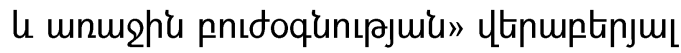
ptuivitinn: Ujnı unmptinulyutine, nuin nuunứumupnnıрju'u' hntiughg undtp $\mathrm{l}$

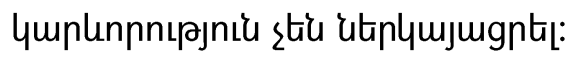

tqnulyugnıpjnıl: Ujumhunl'

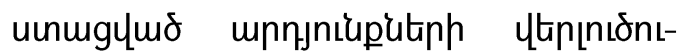

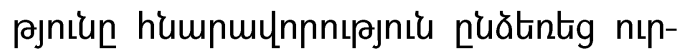

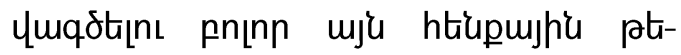

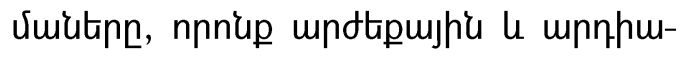

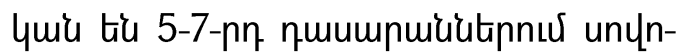

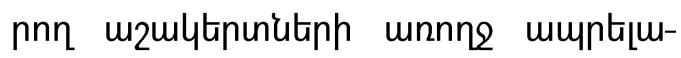

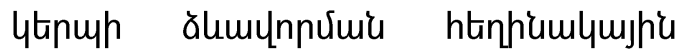

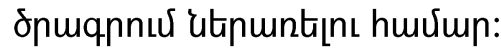

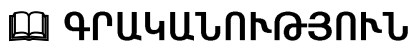

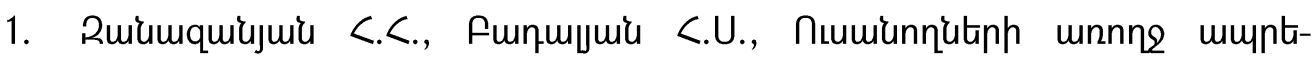

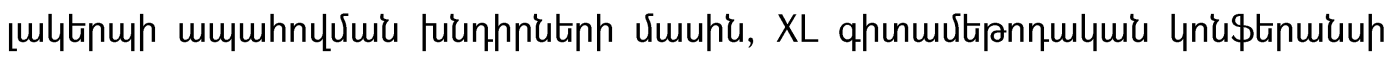

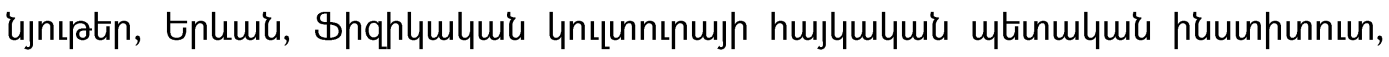
2013, t2 128-132:

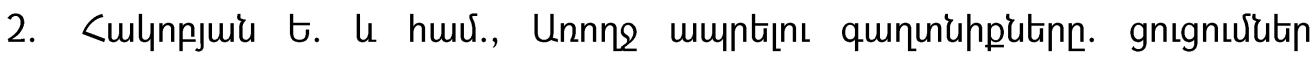

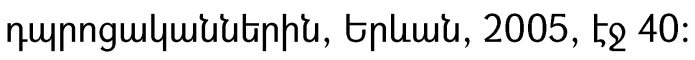

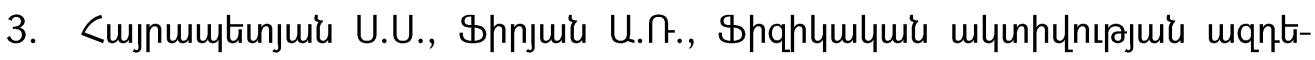

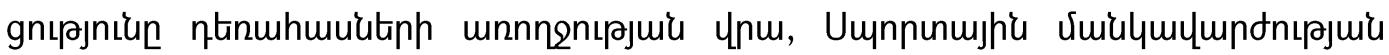

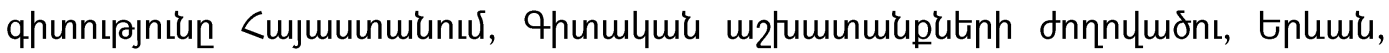

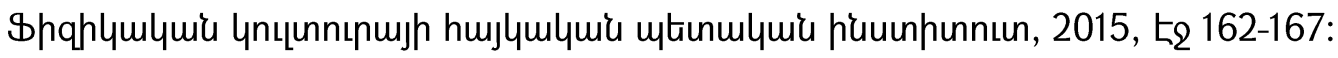

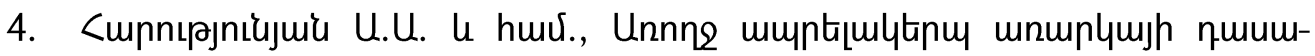

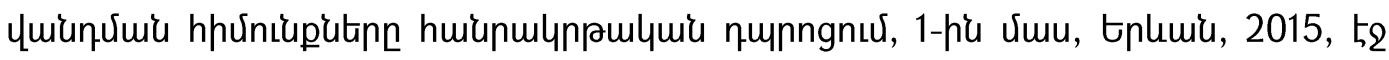
29, 31, 104-120: 
5. Хачатрян С. Г., Знания и интересы старшеклассниц к самостоятельным физкультурным занятиям, Восток-Россия-Запад Физическая квультвура, спорт и здоровый образ жизн в XXI веке Материалы XIX Международного симпозиума, проведенного фракультетом физической культурй и спорта Сибирского государственного аэпокосмического университета имени академика М.В. Решетнева (25-27 декабря 2016г.), Красноярск.: с.195-197

6. Хорошева Т.А., Физическая культура как фактор формирования и укрепления здоровья современных школьников // Физическая культура в школе.2017.-N3.-c.16-20.

7. Tshmarityan Marina, Aghajanyan Marina, Ter-Margaryan Nune, Healthy Lifestyle of Armtnia's Schoochilden, Children and Youth in Emerging and TransForming Societies. Childhoods. International cjnference, Oslo, 2005, s.479

8. https://blog.168.am/blog/35164.html

\section{THE BASICS OF DEVELOPING HEALTHY LIFESTYLE AMONG SCHOOLCHILDREN OF 5-7 CLASSES OF SECONDARY SCHOOL. (ACCORDING TO VARIOUS EXPERTS)}

Applicant S. Khachatryan Armenian Stat Institute of Physical Culture and Sport, Yerevan, Armenia

\section{SUMMARY}

Key words: Healthy lifestyle program, secondary school, schoolchildren of 5-7 classes, parents, teachers.

Research relevance. Health problems of people attract more and more attention every year. This fundamental issue is problematic for all the countries of the world. The solution of health problems requires coordinated work of different specialists, especially doctors and teachers. Studies have shown that a person's health largely depends on his or her lifestyle, therefore it is necessary to equip the younger generation with knowledge of health maintenance and strengthening.

Experts believe that the sooner children are educated to take care of their own health, the more efficiently skills develop. Therefore, it was decided to work out a 
program for the development of a healthy lifestyle for schoolchildren of 5-7 classes. The choice of this age is based on the program for schoolchildren of 8-11 classes.

The development of healthy lifestyle of schoolchildren should be successful in case when school and family act jointly and develop sustainable interests in health and physical education.

Research objective: to develop the content of the "Healthy Lifestyle" program for schoolchildren of 5-7 classes of a secondary school.

Research methods and organization: study, generalization and analysis of literary sources, sociological survey.

An author's survey was conducted among schoolchildren of 5-7 classes of secondary schools of all the regions in Armenia, as well as Yerevan (6653), teachers of physical culture (760), teachers of other subjects (2350) and parents of schoolchildren of 5-7 classes (1531).

An attempt was made to identify all current and problematic issues, the study of which can develop a positive attitude towards organizing and leading a healthy lifestyle.

Conclusions. All the relevant and problematic topics of teenagers' life have been identified. And as a result of grouping these topics, it is planned to create an experimental program «Healthy Lifestyle» for schoolchildren of 5-7 classes.

\section{ОСНОВЫ ФОРМИРОВАНИЯ ЗДОРОВОГО ОБРАЗА ЖИЗНИ В 5-7 КЛАССАХ ОБЩЕОБРАЗОВАТЕЛЬНОЙ ШКОЛЫ}

\section{Соискатель С.Г. Хачатряан}

Государственный институт физической культуры и спорта Армении, Ереван, Армения

\section{PEЗЮME}

Ключевые слова: программа здорового образа жизни, общеобразовательная школа, учащиеся 5-12 классов, родители, учителя.

Проблемы здоровья людей с каждым годом привлекают все большее внимание. Этот фундаментальный вопрос проблематичен как для всех стран, так и для Армении. Он требует слаженной работы разных специалистов, осебенно врачей и педагогов. Исследования показали, что здоровье человека во многом 
определяется той жизнью, которую он ведет, поэтому нужно вооружить подрастающее поколение знаниями и навыками о сохранении и укреплении здоровья.

Эксперты считают, что чем ранше обучить детеи заботиться о собственном здоровье, тем эффективнее будут развиваться навыки здорового образа жизни. Поэтому была разработана программа соблюдения принципов здорового образа жизни школьниками 5-7 классов.

Соблюдение принципов и требований здорового образа жизни школьников может быть успешным, если благодаря совместным усилиям семьи и школы в сознании учащихся будут сформированы устойчивые интересы укрепления здоровья и отношение к физической культуре.

Цель исследования. Разработать содержание программы «Здоровый образ жизни» для учащихся 5-7 классов общеобразовательной школы.

Методы и организация исследования. Изучение, обобщение и анализ литературных источников, социолигический опрос.

Анкетирование проведено с использованием авторской анкеты, в опросе приняли участие школьники 5-12 классов обшеобразовательных школ всех регионов страны и Еревана (6653), учителя физической культуры (760), других предметов (2350) и родители учеников 5-7 классов (1531).

Полученные в итоге социологического исследование данные позволили выделить конкретные темы и направления, которые легли в основу разработки специальной авторской программы по формированию здорового образе жизни учащихся 5-7 классов.

Выводы. Содержание програмы по формированию здорового образа жизни, естестевенно, будет апробировано в ходе формируюшего педагогического эксперимента.

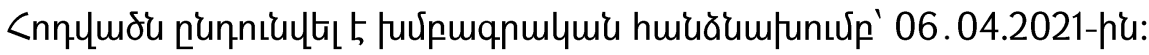

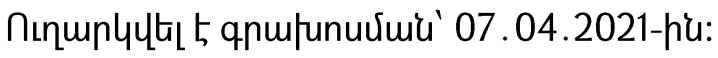


DOI: 10.53068/25792997-2021.1.3-181

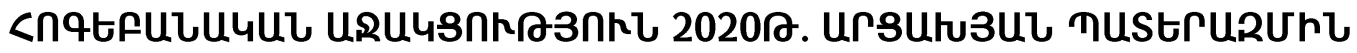

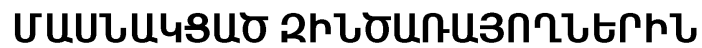

\section{<.q.p., nngtiun U.9. Uythywirjuil,}

4.9.P., nngtiuy L.U. Uytrhwitjuit,

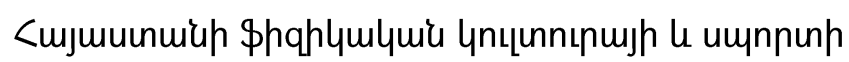

utinumuiu huuunhunnun, tplumiu, <mjuuunuiu

E-mail: anna.stepanyan@sportedu.am, lusine.stepanyan@sportedu.am

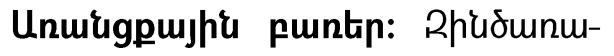

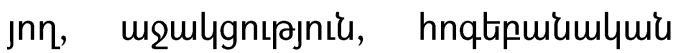

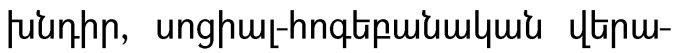

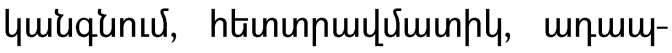
unughu:

<tunmqnunnıرuis upnhulyuiunt-

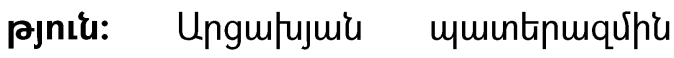
(2020p.) Surumlymo hupjnı-huqunuilnn qhulnnitin, mjuon poh2lutinh $\mathrm{u}$

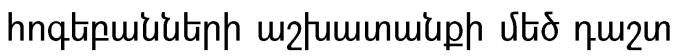
tiu utinlumjugunux: <mjununuiuh < <iunumbinnıpjuis puquiuphy hpluiunu-

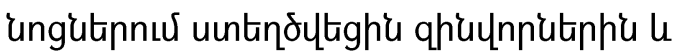

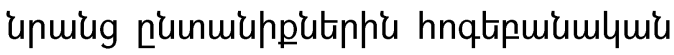

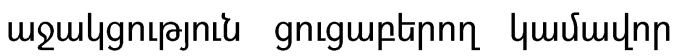

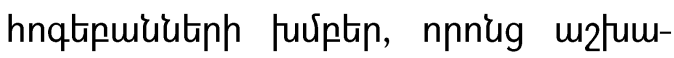
unuiuputinn zunnizumlyunux tiu un ujuop:

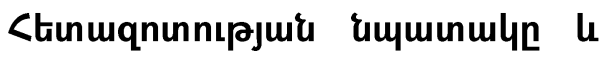

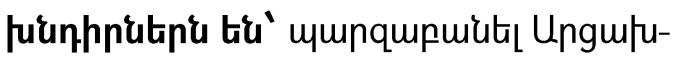

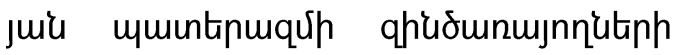
htinunnuyuduinhly upptumshis jumiqu-

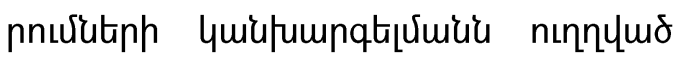

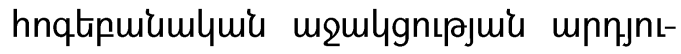
umultunnıpnııนn:

Ujunnuhnqtpuiumlquiu jưnppita-

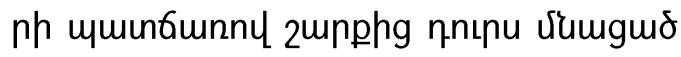
qhưunmunnutinh 2unp ytanunumăh umuhnunux:

Stunuqnunnıرuí vitpnnitinn $\mathrm{l}$

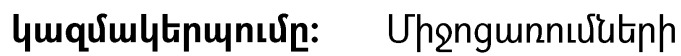

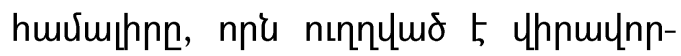
utiph unghu[-hnqtapuiumlyuir ytanu-

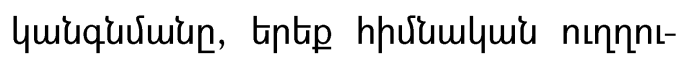

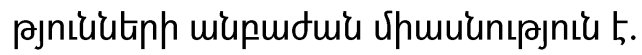

1. hnqt\$hqhnцnqhulquiu,

2. hnqtizunynn,

3. unghur-hnqtipuiumlumi:

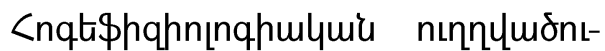

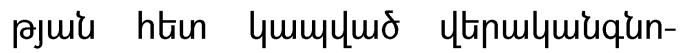

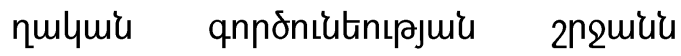

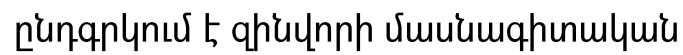
ymplunn nnulyutiph muunnnn2nux \& ytanulquiuquanu' hnqtiuluunnnnzhs vthannutiph uhnunưuup: 
upnuulnnutiph hưumph hnqtipu-

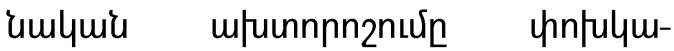

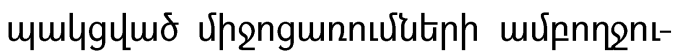

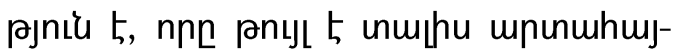

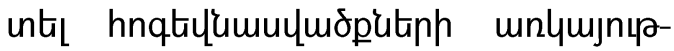
jniun, unyjumlymiumguta npuiup u quehuuntr:

<numpunmu untqumpntuy uro thnuUnnutinn (multh puí 172 hnqh) htinuqnunnıpjnı́ wiuguiu hujunup vitipnn'utph' Ujqtiuph ptiuunh, Lnphp ptiuunh

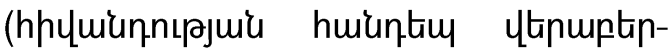
Unıup), UhU-h (unıpjtyunhy hupumumpquinnưuiu vilympnul), hUS hungu-

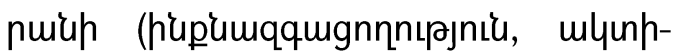

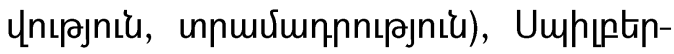

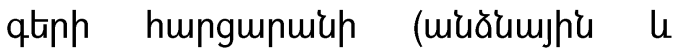
ntimlunhy unmqummmjunıрjui), «2tnp-

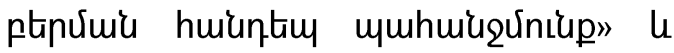
Ljnıtiph ptiuuntiph upnjniuputiph oqunเpuuরu:

3nıpupuiusnın पhpurunn ytipu-

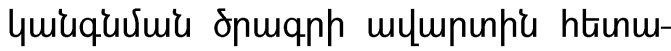

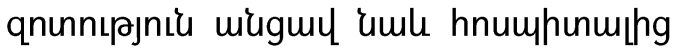

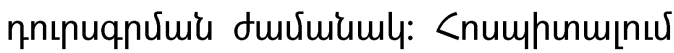

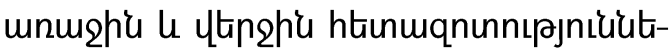

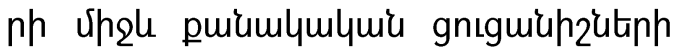
unnunnfunıpjniun pnıl unltig quints Uhnulnnitiph unghm[-hnqtipuiumlymis

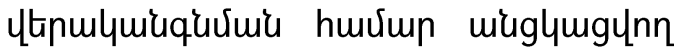
unengunnuluteph nnuly le mpn.jntumultinnıрuiu vimuhi: бpuqph hpulquiumgnứn uuntindtig

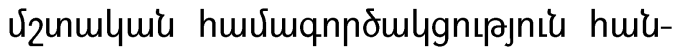
numitunnıرuis qhiulnnulyuir hnumhunujutph, hpumiunuiungutiph, <nqtun-

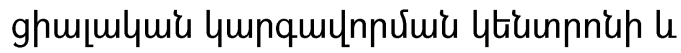

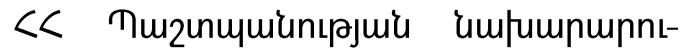
pjuis punnjuhnqtipuiumlum yunsntpjuir úngle (ytanghuutinu hnulymiumgunsu tiu m2łumumiupatinh quqưulytinunnuर्u nı hulnnnıpjnıนun):

Uhnuunnuitiph' unghut-hnqtipu-

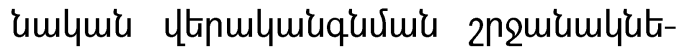

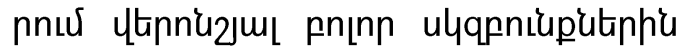
huxumumunuu|umis misglumgynn uhengunnuरutiph huviulygnuरn anıJ unltig

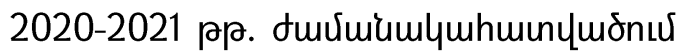

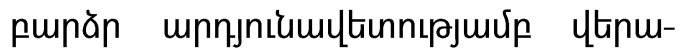
quiuquats qhuunnhutinh unnngnıpnniun u unghme-hnqtpuiumlumi yhrulyn:

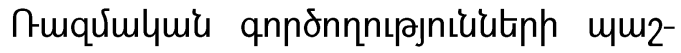
innumlymís qunumpg htionn hnqtipu-

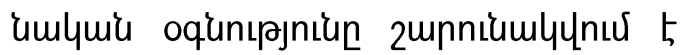
un mjuop:

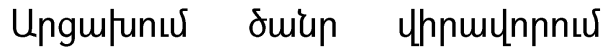
uunugur qhulnnitiph vtsomúuuunt-

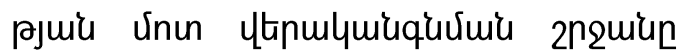
punıpuqnunuर 5 trplumuinle hnqtînnquiluir unıp upptiund: Ytinghühu nod'u

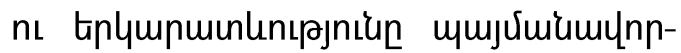

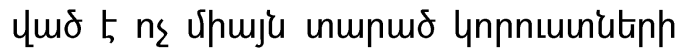
pugmumlymí htunlumistutipny, hu6uru'

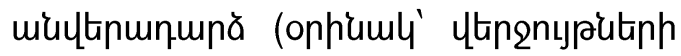




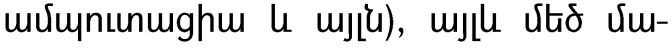

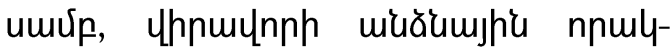
Gitpnu:

<nqtiquir प'umulmóp unmpmo vimpnlyming unin mnmougur fumiqqu-

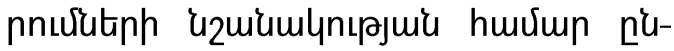

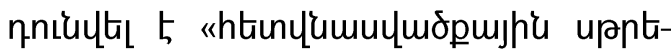

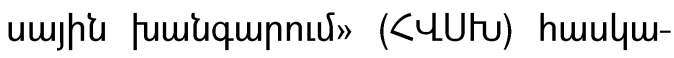
gnıpjnıนn' nnutu unwiuăhu, h'upunt-

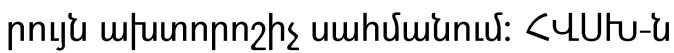

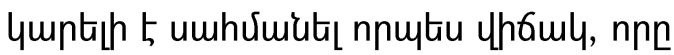

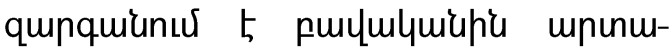
hmjunymo hntquiluir le \$hqhlymluie upptu unupmo vimpnns unon $\mathrm{l}$

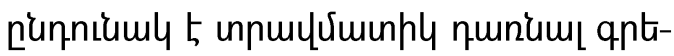
pts guilymguro Umpnns huvium:

<UUtu-h unmemguimis huviup wuhnudtizen t, nnuktuqh vimnn qqu

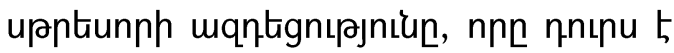

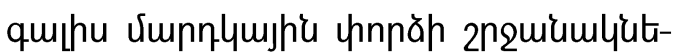

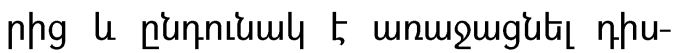
upptu (9. Utijt) [3]: Uju untumulh upptunnhutiph zunphes tiup quunú Uunnns 4juiuph's umunumgnn [nıne

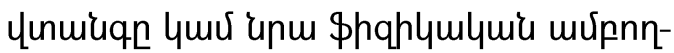

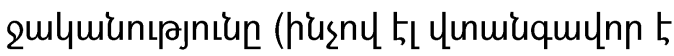

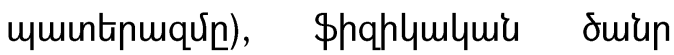

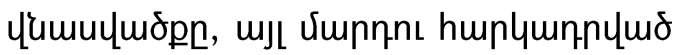

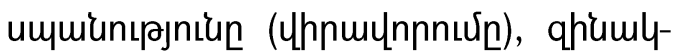

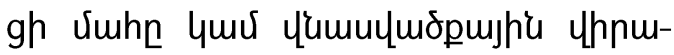
unnnuर्un, unwing nnp muintinuqu sh Lhunuर:
tpuinptiumL upptiunnh mqntigntponiun huiuqtigunus 5 < <Utu-p tiptp untuumly nnulunnưui' hiunnnıqhush,

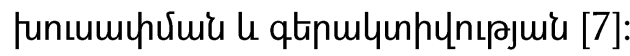

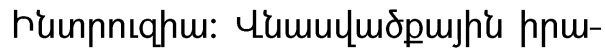

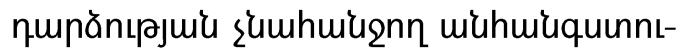

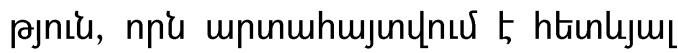
ăluting vituny'

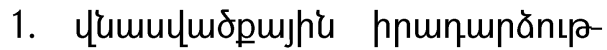

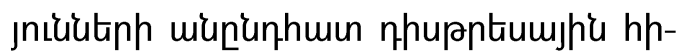
2nпnıpjniuiutin,

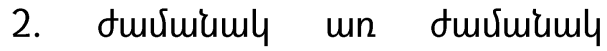

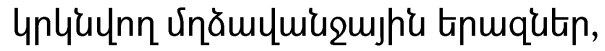

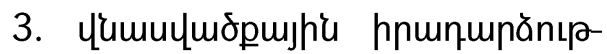

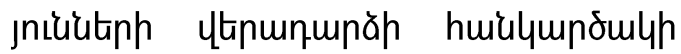

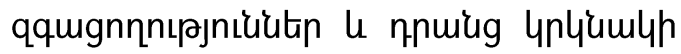

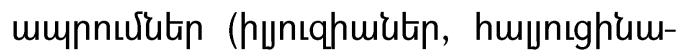
ghwiltip, npunghwinny nnumqutin),

4. huiqquiviuputiph mqntignı-

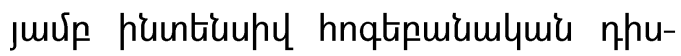
upptiu, nnn funnhnnuiuznux 5 y'uuu-

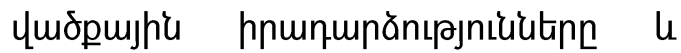

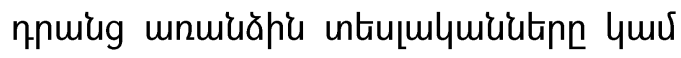

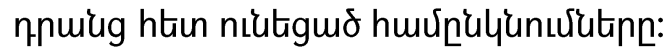

funsumunnux: पlumuluoph htion

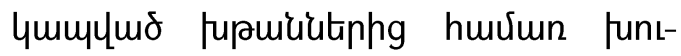
umunnuर, nnu nıntilgunuर 5 hnıqulum-

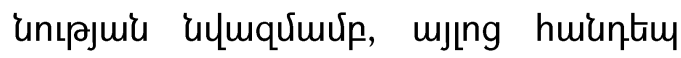

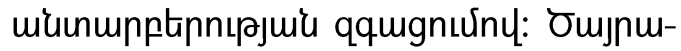

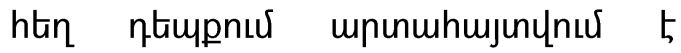

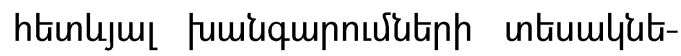
nny. 


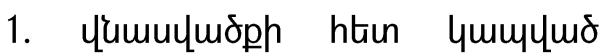
Uunptinhg le qquaguniuputiphg funıuuuhtinn qhunulyglud quiuptin,

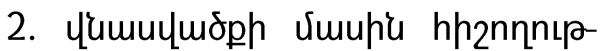

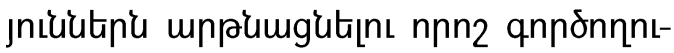

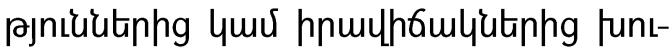
umuhtı̨nı thnnătin,

3. y'umuцmopp ymplenn intugulym-

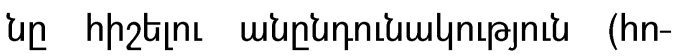
qtyuiu múutighm),

4. umbulphunu ismumlymin mlyonhunıpjuí intrumlyutiph huintius htunupppnnıрjuí đuluqnuर,

5. 2nеwumunh huiuntiuy oununuum[nı qqugnnnıpjnı'u,

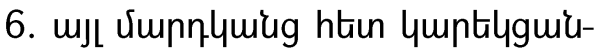
ph lu hnqtilyuí vitpătagưư nunnnium-

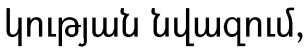

7. «lum

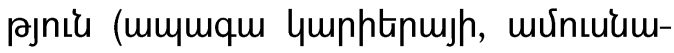

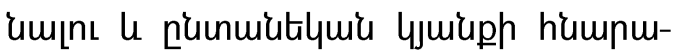

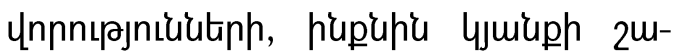
pniumlymlumunısuiu huiuntim wisЧuinuhnıرnเu):

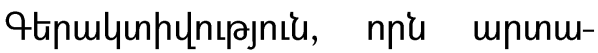

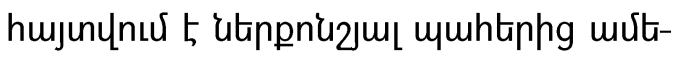
'umphen tiplynuunux'

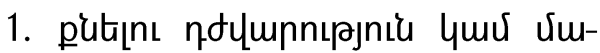
ytantuumshu pnı́u,

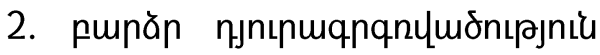

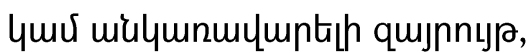

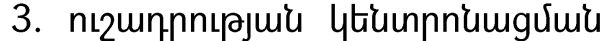

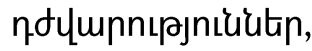

4. punăp qqnünıрjnıนu,

5. huilympromh mqqulutiph huit-

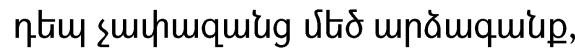

6. \$hqhnnqpulquir ntimlqunhunt-

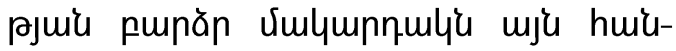
quviuiuputiph huiuntiu, nnnup

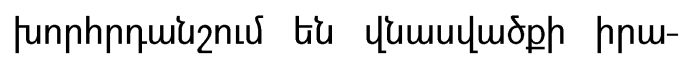

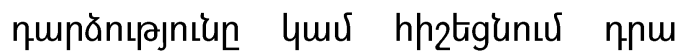
unmults trulquie intrugulquiutinn:

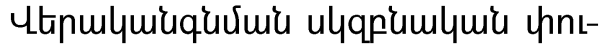
¿nuर hnumpunush pop2lutipis ne hnqta-

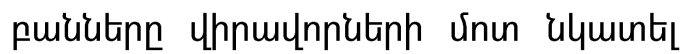

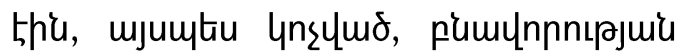

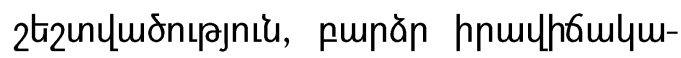

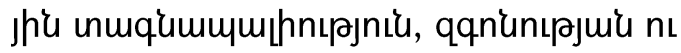

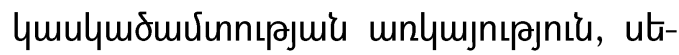

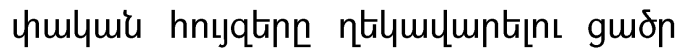

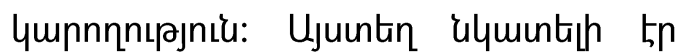

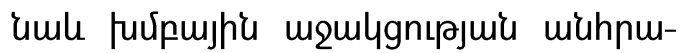
dtrznnıpjnıน:

Unultil mponmhujunluo pugu-

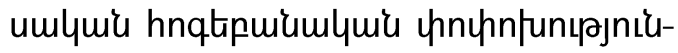
utann ulymununux tiu mju qhiulnnmymulutiph unne, nnnup muintipuquium-

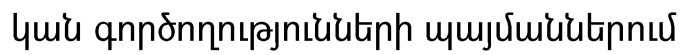
tiu qunultal tiptp zmpuphg multh:

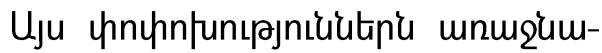

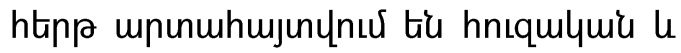

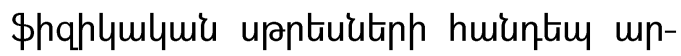
àmquiuph ălunl' ulqumo hnqtihnsqulymir 


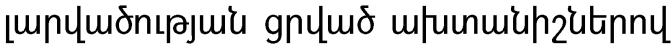

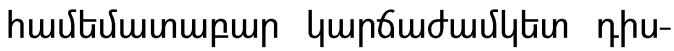
ynư⿱\$nnunhy uhisle ulunnunhly hnqtiumu-

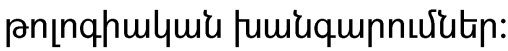

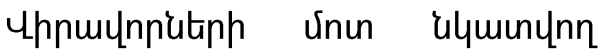
upptumog's fumiuquennulutiph hnqtiqt-

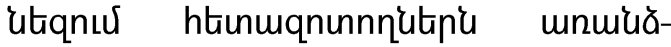

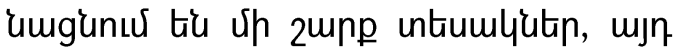

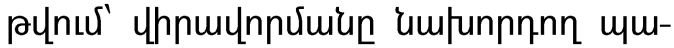

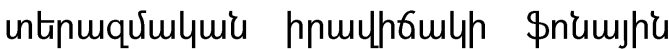
hnqtilumuluopmujhe qnnonuiutph mq-

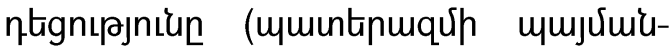

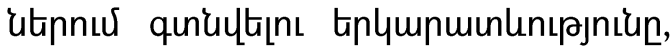

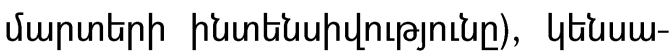
quí umunimuphp huiuntim miuhmunu-

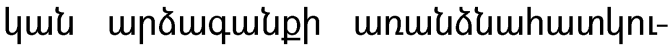

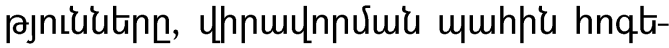

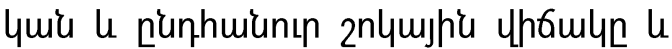
uJ!u [6,7]:

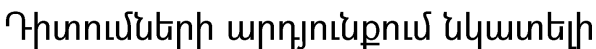

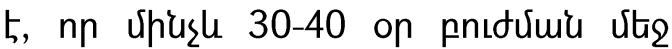
quniulnn qhiulnnutiph unin tiplumuinle

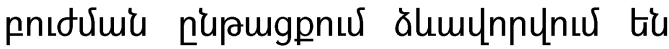
pugmumlymis hnqtiluis upptiumphis ntimlghmitin, nnnup vtio vmumunp niutúu gnıgunnulquiu u nünnhưunhn-

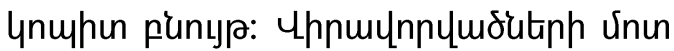

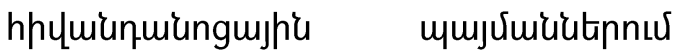

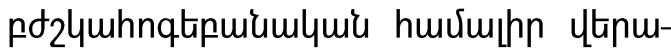

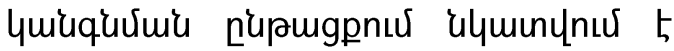

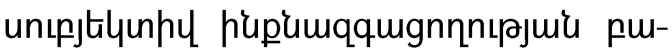

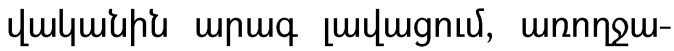

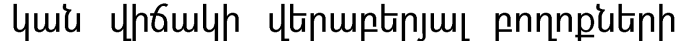
puiumle ilymunt|pnntiu ennpnuiunus 5 ,

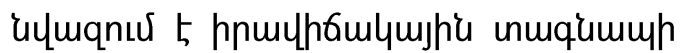

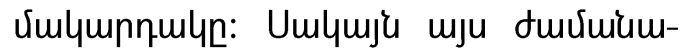
quhmunymontu ulquinutat 5 mju gnıgu-

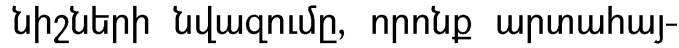

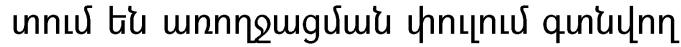

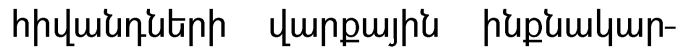
quunnuluí, punnjuspplymlymís unnvitpp le hunnnnulygulymiz yunnnnt-

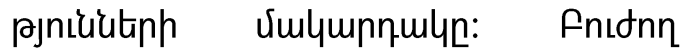

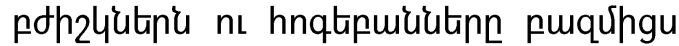

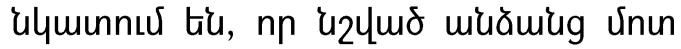

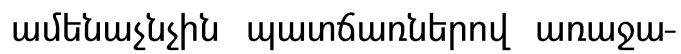
unuর tiu nữpnưnuăle mpămquiupatan

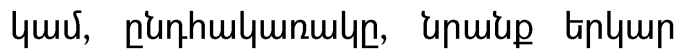
duxumumlyny «hulyunu tiu pptiup

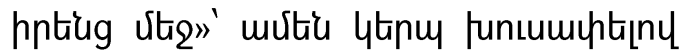

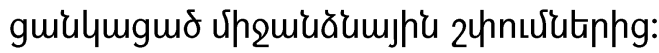

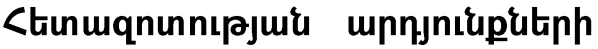

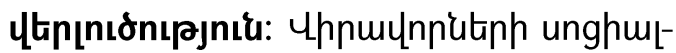

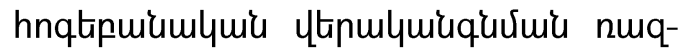

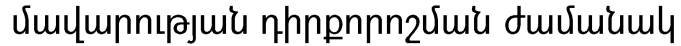

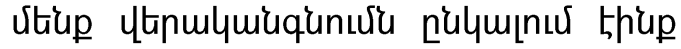

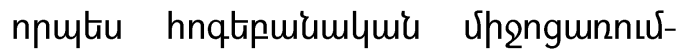

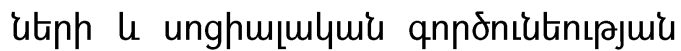
hurumlumph nnnzmly huviunh: $匕^{\prime} y$

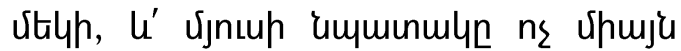

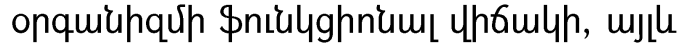
winăp hnsqulquiu, punnjutpplqulquin $\mathrm{l}$

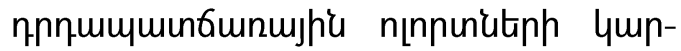
quunnnuर्u 5, puszutu umb qhưou- 


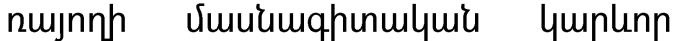
nnulyutiph ytamulymizqunune, nnnughg

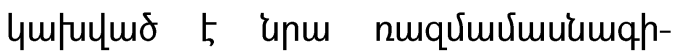

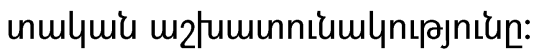

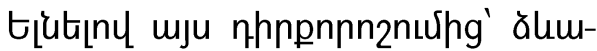

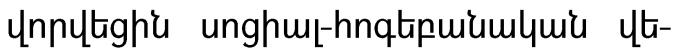

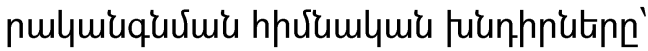

- unnıdudutiph hnqti\$hqhninqhu-

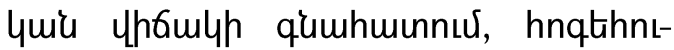

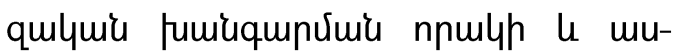
unh6uüh n.pnpnnn2nuर,

- hrumianh hnqtiquir unnngnt-

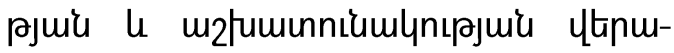

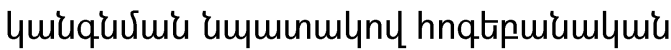
mqntgnıрjuiu nınhutiph u vitannutiph n'uunnnıpjnıน,

- yhnurynnuimir htinlumiaputinh u

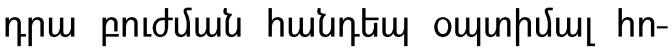

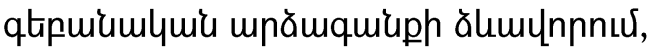

- pnıdúura nupaugpnú hnqtiluir

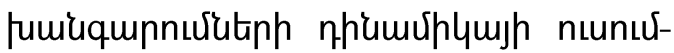
umupnnuर,

- \$hqhquiquia, qqujulquir la há-

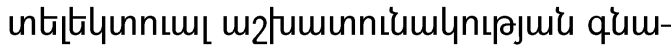
huinnuर, ynngnuid hnqtilume \$nialghuibitph ytanuluiuqunu,

- hnqtiptanumlunnly, hnqti\$hqhnnnqhulymir le hnqtipunvumlnninqhulquirs

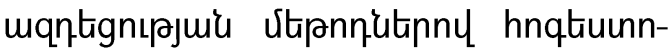

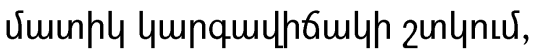

- hupaumqhunulgnıрjuí, hupumqumburnmumiuh le hupumqqugnnntगjǘ 2unlnuर,

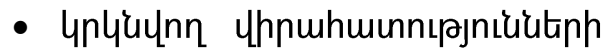

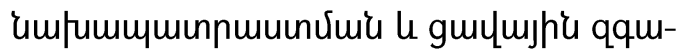
gnnnıpjniuutiph ptiplumgưuru oquntpjưu gnımuptinnuर:

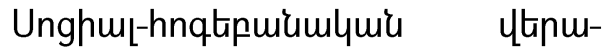

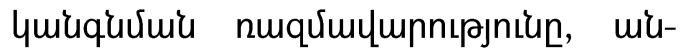

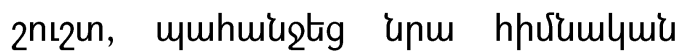

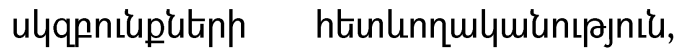

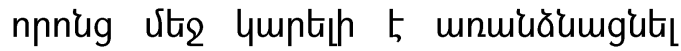
unmęumphüutnn [1,5]:

Tpn\$tupnium Ununtiguluiu ulqpnitup: Uhengunnulutinn uting miglymgutíu mju pon2lutine no hnqt-

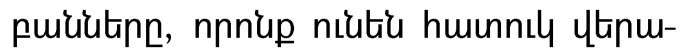

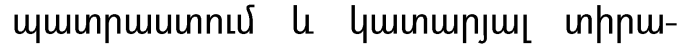

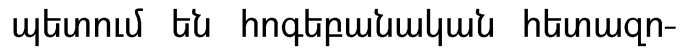

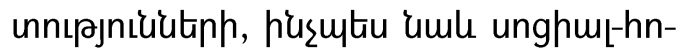

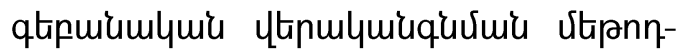
utpph:

Chưumunnưuir ulqpniup: <mum-

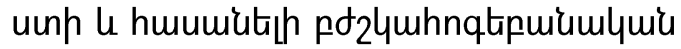

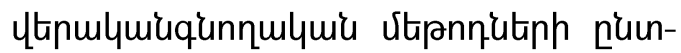
pnıpjniu, nnnúp uunnıqumo tiu ppting

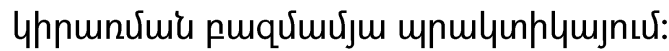

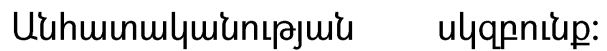

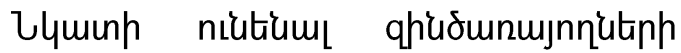

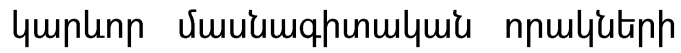

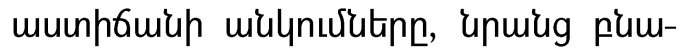

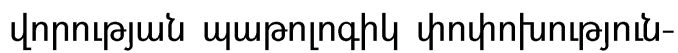




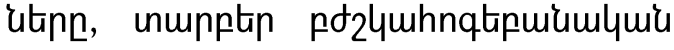

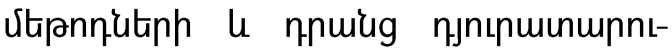
pjuis munnfiuih huiuntius qqujntunıpjứ punănugnıưn:

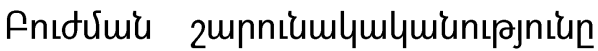

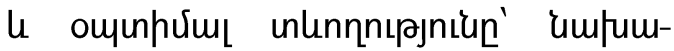
untuulnuर th ulqumo qhudunmjnnh' hnu-

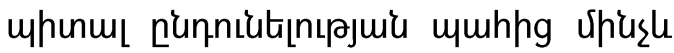
upu \$niulgghnuml uhfiulh ympqu-

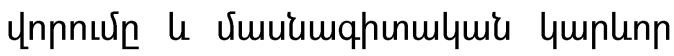
nnulyutiph ytanulymiuqunurn:

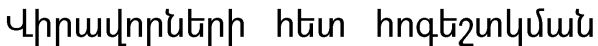
m2fumumusutiph hpúpnux nulquir

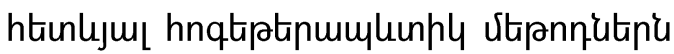

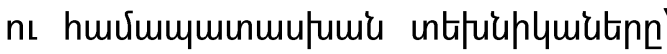

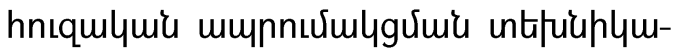
utp (toúumphu), htintipn le ununnpntjugunn untipühlyuitin, unquhunhy hn-

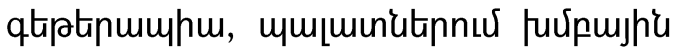
mqulgnn qnnıgutin, muhumanptipuuhm (4tiqnuiumptinumpur huinnsl

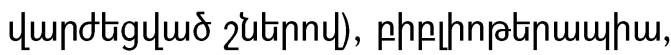

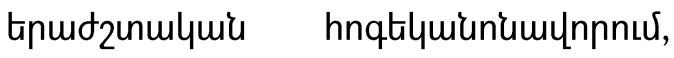

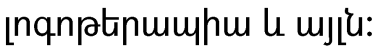

U2łumunuiuputinh vtipnnitinh $\mathrm{u}$

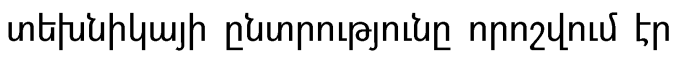

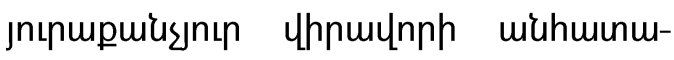

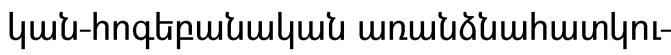

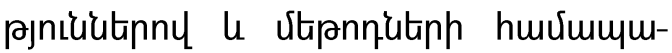

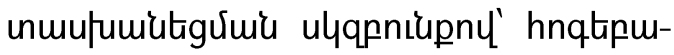

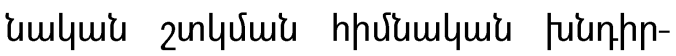
utph uhengutinnu'
- hnqtihntquiquir junцuónıрjuir uцumqnuर,

- onquiuhqún \$nialighnium $4 h-$ fulyh ytanulyuiuqunur,

- hnqtapuiumlquir hapamulunqu-

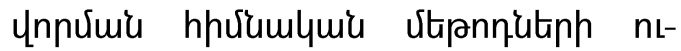
unıgnuर,

- cuuăumjhí hunúununnulyuiunt-

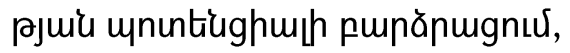

- qhidounujnniatph wiuăh punn-

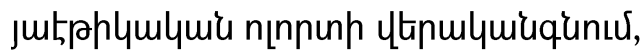

- yunph yunntgnnulyuira yundnumpump ălumunnnuर, nne vemuaum-

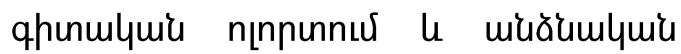

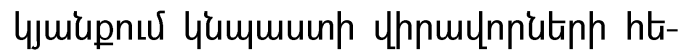
unmqu punopnıpjuiun,

- hunnnnulygulyuír núnniłumlyntPJniüutiph qunquignux $[2,4]$ :

tqnulymgnıpjnitu: Ujumpund'

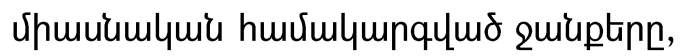

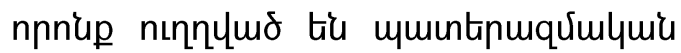

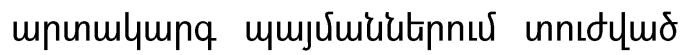
qhudunujnnutph unghut-hnqtipuium-

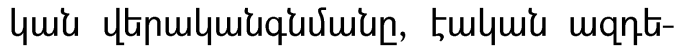

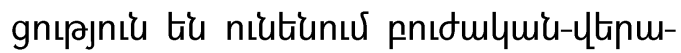

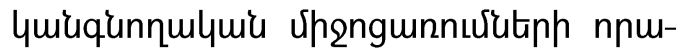

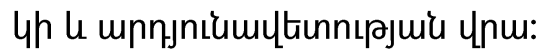

Jpmqnh hpulymiumgnưhg tiplynttphtp mưhu wing' unnoă mpltig unlüts hnqtipuiumlquiu-htinmqnunulymi $\mathrm{m}_{2}$ fumunuiuplatinn, nnuntin qnuikgytigg qhiunnh miuăh utnnmżumlnıрjuiu, unuq- 


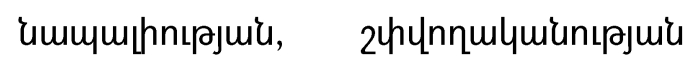

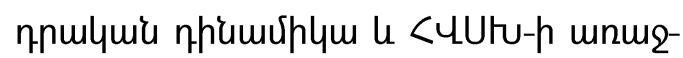
umjh's mpunmuhziutiph pugmumjntpjniu:

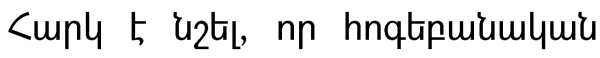

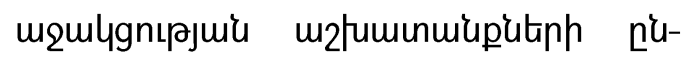

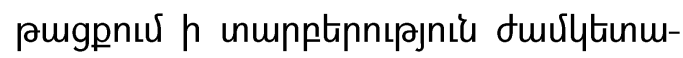

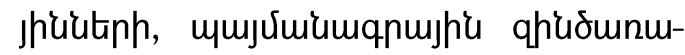

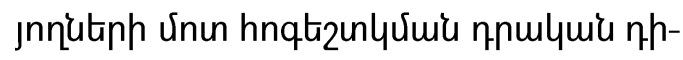

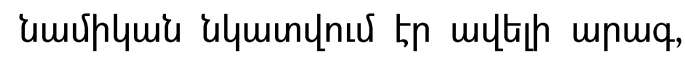
husn yuntis 5 puguinnta unuing punăn unuphpny le nuquiulyuiu unnnànu:

umplunnnuर tiup mju thuuinn, nn

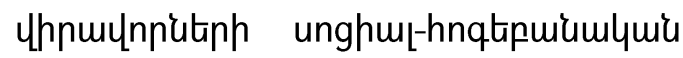

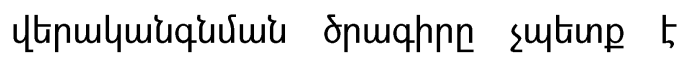

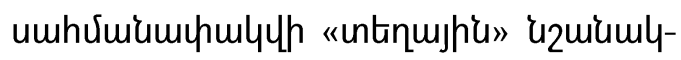

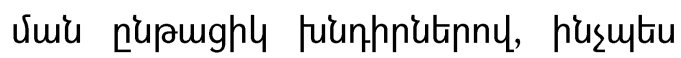

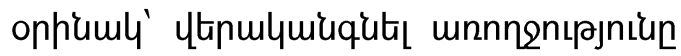
u hnqtiquiun, hnulymiumghts upnptiquunnnux le mjlu: Uhengunnusutiph

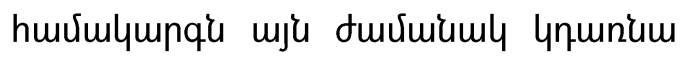

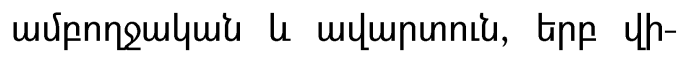

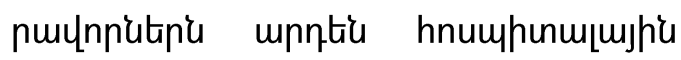

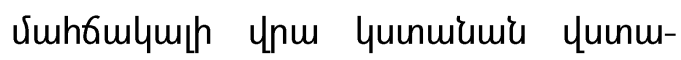
hnıрлníu чunчu onцm huiunteu: Uju

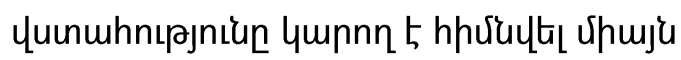
htinmqu niunsguimis le m2fuminuiuph

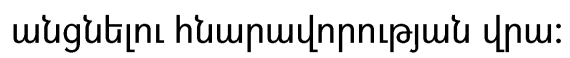

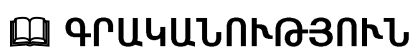

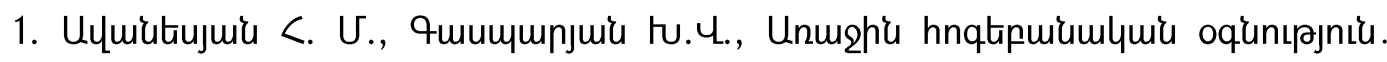

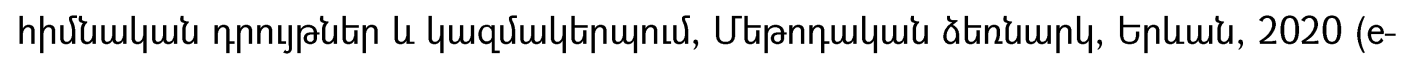
book), 21 52:

2. Шахвердян Г.М., Овновы психотерапии, СПБ. 2013.-206 с.

3. Романин А.Н., Основы психотерапии, уч. пособие, Москва 2006. 215 с.

4. Тодт Дж., Богарт А.К., Основы клинической и консультативной психологии, СПБ, Сова, 2001.

5. Пушкарев А.Л., Доморацкий В.А., Гордеева Е.Г., Посттравматическое стрессовое расстройство: диагностика, психофармакотерапия, психотерапия. - М.: Изд-во Института психотерапии, 2000. - 128с.

6. Тарабрина Н.В., Практикум по психологии посттравматического стресса. - СПБ: Питер, 2001. - 272 с.

7. Тарабрина Н.В., Лазебная Е.О., Синдром посттравматических стрессовых нарушений: современное состояние проблемы // Психологический журнал. - 1992. - T.13. №2. - C.1426. 


\section{SPECIFICITY OF PSYCHOLOGICAL SUPPORT TO MILITARY SERVICEMEN PARTICIPATING IN THE ARTSAKH WAR OF 2020}

PhD of Psychology, Associate Professor A.G. Stepanyan
PhD of Biology, Associate Professor L.S. Stepanyan Armenian State Institute of Physical Culture and Sport, Yerevan, Armenia

\section{SUMMARY}

Key words: serviceman, support, psychological issues, post traumatic stress, social-psychological rehabilitation, adaptation.

Relevance. Thousands of soldiers participated in the Artsakh war of 2020 represent a large focus area for doctors and psychologists. For this purpose, groups of volunteer psychologists were created in many hospitals of Armenia. They expressed readiness to provide psychological support to the soldiers and their families and stay engaged in those activites until now.

The research purpose and issues have mostly centered on the organization of psychological support and prevention of post-traumatic stress disorder for soldiers with severe injuries.

Methods and organization. The set of measures aimed at the social and psychological rehabilitation of the wounded is an indissoluble unity of three main directions: psychophysiological, psychocorrectional, social and psychological.

The war-wounded admitted to the hospital were examined through Eysenck's methods, the Loby test (attitude to the disease), the LSC (level of subjective control), the WAM questionnaire (well-being, activity, mood), the Spielberger questionnaire, the "Need for Achievement" test alongside the Luscher test. Consistent with the same program, each wounded was examined upon discharge from the hospital. Changes in the quantitative indicators of the first and last examinations made it possible to judge the quality and effectiveness of measures taken in the hospital for the social and psychological rehabilitation of the wounded.

Results analysis. Psychotherapeutic methods and techniques underpinning the psychocorrectional activities with the wounded are as follows: psychological 
counseling; techniques of emotional empathy; hetero- and autorelaxation techniques; cognitive psychotherapy; group conversations in wards, etc.

The choice of work methods and techniques was determined by the individual psychological characteristics of each wounded in compliance with the adequate method based on he main tasks of psychological correction:

- reduction of psycho-emotional stress,

- body functional restoration,

- teaching the basic methods of psychological self-regulation,

- increasing personal adaptive potential,

- restoration of servicemen moral and ethical position,

- formation of a constructive behavioral stereotype which will contribute to the further well-being of the affected serviceman in the professional sphere and personal life as well,

- development of communication skills.

Conclusion. Joint systematic efforts aimed at the socio-psychological rehabilitation of servicemen suffered in extreme war conditions have a significant impact on the quality and effectiveness of treatment and rehabilitation measures.

\section{СПЕЦИФИКА РАБОТЫ ПСИХОЛОГИЧЕСКОЙ ПОДДЕРЖКИ ВОЕННОСЛУЖАЩИХ УЧАСТВОВАВШИХ В АРЦАХСКОЙ ВОЙНЕ 2020 ГОДА К.псих.н., доцент А.Г. Степанян, К.б.н. доцент Л.С. Степанян Государственный институт физической культуры и спорта Армении, Ереван, Армения}

\section{PEЗЮME}

Ключевые слова: военнослужащий, поддержка, психологические проблемы, посттравматический стресс, социально-психологическая реабилитация, адаптация.

Актуальность исследования. Сотни-тысяч солдат принимавших участие в Арцахской войне 2020 года представляют большое поле для работы врачей и психологов. С этой целью для психологической поддержки во многих госпиталях и больницах Армении были созданы группы психологов-добровольцев, которые 
были готовы оказать психологическую поддержку солдатам и их семьям, данные работы продолжаются и по сей день.

Цель и задачи работы: организация психологической поддержки и профилактика посттравматического стрессового расстройства военнослужащих, получивших тяжелые ранения.

Методы и организация работы. Комплекс мероприятий направленный на социально-психологическую реабилитацию раненых, представляет собой неразрывное единство трех основных направлений: психофизиологические, психокоррекционные, социально-психологические.

Поступающие в госпиталь раненые, прошли обследование с помощью методик Айзенка, теста Лоби (отношение к болезни), УСК (уровень субъективного контроля), опросника САН (самочувствие, активность, настроение), опросника Спилбергера, теста “Потребность в достижении”, теста Люшера. По такой же программе каждый раненый прошел обследование при выписке из госпиталя по завершении программы реабилитации.

Изменения в количественных показателях первого и последнего измерений и позволили судить о качестве и эффективности проводимых в госпитале мер по социально-психологической реабилитации раненых.

Анализ результатов. В основу психокоррекционной работы с ранеными легли следующие психотерапевтические методы и техники: психологическое консультирование; техники эмоционального сопереживания (эмпатия); гетеро- и ауторелаксационные техники; когнитивная психотерапия; групповые беседы в палатах и т.д.

Выбор методов работы и техник определялся индивидуально-психологическими особенностями каждого раненого и принципом соответствия метода по основным задачам психологической коррекции:

- снижение психоэмоционального напряжения,

- восстановление функционального состояния организма,

- обучение основных методов психологической саморегуляции,

- повышение личностного адаптационного потенциала,

- восстановление морально-нравственного положения военнослужащих, 
- формирование конструктивного стереотипа поведения, который будет способствовать дальнейшему благополучию пострадавшего в профессиональной сорере, в личной жизни,

- развитие коммуникативных способностей.

Заключение. Совместные систематические усилия, направленные на социально-психологическую реабилитацию военнослужащих, пострадавших в экстремальных условиях войны, оказывают существенное влияние на качество и эффективность лечебно-восстановительных мероприятий.

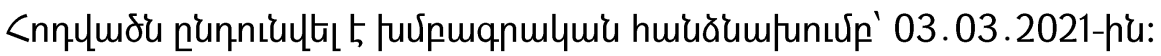

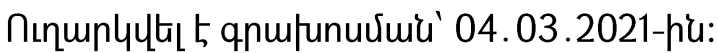


DOI: 10.53068/25792997-2021.1.3-193

\title{
ДЕТЕРМИНАНТЫ ОЗДОРОВИТЕЛЬНОЙ АЭРОБИКИ СКВОЗЬ ПРИЗМУ МНЕНИЙ ЖЕНЩИН
}

\author{
Д.п.н., профессор Ф. Г. Казарян, \\ магистрант М. Н. Казарян, \\ Государственный институт физической культуры \\ и спорта Армении, Ереван, Армения \\ Учебно-спортивный комплекс Газпрома Армении \\ Ереван, Армения \\ E.mail: frunz.ghazaryan@sportedu.am, immaggic@gmail.com
}

Ключевые слова. Фитнес, оздоровительная аэробика, система фризических упражнений, двигательная активность, тренировочное занятие, состояние здоровья, двигательные способности

Актуальность исследования. Во все времена, как и сегодня особую актуальность имеют вопросы сохранения и укрепления здоровья граждан. К сожалению, современные социальноэкономические условия негативно влияют на здоровье, фризическое развитие, двигательную подготовленность человека (Ł.U.qunnquulu lu hur., 2008: \$.9. Zuqunjuiu, ก.U. Umunıljui, 2004; <.9. Onuviujuiu, U.9. Umiappnujuit, 2011).

Поэтому в практику фризического воспитания уверенно внедряются оздоровительные технологии, к числу кото- рых относится и оздоровительная аэробика (Т.С. Лисицкая, 1994; 4.9. Fuрuјшu, 2006; Ł.9. Unuर्ujuiu, 2012; Ł.U.Uuцuцjuน, 2016 и др.). В пользу оздоровительной аэробики говорит и то, что женщины в силу своей повышенной эмоциональности плохо переносят монотонную физическую нагрузку, а аэробика пластична и изменчива, в полной мере отвечает потребностям женского организма (Л.И. Лубышева, 1984).

В мировом масштабе исследования научно-прикладных вопросов оздоровительной аэробики продолжаются, что подтверждает и актуальность данного исследования.

Цель и задачи исследования. Целью данной работы является ретроспективный анализ сущности оздоровительной аэробики как одного из 
направлений физкультурно-спортивной деятельности граждан.

Решались следующие задачи: очертить современную сущность оздоровительной аэробики и определить ее детерминанты сквозь призму мнений женщин.

Методы и организация исследования. Использовались общенаучные методы теоретического исследования - теоретический анализ и обобщение научно-методической литературы, и социологический опрос.

Авторская анкета социологического опроса состояла из 8 опорных вопросов с 35 альтернативно возможными ответами. Выбор социологического подхода предусматривал определение социально-демографических характеристик объекта изучения.

Исследования проводились на базе Учебно-спортивного комплекса Газпрома Армении. В социологическом опросе приняли участие 100 женщин в возрасте от 25 до 57 лет. Возрастная сере-

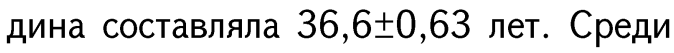
опрошенных - домохозяйки, работающие женщины и учащаяся молодежь.

Анализ результатов исследования. Литературные данные свидетельствуют о том, что путь женщин в современную фризическую культуру был крайне противоречив и мучительно труден, обусловлен процессами эмансипации и феминизации, как объединение женщин с целью достижения равноправия с мужчинами.

Тем не менее, конец 20 века отличился активным развитием фризкультурно-оздоровительных направлений и множества узконаправленных оздоровительных и эстетических систем для женщин.

Так сформировалась система упражнений для мышц лица - фейсфрорминг, дыхательная практика, организованы курсы по формированию эстетической походки, релаксационные методики для улучшения психического и эмоционального фона женщин (А. И, Хаткевич, 2005). 50 лет тому назад панацеей оздоровления считался оздоровительный бег.

Сегодня в практику оздоровительной фризической культуры внедрены новые технологии, к числу которых относится и оздоровительная аэробика (А.А. Виру, 1988; Т.С. Лисицкая, 19872012, Е.М. Лахина, 2012; Е.С. Акопян, А.А. Ковалева, 2018; Е.Б. Мякиченко, М.П. Щестакова, 2002; Ł.9. Uпuर्ujuи, 2012; Ł.U. Uицшนјuน, 2016 и другие).

Система фризических упражнений под названием «аэробика» была соз- 
дана прошлом веке (К.Купер, 1979) и получила прикладное развитие известной американской актрисой Джейн Фондой. Именно отсюда стали развиваться различные направления аэробики.

Как основное направление занятий главным образом с девочками, девушками, женщинами оздоровительная аэробика призвана решать оздоровительное, развивающие и эстетические задачи.

В настоящее время оздоровительная аэробика стала очень популярной, сложно-координационной и эстетической. В отличие от спортивной аэробики здесь нет рискованных и травмоопасных элементов.

Аэробные упражнения в оздоровительном аспекте полезны не только для учащейся молодежи, но и для лиц разного пола и возраста, особенно женщин, являются единственным универсальным средством в профилактике различных заболеваний.

Конечная цель оздоровительной аэробики - дать каждому занимающемуся оптимальный и адекватный его личным склонностям рецепт двигательной активности.

В итоге социологического опроса нами установлено, что в столице Арме- нии каждая четвертая женщина занимается теми или иными видами физических упражнений, 18\% в прошлом занимались, самостоятельными формами физических упражнений увлечены $12 \%$ респондентов. В этом плане наши данные в некоторой степени согласуются с результатами исследований армянских авторов (Е.С. Акопян, А.А. Ковалева, 2018).

K сожалению, В силу различных причин 45\% девушек и женщин не вовлечены в физкультурно-оздоровительные занятия.

Конечно, на это есть объективные и субъективные причины: низкий уровень двигательной подготовленности (24\%), семейные обстоятельства (58\%), материальные условия жизни (13\%) и состояние здоровья (5\%). Каждая 6-7 женщина свое свободное время проводит в кругу семьи, каждая четвертая - с друзьями, 11\% - в одиночестве.

Особый интерес представляло мнение респондентов относительно оценки своего здоровья. Так, 27\% их считают себя абсолютно здоровыми, $56 \%$ - имеют хорошее здоровье, а 17\% должны укреплять состояние своего здоровья. С состоянием здоровья женщин, естественно, связана и степень их утомления в течение дня. Оказалось, 
что 16\% женщин постоянно находятся в состоянии утомления, $31 \%$ - время от времени, 45\% - иногда и 8\% - вообще не утомляются.

Узловым вопросом социологического опроса являлось выяснение степени знакомства девушек и женщин с современными видами двигательной активности и их интересам, и предпочтениям к конкретному из видов. Отрадно, что опрошенные респонденты имели представление о таких разновидностях фитнеса как аэробика (47\%), шейпинг (44\%), аквааэробика (36\%), стретчинг (24\%).

С другой стороны, справедливо желание девушек и женщин зрелого возраста заниматься отмеченными видами двигательной активности, где доминируют оздоровительная аэробика, оздоровительная ходьба (35-37\%), аквааэробика и плавание (25\%), менее приоритетное значение имеют езда на велосипеде и бокс.
Выводы. Таким образом, совре менный жизненный уклад и философия меняют отношение женщин к своему здоровью, собственному телу. На первый план выходит чувство сохранности внешности женщины. Идеальный образ женщины настолько искривлен, что только одна из 100 тысяч женщин рождается с телосложением куклы Барби, которая стала аспирационной моделью для многих девушек в западном мире (M. R. Powel, B. Hendricks, 1999).

Если идеальный образ мужчины обладает качествами мускулистости, то идеальная женщина, наоборот, обладает детской, незрелой внешностью, худобой. Поэтому, не случайно, что и в нашей стране, женины ориентируются на Запад и наблюдаются девушки и молодые женщины с абсолютно нормальным весом, которые недовольны своей внешностью и стараются сбросить вес, обрекая себя на строгие диеты и безмерные занятия спортом.

\section{Ф СПИСОК ЛИТЕРАТУРЫ}

1. Акопян Е.С., Ковалева А.А., Отношение женщин к физической культуре, Ежегодник, Ереван, 2002, С. 377-381.

2. Лисицкая Т.С., Аэробика на все вкусы, М.: Просвещение - Владос, 1994 97c.

3. Лисицкая Т. С., Сиднева Л. В., Аэробика. Теория и методика, М.: Федерация аэробики России, 2002, т.1, С. 232, т. 2, С. 216. 
4. Хаткевич А. И., Лицо без морщин за 5 минут в день, Минск: Ильгарис, 2005, C. 125.

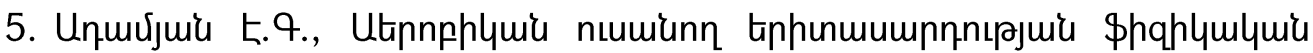

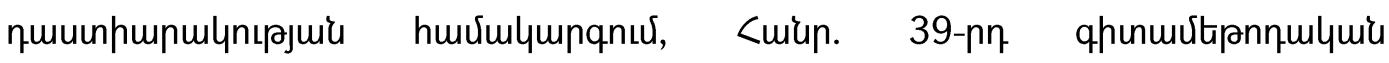

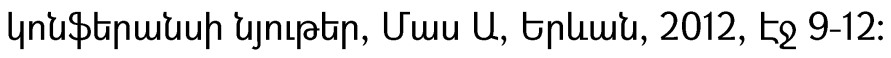

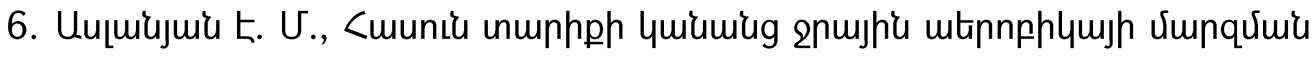

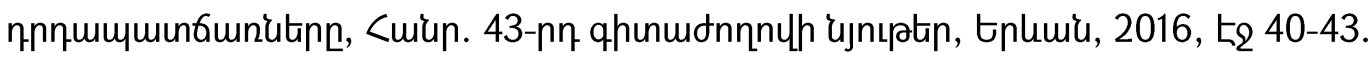

7. Powel M. R., Hendricks B. Body schema, gender and other correlates in nonclinical populations. Genetic, Social and General Psychology Monographs, 1999, 125:333-80.

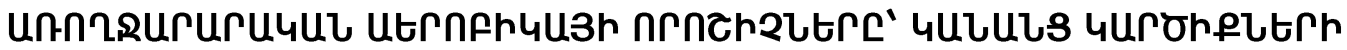 cひ4ULUUน TกhRUU3ก4
}

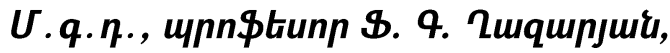 \\ viuqhuypuiry $U$. $Z$. 2urqunjuir

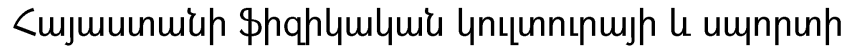

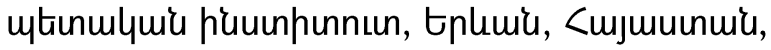

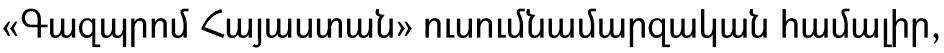 \\ tphuiu, <mjuuunuik
}

\section{UUФПФU१९ৎ}

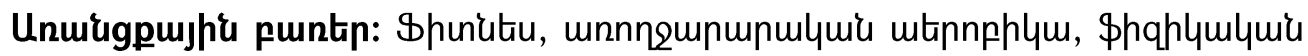

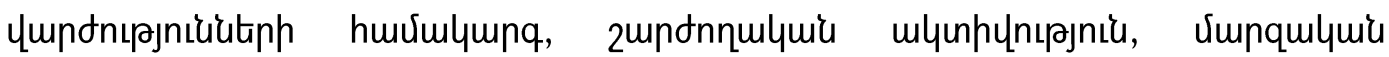

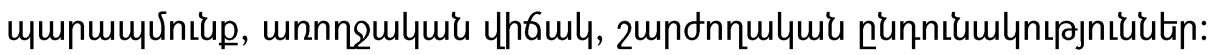

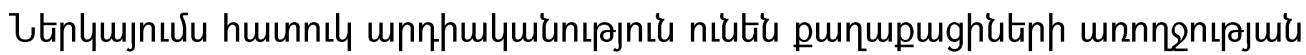

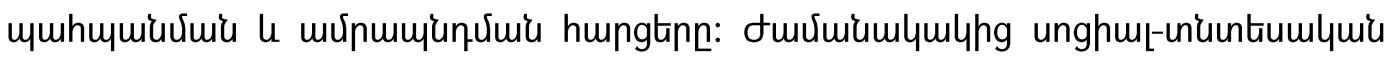

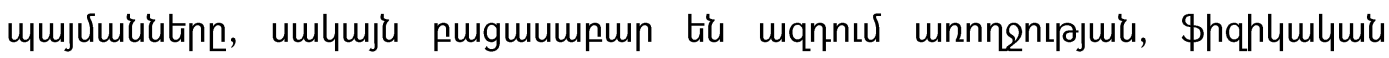

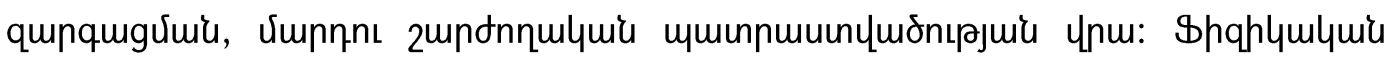

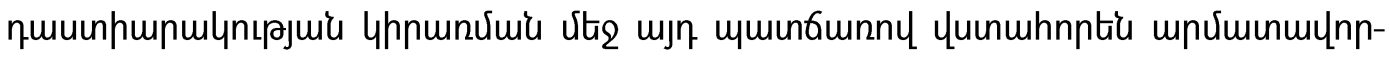

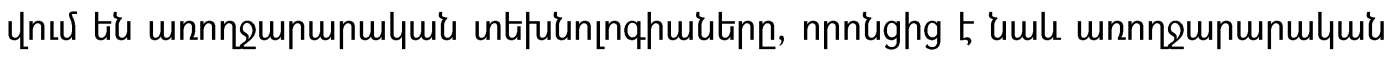

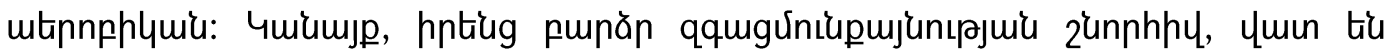

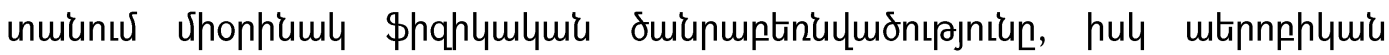

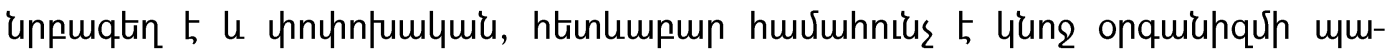




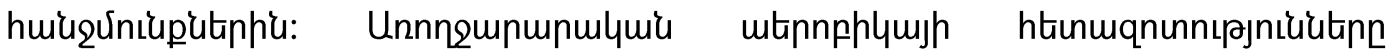

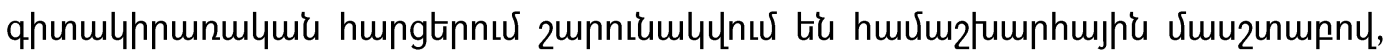

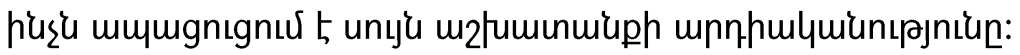

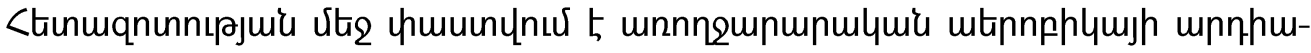

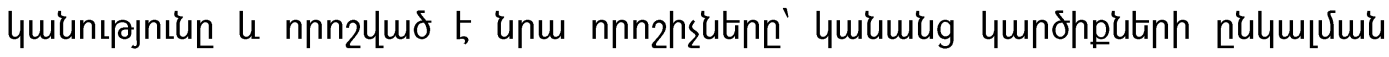

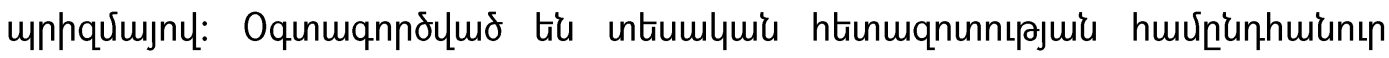

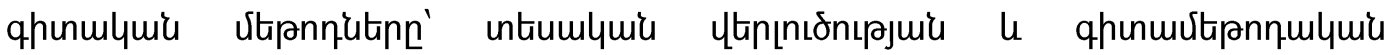

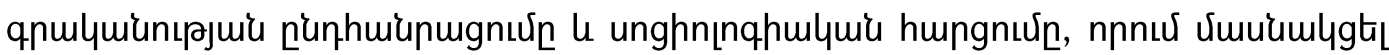

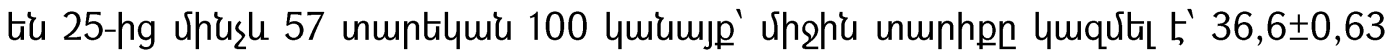

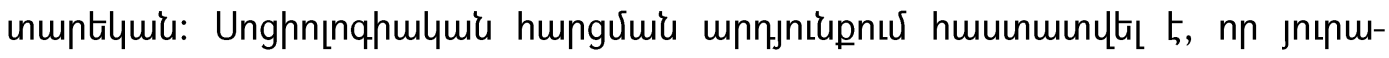

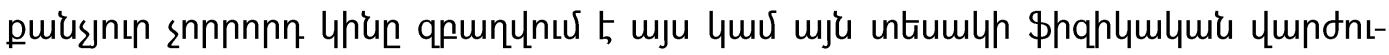

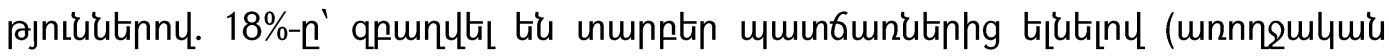

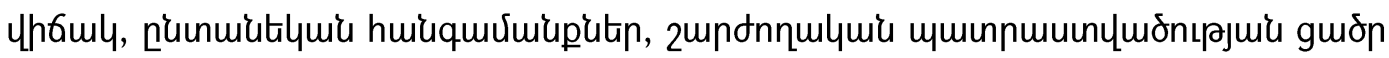

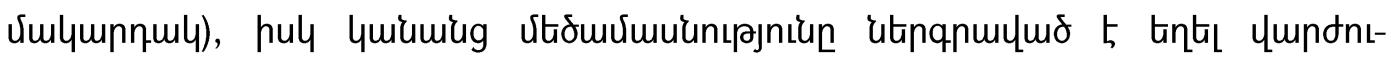

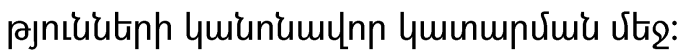

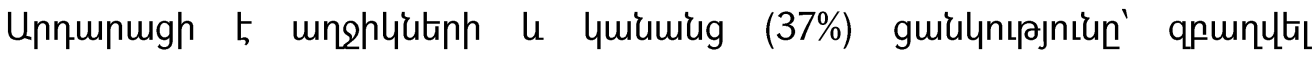

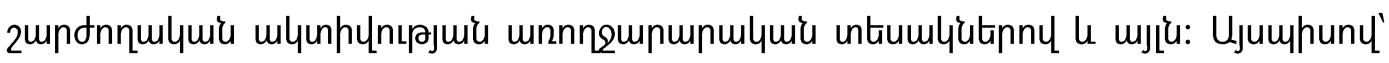

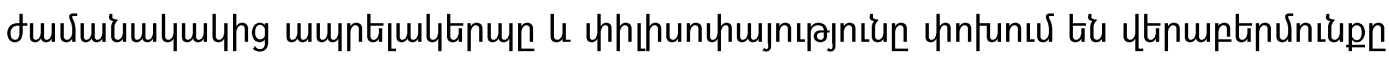

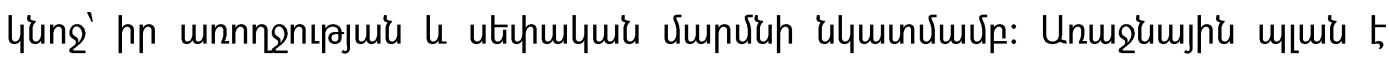

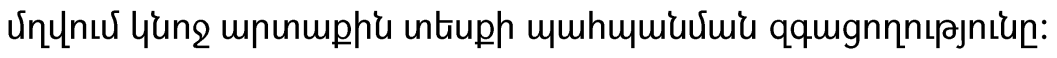

\section{DETERMINANTS OF HEALTHY AEROBICS THROUGH THE PRISM OF WOMEN'S OPINIONS}

Doctor of Pedagogy, Professor F. Ghazaryan Aerobics coach, Master's degree student M. Ghazaryan

Armenian State Institute of Physical Culture and Sport

Yerevan, Armenia

Armenian Gas-prom educational and sport complex

Yerevan, Armenia

\section{SUMMARY}

Keywords. Fitness, wellness aerobics, physical exercises system, motor activity, sports training, health conditions, motor skills. 
At present, the issues of preserving and strengthening the health of citizens are of particular relevance. Yet modern social-economic conditions, unfortunately have negative effect on health, physical development, and fitness of a person. Therefore, technologies to improve the health are being confidently introduced into the practice of physical education, including healthy aerobics. The improvement of healthy aerobics has an advantage: women due to their increased emotionality, poorly tolerate monotonous physical loading, while aerobics is flexible and variable meeting full needs of woman's body. The investigations of healthy aerobic in scientifically applied issues develop worldwide, which confirms relevance of this work.

In the research it is outlined modern concept of healthy aerobics and determinants defined through the prism of women's opinions. General scientific methods of theoretical research were used - theoretical analysis and generalization of scientific-methodological literature and sociological survey, in which 100 women from 25 to 57 years old were included: the middle age was $36,6 \pm 0,63$ years. As a result of sociological survey, it was found that every fourth woman perform physical exercises currently, $18 \%$ - were engaged in physical activity in the past due to various reasons (health conditions, family circumstances, low level of motor readiness), most women are not involved in systematic physical activity. The girls' and women's (37\%) wish to be engaged in healthy motor activity is justified.

Thus, modern lifestyle and philosophy are changing the attitude of women to their health and body. The feeling of the appearance maintenance becomes primary. The perfect look of women is so complicated, that only the one from 100,000 girls is born with the wish of most of the girls, that is Barbie doll physical appearance.

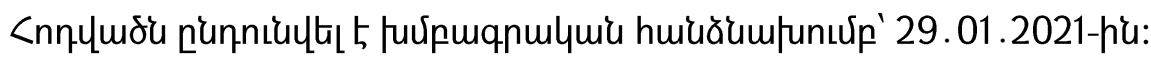

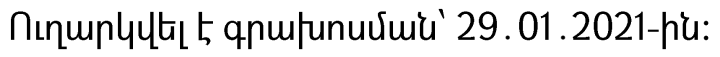


DOI: 10.53068/25792997-2021.1.3-200

\section{MYTHS AND REALITES OF STUDENT ASSESSMENT IN HIGHER EDUCATION OF ARMENIA}

Head of the ASIPCS Quality Assurance Department, Postgraduate G. A. Muradyan Armenian State Institute of Physical Culture and Sport Yerevan, Armenia E-mail: gohar.muradyan@sportedu.am

Key Words: Student assessment, assessment methods, student assessment myths and realities, assessment as a feedback, formative and summative assessment, rubrics.

Abstract. Student assessment is an integral part of any teaching learning process. Assessment practices have a large number of functions to perform in the context of the teaching, learning process.

This article challenges several myths about student assessment: that we know what we're grading, that we know what the results mean, that we can agree in practice on various criteria, which is possible to establish and apply unanimously.

Despite these seeming difficulties, this article argues for the validity of assessments developed within particular academic environments in the higher learning institutes of Armenia.
Do contemporary assessment practices perform these function: it is a critical question to be analysed. In this paper, an attempt has been made to analyse the myths and realities of the assessment practice in the higher education sector.

Introduction:Evaluation and assessment of students performance are key to understanding how well students are learning. The results can guide improvements in teaching practices and help to increase accountability to the stakeholders of the high learning institution.

Over the past two decades there has been a lot written, and much discussion, around the effective use of assessment in the classroom.How to assess, and the closely related issue of the effects of assessment on students, have been discussed extensively in most academic platforms as well as studied by local and international experts [1, 2]. 
The issues came from self-evaluation report'that targets assessment methods of Journalism master degree education program which is carried in the Armenian State Institute of Physical Culture and Sport, as we see them, of general interest. Our findings illustrate the need to not take the effects of assessment, nor what it measures, as a remedy to the pitfalls thatare common in grading system in the higher education.

Education research as an essential area for improving tertiary education, in this case by exposing myths about assessment tools.

According to the survey conducted among the teachers of the Armenian universities and TLIs, the main goal of student assessment is monitoring of learners' knowledge and their abilities and skills. The results of the students assessment are intended to improve the learning process and student achievements.

To assess learning achievements, Armenian HLIs resort to three types of student assessment: classroom assessment, system level diagnostic testing and written tasks. The most commonly used

\footnotetext{
${ }^{1}$ The independent expert survey was carried out within
} the frameworks of OSI grant program. methods are questioning, oral tests and homework tasks ("control tasks").

Student assessment in general is delegated to teachers who are free to choose the methods and set the assessment standards.

Unfortunately, many educators, continue to cling tenaciously to 'traditional' practices which are, at best ineffective and at worst, counterproductive to the goals of modern education.

Research methods:The investigation of 6 assessment myths is based on the arguments garnered from online opinion polls and in-depth interviews conducted with 45 teachers from $5 \mathrm{HLI}$ of Armenia (academic staff involved in the research was both from bachelor and master degree educational programs).

Research purpose:Every assessment is said to be SMART; specific, measurable, achievable, realistic and time bound [3].

Whether the contemporary assessment could claim these features is a debatable issue Whether students are really getting the benefits of continuous assessment and evaluation is another issue to be addressed especially in the context of digital reviving of teaching and learning process at the higher education 
sector. Many times the assessment practices are criticized by students labeled as biased, subjective and as a tool for oppression. At the same time teachers stress that assessment of student learning is a means of increasing the mutual engagement in the learning process for boosting educational higher pursuits.

The primary purpose of the research made in the Armenian HLIs is to explore and unravel truths about assessments myths which $t$ more and less hinder the further improvements of the quality of educational programs.

Research findings and results: Research results uncovered 6 common assessment myths which are reflected in Chart 1 and elaborated in this article.

\section{Chart 1.The prevalence of assessment myths in HLIs}

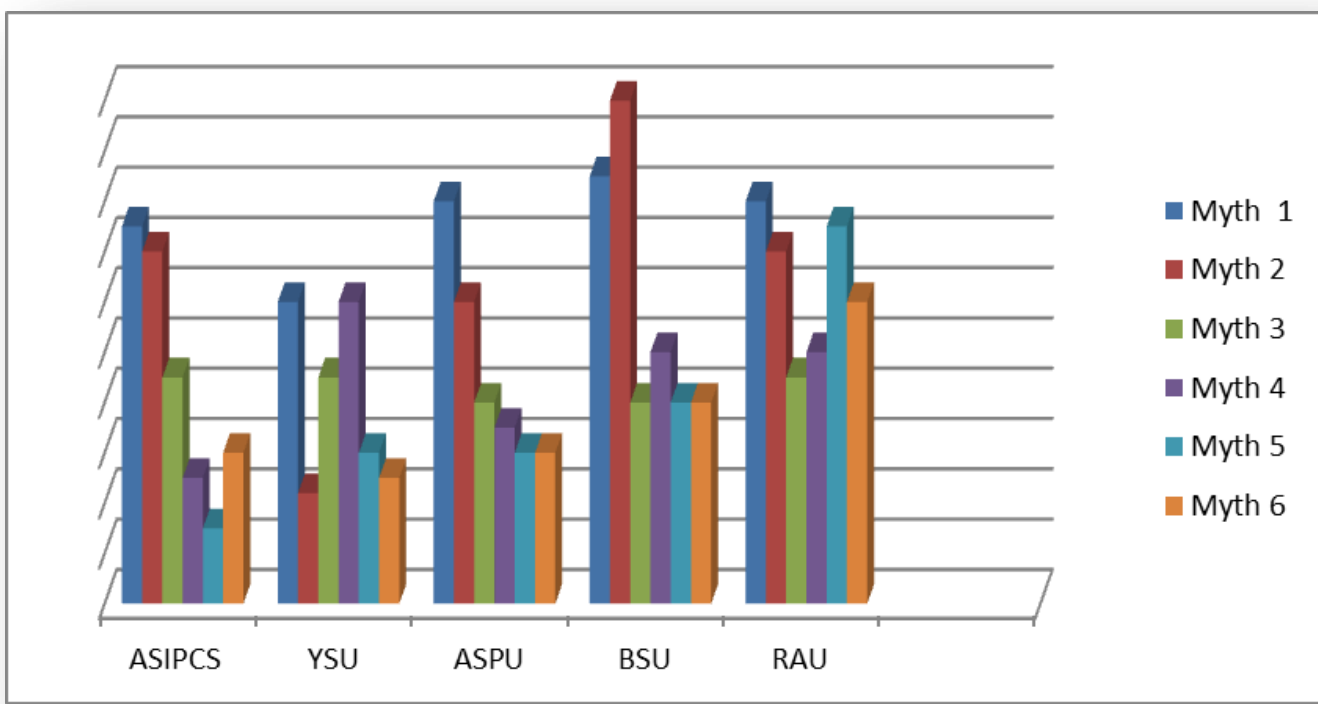

\section{The Myth of validity and} reliability

Validity is the quality of any assessment that really assesses what it intends to assess. There are different types of validity like content validity, construct validity, criterion reference validity, etc. These are ensured by following systematic procedures while developing assessment tools. Since the systematic procedures are often violated while developing the 
assessment tools, the validity of assessment practices is in question. There is an agreement among academicians that the contemporary assessment practices in higher education sector do not assess truly real competence and skills of learners. Hence, the assumption of validity is still an unobtainable as far as assessment practices at the higher education sector are concerned.

Reliability checks the subjectivity in assessment practices but there are as many instances to show that assessment practices are subjective especially at the higher education level [4].

Even more the assessment practice must be comprehensive and assess the multidimensional aspects of learners. To make assessment comprehensive there must be provision for different techniques of assessment with written, oral and alternative types of assessments.

Contrary, as the results of the opinion poll surveys show Armenia HLIs still heavily rely on written examination to assess students' abilities and competences as examiners fail to make it objective (75\%).

\section{The Myth of assessment as a feedback tool: assessment is one- way communication}

The most productive assessment should be a dialogue. Assessment is a means or a tool that lead the learners and the entire education system to the desired ends. In traditional assessment and evaluation models, students complete a task, the teacher assesses the work and tells the student how they've done and, in formative cases, how to improve the work. As students engage with the teacher to discuss work, talk about what they've done and why, both student and teacher stand to gain far more from the experience. Assessment practices involves giving feedback, motivating, directing of learners, etc. [5].

Modern technology makes twoway communication between teacher and student much easier and far more ubiquitous. It is paradoxical that being provided with infinite platforms and online tools, in contemporary contexts, assessment became an end in itself.

As study results show contemporary assessment practices in higher education do not perform these functions. Assessment ends with 
the assessment: every educative process starts and end with narrow assessments and learners shrink into meaningless scores or grade.

\section{The myth of continuous} assessment through semester end examinations

Some universities practice continuous assessment through semester end examinations. With the introduction of internal continuous assessment at bachelor level, $35 \%$ of the total score of each course has been assigned through continuous internal assessment and 80\% through semester end written examination in examined universities. Here $35 \%$ of the scores of the course will be based on the continuous assessment by the concerned teachers themselves. But in the case of students who learn different programs through distance education mode, it is found that for this $35 \%$ they have to write another examination on the basis 20 multiple choice type questions.

As a result teacher-administered assessments are an important source of information about student success, but they are not necessarily the most reliable one. When marking, teachers in Armenian HLIs, resort to comparing each student's achievement with those of other students. No matter how experienced they are in doing doing this the judgments are prone to subjective bias, especially when assessment norms can be chosen and changed freely at any time. The remarks given by the teachers at the focus groups show that teachers tend to reward certain students characteristics and proficiency are not related to learning achievements such as big desire to learn, punctuality, keeping up with the deadlines.

\section{The myth of formative}

\section{assessment}

Teachers interviewed agree on that assessment can be a very powerful learning toolfor constantlyassessing both student work and teacher experiences, making necessary adjustments in teaching and learning methods. But the practice shows that there are still far too many teachers who rely on formative assessment: most assessment is summative.

$65 \%$ of the teachers consider summative assessment as the recognition of student achievement. In summative assessment where grades/ marks are necessary, this assertion is 
true.But too often teachers put a mark on student work when they're hoping to use the work formatively, which is a mistake.

Teachers continue to use assessment for marking purposes. Assessment is basically used to classify students, to label them, to ensure presumed discipline in the classroom, to punish, and to encourage.

While the main purpose of evaluation is to contribute to the effectiveness of the education process, assessment is an indispensable tool in the education process to ensure feedback between student and teacher. Assessments should serve to reduce the discrepancy between what the teacher is teaching and what the student is learning.
The consequence is superficial compliance (if any) with the new requirements, facilitated also by the fact that the new assessment dimensions and criteria are quite diversified, but at the same time also formulated broadly, leaving ample room for personal interpretation.

Evidences analysed in the course of the preparation of this research pinpoint visible manifestation of malpractices of inflation of marks (grades) due to pressure of having good grades at the end of the year and marking in absentia. The latter is a form of informal "support" by teachers tolerating the prolonged absence from the class of students who have to work for paying their tuition fee.

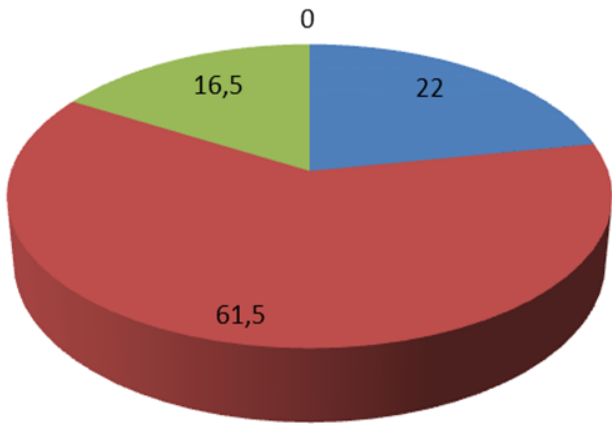

asssessment misuse through grading in absence

Asessment misues through subjectivity

assessment misuse unspecified 
5.The myth of developing and using rubrics

Rubrics are guidelines for assessing complex tasks or behavior which are subjective in nature. It helps to make assessments more accurate and objective. Whether the teachers or institutions develop and use such rubrics is doubtful. In many instances, even if the curriculum provides the rubrics for assessing different learning, teachers are not making the assessment based onit and thereby fails to satisfy the real purpose. During the interviews teachers were voicing the opinion that there is no valid way to use rubrics for assessing qualities like critical thinking and sport dancing performances [6].

At the same time the vague assessment criteria make it nearly impossible to prove there is difference between learning achievement that deserve A or B. In fact the same vagueness makes it relatively easy to "change" any grade to the best if need be.

6 . The myth of teacher trainings for using assessment methods and techniques more productively

Myth 6 envelopes the previous myths. Even though there has been multiple choices of internal and international training programs that most of teachers attended, teachers are still experiencing difficulties in applying the new assessment methods and principles in their daily work - methods that have the potential to make student assessment more reliable and resistant to bias. Before the barriers to the implementation of the new assessment framework can be removed, it is paramount to understand what these barriers are. Not much is known about what factors precisely limit the teachers in applying the novelties they have been trained in, whether they are the same for all teacher profiles.

Proper and reliable assessment of student success depends not only on the ability and knowledge of particular teachers or groups of teachers, but also on the professionalism of the teachers' team as a whole and on its capacity for peer collaboration.

Teachers can spend a quarter or more of their professional time involved in assessment-related activities. If they assess accurately and use results effectively, their students can prosper.

Conclusion:This study that somehow shed light on assessment myths and truths is not refuting the core principle that assessment of student learning 
reforms teaching activities .On the monitoring, directing towards and contrary, when you conduct an reviving the goals and objectives of the assessment, you expand the boundaries educational programs. The practice of and go beyond grading; as an instructor, valid, reliable, justifiable and fair you start examining patterns in their assessment is a prerequisite for the performance along a timeline. These success of any education system. It is the patterns enable the efforts to fill learning duty of the teachers and educational gaps to be a more fruitful intervention, administrators to redefine the assessment for both the learner as well as the practices and inculcate the culture of fair instructor. and unbiased assessment behavior.

Given the critically important roles of assessment, that helps in the formulation,

\section{Refernces}

1. Harutyunyan K., The Development of the Student Assessment System in the Republic of Armenia: Achievements, Challenges and Lessons Learned, Armenia, 2015

2. Barnes N., Fives H., Managing assessment to enhance student learning, 2020, USA

3. Steinle V., Chick H., Eugene Gvozdenko, SMART Assessment for Learning, University of Melbourne, Australia, 2019

4.Importance of Validity and Reliability in Classroom Assessments, 2018

5. Rhind S., Engaged in feedback and assessment, University of Edinburgh 2017

6. William D., Assessment: The bridge between teaching and learning, University College London, 2013 


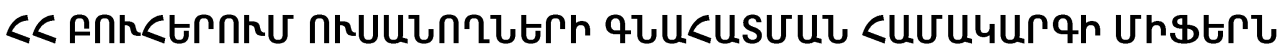

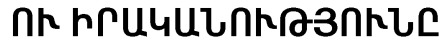

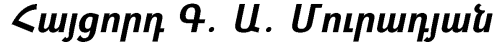

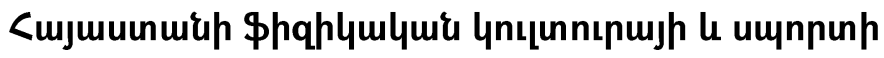

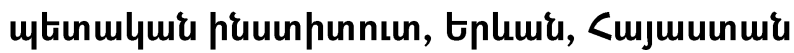 UUФПФU१९ৎ}

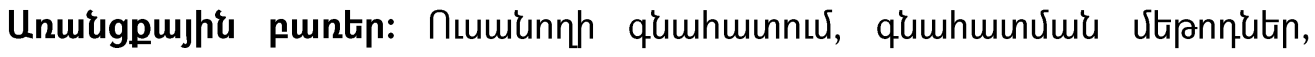

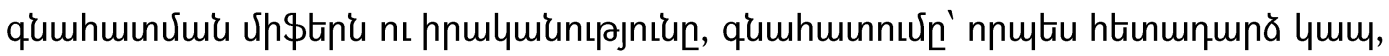

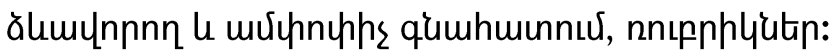

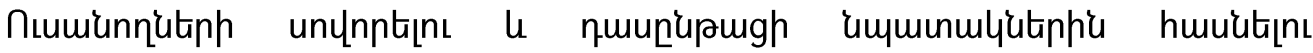

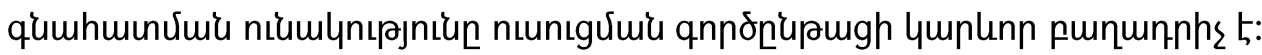

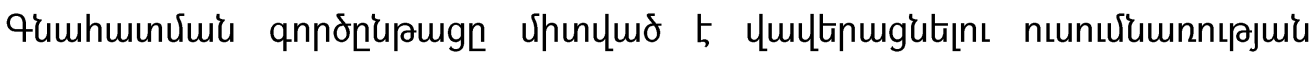

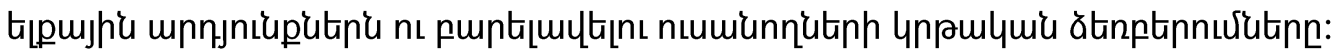

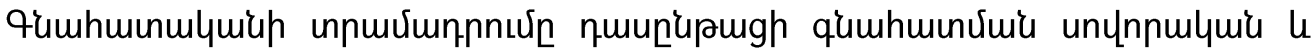

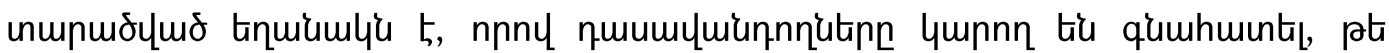

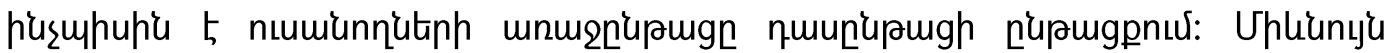

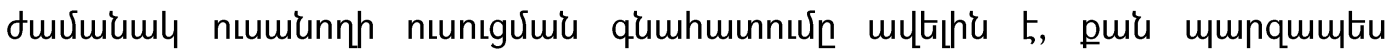

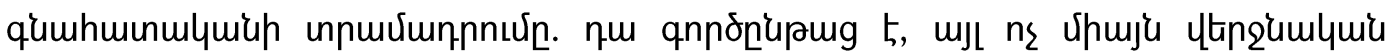

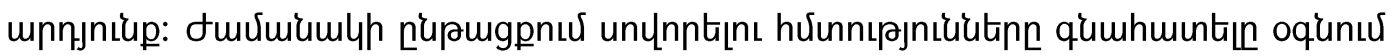

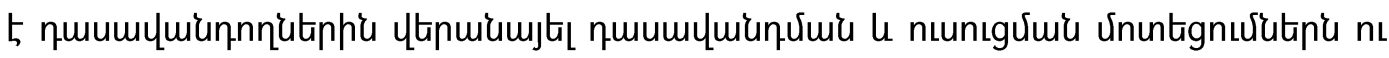

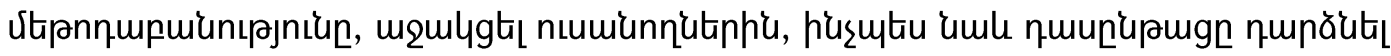
uцLth htinupnphn:

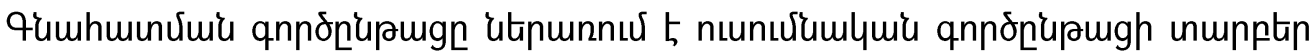

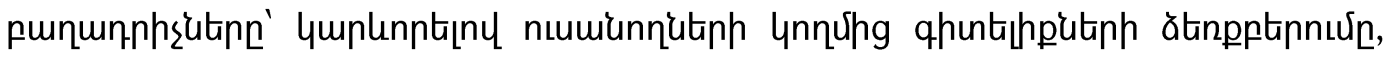

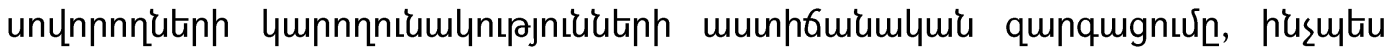

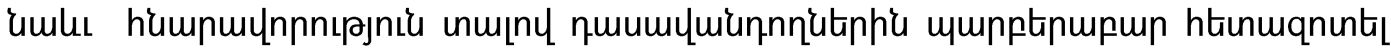

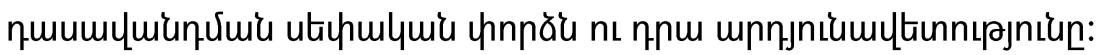

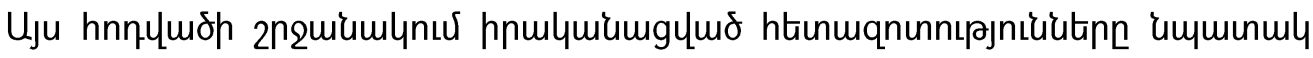

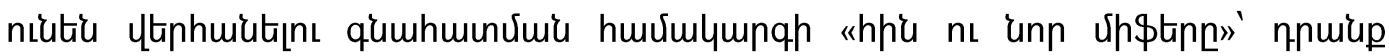

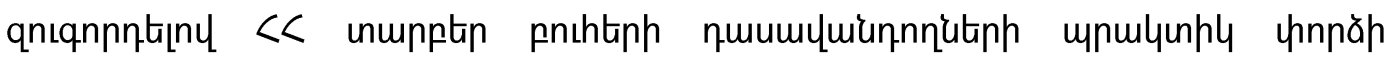

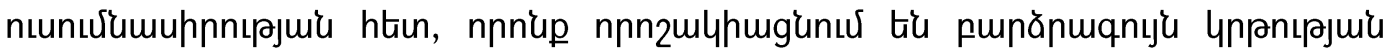




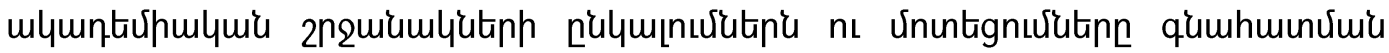

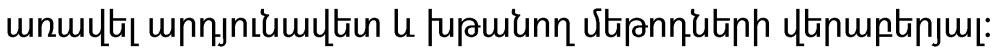

\section{МИФЫ И РЕАЛЬНОСТИ СИСТЕМЫ ОЦЕНИВАНИЯ СТУДЕНТОВ ВЫСШЕГО ОБРАЗОВАНИЯ РА}

Соикатель Г.А. Мурадян

Государственный институт физической культуры и спорта Армении, Ереван, Армения

\section{PEЗЮME}

Ключевые слова: оценивание студентов, методы оценивания, мифы и реальности, оценивание как обратная связь, формативное и итоговое оценивание, рубрики.

Оценивание- неотъемлемая часть любого учебно-педагогического процесса. Практики оценивания имеют большое количество функций, которые необходимо выполнять в контексте преподавания, процесса обучения.

Эта статья раскрывает мифы об оценивании студентов: о том, что мы оцениваем, как в практике мы можем согласовать различные критерии, которые можно установить и применять единогласно.

Несмотря на эти кажущиеся трудности, в данной статье приводятся доводы в пользу обоснованности процесса оценивания, разработанных в определенных академических условиях в высших учебных заведениях Армении.

Процесс оценивания включает в себя различные компоненты учебного процесса, позволяя учащимся приобретать знания, постепенно развивать способности последних, а также позволяя учителям регулярно исследовать свой собственный педагогический опыт и его эффективность.

Согласно опросу, проведенному среди преподавателей армянских университетов, основной целью оценки студентов является мониторинг знаний студентов, их способностей и навыков. Результаты оценки студентов предназначены для улучшения учебного процесса и достижений студентов.

Для оценивания учебных достижений армянские вузы прибегают к трем типам оценки учащихся: аудиторная оценка, диагностическое тестирование 
конкретного уровня и письменные задания. Чаще всего используются анкетирование, устные тесты и домашние задания («контрольные задания»).

К сожалению, многие педагоги продолжают «традиционную» практику, которые, в лучшем случае неэффективны, а в худшем, контрпродуктивны целям современного образования.

Студенты часто критикуют методы оценивания, называя их предвзятыми, субъективными и инструментами притеснения. В то же время преподаватели подчеркивают, что оценивание успеваемости студентов- это средство повышения взаимной вовлеченности в учебный процесс для стимулирования более высоких образовательных достижений.

Исследование, проведенное в рамках данной статьи, направлено на выявление «старых и новых мифов» системы оценивания, совмещая их с изучением практического опыта преподавателей различных вузов Республики Армении.

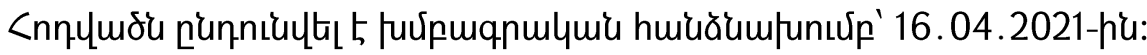

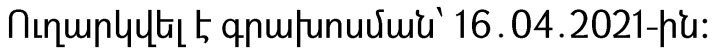




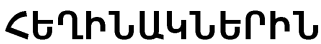

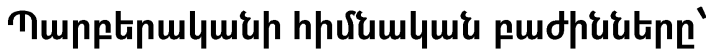

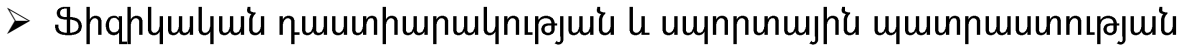

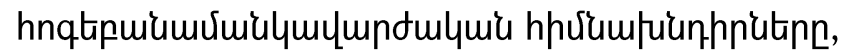

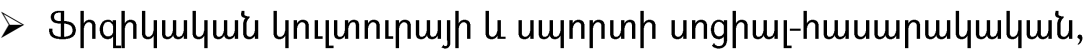

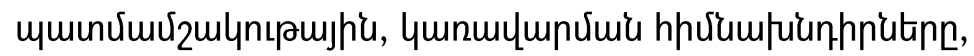

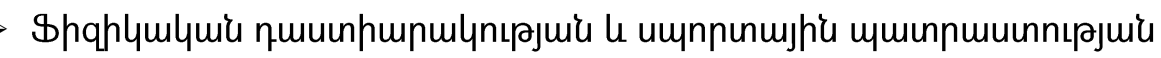

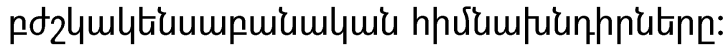

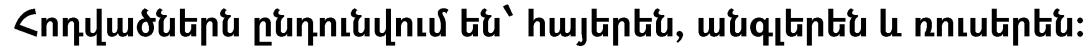

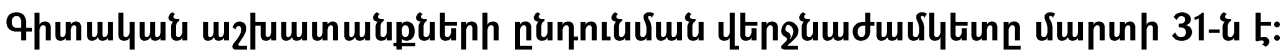

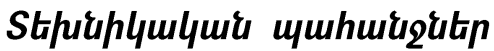

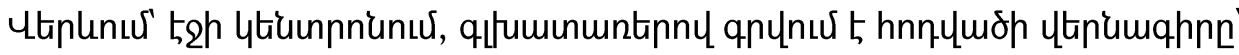
purl (bold),

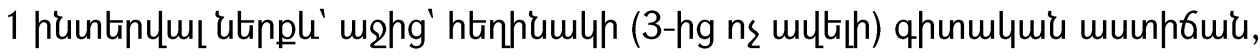

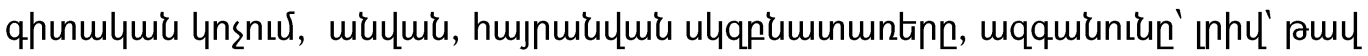
(bold),

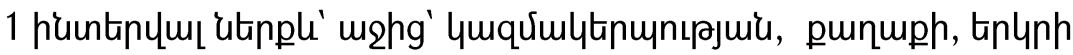
'u'ulu'unudutinn' purl (bold),

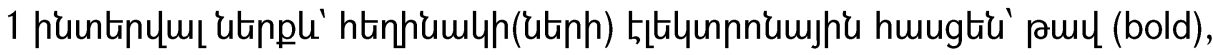

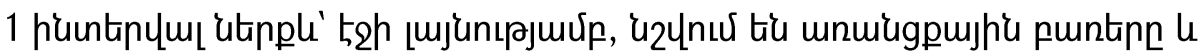
punulymumugnıpлnıutitnn (8-10 pun),

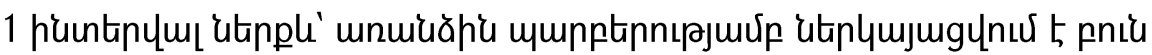
untpuunn:

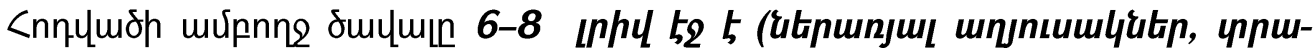
viuqptrn):

Stipuunh ălumşuuhn' A4 \$npưuunh pnınß (210x297 ứ), MS Word 2007, unu-

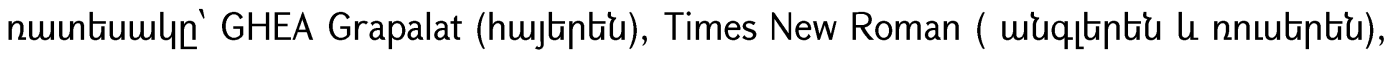

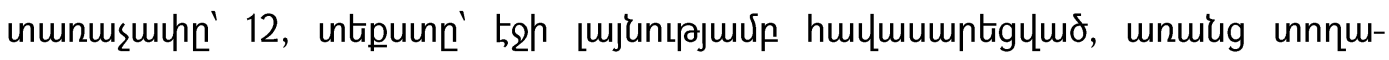
qunătiph:

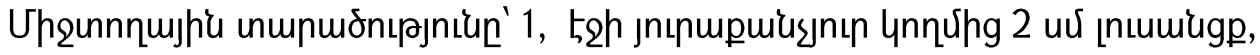




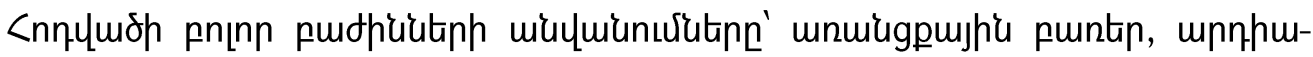

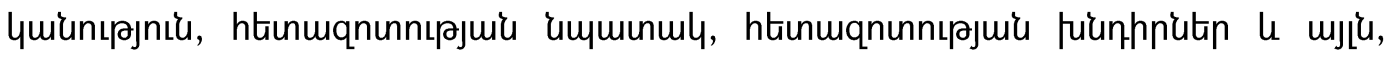
'ù 2 nư tiu' puru (bold):

\section{Stpunn luunnıgluidpn.}

\section{Unwugpumpi puntin:}

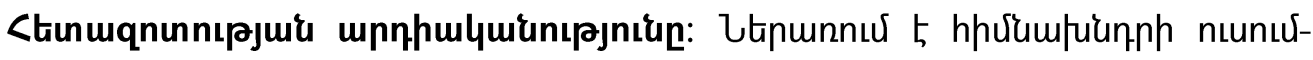

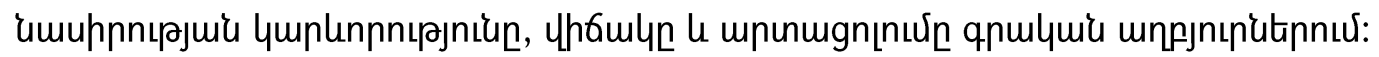

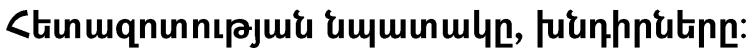

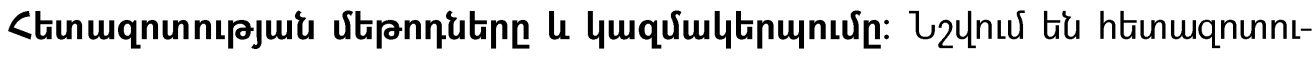

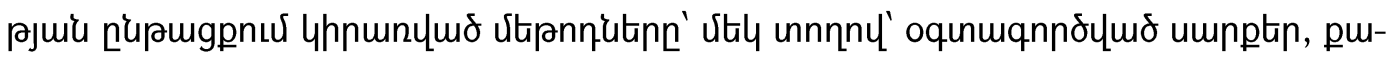

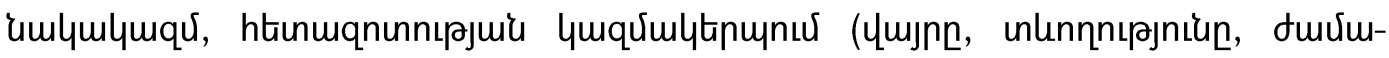
umlquhmun $(m \delta \delta$ ):

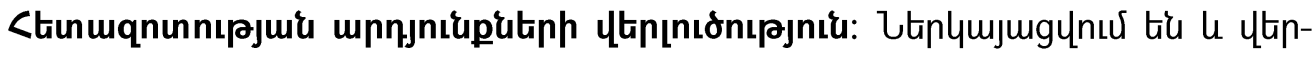

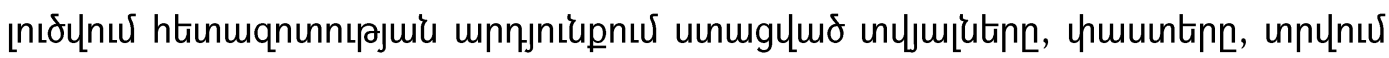

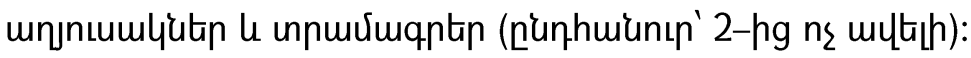

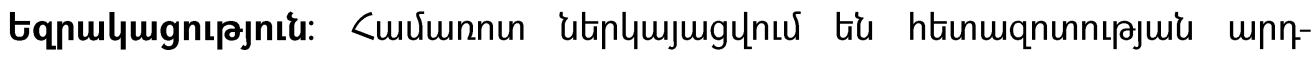

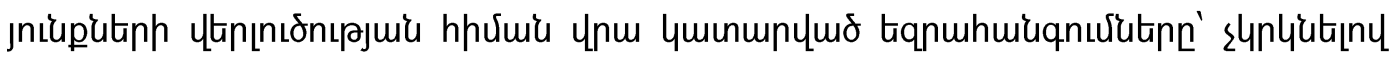

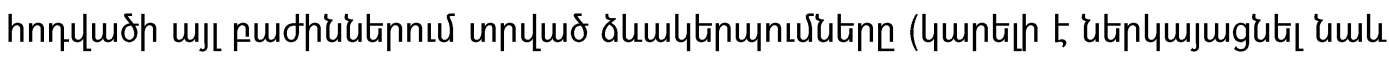

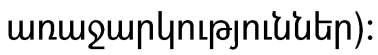

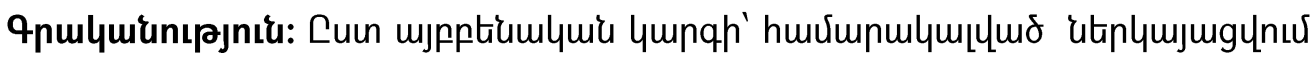

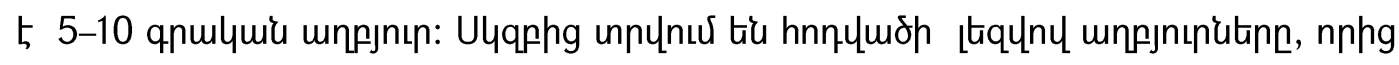

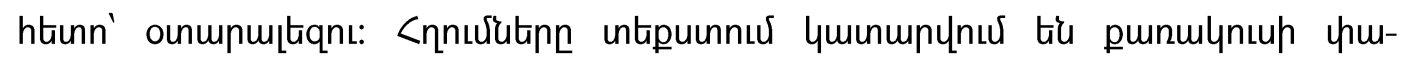

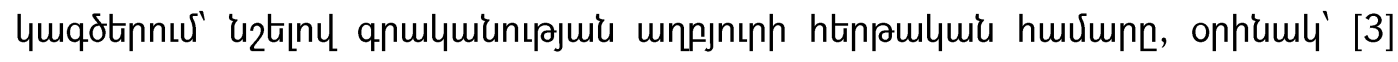
पuार $[1,5,6]$ :

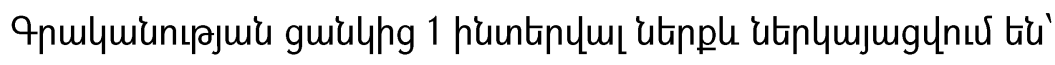

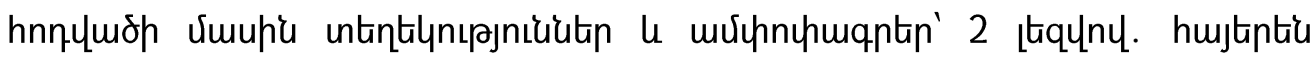

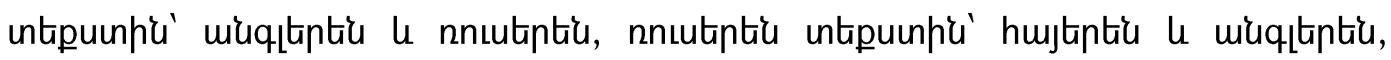
muqqutintuhu' hujtintiu u nniutintú.

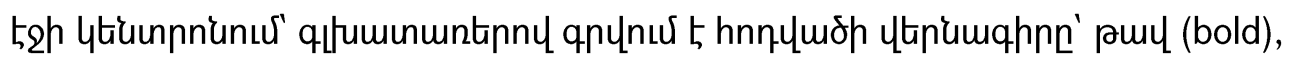

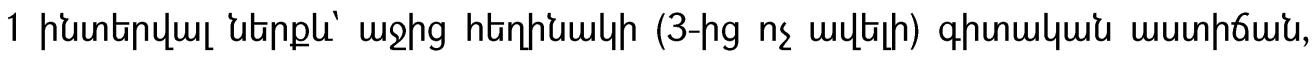

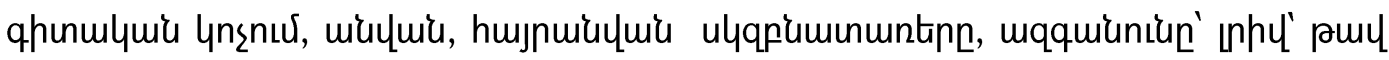
(bold), 


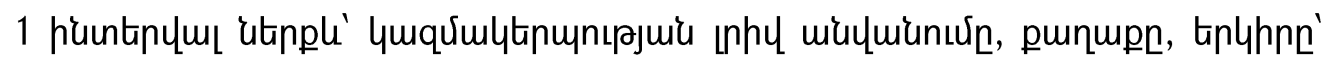
purl (bold):

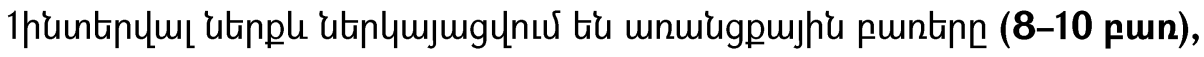

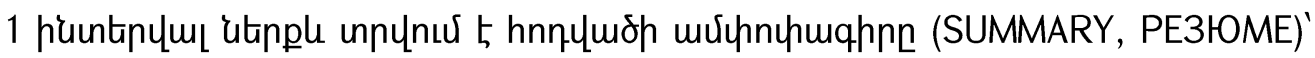

\section{0-250 pun:}

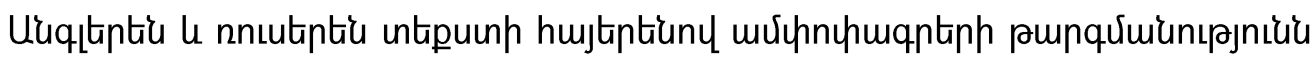

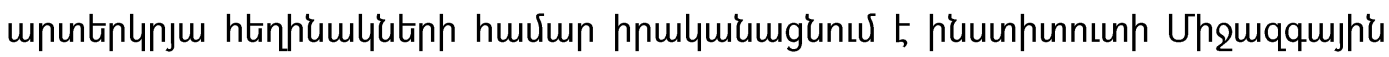

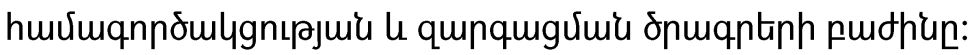

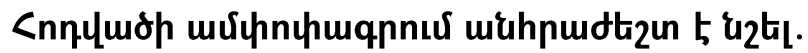

\section{Unwiggmujhi puntip}

\section{Stenuqnunnıpjui \&umuunuly}

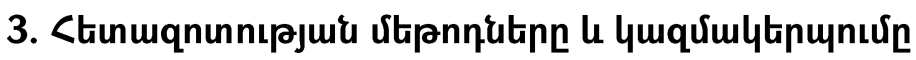

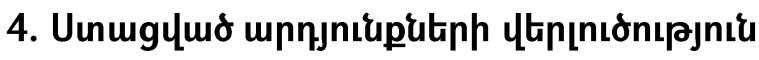

5. Cuxumnnun tqpulumgnıpjnıtu

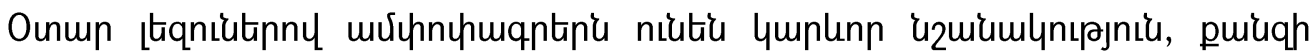

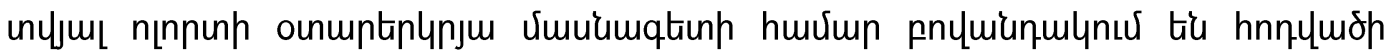

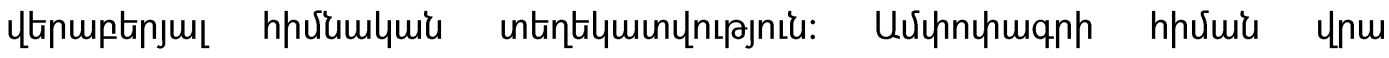

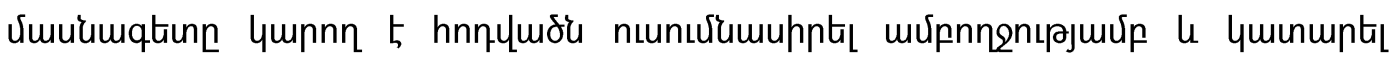
hưumumunuu|umu hnnứtitp:

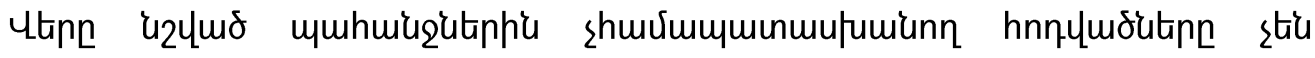

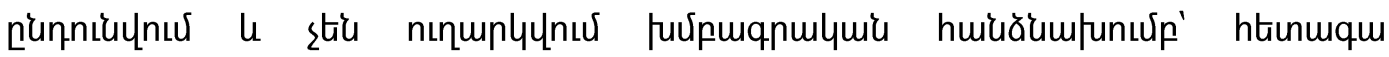

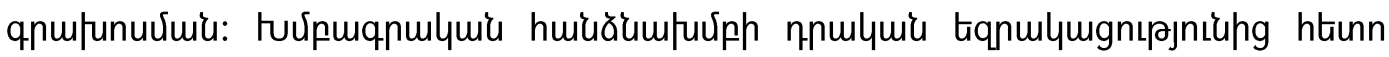

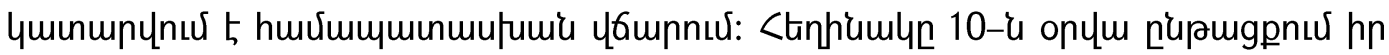

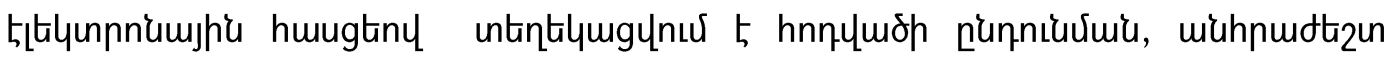

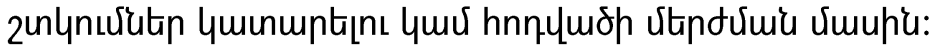

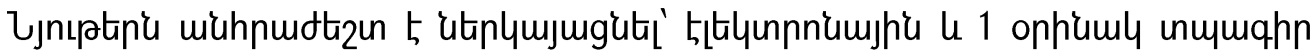
ununptrpulyny:

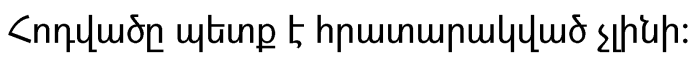

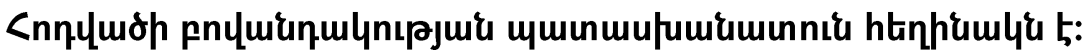

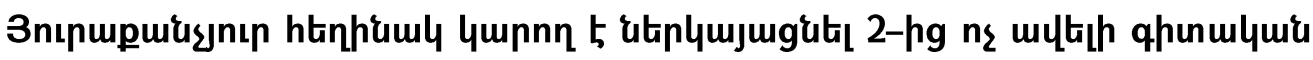
malumunuitup: 


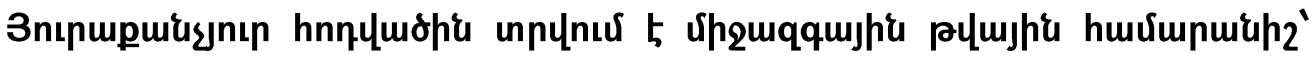
DOI:

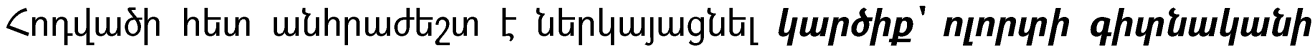

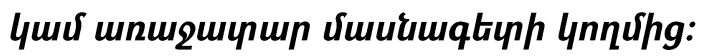

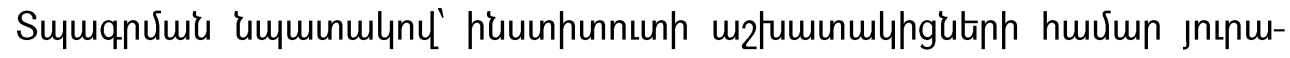

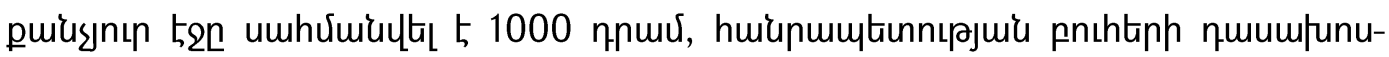

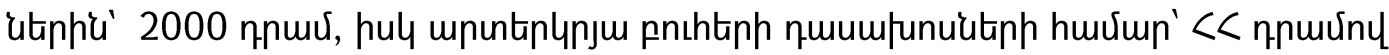

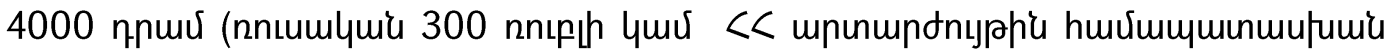
qnulump):

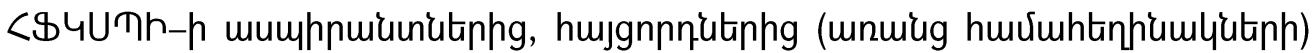

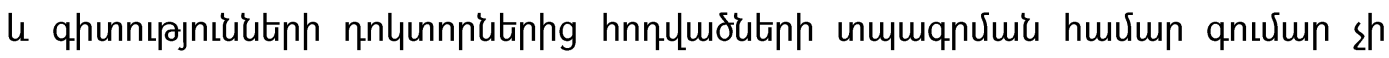
quiuăunư:

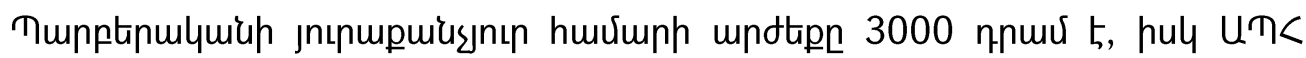

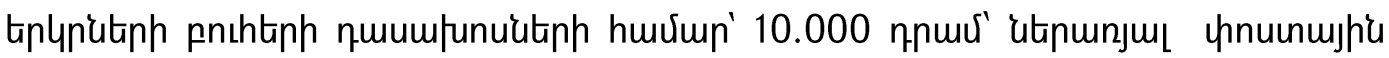
unupnuxu:

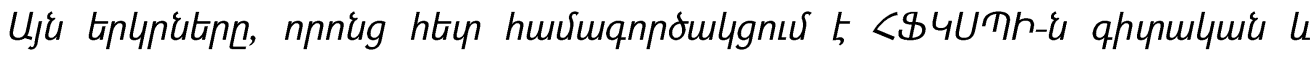

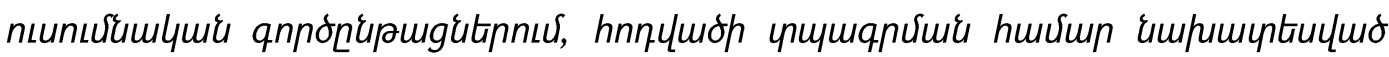

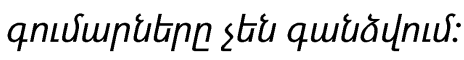

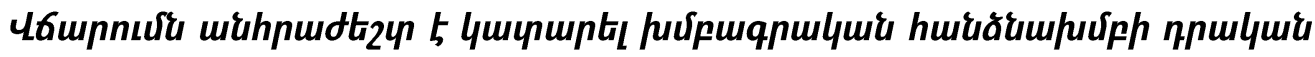

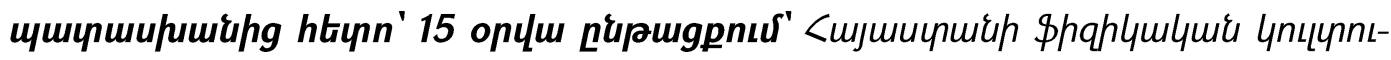

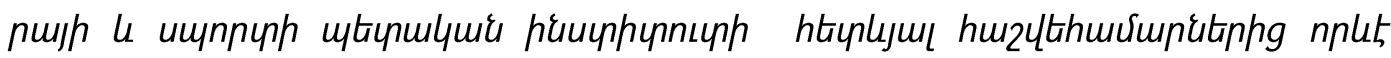
vitupi'

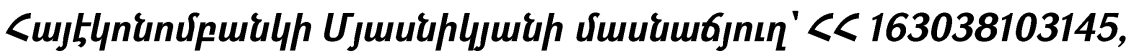

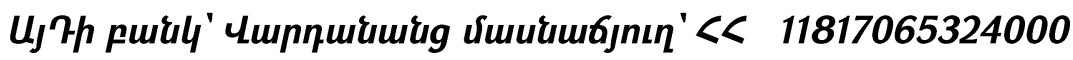

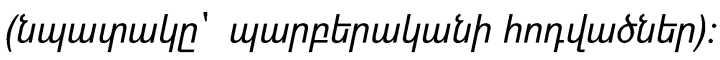

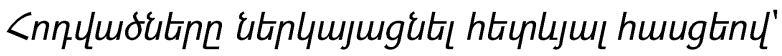

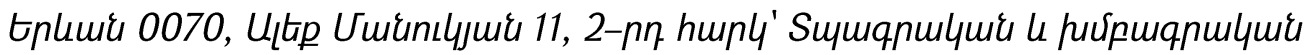

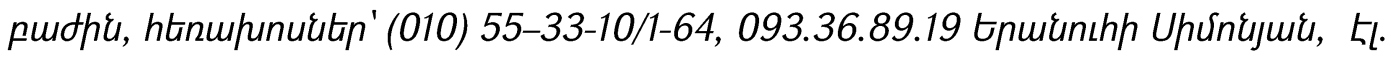
huugt'eranuhi.simonyan@sportedu.am

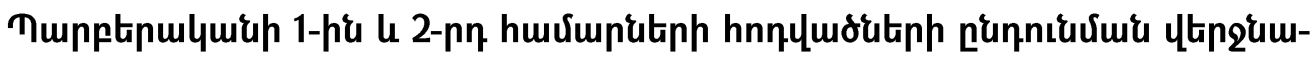
duviltinn viununh 31-4 $5:$ 


\title{
2hulytnuxumu ophimul
}

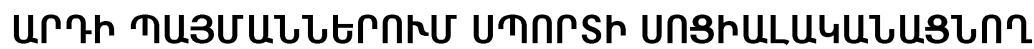 9กกбUกกหзə孔trc}

\author{
U.q.P., qngtiun U. U. nuluizjui, \\ hujgnnn 4. ก. Utinnpjuir

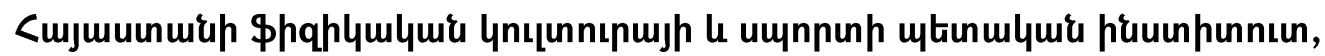 \\ tplumi, <mjuruinuid,

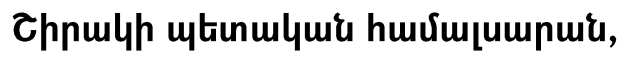 \\ 9.nuर्up, <ujuuunuir \\ E.mail: a.vosk@sportedu.am, k.ser@ssy.am
}

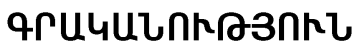

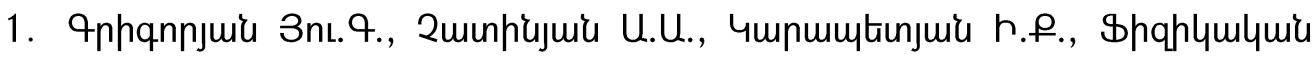

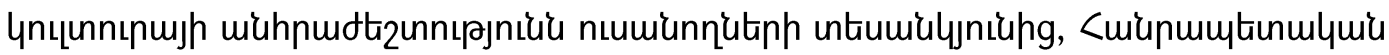

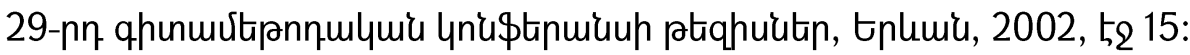

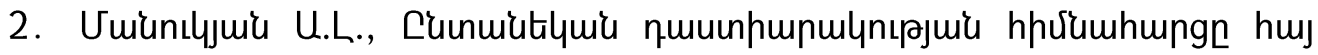

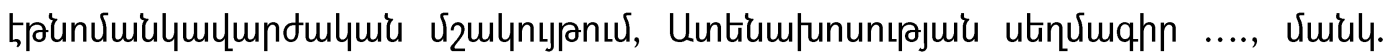
qhun. ptil., tplumiu, 2020, 22 Ł2:

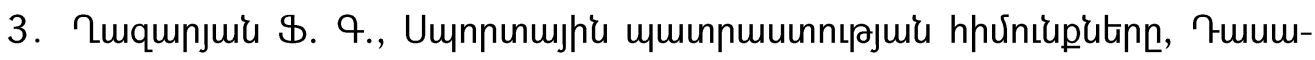
qhnp, tpluwiu, Rnptip hnuin., 1993, 212 52:

4. Терехина Р.Н., Уровень специальной подготовленности лидеров гимнастического помоста в первый год олимпийского цикла / Р.Н. Терехина, С.В. Борсиенко, Н.Н. Коврижных // Ученые записки университета имени П. Ф. Лесгафта. - 2017. - № 10 (152). - C. 244-248.

5. Dowling M., Edwards J. \& Washington M., Understanding the Concept of Professionalisation in Sport Management Research, Sport Management Review, 2014; 17(4)p. 520-529.

6. Романовская Н.Е., Понятие профессиональной компетенции [5[tцunnnuшJh' ntunınu] http: //media.miu.by/files/store/ items/lifelong/11/ 11 life long learning 5 10.pdf

7. https://fkis.ru/page/1/161.html 


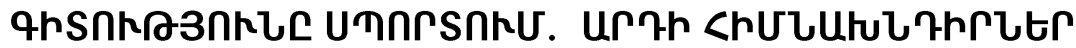

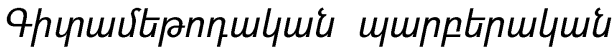

\author{
SCIENCE IN SPORT: MODERN ISSUES \\ Scientific and methodical journal \\ НАУКА В СПОРТЕ: СОВРЕМЕННЫЕ ПРОБЛЕМЫ \\ Научно-методический журнал \\ 2021 №1 (3)
}

Unpuqnhs'

๒.บ.Uhưnนjuนน

<urumlqunqsujhi

ălumunnnn'

L.U.Utionjuiu

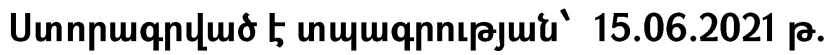

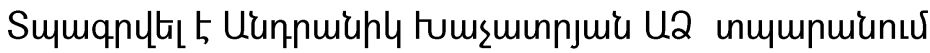

2uihun' 60x84 1/16: Su. Jữnцn' 13,5:

Sumpuiumly' 50 